\title{
Technological change, international trade and growth
}

Citation for published version (APA):

Nomaler, Z. O. (2006). Technological change, international trade and growth. [Doctoral Thesis, Maastricht University]. Datawyse / Universitaire Pers Maastricht. https://doi.org/10.26481/dis.20060126zn

Document status and date:

Published: 01/01/2006

DOI:

10.26481/dis.20060126zn

Document Version:

Publisher's PDF, also known as Version of record

\section{Please check the document version of this publication:}

- A submitted manuscript is the version of the article upon submission and before peer-review. There can be important differences between the submitted version and the official published version of record.

People interested in the research are advised to contact the author for the final version of the publication, or visit the DOI to the publisher's website.

- The final author version and the galley proof are versions of the publication after peer review.

- The final published version features the final layout of the paper including the volume, issue and page numbers.

Link to publication

\footnotetext{
General rights rights.

- You may freely distribute the URL identifying the publication in the public portal. please follow below link for the End User Agreement:

www.umlib.nl/taverne-license

Take down policy

If you believe that this document breaches copyright please contact us at:

repository@maastrichtuniversity.nl

providing details and we will investigate your claim.
}

Copyright and moral rights for the publications made accessible in the public portal are retained by the authors and/or other copyright owners and it is a condition of accessing publications that users recognise and abide by the legal requirements associated with these

- Users may download and print one copy of any publication from the public portal for the purpose of private study or research.

- You may not further distribute the material or use it for any profit-making activity or commercial gain

If the publication is distributed under the terms of Article $25 \mathrm{fa}$ of the Dutch Copyright Act, indicated by the "Taverne" license above, 
Technological Change, International TraDE AND GROWTH 
(c) 2006 Z.Ö. Nomaler

All rights reserved.

Typeset in Computer Modern

Prepared with IATEx, using the memoir class

Published by Universitaire Pers Mastricht ISBN 9052785090

Printed in the Netherlands by Datawyse Maastricht 


\section{Technological Change, International Trade and Growth}

An Evolutionary Multi-Agents-Based Modeling Approach.

PROEFSCHRIFT

ter verkrijging van de graad van doctor aan de Universiteit Maastricht, op gezag van de Rector Magnificus, Prof. Mr. G.P.M.F. Mols, volgens het besluit van het College van Decanen, in het openbaar te verdedigen op donderdag 26 januari 2006 om 16.00 uur

door

Zübeyir Önder Nomaler

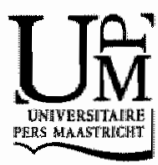




\section{Promotor:}

Prof. Dr. H.H.G. Verspagen, Technische Universiteit Eindhoven

Beoordelingscommissie:

Prof. Dr. R. Cowan (voorzitter)

Prof. Dr. G. Dasi (Sant'Anna School of Advanced Studies, Italia)

Prof. Dr. L.L.G. Soete 
Assumptions can be dangerous, especially in science. They usually start as the most plausible or comfortable interpretation of the available facts. But when their truth cannot be inmediately tested and their flaws are not obvious, assumptions often graduate to articles of faith, and new observations are forced to hit them. Eventually, if the volume of troublesome information becomes unsustainable, the orthodoxy must collapse.

John S. Mattick - "The Hidden Genetic Program of Complex Organisms", in Scientific American, October 2004.

The charlatan is allways the pioneer. From the astrologer came the astromomer, from the alchernist the chemist, from the mesmerist the experimental psychologist. The quack of yesterday is the professor of tomorrow. Even such subtle and elusive things as dreams will in time be reduced to system and order no longer be the amusement of the mystic, but the foundations of a science.

Sir Arthur Conan Doyle - Murder Rooms, 1922 


\section{Preface}

Writing a PhD dissertation is essentially a process which stars with looking at: a blank page and see it evolve into a book throughout a period of $\mathrm{N}$ years; $\mathrm{A}$ process of turning nothingness into something which hopefully makes a change even the magnitude of the value of change can be considered as marginal (in many cases) given the sea of knowledge already accumulated throughout the history. In some sense, this is a blessing because no matter how blank the first page of the dissertation may seem at the first day of the $\mathrm{PhD}$, the accumulated knowledge base upon which the thesis is to be built can hardly be considered as tabula rasa especially if one chooses to write a dissertation that aims at covering an immense spectrum that spans technological change, economic growth and international trade. In an other sense, given the voluminous amount of earlier contributions, it is also an agony to find one's way to novelty even through an unorthodox approach like Evolutionary Economics which appraises system dynamics and heterogeneity in a way that can hardly be captured within the rather limited tools and definitions of the mainstream.

Therefore, I believe that the people who contributed to this dissertation and also those who paved the way to the point which rendered this dissertation conceivable at the first place can not be acknowledged enough within the few lines of a section devoted to acknowledgements, especially if one appraises qualities like open-mindedness, non-conformism, scepticism and vision, and the courage to stray the beaten paths and to create according opportumities, along or above other academic merits. In all such senses, I am truly indebted to my supervisot" Bart, Verspagen whose hands-in contributions in indulging and guiding me in findingout and in pursuing what I believe is right, are unmatched by those of anybady else. Yet above all, I would like to thank him for his noble, considerate and highly refined human qualities to which I owe greatly. I would also like to thank Erol Taymaz for similar contributions to my pre-PhD studies.

The PhD process is a strange mix of fun and suffering. It is fun because one is granted a generous period to learn, to explore, and to build. It makes one suffer because despite the pleasure of overcoming various scientific and technical challenges, the process is essentially a manifestation of endurance, persistence and patience. Generally the fun part is enjoyed pretty much alone while the emotional implications of the suffering inevitably spill-over to peoplle who are unfortunate enough to happen to be nearby. However, their existence, support and co-endurance are invaluable ingredients. In the fist 4 years of my PhD studies one of the two most unfortunate persons that happened to be around (99 percent of my office time in MERIT and a considerable deal of the rest) had been Machiel van Dijk. I would like to thank him first for saving me from being confined to enjoy the fun parts of writing a thesis in solitude, and much more for his valuable 
and lasting friendship which turned out to have gone beyond our 4 years of almost symbiotic life style.

Many thanks to Wilma Coenegrachts for her highly-advanced wizardry in the art of administration and helping people out of all kinds of trouble, and to Bas Stratathof especially for sharing his profound WIEXexpertise with me and Alessandro Nuvolari for many tasteful discussions and suggestions.

I wish I could express my gratitude to my late father Enver Nomaler who could not live to read these lines. There can be few people in the world who can offer their children as much as my father could. His personal contribution to my mind and wy of seeing things is not less than his genetic and material contributions to my physical existence. Also many thanks to my mother for all she did for me and also my apologies for having left her alone for a PhD in the Netherlands.

After also adding my gratitude to all other friends and colleagues who have supported, stimulated and enriched my work and the rest of my life, according to my calculations, the major stakeholder of my total indebtedness is my doemon, my other half, Funda for a full-score in each of the imaginable qualities that one could expect from a life-time companion, and above all, for her mere existence as she is. 


\section{Contents}

1 A selective formal revisit to an eclectic literature 1

1.1 Introduction ...................... 1

1.2 Traditional models of comparative advantage . . . . . . . . . . 3

1.2.1 The Ricardian Model . . . . . . . . . . . . . . . . . . 4 4

1.2.2 The traditional neoclassical models . . . . . . . . . . 9

1.2 .3 Economic growth in traditional models of trade ...... 15

1.2.4 Empirical testing of traditional models and neo-endowment approaches . . . . . . . . . . . . . . . 20 20

1.2.5 An integrating static approach: The Heckscher-Ohlin-Ricardo model .................... . . 24

1.3 A brief look at the (new) growth theories . . . . . . . . . 25

1.3.1 Knowledge/Human capital accumulation and leaming by

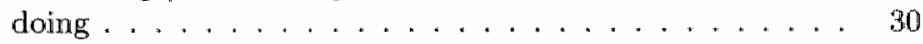

1.3.2 Growth by quality improvements ........... 32

1.3 .3 Growth by variety ................. 35

1.4 The new trade theories ....................... 37

1.4.1. Models of external increasing returns of international scope 38

1.4.2 Models of external increasing returns of national/sectoral scope . . . . . . . . . . . . . . . . . 39

1.4.3 Models of internal economies of scale . . . . . . . . . . . 43

1.5 Technology gaps models . . . . . . . . . . . . . . . 47

1.6 An evolutionary example on international trade and growth differentials ...................... 52

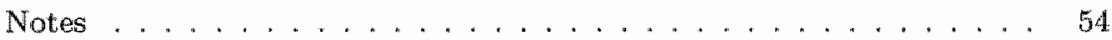

2 A niche for an alternative approach $\quad \mathbf{5 7}$

2.1 Introduction . . . . . . . . . . . . . . . 57

2.2 "Evolutionary philosophy" as an alternative embracing framework 60

2.3 Brief look at formal evolutionary modeling . . . . . . . . . 68

2.3.1 Agent-based framework as a medium for evolutionary mod. eling ........................ 71

2.3.2 Semi-agent-based models of higher levels of aggregation . 76

2.4 An overview of the book: Objectives and organization . . . . . 85

2.4.1. An overview of research objectives and the resulting simulation platform .................... 85

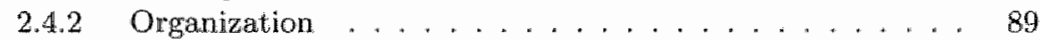

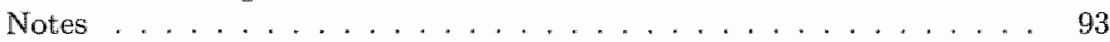


3 The core: a supply side multi-country/sector model of selection 101

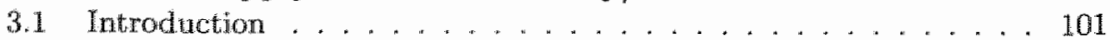

3.2 The basic workings of economic selection ........... 105

3.2.1 Production, labor markets and labor costs ........ 105

3.2 .2 The final good markets: Price formation . . . . . . . 108

3.2.3 Economic selection 1: Investments and disinvestments . . 110

3.2.4 Firms" willingness to grow: Dernand for investment ... . 117

3.2.5 Econornic selection 2: Entry and exit of firms . . . . . . 124

3.2.6 Capital good production and unit purchase/replacement prices of capital goods . . . . . . . . . . . . 125

3.3 Various extensions built into the simulation software . . . . . . 127

3.4 List of the key parameters of the core selection module ... . . 129

3.5 Conclusive remarks ..................... 130

Notes . . . . . . . . . . . . . . . . . . . . . . 132

4 Selection with constant technologies: Stationary Fundamentals 135

4.1 Introduction . . . . . . . . . . . . . . 135

4.2 Selection in closed economies: Macroeconomic implications . . . 137

4.2.1 Equilibrium employment and output levels in cases characterized by output maximizing firms . . . . . . . 137

4.2.2 An algebraic comparison of the macro-consequences of output vs. profit maximizing behavior .......... 144

4.2.3 An overview of a number of illustrative simulation rums with closed economies . . . . . . . . . . 146

4.3 Intemational Trade with Constant Technologies . . . . . . . . 150

4.3.1 Specialization only due to productivity differentials across countries ......................... 150

4.3.2 Specialization due to productivity and capital intensity differentials ...................... 151

4.3.3 Specialization due to simultaneous differences in productivity, capital intensity and quality ............

4.3.4 An overwiew of a number of illustrative simulation runs with open economies ............... 154

Notes .............................. 161

5 The stochastic technological change formulations $\mathbb{1 6 5}$

5.1 Introduction . . . . . . . . . . . . . . . . 165

5.2 Technological change as exogenous increases in labor productivities 167

5.2.1 Innovations in the finall good sectors . . . . . . . . 167

5.2 .2 Imitations in the final good sectors ... . . . . . . 172

5.2.3 Technological change in the capital sectors: The motion of capital intensities . . . . . . . . . . . 176

5.2 .4 A capital vintages framework ............ 178

5.3 Endogenisation of technological change . . . . . . . . . . . 180

5.3 .1 Cumulativeness as an endogenising principle . . . . . 181

5.3.2 The alternative "Learning By Doing" formulation . . . . . 182

5.3.3 The "R\&D effort" formulation: Basics .......... 183

5.3 .4 R\&D expenditures and rationality ......... 185

5.4 Initial technological competency of new entrants . . . . . . . 189

5.5 Decomposition of necessity and chance ............. 190

5.6 Endogeneity of sectoral preferences . . . . . . . . . . . . . 190

5.7 An overview of the technological change formulations . . . . . . 193 
5.8 An overview of the technological change related parametert . . . 194

5.8 .1 Basis parameters (Innovations) ............ 194

5.8 .2 Imitations-related parameters . . . . . . . . . 195

5.8.3 Parameters of the technological paradigms module . . . 195

5.8.4 Parameters related to the endogenisation of technological change .................... . 196

5.8.5 Parameters of the "Endogeneity of Sectoral Preferences" module . . . . . . . . . . . . . . . . . . 197

Notes ... . . . . . . . . . . . . . . . . . . 198

6 Technological change growth and trade in simple settings 201

6.1 Introduction ........................ 201

6.2 Technological change and growth . . . . . . . . . . . . 202

6.2.1 Basic properties of technological change-induced growth . 202

6.2 .2 A comparison with the Solow growth model . . . . . . 20. 204

6.2.3 Progress trajectocies and sustainability of growth . . . . 207

6.2.4 Experiment \#1: Technological Change and Unemployment 211

6.2.5 Experiment \#2: Economic selection and diffusion of capitall embodied technologies . . . . . . . . . . . 217

6.2.6 Scenario \#1: Technological Progress in Paradigms and Long Waves in Growth Rates . . . . . . . . . . . . . 225

6.2.7 Scenario\#2: Economic growth in multi-sectoral settings . 231

6.2.8 Concluding remarks on economic growth in the model . . 237

6.3 Technological change and international trade . . . . . . . . 237

6.3.1 Experiment \#3: Cross-country/sector asymmetries-based specialization with technological change . . . . . . . 239

Notes . . . . . . . . . . . . . . . . . . . . . 245

7 Industrial Organization and International Trade 249

7.1 A brief look at industrial organization and dynamics . . . . . . 249

7.1.1 Experiment \#4: Firms' Size and Growth Rate Distributions250

7.1.2 Experiment \#5: Industrial Organization and Aggregate Growth ..................... . . 255

7.1.3 Experiment \#6: Optimality versus arbitrariness in R\&D expenditures in the context of selection . . . . . . . 259

7.2 International trade and endogenous growth . . . . . . . . . 272

7.2 .1 Introduction . . . . . . . . . . . . 272

7.2.2 Experiment \#7: Self-organized emergence of specialization and international growth differentials . . . . . . . 274

7.2.3 Experiment \#8: Knowledge spill-overs and specialization. 282

7.2.4 Experiment \#9: Specialization in the context of boundedly

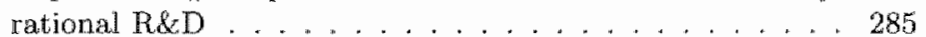

Notes ... . . . . . . . . . . . . . . . . 290

8 Final notes and future perspectives 293

8.1 Introduction . . . . . . . . . . . . . . . . . . 293

8.2 Summary . . . . . . . . . . . . . . . . . . . . . . . . 294

8.2.1 Chapter $4 \ldots \ldots . \ldots . \ldots 294$

8.2 Chapters 5 and $6 \ldots \ldots \ldots . . \ldots . . . \ldots 300$

8.2 .3 Chapter $7 \ldots \ldots . \ldots . \ldots 304$

8.2 .4 An overall overview . . . . . . . . . . . . . 308

8.3 Future perspectives ................. . . . 312 


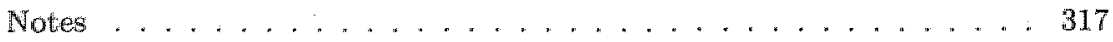

A Appiendices and extras (on the accompanying CD) 319

$\begin{array}{ll}\text { References } & 321\end{array}$

$\begin{array}{lr}\text { Samenvatting (Summary in Dutch) } & \mathbf{3 3 1}\end{array}$

About the Author $\quad 335$ 


\section{List of Tables}

6.1 The structural parameters that characterize Experiment 1 . . . 21.2

6.2 Growth and Unemployment Results . . . . . . . . . . . 215

6.3 Diffusion potential matrix for experiments 2.2 and $2.3 \ldots 223$

6.4 The structural parameters that characterize Experiment 4 . . . . 240

7.1 Summary table for the results of Experiment $4 \ldots \ldots . \ldots 252$

7.2 Summary Table for Experiment 5 . . . . . . . . . . . 257

7.3 Summary Table for Experiment 6b . . . . . . . . . . . . . . . 269

7.4 Summary Table for Experiment 7 -Mean Values- . . . . . . . . . 277

7.5 Summary Table for Experiment 7 -Percentage Variation Around Means- 277

7.6 Summary Table for Experiment $8 \ldots \ldots . \ldots . \ldots 284$ 


\section{List of Figures}

3.1 The function $W g S u p(.) \ldots \ldots \ldots \ldots$

3.2 The function $C r \operatorname{Dem}_{i j k}(.) \ldots \ldots \ldots \ldots . \ldots \ldots 114$

5.1 Fitmess v.S. labor productivity (or product quality) in technological paradigms ........................ . . 170

5.2 A three-sector example of endogeneity of preferences. . . . . . 193

6.1 Employment time series in Experiment 1.......... 216

6.2 Motion of vintage market shares in runs with simultanous introduction of vintages. . . . . . . . . . . . . . . . . 221

6.3 Productivity, Output Growth and Unemployment in Scenariola . . 230

6.4 Output Growth and Unemployment Motion in Scenariolb . . . . . 231

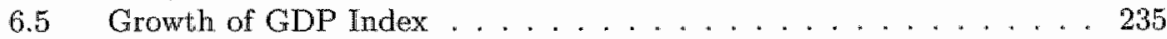

6.6 Growth path of production in agriculture ............ 235

6.7 Growth path of production in manufacturing . . . . . . . . . 236

6.8 Growth path of production in services .............. 236

7.1 Firm's size distributions in Experiment 4 . . . . . . . . 255

7.2 The relation between R\&D effort and expected average productivity growth in Experiment 6.................. 261

7.3 Summary charts for the non-stochastic runs of Experiment 6a. . . 264

7.4 Summary charts for the stochastic runs of Experiment 6a. . . . . 265

7.5 The firm-level relation between $R \& D$ effort and expected average (per 10 periods) productivity growth in Experiment $7 \ldots . . . . .278$ 


\section{A selective formal revisit to an eclectic literature}

\subsection{Introduction}

Within a very short description, the study that underlies this dissertation is essentially a modeling exercise. This exercise aims to build and analyze a multi-agents system of many countries composed of many sectors, each characterized by many interacting firms in competition with each other. The agent-based nature of the model lies in the fact that the model, which is implemented as a collection of computer simulations, incorporates economic agents as explicitly separate and actiwe entities (in computer science terminology objects). Each individual agent that belongs to the artificial population of the model observes its environment and interacts with the others, and individual behavior, which reflects a bounded type of rationality, is adaptive. Accordingly, the model basically targets to describe the growth, international trade and specialization of the artificial national economies as emergent aggregate outcomes of firm-level technological change together with the behavior of such individual agents, and to suggest accordingly an alternative micro-foundation structure with a strong evolutionary flavor.

There exists an immense and eclectic literature in either of the topics "international trade", "economic growth", and "technological change", all of which we aim to address under a single integrated model framework. Traditionally, the formal theories of international trade have been based on the comparative advan. tage principle introduced by Ricardo [1817], which is believed by the majority of economists as the dominant determinant of international specialization and trade patterns. The importance attributed to the principle (as a basis, substitute or complementary to other plausible explanations), as well as the understanding of its determinants, show variations among different scholars (especially of different schools of thought). These variations are revealed by a vast amount of highly diversified literature ${ }^{1}$. The early formal approaches of mainstream economics to the issues of technological change and growth are basically reflected by the Solow [1956] growth model, which basically explains economic growtin on the basis of exogenous advances in productivity.

There also exist a vast amount of literature outside of the formalism of the mainstream economics, which approach issues on international trade and economic growth from alternative perspectives in a way that is rather critical on the mainstream formulations. These critical approaches come from different schools of 
economic thought such as institutional economics, Post-Keynesian economics etc. In the context of our discussion, the most important of such is the approach of Schumpeter, who, already as of 1930 ss stresses on the endogeneity of technological change in various contexts.

Starting from early $1970 \mathrm{~s}$, mainstream theorizing goes through a process of a radical transformation in which one observes the endogenisation of technological change in various contexts such as monopolistic competition, dynamic increasing returns and $R \& D$ effort. In the domain of growth, this transformation is embodied in a new strand of models referred to as new growth theories. Under this broad classification one finds models that specify economic growth in terms of progress in productivity, product quality and/or product variety. Parallel to these developments one also observes the emergence of yet another strand known as the new trade theory, which is essentially based on various generalizations of the former into open economies.

Ontside of the mainstream formality, a heterodox school of economic thought that emerges around the 1980s, following the seminal work of Nelson and Winter [1982] is the evolutionary economics which pays particular attention to dynamic issues surrounding endogenous technological change and econornic growth in a neo-Schumpeterian sense. Though some of the Schumpeterian ideas (such as creative destruction) have successfully been internalized by the mainstream economics, the evolutionary approach mainly draws on a framework that criticizes the very basics of the mainstream framework such as the overrated rolle of ram tionality, equilibria/steady state-based analysis, representative agents, excessive acknowledgment of price quantity adjustments while ignoring heterogeneity, lack of essential uncertainty and institutional based dynamics, and oversimplification of the technological change process which has a complex, uncertain and discrete nature etc. Many of the criticisms (especially by evolutionary economists) of the mainstream theorizing are actually on technical issues that characterize the ways in which mainstream philosophy are reflected in terms of formal models.

Although one can find many examples of evolutionary models that address issues on endogenous technological change and economic growth, models that also bring international trade (i.e., open economies) into their framework are rather rare. The model that is presented and analyzed in this dissertation basically aims to contribute to the filling of this gap.

Accordingly in this chapter, we will start by giving a rather technical overview of a selection of salient mainstream models pertaining to the subject matter in question, in a way that follows the historical order of developments as briefly summerized above. That is, first, the traditional models of international trade that are based on pure elaborations of the principle of comparative advantage will be discussed. This discussion will also include a selection anong various efforts that have been aiming to test and validate the traditional theories, and the resulting observations that have been pointing to various shortcomings of these. Following the traditional models, we will switch to a discussion on a collection of rather unorthodox early approaches that inspires some of the later models and also a discussion on the developments on (new) growth theories that progress in line with the next generation of (new) trade. The rest of the section will proceed with examples from new growth and new trade theories and also some selected examples of unorthodox work that approach the relation among growth, trade and technological change from different points of view ${ }^{2}$.

As mentioned above, the theoretical premises of the modeling exercise that underlies this dissertation pertains to those of the evolutionary economics than 
those of the mainstream. Accordingly we devote a separate (i.e, the next) chapter for an elaborate discussion on the evolutionary framework and models, where we also discuss the research questions that motivate our study and give an owerview of the dissertation.

\subsection{Traditional models of comparative advantage}

Since Ricardo introduced his comparative advantage principle in 1817, despite various expansions of the range of topics and the emergence of accompanying analytical tools, the core concerns of the pure theory of anternational trade thave been on the causes, structure and the volumes of international trade and also on the magnitude and the distribution of the gains from such trade. Furthermore, the effect of intemational trade on the domestic production structures, and the effects of tariffs and quotas and other impediments to trade have been the main causal relations of interest.

The modern phrasing of the law of comparative advantage essentially relies on a comparison of autarky (no trade) prices: "Countries will tend to export under free trade the commodities with the lower relative prices in autarky ${ }^{3}$. These are the goods in which countries have comparative advantages". In the notation that we will be using throughout this book and in a 2 good 2 country setting:

$$
\frac{P_{s 1}^{A}}{P_{r 1}^{A}}<\frac{P_{s 2}^{A}}{P_{r 2}^{A}} \Rightarrow\left(Q_{s 1}^{T}>C_{s 1}^{T}\right) \wedge\left(Q_{r 2}^{T}>C_{r 1}^{T}\right)
$$

where $P_{i, j}^{A}$ is the pre-trade (autarky) price of good $i$ in country $j, Q_{i j}^{T}$ and $C_{i j}^{T}$ are the after trade levels of good $i$ in country $j$, respectively of production and consumption. The condition implies that $\left(Q_{r 1}^{T}<C_{r 1}^{T}\right) \wedge\left(Q_{* 2}^{T}<C_{31}^{T}\right)$, since the amount of any good exported by one country (i.e., excess of production over consumption) must be equal to the amount imported by the other country.

This phrasing is apparently more general than the original one by Ricardo, who imposed an extra mecessity condition for specialization and trade: "the worldl relative prices that emerge in the world markets after trade, must be between the autarky prices":

$$
\frac{P_{s 1}^{A}}{P_{r 1}^{A}}<\frac{P_{s W}^{T}}{P_{r W}^{T}}<\frac{P_{s 2}^{A}}{P_{r 2}^{A}},
$$

where $P_{i W}^{T}$ denotes the emergent world price for good $i$ after trade. Ricardo, who in his time did not have access to a theory of demand, does not explain the emergence of trade prices and takes $P_{s W}^{T} / P_{r W}^{T}$ as exogenous.

Clearly, the formulations that specify necessity conditions, do not explicitly define the workings of any causal mechanism. Furthermore, for empinical purposes these formulations are not very useful, since in reality (with international trade) autarky prices are not observable. Yet, the importance of the prices lies in the fact that their cross country difference in autarky is theoretically an indication of the existence of differentials of some country specific characteristics, which drive the countries to mutually beneficial specialization and trade. In the Ricardian model with fixed labor coefficients, differences in autarky prices is a revelation of across country-sector differences in these fixed labor coefficients, which explains the potential gains from trade, whereas in the H-O-S model which assumes unambiguous (factor price independent) factor intensity differences across sectors, differences in relative autarky prices are indications of across country differences 
in factor endowment proportions, which drive countries towards specialization and trade.

The common feature underlying the formal models that constitute the pure theories of international trade is their disregard of money. Unlike the complementary theories that are classified under the title international monetary theory" trade flows are assumed to be in strict conformance with the "balance of payments constraint". Money, if exists in any model, serves as a reference unit and trade takes place in the form of barter. Following our notation and the condition in 1.1, the balance of payments (or trade balance) can be expressed as

$$
P_{s W}^{T}\left(Q_{s 1}^{T}-C_{s 1}^{T}\right)=P_{T W}^{T}\left(Q_{r 2}^{T}-C_{r 1}^{T}\right) .
$$

The other properties that are almost common to the mainstream models of international trade that we will be discussing are:

- Unless specially specified otherwise, factors of production are immobile between countries but fully mobile within various sectors of the same country.

- Optimization by price taking is the basic behavioral mode.

- There are no rigidities in the adjustment process of the goods and factor input prices.

- Accordingly economies ${ }^{3}$ optimally determined demand for factor inputs never exceed or fall short of the exogenously given endowments.

- Similarly, all the commodity markets clear simultaneously and the balance of payments (trade balance) constraint always holds. Economies are characterized by such equilibria at all times.

- Unless especially specified otherwise, transportation costs are zero.

- Each set of profit maximizing firms operating in the same sector of the same country under perfect competition (where in the long run equilibrium, unit cost equals to the market price), is represented by one single representative entity (firm) whose behavior reduces to an output maximizer subject to non-negativity of output and resource constraints.

Despite these commonalities and their compliance to the principle of comparative advantages, the main difference between the competing traditional theories of trade lies in the specification of the various country specific differences that lead to comparative advantages structures and the consequent trade flows. As the founder of the concept, Ricardo proposes cross-country differences in technology (i.e. labor productivity) as the ultimate source of comparative advantages. The first model that we will discuss in a formal representation is the Ricardian model, that restricts differences in technology to exogenously given differences in labor productivities, in a world characterized by one single factor, which is labor.

\subsubsection{The Ricardian Model}

\section{The basic 2 country 2 good model}

Assume an economy that uses merely labor and production is characterized by country sector specific fixed labor coefficients $\left(a_{i j}\right.$ for the $i^{\text {th }}$ sector of the $j^{\text {th }}$ country) that are independent of the imput prices. That is $Q_{i j}=a_{i j} L_{i j}$, where $L_{i, j}$ is the part of total labor force $\left(\overline{L_{j}}\right)$ in country $j$ that is allocated to the production of good i. Thus, full employment $\left(L_{1 j}+L_{2 j}=\overline{L_{j}}\right)$ requires that, in 
the 2 good setting, $\frac{Q_{1 j}}{a_{1 j}}+\frac{Q_{2 j}}{a_{2 j}}=\overline{L_{j}}$, must hold separately for each country and this relation yields downward sloping and linear production possibility frontiers (PPFs), the slopes of which are different across countries.

Due to perfect competition, long run profits should be equal to zero in all sectors, which imply that in the autarky (where both countries produce both products), $P_{i j}^{A}=w_{j} / a_{i j}$, where $w_{j}$ denotes the wage rate in country $j$. Substituting this price relation in relation 1.2 yields

$$
\frac{a_{11}}{a_{21}}>\frac{P_{2}^{T}}{P_{1}^{T}}>\frac{a_{12}}{a_{22}} \quad \text { OR } \frac{a_{11}}{a_{21}}<\frac{P_{2}^{T}}{P_{1}^{T}}<\frac{a_{12}}{a_{22}},
$$

as alternative conditions for trade. For convenience in presentation, in the rest of our discussion we will assume that the former condition holds, so that the first (second) country has comparative advantage for the first (second) good.

Ricardo's own explanation of this theory does not explicitly inchude the demand side (no utility functions or alike). He takes the trade relative prices $\left(P_{2}^{T} / P_{1}^{T}\right)$ as given and shows the potential gains from trade. He only makes some (descriptive) comparative statics between open and closed economies in terms of potential gains. In terms of an optimization based formulation, his claim can be represented by the two linear programming problems which, simultaneously maximize countries" national incomes $\left(Y_{1}\right.$ and $\left.Y_{2}\right)$, independently from each other but according to the world prices that emerge after trade.

$$
\begin{array}{llll}
\operatorname{Max} & Y_{1}=P_{1}^{T} a_{11} L_{11}+P_{2}^{T} a_{21}\left(\overline{L_{1}}-L_{11}\right) & \text { s.t } & L_{11} \leq \overline{L_{1}} \\
\operatorname{Max} Y_{2}=P_{2}^{T} a_{22} L_{22}+P_{1}^{T} a_{12}\left(\overline{L_{2}}-L_{22}\right) & \text { s.t } & L_{22} \leq \overline{L_{2}}
\end{array}
$$

These simple linear programming problems normally yield corner solutions indicating full specialization. Nevertheless, in order to clarify let us differentiate both problems with respect to their decision variables and see the conditions that tend to increase national incomes. That is, since $\frac{d Y_{1}}{d L_{1 \Perp}}=P_{1}^{T} a_{11}-P_{2}^{T} a_{21}$ and $\frac{d Y_{2}}{d L_{22}}=P_{2}^{T} a_{22}-P_{1}^{T} a_{12}$, increasing of national incomes by reallocation of labor between sectors $\left(\frac{d Y_{1}}{d L_{11}}>0\right.$ and $\left.\frac{d Y_{2}}{d L_{22}}>0\right)$ respectively require that $\frac{a_{11}}{a_{21}}>\frac{P_{2}^{T}}{P_{1}^{T}}$ and $\frac{p_{2}^{T}}{P_{1}^{T}}>\frac{a_{12}}{a_{22}}$, which are nothing but the conditions specified by the law of comparative advantages (in the direction we assumed above). "That is, if these conditions are satisfied, the first (second) country can increase its national incone (consumption opportunities) by allocating more of its resources to the production of the first (second) good. And national incomes are maximized in case of full specialization, which is the case where $L_{11}=\overline{L_{1}}$ and $L_{22}=\overline{L_{2}}$. The national income maximization problems in equation 1.5, also shows that gains from trade for any country is an increasing function of the difference between trade and its own autarky relative prices.

In case of full specialization, the first (second) country becomes the only world supplier of the first (second) good. Thus perfect competition mandates that world prices reflect production costs which can only be achieved if $P_{1}^{T}=w_{1} / a_{1}$ and $P_{2}^{T}=w_{2} / a_{22}$ (and for exogenously given world prices), equilibrium can only be maintained by relative wage adjustments. In the full specialization equilibrium, the relative wage rate (which, in this simple framework is the measurement of relative welfare) should satisfy $\frac{w_{2}}{w_{1}}=\left(\frac{P_{2}^{T}}{P_{1}^{T}}\right)\left(\frac{a_{22}}{a_{11}}\right)$. Therefore, the relative welfare of a country after trade is an increasing function of its terms of trade (the world price of its export good relative to that of its import good) and also its productivity in 
the production of its export good. Besides, in case of complete specialization, the productivity in the irmport competing sectors (which disappear) does not play any role in relatiwe wage determination.

Yet, this does not mean that productivity in the import competing sectors does not matter at all. In other words, if a good is to be produced and exported by a country, its production should be cheaper than it would be in the other country. Thus, following our example, regardless of whether a good is produced in a country or not, trade requires that $w_{1}^{T} / a_{11}<w_{2}^{T} / a_{12}$ and $w_{2}^{T} / a_{22}<w_{1}^{T} / a_{21}$. Rearranging yields

$$
\frac{a_{12}}{a_{11}}<\frac{w_{2}^{T}}{w_{1}^{T}}<\frac{a_{22}}{a_{21}}
$$

which points to the fact that absolute adwantages determine an interval for relative wages adjustments, within which specialization and trade is feasible. This alternative presentation of comparative advantage is especially important for formulations that generalize the Ricardian model to more than 2 countries and/or more than 2 goods.

Although this formulation clearly presents the universal gains from trade, in the way Ricardo explained with his example on trade of cheese and wine between Portugal and England, the absence of an explicit demand relation leaves a couple of questions open. First, how are the trade prices determined and accordingly how are the gains from trade distributed among the countries? Besides, are there any extra. requirements for full specialization? The original form of the Ricardian theory is criticized for these shortcomings, yet introducing a demand side on the basic framework is sufficient to save the theory from these criticisms. In an appendix to this chapter which is supplied on the accompanying $\mathrm{CD}^{5}$, we present an example where the introduction of an explicitly defined demand side is achieved on the basis of Cobb-Douglas preferences.

Other criticisms of the Ricardian model are mainly due to its simplicity in assuming only one factor of production, which makes it unable to say anything on the income distribution impacts of international trade. Besides, the model does not explain the reasons that bring about cross country differences in labor productivities and also it predicts extreme extents of specialization which can hardly be observed in reality.

\section{Generalizations of the Ricardian model}

-For 2 goods $n$ countries:

If at least 2 of the $n$ countries have different comparative costs, there are incentives for (at least those 2 countries) to get into trade. In other words if the countries can be ordered in such a way that

$$
\frac{a_{11}}{a_{21}}<\frac{a_{12}}{a_{22}}<\ldots<\frac{a_{1 n}}{a_{2 n}}
$$

then provided that the trade terms of trade $\left(P_{2}^{T} / P_{1}^{T}\right)$ strictly remains between the two extreme relative costs:

$$
\frac{a_{11}}{a_{21}}<\frac{P_{2}^{T}}{P_{1}^{T}}<\frac{a_{1 n}}{a_{2 n}},
$$

the countries satisfying the condition $\frac{a_{1 j}}{a_{2 j}}<\frac{p_{2}^{T}}{P_{1}^{T}}\left(\frac{a_{11}}{a_{21}}>\frac{p_{2}^{T}}{P_{1}^{T}}\right)$ will export the first, (second) good. 
-For $m$ goods $n$ countries:

Starting with $m$ goods and 2 countries consider the following ordering of $a b$ solute advantages:

$$
\frac{a_{12}}{a_{11}}<\frac{a_{22}}{a_{21}}<\frac{a_{32}}{a_{31}}<\ldots<\frac{a_{m 2}}{a_{m 1}}
$$

If the condition

$$
\frac{a_{12}}{a_{11}}<\frac{w_{2}^{T}}{w_{1}^{T}}<\frac{a_{m: 2}}{a_{m 1}}
$$

holds, reminding that unit costs (which has to be equal to the potential unit prices at the trade equilibrium) are $P_{i j}^{T}=w_{i} / a_{i j}$, the following two inequalities may be written as

$$
P_{11}^{T}<P_{12}^{T} \quad \text { and } \quad P_{m 2}^{T}<P_{m 11}^{T} .
$$

Since a good will be produced and sold by the country which has the least cost (price), this last inequality implies a potential scope (incentive) for the first (second) country to fully specialize and export the first (second) good.

The same logic can be generalized for $n$ countries as well (as formulated by Viner [1.937]). Arbitrarily choosing any country's real wage rate as the numéraire (say country 1) define the variable $O_{i j}$ such that

$$
O_{i j}=\log \frac{w_{j}^{T}}{w_{1}^{T}}-\log a_{i j} .
$$

Then the country $k$ which satisfies

$$
O_{i k}=\min \left(O_{i 1}, O_{i 2}, \ldots \ldots O_{i n}\right)
$$

should specialize on and export the good $i$ and import the goods in which it does not have such an advantage.

It must be recalled that the trade real wage rate vector is a function of trade world prices, thus the tastes of all countries and the labor productivity vector.

\section{For a continuum of goods and 2 countries:}

Dornbush, Fischer and Samuelson [1977], have geveralized the two country $m$ good model to a 2 country model with an infinite number (continuum) of goods by introducing a continuous version of the discrete chain in inequality 1.9 such that for the commodities indexed by $z$, where $0 \leq z \leq 1$.

$$
A(z)=\frac{a_{2}(z)}{a_{1}(z)}
$$

with $A^{\prime}(z)<0$. Then if $\varpi=w_{1} / w_{2}$, the first (second) country will specialize on the goods indexed with a number lower (higher) than $\widetilde{z}_{3}$ where $\widetilde{z}$ is defined as

$$
\tilde{z}=A^{-1}(\varpi)
$$

Given this negative supply side relation between relative wages $\varpi$ and the pat; tern of specialization $\widetilde{z}$, the determination of the values of these variables requires a demand side to close the model. The demand side is modeled by assuming internationally identical tastes and constant expenditure shares for each (differentiall) 
good $b(z)$ siluch that $\int_{0}^{1} b(z) d z=1$. Thus the fraction of world income spent on the products of the country specialized on goods $[0, z]$ becomes $\nu(z)=\int_{0}^{z z} b(z) d z$, whereas it is $1-\nu(\tilde{z})=\int_{\tilde{z}}^{1} b(z) d z$ for the other country. This leads to the positive relation $\omega=\frac{\mu(\widetilde{z})}{1-\bar{x}(\widetilde{z})} \frac{L_{2}}{L_{1}}$ between $\omega$ and $\widetilde{z}_{3}$, which can also be seen as the trade balance condition (i.e. the value of the imports of the first country $(1-\nu(\bar{z})) w_{1} \overline{L_{1}}$ is equal to the value of its exports $\left.\nu(\widetilde{z}) w_{2}, \overline{L_{2}}\right)$. The equilibrium point lies where $A(z)=\frac{w(Z)}{1-v(z)} \frac{T_{2}}{L_{1}}$, which impllies that the specialization pattern $(\widetilde{z})$ is jointly determined by technology, tastes and relative sizes (labor forces) of the countries. Simple comparative statics on these parameters yield the following conclusions.

1. Increase in the relative size of a country increases the range of products it produces, while reducing the wage rate relative to the other country. Welfare effectsi are ambiguous.

2. A (uniform) reduction in the unit labor requirements in a country, changes the comparative advantages in favor of this country. The country increases the range of its products and enjoys higher relative wages. Intermational diffusion of (least cost) technologies on the other hand, reduce wage differentials.

3. Demand shift towards the products of a country increases the relative wage rate but decreases the range of the products of the country. Due to taste changes welfare effects can not be identified.

4. Unilateral transfers have no effect. The reason is the fact that (in this model where tastes are identical and all goods are tradable) they do not change the world demand structure.

The model is further extended to capture non-traded goods as well. Simply assuming that $(1-k)$ of income is spent (everywhere) on non-traded goods (so that $\int_{0}^{1} b(z) d z=k$ where $\left.0 \leq k<1\right)$, the equilibrium condition changes slightly to $A(Z)=\frac{\nu(\tilde{z})}{k-v(\tilde{z})} \frac{\bar{L}}{L_{1}}$. In this case, a unilateral transfer has an impact. The trade balance equation that reads $[\mathbb{1}-\nu(\widetilde{z})-(1-k)] w_{1} \overline{L_{1}}=\nu(\widetilde{z}) w_{2} \overline{L_{2}}$ in the absence of a transfer, can be reformulated as $(k-\nu(\widetilde{z}))\left[w_{1} \overline{L_{1}}+T\right]=T+\nu(\widetilde{z})\left[w_{2} \overline{L_{2}}-\right.$ $T^{7}$, where $T$ denotes a transter from the second country to the first. If $T$ is measured in terms of the wage rate of the second country (i.e. $T^{*}=T / w_{2}$ ), the equilibrium condition changes to $A(\tilde{z})=\frac{\nu(\tilde{y})}{k-\nu(\tilde{z})} \frac{\bar{L}}{L_{1}}+\frac{1}{k-\frac{k}{k}(\bar{z})} \frac{T^{*}}{L_{1}}$, which apparently shows that at the new equilibrium, the transfer results in higher relative wage and a lower range of commodities produced in the first country. This difference in the result of the transfer is due to the fact that (thanks to the existence of nontradables), the increase in the value of the imports of the first country is less than the transfer, which leads to a trade surplus at the initial relative wages. Thus, at the equilibrium, the surplus is eliminated by an increase in the relative wage of the first country which brings about an improved terms of trade.

As we will discuss later, this generalized model has been widely used in many other models as the basic specialization module. 


\section{-Ricardian model with increasing returns to scale:}

Ethier [1982a] builds a model that aims to generalize the Ricardian model in the existence of increasing returns to scale in one sector. As a well known property, increasing returns to scale internal to firm normally lead to a theoretical inconsistency with perfect competition. Yet, consistency can be maintained (as will be discussed later in this chapter) by assuming that the externality is external to the firm and internal to the industry. Amother way to introduce increasing returns to scale is to assume monopoly in the sector, where the monopolist, faced with the threat of potential entrance of new firms, resorts to average pricing and makes zero economic profits. Increasing returns to scale is introduced into only one sector (manufacturing) through the production function $Q_{M}=\left(L_{M}\right)^{\alpha}$ (where $\alpha>$ 1). The other sector (wheat) remains with constant $\left(Q_{W}=(L w)\right.$ ) or decreasing $\left(Q_{M}=\left(L_{M}\right)^{\beta}\right.$ where $\left.0<\beta<1\right)$ returns. The analysis of the model reveals that the Ricardian model predictions are mostly immune to the presence of increasing returns. Nevertheless, Ethier argues that cases in which a country can suffer from engaging in trade (and which accordingly justifies protection by policy), are only confined to trade between more or less equally sized countries. Besides, the loss of one country (the wheat producer) can happen only when preferences have sufficient: bias toward manufactures, and surprisingly if the degree of increasing returns is not too strong (i.e. $\alpha$ is not too large).

\subsubsection{The traditional neoclassical models}

The neoclassical approach to international trade, which is essentially a general equilibrium approach, can be found in any textbook and we will not go over the details of the whole theory. Instead, we will mention the basic assumptions and adjustment mechanisms and also two salient examples of the neoclassical modeling, which are the Heckscher-Onlin-Samuelson model and the specific factors model.

Given the usual tools of the neoclassical school, the resulting theories are theorems based on a series of comparative statics that compare various key outcomes (resource allocation, income distribution, prices etc.) of the autarky and trade equilibria. The difference between the formulations of these two cases mainly relies on the demand side. In the autarky case, the consumption of any good by the residents of any country is equal to the country's production of that good (thus, the consumption vector is a point on the production possibility lrontier characterized by the tangency point of an indifference curve), whilst the relative prices can be inferred from the slope of the production possibility frontier at the point of production and consumption. In the trade case, the equality of world demand and supply for each good (consistent with the BOP constraint) is the sufficieat condition for the good markets. Therefore, for any country, the consumption wection after trade is not necessarily on the production possibility frontier but somewhere on a line tangent to the frontier. In cases where the mathematical properties of the production function (decreasing or constant returns in all sectors) result in a production possibility frontier which is concave to the origim, together with the convexity of the indifference curves, one may see that the points on the line tangent to the production possibility frontier is apt to yield a higher utility than the tangency point which is known as the consumption gain from trade. Furthermore, if the world reallocation of resources in response to the opening of trade (convergence to one world price vector instead of the autarkic two) leads to a more efficient allocation of the world resources, this change is called the production gains from trade. 
What we have described so far only constitutes the general framework of the neoclassica: approach to international trade and no clear-cut results regarding international trade can directly be inferred from the framework itself. The predictions from this general framework about the patterns of trade and the resulting gains depend on some additional assumptions (on functional forms and parameter settings that describe the production and utility functions and also on the endowments).

The adjustment process that is supposed to bring the trading economies to the general equilibrium point, the properties of which are the focus of the neoclassical models is no different than the typical adjustment process that one can find in an introductory economics text book. This process is supposed to work by a tâtonrement like process (by the famous invisible hand), which leads to existing and unique equilibria only if a number of assumptions are satisfied. The invisible hand (who works through the price mechanism) introduces a perfect metarationality, which nomally can not be expected from the individual economic agents.

At any price vector other than the one that is the solution to the general equilibrium problem, there exist excess supply or excess demand to some good or product. Excess demand (supply) in goods market implies marginal costs lower (higher) than market price which gives firms of that sector a signal to increase (decrease) production. Furthermore, disequilibrium in goods markets implies prices higher (lower) than average costs, which implies sectoral profits (losses), thus signals for new firms to enter (some firms to exit). Since the endowments are assumed. to be fixed in supply, within each country, growth of some (profitable) sector, which requires higher amounts of factor inputs, is maintained by the smooth shift of those factors from the sectors that are not profitable and thus should shrink in output. The amount of factor transfer between sectors is determined by the techniques of choice (profit maximizing techniques given prices) among the infinite costless possibilities offered by the production function ${ }^{6}$ and at each point of the adjustment mechanism (each new cost minimizing production technique), the output combination creates a new excess demand (supply) structure for factors, which further feedback the system with another input price vector, and thus further choices to be made. At the cost of repeating ourselves, we find it useful to re-mention that the whole process relies on the firms' deliberate and rational choices of techniques amongst a continuum of timely and costless set, and the generic nature of the fully mobile (within country) factors which makes them smoothly reallocatable between sectors. In other words, constrained by the production and utility functions and the factor endowments, agents simply try to use (consume) less of the relatively expensive factor (good).

Within the neoclassical framework, two models have received special attention. The reason is apparently the clear-cut strong results they suggest. Naturally, these results are obtained by extra restrictive assumptions at the top of the usual neoclassical general equilibrium assumptions.

In comparison to the original Ricardian model, the traditional neoclassical models of trade basically introduce two important elements into the picture. The first is, as discussed before, the demand side (which mostly assumes similar tastes across countries) and the second is the dependence of production on more than one production factors. Therefore, the first logical step is to make an analysis of the demand side, isolated from the production side, which is the exchange model. 


\section{The Exchange Model}

Once production levels are fixed to exogenously given magnitudes (outputs do not respond to price changes), international trade reduces to an exchange problem that: can be analyzed with the standard Edgeworth box framexork whene determination of prices and the distribution of products over individuals are explained by tasted and initial (given tastes, potentially suboptimal) endowments. With this tool, the standard issues of exchange may be revisited in the international trade context. These issues are:

- Stability of equilibrium: In the general equilibrium framework, due to the non-negative relation between price and output, output response of firms always enhances stability ${ }^{7}$. Therefore, eliminating the production side is a convenient way to isolate the stability problem inherent to exchange economies that is sourced by the possible asymmetric income effects in demand. The conclusion of such analyses is the fact that instability only arises in cases where each country has a higher marginal propensity to consume its own export good. That is, any rise in the price of a country's export good (which raises the real income of that country and lowers the other) tends to increase the world demand for that good instead of decrease (Jones [1961, 1974a], Dornbush [1975]).

- Regarding terms of trade, again in cases where a country has a higher marginal propensity to consume (than the other country) its own export good, the opening of trade will worsen its terms of trade (Samuelson. [1952]).

- It is also possible to study the effects of exogenous shocks on the income distribution between countries. Particularly, the case known as ummiserizing growth" arises when growth introduces a burden to a country due to an increase in excess demand for imports at the initial terms of trade. This may of course happen only if the import demand elasticity of the growing country is sufficiently higher than the rest of the countries. In such a case, since the supply abroad does not match to the increased import demand, the deterioration (for the growing country) in the terms of trade may be enough to leave it worse off (Johnson [1953,1955], Bhagwati [1958]).

- The exchange model is mainly used to study the effects of tariffs.

\section{The $2 \times 2 \times 2$ Heckscher-Ohlin-Samuelson Model}

The introduction of the following extra assumptions into the two-country, twogood, two-factor (originally capital and labor) neoclassical framework leads to the Heckscher-Ohlin-Samuelson (H-O-S) model:

1. The structure of demand is identical in both countries (the aggregated customers that represent each country are characterized by one and the same homothetic utility function with the same preference parameters). In other words, the proportions in which the two goods are consumed are identical in both countries at any price and independent of the level of income.

2. Both countries has excess to the same set of available production techniques. That is, the production function of any good is the same for every country but different than that of the other good.

3. Furthermore, the production functions exhibit positive but decreasing returns to each factor (positive first, negative second partial derivatives with 
respect to each factor) and constant returns to scale (first degree homogeneity).

4. No factor intensity reversals in production. This assumption requires that if the capital-labor ratio $\left(K_{k} / L_{k}\right)$ that characterizes the cost minimizing beclanique chosen by the representative firm (of sector $k$ of any country) at some given relative factor price $\left(p_{K}^{0} / p_{L}^{0}\right)$, is greater (or less) than the cost mimimizing capital output ratio $\left(K_{m} / L_{m}\right)$ for the other sector $(m)$ of the same country (of course at the same relative factor price), than the same condition should hold for all factor price ratios $\left(0<p_{K} / p_{L}<\infty\right)^{8}$. This assumption makes sure that the classification of the goods according to their factor intensities becomes unambiguous so that the goods can be ranked according to their intensity to any factor, independent of the relative factor prices.

5. The relative endowment structure is asymmetrical between the countries. That is, each country enjoys the relative abundance of only one of the factors.

The Heckscher-Ohlin model is an analytical proof of the following theorem under the assumptions mentioned above:

If two countries open to trade, each country will tend to export the good, which uses the country's more abundant factor more intensely. Furthermore each country gains from the opening of trade in terms of increased welfare (broader set of consumption possibilities).

There are also three corollaries to the theorem. The first is known as the "factor price equalization" theorem (by Samuelson):

If none of the countries specializes completely as a response to the opening of trade (the general equilibrium problem yields an interior solution for both countries), not only the relative but the absolute factor prices equalize across the countries.

The second corollary is the Stolper-Samuelson theorem on income distribution properties and points to the effect of protection/trade on real income of the factor owners.

Increase in the relative price of a commodity increases the real income (rental rate) of the factor ased intensively in the production of the commodity, while the real income of the other factor decrease.

The last corollary is the Rybczynski theorem:

At fixed commodity prices, an increase in the endownent of one factor brings about a more than proportional increase in the output of the commodity that uses this factor and a decrease in the output of the other commodity.

It is possible to describe the properties of the $\mathbf{H}-\mathrm{O}-\mathrm{S}$ model in more than one ways, most of which are based on the dual model formulation of the general equilibrium problem that describes the H-O-S conditions. In an appendix to this chapter which is supplied on the accompanying $\mathrm{CD}^{9}$ "we provide an explicit demonstration which draws on the presentation in Jones and Neary [1984] and assumes Cobbm-Douglas production functions.

\section{Some generalizations of the $2 \times 2 \times 2 \mathrm{H}-\mathrm{O}-\mathrm{S}$ model}

- 2 countries, 2 factors, many goods: It was shown by Jones [1956] that, similar to the Ricardian model generalization, within a chain of factor intensities which ranks commodities according to their capital-output ratios with no 
factor intensity reversals) it is possible to find a threshold point, the products above (below) which are produced by the capital (labor) abund ant country. Yet, it was later shown by Deandorff [1979] and Bhagwati [1972] that the validity of this positive argument is restricted to the prevalence of autarky factor price differences across countries in trade as well. It is concluded that in cases where the number of commodities is highen than the number of factors, factor price equalization brings about indeterminacy of the specialization pattern, though factor equalization and Stolper-Samuelson properties remain intact.

- This indeterminacy is shown to resolve partially (Jones [1974b]) in case of a (price taking) small country. The small country produces goods, the capital intensity of which are close to its own factor endowment proportions. Yat; the country's imports do not reflect the relative endowment structure in the country.

- If the number of factors are higher than number of goods (say m), contrary to the $2 \times 2 \times 2$ model, factor prices are not determined solely by commodity prices anymore ( $m$ unknowns 2 equations). The complications further induced are well illustrated by the specific factor's model, which we will discuss below.

\section{The Specific Factors Model}

This model is developed by Jones[1971] and Samuelson [1971]. With regard to its assumptions, the model is quite similar to $\mathbf{H}-\mathbf{O}-\mathbf{S}$ but diverges from it in one major respect. Instead of both, only one factor of production is assumed to be mobille between sectors whereas production in each sector is dependent on a second sector specific factor which is immobile, which in total makes three types of production factors. To visualize, one may think of two sectors, manufacturing and agriculture, both using the common factor labor, where the former requires capital (and no land) and the latter requires land (and no capital) for production.

The specific factor model, unlike the $\mathbf{H}-\mathbf{O}-\mathbf{S}$, does not provide clear-cut propositions on factor price equalization and specialization, yet surely, unlike in the Ricardian model, complete specialization can not take place since the model assumes that all factors are fully employed. The main effect of international trade is to reallocate the mobile factor between the sectors, which is accommodated by changing production techniques so that full employment can be maintained and thus the full employment constraint on all endowments imposes an upper limit to the amount the mobile factor (labor) that can be reallocated between the sectors. In other words, in comparison to the Ricardian model, the presence of sector specific factors introduces a friction mechanism to inter-sectoral reallocation of labor, which prevents complete specialization. However, the Specific Factors model bears some resemblance to the original Ricardian model if the sector specific capital is interpreted as technological inputs (that determine the sectoral productivity of labor). Yet, the important dissimilarity is the fact that in the Ricardian model, the sectoral marginal (average) productivities of labor are assumed to be constant, while in the specific factors model they are variable and dependent not only on the sectoral abundance of the specific factor but the nation-wide abundance of labor: relative to the specific factor endowments and also the sectoral allocation of the labor force.

For an analysis of the specific factors model, it is not fruitful to follow the unit cast curve approach (that is used in the demonstration of the H-O-S model 
which we present in the second appendix to this chapter). The reason is the fact that in the specific lactors model, due to the presence of three production factors, mutual dependency between sectors is not a matter of finding a wage-capital rental rate $(w-r)$ combination that is consistent with the efficient production in both sectors. Instead, the efficient production is characterized by the equalization of marginal product values to factor rewards such that (for $M P_{i}^{*}$ denoting the marginal product of factor $k$ in sector $i) w=M P_{L}^{1} P_{1}=M P_{L}^{2} P_{2}, r_{K 1}=M P_{K 1}^{1} P_{1}$, and $r_{K 2}=M P_{K 2}^{2} P_{2}$. The former equality requires that $\frac{P_{1}}{P_{2}}=\frac{M P_{L}^{2}}{M P_{L}^{1}}$, so that price increase of the product of a sector, should be accommodated by decreasing (increasing) the marginal productivity of labor in that (the other) sector. Since the endowments of the specific factors are constant, marginal productivity of labor in any sector is a decreasing function of the amount of labor employed in that sector (or the share of labor employed in that sector) and therefore price increase of a good can only be accommodated by employing more labor to increase the output in that sector. Thus, employment and output of a sector is an increasing function of the price of the good. The latter two equalities point to the independency between the determination of the eamings of the two specific factors (which are not necessarily equal). These equations simply show that the earnings of the specific factor owners are simply increasing in the price of the good that uses the specific factor in question. Besides, the increase in these earnings are more than proportional to the price increase due to a magnification effect that also increases the marginal productivity of the specific factor in response to the increased employment in the sector. To illustrate, assume that the price of the first good increases and let us write the marginal value product equation in rate of change form: $\widehat{T K 1}=\widehat{M P_{K 1}^{1}}+\widehat{P_{1}}$. The price increase of the first good (due to labor market equilibrium) will divert a higher proportion of the labor force to the first sector, and since the specific factor used in sector $\mathbb{1}$ is fixed in supply, a higher labor input will increase the marginal productivity of this specific factor $\left(\widehat{M P_{K 1}^{1}}\right)$. Thus, $\widehat{r_{K 1}}>\widehat{P_{1}}$, which shows that the owners of the factor specific to sector 1 are unambiguously (measured in both commodity prices) better off. Yet the same type of analysis shows that, since the marginal productivity of the labor decreases in the first sector $\left(\widehat{M P_{L 1}^{J}}<0\right)$, it follows that $\widehat{w}>\widehat{P_{l}}$, which implies that wage earners are worse off in terms of the price of good 1 and better off in terms of the price of the second good (provided that $\widehat{M P_{L 1}^{1}}<\widehat{P_{1}}<=>\widehat{w}>0$, since our comparative statics assume $\widehat{P_{2}}=0$, change in the wage rate must be such that $\left.\widehat{w}>\widehat{P_{2}}\right)$. Therefore, the effect of a price change on the real return to labor $\left(\alpha\left(\widehat{w}-\widehat{P_{1}}\right)+\beta\left(\widehat{w}-\widehat{P_{2}}\right)\right.$, where $\alpha$ and $\beta$ denote the relative importance of the goods for the customer) is not unambiguous and is a matter of tastes.

Similarly, unlike in the H-O-S model the factor endowments and factor intensities do not unambiguously imply an pattern of trade. Instead, factor prices and pattern of trade are also functions of demand elasticities thus the parameters of the utility functions. In order to clarify the properties of the Specific Factors model, as we have been doing so far, in an appendix to this chapter which is supplied on the accompanying $\mathrm{CD}^{10}$, we supply a specific example using Cobb-Doug]as type production and utility functions.

\section{Increasing returns to scale and traditional neoclassical models}

The well-known problem of neoclassical tracle theories with increasing returns to scale (IRS) is the distortions it induces on the (otherwise concave) production 
possibility frontier (PPF). Following Gandolfo [1987] these distonthons (for a 2 commodity neoclassical model) can be classified as ${ }^{11}$ :

- Slight IRS in both sectors make the PPF strictly convex near the coordinate axes and strictly concave in the intermediate region,

- The PPF is strictly convex everywhere if and only if no sector has decreasing returns to scale and one sector has strong IRS,

- The PPF has at least one point of inflection if there are IRS in one sector and decreasing returns to scale in the other,

where convexity/concavity are referred to the origin, IRS in one sector is de fined via a homogenous production function of degree higher than the other sector, and the factor intensities of the sectors are assumed to be different. In case of equal factor intensities, conclusion number 2 does not require a strong IRS in one sector.

The properties of a case where two countries with strictly convex. PPFs open to trade, are again summarized by Gandolfo [1987] as

- In general there are multiple equilibria, and the direction of trade may be ambiguous.

- The world relative prices that emerge after trade may lie outside the interval between the autarky relative prices.

- Even if relative prices are equal in the autarky, international trade may still take place.

\subsubsection{Economic growth in traditional models of trade}

Until the emergence of new trade theories, intemational trade theory and growth theory were separate fields of economics, trying to explain different phenomenon. Within this division of labor scheme, the former was responsible for understanding the resource reallocation that takes place once and for all and the welfare implications of trade in comparison with no trade, while the subject of the latter was of a temporal nature, that aims to see the effects of accumulation and technological change on growth over time. Although, possible effects of international trade on growth performance were not unthought of, such lines of causation could not be formalized before the introduction of new growth/trade theories, which incorporated endogenous sources/processes of growth (as substitute/complementary to the traditional exogenous sources) that may behave differently in the presence of: trade.

Yet, causal links running from exogenously determined growth to variables in the domain of international trade theory were somehow explored already before the new trade theory. The first of such efforts are the comparative statics exercises that explore the effects of factor endowment changes on trade patterns and welfare. Although such exercises only point to the impacts of once and for all changes, they are yet capable of describing the direction of the changes in endogenous variables in response to growth of factor endowments and/or productivities. One of the most well known of these comparative statics is Rybczynski's theorem, which as discussed before, asserts that an increase in the quantity of a factor (given the other) will cause an increase (decrease) in the output of the commodity, which is relatively more (less) intensive to that factor.

Another one is by Johnson [1959], who classifies the effects of growth on trade based on a small (price taker) country assumption, which implies unchanged terms of trade. In other words, the changes in the country's demand for imports and 
supply of exports have negligible effect on world prices. Growth shifts the production possibility frontier and (due to the openness of the economy) the national budget line outwards and the new equilibrium can be compared to the old (before growth) in terms of consumption and production separately. On the demand side, the question is whether the increase in national income (due to growth) will ceteris paribus (i.e. ignoring production effects and assuming unchanged terms of trade) increases the demand for the importable or the exportable good proportionally. In other words "Will growth increase or decrease the self sufficiency of the country?". The case where demand for the importable (exportable) increases more than proportionally to the increase in national income is called the "pro-trade based" ("anti-trade biased"). The same classification can be made with regard to production as well. Growth bringing about (again ceteris paribus) a more than proportional increase in the production of the exportable (importable) it is called "pro-trade biased" ("anti-trade biased"). With regard to both (production and demand), equiproportional increases are called "natural". The effect of growth on trade volume is an outcome of the combination of these two separate effects.

We can give an example on a neutral case following our Ricardian model example with Cobb-Douglas preferences (which can be found in the first appendix to this chapter). With Cobb-Douglas (fixed income shares for goods) preferences, demand for all goods is always neutral with respect to growth. On the other harnd, in the Ricardian model, a small country is always completely specialized and therefore income growth (which can only happen in case of labor force growth or productivity growth in the production of the export good) always brings about a proportional increase in the output of the export good. Consequently, self sufficiency of the small country (trade pattern) is neutral with respect to income growth, unless income growth is caused by a productivity increase sufficient to disturb the existing comparative advantage structure.

Departing from the small country assumption, change in the terms of trade (relative commodity prices) turns out as another source that determines the resulting trade volume and the favorableness of trade. As a consequence of growth, the terms of trade can deteriorate (the relative price of the importable increases) so much that growth might cause a reduction in the welfare of the growing country which is called "immiserizing growth" (Bhagwati [1958]). We hawe already presented a case of immiserizing growth in our discussion of the Ricardian model where in case of complete specialization, increase in the labor force of one country may lead to a decline in welfare of that country, due to worsening of its terms of trade. Yet, this trend does not go forever. If the labor force keeps on growing in only one country (or labor forces of the countries grow with different rates), complete specialization does not prevail and eventually the faster growing country starts to produce both goods and the slow growing country turns into a price taker (small country). After this point both countries enjoy the labor force growth in any country but without doubt the small country reaps a greater deal of the world income growth (recall our previous discussion on the fact that in case of incomplete specialization of one country, the entire gains from trade are reaped by the completely specialized country).

On the technological change side, following the Hicksian classification of technical change (Hicks [1932]), the isolated effect of technical progress as a source of growth is studied (see Findlay and Grubert [1959], and Gandolfo [1987] pp.178184). Technical chance is classified as neutral, capital saving and labor saving ${ }^{12}$. Given this classification, the neoclassical analysis yields the following results:

1. Neutral technical change in one sector decreases the relative price of the 
innovating sector"s product.

2. A similar result will occur if a capital (labor) saving technical progress takes place in the capital (labor) intensive sector.

3. Other combinations lead to ambiguous results. In all cases the change in terms of trade is in favor of (against) the country if the innovating sector produces an importable (exportable).

The models that relate international trade and growth in a traditional sense (perfect competition and non-increasing returns) are not confined to comparative statics, and there is a broad literature on dynamic models as well. A salient one of this (Findlay [1974]) draws on the Ricardian model, and suggests that although the beauty of the comparative advantage story that points to the static gains from trade was adopted by the economic theory, Ricardo's main point in his Essay was actually on gains for growth, which is of a dynamic nature. The model by Findlay that aims to present this dynamic description of Ricardo, assumes an economy that produces only corn and manufactures. Four important assumptions make the model diverge from the standard one. The first two are that there is a natural (subsistence) wage (paid to workers in terms of corn), and wages are paid in advance. Therefore, the production in the economy at a point in time is confined to the available stock of corn (wage fund) that can be invested in advance to produce the output, which comes after a time lag. Thus, the wage fund is nothing but the capital stock of the economy. The third one is that, since land (which is necessary to produce corn) is limited in supply, marginal productivity of labor in the corn sector is decreasing in output. The fourth assumption is that the capitalists are utterly thrifty and they invest their entire profits (thus landlords are the solemn customers of the manufactures) so that the wage fund grows by the profit rate.

In the case of a closed economy, perfect competition equates the rate of profit between the sectors. As time passes and the wage-fund grows, since decreasing marginal productivity of labor in corn production reduces the economy-wide profit rate, at the point where the marginal product of labor in corn production equalizes with the natural wage rate, profits become zero and at this steady state accumulation stiops.

Since the relative price of the manufactures, profitability and accordingly the capital accumulation in the economy are dependent on the marginal productivity of labor in the corn sector, international trade makes it possible to buy cheaper corn from abroad (where the power of the soil is not exhausted yet) in return for manufactures. With world corn prices lower than in home prices, it is possibie to feed the increasing domestic labor force, which can be employed in the manufacturing sector in order to increase manufactured output thanks to sustained profitability made possible by international trade (cheaper corn). Meanwhulle, the trading partners (who do not have access to a high wage-fund/capital as much as home) can enjoy the mamufactured output produced and exported by home. Yet, in the very long run, where the productive powers of land is pushed to the extremes also abroad, the stopping of world accumulation is still inevitable.

The model by Findlay, which reflects the "decreasing marginal productivity" based growth pessimism of Ricardo, has important similarities with the H-O-S moclel and the Specific Factors model as well. The model, specifies two sector specific factors (capital and land) and one intersectorally mobile factor (labor) as in the specific factors model. It also incorporates cross-country differences in the relative abundance of land and capital (wage-fund), and given that given 
that corn (manufactures) production is labor (capital) intensive, the capital (land) abundant country exports the capital (land) intensive good. Trade decreases the relative price of the land intensive corn and landowners at home are hurt while the capitalists are better off (as in the Stolper-Samuelson theorem). Accordingly, the landowners of the com exporting country are better off while the capitalists are hurt. Thus, in the corn exporting country, trade implies a reduced rate of growth, since the fall in profits imply a lower rate of capital accumulation and growth. Meanwhile, the increased rents of the landowners are fully used to import the manufactures, which can be considered as luxury. This suggestion in the context. of development is fully in line with the "dependency" arguments of the free trade sceptics

Another model by Findlay [1.981] is referred to as the Lewis-Ricardian model, since the point made is basied on an analysis by Lewis [1954] on trade between advanced and developing countries. In the corresponding model of two countries, three goods are produced. The advanced North produces Food and Steel, while the less developed South produces Food and Coffee. The labor productivity in Food production is assumed to be higher in North than in South. Due to perfect competition and tradeability, the relative prices of Coffee and Steel (measured by Food) are determined purely by cost independent of demand (demand only determines output levels). Thus, North (South) exports Steel (Coffee), and the deficit in this exchange may also lead to a net flow of Food between the countries. Given this setting, the essence of the model relies on the dynamic presumption that productivity increase in Food (Coffee) is higher than in Steel (Food) in the North (South). Thus in comparison to the value of Food the value of Steel (Coffee) increases (decreases) in North (South), which deteriorates the terms of trade (price of Coffee relative to that of Steel) for Sonth over time. Assuming that the income share spent on Coffee is not very high in both countries (and even lower in the South), for South productivity increases in Coffee does not bring about much welfare gain since imports do not increase significantly due to decreased terms of trade. Yet, welfare implications are totally different for productivity increase in South's Food sector, which not only increases consumption directly, but makes more Steel available due to increased terms of trade (increased price of Coffee in terms of Steel).

In the neoclassical domain, one can find other lines of inquiries, some of which can be seen as extensions of Harrod"s growth model and multi sector growth models (e.g. Uzawa [1961]) to open economies. Growth models are mainly about the accumulation of capital in time and therefore in the context of growth, it is not possible to treat capital as a fixed endowment anymore. It must be produced and its accumulation must be determined by investment. This fact was successfully used to save the traditional neoclassical models from the major critics on the way they unrealistically specify capital as an endowment. Additionally, the H-O-S assumption that makes capital perfectly mobile between sectors (which is ruled out by the specific factors model) has been an important source of criticism as well. For example as pointed out by Neary [1978] p.507 (and as quoted by Smith [1984], p.298):

medium run resource allocation does not for the most part take the form of a diversion of physical capital equipment from one use to another, with the total stock of homogenows, infinitely long-lived machines remaining constant throughout. Rather it appears frequently to take the form of a slowing down in the rate of replacement of depre- 
ciating capital goods in the declining sector, coinciding with a rechanneling of new investment towards the expanding sector. Once it is recognized that investment requires abstinence from consimption, it is clear that except under very strong assumptions, this process will lead to a change in the total capital stock between the old and the new long-run equilibria.

One line of the important studies that respond to these criticisms (Oniki and Uzawa [1965], Johnson [1971], Deardorff [1973]) assumes that one of the commodities is capital, whereas the other is a consumption good. In order to retain the immobility (of factors) assumptions, the capital as a flow (annual product as a commodity) is assumed to be tradable, whereas the stocks (capital already produced and added into the capital stock as a primary factor of production) are strictly non-tradable (immobile). Thus for each country, the change (increase) in capital stock is equal to its capital production plus its net capital imports. Finally, the model is closed by the introduction of a savings function (out of national income in some, and out of profits in some other models), which determines national demands for capital (and the rest, the unsaved part constitutes the national demands for consumption) and letting the labor forces grow exogenously. Such a model is typically investigated for the existence and the properties (including specialization) of the growth path and also the convergence properties. The important requirement for uniqueness and stability is the assumption that the consumption good is more capital intensive than the investment good. With this assumption, the model leads to a steady state that exhibits H-O-S properties. The country with the higher propensity to save specialize and export the capitial intensive consumption good, while the country that grows in population produce and export the less capital intensive investment good.

A similar and highly interesting model by Findlay [1970] does the trick in a way that is even closer to the spirit of the original $\mathbf{H}-\mathbf{O}-\mathbf{S}$ model. The two traded consumption goods specified with different capital intensities use the capital produced by the third sector, which produces the nontradable capital goods. The revenues of the capital sector are financed by the savings of the country and therefore the country with the higher propensity to sawe keeps on building a capital stock, which becomes larger than that built by the other country (at all times). The only restriction required for stability is that the capital intensity of the capital good sector is between those of the consumption sectors. In the steady state growth path (where population and capital growth rates converge), the country with the higher (lower) savings propensity exports the capitall (labor) intensive good, thus across country differentials in saving propensity and labor force growth rates assume the role of the differences in factor endowment proportions in the original static H-O-S model.

Equally important is the fact that there is nothing in the model that excludes the sector-specificity of capital per se. Capital, once produced and installed, can well be assumed to be intersectorally immobile, yet the financial capital (savings) is perfectly mobile since it can be used in the production of any sector specific capital good. Since the capital is produced on demand, the inevitable across sectors differentials in rate of return on capital (which inevitably happens due to the endowment nature of capital in the original specific factors model) is eliminated on this model. If capital is defined to be sector specific, the only restriction may be that the production of each capital variety should be produced subject to the same production function. 


\subsubsection{Empirical testing of traditional models and neo-endowment approaches}

As discussed by Deardorff [1984], there exist many complications in testing of the trade models, due to the enormous differences between the abstract worlds specified by theoretical models and the reality. The results that the models generate essentially are proofs of theorems that point to a necessity relation between a set of well defined assumptions and some specific outcomes. First, trade models almost always start with specifying two fictitious countries and make comparative statics between tracle and autarky cases and generalizations to many countries many goods and many factors generally lead to a significant amount of complexity and ambiguity (for example recall the fact that if the number of goods is larger than the number of factors the trade pattern in the $\mathrm{H}-\mathrm{O}-\mathrm{S}$ model is indeterminate). Therefore, the first question that trade models fail to answer is "with whom do countries trade?".

Second, trade models, which are based on the law of comparative advantages, explain trade as a matter of autarky and trade relative prices, yet in reality there exists no definite time point, at which countries (not trading at all so far), suddenly fully liberate trade. Therefore, in reality there is nothing like "autarky prices" that: can be observed. Besides, in reality countries have been trading since a long time, but it is still hard to define any country as completely open to trade. There have always been many non-tracled goods, and the tradeability of any good may differ with respect to different trade partners. For example a good that is tradable among the EU partners may be mon tradable between an EU country and the USA or an Asian country. Shortly, it is very hard to classify the openness of countries with respect to the rest of the world.

In addition to the perfect tradeability of all goods, trade models generally assume that transportation costs are zero. Of course, there are models that aim to incorporate transportation costs and non-tradable goods, yet the original versions of the basic theoretical (Ricardian, Specific Factors, H-O-S) models, which generate the well. known strong predictions of the trade theory (and which have mostly been subject to empirical testing) ignore these issues.

The other complication is with the trade volumes. The law of comparative advantages itself only points to the direction of trade but not to volumes. Except for differences in country characteristics, trade volume is a matter of demand, and also the relative country sizes and transportation casts impose an upper limit to it. The general versions of comparative advantage based general equillibrium models (such as Ricardian or $\mathbf{H}-\mathbf{O}-\mathbf{S}$ ), can potentially be refined by parametric demand modules, and absolute levels of factor endowments, yet in the existence of the above mentioned complications this proves to be a rather futille effort. A very interesting set of studies ${ }^{1.3}$ that point to the importance of relative country sizes and distance related cost are commonly known as gravity-type models, since they specify bilateral trade volumes as nonlinearly increasing in country volumes and non linearly decreasing in the distance between the two countries, in a way similar to the gravity equation in physics that specifies gravitational forces between two bodies as increasing in either masses and decreasing exponentially by the distance in between. Billateral trade flows naturally include intraindustry flows as well. Since this type of formulations do not explicitly draw on any of the accepted trade models and basically follow common sense, they are typically stigmatized as ad hoc, yet empirically (on the basis of cross-sectional data) they were shown to be capable of explaining almost $80 \%$ of the variance of bilateral trade flows among 
large sets of countries.

Yet, another major source of complication lies in the strength of the trade balance constraint, on which the predictions of trade models strongly depend. In reality this constraint is often violated and countries may build up trade deficits (international debt) or surpluses for prolonged time intervals. Theoretically, in case of persistent trade balance violations, the results of trade models become ambiguous.

With all these complications in mind, the testing of traditional models essentially reduces to a search for any correlations between the flow of aggregated sets of goods and the differences in given characteristics of arbitrarily chosen (and/or aggregated) countries. In many studies, one of the countries is the USA, trading with the rest of the world. It is clear that such tests, which are based on a basic verification of the existence of correlations, are far from testing the causal mechanisms asserted by the models, but are confined be plausibility checks for the main predictions of the models.

\section{Empirical testing of the Ricardian model}

At the outset, the Ricardian model, which predicts complete specialization, has accordingly a major theoretical shortcoming with respect to evidence: such extreme specialization patterns do not exist in reality. Even if such extremity were observed, there would be another big problem of observability: how to guess the labor productivity in a sector that does not exist anymore in a country due to the de-specialization brought about by comparative advantages? Nevertheless, since complete specialization does not exist in reality, labor productivities remain observable and if the absence of full specialization is somehow justified (e.g. transportation costs and/or intraindustry trade), the plausibility of the essence of the Ricardian theory can still be tested potentially. The other shortcoming of the Ricardian model, as discussed before, is the fact that it does not explain the reasons underlying across country labor productivity differentials (and their change over time) and takes these as given constants.

The most well known test of the Ricardian model is by MacDougal [1951,1952], who successfully detects the existence of a strong and positive cross-sectional relation between the sectoral breakdown of U.S. to U.K. exports ratios and the sectoral breakdown of U.S. to U.K. labor productivity ratios, through a log linear regression on the basis of 1950 export data. Following the same methodology, a similar significant correlation was detected by Balassa [1963] in 1951 data for the same countries as well.

In comparison to the original Ricardian model that specifies trade between two countries, MacDougal's approach, which compares the trade performance of two countries with the rest of the world, can clearly be seen as a major divergence from the original theory. Indeed, Bhagwati [1964] criticizes the study for having no theoretical basis. Yet, trade between two arbitrarily chosen countries mostly constitutes only a minor part of the total trade of each the country with the rest of the world, and therefore one can hardly expect the specialization pattern (comparative adwantages) of the counties in question to be determined by the distribution of sectoral productivities relative to each other (as opposed to rellative to the rest of the world). Accordingly, a finding that shows the existence of a strong relation that links relative labor productivity to relative export performance (though with regard to rest of the world) is sufficient to bring out the importance of the role of relative labor productivities in the determination of trade patterns, although the 
causal mechanism remains ambiguous. The existence of such a relation does not necessarily have to be due to relative productivity based comparative advantages but may as well be brought about by productivity differentials based absolute advantages. Nevertheless, these tests point to the plausibility of the Ricardian model in some way.

However, the major causation related problem that brings the MacDougal type tests of the Ricardian model under the attack of critics is not exactly the ambiguity with regard to absolute advantages. Ford [1967] and Falvey [1981], suggest that the significant relations detected by the test can as well be due to a causal process of the H-O-S type. That is, to the extent by which labor productivities are determined by the interplay between the amount of capital used in production and labor intensity, the equilibrium allocation implied by the trade equilibrium of the I-O-S model is well capable of bringing about labor productivity differentials consistent with the trade pattern implied by not only the Ricardian model but the H-O-S model as well ${ }^{14}$. Therefore, what is shown by the test is not necessarily a confrmation of validity but only plausibility.

\section{Testing of the H-O-S model}

The names Heckscher, Ohlin, Samuelson, without saying go together with the name Leontief. The reason is of course the first known test of the $\mathrm{H}-\mathrm{O}-\mathrm{S}$ model by Leontief [1953], the negative findings of which are referred to as the "Leontief Paradox". With this test, which has been the basis of the ongoing attempts to validate the H-O-S model (though in modified forms), Leontief measures the capital and labor (directly and indirectly) emborlied in the US exports and import substitutes, by incorporating the direct and indirect factor embodiment by the use of the input-output table for the US economy. These measures are not directly suitable to test the original Heckscher Ohlin theorem, but the factor content version of the theorem, which suggests that under the usual H-O-S assumptions and factor equalization, each trading partner must turn out to be a net exporter of the factor that it possesses in relative abundance ${ }^{15}$. Accordingly, due to US capital abundance relative to that of the rest of the world, finding more labor in US import substitutes than that in its exports would add to the plausibility of the H-O-S model.

On the contrary, Leontief finds that the ratio of the capital to labor embodied in the US exports is smaller than that in import substitutes. Ironically, Leontief presents this fincling as evidence in support of the H-O-S model, due to his presumption that (due to the high labor productivity in the US, which goes beyond that of the rest of the world) compared to the rest of the world, the U.S. should be relatively labor abundant, in terms of productivity equivalent units. Yet, the following reviewers of this argument pointed out to the fact that, on the basis of the data used by Leontief, the argument could be justifiable only if U.S. labor productivity were more than 3 times as large as that of the rest of the world, which is not the case. Accondingly, the Leontief test turns out to be the first to cast shadow on the validity of the $\mathbf{H}-\mathrm{O}-\mathrm{S}$ model.

The Leontief paradox leads to a variety of studies that aim to resolve the paradox. An important one of these is the suggestion by Leamer [1980] that the data used by Leontief which reveal the relatively higher embodiment of labor in exports than in imports, also reveal US position of being a net exporter of not only labor but capital as well. His explanation for this phenomenon is twofolded. The first important reason of the paradoxical finding by Leontief could 
have been the US trade imbalance (surplus) with the rest of the world, the case in which the theoretical relation between factor embodiment of exports/imports and relative factor endowments weakens/disappears. Accordingly, Leamer suggests that, given the truth in the proposition that U.S. (around to 1950s) had a trade surplus, the Leontief test must be modified and be based on the difference between factor embodiment in production and consumption, rather than that between exports and imports. Various tests following this idea (starting with Leamer [1980] himself and followed by others for later instants of time, such as Stern and Maskus [1981]) show that the paradox exists for 1951, 1958, and 1962 but seems to have disappeared after the 1970 s. Consequently, the validity of the $2 \times 2 \times 2$ version of the H-O-S model is still highly doubtful, especially for the immediate post war period.

According to Leamer, the second reason could be the exclusion of important production factors other than homogenous capital and homogenous labor (such as human capital, knowledge, land and though can hardly be considered as an endowment, R\&D expenditure as a proxy for technology) that could potentially explain the real comparative advantage structure of the US, the net flow of embodled capital and labor across U.S. borders do not necessarily need to be in opposite directions. The efforts that aim to pursue this possibility by adding other factors, the relative proportions of which may potentially be in the list of key determinants of comparative advantages, can be classified under the neo-endowment approaches title and a comprehensive overviews of these studies can be found in Wakelin [1997] and Leamer and Levinsohn [1984]. To summarize in one sentence, these studies point out to the importance of skills, scientists and engineers, and technology (all of which can hardly be considered as endowments except for the short run, due to their dynamic and reproducible nature) as the basis of the comparative advantages of highly developed countries, especially the US.

The H-O-S model does not only consist of the Hecksher-Ohlin theorem, but also of theorems based on other derivatives of the dual equations that make up the general equilibrium system. An excellent overview of the various empirical tests of these corollaries (Stolper-Samuelson,Rybcyzinski), can be found in Leamer and Levinsohn [1984] and are skipped here due to their tangential relevance to our discussion. Yet, two interesting findings will briefly be touched upon. The first is on the factor price equalization theorem. To nobody's surprise, it has not been possible to find even the slightest evidence on equality of factor prices across the countries of the world. Nevertheless, studies that explore the reasons underlying the cross-country differences in factor prices suggest that these are (to some extent) brought about by differences in skills, work conditions, vacations etc. For example Trefler $[1993,1994]$ shows that proxies for labor productivity and capital productivity explain some part of the across country wage and capital price (measured by investment price indexes) differentials, though a significant part remains unexplained.

The second interesting finding is due to Grossman [1987] who aims to test the Stolper-Samuelson theorem via partial equilibrium analysis based estimations of sectoral import price elasticity of wages (in $9 \mathrm{US}$ manufacturing industries). He estimates highly small and statistically insignificant wage elasticities, while the sectoral import-price elasticities of employment generally appear to be positive and significant. He interprets these findings as an indication of high degree of labor mobility between sectors.

To summarize what we have discussed so far, the evidence can hardly be considered to be in favor of the H-O-S model. First, it has not been possible 
to defend the original capitallabor version of the H-O-S model on the basis of evidence. Only the inclusion of variables such as human capital, knowledge and technology seems to have relaxed the paradoxical finding originally detected by Leoritief. The integration of the stock of these additional variables into the original model as endowments can be considered as heroic, and furthermore all of these variables are closely related to technology and its change. In a way similar to the Ricardiar model, which does not explain at all the reasons underlying labor productivity differentials, the H-O-S framework does not explain why human capital, skills or technological knowledge should be unequally distributed over the countries. The bottorn-line of the H-O-S model is that, somehow some countries happen to be lucky enough to have knowledge and skills in abundance and it is rational for these countries to switch production towards goods, which intensively demand the use of these resources that are relatively cheaper thanks to their abundance. Accordingly, the important issue is not whether the predictions of the traditional models are supported by evidence, but the relevance of the causal mechanisms that bring out the predictions. Even the most casual observation shows that the accumulation of factors such as technical knowledge, ability and human capital is the (stochastic) outcome of the deliberate and wishful actions of economic agents and this endogenous, self reinforcing and thus cumulative creation and spill-over process can hardly be explained as a function of propensity to save.

Such considerations, together with empirical predictions (based on data that is made available by natural experiments of complete trade liberalization as in the case of $\mathrm{EU}$ ) that point to the insignificant size of static comparative advantage based gains from trade (e.g. Baldwin [1992], who predicts 0.1 percent welfare gains from the establishment of the EU trade liberation), and also to the high share of intrasectoral tracle in total trade volumes, bring out the recessity of complementary theories that could close the gap in owr understanding. This is where new trade theories and other, more unorthodox, approaches (such as technology gaps, evolutionary models) come into the piciure.

\subsubsection{An integrating static approach: The Heckscher-Ohlin-Ricardo model}

Consider the example in the beginning of this chapter on the two individuals stranded on an island living on wheat and milk. Let us add two other goods to their necessities: wood products and metal products. Further assume that due to skill differentials, indiwidual $\mathbf{A}$ (in addition to milk) has comparative advantage in carpentry, while $\mathbf{B}$ (in addition to wheat) has that in metal work. Thus, $\mathbf{A}$ specializes on milking and carpentry, and $\mathbf{B}$ specializes on wheat production and metal work. Now consider a statistical agency, collecting data on an arbitrary aggregation. Assume that she categorizes milking and wheat production as agriculture, and carpentry and metal work as manufacturing, and analyses trade flows between $\mathbf{A}$ and $\mathbf{B}$ accordingly. Based on this arbitrary industrial classification, she may or she may not observe any inter-industry trade flows, depending on the distribution and extent of productivity coefficients (over the 4 goods) and relative demand structure. That is, the net sectoral trade flows may be zero and even if not, the tests that she would make to examine the correlation between comparative advantages (calculated on the basis of labor productivities that are calculated as. averages within the arbitrarily defined sectors) may fail to validate the Ricardian model, although the Ricardian forces fully dominate trade by (our) assumption. 
This basic point of this example is generalized by Davis [1905] to integrate the H-O-S model, the Ricardian model and intraindustry trade to demonstrate that such a Ricardian explanation of intraindustry trade can be seen as complementary to the H-O-S inter-industry specialization, simply by re-examination of the definition of an industry. Clearly, the $\mathbf{H}-\mathrm{O}-\mathrm{S}$ model relies on a definition that unambiguously classifies industries according to their factor intensity. That is, regardless of the composition of the arbitrarily chosen sub-industries that arbitrarily define an industry, it is sufficient for the purposes of the H-O-S model that the factor proportions demanded by one industry is on the average (and all possible relative factor prices) different than that demanded by other industries. 'Therefore, there is no reason to exclude the possibility that production in the sub-sectors of the H-O-S sectors are subject to Hicks natural ${ }^{16}$ technological differences across countries. If such cross-country technological differences (which may lead to differences in comparative costs) exist in the sub-sectors, each country could accordingly have comparative advantages over some sectors in the Ricardian sense, specialize on these sectors and tradie, which on the sectoral scope, would look like nothing but intraindustry trade. Based on this idea, Davis builds the model, which he refers to as the Heckscher-Ohlin-Ricardo model, and demonstrates that factor proportions based specialization (over sectors, which are defined as aggregates of many sub-sectors that, on the average, embody similar factor intensities but produce subject to varying TFPs) is complementary to Ricardian specialization aver the sub-sectors, which underlies the motive for intraindustry trade. He shows that the share of intraindustry trade is an increasing function the similarity of factor endowment composition across countries. To the contrary, as factor endowment composition dissimilarity across countries increases, trade is increasingly driven by the H-O-S lines and inter-industry trade (unidirectional net sectoral trade flows) takes over.

\subsection{A brief look at the (new) growth theories}

The traditional neoclassical growth model is the Solow [1956,1970] growth model, which essentially consists of three equations. The first is a (Cobb-Douglas type) constant returns to scale macro production function that incorporates labor angmenting technologicial progress:

$$
Y_{t}=A\left(e^{\alpha t} L_{t}\right)^{\beta} K_{t}^{1-\beta} .
$$

The second equation specificities a constant growth of the labor force as

$$
L_{t}=e^{\nu t} L_{0}
$$

and the third describes a saving/capital accumulation process such that

$$
\frac{d K_{t}}{d t}=s Y_{t}
$$

The system solves for a balanced growth path where output $(Y)$ and capital stock $(K)$ grow at a rate equal to the sum of population growth $(\nu)$, and the rate of labor augmenting technological process $(\alpha)$. That is,

$$
\widehat{Y}=\widehat{K}=\widehat{v}+\widehat{\alpha} \text {. }
$$

Along this steady-state motion, capital labor ratio (labor measured in terms of efficiency labor units so that the ratio is $\left.K_{t} /\left[e^{\alpha t} L_{t}\right]\right)$ remains at its equilibrium 
value $[s A /(\alpha+\nu)]^{1 / \beta}$. Any exogenous disturbance to this process (e.g. saving rate increase) is accommodated by price movements which induce substitution between the factors (change of production technique that would maintain full employment), and as the system reaches its equilibrium capital labor ratio again, the economy moves back to the balanced growth path. Stability of the balanced growth path achieved accordingly is one of the most important technical properties of the Solow model, especially in relation to its post-Keynesian predecessor "the Harrod-Domar" model, which is similar" to the Solow model except that it specifies a fixed coefficient production function $\left(Y_{t}=\min \left(\frac{e^{x t} L_{t}}{a}, \frac{K_{t}}{b}\right)\right.$, and, that it inevitably allows for the under-utilization of production factors. The well known property of this model is that a full employment balanced growth path (similar to the Solow model) is only possible if the economy happens to be in full employment in the base period and subsequently factors grow at the same rate, thus balanced growth may only happen by chance (disturbances in factor growth rates takes the system away from the balanced growth path).

At the first look one may be surprised to see that the output growth of the econorny along the balanced growth path of the Solow model is determined only by the growth of the labor force and technological progress, independently from the saving rate (see equation 1.19 ). The reason underlying this property can clearly be seen if the labor force and productivity growth rates are set to zero, which together imply that the steady state growth rate should be zero as well. Because, for $Y_{t}>0, \frac{d K_{t}}{d t}=s Y_{t}>0$ and therefore output growth, even in case of zero productivity and Jabor force growth should be $\widehat{Y}_{t}=(1-\beta) \widehat{K_{t}}=s(1-\beta) \frac{Y_{t}}{K_{t}}$. But the term $(1-\beta) \frac{Y_{t}}{K_{t}}$ is nothing but the marginal product of capital $M P_{K}$. The $M P_{K}$ is a decreasing function of the capital stock and if $\widehat{v}=\widehat{\alpha}=0$, it asymptotically converges to zero at the steady state (where the capital stock goes to infinity). Therefore, the saving propiensity has an effect on the transient growth rate but not on the steady state growth rate and accordingly at the steady state the only effect of the saving propensity is on the level of output but not its rate of growth.

Therefore the Solow model suggests that given a technology level, an economy can increase its per capita consumption by mechanizing (increase capital by worker by savings), yet due to decreasing marginal returns to capital arising from the everincreasing capital-labor ratio, the return on (marginal) investment steadily falls and at the steady state growth stops. Thus, per-capita consumption growth can only be achieved by exogenous technological advance. Consequently, according to the Solow model, the empirical fact that capital labor ratios and real income per capita have been rising over time, can be explained in three ways. The first possible explanation is that the world economies have been in a transient process so that the marginal product of capital is still far from its steady state value zero. Yet, such an explanation is naturally outside of the scope of the mainstream thinking who tends to see the world economy as one that proceeds around its steady state path. The second reason is based on the possibility that the Cobb-Douglas is an erroneous specification for the production function. With another production function, which specifies the marginal product of capital as asymptotically convergent to a positive value (as opposed to the dead end to zero), sustained steady state growth can be maintained. The last explanation left is naturally that there has been technological change, sufficient to keep the marginal product of capital significantly above zero.

In order to see the relative contribution of the three potential sources of growth on the observed rates of growth, Solow [1957] decomposes a Cobb-Douglas production function $Y_{t}=A \cdot L_{t}{ }^{\beta} \cdot K_{t}^{\alpha}$ (which is equivalent to the one before) by 
differentiation. The resulting equation

$$
\widehat{Y}=\widehat{A}+\beta \cdot \widehat{K}+\alpha \cdot \widehat{L}
$$

where $\alpha+\beta=1$, was applied to historical data (on US). This procedure, known as growth accounting, specifies output growth as a weighted (by factor intensities) average of the growth of production factors $(\widehat{K}, \widehat{L})$, plus a residual ( $\widehat{A}$, called as the Latal factor productivity), which is an overall measure of technological change ${ }^{1.7}$. In this exercise, $\widehat{A}$ (the residual term total foctor productivity) turns out to explain $80 \%-85 \%$ of the actual growth $\widehat{Y}$. This finding (which almost implies $\widehat{Y} \cong \hat{A}$ ) points to the fact that the Solow model, which essentially aims to describe per capita income growth as a process of capital accumulation (through exogenous savings), does not add much to our understanding of the ways in which the economy generates long run growth. Instead, the bulk of the growth seems to be generated by technological change, which is exogenous to the model.

The other two issues that the Solow model fails to explain, are the observed growth differences between countries ${ }^{18}$, (and the possible changes of these differentials in time: catching up and falling behind) and also the fact that growth rates of many the countries have been observed (on the post-war period) to move around constant levels ${ }^{19}$ (while secular increase and decrease are also observed) over time. The reason for the second fact can already be sensed from the growth accounting decomposition: the enormously high technological change must have preserved the marginal product of capital from decreasing.

In the light of the more recent formulations, the original formulation of the Solow model has a descriptive shortcoming in terms of its alssumption to take saving propensity as exogenous, which ignores the equilibrium forces that govern the financial market. In other words, in comparison to today's standards, the Solow model misses an important link by not incorporating the two behavioral equations that describe the working of the financial market:

1. The inter-temporal utility maximization problem, which requires that consumption should be responsive to the difference between the interest rate $(r(t))$ and the customers' subjective disconnt rate ( $\beta$, which reflects the trade-off between today's and future consumption for the representative customer), such that

$$
\widehat{Y}(t)=\frac{1}{\varpi}[r(t)-\rho]
$$

where $\varpi$ is the elasticity of marginal utility of consumption.

2. The standard asset pricing equation, which requires that interest rates should go in tandem with the marginal productivity of capital

$$
r(t)=M P_{K} .
$$

These equations (see Helpman [1988] for the basic derivations) more or less describe the formulation common to most new growth models and together yield

$$
\widehat{Y}(t)=\frac{1}{\varpi}\left[M P_{K}(t)-\rho\right]
$$

which suggests that consumption (output) growth is (only) possible as long as the marginal product of capital exceeds the subjective discount rate of the customers, so that incentives for investment remain positive. 
The implications of this last equation actually do not cast the Solow model any generality. The only difference is the fact that in the absence of TPF growth, output growth in the original Solow model stops were $M P_{K}(t)=0$, while according to equation 1.22 , it stops much before, where $M P_{K}(t)=\rho$. Accordingly, in the presence of an efficiently working financial market, the conditions for sustained growth are more demanding in comparison to the case, where countries save irrationally by following a rule of thumb.

The explanation of the stylized facts on cross-country growth rate differentials mentioned before, demands two things in light of equation 1.22:

1. In order to generate constant (increasing) growth rates over time $M P_{K}(t)$ must be constant (increasing) over time. In Solow's formulation (CobbDouglas production function) $\widehat{M P_{K}}(t)$ requires that

$$
\widehat{M P_{K}}(t)=\widehat{A}+\beta(\widehat{L}-\widehat{K}) \text {. }
$$

Since the important issue is growth of per-capita consumption, given the fact that the contribution of capital growth to marginal product of capital is negative, almost the whole burden of keeping $M P_{K}(t)$ constant (rising), falls to technological change $\widehat{A}$.

2. If the trivial solution, which relies on possible cross-country differentials in the subjective discount rates $(\rho)$, is ruled out, the bulk of the burden in explaining across country differentials also balls on to technological change $\widehat{A}$.

These two necessities that define the basic (perceived) problem facing the growth theory, had apparently been asking for a reformulation of technological change, which is sufficient to generate increasing (or at least constant) ${ }^{20}$ and divergent growth rates endogenously.

Since a long time it has been sensed that increasing returns could give the growth theory what it yearned for, but there has been two essential complications. The first is the fact that increasing returms was hard to fit in the perfect competition framework upon which the existing theories of growth heavily depend. Traditionally, increasing returns to scale has conveniently been associated with industrial structures other than perfect competition (especially with monopoly as a package offer). Depending on the extent to which larger scale implies a higher productivity for the firm, the industry can hardly be assumed to consist of a multiplicity of very small price taking firms, since (in the case of increasing returns) individual firms would have incentives to grow and start to affect prices. Secondly, although it had been known since Marshall [1890] that the concept of increasing returns external to the firm but internal to the industry/economy could solve the problem regarding perfect competition, the concept had generally been perceived to be vague with respect to its micro-foundations. To be precise, increasing returns external to the firm could well be justified by some sort of positive externality, yet a substantial explanation on the very workings of such an externality had not been formulated yet.

To clarify our discussion so far, consider the following production function specified for a price taking firm $k$

$$
Q_{k}(t)=A \cdot[T(t)]^{\gamma} \cdot f\left(K^{1-\alpha c}(t), L^{\alpha}(t)\right),
$$

where the function $f(K(t), L(t))$ has the usual properties assumed for a firm operating in perfect competition (i.e. positive first partial derivatives, negative 
second partial derivatives and homogeneity of degree one). Assume that at time $t=1$, there are $n$ identical firms in the economy each endowed with 1 unit of each production factor, $\gamma=1$, and $T(1)=1$. Thus the industry output at time $t=1$ is $Q(1)=\sum_{k=1}^{n} Q_{k}(1)=100$. Now assume that each firm's capital and labor endowments are doubled at time $t=2$, and also $T(1)=2$. Then the aggregate output $Q(2)=400$. Total output is quadrupled while endowmerts are only doubled. Accordingly, the question facing the prospective authors of the new growth theories was to find a justification for the existence of something that would play the role of $T(t)$, which is capable of increasing the output more than proportionally for given increases in endowments. And most importantly (as pointed out by Romer [1990]), since $T(t)$ should somehow be related to some asset, whatever asset this $T(t)$ represents, it must be of a non-rival nature so that all the firms can enjoy it equally without necessarily being forced to share.

After, almost two decades after the Solow model, the solutions present themselves in three forms. The inspiration for the first two comes from informal (de scriptive) studies on technological change which point out to the importance of learning by doing ${ }^{21}$, investment on human capital and $\mathbb{R} \& \mathrm{D}$, knowledge (technological) spill-overs, cumulative nature of technological chance and product quality. The third alternative solution comes from developments in the imperfect competition, especially the Chamberlinian formulation (Chamberlin [1962]). According to these solutions, non-rival (and preferably cumulative) resource $T(t)$ that is responsible for the increasing returns generating externality can be either of knowledge, experience, artifacts of human capital, quality level or the quantity of intermediate goods (both of which can be enjoyed by all final product producing firms equally in terms of increased productivity). While the non-rival nature of all these assets is clear, the next question that comes to mind (except for the latter two) is about the excludability ${ }^{22}$ of the assets. That is, knowledge, experience, artifacts of human capital are cumulative and can potentially be shared by everyone (non-riwal), but only to the extent with which they can be assumed to be public goods. In general, knowledge of generic and purely scientific nature (that one can find in books, the Internet etc.) are indeed non-excludable as well as non-rival. Yet a good deal of knowledge and human capital either built over time as an inevitable by product of cumulative experience (learning by doing), or purposefully generated through investment ( $R \& D$, training etc.), reside in people's minds, in blue-prints, or in company cultures. Firms that employ human capital, and/or keep the rights to employ such potentially non-rival assets (through patents or due to the tacit nature of some types of knowledge), naturally would not want to share them with other firms. Besides, if sharing were inevitable (without patents or tacitness of knowledge), they would not even make the (essentially risky) investment to generate them although such spill overs are good for the economy as a whole. Shortly, there exist a natural trade-off between private and public returns to investment on knowledge, yet the spilling of some knowledge over to other agents is inevitable at least in the longer run. Therefore, the strength of knowledge/human capital related externalities is partially determined as a function of the pace/incentives of generation and the rate of diffusion.

We will base the rest of our discussion on new trade theories according to a classification of the ways they specify the assets that potentially generate increasing returns, and the mechanisms through which these assets are generated (or automatically emerge) and diffuse to bring about the actual growth generating externality. 


\subsubsection{Knowledge/Human capital accumulation and learning by doing}

The first avenue explored was growth due to accumulation of knowledge or human capital, wither automatically by learning by doing or purposeful investment.

Romer [1986] specifies a production function as $Q k(t)=F\left[x_{k}(t), h_{k}(t), H(t)\right]$, where the function $t$ is homogenous of degree one in the firm specific traditional factors $x_{k}$ (a vector of factors such as capital, labor, etc.) and the firm specific knowledge stock $h_{k}$. The variables $x_{k_{k}}$ and $h_{k}$ exhibit decreasing marginal returns. Nevertheless, $F$ is not linear on the economy wide knowledge stock $H(t)=\sum_{k=1}^{* t} h_{k}(t)$. That is $F\left[\lambda x_{k}(t), \lambda h_{k}(t), \lambda H(t)\right]>F\left[\lambda x_{k}(t), \lambda h_{k}(t), H(t)\right]$ $>\lambda F\left[x_{k}(t), h,(t), H(t)\right]$, therefore $H(t)$ is responsible for the external increasing returns. The increasing returns are external to the firm because the firms in perfect competition are too small and they either ignore or do not know about their little contribution $H(t)$, and are assumed to behave as if they take $H(t)$ given. Accordingly, they try to maximize their output only via choices on $x_{k}$ and $h_{k}$, which is perfectly consistent with the behavior of a firm operating in a perfectly competitive environment.

For simplicity, factors other than knowledge are assumed to be fixed in supply and $h(t)$ is assumed to be generated by purposeful research (which is the only investment mechanism of the society. The emergence of sustained growth is clear. The society is willing to invest in research (knowledge accumulation) as long as the marginal product of research exceeds the societies' subjective discount rate (as in equation 1.22). The former is assumed to be decreasing in $h(t)$, but the increasing returns generating link $H(t)=\sum_{k=1}^{n} h_{k}(t)$ works its way in the opposite direction and keeps the marginal returns to investment from decreasing, which maintains sustained growth for the economy. Accordingly, the economy grows at a rate that is an increasing function of the difference between the marginal returns to research and the subjective discount rate. Besides, any across country differentials in $H(\tau)$ (brought about by historical contingencies) can lead to significant growth rate differentials in the period $t>\tau$. Therefore, as in all models with increasing returns, history matters, not only in terms of explaining current differences but with respect to future developments as well.

As is well known from the literature on externalities, in the presence of positive externalities, the private returns oriented market system leads to welfare levels that fall short of the socially optimal levels. This is naturally one of the important results of the Romer [1986] model as well. If the optimal growth problem is solved by a social planner, who, contrary to the individual firms, takes the externality $H(t)=\sum_{k=1}^{n} h_{k}(t)$ into account in the dynamic sense, the socially optimum investment (saving) scheme turns out to be higher than that implied by the private returns motivated competitive equilibrium. This property immediately introduces an important addition to the growth related policy recommendations: Governments should subsidize R\&D activities.

An apparent shortcoming of this model is its assumption that knowledge is a purely public good which, upon generation, immediately spills-over to the public domain where it can be enjoyed by everyone. Knowledge is assumed to be not only non-rival but non-excludable as well. Therefore, the model ignores the Schumpeterian argument that the motivation of the firms in investing in research is the expectation to reap the benefits in terms of the (temporary) monopoly profits made available by the advantage brought about by research.

Lucas [1988] introduces two similar models in one article both based on human 
capital (skill level) accumulation related externalities, which stimulate productivity in production. In the first model, such as in Romer [1986], human capital accumulates as a result of deliberate investment, while it accumulates automatically by cumulative experience (learning by doing) in the second model.

In the first model, human capital $\left(h_{s}(t)\right)$ accumulates through decisions of the individuals (workers, each denoted by subscript $s$ ) on the time they are willing to allocate between actual production $\left(u_{s}(t)\right)$ and education $\left(1-u_{s}(t)\right)$. The effect of education on the building of skills is specified as $\widehat{h_{s}}(t)=\delta\left(1-u_{s}(t)\right)$. Assuming that all individuals are identical, human capital is specified as a labor augmenting multiplier, such that the effective labor force available to production is $u(t) h(t) L(t)$. That is, a worker $s$ endowed with $h_{s}$ unit of skills is assumed to be equivalent to $h_{s}$ workers and accordingly the essential role of human capital growth is to relax the labor constraint and keep the marginal productivity of capital from falling so that investment on physical capital and thus growth can carry on. In this sense the human capital in this model is equivalent to the labor productivity augmenting process $\left(e^{\alpha t}\right)$ of the Solow model, and the only difference is the generation of the augmentation is endogenised as a function of deliberate investment. Thus, even substituting the term $\nu$ with $e^{\text {at }} L_{t}$, (which shows up in the Solow production function) is sufficient to generate a non-zero steady growth rate $\delta\left(1-u_{s}(t)\right)$ even if the physical labor force does not grow at all. This process is able to yield constant growth rates. Lucas also introduces another externality that works as an additional TFP augmenting process brought about by the average amount of skills in the economy. Accordingly he formulates the production, consumption and physical capital accumulation process as

$$
L(t) \cdot c(t)+\dot{K}(t)=A \cdot K^{\beta}(t) \cdot[u(t) \cdot h(t) \cdot L(t)]^{1-\beta} \cdot\left[h_{a}(t)\right]^{\gamma},
$$

where the last term $h_{a}(t)$ denotes the average skill level in the economy, which is responsible for the increasing returns generating externality, and $c(t)$ is the per capita consumption.

Similar to Romer, the balanced growth path (where steady state optimal growth rates of output and capital accumulation are equal) is solved ${ }^{23}$ not only for the market equilibrium, but for the perspective of the social planner (who takes the fact $h_{a}(t)$ is the average of the indiwidual worker's skill levels into account in a dynamic sense $)^{24}$. As expected, the optimal investment on human capital $\left(\left(1-u_{s}(t)\right)\right.$ dictated by the competitive market, appears to be less than that required for the social optimum. As usual, path dependency (i.e. history matters) is pronounced, which points to the importance of policy measures that would invest more on schooling. That is, even temporary periods of extra investment, in schooling can be sufficient to shift the country to a higher growth rate path, with higher levels of welfare. Besides, it is clear that higher efficiency of investment in human capital (as denoted by the parameter $\delta$ ) have the potential to boost growth and wellfare.

In the second model in Lucas[1988], the growth generating externality is created only by learning by doing. The model assumes only one production factor labor, and since learning by doing is by definition a by-product of production activities, the model does not involve any inter-temporal trade-off. Instead, Lucas introduces a two sector economy and sectoral trade-off is introduced into the model. That is, for $u_{v}(t)$ being the share of labor force allocated to the production of good $i$ (i.e., $u_{1}(t)+u_{2}(t)=1$ ), the building up of sector specific human capital (skills) is specified as $\widehat{h}_{i}(t)=\delta_{i} u_{i}(t)$ and per-capita production (which is equal to per-capita consumption) of good $i$ is specified according to $c_{i}(t)=h_{i}(t) u_{i}(t)$. 
The learning rate in one sector is set to be higher than that in the other, and the product of the high learning sector is labelied as the "high-technology good". Furthermore, to focus on the trade off in the analysis a CES type utility function $\left(U\left(c_{1}, c_{2}\right)=\left[\alpha_{1} c_{1}^{-\rho}+\alpha_{2} c_{2}^{-\rho}\right]^{-1 / \rho}\right)$ is specified. The advantage of this functional. form is naturally the fact that it allows analysis for varying degrees of substitutability (by varying the parameter $\rho$ ) between the goods.

The analysis points out that for high degrees of substitutability between the goods $\left(\sigma=\frac{1}{1+\rho}>1\right.$ ), the economy converges to full specialization in the high technology good production In case of low substitutability $(\sigma<1)$ the economy converges to a labor allocation purely based on learning rates $\left(\frac{u_{1}}{u_{2}}=\frac{\delta_{2}}{\delta_{1}}\right)$, and in the limit between high and low ( $\sigma=\mathbb{1})$, the allocation is purely based on demand $\left(u_{i}=\alpha_{1}\right)$. It is clear that compared to the maximum possible output growth rate, which happens in case of full specialization in the high-tech good, all of these scenarios are sub-optimal. The reason for the loss in growth (in comparison to the maximum possible rate) is the customers' preferences towards consuming a more desirable mix of goods. Yet, this shortcoming can be overcome in case of international trade, and this issue will be discussed in the following subsection on new-trade theories.

\subsubsection{Growth by quality improvements}

Consider an economy where a continum of intermediate goods exist (each denoted by an index in $[0,1]$ ) the aggregate output at time $t$ is defined as

$$
Q(t)=\int_{0}^{1} \frac{F[x(i, t)]}{a(i, t)} d i
$$

where $x(i, t)$ is the intermediate good $i$ output and $a(i, t)$ is a coefficient that indicates the unit $x(i)$ requirement to produce one unit of aggregate output at time $t$. Thus, each intermediate good has its own intrinsic quality. Further assume that each intermediate good $i$ is produced by another firm by pure labor in a monopolistically competitive industry, and regardless of the productivity advantage it offers $(a(i, t))$, the production of each intermediate good takes exactly one unit of labor.

It is clear that since there is no direct link between the quality (productivity) of intermediate products and the amount of labor required for their production, by the introduction of new intermediate goods of higher quality and parallelly by the disappearance of the lower quality ones (which together imply an increase of the average quality/productivity of intermediate goods), the economy can grow indefinitely. The questions that remain are, how, by whom and why are the intermediate goods going to be introduced into the market incessantly.

Aghion and Howitt [1990] introduce a model that generates growth along these lines. They follow the neo-Schumpeterian argument that the dominant source of technological change is costly R\&D activities of firms, made in the wishful expectation of enjoying the monopoly rents that the (lucky) outcome of the research will. bring about. Yet, the monopoly rents can not last forever, since someone else might come up with a better product (of higher quality or lower priced) that outperforms the existing one. Naturally, the new industry leader, although the superiority of its product may draw on the technologies of the former industry leader(s), does not compensate the existing leaders for the loss of their monopoly profits and accordingly steal their business in some sense. Besides, the superiority of the new design may drive some of the existing firms out of business. The 
first link, (that new products are not designed from the scratch but incrementally build on the existing designs) is a positive externality and the second link (business stealing is a negative externality. This Schumpeterian process, known as creathe destruction is the essential mechanism of the Aghion and Howitt model.

The model specifies each new intermediate product as a proportional improvement (by $\gamma<\mathbb{1}$ ) over the best design in the market. That is, if the initial productivity given by the history is $a(0)$, and from the beginning of history, till time $t$, the number innovations made is $\pi$, the intermediate good produced by the market leader $m$ at time $t$, is

$$
a(m, t)=a(0) \gamma^{\top}
$$

which constitutes the important positive externality of the model. Since each new innovation builds upon the previous one, the productivity introduced by an innowation is not temporary but permanently extended to the future, embodied in the next generation products. In other words, although the value of an innovation for a firm only last until the next innovation (by some other entrepreneur), its value for the society lasts indefinitely in time.

The innovations arrive according to a Poisson process, the arrival rate of which is an increasing function of the number of $R \& D$ workers employed ( $\lambda n$, if $n$ denotes number of R\&D workers). For each entrepreneur, the incentives to make R\&D (the extent of expected monopoly) is an increasing function of the extent of innovation step $\gamma$ and a decreasing function of the market interest rate $r$, which is determined by the societies' subjective discount rate and thus is constant. Besides, since imitation is not allowed, at a given time there is only one monopolist that meets the whole demand of the final good sector, and therefore the monopoly profits in case of a lucky innovation are also dependent on the monopoly power of the innovator, which is a function of the price elasticity of intermediate good demand of the final product sector (if the integrand in the RHS of the equation 1.26 is specified as $\frac{[x(i, t)]^{\alpha}}{a(i, t)}$, since the monopoly profits will be equal to $\frac{1-\alpha}{c x} w(t) x(i, t)$, monopoly power becomes a decreasing function of $0<\alpha<1$ ).

Yet, the important trade-off is brought about by the R\&D efficiency parameter $\lambda$, which affects the arrival rate of innovations. From the perspective of the individual entrepreneur, a higher $\lambda$ implies less R\&D costs for a successful innovation and thus is an incentive. On the other hand, a higher $\lambda$ also implies a shorter expected time interwal, before which some other entrepreneur introduces the next innovation and captures the whole market and the monopoly profits. The difference between the positive and the negative externalities (thus incentive to make $R \& D$ ) in the model is significantly affected by $\lambda$ and accordingly the investment decision of the entrepreneur is specified via a Bellman equation, which intuitively expresses the fact that the value of the R\&D effort under an optimal policy must equal the expected return for the chosen level of investment on R\&D.

The model solved under the perfect foresight assumption (i.e. agents can pre cisely estinate the future values of the endogenous variables of the model) leads to many different cases ranging from no-growth, to cyclical or stationary equilibrium with positive growth. Generally, no-growth and cyclic behavior (movement of lam bor between research and manufacturing) are outcomes that are observed in cases of extremely low interest rates (subjective discount rates) and/or high monopoly power (high price elasticity of demand for intermediate goods). The emergence of both outcomes are due to perfect foresight. No-growth trap can occur, if the (rational) expectations foresee that the booming of research activities due to the proftable success of the next innovation will bring about a new innovation in a very 
short time. The shortage of the time interval during which monopoly profits can be expectecl, is clearly a disincentive for investment for research and accordingly growth can not start off.

Similarly, the monopoly profts enjoyable after an innovation are an increasing function of manufacturing output which implies lower research and this expectation togethwr with the business stealing effect may lead to oscillations in research activities and growth rates. The authors hesitate to link the cyclical behavior of their model with the business cycles in reality, since the model generates these under perfect foresight assumption. They cite the work by Grandmont and Larque [1986], which shows that equilibria stable under perfect foresight can be unstable under learning ${ }^{25}$ and accordingly confine their analysis with the cases where the model generates stable equilibria with positive growth.

As intuitively expected, as long as the parameter setting intervals that make balanced growth (where allocation of labor between research and manufacturing. is constant) possible are not violated, the effects of model parameters on average growth rates follow simple intuition. That is, the amount of research (thus growth) is decreasing with interest rates and increasing with the parameter for innovation arrival $(\lambda)$ and proportional innovation step size $(\gamma)$. Furthermore, since a larger labor endowment implies higher manufacturing output and accordingly higher monopoly profits, the total labor endowment also has positive effect on research and growth.

Aghion and Howitt also specify a different type of trade-off by introducing leaming by doing into their model. 'The trade-off is due to the fact that learning by doing is defined as increases in the intermediate good productivity between two successive innovations and accordingly it is an increasing (decreasing) function of employment in manufacturing (research). Learning by doing raises the return to research activities (the present value of discounted monopoly profits) but not the marginal benefit of increasing manufacturing output since the learning by doing externality is defined as external to the frm. Thus, while social optimum requires a decrease in research and exploit the learning by doing externality, the market choices will imply a higher research employment and less exploitation of the learning by doing.

Grossman and Helpman [1991a] make a similar model of quality. The major difference in formulation is the presence of a finite range of sectors producing complementary intermediate goods. Within each sector, the process of quality improvements takes place in a way similar to the Aghion and Howitt [1990] model. The existence of many sectors presents a potential complication in terms of the decision of entrepreneurs to target sectors for R\&D. Yet, due to the symmetry of the sectors (in terms of costs and denand), each is shown to receive equal attention by the entrepreneurs and the research effort is stochastically distributed over the sectors uniformly. Due to the similarity of the essential trade-offs and externalities, the results are similar to that of the Aghion and Howitt model.

An interesting property pointed out by the model is that the aggregate production function that generates final consumption from an array of quality adjusted intermediate goods, can be defined as a temporal utility function that generates welfare from an array of quality adjusted consumption goods as well. It is just: a matter of naming the nature of the complementary goods as intermediate or consumption. Formally: consider the production function

$$
\left.\log Q(t)=\int_{0}^{1} \log \left[x_{j t}(\varpi) q_{j}(\omega)\right] d \omega\right)
$$


where $x_{j t}(\omega)$ is the output of the intermediate prodnct $\infty$, with the highest quality level attained after $j$, successive innovations and $q_{j}(\omega)$ is the quality level of the product (i.e. $q_{j}(\varpi)=q_{0}(\varpi) \gamma^{j}$ ). The complementary between the intermediate inputs are clear from the formulation: each quality adjusted intermediate input has an additively separable contribution to the aggregate output.

With a redefinition of the intermediate goods as final consumption goods, the same function turns into

$$
\left.\log U(t)=\int_{0}^{1} \log \left[Q_{j t}(\varpi) q_{j}(\varpi)\right] d \varpi\right)
$$

where $U(t)$ is the welfare of the society at time $t$.

\subsubsection{Growth by variety}

Models that generate growth by variety are essentially not too different from the external increasing returns models discussed before. The common property of this category of models is their reliance on a production (utility) function ${ }^{26}$, the value of which responds more to an increase in variety than to a proportionall increase of the quantities of the existing varieties. To clarify, consider the following CES alike functions:

$$
\left(\sum_{k=1}^{n} x_{k}^{\alpha}\right)^{1 / \alpha}
$$

where $x_{k}$ represents the supply of the intermediate (final consumption) good $k$. Similar to our discussion on the Grossman and Helpman [1991a] model, if each $x_{k}$ is assumed to be an intermediate (final consumption) good, the function can be used as a production (utility) function. Let us assume that it is a utility function and experiment by changing $n$ and $x_{k}$, proportionately, one at a time, and assuming that all $x_{k}$ are equal to $x$. It can easily be seen that $U(n, \phi x)=\phi U(n, x)$, while $U(\phi n, x)=\phi^{1 / \alpha} U(n, x)$, which implies that if $\alpha<1$ then $\frac{U(\phi n, x)}{U(n, \phi x)}=\phi^{(1-\alpha) / \alpha}>1$. for $\phi>1$. Alternatively, assume that the resources of the economy are limited and the existing varieties share the resources equally. Then, an increase in variety implies a proportional decrease in the quantity of the output of each variety $\left(n(1)=\phi n(2)=>x(1)=\frac{x(2)}{3}\right.$, which is an effect similar to the business steal ing externality of the Aghion and Howitt [1990] model). Comparison of the two according alternatives show that $\frac{U(\phi n, x / \phi)}{U(n, \infty)} \phi^{(1-a) / \alpha}>1$, which implies that an economy can grow indefinitely (though the contribution of each new variety $\frac{n+1}{n}$ falls with increasing number of varieties) by reallocating its resources over an ever increasing number of varieties. The question is, how much investment is required to increase the total number of varieties in the economy?

This is exactly what is accomplished in the second part of the Grossman and Helpman [1991a] model. The growth generating capability of variety that comes with an integral (instead of summation) version of equation 1.30, is combined with a learning by doing type externality. That is, the cost of developing a new variety is assumed to be decreasing with experience, and experience at time $t$ is proxied by the number of current varieties $\left(\frac{\hbar}{n(t)}\right.$, where $*$ is a constant and $n(t)$ is the number of varieties at time $t$ ). It is clear that due to decreasing marginal utility of variety, the economy can not generate sustained growth with such an externality. The function of the total number of existing varieties in the model is equivalent to that of the capital stock $(K)$ in traditional models. Even if the marginal product 
of capital is decreasing, with a unit capital price inversely related to the capital stock $\frac{\#}{K}$ (which can only happen in case of sorne type of increasing returns), the economy can still grow with a constant rate.

Assume (as Grossman and Helpman do) that the production of each good is subject to a fixed labor coefficient $\left(x_{k}=b L_{k}\right.$ where $\sum_{k=1}^{n} L_{k}=L_{M}, L_{M}$ being the labor force allocated to manufacturing). Also assuming perfect symmetry between the sectors, $x=x_{k}=a \frac{L_{M}}{n_{i}}$, the utility function 1.30 reduces to $U(t)=$ $n(t)^{1 / \alpha} b \frac{L_{M}}{n(t)}=n(t)^{1-\alpha / \alpha} b L_{M}$, and the relation between welfare growth and variety growth to $\widehat{n}=\widehat{U} \frac{\alpha}{1-\alpha}$. Since $\widehat{n}=\frac{\dot{n}}{n}$ by definition, utility growth by a constant rate $(\widehat{C}=g)$ requires that $\dot{n}(t)=g n(t) \frac{\alpha}{1-a}$, which implies that for a constant growth rate, the number of new varieties to be introduced into the economy should grow over time. Thus, if the cost of each variety introduction were fixed, a constant rate of growth would be impossible. Yet, since the increasing returns generating externality reduces the cost of variety introduction $\left(\frac{x}{\pi z}(t)\right.$ proportionally to the number of varieties ${ }^{27}$, the total costs (in terms of labor allocation to research) of constant growth $\left(L_{R}=\dot{n}(t) \frac{x}{n(t)}=g \varkappa \frac{\alpha}{1-\alpha}\right)$, remains constant. In the steady state (where the economy grows by $g$ ), the economy allocates a fixed share of its labor force $\left(\frac{\bar{L}-L_{R}}{\bar{L}}\right)$ to research, and the rest $\left(\left(L_{M}=\bar{L}-L_{R}\right)\right)$ to manufacturing.

In terms of welfare analysis, the authors show that the consumer surplus generated by variety introduction is exactly offset by the business stealing effect (i.e. the introduction of each variety reduces the output, monopoly profits and thus the producer surplus in the other industries), and the welfare growth is only attributable to the externality which reduces the cost of $\mathrm{R} \& \mathrm{D}$ over time.

Another model by Romer [1990], generates growth by a similar principle, while the production function takes a slightly different and extensive form, such as

$$
Q(t)=H_{M}(t)^{\alpha} L(t)^{\beta} \int_{0}^{n(t)} x(i)^{1-\alpha-\beta} d i,
$$

where $x(i)$ in the last term (which retains the essence of the function in formula 1.30), is similar to the intermediate goods discussed before, but are defined by Romer as an array of capital goods, the degree of mutual substitutability amongst which is determined by the parameter $1-\alpha-\beta$. The model discriminates between plain labor $(L)$ and human capital $(H)$, both of which are assumed to be fixed in supply. The fixed supply of the human capital has two alternative uses. It can be allocated to the manufacturing sector $\left(H_{Q}\right)$ to produce $Q$ (i.e., real GDP), or to the research sector $\left(H_{A}\right)$ to produce new blueprints, each of which makes the introduction of a new capital variety possible (i.e., $H_{Q}+H_{A}=H$ ).

The production of a capital good $(x(i))$ is assumed to be sourced by foregone consumption and a constant (incremental) capital output ratio $(\eta)$ is assumed. As in the Grossman and Helpman [1991a] model, each variety is assumed to be produced by a monopolist, who buys the blueprint (patented indefinitely) of the design from the inventor. Symmetry imposed by the production and cost functions implies that the stock of each variety tends to equalize in the steady state so that $x(i)=\bar{x}$. Thus, since the capital output ratio is assumed to be constant, the capital stock of the economy at time $t\left(\int_{0}^{n(t)} x(i)^{1-\alpha-\beta} d i\right)$ is equal to $n(t) \cdot \eta \bar{x}$. The most important assumption of the model imposes growth by the introduction of an increasing returns mechanism: The knowledge stock of the economy (A) is assumed to be equal to the number of capital good varieties, which proxy the cumulative effort put into lnowledge (variety) generation. Most importantly, the growth rate of the knowledge stock $(\widehat{A}$, which is equal to the growth of number of 
capital good varieties $\widehat{n}$ ), is assumed to be linear on the amount of human capital used in research (i.e., $\widehat{A}=\widehat{n}=\delta \cdot H_{A}$ ). Thus, the decision of the society reduces to an allocation of the human capital between manufacturing and research, in a way consistent with their inter-temporal preferences (subjective discount rate).

In the steady state, where consumption, production, capital and knowledge stock grow with the same rate $\left(\widehat{Q}=\delta H_{A}\right)$, the society allocates a constant share of its human capital to research (which is only a function of production function parameters, subjective discount rate, and the inter-temporal elasticity of conv sumption), and the growth rate of the economy is determined by $H_{A_{A}}$. Since $H_{A}$ constitutes a constant proportion of the total human capital, the growth rate of the econony is an increasing function of only the total human capital stock and is independent of the plain labor force $(L)$. This finding is employed to explain across country growth rate differentials as a matter of differences in human capital stock: Countries with more human capital grow faster.

\subsection{The new trade theories}

The new growth models formally demonstrate in many alternative ways how knowledge which has a the non-rival nature, and which also diffuses in one way or another, increases the productivity of factors and keeps the incentives for accumulation and growth alive. The traditional theories of international trade have mainly been concerned with trade patterns and the once and for all gains that can be reaped by trade liberalization, which eliminates the allocative distortions caused by uneven distribution of productive assets over the countries. As discussed before, there have already been efforts that combine issues of trade with growth, yet these efforts have mostly been on the exploration of the effects of the interplay between price changes and exogenous growth of the traditional production factors, on the trade patterns and the according distribution of welfare increases over the trading countries. Yet, the sources of growth specified by these models do not incorporate knowledge and skills, the endogenous generation and diffusion of which, as shown by the new growth theories, make capital accumulation and growth possible.

In the rather diverse set of modeling exercises that can be classified under the new trade theories heading, the possibility of international differences in technological capabilities and human capital/knowledge are much more acknowledged, and the dynamic processes that generate, sustain and/or clear away these differences are taken into the scope of the analysis in various ways. Issues surrounding technological change (i.e. R\&D, innovation, imitation) are added to the list of the determinants of the emergence of comparative advantages by turning the focus on (static and/or dynamic) increasing returns and industrial organization structures (other than perfect competition), which justify the incentives and generate the means for R\&D (monopoly profits) as well. The little cast to pay for this integration is apparently the ambiguity with regard to the determination of the direction of trade flows, which turns out to be brought about by increasing returns, especially if the scope of the increasing returns generating knowledge spill-overs is less than international. Accordingly, a possible way to categorize the new trade theories is the scope of knowledge spill-overs and we will pursue this option below: 


\subsubsection{Models of external increasing returns of international scope}

An integrated world econony (as opposed to a fragmented array of countries with closed economies), in one way or another, implies a larger scale. Accordingly, if the production process is characterized by increasing returns to scale, the world can enjoy higher rates of growth to the extent with which international trade leads to an integration of fragmented national/regional economies. Without doubt, the sustained gains that can be reaped from these are far higher than the static gains brought about by trade liberalization, which eliminates allocative inefficiencies only once and for all. Especially following the empiricall findings which point to the insignificance of the estimated gains from various extensive trade liberation experiences (such as EU and NAFTA; e.g. Baldwin [1992]), the potential effects of a growth stimulating process that works its way through the international dissemination of knowledge and ideas, is a powerful argument in favor of trade. Of course, such a line of reasoning depends on the extent with which international flow of commodities and services can be associated with international diffusion of knowledge. Examples to links of this sort of causation are reverse engineering and the externalities related with personal networks facilitated by the connections established throughout import/export transactions (where people get to know each other). The models that formalize these possibilities can be categorized as new trade models of external increasing returns of international scope.

Among the models of this category, Romer [1990] readily extends the main result of his endogenous growth model with a few sentences. If the growth rate of a geographic entity (country/region) $j$ is an increasing function of its human capital stock $\left(\hat{Q}_{j} \approx \delta H_{j}\right)$, an integrated world with an integrated human capital stock will grow faster than the rate that can be maintained by the fragmented individual countries $\left(\widehat{Q}_{W}\right.$ orld $\approx \delta \sum_{j=1}^{N} H_{j} \approx \delta H_{W o r l d}>\widehat{Q}_{j}$ for $\left.\forall j=1,2,3, \ldots, N\right)$. Yet the mechanism that links growth to the human capital stock is based on the existence of knowledge spill-overs, and thus, the higher world growth rates can be a function of world human capital endowment only if an integrated economy implies the global spilling of knowledge over countries. International trade contributes to this process only to the extent with which it facilitates the dissemination of knowledge and ideas.

A second example is from the $7^{\text {th }}$ chapter of Grossman and Helpman [1991b] where a two country, two good (traditional and high-tech manufacturing) two factor (unskilled and highly skilled labor unevenly distributed across countries) setting is considered. Typically, the high-tech (traditional) sector is set to be relatively more high-skilled (unskilled) labor intensive. As in Grossman and Helpman $[1989,1991 \mathrm{a}]$, research leads to the introduction of new differentiated products in the high-tech sector. The production of any differentiated product is limited to the country where it was introduced, and therefore the high-tech sector is characterized by monopolistic competition and markup pricing (equal markups across countries) prevails (whereas the traditional sector is characterized by perfect competition which implies zero economic profits). The production functions that dictate the unit costs are equal across countries, but due to cross-country differences in factor endowments, autarky unit costs (and thus prices) differ across countries. The output of any high tech firm (recall that each firm produces one different variety) is specified by a CES type function, which takes the high tech sector prices and the number of varieties (both variables for either country) as arguments. 
Again as in Grossman and Helpman [1991a] the cumulative technological progress of a country is measured in terms of the number of differentiated products produced within, which is equal to the number of high tech firms (varieties) in the country, $\left(n{ }^{i}, i\right.$ being a country index) and furthermore the worldwide common knowledge base is directly measured by the number of worldwide differentiated products $\left(n=n^{1}+n^{2}\right)$. By assuming that the cost of inventing (and apparently innovating as well) a new differentiated product in conntry $i$ is inversely proportional to the world knowledge stock (the worldwide number of varies $\frac{m}{n}$ ), perfect international spill-overs and cumulativeness is introduced into the model.

The setting closely resembles the H-O-S settings and not surprisingly, the steady state properties of this model validates the $\mathbf{H}-\mathrm{O}-\mathrm{S}$ theorem with the exception that in this model the physical capital is replaced with high-tech labor (human capital). The market forces stemming from scarcity, coupled with optimization and equal technological opportunities (addressed in terms of perfect international spill-overs) lead to specialization such that each country produces an excess of the good, which is intensive to the factor that it has higher in stock. That is, the human capital (unskilled labor) rich country exports the high tech (traditional) good.

Yet, the model adds another dynamic feature to the standard static $\mathbf{H}-\mathbf{O}$ $S$ result. Having its human capital resources released from the production of the traditional good, the human capital rich country can afford not only higher growth rates in the output levels of the existing varieties, but also the generation of a higher number of varieties. Although this country experiences a higher rate of output growth, due to free trade both countries enjoy an equal rate of growth (and higher relative to autarky) in real consumption.

\subsubsection{Models of external increasing returns of national/sectoral scope}

In the traditional models of trade, one of the major problems has always been the fact that the existence of exogenously given cross-country differentials (factor endowments, relative labor productivities), which explain the across country differences in relative autarky prices and the corresponding incentives for trade, remain unexplained. Except for the corresponding theoretical inconvenience, the ambiguity in causal mechanisms also constitutes a problem in empirical testing: Even if one detects theory-consistent correlations between differentials in country characteristics and the direction of trade flows, one can not be sure whether the observed specialization is an outcome of a H-O-S or Ricardian or another mechanism. Yet, introducing the new growth theory framework (which already explains the cross country growth rate differentials) into internation al trade can supply an explanation for the endogenous emergence of differentials in country characteristics and comparative advantages. Moreover, a causal explanation on these lines is also consistent with the empirical findings pointing to the relation between sectoral trade performance (comparative adwantages) and technological change related variables (such as human capital, R\&D intensity etc.). To a large extent, an explanation that aims to explain cross country differences should draw on the assumption that the scope of the knowledge spill-overs (increasing returns) is national and/or sectoral. Therefore, these models can be classified as new trade models of external increasing retums of national/sectoral scope.

The first model that will be discussed is by Krugman [1987], where cumulative past output determines current productivity in the national level (learning by 
doing). The model also introduces the possibility of international spill-overs, yet this feature is modeled parametrically and the extent of it can be adjusted and the model's main findings are driven from cases where international diffusion rates are rather lower than national. The specialization module largely draws on the generalization of the Ricardian model by Dornbush, Fischer and Samuelson [1977] for a continuum of goods in a two-country setting. The learning module explains the emergence and persistence of international productivity differentials in the long-run.

For each good indexed by $z$, production in country $i$ at time $t$ is subject to the single factor production function $g_{i}(z, t)=a_{i}(z, t) \cdot L_{i}(z, t)$, where $q\left(z_{y}, t\right)$ denotes output level and $L(z, t)$ denotes labor allocated to the production of the good in question. Though this implies constant returns to scale at a given time, dynamic increasing returns is introduced such that the labor productivity coefficient for each good increases with the cumulative output; i.e. $a_{i}(z, t)=\kappa_{i}(z, t){ }^{e}$, where, for the two country case specially considered, the cumulative experience index $\kappa$ is not only a function of the cumulative output of the country, but to some extent that of the other one as well:

$$
\begin{aligned}
& \kappa_{1}(z, t)=\int_{-\infty}^{t}\left[q_{1}(z, \tau)+\delta \cdot q_{2}(z, \tau)\right] d \tau \\
& \kappa_{2}(z, t)=\int_{-\infty}^{t}\left[\delta \cdot q_{1}(z, \tau)+q_{2}(z, \tau)\right] d \tau
\end{aligned}
$$

where $0 \leq \delta \leq 1$ is a measure of intermational spill-overs of knowledge. Though these indices individually approach infinity quite rapidly, their relative value, which determines relative productivities $\left(A(z, t)=\frac{a_{2}(z, t)}{a_{1}(z, t)}=\left(\frac{\kappa_{2}(z, t)}{\kappa_{1}(z, t)}\right)^{E}\right)$ converges to a steady state $\left(\frac{d A(z, t) / d t}{A(z, t)}=0\right)$. For each good $z$, the steady state value of the relative productivity is determined by relative labor allocations to this good and also the spill-over parameter; (i.e. $A(z)=\alpha\left(\delta, \frac{L_{2}(z)}{L_{1}(z)}\right)$. For the specific purposes of this moodel, the extreme values of this function (at $\frac{L_{2}(z)}{L_{1}(z)}=0$ and at $\frac{L_{2}(z)}{L_{1}(z)}=\infty$ ) are important. As discussed before the Dornbush, Fischer and Samuelson [1977] is a model of complete specialization where the equilibrium of the model is characterized by the extreme values of $\frac{L_{2}(x)}{L_{1}(x)}$. Thus, any specialization pattern initially established (due to productivity differentials brought about by chance or some historical contingency) will be preserved by the learning by doing process ( $d y$ namic increasing returns) and eventually lead to a bipolar distribution of relative productivities $\left(\alpha(\delta, 0)=\delta^{\varepsilon}\right.$ and $\left.\alpha(\delta, \infty)=(1 / \delta)^{\varepsilon}\right)$, which makes the same specialization pattern more persistent and robust. Persistency and robustness is an immediate consequence of the bipolarity of the relative productivity distribution which can easily be observed in comparison to the original version of the model (i.e. Dornbush, Fischer and Samuelson [1977]), where the comparative statics results are derived on the basis of a relative productivity distribution which is a rather smooth (and monotonically decreasing) function of ranking index $z$ and where exogenous shifts in the demand structure (changes in tastes or relative sizes of the countries) not only affect relative wages but also the speciallization pattern. Yet, in the Krugman version, where dynamic increasing returns eventually lead to a discontinuous relative productivity distribution, demand shocks of moderate magnitudes only affect the relative wage (between $\delta^{\varepsilon}$ and $(1 / \delta)^{\varepsilon}$ ) while the specialization pattern remains intact (thus a lower rate of international spill-overs $\delta$ leads to a more robust specialization pattern). Krugman uses the metaphor " $a$ river that digs its bed deeper" to describe the process captured by the model. As 
the bed gets deeper, a significant derivation of the riwer path can happen only in case of a sufficiently big impact or a sufficiently persistent external effect. And to reverse such a change is equally hard. Krugman illustrates the explanatory power of the model by three examples.

The first example is on the Japanese industrial policies that aimed a gradual widening of product base by selective infant industry protection. In terms of the workings of the model, the process (referred to as the narrow moving band) is nothing but a consecutive selection of slices off an industry (i.e. one slice at a time) and protecting each slice, which would otherwise be lost due to the country's initial comparative disadvantage. The industry with such an initial disadvantage can be protected by making it non-tradable. To illustrate, assume that the second country: has initial comparative disadvantage for good $z$ so that in case of no protection labor shares allocated follow $L_{2}(z)=0$ and $L_{1}(z)>0$. Assuming that each of the $n$ goods receive an equal income share and for $k$ being the income share spent on tradable goods, protection of good $z$ leads to the labor allocation $L_{1}(z)=$ $k L_{1} / n$ and $L_{2}(z)=k L_{2} / n$. Thus, since the steady state relative productivity function $A(z)$ is increasing in $L_{2} / L_{1}$, under protection, $L_{2}>L_{1}$ (which implies that $L_{2}(z)>L_{1}(z)$ ) will eventually turn the second country's initial comparative disadvantage into permanent comparative advantage. After this point, protection is not necessary anymore. Even under trade, the new comparative advantage structure consciously broadened by protection will keep on reinforcing itself by further learning effects, so the country can switch to the protection of the next slice of the industry. Nevertheless, this policy can not be pursued indefinitely. Each slice added to the industrial base (which increases the share of the industry in world consumption) pushes the wage rate of the country further up relative to the rest of the world and introduces a further cost disadvantage. Thus, each new addition to the industrial base will require a higher productivity advantage and thus a longer period of protection. And since the relative wage rate increases by the addition of each slice, after a certain point (the relative wage rate reaches $(1 / \delta)^{\varepsilon}$ ) further broadening is no more feasible. All of this implies that such protectionist policies are only advisable to large countries with low wages.

The second example is on the phenomenon known as the Dutch disease, where the international competitiveness of a nation's productive sectors (such as manufacturing) are undermined due to the real appreciation of its exchange rate and accordingly its wage rate relative to the rest of the world. The currency appreciation may be due to the discovery of some precious (and exportable) natural resource (such as natural gas). In a static sense, this is not necessarily a problem for the welfare of the country. Yet the question is "what happens in the long run, when the natural resource runs out in the future?". Krugman uses the model to construct a possible disastrous scenario by the introduction of the natural resource discovery in terms of a unilateral transfer to the country from the rest of the world. The formulation follows Dornbush, Fischer and Samuelson [1977], where the transfer is introduced by reformulating the trade balance equation into the variant of the main model that incorporates non-tradable goods. As discussed before, due to the continuity of the relative productivity distribution $A(z)$ in Dornbush, Fischer and Samuelson [1977], a transfer leads to higher wages and a lower renge of commodities produced by the recipient country. Besides, the effect of the transfer is irreversible. However, in the Krugman model, the presence of dynamic increasing returns may change these results dramatically in the long run. First of all, due to the bipolarity of the long run relative productivity distribution, the long run specialization pattern is immune to external demand shocks that take place within 
limits (i.e. demand shocks that would result in equilibrium relative wage rates that vary between $\left[\delta^{\varepsilon},(1 / \delta)^{\varepsilon}\right]$ ). Thus, a maderate transfer improwes the recipient country"s welfare. However, a larger transfer that pushes the recipient's relative wage up to $\delta^{E}$, offsets its productivity advantage for a range of products which move abroad. Although this movement is reversible in the short run (if the transfer stops after a short while), due to the dynamic increasing returns mechanism (which gradually transforms the recipient country's relative productivity for the temporarily lost industries from $\delta^{e}$ to $\left.(1 / \delta)^{\varepsilon}\right)$, the loss of these industries may be permanent, if the transfer is sustained for a sufficiently longer duration. In such a case, when the natural resources eventually run out, not only the lost sectors will be lost forever, but the equilibrium wage rate will be lower than the initial rate, which implies a definite welfare loss for the country.

The third example of Krugman is similar to the second, with the exception that the triggering mechanism that restructures the comparative advantage distribution at the expense of the country in question is tight monetary policies (as pursued by Margaret Thatcher in the UK), instead of the discovery of some natural resource. The tight monetary policy works through real appreciation of the exchange rate, which costs the temporary lass of comparative advantage for some sectors. Similarly, if the loss is sustained by a prolonged period of tight monetary policy, the lost sectors will be lost forever. For both of the last examples, the undesirable outcomes will be aggravated by higher rates of international spill-overs $\delta$, which not only reduces the short run range of specialization pattern immunity to demand shocks, but increases the ease of a permanent change in the comparative advantage structure.

Our second example on national increasing returns is Krugman [1981]. The model suggests an explanation of international income differentials through external economies of scale of national scope. A head start, which emerges by chance and reinforces itself due to increasing returns, leads to persistent income differentials among trading countries. The model is based on a two country (North and South), two good (agriculture and manufacturing) setting, where agriculture only uses labor and manufacturing require both labor and capital.

Increasing returns are introduced by setting capital and labor coefficients (in both sectors) as decreasing in capital stock (which is only used in manufacturing). Each country fully employs its capital stock for manufacturing, and given the labor: coefficient and the labor endownent, the labor available to agriculture (and thus the agricultural output) is determined as a residual. All profits (price minus labor costs) are invested and are the only means of capital accumulation (savings). "The income shares (out of wages) to be spent on agriculture and manufactures are given and fixed.

The wage rate, which, together with commodity prices, eventually determines profits and investment, is assumed to exhibit a discontinuity. If agricultural production is non-zero, the wage rate is determined by the agricultural sector (set to be 1 conventionally) which enables positive profits in the manufacturing sector. On the contrary, if a country happens to be fully specialized on manufacturing (the upper limit to capital accumulation), profits are assumed to be zero (in a Kaldorian fashion) and the wage rate is determined accondingly as a residual.

Relative to the workings of a neoclassical model, which equalizes the rate of returm on capital to the market interest rates, this last assumption changes a lot. While the imposed increasing returns is sufficient to generate steady growth, due to the assumption which gives the whole output to the manufacturing workers (who do not save at all), at the instant of full specialization the growth process 
stops.

The main difference between autarky and trade is the convergence of the relative prices of products, which accentuates and reinforces the profitability differ. ences arising due to initial productivity differences. The important finding of this model is the fact that, although an interior solution (where each country produces both products) to the dynamic system exists, it is unstable, and accordingly depending on the initial conditions, tastes and/or technologies, the system is likely to end up in some corner solution, where at least one country fully specializes on one industry and in the sense of industrialization a bipolar structure emerges. The development process that takes the system to this structure is increasing retums, and again Krugman uses the metaphor of a river that digs its own bed. In the early stages of development (small capital stock), both countries (thanks to positive profits) grow by accumulating capital. Yet, the country which initially has the larger capital stock, grows faster due to its cost advantage made possiblle by increasing returns, and this faster growth keeps on reinforcing the cost advantage and generates faster growth. As manufacturing grows, the decline of the relative price of manufactured goods comes to a point where the lagging region can not compete anymore, suffers negative profits and its manufacturing sector starts shrinking. This shrinkage drives the manufacturing industry of the laggard into a downward spiral where shrinkage feeds itself back by further increased unit costs. Interestingly, during this process, as long as both countries are nonspecialized, the wage rates remain equal across countries. Yet, if capitall is assumed to be mobile between countries (it moves towards equalizing profits across countries), the capital flows to the underdeveloped region (which becomes more profitable for the capitalists of the developed country after the point of full specialization to manufacturing) leads to partial industrialization. Since the wage rate is determined by agriculture in the laggard country (as opposed to the zero profit condition of the fully industrialized country where industry is more efficient due to increasing returns), the workforce of the industrialized conntry end up being richer (a labor aristocracy in a Leninist sense).

\subsubsection{Models of internal economies of scale}

As discussed before, the models of growth by variety are mostly based on the suggestion that product variety is a welfare-augmenting asset. This principle, applied to international trade, constitutes a most reasonable basis for the explanation of intraindustry trade, which takes up a significant portion of actual world trade flows. Yet as pointed out by the new growth models, generation of variety is not free and given limited resources, there is an upper limit to the amount of variety that national economies can (are willing to) afford. Yet, the increasing returns to scale related externalities which economize on the marginal cost of variety can imply higher varieties than can be afforded by an integrated world economy; where countries exchange their varieties with that of the others. The models that formalize this variety-based explanation for the existence of intraindustry trade mostly draw on the ance and for all costs of variety generation, which are paid by individual firms. Firms that buy (or generate) the blueprints of a new variety, finance this undertaking by credits from the financial markets and keep on paying rents over the lifetime of the blueprint. Such rents constitute fixed costs and therefore the production of each variety (after the discovery) by the corresponding monopolist is subject to increasing returns to scale. Therefore international trade, which implies a larger market size, lower unit costs and accordingly expectations 
for higher monopoly profits, indirectly implies higher incentives for research and higher amounts varieties on the world scale. The models that follow this link can thus be referred to as new trade models of internal economies of scale.

As discussed before, models that generate growth through variety generation are based on similar trade-offs with models of growth through quality improvements, and accordingly the international generalizations of the former type of growth models can also be classified under the same heading.

In spite of what is just said, the models that can be seen as generalizations of variety/quality based neoclassical growth models mostly come as a package together with the assumption that makes the model satisfy the basic assumptions of the H-O-S model (perfect international knowledge spill-overs, cross-country differences in human capital/labor endowments), and one example was alleady discussed before (Grossman and Helpman [1991b]) under the subsection devoted to models of external increasing returns of international scope. The common property of these models (which are mostly due to Grossman and/or Helpman) is that they essentially reproduce the $\mathbf{H}-\mathrm{O}-\mathrm{S}$ model results in a dynamic fashion. In this sense, these models constitute the theoretical basis for the neo-endowments approaches, which was summarized in our discussion of the empirical tests of the H-O-S model.

Since an example of such models is allready given, in order to increase the coverage of our overview, in the rest of this subsection we will instead discuss a number of models by Krugman, which follow a somewhat different formulation. In general, these models do not formulate the typical trade-off between future variety and current consumption. In other words, the development cost of variety is ignored and variety is simply assumed to exist. Yet, the production of each variety is assumed to be subject to internal increasing returns to scale due to the existence of fixed costs. Thus, the only thing that keeps the economy from producing an infinite array of varieties is reduced to the existence of these fixed costs and the monopolistically competitive market structure it leads to.

Actually, as in Grossman and Helpman [1991a] and Aghion and Howitt [1990], the fixed costs that lead to the internal increasing returns can be seen (without any loss of generality) as the interest paid to finance the purchase of the blueprint (patent) that makes possible the production of the variety in question. In this sense, the workings of the Krugman models resemble the underlying mechanisms of the variety based neoclassical models of growth. Yet Krugman does not resort to this explanation, assumes zero development costs and leaves the source of the fixed cost unexplained. In descriptive terms, this is a divergence from the structure of the growth models, which somehow internalize the Schumpeterian ideas on the importance of the link between growth and appropriability of knowledge (i.e. the incentives for growth is at the firm level. Firms invest on research in the expectations of future monopoly profits, and each new creation leads to the destruction of some obsolete technologies). Nevertheless, in terms of the main model building blocks, the Krugman formulations are technically equivalent to the new growth models of variety and accordingly his formulations economize on algebraic complexity and bring out the essential points of the story told.

Despite the (minor) differences in formulations, definitions and solutions, the central element that underlies the entire set of variety based new growth and trade models is the utility/production function that is formulated as $\left(\sum_{k=1}^{n} x_{k}^{\alpha}\right)^{1 / \alpha}$. This formulation (due to Dixit and Stiglitz [1977]) which was mentioned before, is the major imnovation that leads to the entire set of these models, since none of them can generate their similar results without using some version of this function.

The first two models (Krugman [1979] and Krugman [1980]) to be discussed 
are quite similar and thus are summarized together. As many models of Krugman, these draw on Dixit and Stiglitz [1977] for their Ricardian specialization modules and also on the Chamberlinian formulation of monopolistic competition (Chamberlin [1962]).

Both models incorporate only one production factor (labor). The first element of the model is firm level increasing returns to scale, which are expressed via a cost function (measuring cost in terms of labor units) that specifies (for each firm i) fixed costs in addition to variable (i.e. labor cost $t_{i}=\alpha+\beta q_{i}$ ). The second element is monopolistic competition, which assumes a large number of (potential) goods, each being produced by another firm. The assumption that product differentiation is costless implies that no two firms would want to produce the same product. Besides, due to the large number of firms, which makes the price effect of any good on the demand of others negligible, the indeterminacies of oligopoly are eliminated. The third element is the CES type additive utility function ( $U=\sum_{i}^{N} C_{i}^{\theta}$ where $0<\theta<1)^{28}$. $N$ is the large number of potential products, yet not all potential products are necessarily produced (i.e. the actual number of products $n<N$ ). The parameter $\theta$ determines the degree of substitutability among products (the higher is $\theta$ the less differentiated will the products be). These elements, together with the assumptions that $\alpha, \beta$ and the wage rate $(w)$ are the same for each firm (good) and new firms (differentiated products) enter as long as profit maximizing firms make positive profits (thus equilibrium is the point where profits are zero and entry/exit stops) lead to a perfectly symmetrical situation where the price ( $p=$ $\frac{\beta w}{\theta}$ ) and output level of goods $\left(q=\frac{\alpha \theta}{\beta(1-\theta)}\right)$ equalize. Thus, (for $L$ representing the labor force) at the full employment equilibrium $n=\frac{L}{\alpha+\beta q}=\frac{L(1-\theta)}{\alpha} \operatorname{goods}$ are produced. This result illustrates the essential trade-off between quantity and variety in an increasing returns world.

When the accordingly specified two economies are open to trade, the number of goods produced by each country, the produced quantities, and the real wage rates do not change. Yet, for the same reasons that each good is produced by only one firm, the world economy will produce a greater diversity of goods offering each world citizen a wider range of choice. To clarify, assume a symmetrical case where two countries are identical in size $\left(L_{1}=L_{2}\right)$. Then, in the no trade case, the welfare of any country is $n q^{\theta}$. In case of trade the number of available goods increase to $2 n$, but since the produced quantity for each good which remains unchanged is now being shared equally between countries, the trade welfare becomes $2 n\left(\frac{q}{2}\right)^{\theta}=$ $n q^{\theta}\left(\frac{2}{22^{\theta}}\right)$, which (thanks to the assumption $0<\theta<1$ ) is definitely larger than the before trade welfare $\left(n q^{\theta}\right)$. Obviously, the point made by the model highly depends on this specific utility function, which favors increased product variety more than a proportionally increased level of consumption for existing goods. Besides, the model does not explain the direction of trade (which country produces which good), but only stresses on the welfare gains from increased product variety. The common conclusion of the 1979 article and the first part of the 1980 article is that: trade turns out to be way of exploiting economies of scale by market extension.

In the second part of the 1980 article, Krugman also introduces transportation costs (such that a fraction of goods are lost in transportation) and with slight variations on the same model, shows that in an increasing returns to scale world where market sizes differ between countries (due to different country sizes or different preferences), transportation costs not only induce incentives to locate production near its largest market, but may have countries specialize on and export the products for which they have relatively larger domestic demand (as in the case of USA exporting aircrafts). 
The next model of this subsection is again by the same author (Krugman [1981b]), and aims to explain simultaneously three stylized facts, which are perceived by the author to be in conflict with the traditional trade theories of specialization. That is: 1) A great deal of the world trade is between countries with similar endowment compositions. 2) A large part of international trade is of intraindustry nature. 3) Historically (in the post-war period), expansion of trade has taken place without significant reallocation of resources or income distribution effects. The model introduces comparative advantages (defined over sectors) over increasing returns that apply to individual firms of monopolistically competitive industries, in a way similar to the two 1979 and 1980 articles.

The model, which is closer to the neoclassical spirit than the ones just discussed, is based on a 2 country 2 industry setting where each industry is characterized by monopolistic competition. The introduction of intraindustry versus interindustry divide is achieved by defining two industries each comprising a group of closely substitutable products, while substitutability is more limited between the products of the different industries. Formally, the utility function used is a combination of Cobb-Douglas and CES, such that

$$
U=\ln \left(\sum_{i=1}^{N_{1}} C_{1_{, i},}^{\theta}\right)^{M / \theta}+\ln \left(\sum_{j=1}^{N_{2}} C_{2, j}^{\theta}\right)^{1 / \theta}
$$

where $C_{k, m}$ is the consumption of $m^{\text {th }}$ product of industry $k$, and $N_{k}$ are large numbers of potential products in each industry. The Cobb-Douglas type part (the logarithms) ensure that income is equally divided between the two industries, and due to the CES type part (as in the two other Krugman models discussed before) firms in each industry face a demand curve with elasticity of substitution $1 /(1-\theta)$.

On the supply side, labor force is differentiated. Production in each industry requires a specific type of labor and accordingly for each firm $m$ of industry $k$, the cost (requirement for the industry $k$ specific labor $l_{k, m}$ ) function that exhibits increasing returns to scale is clefined as $l_{k, m}=\alpha+\beta q_{k, m}$. Trade in the Ricardian sense is thus ruled out by assuming away technological differences ( $\alpha$ and $\beta$ apply to all industries and countries). Furthermore, the endowments of these two types of industry-specific labor are assumed to be giwen (fixed) and immobile between the sectors. Thus, at (assumed) full employment, $\sum_{i=1}^{n_{k}} l_{k, i}=L_{k}$ for each industry k. Conventionally, the total labor force $\left(L_{1}+L_{2}\right)$ is set to 2 for each country and symmetry is assumed between countries. That is both countries are assumed to be exactly identical with the exception that the specific labor endowments are the mirror image of each other; i.e. $L_{1}^{*}=L_{2}=z$ and $L_{2}^{*}=L_{1}=2-z$ accordingly (an asterisk is used to differentiate the two countries). At the autarky equilibrium, due to the assumed immobility of the labor types between the industries, the wage rates are not necessarily equalized; i.e. $\frac{w_{1}}{w_{2}}=\frac{w w_{2}^{*}}{w}=\frac{z}{2-z}$

The equilibrium solution (where the entry of new firms eventually pushes profits down to zero) to the sectoral output and number of products is naturally similar tho that of the other two Krugman models discussed before (for example, for the home country the number of goods produced are $n_{1}=n_{2}^{*}=(2-z) /\left(\alpha+\beta q_{1}\right)$ and $\left.n_{2}=n_{1}^{*}=z /\left(\alpha+\beta q_{2}\right)\right)$. Accordingly, with the opening of trade, any welfare increases are brought about through increased product variety. Additionally, since the mirror image assumption makes the total world output of the two industries equal, product prices and wages equalize, both across countries and across industries. 
Yet, the striking result of the model is highlighted by the relation between intrasectoral trade volume and the similarity between the endownent structure between the two countries (measured by the paraneter $z$ ) Krugman adopts an intraindustry trade measure (index) from the empirical literature (e.g. Hufbaver and Chilas [1974]) on intraindustry trade:

$$
I=1-\left(\sum_{k}\left|X_{k}-M_{k}\right|\right) /\left(\sum_{k} X_{k}+M_{k}\right)
$$

which measures the trade overlap for $X_{k}\left(M_{k}\right)$ being a country's exports (imports) in industry $k$. The index equals 0 in case of full specialization and equals 1 if trade is balanced. Krugman shows that the modell solves for $I=z$, which implies that the more similar are the countries in their factor endowments $(z->1)$, the higher is the volume of intraindustry trade and dissimilarity in endowments lead to specialization on the industry level. Thus, as in Davis [1995] (which was discussed before) inter-industry and intraindustry trade are not substitutes but are complementary to each other.

In terms of the distribution of gains from trade (across industry specific labor and countries), Krugman shows that similarity in factor endowments $(z->1$, which increase intraindustry trade) is mutually beneficial for all parties, whereas dissimilarity (and the resulting specialization) may lead to conflict of interest among groups especially if the substitutability among the products within industries is not sufficiently low (i.e. societies do not weigh variety sufficiently higher than total consumption quantity).

A highly similar model can be found in Ethier [1982b], who renames the firm level increasing returns as "national increasing returns" and the global welfare gains from increased product variety (i.e. under trade, the consumers of every country enjoys the welfare implications of increased number of varieties in any country) as "international increasing returns". In Ethier"s wordis "the interaction between national and international increasing returns" (which is essentially a process similar to that in the Krugman model just discussed), leads to a situation, which satisfies the entire set of theorems (Stolper-Samuelson, Factor price equalization etc.) that define the H-O-S framework. Besides, it also points to the complementary nature of the relation between intraindustry and inter-industry trade: If factor endowments proportions are different countries export (import) their relatively abundant (scarce) factor embodied in goods, whereas countries with similar endowment structures get involved in intreindustry trade and gain from increased variety.

\subsection{Technology gaps models}

As discussed before, the technology gap theories by Posner [1961] and Hufbauer [1956] and the product cycle theories by Hirsch [1967] and Vernon [1966], both supply heterodox and informal description of various processes that give some countries the monopoly to introduce new goods and processes that make the production of these goods migrate to other (lower wage) countries. Below we will discuss three alternative formalizations of these ideas. The first two (by Krugman) have a more mainstream taste, whereas the last, by Cimoli, also draws on additional elements form development economics and structural economics.

The first model by Krugman [1979] aims to explain income differentials between developed and less developed countries in the context of innovation and technology transfers. The workings of the model highly draw on Vernon's [1966] 
"product life cycle" concept, where the introduction and development of new products is under the monopoly of a technologically superior North, while at the maturity stage, the production migrates to the low cost (and technologically inferior) region South and is adderd to its range of exportables. In its extreme form, the model assumes that North only produces (and exports) new goods while production in the South is confined to ald goads. The introduction of the old-new divide into the model is achieved through two differential equations. The first one is responsible for the introduction of new goods such that the innowation rate (number of new goods per time) is proportional to the number of existing products at time $t$ (i.e. $d n(t) / d t=i n(t))$. On the other hand the technology transfer from North to South, which is the process through which new products become old, is subject to the equation $d n_{s}(t)=g n_{N}(t)$, where the subscripts $N$ and $S$ stand for North and South respectively. Though the number of goods for the both regions tend to explode in time, the share of the countries in the total number of goods $\sigma=n_{N} / n$ moves according to $\frac{d \sigma}{d t}=\frac{d n / d t}{x_{2}}-\frac{\sigma(d \mathrm{~m} / d t)}{\pi}=i-(i+g) \sigma$, and tends toward the equilibrium $\sigma=i /(i+g)$. Thus in steady state, the ratio of new to old goods $n_{N} / n_{S}=\sigma /(1-\sigma)=i / g$.

On the production side, only one factor of production (labor) is assumed. One labor unit is assumed to produce one unit of output and perfect competition prevails (profits are zero). Thus, the price of the new goods relative to the old goods $\left(P_{N} / P_{S}\right)$ is equal to the ratio of Northern to Southern wage rate $\left(w_{N} / w_{S}\right)$. As long as $w_{N} / w_{S}>1$, North has comparative advantages for only the new goods.

The demand side is modeled according to the utility function $U=\left(\sum_{j}^{n} c_{j}^{\theta}\right)^{1 / \theta}$, which is an increasing function of the number of products $n^{29}$. Optimization requires that the relative consumption $c_{N} / c_{S}=\left(P_{N} / P_{S}\right)^{-}(1 / 1-\theta)$ and full emplloyment (together with the unit labor coefficient assumption) requires that demand for each good times the number of goods must equal to the labor force for each country (i.e. $c_{N} n_{N}=L_{N}$ and $c_{S} n_{S}=L_{S}$ ). Putting all together yields

$$
\frac{w_{N}}{w_{S}}=\left(\frac{n_{N}}{n_{S}}\right)^{1-\theta}\left(\frac{L_{N}}{L_{S}}\right)^{-(1-\theta)}=\left(\frac{\dot{z}}{g}\right)^{1-\theta}\left(\frac{L_{N}}{L_{S}}\right)^{-(1-\theta)}
$$

which captures the essence of the model ${ }^{30}$. For fixed inmovation and imitation rates ( $i$ and $g$ ) the relative wage is constant, and the extent to which North enjoys higher wages is an imcreasing (decreasing) function of the innovation (imitation) rate. Both countries (though disproportionately) benefits from innovation, though higher imitation make North worse off. Yet any increase in either (or both) of innovation and imitation increase world output and welfare. While this structure that keeps the world income distribution unchanged, in the micro level progress steadily proceeds; new products keep on being introduced by the North and are imitated (and their production migrates completely to the lower wage country South) by a time $\operatorname{lag}$ of $1 / 9$.

The second technology gap model we will discuss is also by Krugman [1986]. In the Ricardian models of international trade, specialization is a matter of technological differences. Yet, in terms of techmological progress, change can only be described as a vector (a decomposition over industries and countries) and therefore there is not any scalar that would make it possible to rank countries according to their technology or the rate with which technological change takes place. In order to achieve this and establish a link between theories of comparative advantages and (across country) convergence/divergence, Krugman impioses a joint distribution structure between characteristics of goods and characteristics of countries such that while countries that are relatively technologically superior have absolute 
advantages in all sectors, they have comparative adwantages only in sectors that are relatively more intensive in technologies. This structure maturally brings along a feature similar to the H-O-S theory, though specified in a radically different way.

The model essentially consists of a modification over the Dornbush, Fischer and Samuelson [1977] model. For each good $z$, the existence of a best-practice technology is assumed. In the single production factor (labor) world, the best-practice is specified as the unit labor requirement $(A(z, t))$ that falls steadily over time such that $\alpha(z, t)=e^{-g_{z} t}$. where $g_{z}$ is the rate of technological progress for good $z$. Each country $i$ is assumed to follow the frontier with a uniform (independent of $z$ ) time $\operatorname{lag} \lambda_{i}$; i.e. the labor coefficient for good $z$ in country $i$ is $a_{i}(z, t)=e^{-g z\left(t-\lambda_{i}\right)}$. The relative techmologicall. superiority of any country is thus represented by its distance from (lag behind) the frontier, which as discussed above, is a scalar; i.e. if country $i$ is technologically superior to country $j$, then $\lambda_{i}<\lambda_{j}$. Therefore the productivity advantage of country $j\left(\frac{a_{j}(z)}{a_{1}(z)}=e^{g z\left(\lambda_{j}-\lambda_{i}\right)}\right)$ is an increasing function of technological intensity of the good $g_{z}$. After re-indexing the goods such that $\frac{a_{j}(z)}{a_{i}(z)}$ is increasing in $z$, the result that immediately follows is that the technologically superion countries specialize on the relatively more technology intensive (high $z$ ) goods and enjoys relatively higher wages. In other words each country on the technology ladder finds itself a miche in the product range, such that irnmediate neighbors on the technology ladder, specialize on immediately neighboring ranges on the product spectrum (indexed by $z$ as described above). The lower wage rates in backward countries outweigh their productivity disadvantage, which makes international trade possible.

To refine welfare implications, the model is reduced to a two country setting, and is closed (on the demand side) in a way similar to that in Dorrabush, Fischer and Samuelson [1977]. The important result that follows from comparative statics is the asymmetry between gains and losses with regard to catching-up (lower $\lambda_{j}$ $\lambda_{i}$ ) and falling behind (higher $\lambda_{j}-\lambda_{i}$ ). Further falling behind of the technologically laggard country $j$ (a wider gap caused by improved technology in the leading country: lower $\lambda_{i}$, results in higher wages and increased product range for the leading country $i$. While this results seems disturbing for the laggard country, it turns out that it is not; the relative wage increase for the leading country is proportionally less than the productivity increase and thus the laggard country sees its terms of trade improve, and its welfare increase.

On the other hand, in terms of catchimg-up (lower $\lambda_{j}$ ), the case is more conplicated. The laggard starts producing a broader range of products and its wage rate increase (in terms of all goods) thus it definitely gains. Yet, for the leading country, two conflicting effects determine the gain/loss. First, the goods it formerly produced (yet now imports) are cheaper due to lower wages of the laggard country, which is a plus. On the other hand, the goods it has been importing (before and after the narrowing of the gap) are more expensive due to the worsened terms of trade. If the second effect outweighs the first, the leading country may loose from the narrowing of the gap.

The third model by Cimoli [1988 $]^{31}$ introduces the core ideas of structuralist theories (such as Prebisch [1950], Singer [1950], Lewis [1954]) and also the technological gap-product life cycle theories of Vernon [1966], Posner [1961] (as in Krugman (1979]) on the Ricardian framework of comparative advantages and international trade. The former line of thought stresses the institutional differences between countries especially with regard to the structure of the labor markets and the determination of wages. The relative weakness of organized labor unions and 
the dual structure in production (agriculture versus manufacturing) work againsi competitiveness in the determination of wages in the less developed countries, resulting in wages that can be taken as exogenously given (i.e. subsistence wages only sufficient for the consumption of a basic basket of necessity goods). Besides, due to the existence of a reserve army of labor, the labor force is not the dominating scarce factor for the underdeveloped economies. Accordingly, the model is built to analyze the (international trade related) interdependence between countries of different stages of development, in relation to differences in demand elasticities, technological gaps and structure of the markets.

The formal integration of the pieces is realized as follows. In a continuum of goods, ranked according to the productivity ratio between the technologically advanced North and lagging South, the Ricardian specialization pattern is determined by relative wages between. North and South. Yet, unlike in mainstream models, and based on the structuralist views on wage rigidities, wage rates are specified to be exogenous to the model. The sensitivity of the (Ricardian) specialization pattern to exogenous changes in the relative wages is accordingly a matter of the distribution (or slope) of North-South relative productivities over the continuum of goods (ranked according to increasing relative productivities of the North, or equivalently increasing of technological intensity implying that North has comparative advantage bias towards the technology intensive goods). Moreover, unlike in mainstream models, which assume homothetic preferences, demand for each good in the continum is allowed to have different income and price elasticities than the others. Consequently, given the relative productivity distribution, the exogenously given relative wages imply a specialization pattern, and given this pattern and demand for each good, import demand for each country is determinate. Putting these elements into the balance of payments constraint equation yields to a relation that looks like a static version of the Harrod's trade multiplier: Given comparative advantages and demand pattern, since relative wages are also exogenous, the BOP constraint can only be satisfied by adjustments in macroeconomic activity (employment rates). Yet, the formulation is potentially different than the BOP constraint growth models that take the pattern of trade as given, since the former allows for changes in the pattern of specialization as relative wages and/or the technology gap change.

The next step of the models is to endogenise the specialization pattern through the integration of a module that captures the essence of the technology gap literature. This step involves two separate processes of technological divergence and convergence that are brought about respectively by North's monopoly in innovativeness, and imitations by South that take place with a time lag after the innovations. Furthernore, innovations and imitations take place in two separate domains. The first is product innovations, which steadily keeps on adding new products, initially producible only by the North. This monopoly lasts until these new products are imitated by the South. Imitation eventually makes the new products producible by both countries, but after this point the determination of the producer country of these new products reduces to a matter of comparative advantages (i.e. relative productivities of North and South over these new products and relative wages) and thus by imitation the new products join the set of Ricardian (old) products. The second type of innovations, which are also assumed to be under North's monopoly, are process innovations that increase labor productivities in production of the Ricardian goods and thus leads to further divergence in relative productivities, disturb the Ricardian specialization pattern, increase the number of goods produced by the North, and moreover decrease the sensitiv. 
ity of specialization pattern to wage differentials. Imitation of process innowations by South (after a lag) naturally works in the opposite direotion. Accordingly, the only way in which South can increase its wage rate (welfare) whouth losing competitiveness in the Ricardian commodities is to increase its imitation rate.

Technically, the introduction of the life cycle theories is quite similar to Krugman [1979]: North keeps the innovation and the production of new goods at its nonopoly, until they are imitated by South and become old goods. The difference is in the fact that, unlike Krugman [1979], the specialization pattem is not confined to the unique case, where North (South) only produces the innovative (old) goods. This particular case only specifies the upper limit for the range of commodities in which South can specialize. In the conventional notation (the $z$ index represents goods in the continuum), $\left[0, z_{R}\right]$ is the range of old goods, and $\left[z_{R}, z_{T}\right]$ is the range of new goods ${ }^{32}$. Since, imitation only implies the potential increase in the range of products producible by the South, the eventual specialization (specified by the marginal commodity $\tilde{z}$ ) takes place somewhere within the range $\left[0, z_{R}\right]$ (depending on differences in productivities, wages and demand such that $0<\widetilde{z}<z_{R}$ ), while North keeps its monopoly over commodities in $\left[z_{R}, z_{T}\right]$. Accordingly Cimoli refers to the commodities in $\left[0, z_{R}\right]$ as the Ricardian commodithes. Assuming that the goods are indexed such that in $\left[0, z_{R}\right]$ relative productivity advantage of the North $\left(A(z)=\frac{a_{S}(z)}{a_{N}(z)}\right)$ is monotonically increasing $z$, the variable $\psi(\widetilde{z})=[\partial \widetilde{z} / \tilde{D}] /[\partial \varpi / \varpi]=[\partial \widetilde{z} / \tilde{z}] /[\partial A(\tilde{z}) / A(\tilde{z})]$ represents the elasticity of the specialization patterm with respect to relative wages, which is also an inverse measure of the widening of the productivity gap over $z$.

The closing of the model is radically different than the other Dornbush,Fischer and Samuelson [1977] formulation based models discussed so far, all of which assume competitive labor markets, full employment and homothetic and identical tastes. However, the Cimoli model (though without specifying a definite functional form) allows for varying price/income elasticities across countries and over commodities; i.e. the per capita income shares are such that $b_{N}(z)=f_{N}\left[z, u_{N}, p_{S}(z)\right]$ and $b_{S}(z)=f_{S}\left[z_{,}, w_{S}, p_{N}(z)\right]$ and therefore $b_{N}(z)$ and $b_{S}(z)$ are not necessarily equal. The share of imports in Northern wages $B_{N}(z)=\int_{0}^{z(\varpi)} b_{N}(z)$ is only used to buy the Ricardian goods produced by the South $([0, z])$, whereas that in Southern wages $B_{S}(\tilde{z})=\int_{\tilde{z}(\widetilde{z})}^{z} b_{S}(\tilde{z})$ buys the rest of the Ricardian goods $\left(\left[\tilde{z}, z_{R}\right]\right)$ and the immovative goods $\left(\left[z_{R}, z_{T}\right]\right)$ both of which are produced by the North. The balance of trade requires that $Y_{S} B_{S}=Y_{N} B_{N}$, where $Y_{N}$ and $Y_{S}$ are the incomes of the countries in which wages are the only component; i.e. $Y_{N}=w_{N} L_{N}$ and $Y_{S}=w_{S} L_{S}$, where $L$ denotes employment which (given the absence of full employment condition) is not necessarily equal to the labor force. Thus, $B_{N} / B_{S}$ equation clescribing the (Southern) relative income $Y=Y_{S} / Y_{N}$, also look like Harrod's trade multiplier, which was mentioned before during the discussion on BOP constrained growth literature (Kaldor, Thirlwall). "The difference is the fact that the BOP constramed growth models explain relative incomes on the basis of given relative import demands, while the Cimoli formulation allows for changes of specialization patterns as well. Thus, the model explains relative income as a function of relative wages (which affect prices, and specialization pattern), demand and technological gaps which affect the limit and extent of specialization. 


\subsection{An evolutionary example on international trade and growth differentials}

We make in the following chapter of this book fairly broad discussion on the philosophy of the evolutionary economics, together with salient examples from the evolutionary modeling efforts. However, just to give an impression of the evolutionary way of thinking (as blended with various Post-Keynesian elements) we include bere a brief discussion on an evolutionary (yet, non agents-based) model by Verspagen [1993]. The model aims at explaining growth differentials, catching up and falling behind phenomenon in the context of technological change and international trade. The two evolutionary model(s) of Verspagen also exhibit a post-Keymesian tendency. The studly starts with a macro approach (North-South type) that relates output growth to growth of technological knowledge stock, working directly and also indirectly through stimulating export growth ${ }^{33}$. The principle of economic selection that underlies the formulation of this indirect mechanism is actually what gives the model its evolutionary nature. That is, the growth rate of exports is formulated as an increasing function of technological gaps ${ }^{34}$ (the difference between knowledge stocks), which implies that technological superiority (backwardness) leads to increase (decrease) of market share in world markets. The model is closed by the specification of dynamics for knowledge accumulation. For both countries, knowledge accumulation is brought about partially by exogenous learming (exogenous learning rate for the innovative North is assumed to be higher than that for South) and partially due to learning by doing (actually Verdoorn effect which introduces dynamic increasing returns by specifying learning rate to be an increasing function of growth rate) ${ }^{35}$. Moreover, South can also add to its knowledge stock by imitations from the North. The extent of mitations is determined first by the imitation opporturities (the larger the technological gap the more potential there is for imitation) and second by South's capability to exploit the existing imitation potential ${ }^{36}$. The extent of the latter is assumed to be determined by policy decisions on investment in education, infrastructure, etc. The analysis of the model basically demonstrates that there is an inverse relation between catching up possibilities for backward countries and the extent of the initial technological gap: while catching up is only possible with sufficient capability to imitate. This result is highly different from that of the Solow model, which (based on the view that assumes that knowledge is purely a public good) predicts that regardless of the initial gap, backward countries will eventually catch up. According in the Verspagen model, catching up is only possible with persistent investment on building up of imitation capabilities, and even witili sufficient imitation, technological levels will not converge as long as differentials in the exogenous rates of learning persist.

The second phase of the study extends the first part into a microeconomic formulation, where the evolutionary selection process is reformulated separately for each disaggregated sector in a multi country multi product setting. For each country, sectoral penetration of imports (formulated separately for each sector), is an evolutionary time process that gradually change as a decreasing function of the competitiveness of the country (in the sector in question) relative to the average of competitiveness of the rest of the world. For each country, competitiveness in a sector is defined as a decreasing function of the price with which the country brings that sector's output to world markets, and this price is determined by the sectoral productivity, the domestic wage rate and exchange rates ${ }^{37}$. Sectoral productivity is assumed to grow proportional to sectoral output (learning 
by doing with sectoral externalities), wages grow as fast as national productivity (weighted average of sectoral productivity growth rates) with Phillips curve like, unemployment and institutional related variations, and exchange rates tend adjust towards purchasing power parity equalizing levels. Finally, the incone shares that determine relative demand for different products change by increasing income, indicating different income elasticities in the sense of Pasinetti [1981]. The resulting system, unlike the mainstream models, does not restrict sectoral prices to unique world prices and accordingly relates sectoral world market shares of countries tio productivity divergence related price differentials. Furthermore, the model (again unlike mainstream models) does not restrict demand to constant and unitary income elasticity and introduce income elasticity variations (over goods and time) as an explanatory principle to specialization. The resulting system, which can not be solved analytically, is simulated for controlled parameter variations. The results point to the endogenous emergence of international specialization patterns and growth rate differentials made persistent by sectoral learning by doing related externalities (no intemational spill-overs) and non-linearity of Engel curves. 


\section{Notes}

1. Excellent technical and philosophical overviews of this eclectic collection of approaches to this sub-field, which makes the history of international economics. theory, can be found in Jones et al. [1984] and Grossman et al. [1995] (Handbook of International Economics Vols. 1 and 3), Gandolfo [1987] (for a highly technical overview), Dosi et al [1990] (for a rather critical survey), and Wakelin [1997] (for an empirically focused coverage).

2. Also note that, for the readers who are not quite familiar with the subject matter we also supply a basic overview in an appendix to this chapter, which can be found in the CD (the file/Appendices/Chap1App.pdf.) accompanying to this dissertation.

3. Deardorf [1980] and Dixit and Norman [1980] have shown that the principle can be redefined as the correlation between differences in autarky prices and free trade net export volumes.

4. International monetary theory is essentially a macroeconomic approach and is mainly concerned with the adjustment mechanisms and policies of the ballance of payments in relation to the other macroeconomic variables.

5. In the file/Appendices/Chap 1App.pdf.

6. In simple terms, the cost minimizing primciple is to use more (lees) of the relatively cheaper (more expensive) factor up to the extent made possible by the production function.

7. For example, recall our discussion on the introduction of a demand side into the Ricardian framework, where the divergence of world prices from of a special interval leads to partial specialization, which can happen in case of extreme preferences or large preference differentials across the countries.

8. This condition would antomatically hold in case of any Leontief type (fixed coefficient) production function. Nevertheless, the previous assumption on the smooth continuity of the isoquants rules out this possibility.

9. In the file "/Appendices/ChaplApp.pdf"

10. In the file/Appendices/Chap1App.pdf.

11. Gandolfo refers to Herberg [1969] for the formal proofs.

12. For a production function of some good $A$ such that $Q_{A}=f_{A}\left(\lambda K_{A}, \lambda^{\prime} L_{A}\right)$, where $\lambda$ and $\lambda^{\prime}$ are time dependent parameters initially equal to one (and increase as technical progress occurs), technical progress is neutral, capital saving, labor saving if $\lambda$ increases proportionally, more than proportionally, less than proportionally to the increase in $\lambda^{t}$.

13. Independently developed by Tinbergen (1962) and Pöyhönen (1963) and also implemented by Linnemann (1966) and Aitken (1973) who also includes dummy variables for membership in a free trade area.

14. Note that the argument can work in the other way as well. As we will show later in this book, a specialization pattern brought about by the Ricardian causality may look like as if caused by that of the H-O-S model.

15. See our discussion on the Davis [1995] Hecksher-Ohlin-Ricardo model, where the factor content version of the HOS model with factor price equalization is demonstrated through the integrated equilibrium method that draws on the essence of Samuelson's parable.

16. As opposed to labor saving or capital saving: Only the TEP parameter of the production functions are different across countries so that relative to the origin, isoquants are parallel to each other

17. Since $\alpha$ is the share of wage bill in GDP (under the assumption of perfectly 
competitive markets), and $\widehat{Y}, \widehat{K}$, and $\widehat{L}$ are all obserwable, $\widehat{A}$ can be calculated as residual.

18. Which can potentially be explained by transitory dymamics but not by the steadystate properties of the model.

19. See Jones $[1995 \mathrm{a}, 1995 \mathrm{~b}]$.

20. Note that, a number of (new growth) models that follow Solow (such as Romer[1986], Lucas[1988], Aghion and Howitt [1992]), are able to generate constant or increasing growth rates endogenously. In these demonstrations, due to the increasing return effects, increases in human capital and/or R\&D effort may lead to increased (per capita output) growth rates. However, Jones [1995a, 1995b] criticises these models on the basis of evidence which suggests that in the period between 1950 s and 1990 s, the growth rates of most developed countries have been moving around constant levels and even slightly decreasing for some.

21. Which is also formalized by Arrow [1962].

22. See Romer [1990] for a thorough discussion.

23. The solution is found by optimizing a social intertemporal utility function $\int_{0}^{\infty} e^{-\sigma t} \frac{1}{1-\sigma}\left[c(t)^{1-\sigma} L(t) d t\right.$, as subjected to the aggregate production function and the equation responsible for skill generation $\left(\widehat{h_{s}}(t)=\delta\left(1-u_{s}(t)\right)\right.$. The decision variables are the per capita consumption $c(t)$, and the investment on human capital generation $u(t)$. Investment on physical capital $\dot{K}$, is solved as residual.

24. The solution for the market equilibrium, maximizes the social utility function for a given time path for $\overline{h_{a}(t)}$. From this general solution, the particular solution which procures the equality of the exogenous $\overline{h_{a}(t)}$ with the average of the endogenously solved individual workers' skill path $h(t)$, is chosen.

25. For an alternative view, see Silverberg and Verspagen [1995a], where the emergence of $\mathrm{R} \& \mathrm{D}$ investment stability is demonstrated by an evolutionary model of learning.

26. Orinally due to Dixit and Stiglitz (1977)

27. i.e. the number of product varieties proxies the knowledge stock of the economy and generates the externality in question.

28. Another simplifying symmetry condition is the assumption that associates (one to one) individual customers with individual workers so that for $L$ being the labor force $q_{i}=L \cdot C_{i}$. With this assumption, which imposes an equal income distribution, complications related to income distribution are ignored.

29. As mentioned before, this utility function favors higher number of products to proportionally increased amounts of existing products.

30. The equation is valid only if $w_{N} / w_{S}>1$, which guarantees that North produces only the new products. Otherwise, the number of new and old products defined by the innowation and imitation equations do not necessarily represent $n_{N}$ and $n_{S}$.

31. Various other realizations of this model are also discussed in Cimoli and Soete [1992] and Dosi, Pavitt Soete [1991].

32. Similar to Krugman [1979], for $i$ and $g$ representing the imnovation and imitation rates respectively, the steady state the ratio of the number of old to all goods $\left(z_{R} / z_{T}\right)$ converge to $1-\frac{i}{i+q}$, and accordingly the ratio of new to old goods $\left(\left(z_{T}-z_{R}\right) / z_{R}\right)$ to $i / g$.

33. The growth rate of each country $i$ (i.e. $\widehat{Q_{i}}$ ) is specified to be determined by the growth rates of knowledge stack $\left(\widehat{T}_{i}\right)$ and export growth rate $\left(\widehat{X_{i}}\right)$. That is the $\widehat{Q_{i}}=\alpha \widehat{T_{i}}+\varepsilon \widehat{X}_{i}$.

34. $\widehat{X_{i}}=\eta \ln \left[\frac{T_{i}}{T_{j}}\right]+\widehat{Z}$ for $i=N, S$ and $j=N, S$, which constitutes the main 
economic selection mechanism of the model. $\hat{Z}$ is the autonomous part of the export growth.

35. $\widehat{T_{N}}=\beta_{N}+\lambda \widehat{Q}_{N}$, where $\beta_{N}$ is the exogenous learning rate which can be improved by policy (more schooling etc), and $\lambda$ determines the rate of learning by doing (the Verdoorn effect)

36. $\widehat{T_{S}}=\beta_{S}+\lambda \widehat{Q S}+\alpha G e^{-Q / \not{b}}$, where $G=\left[\frac{T_{N}}{T_{S}}\right]$ is the technology gap Thus the term $a G$ is the potential spillower and the term $e^{-G / \delta}$ is the capability of exploiting the superior technologies of the North.

37. The import penetration of a good in a country at time $t$ is formulated as a moving average process, where changes are brought about due to the current sectoral competitiveness gap between that of the country and the world average: The cheaper the (exchange rate corrected) sectoral price (relative to the world average), the faster the country increases its world market share in the sector. 


\section{A niche for an alternative approach}

\subsection{Introduction}

The philosophy and especially the formality of mainstream economics, particularly of neoclassicall economics, have been criticized by many schools of economic thought in various contexts. The following excerpt from Freenan ${ }^{1}$ nicely expresses in a nutshell the scepticism underlying such criticisms in the epistemological sense.

In its anxiety to be the "theoretical physics of sacial sciences" and to achieve logical elegance and mathematical formalisation, neoclassical economics elaborated and refined quantitative equilibrium analysis and mathematical models, which, although useful as a modeling exercise on highly restrictive assumptions, neglected some of the crucial elements involved in the long term behaviour of the system. They therefore appeared to non-economists and to other social scientists to be concerned with the endless elaboration and refincment of assumptions which lacked realism in relation to certain fundamental features of the system"s behaviowr and rigorous falsifiability of the predictions derived from the models.

In the sense of predictive success, the accomplishment of mainstream economics which aspires an infeasible target such as "to make economics converge to a positive science", is indeed highly questionable. Actually, the pretentious motivation underlying the mainstream philosophy "to predict" is not the only conceivable one for a social science as economics. One can as well see or think of more modest and feasible objectives in the lines of "to understand, to appreciate, and to explain", "to describe or to illustrate formally and/or pedagogically", "to build and analyze various scenarios", or "making intellectual exercises/experiments for the future of a better understanding ".

However, the mainstream philosophy apparently does not favor the latter type of motivations over the ambition to make sharp predictions. The mathematical formality that underlies the majority of mainstream modeling exercises can easily be associated with qualities that supply the theoretical framework with "analytical sharpness", which are, nevertheless achieved subject to significant costs in terms of "descriptive/illustrative richness". Following an "ends justify the means" type 
pragmatic philosophy, the black-boxing of descriptive aspects (through as if assumptions that do not necessarily reflect reality) is justified as an acceptable price to pay for having models that predict. This philosophical tendency may nicely be illustrated by an anecdotal quotation from Nicholas Kaldor [1980], who expresses his criticism on Joseph Schumpeter"s technological change based theory on business cycles ${ }^{2}$.

".... The trowble with Schumpeter's theory is that it is descriptive rather than analytical. Although it is easy enough to see how one particular part of the story follows from the preceding part, it is not possible to make the story as a whole into a -model- (meaning by a model the sum totah of assumptions which are just sufficient -no more and no less- tagether to provide the necessary and sufficient conditions for the generation of a recurrent cycle with a clear periodicity) without incorporating into it elemerts which would suffice by themselves to explain the cycle-without necourse to Schumpeter's own stage army of initiators and imitators, or even the very concept of technical progress...."

The fact that Kaldor is known to be a rather "unorthodox" economist renders the point of this quotation more striking, while the other fact that simulated agents-based modeling (that could have made the formal modeling of Schumpeter"s own stage army of initiators and imitators possible) was not yet (in and before the 1970s) a feasible and common practice in economics, makes Kaldor's pessimism for the chances to formalize Schumpeter's theory more understandable. Nevertheless, this example illustrates the philosophical tendency in mainstream economics, which perceives descriptive theories or ideas as less credible than theories that are backed up by analytical models which express things as a matter of necessity and sufficiency relationship between a set of well defined assumptions and well defined regular outcomes (such as equilibrium properties, steady state motion, regular cycles etc.)

Another excellent example can be found in Romer [1994] (p.14), who asserts that the existing evidence has been sufficient to reject all available growth models throughout 1950s-1970s, implying a general shortage of good aggregate level growth models for the discipline. He suggests five necessary conditions, which growth theories should acknowledge". Accordingly he points out that Solow type models account only for the first 3 facts, endogenous growth models aim to accommodate the $4^{\text {th }}$.condition ${ }^{4}$, and neo-Schumpeterian models incorporate 4 and 5. Romer also suggests that the first step in capturing the $5^{\text {th }}$ fact is dependent on abandoning the perfect competition assumption, and concludes in a footnote that the evolutionary Nelson and Winter [1982] model (which, as will be discussed later in this chapter, is an evolutionary agents-based simulation model) takes all 5 conditions into account. However, despite the acknowledgment, the associated footnote reads:

Richand Nelson and Sydney Winter (1982) developed an alternative evolutionary model of growth. Their verbal, descriptive style of theory, which they label appreciative theory, was flexible enough to accommadate facts $1-5$. This style of work can be thought of as a complementary to formal theory, not a substitute for it. It leaves open 
the problem of constructing a formal theory that could acoommodate these facts.

The idea that underlies this excerpt from Romer is almost perfect fon illustrating the point that we are aiming to make in this section. In economics, whether or mot ideas and descriptions are formalized and especially the toolbox used to this end, seem to be as important as the ideas and descriptions themselves. On the other hand, formalization appears to be a binding process that reflects conformance to the philosophy, traditions and common beliefs of a school of thought and may accordingly show variations among the warious schools. The Nelson and Winter [1982] model, as being the mostly cited work in the ewolutionary economics literature, despite its apparently descriptive (as opposed to a predictive and/or conclusive) nature, is considered to be quite formal and analytical (in the sense of being a bottom up, systematical and intemally consistent quantitative analysis) by the majority of researchers who define themselves as evolutionary economists. Yet not surprisingly, for the economists of the mainstream tradition, the modeling methodology of the Nelson and Winter model (which does not conform to the neoclassical norms) is quite unorthodox and thus "informal", al though the descriptive story told by the model (which highly draws on schumpeter) is quite welcome in a way similar to the essence of the Schumpeter-Kaldor example in our previous excerpt. Indeed, some of the Schumpeterian ideas have eventually been formalized and added to the repertoire of the mainstream economics (e.g. Aghion and Howitt [1990]), although the formalizations have been quite different from that of the evolutionary models of growth which will be discussed later in this chapter.

Clearly, the concept "formal" can only be meaningful in the context of a philosophical lineage, and one can assert that the shortcomings of the mainstream theories of international trade and growth do not necessarily lie in the qualities of the underlying ideas and suggestions (which contribute to our understanding by suggesting various cross-sectional suggestions on reality) but in the qualities of the formalization toolbox which has historically been evolving in a way that favors analytical sharpness and clear-cut conclusions (made possible by mathematical precision and a collection of restrictive/unrealistic assumptions) to analytical and descriptive richmess which can be achieved mostly in expense of the former goals and also the possibility of depicting misleading pictures of the essential workings of economies.

Consequently, in a social science which is heavily clominated by a quantitative analysis framework, the criticisms over a school of thought eventually boils down to criticisms over its formal framework and especially over the technical toolbox that constitutes its formality. In terms of the case between mainstream and evolutionary economics, there exist a large amount of criticism directed by evolutionary economics toward the toolbox of mainstream formality. In a nutshell, the elements of the mainstream modeling toolbox which are mostly criticized by evolutionary economists are

- The dependence of the framework on equilibrium or steady states analyzes while the disequilibrium adjustment dynamics and coordination are either ignored or addressed in auxiliary and superficial contexts through abstract, even surrealistic auction-like formulations (i.e., as in the tatonnement process suggested by Walras [1874]) which are also vnlnerable to a set of techmical problems in addition to their highly fictitious nature. 
- Reliance on representative agents, the formulations of which ignore heterogeneity among economic actors and the possible consequences of agent-level heterogeneity on economic dymamics.

- Reliance on multi-factor productions which assume the costless availability of an infinite (continum) of alternative production techniques among which agents can make rational choices. And also the excessive bias of towards factor substitutability (as opposed to complementarity ${ }^{6}$ ) which is reflected by the production functions typically used in matnstream formulations

- Excessive reliance on agents' rationality in making choices, which ignores the essential uncertainties facing real life decisions and which also ignore the important elements of locality and adaptiveness in agents's learning and behavior patterns.

- A general ignoring of the temporal irregularities and complexities ${ }^{7}$ that underlie the processes of technological change due to the steady -state formulations which express the technological change process as a smooth process of exponential accumulation.

\section{2 "Evolutionary philosophy" as an alternative embracing framework}

To the laymen, the first response upon hearing the term evolutionary, would probably be an association of the term with the pattern of something that changes over time. Accordingly, the phrase evolutionary economics could first give the impression of a field of economics that particularly study the change/motion of economies over time. While this first impression is correct by definition, naturally studies of dynamic phenomenon are not under the monopoly of any unique subfield of ecom nomics. Yet, there may be fundamental differences among alternative approaches to dynamic phenomenon, and evolutionary economics indeed follow a radically different one than the rest of the fields in economics. As Dosi and Nelson [1993] point out:

.... the term "evolutionary" ought to be reserved for theories about dynanic time paths, that is ones that aim to explain how things change over time, or to explain why things are what whey are in a manner that places weight on "how they got there." The more controversial question is which of such theories ought to be called evolutionary. Until recently most scholars would have probably muled owt theories that are whole deterministic. There would seem no point in saying that Kepler's laws of planetary motion, together with Newton's gravitational theory that explains them, define an evolutionary system. Neither would it seem useful to regand as evolutionary the execution of a detailed plan for the construction of a building, or any realization of a prespecified blueprint. Similarly, theories of economic change that analyze that process as one of moving equilibrium - as is in the case in neoclassical growth theory - should not be regarded as an "evolutionary" theory.

On the other hand, to the laymen of economics, who have basic training in biology, the term "evolutionary" could describe a paradigm that explains population dynamics, or population related changes over time as the emerging result 
of the complex interplay of two processes. The first is a variety generating process, which continuously introduces heterogeneity to the individund members of the population in terms of one or more of their key characteristics (mainly through mutations on genes or cross-breeding). The second is a selection process that affects or determines the survival and/or spread chances of these key charactenistics and therefore that of their carriers (individual population members), which de termines the overall share of each characteristic and of its carrier over the whole population. As a result, some individual members or a collection of them who have a set of characteristics in common (be it species or families) raay eventually perish, while others keep on surviving, increasing their relative frequencies, co-surviving with others which have different yet sufficiently suitable characteristics. Therefore, the evolutionary way of thinking introduces the evolutionary process as the anonymous intellect that is responsible for the macro-order in nature, despite the simultaneous presence of variety and continuous change at the micro level. This simple explanatory principle has consistently been succeeding in explaining an enormous collection of phenomenon in biological sciences and thus is the contemporary dominating paradigm.

Evolutionary economics is indeed an alternative approach to economics that is inspired by the principles of evolutionary biology in explaining the processes governing change and order in economies. Accordingly, evolutionary economics follows a heterogenous yet co-living/co-evolving population perspective similar to the Darwinian (or better put, Lamarckian) theories of evolution and natural selection, where change and order come about through continuous generation of variety, together with forces of selection which regulate the survival/spread chances of each variety, given the ever changing enviromment characterized by external conditions and the traits of the other varieties ${ }^{8}$. In the evolutionary economics counterpart, the analogy is established by the association of populations with sets of economic agents or sets of alternative/competing technologies, association of variety generation (mutations and/or cross-breeding) with changes in the behavior and/or strategies, or introduction of new technologies (innovations either by incumbent firms or by new entrants), and association of variety elimination (i.e. selection) with diffusion of technologies (and/or strategic behavior) by imitations; exit of unsuccessful firms and/or survival/growth of the successful ones.

In the most plain language these definitions can be reflected in arguments like "the firms that bring the best products to the market with the lowest price survive and take over the market, while the rest shrink, go bankrupt and perish" or "the frequency of any technology (or strategical behavior element) that serves wel. to the relative fitness of the firms that use it increases and the frequencies of those which perform relatively worse, decrease."

One may immediately argue by posing a question like "but are these not the general ideas underlying the long run equilibrium story told by the neoclassical theory as well?", the most suitable answer to which is "only remotely". One possible way to make a clarification may be to use a metaphor that aims to represent the neoclassical models in the biological domain.

Consider a fictitious case, where a creator jump-starts a world consisting of three species: grass growing on its own, rabbits feeding on grass, and foxes feeding on rabbit. Before starting the experiment, the creator introduces some genetic variety among the initial members of the rabbit and fox populations: Some members (of the rabbit and fox populations) are faster runners than the others. Besides, the creator rules out any mutation possibilities so that the running speed of the fastest of each species in the initial state is the highest accessible limit for that 
species.

Assume that, after waiting for a sufficiently long time, the creator observes the following: First, due to sexual reproduction and the selective forces (i.e. slower rabbits will be eaten before while the slower foxes will starve first, and faster members will tend to choose to mate with the faster members of the opposite sex), the genetic variety in both species decreases over time and the populations converge to a point where all members achieve the ruming speed of the fastest members of the initial conditions. Second, the systern comes to an equilibrium point, where rabbit and fox populations converge to fixed levels (i.e., at this level birth and death rates equalize), both determined by the replenishment rate (the fertile area in which grass grows with a fixed rate) of grass, which is set exogenously by the creator.

Clearly, something is terribly missing in this story especially with regard to the second obserwation: Given the settings of the creation, the convergence to such an equilibrium is not a necessary outcome and various lines of fate for the system are possible. Depending on the settings of the parameters that specify the reproductive and feeding habits (or urges) of the species, and also the initial conditions of the system (the relative population sizes of the species and the running speed distribution), one can observe regular or irregular cyclical variations or maybe chaos ${ }^{9}$ in the dynamics of population sizes or one can even observe overall extinction of the two predator species ${ }^{10}$. Amongst all, equilibrium is only one (and maybe the least probable) of the possibilities and to guarantee it, the creator needs to take some additional steps.

The first possibility (which is reminiscent of the theological approach to biology) for the creator is to fine tune the reproductive/feeding urges of the predator species together with additional arrangements on the (average) relative running speed of the species (and also their hunting/hiding skills). This arrangement, which would set the success probability of each individual animal in hunting/evading a predator would have the potential (and despite the inherent stochasticity) to keep the system around some equilibrium level for population sizes, especially if the initial population sizes set by the creator is around this equilibrium.

The second possibility, (which would be reminiscent of the world view of neoclassical economics) for the creator is to endow individual animals with some kind of consciousness (rationality) so that they become aware of the inter-temporal trade-off between eating today and eating tomorrow and also the trade-off between their urges (indulgence of reproductive urges generally implies the introduction of new individuals into the society that: will share the nutritious resources). If the creator can figure out a mechanism in which such individual rationality translaties into some form of collective rationality (for example sending an angel that wil] broadcast the optimal rates of individual feeding and copulation after an auctionlike process), an equilibrium can be achieved. Practically, this second prossibility is not too different than the first, except for the fact that in the second setting, the (optimal) reproduction/feeding rates emerge endogenously as an outcome of rationality/auction process, whereas in the first setting these rates are exogenously determined by the creator ${ }^{11}$. The most important similarity of this metaphorical alternative with the neoclassical framework is that variety (which is eliminated rapidly by the selection forces) does not play any part in the explanation of the essential workings of the rest of the system. There is simply an upper limit to the speed with which animals can run, and those who perform under this level are the first ones to be eliminated. There is no ongoing transformation (further mutations), and eventually the populations converge to a homogenous distribution. 
For anyone who has a basic understanding of the principles of wolutionary biology, it may be clear that the workings of this system in our example is quite different than the essential mechanisms suggested by the evolutionary thinking: The elegance of evolutionary theories lies in their simultaneous explanation of change and order simply as a matter of self-organization, without resorting to any conscious meta-rationality (i.e., no creator or auctioning angel per se). The framework is based on the dominating importance of the existence of micro-level processes that incessantly generate varieties (through mutations on genes), some superior, some inferior. Superiority and inferiority, that is usually summarised by the word fitness, is variable over time, highly dependent on the enviromment around the individuals (or species), and is determined by the availability of resources shared by other (individuals) species and the features (or fitness) of others with which the resources are shared (i.e., some features that present a disadvantage for survival and spread in one environment can be an advantage in another). In this setting, the generation of variety and the selection that restricts (and/or reduces) variety is not only a process of evolution for individual species, but a process of coevolution as well. That is, species do not evolve in isolation but they coevolve as a whole and this fact is the underlying explanation to the existence of order and harmony in nature and the existence of highly complicated and sophisticated organisms such as human.

Evolutionary thinking is clearly affected by an understanding of self-organizing dissipative systems ${ }^{12}$. The change and progress in the system depend on the incessant introduction of new varieties among which the best (most fitting) are selected. Since there is no metamationality that evaluates and regulates the mutations exante, variations (good or bad) are first introduced and then selection applies in a secondary stage. Thus, whatever order there is, it is achieved at the expense of the temporary existence of unsuccessful varieties, which consume some resources before they are eliminated by the forces of selection. In environments (or temporary episodes) where selection forces are weak (e.g. resources are abundant), the inferior variants may survive longer periods and consume resources, which can ex post (after being selected out eventually) be seen as waste (dissipation).

Thus, the metaphoric illustration above has two essential elements that does not fit to the evolutionary thinking. First, the creator disables mutations and the whole system is limited to the mere existence of three species, where the initial variation is rapidly eliminated among each. Second, despite the first, the creator. expects to see order (equilibrium) in the population volumes of each of his creations. Apparently, if the creator had aimed to build up a system on evolutionary foundations, all she needed to do would be to jump start the system with sufficient: wariety and/or set a system of mutations on genes capable of incessantly introducing sufficient variety in the traits (behavior, metabolism, perceptions, abilities etc.) of newborns, and preferably build a complementary mechanism of sexual selection. After this, the rest for the creator would be to sit back and obserwe what happens. Given sufficient time, she could then observe the emergence and extinction of various species, among which fox and rabbit-like creatures (predators and prays that set a hierarchical system of food chain) could show up ${ }^{\text {ji3. Throughout this }}$ process, she could also observe periods of relative order, where the relative sizes of population sizes of the current species would remain rather stable, though each of these episodes of order could end up with the emergence of some new species, the abilities/behavior of which is sufficient to undermine the essential elements (the internal rules of the game) that have been sufficient tio sustain the order. Naturally, another thing that could be observed is a process that would look like 
"progress", such that the abilities, perceptions and the behavior of each succeding generation gradually becomes more complicated and sophisticated, leading to elements that looks ex post like the artifact of a perfect designer ${ }^{14}$.

Evolutionary economics adopts a similar population perspective into its framework, where order, harmony and change in the macro level are perceived and analyzed together with (and despite) heterogeneity and continuous change at the micro level, and also with an understanding that the qualitative nature of order (the composition of populations, the rules of the game) can radically change over longer periods. There are indeed sharp similarities between biological life (as formulated by evolutionary theories) and economies. The first one is naturally the presence and domination of selection as a governing process. In biological life selection (survival of the fittest and sexual selection) comes as a natural outcome of scarcity of resources together with the mindless tendency of living creatures to multiply in number, through a process governed by the mindless tendency of the genes to have their carriers make as many duplicates of themselves as possible. While the biological selection mainly applies on the genes (through the fitness they inmose on their carriers), in economic life one can imagine more than one units of selection. The needs, preferences, aspirations and budget constraints of the customers naturally bring about selection pressures on products and services (in terms of their characteristics and prices) on the market, which indirectly translate to forces of selection that is exerted on the praducer firms. The basic selection forces introduced by the customers are accompanied by the financial markets, which (re)direct financial resources essential for survival and growth, according to the perceived fitness (mostly in terms of current profits or the expected stream of future profits) of the firm. The two other possible selection units that resemble a gene is a techmology (a specific method that makes the achievement of a technical objective possible) and a behavioral element (such as a marketing/production strategy or a rule of thumb guiding some critical decision such as investment). The introduction of new technologies or behavioral elements, and their diffusion over economic agents (together with the disappearance or obsolescing of some other) can be considered as important processes governing economic dynamics.

The second similarity is the incessant introduction of variety into the system and its key role in determining the dynamics of the system. In biological life, variety is mainly introduced through slight random changes on the genes (mutations), which carry the blueprints of each living organism. In economic life, variety is introduced by new technologies (processes and/or products), by behavioral elements, or by the entrance of new firms (which may imply a new product or a production unit that organizes resources in a different way than the others).

The thind similarity is the pace of microwevel change (or variety introduction) which is mostly slow, gradual and local both in biological and economic life. In nature, mutations are not extensive changes in the whole DNA structure but are mostly minor (and random) variations on individual genes (which nevertheless can yield to major variations on the characteristics of their carriers). Similarly, in economics technological novelties are mostly incremental advancements over existing ones and lead to a gradual process of development, while a set of rare inventions such as the steam engine, integrated circuit (or semi-conductor) technologies or capitalism (as a market and entrepreneurship and private ownership dominated technology of production organization), have made a major transforming impact on economies.

The fourth similarity, which is not independent from the third, is curnulativeness. In nature, successive mutations make changes on sets of genes, which, 
together, already prove to have endowed their carriers with some dimension of fitness (i.e. make them able to exploit some niche or competitive advantage). In other words, successful mutations are mostly buit upon gene structures that are already successful in some sense and this process appears like to be leading to some form of progress. The cumulative nature of the gradual process of progress carries within a strong component of irreversibility and the resulting possibility of Jocking-in to characteristic niches. Similarly in economic life, technological change process appears to be characterized by a curnulative nature (i.e, many developments are refinements over/combinations of previous ones which are perceived to be successful in some sense). Thus, it is possible to see technological change as processes taking place through (initial, condition dependent) various irreversible trajectories, which can as well be trapped into to suboptimal locking in paths.

Despite these similarities, it is still hard to say that evolutionary economics is essentially the outcome of a close imitation from the methodology of evolutionary biology. Actually, despite the similarities, the extents of the analogy is a matter of the differences between the two universes ${ }^{15}$, the correct understanding of which wovild clarify that evolutionary economics is (or at least aims to be) something much more (or different) than a mere imitation (or adoption) of evolutionary biology by economics. Thinking otherwise may lead to utterly polemical and misleading arguments such as the following one by Krugman ${ }^{16}$

To read the real thing in evolution - to read, say, John Maynard Smith's Evolution and the Theory of Games, or William Hamilton's new book of collected papers, Narrow Roads in Gene Land, is a startling experience to someone whose previous idea of evolution comes from magazine articles and popular books. The field does not look at all like the stories. What it does look like, to a remarkable degree, is - dare I say it? - neoclassical economics. And it offers very bitle comfort to those who want a refuge from the harsh discipliwe of maximization and equilibrium....

To be fair, there is some justification in the insistence of some economists on pushing very hard on the principles of equilibrium and in particular of maximization. After all, people are smarter than genes. If I offer a model in which people seem to be passing up some opportunity for gain, you may justifiably ask me why they don't just take it. And unlike the case of genes, the argument that the altemative is quite different from what my imagined agent is currently doing is not necessarily a very good one: in the neal world people do sometimes respond to opportunities by changing their behavior drastically. In bialogy purely local change is a sacred principle; in economics it has no comparable justification.

Krugman builds his argument on the definition that economics (similar to evolutionary biology) is the study of those phenomena that can be understood as emerging from the interactions among intelligent, self-interested individuals, and concludes that an immediate consequence of intelligence is that obvious opportunities for gain are not neglected (with Krugman's words: "Hundred-dollar bills do not lie unattended in the street for very long") and the interactions of such individuals can safely be assumed to lead to equilibrium characterized by some form of optimality. 
The obvious truth in Krugman's argument on the human intelligence, though is presented in a polemical context (in line with the mainstream world view) is indeed the first major difference between the evolution of biological and economic systems. A ritical analysis of the heroistic assumptions implicity underlying Krugman's (and the mainstream) arguments sets a useful ground to discuss the standing point of evolutionary economics with regard to the role of human intelligence in bringing about order and change. The first of these assumptions is the reduction of human intelligence (or rationality) to a matter between the exploitation or negligence of obvious opportunities. Of course it is not that wreasonable to assume that a hundred-dollar bill laying on the street will be pocketed by someone passing by in no time, yet the important issue is the (ir) relevance of this example in for the real world. In reality, such obvious opportunities are extremely rare. Opportunities generally do not present themselves as hundred-dollar bills waiting on the street to be picked up, as specified by the mainstream economies as a (contimuous) set of costlessly awailable technological opportunities that can be picked up upon the solution to a cost minimization (or profit maximization) problem. Following the mainstream logic which equates intelligence with resourcemconstrained rational choice over endless possibilities, our currently low level of success in the exploiting of (potential) technological opportunities (which are also challenges) such as treatment of cancer or the colonization of the planet Mars, we must conclude that human beings are irrational or unintelligent. On the contrary, opportunities are created by intelligent people through costly and hard work of searching and experimenting, and by bearing considerable risks, all of which take time and are key processes ${ }^{17}$ in the evolution of economies. And before everything knowable is unveiled and made known by human effort (so that we can make rational choices) life still goes on, decisions are made subject to a complex environment, essential uncertainty (i.e. where it is not possible to assign probabilities to possible outcomes as functions of possible actions) and highly incomplete information, products are produced and (despite their imperfection) are consumed. According to evolutionary economists, economics should be studies of the workings of the economic world as it proceeds subject to the serious limitations of human intelligence and the accordingly gradual, costly and (to some extent) stochastic processes of building up knowledge and technology.

In this sense, two important concepts which form the evolutionary economics? antithesis for the mainstream economics definition of rationality are (instead of irrationality, unintelligence or total randommess) bounded rationality (a concept. originally due to Herbert Simon [1986]), and leaming ${ }^{1.8}$. The former concept asserts that the set of problems facing individuals or firms in economic life (such as how much to invest on capital and/or R\&D, how to set a price etc.) are mostly too complicated, and in their solution relatively simple decision rules and procedures (i.e. rules of thumb or heuristics) are used. Considering all the possible trade-offs and alternatives and evaluating these subject to a highly complex and complicated enviromment (where the exact relations between actions and consequences are highly unclear, or the decision maker does not have the exact model of his/her environment) are too costly (time and money-wise) and especially given the possible presence of multiple objectives (and multiple decision makers with multiple interests in organizations, such as should we maximize profits or revenues or output?), individuals/organzation mostly stick to their suboptimal rules or procedures and do not change these as long as they appear to be satisfactory (i.e. satisficing behavior). Besides, individuals/firms experiment with alternatives, observe what others are doing, learn form their/others success and failures and may 
update their routines and procedures, on a "need to change" basis.

The second obvious difference is the time scale. The biological evolution process have been taking place ower millions of years, whereas economics is mainly concerned with the post-capitalism period, which is not more than a couple of hundred years. Furthermore, the time frame that underlies the majority of formal economic analyzes (for example consider the lang term definition of the mainstream economics) is confined to a couple of decades at most.

The third difference is that nature, which is the domain of evolutionary biology, does not have any major objective (or anything to optimize) per se $e^{\text {ng }}$, whereas the (optimal) satisfaction of human needs, and accordingly maximization of (aggregate) customer welfare can be considered as an objective for the economic systems. In this sense, the randomness of the variety generation process is no concern for the nature. Thar is, nature (or anything but: the human race) cares neither about the composition of species that are co-living on the earth nor about their overall well-being (or even whether or not there exists life on the planet). Despite this lack of an ultimate objective, the evolutionary process have been proceeding in a direction which have been (gradually) increasing the complexity and sophistication of the life forms (and the patterns of their interaction) on the planet, which ex post appears like the work of a designer who has some objective (such as maximizing complexity, sophistication of the individual creatures, or maximizing the variety that can co-survive in order and harmony) in mind. The proposition "evolution optimizes fitness", which refers to the tendency of evolution to increase sophistication and complexity in individual traits and interaction patterns among individuals/species (which can be interpreted as equilibrium by some), can be quite misleading when compared to the optimality definitions used in economics. For example, the "Pareto optimality" concept is highly irrelevant, since with certain changes it would be prossible to increase the well being of all species ${ }^{20}$. The closest imaginable similarity in this sense is the "Nash equilibrium": Given others' characteristics and the environment, it is possible to think that evolution supplies each individual or species with the greatest possible fitness. Even if one accepts this argument; (which is highly controversial among evolutionary biologists ${ }^{21}$ ), it is still hardly possible to build a direct analogy to economics and claim that the evolutionary process in economics is optimizing as well. Variety gemeration and selection processes in economics (both of which are brought about by the conscious actions of intelligent actors) are there with an mission which is (broadly) to enhance welfare, and therefore evaluation of the effectiveness of these processes $^{22}$ is perceived to be one of the major objectives of economics. Even if the evolutionary process would lead to a situation, where each firm's fitness (say profits) are maximized given the other firms' characteristics, nothing guarantees that the set of products and services supplied by this set of firms maximize (given resources) consumer welfare (unless one makes the heroic mainstream assumption that infinitely many technological possibilities are readily and costlessly available to firms).

The fourth limit to the potential analogy between biology and economics can be found in the existing controversies in evolutionary biology on the unit of selection. Should it be the individual gene, a collection of genes, the individual or the species ${ }^{23}$ ? The common understanding that the phenotypic characters (on which selection forces operate, and which eventually determine the fitness and/or the survival chance of individuals accordingly) are significantly influenced but not uniquely determined by the genes is an important reason for the controversy. That is, one can observe that some important elements pertaining to strategic behav- 
ior of individuals or species (which significantly contribute to fitness and survival chances) are shaped by learning during lifetime. Such learning, which can be seen as a transmission of culture across generations, obviously introduces another dimension to the list of the phenotypic deteminants and diminishes the appropriateness of the gene as the ultimate and unique choice of a selection unit, and points to the species which are sets of individuals not only having genetical similarities, but also having common traits that are learnable and thus transmissible within the group. Yet in economics, the introduction of novelties that affect the fitmess of organizations are mostly outcomes of competition, and furthermore the transmission (diffusion) of such elements (i.e. knowledge, technologies, behavior), which is mostly a process of imitation, is often a non-cooperative process ${ }^{24}$. Besides, it is not that straightforward to find a economic counterpart for the biological fact consecutve generations, which constitutes the main link for the diffusion of the determinants (genes or elements subject to social learning) of phenotypic characteristics of biological individuals. Therefore, the choice of a unit af selection for economic analysis is subject to a set of constrains and concerns that are quite different than that in biology.

Having briefly discussed the philosophy and concerms of the evolutionary economics, the question that naturally follows is "What is the practical framework that evolutionary theorizing use to formalize swch a world view?"

\subsection{Brief look at formal evolutionary modeling}

Naturally, evolutionary economics is not merely a philosophy or a collection of descriptively rich stories. Evolutionary economists also make "formal" models as complementary to their descriptive arguments. Yet, the concept formal is a tricky one, which (at least according to our understanding) reflects a collection of dogmatic set of restrictions, which a scientific paradigm imposes on itself in the process of demonstrating/illustrating its philosophy and according suggestions on the underlying workings of the systems in question. Given its relatively short history, it is not quite possible to talk about an evolutionary formality comparable to the highly dogmatic and restrictive one of the mainstream economics, especially after having observed the heterogeneity of the work (especially with regard to the modeling toolbox resorted) in evolutionary economics literature. Nevertheless, there are of course also commonalities in these applications, especially with regard to their basic understanding of the principles of evolution, and the essential qualities and the reasoning underlying their descriptive/suggestive nature.

In a discipline which is dominated by quantitative modeling, there is an apparent need for formal (in the sense of being mathematical or computational) modeling for the demonstration and backing up of ideas, in a way that supplies illustrative/analytical sharpness by bringing out the essence of the primary lines of causation by a selective focus on a reduced number of issues, mechanisms and processes. Indeed, a good deal of quantitative modeling exercises in evolutionary theorizing which have been aiming at filling the causal gap between explanatory premises and their outcomes by dynamic processes (that somehow abstract the evolutionary principles of heterogeneity and selection,, have been reasomably successful in building up of mathematical and/or computational reconstructions of evolutionary processes with a complexity introduction/analysis toolbox (of nonlinear systems approach or agent-based modeling). One of the important lessons that emerge from this literature that have been gradually turning into a reasonably systematic way to address various issues (which would otherwise remain as 
mere lip services), is that microeconomic heterogeneity, non-linearity, and the lack. of imposed equilibria (or disequilibrim dynamics) are promising ingredients for our future understanding of the complexities in economic life, rather than being obstacles to economic analysis ${ }^{25}$.

Among the elements of the exolutionary modeling toolbox, an important set (that can be seen as tools for first approximations) consists of the dynamic system analysis tools, the mathematical richness and empirical realism of which has been understood to increase significantly when intrinsic nonlinearities are taken into scope. Such systems expressed in differential/difference equations, are not only capable of generating cyclic behavior endogenously (as in the self sustaining business cycles of the predator-pray type model by Goodwin [1967]), but introduce the possibility of multiple equilibria, bifurcations of solutions, and also deterministic chaos.

The most central element of such evolutionary models is naturally the formulation of a selection mechanism. A commonly used formulation for this aim has been the well known replicator equation of evolutionary biology (originally due to Fisher [1930]), which suggest a mechanism of selection over a popullation characterized by $n$ distinct characters (or species) upon which selection forces operate. For $x_{i}\left(i=1,2,3, \ldots, n\right.$, where $\left.\sum_{1}^{n} x_{i}=1\right)$ denoting the relative frequency of each characteristic (species) $i$, the replicator equation can be specified as ${ }^{26}$ :

$$
\frac{d x_{i}}{d t}=x_{i} \cdot\left(f_{i}(x)-\bar{f}(x), \text { for } \forall i=1,2,3 \ldots, n\right.
$$

where $f_{i}(x)$ is a measure of (possibly frequency-dependent) fitness and $\vec{f}(x)=$ $\sum_{1}^{n} x_{i} \cdot f_{i}(x)$ is the (frequency-weighted) average fitness. The equation specifies that the relative frequencies of characteristics with above (below) average fitness, will tend to expand (contract). This process also tends to increase the average fitness $\bar{f}(x)$ over time $(t)$, which is the main reason underlying the proposition "evolution maximizes fitness", as discussed before. Indeed, it can be shown that if fitness is taken to be frequency independent (i.e. $f_{i}(x)=c_{i}$, thus constants), for any given initial fitness distribution, the average fitness is asymptotically maximized by the selection process ${ }^{27}$ (i.e., $\frac{d \bar{f}}{d t}=\operatorname{var}(f) \geq 0$, where $\operatorname{var}(f)$ is the frequency weighted variance of population fitness). In economic applications, it has been possible to establish the analogy by replacing biological characteristics (or species) with products, and specifying fitness as product competitiveness, or alternatively building the analogy with firms, the growth (or market shares) of which are related to profits chosen as a reduced fitness indicator ${ }^{28}$.

While the basic formulation, specified together with the constant (frequency independent) fitness functions is a useful starting point (especially to study the properties of the accordingly specified selection mechanism ${ }^{29}$ ), more interesting results (that are in closer conformance with the evolutionary philosopliy) start to emerge when the basic selection module is complemented by a variety generation process and/or various (non-constant, frequency dependent) specifications for the fitness function. Regarding the latter possibility, especially if fitness is specified to be increasing in the relative frequency of the characteristic ${ }^{30}$ (which characterizes some increasing returns to scale mechanism), the optimizing property of the selection process weakens (or disappears), since the accordingly path dependent ${ }^{31}$ system opens up the possibility of multiple asymptotic equilibria ${ }^{32}$ and accordingly the possibility of locking-in to relatively inferior characteristics ${ }^{33}$ (diffusion and persistence of inferior technologies, products etc, as in the case with the QWERTY keyboard discussed by David [1985]). 
Regarding the efforts on the introduction of variety generation onto the replicator systems, one can cite work by Henkin and Polterovich [1991], where a stream of new (and superior) technologies arriving into the selection system with a constant rate, are shown to bring about a steady stream of successive diffusion waves. This simple, yet inspiring setting is taken a step further by Silverberg and Lehnert [1993] with the specification of the novelty arrivals as a Poisson process, instead of a constant stream. The highly interesting result found by this study is that; despite the stochastic uniformity of the Poisson process (i.e. in terms of expected values), actual technological change patterns that emerges from the model are obserwed to follow long-uraes (in growth rates), instead of a (statistically) uniform distribution over time. Furthermore, the spectral analysis that diagnoses the presence of long waves also reveals that the system of the model is characterized by deterministic low-dimension chaos (referred to as evolutionary chaos by the authors), wich implies an unpredictable nature for the system except for rather short tine periods.

The importance of stochasticity relative to deterministic (systematic) forces, shows variations over evolutionary models. In addition to the type of work (just discussed), where the stochasticity is confined to the exact timing of the arrival of innovations, one can observe another line of approach (outside of the replicator formulation) where relative share dynamics (or the diffusion patterns) of technollogies are modeled in a pure stochastic manner. The two alternative formulations in this area use either Markov processes or discrete time Polya urns. The former approach is based on given probabilities of transition among the elements of (finite and discrete) state spaces, for each of the elements of a population (specified to be fixed in size). The second approach specifies a monotonic increase of the population size, where each addition to the population (who is a new potential adopter to one of the existing technologies), randomly draws one of the existing technologies according to an allocation function. As in the replicator type models, the main concern is the diffusion of various technologies and their frequency of being adopted by the population. The main lesson to be driven from this type of approaches (similar to those discussed before) is the possibility of multiple equilibria and locking-in to technologies which are not necessarily optimal. The main difference between the two different approaches (both of which pertain to a fromework of highly stochasticity) is the fact that, while Polya urns processes lead to convergent lock-ins, the limiting distributions of Markov processes allow the revisiting of the allowable states in longer terms (no necessary absorbing states).

An important element of all technology related models is the specification of "what nature allows", and "how and with what pace human effort uncover and bring into use in products serzices and processes". Apparently, in all of the (purely selectionist) approaches discussed above, where the basic unit of selection is a tech nology ${ }^{34}$, the set of technologies made available by nature and also their intrinsic usefulness or economic value (summarized by their fitness) is explicitly specified by the modeler, and the essence of the models reduces to an issue of the processes of the diffusion of these technologies into the economic system ${ }^{35}$. Models that specify such selection/diffusion processes through low dimensional search spaces and/or reduced form formulations ${ }^{36}$, are indeed attractive in bringing out important insights within the formality of mathematics. Furthermore, they raise further questions on the underlying micro principles (which conventionally remain implicit/black-boxed in their formulations), which point to the (at least complementary) necessity of modeling exercises of a different nature. As examples, one can mention questions such as: "what are the micro (behavioral and cognitive) 
processes that generate the discovery and difusion (search and imitation) of technologies?", "what kind of mutual interactions underlie the diffusion processes of technologies?" "how do the intrinsic characteristics of technologies translate into the fitness/growth of their users (i.e. firms and/or industries) ) $^{37}$ ?" and "In what ways do all of these processes (combined with other decisions of actors) affect (and be affected by) markets, industrial organization/dymamics, growth and international trade?". "There are yet other strands of evolutionary models, which aim at addressing such issues by using the flexibility of the agent-based computational framework as the medium for a micro-founded (bottom-up) approach .

\subsubsection{Agent-based framework as a medium for evolutionary modeling.}

Agent-based framework is a radically diflerent way (research paradigm) of conceiving, building, exploring, analyzing and evaluating models, than those typically observed in social sciences. This computational approach is mainly based upon keeping individual (and heterogeneous) entities separately in the computer memory and endowing them with the ability to behave and mutually interact with each other (in both equilibrium and disequilibrium conditions) on an individual basis. This enomous potential makes possible to represent individuals fully and relaxes the mathematical tractability constraints which leads to conceptually illnatured constructs such as the representative agent and also to further unrealistic assumptions on agent homogeneity and equilibrium behavior.

In practice, the modeler essentially specifies (in computer code) a prototype of each type of agent ${ }^{38}$ (specification of the state variables, behawioral or characteristic parameters, and behavioral algorithms ${ }^{39}$ ), tells the computer to create an initial population(s) ${ }^{40}$ of such agents, initializes the state values and specifies the behavioral/perceptive parameters of each agent ${ }^{41}$, jump starts the system with these initial conditions, and finally sits back and observes what emerges (especially on the aggregate level) without further intervention into the system. It is also possible to allow new agents enter into the system (for example entry of new firms or technologies) or some exit (for example a firm which goes barkrupt) during the run time of the system endogenously, or according to some preset (and/or stochastic) procedure.

The according scalability brought about by the object-oriented programming framework implies an immense power to capture computational complexity levels equivalent to millions/billions of executions (calculations) brought into action with a relatively negligible amount of source code. In addition to the various instances of the local interactions annong individual agents, the high number of executions might as well arise due to the procedures/algorithms that represent the internal workings of the perceptions/cognitions/learning and the associated behavior of the individual agents.

Ironically, although one of the most important qualities of agent-based models is their flexibility as a tool to model many ways of boundedly rational behavior (through various tools of modeling Artificial Intelligence) ${ }^{42}$ "it is not possible to introduce into these models the perfect rationality of the mainstream econonics, which is (by definition) non-procedural ${ }^{43}$ in its nature. In a system, which explic-. itly evolves through real time, and which consists only of finite number of actual agents (as opposed to the bypothetical infinite number of the mainstrearn perfect competition condition), it has not been possible so far to discover any generic AI procedure/algorithm that would be representative of the mainstream rationality, 
even if one assumes that the whole set of information in the system (the values of the current and past state variables characterizing the condition and behavior of all other agents, and all the agent/system parameters) is made available to all the agents at each instant of the process. For example, as long as the number of agents are finite, for each agent the oligopolistic indeterminacy (i.e. how will the other agents behave in the short and medium run?) remains at every instant of the disequilibrim process ${ }^{44}$. This is typically a source of essential uncertainty, where the existing information on the current and historical values of state variables (although its fhlly perfect) is not sufficient to assign a probability distribution to the future states of these variables, leave alone building rational expectations ${ }^{45}$. Actually, the philosophy of evolutionary economics, on the contrary, is more interested in the emergent outcomes of (individual and/or interactive) behavior stemming upon bounded (and more realistic) procedures of rationality.

As mentioned earlier, the modeling options made available by the agent-based framework not onlly introduce radically different ways of conceiving and building models. The motivation for building such models (the types of outcomes, illustrations and insights expected to be yielded by the models) and accordingly the ways in which they are explored, analyzed and evaluated are quite different than that of the conventional models of orthodoxy as well. In other words the question is, after building the model what does one do with the various time series (or agent level panel data) generated by the simulation of a highly complex and complicated system, in order to draw useful conclusions?

In this sense, the perception of useful may show variations between the advocates of the evolutionary and the mainstream schools of thought, as highlighted by the following excerpt from Krugman ${ }^{\text {at }}$

... Notice what is missing from this analysis. Hamilton does not talk about the evolutionary dynamics by which frogs might acquare a sit-with-the-other-frogs instinct; he does not take ws throngh the intermediate steps along the evolutionary path in which frogs had not yet completely "realized" that they should stay with the herd. Why not? Because to do so would involve him in enornous complications that are basically irrelewant to his point, whereas - ahem-leapfrogging straight over these difficulties to loak at the equilibrium in which all frogs maximize their chances given what the other frogs do is a very parsimonious, sharp-edged way of gaining insight.

Now some people would say that this kind of creation of useful fictions is a thing of the past, becarse now we can study complex dynamics using computer simulations. But anyone who has tried that sort of thing - and I have, at great length - eventually comes to realize just what a wonderful tool paper-and-pencil analysis based on maximization and equilibrium really is. By all means let us nse simulation to push out the boundaries of our understanding; but just running a lot of simulations and seeing what happens is a frustrating and finally unproductive exercise unless you can somehow create a "model of the model" that lets you understand what is going on.

Indeed, an almost common ingredient of evolutionary (and particularly agentbased) models is complexity. As argued in the begimning of this chapter, simplicity is one of the basic qualities expected from a model. Yet complexity is sometimes 
(even often) confused with complicatedness and (awfully erroneously) perceived to be the antithesis of simplicity. Complexty is a phenomenon pertaining to systems characterized by bounded rationality, micro-level bilateral interactions, heterogeneity and various other intrinsic nonlinearties in their dynamics. When one perceives such complexity as a key ingredient of the economic processes one can not ignore it anymore. That is, by definition, complex systems can not be represented (modelled) with the mathematical tools build to model simple systems and understandability (or analytical sharpness) sonds to be a highly poor excuse to do so. Especially for mainstream economists, who are traditionally used (and trained) to find understandability (or simplicity) of a model in algebraic/axiomatic. representations of linearized causations of necessity (such as if $A$ and $B$ then definitely $C$ ) and linear dynamics, the essential complicatedness (with regard to understandability) inherent in the complex processes of agent-based models may (not surprisingly) be a major source for objection.

Although the underlying reason why some scholars have still been working on the building of agent-based models, is apparently their understanding of what is useful and what is unproductive down the way to a better understanding of the realities of economic life, it is still true that the exploration, analysis and evaluation of these models are significantly challenged by major technical difficulties.

Such challenges mainly arise due to the fact that in any agents-based simulation there is simply too much (executions) going on, and furthermore a good deal of the multiplicity of events in an agent-based simulation take place stochastically and may accordingly show significant variations (at least with regard to their timing) among different runs. Therefore, it is often not feasible to follow the model event by event (execution by execution) to figure out the exact causality among particular events. Especially given the fact that, path dependence is a highly prevalent phenomenon (at least in the individual agent level ${ }^{47}$ ), it may even be impossible to find out the major event $(s)$ in the simulation history which dominate(s) the rest of the evollution of an individual agent, leave alone the detection of events that dominate/affect the evolution of aggregate level magnitudes ${ }^{48}$.

Furthermore, path dependence is normally defined as the long lasting effect of some (random) event(s) that take(s) place during the evolution of the system. Nevertheless, simulation models need to be jump started at a point in time, arbitrarily chosen (as $t=0$ ) from the entire history ${ }^{49}$ of the system represented by the model, and the initial conditions that are chosen to describe the state of the system at $t=0$ may as well have long lasting effects in the rest of the evolution of the system at times $t+n$ (where $n$ can be quite large) as transients. Even if the system is not disturbed by stochasticity over time, such long lasting transient effects may as well be sources of path dependence, especially if the choice of the initial conditions involves randomness. Consequently, any dependency of the system states on (stochastic) initial conditions constitutes some sort of path dependency and the association of initial conditions to the events (outcomes) that follow is not that straightforward.

Shortly, if one's eventual aim is to understand the exact ways in which the states at time $t$ lead to the states at time $t+n(n=1,2,3, \ldots$.$) , then under-$ standability of the model indeed becomes a frustrating concern, as criticized by Krugman. Yet for the advocates of agent-based framework, the way to explore computational models is different. Instead, an agent-based simulation may be seen as a mapping (or a quasi-theorem) from the model structure (built in behavior and/or interaction and learning modules, the specification of selection and variety generating mechanisms), to some identifiable structure or history that emerges 
accordingly. If the emergent structures qualitatively resemble those observed in reality (1.e. macro level stylized facts) and if the micro-foundations built into the model can be justified in terms of their proximity to the ways in which agents behave, learn and interact in reality (i.e. micro level stylized facts), then one can safely claim to be suggesting some reasonable explanation for the workings of some process(es) in reality.

Although, using simulations as quasi-theorems that map micro-structure to emergent macro-structure $e^{50}$ is quite a justifiable methodology, the analysis framework is seriously challenged by some technical difficulties. The first challenge is the identification of any emergent macro-pattern. Clearly, any simulation generates an array of time-series (or panel data if one collects agent level information) and a simultaneous analysis of these series are technically quite challenging. In addition to the usage of sheer visual inspection (which is sometimes sufficient to draw many useful conclusions) and basic time series and panel data analysis tools, finding alternative/complementary analysis methods ${ }^{51}$ (including techniques that can be classified as data mining) is an important entry in the research agendas of those who work in the field of computational economics.

The second type of challenge, which exacerbates the first, stems from the necessity to introduce rigor into the analysis. Apparently, the outcome of any simulation model is not only affected by its underlying structure, but the initial conditions, parameters and stochasticity as well. Therefore, given the infeasibility of applying the usual sensitivity/bifurcation analysis tools of difference/differential equation models, in order to conclude on the robustness of the model findings (the quasi-theorems), the only method is to run the model many times (as in Monte Carlo simulations), for combinations of different random number generator seeds, various levels of initial conditions and various levels of parameters. To demonstrate the challenge, consider a simple model, characterized by 5 parameters and 5 state variables to be initialized for $t=0$. Given the impossibility of working in the continuous domain, consider that the analyst chooses 3 level values (corresponding to low, medium and high) for each of these 1.0 magnitudes. Considering the possible nonlinearities in the effects of these 10 magnitudes on the system behavior, a rigorous analysis (theoretically) requires running the simulation for at least $3^{5} \cdot 3^{5}=59049$ times, each run corresponding to a different parameter/initial condition level ${ }^{52}$. Furthermore, if the nodel is stochastic, each combination should be run sufficiently many times (say 5), which, in total, corresponds to $59,049 \cdot 5=295,245$ (almost 300 thousand) runs. Given that each run generates at least one time series, the question is "how does one analyze (multiples of) 300 thousand time series simultameously and generate rigorous results on sensitivity?". Unfortunately yet understandably, such highly time consuming undertaking is not yet the standard in the exploration and analysis of agent-based models. Mostly, the findings of such models (which are often of qualitative nature) are presented on the basis of a restricted (and arbitrary) number of (hopefully representative) runs and accordingly restricted rigor in analysis. Finding solutions to this challenge on rigor, is another issue high in the agendas of the advocates of evolutionary agent based models.

Despite these major challenges, agent-based modeling efforts have been yielding quite interesting, reasonable and useful results. In one of his articles Axtell [2000], discusses possible cases where agent-based models can especially be fruitful. Among these, the first type involve cases where a social/economic process can be characterized by (only) numerically soluble mathematical equations, while the stochasticity in the essential process (for example heterogeneity of agents which 
conform to some known random distribution or stochasticity in arrival times of some events) justifies a fruithul use for agent based modeling as some form of Monte Carlo simulation ${ }^{53}$. Other categories include cases,

- Where equilibria (of some social process) are not computable,

- Where (empirically justifiable) bounds on rationality are likely to inlabit the attainment of equilibrium,

- Where existing equilibria are unstable,

- Where the dependence of the (mathematical) model results on the model assumptions and/or parameters are mknown (i.e. Does mathematical results hold when specific assumptions are relaxed?), and most importantly, cases

- Where equilibrium is less inoportant than fuctuations and extreme events ${ }^{54}$, and cases

- Where writing down equations is not a (sufficiently) useful activity in representing the essential workings of a system.

Probably, the best way to observe and evaluate the ways in which the usefulness of agent based models are revealed, is to take a look at some of the examples in the literature. A very good example of such surveys can be found in Tesfatsion [2002], who categorizes the existing work in (pure) agent-based computational economics into various research areas such as:

Learning and the embodied mind: Research in this category, Locuses on the evolution/coevolution of (strategic) behavior of individual agents as an outcome of individual levrning and/or co-learning (global leaming) processes. Learning is mostly modelled by genetic algorithms, classifier systems, or action-based reinforcement learning algorithms, and is characterized by processes of trial and error (imnovation) and/or imitation of others in environments where selection forces dynamically determine the effectiveness of current individual strategies and behavior, given those of the others. A central theme in these exercises is the systematical investigation of the performance of various learning algorithms (especially with respect to the market/allocative efficiency implications of the accordingly evolving behavior), rather than using learning/co-learning algorithms as tools to compute (otherwise non-computable) global optima of decision problems ${ }^{55}$. For example Vriend [2000], in a Cournot game setting (where the quanitity levels chosen by individual firms determine the market price), experiments with genetic algorithm learning modules with two different specifications: one where firms learn from their own experience (individual learning), and one where firms learn not only from their experiences but those of the other firms as well (population learning). The author detects that in cases where firms are specified to be identical (with regard to their costs), population learning leads to much higher production levels (closer to social optimal) than indiwidual learning. On the contrary, Nicolaisen et al. [2001] find that in cases of cost heterogeneity across the firms, the opposite turns out to be true.

Evolution of behavioral norms: In some social settings, straying certain ways of behavion (followed by the majority or by sub-classes of the population) may bring negative consequences for individual actors. Furthermore, such behavioral. patterns, which may be referred to as behauioral norms, emerge, disappear or be replaced by others after rather prolonged periods of persistent existence. A number of agent-based studies ${ }^{56}$ demonstrate hypothetical environments where local interactions among (rather) simple behaving agents suffice to generate such dynamics for behavioral norms. Epstein [2001], takes another perspective and focuses on the inverse relation between the strength of the noms and the time agents invest (to think and evaluate) in making decisions. 
Bottom-up modeting of market processes: The models in this category mainly aim to deal with the emergence of market transactions and prices (and their cross-sectional and/or temporal variations) as outcomes of locally-learning/locallyinteracting firms in competition, paying special attention to the idiosyncrasies of various types of markets (financial, labor, perishable goods, auctioning etc.). For exarnple, various models of fnancial markets are built to explain the high trading volumes, the cross correlations between trading volumes, volatility and asset returns, all of which are observed in real financial markets ${ }^{57}$. Alternatively, in Chen and Yeh [2001], agents compete in hypothetical financial norkets through their choices of forecasting models. A very interesting finding is that, as any forecasting method becomes increasingly popular among the players (the model becomes increasingly better than others in its forecasts), its predictive power starts to decrease and becomes obsolete, which introduces volatility to market behavior ${ }^{58}$.

Analysis of economic networks: Studies under this category are not only aimed at analyzing the (transaction cost/efficiency) implications of various (given) network structures ${ }^{5 \%}$, but in the endogenous emergence of such networks ${ }^{60}$ as well. In the latter type of efforts, the central focus is on the stochasticity ${ }^{61}$ and determinism $^{62}$ in the formation of bilaterall connections (i.e. the unit element of a network) and the factors/processes that can bring about persistency in the connection ${ }^{63}$. A salient, example is by Kiman and Vriend [20011, which is an agent-based reconstruction of the findings of the authors' analyzes of the (panel) data on the daily buyer seller transactions in the Marseilles fish market. The model, which is built on a learning through a classifier system representation of the multiple decisions of actors (on price, quantity, trade partner and behavioral discrimmation towards. various trade partners), demonstraties the coevolution of behavior that generates price dispersions and loyalty (repeating business) patterns observed in the real data.

Other categories defined by Tesfatsion [2002] include models on the modeling of organizations, design of computational agents for automated markets and building of ngent-based computational laboratories for those who are interested in designing agent-based experiments but does not have sufficient computational skills to build and implement their own models.

\subsubsection{Semi-agent-based models of higher levels of aggregation}

The examples of purely agent-based models discussed above, have two important commonalities: First, they are highly behavioristic. In these culture dish laboratory experiments ${ }^{64}$, agents are initiated with an empty set (tabula rasa) of knowledge about their environments, and the outcomes of their built-in learning skills (modeled as algorithmic tools of AI) are observed with respect to development of networks, markets, institutions etc. Second, their focus is on individual markets. Accordingly, a highly important lesson (amongst ail) that emerges from this literature is the necessity of the acknowledgment of the idiosyncrasies that underlie behavior and emergence in different markets/sectiors of the economy. Yet, what about the macro level issues of the hard-core economic theory (such as growth as the national level or international trade flows and comparative advantages) that are elegantly addressed by the general equilibrium framework, which simultaneously incorporates various types of markets (many goods, labor, financial, capital, foreign exchange)? Given the sectoral idiosyncrasies in behavior and interaction patterns, is it feasible to study macro phenomenon through purely 
agent-based models, or in other words, is it possible to make evolutionary and perfectly bottom up models that procure functionality that is similar to that of the general equilibrium framework, and to generate results exclusively from the forceful imposition of equilibrium and rationality, merely as descriptions of emergent phenomenon arising from selection, variety generation, bounded rationality, learning/co-learning, local interactions and network formations?

With our current model building and analysis toolkit, it does not seem too feasible to build general equilibrium alike purely agent-based models that incorporate each existing market as a separate module, modeled in ways similar to the purely agent-based approaches discussed above ${ }^{65}$. Yet, although such level of detail and richness in a macro-focused model do not seem to be attainable yet, one can find important pieces of work in the evolutionary agent-based modeling literature, which address growth, trade, technological change and learning related issues simultaneously by introducing simplifying (dimension and complexity reducing) assumptions on various features of the models, although such assumptions may inevitably imply divergences from reality. Yet these assumptions (such as market clearance in various markets) are only imposed on selected modules of the model, making it possible to formulate the rest within the agent-based framework, while maintaining the internal consistency ${ }^{66}$ of the model.

The most well known of this family, which we refer to as "semi-agent-based models", is the seminal Nelson and Winter [1982] model, which historically precedes almost all agent-based and semi-agent-based models in the evolutionary economics literature. As we have almost reached the modeling/analysis niche, into which the modeling exercise in this book aims to fit we will conclude this section with a brief discussion of the Nelson and Winter [1982] model, and two other salient models, all of which have been sources of inspiration (in terms of their internal workings and their specific formulations) to our own study.

The most central simplifying characterization underlying the artificial economy of the Nelson and Winter model is the presence of firms that produce a homogenous product: GDP. Having reduced output to a homogenous agglomerate, the model focuses on heterogeneity among firms with respect to the production techniques they use, which are apt to change/progress over time as the stochastic outcome of deliberate search. Each production technique is characterized by two coefficients: one for labor and one for capital imput. Search (by firms) for better techniques (the main process of novelly generation in the model) is undertaken within a given, finite, and discrete set of such coefficient combinations ${ }^{67}$ and success in search is stochastic.

The costs (and the profits) of each firm is thus determined by the best technology available to it and also unit costs of capital and labor. The cost of capital (required dividend rate) is a parameter for the model, yet the wage rate is determined endogenously (through to a dynamic Phillips curve relation) ats a function of aggregate labor supply and demand. While the aggregate labor supply is exogenous, the aggregate labor is determined by the firms' individual labor coefficient and output level. Thus, the wage rate adjustments take place through a disequilibrium process. The determination of a firm's output level involves ro decisions. Output is simply assumed to be equal to productive capacity (i.e. firms" capital stock diwided by the capital coefficient) and the entire output is sold for the unit price 1.0 which is the numeraire of the model. In other words the model assumes equilibrium in the goods market (i.e. whatever is produced is sold in the same period) at all times.

With no individual output level decision rule, the growth dynamics reduce 
to a mere matter of capital accumulation brought about by technological change, which basically relaxes the resource constraint (i.e. basically labor) of the economy. Firms invest all their profits (revenues minus labor costs minus dividend payments, minus R\&D expenses) on capital expansion. Therefore, firms with positive profits see their capital stock (productive capacity) grow, while those suffering negatiwe profits shrink in productive capacity. Clearly, this construction represents the minain selection mechanism that gives the model its evolutionary character:

Firm's involvement with search (R\&D activities) is modeled in terms of satisficing behavior. Firms, which see the rate of return on their capital stock fall below a threshold value (an arbitrary $16 \%$ ), start with search for better techniques that would (hopefully) yield a higher rate of return (given current factor costs). Success in search (which is probabilistic) may come about in two alternative forms: discovery of a novel technique or imitation of another firm. That is, firms which engage in R\&D (determined by the 16\% rule), first draw a random number that determines the type of search (search for novelty or imitation). In case of a draw for imitation of another firm, the probability of the eventual success is determined by (proportional to) the share of the targeted technique in the total output ${ }^{68}$. If the firm makes a draw for novelty search, the probability of each undiscovered technique (in the pre-defined discrete technological opportumity set) is proportionall to its technological distance ${ }^{69}$ to the technique actually used by the firm in search. Thus, search for novelty is restricted to be of a local nature, which is another assumption that reflects the evolutionary philosophy.

The number of firms in the model is neither restricted nor fixed. New firms are allowed to enter into the market for GDP. The entry process is modeled by empty firms, which have a zero capital stock. These potential entrants are in continuous search for novelty and any of these which discovers a technique that can yield the $16 \%$ rate of return (based on current input costs), enters the market with a $25 \%$ chance. The initial capital stocks of entrants are determined randomly.

Nelson and Winter finally callibrate their model according to the data used by Solow [1957]. That is, the discrete set of technological opportunities (factor input coefficient pairs) is generated as the outcome of (100) random draws from the historical intervals of these coefficients as implied by Solow's data. Furthermore, the initial conditions (the initial set of already discovered techniques, initial employment and wage rates) are also chosen in conformance with the first year (1909) of Solow's data.

The major important result yielded by the simulations of this calibrated model is the emergence of time series (of output-labor, capital-labor ratios, wages, total factor productivity, capital share in GDP) that bear qualitative resemblances to those observable in the Solow data. Despite the lack of a continuous production function that allows for immediate capital-labor substitution possibilities, and also the lack of rational agents to choose optimal techniques, the simulation model generates technological change and growth patterns, which nicely fit the Solow type sources of growth decomposition (with $R^{2}$ levels around 0.99 ), and which look like to be the result of movements along/shifts of a well behaved production function. These results are used by the authors as evidence, showing that an evolutionary model is well capable of explaining macro phenomena coherently through agreeable micro-foundations (that allow heterogeneity and bounded rationality), and without resort to a set of unrealistic assumptions on behavior and market structure.

In addition to this contribution (which is utilized in a highly defensive manner to illustrate the advantages of evolutionary modeling), Nelson and Winter also 
present some further interesting findings through a rather systematic (yet partial) exploration of the parameter space of their model. For example, decreasing the locality of search (i.e. allowing for larger jumps in the factor input coefficient: set) or increasing the R\&D bias towards imitation (as opposed to novelty search), both result in lower market concentration and higher capital intensity in production. Bias in search towards labor saving technological change results in higher capital intensity and higher capital costs, decreases capital intensity and pace of technological change.

The second model in our list is by Silverberg and Verspagen [1995a]. The model can be considered to be similar to the Nelson and Winter model in many senses in terms of the formulation of the playground which represents the selection environment $^{70}$, though its research target is quite different in scope. On the surface, one can see mild differences such as the capital embodiedness of technological change (which gives the model a vintage model character), or the reduction of the technological coefficient space to one dimension (the capital coefficient is assumed to be fixed) and to the continuous domain. Yet the essential difference is in its be havioristic nature, which aims to demonstrate the endogenous emergence of R\&D strategies through learning/co-learning (which is modeled by a genetic algorithm). The R\&D strategy of firms is represented by a single number (in the continuous domain) representing the ratio of $R \& D$ expenditures to revenues (and/or profits). R\&D effort and distance to the best practice technology (i.e., the technology used by the firm which supplies the lowest labor coefficient amongst all) increases the probability of innovation. However, each successful innovation corresponds to the introduction of a new type of capital vintage which embodies a labor productivity level characterized by a proportional increase ower the labor productivity level made available by the existing best practice capital vintage of the firm ${ }^{71}$. Firms lagging behind others can catch up by intensifying their R\&D efforts and/or imitating the technologically leading firms, both of which need spending and effort. Firms can not only innovate or imitate technologies but they can do so for the R\&D strategies ${ }^{72}$ as well. "The genetic algorithm responsible for this process gives each firm the chance (with a small probability each simulation period) to make an incremental and random change ${ }^{73}$ in its $\mathbb{R E D}$ strategy coefficient, as well as to imitate the R\&D strategy of another firm. Nevertheless, the probability of an imitation is variable and is a decreasing function of frrm's success and growth rate (i.e. firms lagging behind others have more chances/motivation to imitate). On the other hand, the probability of an existing R\&D strategy to be imitated is an increasing function of the market share of firm, which follows the strategy at the instant.

In their conclusions the authors report that, following a prolonged adjustment period, R\&D strategies cluster around a certain mean levell, the crossmectional and temporal variances around which is quite small. Similar to the reduced form diffusion model. by Silverberg and Lehnert [1993], the growth rate of the economy exhibits low-dimension chaos $\left(1 / f^{\alpha}\right.$ noise pattern detected by spectral analysis). Furthermore, simulation runs that start with zero R\&D expenditure by firms, are observed to go through various identifiable phases, characterized by various market concentration levels and technological change rate levels: In the initial phase where R\&D expenditures are still low, occasional innovations suffice to give their holders a significant monopolistic position, which leads to high market concentration levels, though the monopolist is occasionally replaced due to the innovative success of some other firm. After an intermediate period of moderate R\&D expenditures, the system converges to a state (where individual $R \& D$ strategies mutually con- 
werge), where the frequent arrival of innovations keep firm sizes around an even distribution, which implies a low market concentration given the high number of firms that remain.

Both in the Nelson and Winter [1982] and Silverberg and Verspagen [1995a] models, the specification of the selection mechanism is purely based on supply side dynamics. Since market clearance is assumed (i.e. supply creates its own demand) and also the unit price of the final good is taken as the numeraire, at any given output level the rewenue of each firm is equal to its output level (which is determined by its capital stock). Similarly, given the technological coefficients and factor prices, the total costs and accordingly the profits of each firm are determined. In both models, the selection forces are represented by an investment/disinvestment mechanism where growth (i.e. output level) of each individual firm follows its profitabillity. This firm-level "positive (negative) profits are invested (disinvested)" rulle appears to be sufficient to translate firm-level technical change shocks (which, instantaneously increase the firm's profits and gradually diffuse into the entire economy by the taking over of relatively more productive firms, and/or by imitations) into aggregate growth of economies. This simple rule is based on a key (implicit) assumption on individual firms' behavior regarding investment on physical capital (i.e. output expansion): that each firm is willing to increase its output level as much as possible and the only immediate constraint to the realization of this tendency is the firm's current profitability. In other words, firms are assumed to be profit-constrained dynamic output maximizers, while this optimizing tendency is revealed gradually through a discrete time process where each increment to output level is subject to the amount of capital goods that can be purchased by current profits ${ }^{74}$. Clearly, this assumption is a radically different way of representing firm behavior compared to the mainstream (general equilibrium) specifications where firms are assumed to be profit maximizers. However, in general equilibrium formulations, at the long-run perfect competition equilibrium, each industry is reduced to a single entity that behaves like a profit-constrained output maximizing firm. The selection mechanism specified by the former two evolutionary models basically imposes profit-constrained output maximizing behavior to individual firms instead of the industry and accordingly rejects profit maximizing behawior.

The capital accumulation dynamics, together with the specification of the labor market in terms of a dynamic Phillips curve relation ${ }^{75}$, constitutes a predator-prey type process $^{76}$ as in Goodwin [1967] and Silverberg and Lehnert [1993]. Consequently, throughout the process of economic growth and accumulation, employment and wage rates exhibit incessant oscillations at the background ${ }^{77}$.

The last model in our brief overview is Dosi et al. [1994]. The model differs from the former two, in terms of its multi country-multi-commodity nature, which allows for the flow of commodities among countries. The most significant difference is its specification of the selection mechanism, which, instead of the profit-investment-disinvestment link, resorts to a reduced form replicator equation where the market share of each firm is determined dynamically by the price it asks on the market. Firm heterogeneity with respect to price is essentially based on heterogeneity in costs and the mark-up rate used by firms as a rule of thumb ${ }^{78}$. In other words, contrary to that in the Nelson and Winter [1982] and Silverberg and Verspagen [1995a] models, the specification of economic selection in Dosi et al. [1994] is purely based on demand-side dynamics (i.e., the output level of each firm is determined by its demand). Demand formation is modeled in three stages. First, a constant-share demand function allocates the total consumption budget 
of each country (i.e. the wage bill paid to workers) among the sectors. Namely, the sectoral allocation of the consumption budget of each country conforms to a demand curve characterized by a Cobb-Douglas type (national) welfare function, which would represent the preferences of a representative customer. The second stage distributes the total consumption budget for each sector among all firms (of the world) which operate under the sector in question. This stage is achieved by the replicator equations (a separate one for each sector), wach which determine the market share of (i.e. monetary demand for) each firm in the sector where it operates. The market share allocation governed by the replicator dynamics does not specify a static mapping of individual prices on market shares, but describes a dynamic process where price differentials among firms determine the (discrete time) changes in market shares. At the third stage, the monetary demand for each firm is determined as the sum of demands from all the national markets.

Compared to the well-defined workings (i.e. explicit micro-foundations) of the supply-side selection mechanism specified by the Nelson and Winter [1982] and Silverberg and Verspagen [1995a], the purely demand-side based (black-boxed) formulation of Dosi et al. [1994] remains highly implicit with regard to its microm foundations. Although it has formally been demonstrated (in Hofbauer and Sigmund [1988]) that both formulations on selection dynamics lead to similar aggregate dynamics ${ }^{79}$, given the assumption that the competing products in each sector are assumed to be perceived as perfectly homogenous by the customers, the question that immediately arises is "why do the firms that ask relatively higher prices for the exactly same product still have non-zero market shares?". Clearly, the replicator dynamics specified by the model introduces the tendency to decrease (increase) the market shares of the relatively more expensive (cheap) products. However, this process is not instantaneous but only gradual. The only reasonable explanation for the gradual nature of this process is consumers' learning. 'That is, a given point in time (or in the short-run) consumers may exhibit less than rational behavior in their purchases (i.e. purchasing the relatively more expensive products, due to habit and/or unawareness of the existence of cheaper products and/or various imperfection in the spatial distribution of products, etc.), yet as time goes by they find out about the cheaper products (by searching about or by chance) and rearrange their purchases accordingly.

Given its demand-side focus, Dosi et al. [1994] does not incorporate capital as a factor of production. Not only technological change is capital disembodied but the output level of the individual firm is not bounded by any immediate capital/capacity constraint. The output of each firm is equal to its demand unless the firm is rationed for (financial) credits. In ather words, the model is not one of capital accumulation. The only accumulation pertains to technical knowledge, in the sense that each new innovation is built upon the best practice technology accessed by the firm so far (as in the two other evolutionary models just discussed): each successful innovation introduces a proportional increase in labor productivity over the level at which the innovating firm operates at the instant of the innovation. The model also allows for imitations between individual firms and the probability of a successful imitation is a decreasing function of the technological distance (i.e. labor productivity distance) between the potential imitator and the targeted firm. Furthermore, the model incorporates the possibility to decrease the possibility of international imitations. In other words, international technology spill-overs can be rendered (by parameter setting) less likely than international ones. This constraint introduces a major source of positive externality of national. scope.

Contrary to the Silverberg and Verspagen [1995a] model, the rules of thumb 
that characterize strategic behawior are not permitted to change and accordingly they remain fixed as initialized. Since countries are defined as units, each having a separate labor market and local currency, the competitiveness of a firm in the international arena is not only determined by its own productivity but by two (endogenous) macro wariables (local wage rate and the exchange rates) as well. The formulations of the labor and currency markets specify disequilibrium adjustment processes where equilibrium in these markets are by no means guaranteed. The labor market module specifies the local (nominal) wage rate dynamics of each. country as a separiate process driven by the local labor productivity growth, aggregate consumer price changes, and changes in the level of local, employment. The model does not impose any constraints on labor supplies. Thus, unemployment is not an issue addressed by the model. However; the labor market formulation specifies a positive relation between the growth rates of (local) nominal wage rates and (local) labor demand, which indirectly limits the explosive growth of labor demand. In the currency markets, exchange rates vary as a function of current and past (accumulated) foreign balances (i.e. international debts). In other words, the relative value of each currency follows its excess demand (by a time lag) through a disequilibrium process.

As in the former two models, neither type of technical progress is free. The firm allocates separate budgets for innovation and imitation activities. Namely, the $R \& D$ behavior of the firm is determined by two firm specific parameters: The first one determines the total R\&D spending as a proportion of the firm's sales turnover (at each period separately), and the second one allocates this total budged between innovative and imitative activities. Accordingly, the specific formulation of the endogenisation of the technological change (on R\&D spending) specifies the innovative and imitative potential of each firm as linear on its sales revenues, which implies a strong increasing returns to scale effect in innovative/imitative success. In other words, for identical R\&D behavior, larger firms have higher chances to access to techmological progress. Yet, since being larger (i.e., having a higher market share) is an outcome of past success, the increasing returns to scalle effect in R\&D effort implies a "success breeds success" mechanism. The number of firms during each simulation is kept constant by a mechanism which replaces firms that exit ${ }^{80}$ with new ones that enter with an initial labor productivity equal to the average productivity in the sector and in the country where the replacement takes place. Naturally, this specification also implies some sort of country-specific externality.

Despite its high complexity and technical sophistication, the exploration and analysis of the model is quite limited and is confined to the presentation of a few runs, the representaliveness and robustness (with respect to parameter settings) of which are not thoroughly presented. The main conclusion driven from these runs is that the model leads to the endogenous emergence of persistent (per capita income) growth rate and level differentials among the countries, despite that the simulation is initiated with settings that specify countries and firms as identical. Furthermore, the model leads to the endogenous emergence of comparative advantages (through micro-level innovations and imitations) which lead to the specialization of some countries. The importiant point made is the fact that the emergence of (cross-country) persistent growth rate differentials and specialization take place essentially due to the persistence in individual firm's success (i.e., the success breeds success mechanism discussed above, which makes more resources for R\&D available to more successful firms), the propagation of these by imitations, and most importantly the dyamic increasing returns mechanism brought 
about by the assumptions ${ }^{81}$ that render international technology spill-overs less likely than those with nationall scope. The dynamics responsible from the emergence of the sectorall as well as cross-country differentiation is clearly triggered by frm level micro-shocks (i.e., the stochasticity in the exact timing of the arriwal of technological change to individual firms), or in other words, pure chance.

It is clear that the emergence of specialization in Dosi et al. [1994] follows the causality suggested by the Ricandian model, which shows that labor productivity differentials across countries and sectors, together with the balance of payments and labor constraints are sufficient to bring about internationall specialization. However, as discussed above, in Dosi et al. [1994], labor and currency markets adjustments are both modelled as disequilibrium processes. Thus, throughout the simulation runs neither the balance of payments nor the labor constraints are strictly imposed. Yet, though not clearly reported by the authors, one can presume that the adjustment dynamics built into the formulation of the workings of these two markets, suffice to keep the markets rather close to the states which can be called equilibrium (or market clearance) ${ }^{82}$. In this sense, it is hard to claim that the disequilibrium nature of the adjustment processes in currency and labor markets necessarily contribute much to the emergence of the phenomena demonstrated by the model. Given the agent-based formulations of the rest of the model, it is hard (if possible) to impose persistent equilibria in these two markets, and accordingly it is inevitable to formulate some sort of disequilibrium dynamics, consistently with economic intuition ${ }^{83}$. The authors accomplish this in quite a reasonable manner ${ }^{84}$.

If one compares the basic suggestions of these three evolutionary examples, with those of the mainstream literature on international trade and growth, one observes many close similarities on the surface: Similar to the suggestion by the Solow [1956,1970] and many other mainstream models, the one and only source of economic growth in these evolutionary models is technological change. In mainstream models of growth, technological change brings about economic growth by keeping the marginal return on capital sufficiently high (so that the capital accumulation process can rationaliy proceed), while in Nelson and Winter [1982] and Silverberg and Verspagen [1995a], economic growth takes place due to the relaxation of the resource (labor) constraint by technological change, which essentially increases factor productivity gradually. However, the process that translates technological change into economic growth is coordinated by profitability signals. In other words, despite the across-firm heterogeneity of these profitability signals in the evolutionary models, in the context of the aggregate level, the causal mechanism that generates economic growth are technically similar in mainstream and evolutionary models of growth.

Similarly, the basic points made by Dosi et al. [1994], (i.e., that under dynarnic increasing returns, stochastically induced productivity differentials can be translated into persistent growth rate differentials and international specialization) are also suggestions demonstrated by a number of new growth/trade models ${ }^{85}$. Furthermore, given the endogenous emergence of across country/sector labor productivity differentials (i.e. comparative advantages), the emergence of international specialization takes place fully in line with the Ricardian model of international trade.

Despite such similarities between the evolutionary and mainstream models of international trade and growth, the important issue that differentiates these two classes of modeling efforts is frst of all, the ways in which the underlying suggestions are illustrated. First, the evolutionary models discussed above (as well as a 
number of others) show that in order to illustrate the essence of the processes that govern technological change, growth and trade, one does not need a long list unreallistic assumptions such as perfect information, perfect rationality/foresight, profit maximization, perfect competition, agent homogeneity (or identicity), contimuous production functions that make an infinite number of alternative production techniques (i.e. endless factor substitution possibilities) costlessly and simultaneously available to everyone, instantaneous diffusion of technologies, etc. Second, the results of evolutionary models are findings/observations made on time series produced by simulations of a finite time interval. The story-line told by the model is actually in dymamic formulations of the underlying processes and the time series endogenously generated by the model withim a finite time interval (during which dramatic changes may take place), and accordingly model results are not a mere collection of steady-state properties of some moving equilibrium process accompanied by a straightforward verbal story of what has been happening. In other words, the main focus of the evolutionary models are about "how things move" over time and "what happens down the way" as opposed to "where does the system reach eventually" or "how does the system look like when one or more things steadily accumulate and nothing dramatic can happen?"

Shortly, the most distinguishing feature of evolutionary models is the existence of elements of drama in the time series they generate, which also exists in reality. One can perceive economies as a collection of individual success and failure stories which may translate into emergence of rather persistent (yet not necessarily permanent) patterns of success, failure and irregular patterns of change at higher levels of aggregation. In reality, things fluctuate (mostly in an irregular fashion), systems may experience unexpected and abrupt phase transitions (or percolations). Various elements in evolutionary formulations set the stage for the emergence of such drama within finite time intervals. For example in Silverberg and Verspagen [1995a], the sources for such emergence are the predator-prey dynamics (which generates persistent background oscillations), and the strategical learning module, which constitutes an organic relation between firms and accordingly a mechanism prone to coevolution and self-organization. These two sources, mutually interfering with each other and also with the stochastic innowation arrival process leads to various phases of development (i.e. slower, faster) in the growth process. In Nelson and Winter [1982] and Dosi et al. [1994:] the organic nature of the model lies in the imitations between individual firms. The latter also set the stage for the emergence of drama by the disequilibriun formulations of intemational currency and labor markets, the nonlinearities in which facilitate the emergence of divergence and oscillations in growth rates.

Such evolutionary efforts are of course, not necessarily the conclusive final words on the dynamics of economies. However, the important point is that they demonstrate the existence of promising avenues to explore which are apparently more interesting than the axiomatic causal mappings of the mainstream economics, which do not tell a story but only demonstrate rather simple and straightforward causal relations. 


\subsection{An overview of the book: Objectives and organization}

\subsubsection{An overview of research objectives and the resulting simulation platform}

The model, whose building blocks, internal workings and analyzes will be presented in this book, aims to tackle with various international trade, growth and technological related issues simultaneously within an evolutionary semi-agent-based modeling framework. The basic motivation is, starting from foundations similer to those of the semi-agent based models discussed in the previous section, to take a few steps further, build a relatively more elaborate model which brings together various elements in a modular structure, demonstrate the workings and the illustrative potentials of the model in a rather systematical way, and also present the reader with a fully functional and user-friendly copy of the model software for the design and analyzes of own experiments. Let us first make a brief list of the basic (technical) points where onr model builds upon/diverges from the existing evolutionary models discussed in the previous section.

The first two examples of evolutionary semi-agent based models (i.e. Nelson and Winter [1982] and Silwerberg and Verspagen [1995a]), which relate technom logical change and economic growth, are based on a supply-side formulation of selection dynamics which are justified by explicit and clear micro-foundations. However, the scope of these two models is confined to national economies and a highly aggregate level (i.e., no international trade and no sectoral differentiation in output). The third one (Dosi et al. [1994]) has a multi-country multi-sector scope. Yet the demand-side based specification of selection dynamics (which basically adopts the replicator dynamics in a way where prices and exchange rates determine competitiveness and accordingly the market share dynamics of individuall firms) is not explicitly micro-founded in any well-defined theory. Our primary motivation and starting point have been the building of a discrete-time model which follows the supply-side dominated selection dynamics specified by the former two models, and which also allows for the broadening of the analysis scope to more than one sectors and more than one mutually trading countries.

Given this objective, the first challenge that anises is the specification of a consumer demand module (i.e. a reasonable theory of consumption). As discussed in the previous section, in formulations of selection mechanisms which follow the causation that links cost to profits and accordingly to competitiveness, one needs to determine (at each period of the discrete-time model) the price at which each firm can sell its entire output, given the output level of other firms ${ }^{86}$. In other words, one needs some sort of an inverse demand function, which maps the vector of firm level output to a vector of firm level prices in a multi-sector multi-country setting. The solution to this challenge can unfortunately not be found in the evolutionary literature. As discussed before, in the evolutionary literature, there exist various (agent-based) models aimed at explaining the formation of markets and disequilibrium price dynamics. However, these highly behavioristic approaches (which focus on temporal price variations, customer's learning, formation of networks and institutions, customer loyalty etc.) are highly sector-specific in scope and they do not yet offer the functionality and practicality needed in a multi-sector multi-country model the focus of which is more on supply-side than on explaining price formations.

Accordingly, we adopt a version of the versatile utility/welfare function form 
often used in models of new growth and new trade literature (i.e., the Dixit and Stiglitz [1977] formulation which is the combination of the Cobb-Douglas and the CEs forms), where we also introduce the possibility to introduce firm-level product quality differentials into firm-level price determination. Furthermore, the CES part of the welfare function intraduces parametric control on the extent of withinsector substitutability between competing products (i.e., the extent of demand for variety), which is a nowelty in terms of evolutionary formulations due to its potential on the workings of the selection mechanisms of our artificial economy. As discussed before, in Nelson and Winter [1982] and Silverberg and Verspagen [1995a], due to the underlying assumption on perfect product homogeneity, all firms sell their output at exactly the same price and accordingly the selection mechanism discriminates firms purely on the basis of their individual unit costs. Given the ongoing processes of technological change, which incessantly heterogenise firms according to their productivities, it is clear that the selection mechanism has the tendency to generate highly concentrated patterns of industrial organization. The only mechanism that works against this tendency is the possibility of imitations between firms, which works against the heterogenising effect of stochastic technological change. However, demand for variety (which implies that customers are not only interested in the total quantity they can consume but also the number of products in their consumption basket) also seems to be an important factor that may decrease the extents of the pressure of the selective forces of the economy on individual firms. The selection mechanism normally tends to decrease the market: share of relatively less productive firms, yet since demand for variety is nothing but a tendency of the consumers to divide their consumption budgets rather equally over an as large as possible number of competing products ${ }^{87}$, limited product substitutability has the potential to give relatively less productive firms persistent survival chances, though survival is inevitably possible only in case of low output levels (i.e. low market share). Shortly, the incorporation of demand for product variety in an evolutionary model of selection, introduces an interesting dimension to the addressing of issues on industrial organization and dynamics, and the demand module adopted into our model gives the opportunity to explore this avenue with experiments by controlled parametric variations.

The second modification we introduce in our model is our alternative formulation of the labor markets. As discussed before, the dynamic Phillips curve representation of the labor market leads to predator-prey dynamics in evolutionary formulations similar to Silverberg and Verspagen [1995a], which implies permanent: oscillations in income distribution (thus real wage rate) and unemployment rate. The endogenous generation of such permanent oscillations has been suggested by Goodwin [1967] as a dynamic implication of class struggle in capitalist economies. Despite the fact that this suggestion is quite an interesting one (especially for political economics), it is not generally acknowledged as the primary explanatory principle underlying the business cycle (or long wave) phenomenon 88 . One of the objectives of our study is to eliminate the emergence of Goodwin cycles in our model, in order to be able to demonstrate the convergence properties of our model in cases where there is no technological change (i.e. no disturbance to the adjustment process in labor markets), and also the effects of technological change on economic growth and unemployment in isolation from the interference of unnecessary background oscillations. Accordingly, we suggest an alternative formulation that specifies an institutional (i.e. invariant as opposed to dynamic) relation between unemployment and income distribution (i.e., where the share of total wage bill in GDP is institutionally determined as an increasing function of current em- 
ployment rate), which still retains the intuition of the Philips curve relation. We also build into our model a complementary formulation that iritroduces some stickiness in wage rate (or income distribution) adjustments. As we will clemonstrate later, these modifications undermine the conservative nature of the predator-prey dynamics and for the resulting adjustment process, full employment equilibrium appears to be a stable focus under certain conditions.

Our third modification regards firm's investment behavior. As mentioned before, the simple selection rule "positive (negative) profits are invested (disinvestedi)" implicitly implies that the firms in evolutionary models have the tendency to maximize output dynamically, as opposed to the profit-maximizing firms of the neoclassical models ${ }^{89}$. Naturally, our formulation of locality and adaptiveness in firms: investment behavior also introduces the dynamic profit-constrained output maximizing tendency into firm's behavior as its basic working assumption. However, our formulation of the firm level investment process is made in a way that is slightly more elaborate than the profits are invested rule, and it also introduces the option to incorporate some sort of dynamic profit-maximaization tendency (procedure) into the incremental investment behavior, which allows us to compare the effects of these two alternative behavioral assumptions on the macroeconomic properties of our model. Our formulation defines a concept as the instantaneous grouth desire of the firm, which determines (at each period of the simulation) the firm's maximum demand for financial resources to be used in expanding productive capacity. The firms" growth desire is a dynamic variable, which is determined at every other period as a function of current profitability, market share and most inportantly whether the firm is a profit-constrained output maximizer or a profit maximizer. Naturally the total demand for credits is not necessarily equal to the avallable financial resources, which is restricted to be equal to the sum of the positive profits of all firms in the economy ${ }^{90}$ minus a part. which is retained by shareholders for current consumption. The (re)distribution of the profits of the economy (which are nothing but the pooll of collected but not. consumed part of the dividend payments) over the firms is achieved by a financial market formulation, which, through an auction-like process, grants firms credits in line with their credit demand (growth desire) and more importantly their relative profitability. Namely, as in the mechanism proposed by Soete and Turner [1984:] (and also adopted by Silverberg and Verspagen [1995a]), the financial market redistributes the collected dividend payments in such a way that the credits received by more (less) profitable firms for capacity expansion may turn out to be more (less) than their own profits.

We also base the formulation of our capital accumulation mechanism on a somewhat different definition of the capital measurement unit than usual. In neoclassical as well as various evolutionary (as Nelson and Winter [1982] and Silwerberg and Verspagen [1995a]) formulations, capital goods are taken as homogenous entities or at least, it is assumed that capital stock can be measured/represented on a cardinal scale. In these models, the capital intensity of production is represented by the capital-output ratio, which denotes the number of such homogenous capital units required to produce one unit of final output. The same ratio can also be interpreted as the value of capital stock measured in terms of GDP. Such formulations have been the subject of a number of controversies (for example the one known as the Cambridge debate) in economics literature. Although our aim is not to elaborate on such controversies, we slightly diverge from such formulations that directly assume homogeneity in capital goods, and/or two-way convertibility between final products and capital goods. First, we assume that capital goods are 
(at least) sector specific (i.e., immobile between sectors), such that once produced and installed for the use of a given sector, they can not be used in production in other sectors. Second, our formulation is not based on units of capital, but capital is measured in terms of productive capacity. "The simple question we ask is: how much extra productive capacity can a firm purchase and install given its investment budget (i.e, its financial resources), and how much dividend payments is the firm expected to distribute to shareholders, giwen the stock of capital goods that constitute the firm's productive capacity? These questions reduce to the simpler question: what is the price (i.e., current market value or replacement cost) of the set of capital goods that facilitates the production of one unit of final good in each given sectior and country, and how do these prices change over time? Since capital goods are reproducible commodities, their production requires labor and capital as all other commodities, and accordingly their prices are determined by labor costs and profits. Thus the question further reduces to: for each sectorcountry, how much labor is required to produce the set of capital goods, which is required to produce one unit of final output in that country-sector, and what is the profit mark-up rate applied over the according labor costs? We introduce into our model various alternative assumptions on the (dynamic) determination of these two sector-country specific coefficients (labor coefficient and profit mark-up in capital production). For each sector-country, the dynamics of labor productivity motion in capital production is formulated in relation to the motion of labor productivity in the final good sector, which gives us the ability to asses $\mathbb{m}$ a controllable fashion the effects of technological change rate differentials (biases) between sectoral capital and final good production, on the motion of aggregate level magnitudes such as income distribution, employment, and output growth.

So far in this section, we have been discussing the ways in which the specification of the basic selection environment in our model diverges from those of the evolutionary models in which our effort finds inspiration. The second set of modifications introduced in oux model regards the specification of the technological change process, which is the essential driving force of motion, as in all models that associate technological change and growth. Our formulations have many commonalities with the earlier evolutionary efforts, in the sense that innovations are modelled as firm-level, incremental productivity shocks which arrive according to a Poisson process, and imitations between firms are also stochastic where the probability of imitation between any given two firms is affected by the technological distance between the firms, the market shares of the firm targeted for imitation, and (as in Dosi et al. [1994]) by the existence of national borders between the firms.

It is possible to have the model generate technological change either in labor productivity or in product-quality dimension. For our two-stage frm-level innovation process, we introduce alternative (preset) technological trajectories. In the relatively more simplistic first two formulations, each time a firm draws an innovation arrival it either increments its productivity (or quality) by an (on the average) fixed increment, or alternatively experiences an (on the average) fixed proportional increase over its current labor productivity (or quality) similar to the formulations in Silverberg and Verspagen [1995a] and Dosi et al. [1994]. "The third alternative follows the "technological paradigms" concept introduced by Dosi [1982]. In this case, technological opportunities are assumed to emerge through a consecutive series of progress trajectories (i.e., technological paradigms) where the incremental progress opportunities within each eventually diminish and disappear as learning goes on. This formulation basically introduces a finite number of discontinuities 
into the technological change process.

While innovations and imitations respectively constitute the technological accumulation and technology spill-overs, we also introduce alternative formulations to capture knowledge accumulation and knowledge spill-overs. That is, thechnological change (innovations) and technology spill-overs (imitations) are the endproducts of search processes, yet knowledge is a key input to the innovative process and accordingly the accumulation and the spilling-over of knowledge are important determinants of success in innovative effort. We introduce this link into our model in two alternative forms. The first alternative formulates the innovative potential of each firm (i.e., the arrival rate of stochastic innovations) basically as an increasing function of the cumulative number of its earlier innovations (which proxies the accumulated knowledge stock of the f(rm). In this cumulativeness formulation, it has also been possible to incorporate the effect of the cumulative number of innovation of firms on the innovativeness of others, which represents the spilling-over of knowledge. Furthermore, by differentiating the extent of such spill-overs between the countries, it has also been possible to control the international pervasiveness of knowledge. In our alternative cumulativeness formulation, output level is assumed to be the proxy for accumulated knowledge. We show later in the book that this second alternative cumulativeness formulation represents a learning by doing mechanism which can be seen as an agent-based equivalent of the Lucas [1988] formulation.

As in all three evolutionary models discussed in the previous section, the endogenisation of technological change is formulated through alternative functions, which relate a firm's innovativeness (i.e. innovation arrival rates) to its $R \& D$ effort (which is represented by the share of $\mathrm{R} \& \mathrm{D}$ budget in its sales revenues). Regarding firms' R\&D strategies, we also introduce alternative assumptions. In the first of these, $R \& D$ behavior (i.e. target $R \& D$ to sales ratios) is specified to be determined as constant rules of thumb (as in Dosi et al. [1994]), which are allowed to exhibit heterogeneities among individual firms. The other two alternatives are based on boundedly rational and/or satisficing behavior, where firms are assumed to have some limited idea on the relation between the level of their own R\&D expenditures and its possible consequences in terms of innovative success.

\subsubsection{Organization}

What we have in the end can clearly not be interpreted as a single model. It is more of an experimenting platform where one can construct various models as some combination of the alternative assumptions which are built into various modules of the model. For example, it is possible to construct experiments with arbitrarily chosen number of countries and sectors, turn international trade on or: off, assume profit or output maximization tendency in firms' investment behavior, render innovation arrivals purely exogenous or endogenous on R\&D effort by alternative (linear or logistic) innovation potential functions, turn stochasticty in irnovations and/or imitations on and off, include or exclude cumulativeness or learning by doing effects in knowledge accumulation and also control the scope (national versus international) of the spilling-over of accumulated knowledge, control the entry rate of new firms, make a selection among a number of assumptions regarding the initial fitness level of entrants, etc. Furthermore the model gives itis user the freedom to make firm-level settings of the initial values of a number of state variables. 
The introduction of a broad range of alternative assumptions into the model platform naturally implies quite a broad parameter space. However, note that the implementation of the platform is carried out in a modular way. That is, each causal module of the platform, each of which is specified by no more than 2-3 parameters, can be activated or inactivated by binary switches. Thus, while making experiments one does not need to worry about the parameters of the modulles which are left inactive in a giwen design. As will be apparent in the rest of this dissertation, in the actual experiments presented in later chapters, we have kept only one or two of our modules simultaneously active and designed our control runs on the basis of control variations over the parameters of the selected modules.

These features have certainly affected the way in which we deploy, present and analyze our model platform and our results. As the most important initial step, the model platform has been turned into an executable software application, complemented with a graphical-user-interface. The resulting software is capable of letting its user set/edit the parameters and the modular switches of the model, save these settings as project files, and retrieve settings from existing project files later, when necessary. The software is supplied in the CD accompanying this book.

The simulations runs presented in this book are essentially a collection of simulations selected among the many with which we experimented during our research. For each of these, we supply the associated project file (as well as the output of the simulation rums) in the accompanying CD. These project files, in which the switches, parameter values and initialization settings of individual simulation designs are kept, can be retrieved (and visualized) by using the software supplied in the accompanying CD. Furthermore, the reader can make re-runs (i.e., verifications) of the simulations associated with each project file and also design his/her own experiments not only by introducing arbitrary variations over the parameter/switch combinations we supply, but also by starting from scratch.

In addition to facilitate presentation, edition and the retrieving of parametier/switch settings that pertain to various scenarios/experiments, the simulation software supplied on the accompanying $\mathrm{CD}$ also helps visualize the output of the simulation runs (i.e., a broad range of time series on the values of selected aggregate variables and statistics) by Microsoft Excel automation. The graphical-userinterface features a menu of various aggregate variables (such as sectoral output, profits, consumption, welfare, nominal GDP, currency exchange rates, Herfindahl Index on firm size distributions, number of firms etc.). The user can select any of the items in this menu, and the during the run-time of the simulations, the software launches Microsof: Excel, sets up the charts for the selected time series, plots them on the fly as the simulation progresses ${ }^{91}$ and saves the resulting output at the end of the simulation run. For the presentiations of our experiments, we also supply the $M$ crosofi Excel charts of all the time series generated by of our simulation runs on the accompanying CD.

The effort made for the construction of a tool offering such functionality has a number of reasons. The first is to avoid the general problem of "reproducibility", which is pertinent to the presentation of almost any work in evolutionary economics. As discussed before, complete controlled analyzes of models characterized by a rather large number of parameters and/or initial conditions are practically not possible. Consequently, the presentation and analysis of such simulation models, especially given the page limitations of scientific articles, are confined to either a small set of simulation runs with arbitrarily chosen parameters or a rather low number of controlled experiments. Furthermore, though it is generally possible 
to generate time series of broad range of variables (sectoral, aggregate or agent level state variables in form of panel data etc.) which may facilitate an better understanding of what is going on under the hood, the readers' access to such time series remains limited to the author's priorities and selections with regard to addressing the issues under inspection. Besides, the readers' chances to make his/ her own controlled experiments (for a more through understanding of the model and its potential results) are quite limited unless (s)he is willing (and able) to make the effort to re-program the entire the computer code of the given model from the scratch or approach to author for advice or the source code ${ }^{92}$. These issues constitute a particular shortcoming in terms of the general acceptance of evolutionary modeling exercises by a broader set of scholars, especially given that competing models of mainstream economics, which are generally of a purely mathematical (as opposed to numerical) nature, are perfectly reproducible and verifiable for anyone who has a sufficient command in mathematics, which generally is the case for theoretical economists.

The existence of a software that supplies functionality in lines discussed above, combined with the existence of a CD that accompanies the book, open up possibilities for the strategy to be followed in the organization of our presentation and analysis of the model. As mentioned above, our software not only keeps and visualizes the parameter and initial value settings of particular experiments, but also generates a broad range of output time series ranging from firm-level to country level (both in ASCII text format and as formatted Microsoft Excel charts). The majority of the experiments presented in this dissertation are control experiments, in the sense that each is based upon many simulation runs that are differentiated in terms of controlled variations over a small subset of selected parameters and also with respect to variations of the seed of the random number generators of the software which introduce stochasticity into the model. Naturally, each individual run generates a high number of time series on different indicators. While the reader can find these detailed time series (as well as firm-level panel data) on the accompanying CD, the analyzes and discussions presented in the dissertation are based on selected statistics, charts and tables that summarize and highlight the essence of the underlying control runs together in a comparative sense. In addition to our control experiments, the interested readers can also find in the accompanying CD a number supplementary simnlation runs as well as further discussions that are complementary to the experiments and discussions presented in the dissertation.

The organization of our presentation is based upon the order and change duality. As discussed before, in typical evolutionary formulations, while the stochastic introduction of subsequent micro-level disturbances is responsible for bringing about change, selection tends to lead the system to more orderly states. In our formulation, change is basically induced by firm-level incremental advances in technology coefficients. Accordingly we start our presentation with first ruling out technological change and focusing in the emergence of order in the context of economic selection. In doing that, we first present the core selection module of our model in chapter 3 , which specifies the infrastructure of the artificial economies speciffied by our formulations.

In chapter 4 we provide a number of analytical exercises (i.e., reduced form equations) that describe the expected behavior and macroeconomic properties of our selection based economy at states which can be referred to as steady state or equititrium. These exercises on the stationary fundamentals of our core selection module are based ex ante on the presumption that in case of no technological 
change (i.e., fixed production coefficients) our dynamic process tends to converge to an equilibrim-like point where observable change at the aggregate level stops. Naturally, the next logical step is to verify the validity of this assumption by accual simulation runs. Or in other words, one needs to answer questions as "In the absence of technological change, does our dynamic system indeed eventually converge to some point?", "If yes, how close is this point to the one predicted by our reduced form equations, and in what ways/extent dio various parameters and initial conditions affect this proximity?", "What are the properties of such fixed-points in terms of employment, output level, international trade flows and specialization?" and "How stable is the point of convergence against external disturbances?" In order to answer such questions we have designed and run a high number of simulations ${ }^{93}$. In chapter 4 we summarize the outcomes of these verification efforts both in terms of closed and open economy settings. We also compare and contrast our findings with those of a number of relevant mainstream formulations.

In chapter 5, the building blocks and the formulations of our techological change module are presented. In chapter 6 , we will focus on the consequences of techmological progress (in most cases, generated endogenously) for economic growth and international trade. The chapter can be seen as a logical follow-up to chapter 4 , where the steady-state properties of the model were analyzed in situations without technological progress. That is, generally by assuming away micro-level heterogeneity that is central in evolutionary models, we will keep the emphasis still on situations that are relatively tractable. Our objective in doing so is that in the chapter 6 , we wish to show how a number of particular features found in existing models and theories (most of which can be characterized as "mainstream") can be reproduced by our rather broad model which encompasses a number of theories and models found in the literature, and how our model produces additional insights not very common in the literature.

Following these simplified experiments which ignore the possible direct effects of competition (or economic selection) on industrial dynamics, in chapter $\bar{\tau}$ we turn our focus to firm-level heterogeneity and interactivity as importiant determinants of level and variations (over time, sectors or countries) in performance at the macro-level. The experiments and discussions presented in this chapter basically brings out the importance of the explicit (i.e., agents-based) modeling of firm-level dynamics. We show how the model can generate specific stylized facts of industrial organization found commonly in the literature, and we focus the discussion on how the self-organization-based industrial organization dynamics are related to macroeconomic properties such as economic growth, especially where various dynamic increasing returns mechanisms, such as learning by doing or scale effects in R\&D efficiency, and/or various externalities such as knowledge and technology spill-overs between the firms are in action. In the second part of chapter 7, we extend such lines of investigation to the context of international trade by introducing multiple countries and multiple sectors, while maintaining the model settings in terms of firm heterogeneity and micro dynamics. In this part of the analysis, which concludes the simulation experiments in the dissertation, we show how micro dynamics interact with macro results in the specific case of analyzing the relationship between specialization and economic growth.

In the concluding chapter (i.e., chapter 8) we will present final remarks on our modeling and analysis effort, and also make a brief discussion on the potential future prospects of our model. 


\section{Notes}

1. in Dosi et al [1988b], p. 3 .

2. In his explanation, Schumpeter [1939] asserts that major innowations followed by a host of imitations give rise to an investment boom, and when the innowations are fully exploited or over-exploited, the economy relapses into a recession and even a depression until new ideas re-introduce an euphoric climate of a new wave of innovating investments.

3. i) There are many firms in the market economy,

ii) discoveries differ from other inputs in the sense that many people can use them at the same time,

iii) it is possible to replicate physical activities,

iv) technological advance comes from things that people do,

v) many individuals and firms have market power and earn monopoly rents on discoveries.

4. Mainly referring to his 1986 model and Lucas [1988], where technology is provided as a side effect to private investment decisions yet from the end users' point of view it is still a public good.

5. The reader can also find in the accompanying $C D$ an appendix (in the file /Appendices/Chap2App.pdf), where we discuss a number of shortcomings and restrictive properties of the mainstream modeling framework in higher detail.

6. One can argue that in the short/medium run production in the majority of industries are characterized by complementarities among production factors (fixed or rather inflexible factor input coefficients), the conditions of which can only be changed by costly research and development activities (technological change).

7. For example, consider the stylized facts observed by various research in the fields of technology studies and history of technological change are: i) The rates of technological change have not been regularly distributed over time: there have been rapid and slow episodes. $2 i$ ) There have been key technologies (steam power, information technologies etc.) that affect the technological progress in others, and the emergence of such technologies can to some extent be associated with the irregularity of the overall technological progress. $i i i$ ) The diffusion of new technologies is much slower than instant and the process goes together with further developments in the diffusing technology. iv) In the development of new technologies the progress path sometimes come to a crossroads, where alternative trajectories can be chosen. The potential offered by the alternative trajectories are often not: foreseeable ex ante, and the path actually taken may turn out to be suboptimal (compared to the known alternatives) ex post. Nevertheless, due to locking-in effects, sometimes it is not possible to jump to or start all over again along the seemingly optimal trajectory.

8. In the biological counterpart, the environment surrounding each species or individual organism is partially exogenous (like weather, natural supplies, meteorites etc.) and partially determined by the existence and distribution of other surrounding species or individuals endowed with various traits and competing for (partially or exactly) the same resources. As claimed by Dawkings [1976] genes (which carries the blueprint of the traits of the individual living creature or more generally the species that the individual belong to) selfish in terms of its unconscious desire to create as many copies of itself as possible, brings about competition among the genes, revealled as competition among their beholders which are endowed by different combinations of traits, each trait coded by a set of underlying genes.

9. I.e., foxes overfeed on rabbits, the decreased number of rabbits fail to sustain 
the fox population so foxes begin to die, with this decreased number of predators the rabbit population start to increase which is followed by the increase of the fox population. The process repeats itself in cycles.

10. I.e. loxes eat all the rabbits, and then become extinct by starvation.

11. It is possible to carry on using this metaphor to revisit the logic of Solow growth model and also the new growth theories. For the former, consider that; after taking the essential steps to maintain equilibrium, the creator decides not to keep the grass availability at a fixed level and make arrangements such that it grows by a fixed rate throughout the experiment. The creator might then observe (after a certain time) that the rabbit and fox populations keep on growing steadily with at fixed (and balanced) rate.

In a last set of experiments the creator decides to engogeneize the grass avallability and growth rate, by making it a function of the droppings and the dead bodies of the animals, which function as fertillizers after decomposition. Therefore, increases in animal populations feed back to the system as increased opportunities to feed and/or reproduce as an externality. In this set of controlled experiments, the creator may again observe steady state growth paths, the growth rates through which depend on the sensitivity of grass growth on amimal remains and also the initial conditions (grass availability and initial populations). The creator also realizes that the egoistic rationality she has built into, is not sufficient for the animals to realize the feedback system (the externalities with regard to reproduction) and she verifies with further experiments that by decreasing the appetite of both animals for food and increasing their urge to reproduce, she can observe higher rates of steady state growth rates for all populations.

12. Regarding the processes that generate order from disorder and maintain it, the most important reference to be cited is the work of Prigogine [1984]. In his seminal book "Order Out of Chaos", Prigogine discusses such process in the context of selforganizing, dissipative systems, which generate and maintain order at the expense of (by wasting) energy over the optimal (or normal) needs of the system. The emergence of relative order comes about in the form of emergent, unintentional (spontaneous) macro-level regularities, along with prevailing dynamism, change and heterogeneity in the micro-level.

13. Of course, unless she intervened in the mutation processes, this would not be guarenteed at all, though it remains a possibility.

14. For example, a slightly light sensitive tissue observed in some species, evolves to be the perfectly designed eye of some latter species.

15. See Dosi and Nelson [1993] and Silverberg [1988] for comprehensive overviews.

16. Excerpt from his talk "What Economist Can Learn from Evolutionary Theorists", given to the European Association for Evolutionary Political Economy, November 1996. A link to the full text can be found at wwwecon iastate edu/ tesfatsi/aintro.htm, which is a web site on agent-based computational economics maintained by Leigh Testatsion.

17. As discussed in the literature by technological studies, this search processes take place along technological (or scientific) paradigms (or trajectories), where search and progress is highly localized, gradual and cumulative, which is reminiscent of the locality, graduality and cumulativeness of mutations and progress in natural life, despite the dominance of randomness that lie underneath.

18. See Dosi et al. [1996] for a thorough discussion.

19. Of course, unless one resorts to theology.

20. For example, an epidemic mutation that would suppress human's greed to exploit world's resources mindlessly, would make every creature on earth (including 
humany better of:

21. i.e. Given the complexity of the processes that link genes to phenotypes, the outcomes of the highly local and random mutation process can easily be considered to be as local optima, compared to what might have been. This argument becomes even stronger, when one considers the fact that the others" characteristics and thus the selection enwromment does not remain unchanged, while mutations change the characteristics of the individual (or species) in question.

22. Which is reduced to a matter of necessity of optimality by the mainstream economics (by its perfect competition and constant returns assumptions), except: for cases where dynamic increasing returns prevail.

23. In the economics counterpart one may ask whether the best possible selection unit is a technology, a (strategic) behavioral element, a decision rule or procedure, a. firm, or an industry.

24. Thus, it is not easy to make an analogy between species (in biology) and industries/sectors (in economics).

25. For various taxonomies and according surveys on evolutionary models on economic growth see Silverberg [1988] and Silverberg Verspagen [1995b].

26. The notation draws on Silverberg and Verspagen [1995b]. As further discussed in this reference, while the original form of the replicator equation describes the dynamics of relative shares (which take place on the unit simplex $S^{\text {pr }}$ ), an equivalent variant of this basic formulation (by Lotka [1925], and Volterra [1930]) specifies growth dymamics for the absolute populations.

27. Known as Fisher's Fundamental Theorem of Natural selection.

28. In this sense, one of the often-used abstraction in models of evolutionary economics is the reduction of a high dimensional fitmess space (for example price, quality, delivery speed etc) into a single fitness indicator.

29. For example, the taking over of the fittest characteristics (species), foljows a diffusion-like pattern (i.e. S-shaped or logistic curve).

30. Such as the market share of a firm or the frequency of the adopters of a technology, or producers of a product, etc.

31. Evern in non-stochastic models, one can still talk about (deterministic) path dependency, that refers to the dependence of system evolution on the initial conditions.

32. To be more precise, asymptotical convergence levels, which are stable in Lyapunov sensie.

33. For example as in Amable [1992] and Metcalfe [1994].

34. For another major line in evolutionary economics known as the evalutionary game theory, which basically replaces the perfect rationality assumptions of the standard game theory with varions formulations of bounded rationality and learning. the unit of selection is a strategic behavior rather than a technology or production technique.

35. As in the Silverberg and Lehnert [1993] model which is coupled with a stochastic discovery process.

36. Such as replicator equations, explicitly formulated Markov processes (that reduce to differential equations for the time rate of change of the probability distributions over the states), Polya urn processes, and other "macro" evolutionary models resorting to reduced form formulations such as the Verspagen [1993] (which, as discussed in the previous chapter, specifies an industry as the basic unit of selection in the international competition arena), Conlisk [1989] and Metcalfe [1988] (both of which explore the growth implications of selection, the former with stochastic technological change, the latter only as confined to a set of given technologies). 
37. Similar to the ambiguity of the genotype-phenotype link in biology that (as discussied before) arises due to the fact that genotypic characteristics are not the only determinants of phenotypic characters, which are those that are directly exposed to the actual selection forces.

38. Such as firms, customers, traders, intermediaries, financial institutions (economic agents) or government, land etc. (agents representing environmental phenomena) or observer/aggregator agents which collect information from other agents and produce aggregate variables/statistics for the modeler and/or as feedback to the other agents.

39. i.e. the ways in which an agent collects (emits) information from (to) its own enviromment (other agents) and utilizes these to make adaptive decisions and to shape the according behawior.

40. Where the initial size of (each) population is specified by the modeler.

41. Since, the approach is based on heterogeneity, the initial values of individuals' state variables and parameters are mastly set according to some (probabilistic or deterministic) distribution or pure randomlly.

42. Which constitutes a challenge despite the flexibility. Normally analytical approaches involve decompositions that seek for subsystems, the behavior of which are easier to comprehend in isolation, find the patterns of interaction among the subsystems and describe the workings of the larger system. Yet, as in the case of relativity and quantum physics, the complexity (or confusion) does not clear away by going towards any end (i.e. human cognition and behavior is a universe within itself). The realism of any agent-based model is directly determined by the proximity of the modelled behavior to that of agents in reality. Yet our repertoire of empirical regularities in individual behavior (micro stylized facts) and accordingly our modeling toolbox are currently quite limited. Accordingly, the behavioral specifications in agent-based models are sometimes criticized as ad hoc. Nevertheless, a good deal of agent-based models introduce some learning module (mostly drawing upon genetic algorithms or classifier systems), which let behavior emerge (individually or globally) through learning, co-learning or even learning to learn, instead of imposing it on the agents.

43. A purely conceptual outcome of the key assumptions of the mainstream framework, which can not be introduced exactly in a framework where a finite set of explicitly defined agents exist and evolve through the irreversibility and essential uncertainty brought about by the arrow of real time. In other words, the essential steps of the perceptive and cognitive processes (i.e. the ways in which agents collect information, the types of information collected, and process through which these are processed and made useful) underlying rational behavior is not specified.

4. Even if the system is at equilibrium, how can an individual agent perceive that it is equilibrinm and safely assume and base its behavior on the ceteris paribus assumption?

45. Even the most sophisticated state of the art forecasting tools available to economists fails to accomplish the task. The problem remains simply too complex.

46. In the same talk ("What Economist Can Learn From Evolutionary "Theorists" ${ }^{31}$, from which the previous excerpt is extracted, Krugman cites the work by William Hamilton titled as "Geometry for the Selfish Herd", where the instinctive urges of frogs to locate themselves close to other frogs (in order to minimize their chances to be eaten by a predator) is presented as the optimum outcome of the evolutionary process.

47. For example, some unlucky event or wrong strategy followed at a certain point in time $t$ may have long lasting effects on the options, belhavior, and success of a 
firm in times $t+n$, where $n$ can be quite large.

48. i.e. is path dependence also prevalent in an aggregate magnitude, and if yes how does one detect its existence and the individual events that dommate the rest of the exolution?

49. Otherwise, all simulations should have started from the Big Bang or Adam and Eve.

50. Though the exact working of the complex self-organization/co-learning processes that lead to macro-level emergence remain rather obscured (black-boxed) within the multiplicity of computations that take place in the computer.

51. For example, spectral anallyzes (as used by Silverberg and Lehnert [1993]), which decompose time series to cyclical components of various frequencies.

52. For the parameter/initial condition vector $\left(p_{1}, p_{2}, p_{3}, p_{4}, p_{5}, I_{1}, I_{2}, I_{3}, I_{4}, I_{5}\right)$, the set of all possible combinations \{low, low, low, low, low, low, low, low, low, low), (medium, low, low, low, low, low, low, low, low, low), .... (high, high, high, high, high, high, high, high, high, medium), (high, high, high, high, high, high, high, high, high, high)\} has $3^{10}$ elements.

53. For example, an agent based simulation of a bank teller line (a queuing model), where customer arrival times and service times are stochastic.

54. The example given by Axtell for this category are the models of traffic that focus on the emergence distributions of congestions. It is known that differential equation models that draw on fluid mechanics fail to address the observed nonstationarity in raffic flow rates on highways. Yet agent based models, which rely on simple driving behavior (such as go from $\mathrm{A}$ to $\mathrm{B}$, do not touch other cars, take over when possible etc. J are shown to generate autonomously non-stationary flow rates similar to those observed in reality. Occasionally such non-stationarities extend to extremities such as traffic jams, which are demonstrated (by agent-based simulations) to be triggered by changes in the inflow and outflow rates of joining and leaving vehicles.

55. As in Operation Research applications.

56. For example Epstein and Axtell [1996] and Arifovic and Eaton [1995].

57. For example Tay and Lin [2001], build a model of fuzxy logic based inductive reasoning through a so-called genetic-fuzzy classifier system.

58. One can easily observe the qualitative difference of such a result from those emerging from the "how to make money on the financial market?" type literature or the literature which are built on the assumption that the financial markets are efficient im terms of forecasting firm competence and/or future (relative) returns on assets of individual firms.

59. Such as completely connected, locally connected/disconnected and small-world networks.

60. For example, the building up of habitual or trust-based relations between buyers and sellers, who determine their trade partners and their behavior towards those adaptively.

61. The process through which any two agents run across each other.

62. Does the matching of two parties result in a transaction, partnership or information How?

63. Such as mutual trust or expectations toward the possibility of fruituful transactions in the future.

64. Metaphor due to Tesfatsion [2002].

65. Even if accomplished up to the model building stage, enormous complications would arise in terms of the exploration and analysis of such a model.

66. For example, the conformance of aggregate magnitudes to the standard macro- 
identities (such as saving-investment, balance of payments etc.).

67. Within this Leontief type specification, naturally instantaneous substitution between labor and capital is out of question.

68. i.e. the techniques that are used by a relatively higher number of firms, have a higher chance to be adopted by imitation.

69. Defined through a diamond metric in the two dimensional technological coefficlent space (under a logarithmic transformation). The skewness of this distance function is controllable by the parameter settings of the logarithmic transformation, in order to introduce labor or capital bias in search.

70. I.e. The main source of growth is technological change which relaxes the labor constraint of the economy, all firms produce a single homogenous product (GDP) while they are heterogeneous in their production technique, firms produce at full capacity and all produced output is sold instantaneously at the market price 1.0 (which is the numeraire of the system), firms select better technologies while this genotypic choice translates into firm profitability differentials as phenotypic characters, over which the selective forces of the market operate, etc.

71. At any given time instant, a firm may make production by more than one type of capital vintage.

72. which is an integral part of the genetic algorithm of learning.

73. The increment is withdrawn from a normal distribution with mean zero. Thus, the change may imply a decrease as well.

74. Note that the Silverberg and Verspagen [1995a] model is also enriched by a financial market specification (which draws on Soete and Turner [1984]), which redistributes total profits in such a way that more (less) profitable firms can accumulate capital even faster, than would of herwise be the case.

75. For example in Silverberg and Verspagen [1995a], the formulation is given as $\widehat{w}=-m+n v$, where $\widehat{w}$ is the growth rate of the real wage rate, $v$ is the employment rate (i.e. endogenously determined aggregate labor demand divided by the exogenously determined labor supply), $m$ and $n$ are parameters.

76. As imvestigated by Lotka [1925] and Volterra [1931], the predator-prey dymamics addresses the relation between the population dynamics of two interdependent species living in an ecosystem. For $x$ being the total prey and $y$ being the total predator population, the non-linear dymamic system consists of two difierential equations similar to $\frac{d y}{d t}=a x-b x y$ and $\frac{d y}{d t}=-c y+d x y$, where the parameters $a, b, c, d$ are all positive. These equations imply that if there is nothing for the predators to feed upon (i.e. for $x=0$ ) the predator population decreases exponentially at the rate $c_{3}$ and similarly in case of no predators in the ecosystem (lon $y=0)$, the prey population grows exponentially at the rate a. This equation system generates, for each initial value combination of $x$ and $y$ a different trajectory which is always a closed orbit (on the phase plane) around the fixed point of the system (i,e. $x=\frac{c}{d}$ and $y=\frac{a}{b}$ ). In other words, the oscillations of the state variables $x$ and $y$ are persistent (i.e. do not dampen or converge to the fixed point). Accordingly, one observes the indefinite recurrence of a succession of various phases during which population sizes both increase, both increase, or move in opposite directions.

77. In formulations in economics, the employment rate acts like the prey and the wage rate as the predator. In case of zero employment, wage rate exponentially converges to zero and when the wage rate is zero employment exponentially goes to infinity. "The system basically suggests that income distribution determination is the dynamic ontcome of the class struggle between workers and capitalists and is characterized by permanently oscillations. 
78. Thus, price mark-up is an additional strategic decision made by each firm jndividually.

79. i.e. basically in terms of market share dynamics and accordingly the diffusion patterns of competing technologies.

80. A firm exits if its market share fall below a threshold level.

81. i.e. including the one which assigns entrants the initial labor productivity level, which is equal to the average labor productivity attained in the country, as opposed to the world average.

82. i.e. none of the countries accumulate excessive amounts of intermational debt, nor the total number of workers employed significantly diverges from some constant level.

83. i.e. excess demand (supply) brings about a relative appreciation (depreciation) of value/price.

84. Note that the case is not too different for the Nelson and Winter [1982] and Silverberg and Verspagen [1995a] models, which specify disequilibrium dynamics in their labor markets by a dynamic Philips curve formulation. The according disequilibrium dynamics (which lead to persistent oscillations in employment and wage rates as in Goodwin [1967]) hardly contributes anything to the emergence of the phenomena explained. However, the Philips curve formulation of the labor market, nicely imposes the labor constraint upon the models and relates real wage dynamics to employment and productivity in a way consistent with empirical realities.

85. I.e. as discussed in the previous chapter, the self-reinforcing process which is referred by Krugman as "like a river that digs its bed deeper".

86. In the single commodity settings of Nelson and Winter [1982] and Silverberg and Verspagen [1995a] models, the determination of unit prices is naturally not an issue, sunce (thanks to the assumption that takes competing products as perfect substitutes) unit prices are assumed to be identical for the output of all fims and this single price is taken as the numeraire.

87. i.e. smaller firms can sell their output at relatively higher prices than those asked by larger firms.

88. For example in Silverberg and Lehnert [1993], the periodicity of Goodwin cycles are found to be much higher than that of the technological change inflicted long waves.

89. This dichotomy is addressed by various scholars (as Baumol [1962], Rosenberg [1971], Simon [1962] etc.) with the conclusion that in modelling exercises, revenue maximizing is a more preferable assumption than profit maximization. Furthermore in a technical sense, profit meximization behavior implies a negative relation between market concentration and industry output, which is the main reason underlying the neoclassical insistence on assuming an unrealistic industrial organization structure as perfect competition in general equilibrium models where each sector reduces to a profit constrained output maximizing entity

90. i.e. In this version of our model we do not allow money creation by banks (as assumed by Dosi et al. [1994]) and accordingly confine financial resources to the total profits (dividends) of the economy which is redistributed back to firms through the financial system.

91. Optionally, the user can also have the software only plot sampled time series (i.e. the selected output variables are plotted only once in every $S$ periods where $S$ is determined by the user).

92. Note that there have been various efforts (though limited in number and scope) aimed at making-up of such shortcomings. For example, an evolutionary model- 
building and experimentation platform LSD (Laboratuary for Simulation Development) developed by Marco Valente allows users (among its other various functionalities in simulation development) to develop and analyze industry dynamics models that draw on Nelson \& Winter [1982]. Similarly, a Java applet developed by Murat Yildizoglu also implements the Nelson \& Winter [1982] model and lets its users to experiment with a collection of parameters and understand the underlying evolutionary dynamics.

93. Specially focusing on issues such as firms' investment behavior, institutional settings of labor markets, capital embodiedness of productivity differentials, increasing returns to scale (internal or external to individual firms), product heterogeneity (i.e, demand for variety) and quality. In open economy settings, we address various issues on adjustment dynamics in international trade and specialization on the basis of given labor productivity, quality and capital intensity differentials (across sectors and countries), for varying extents of demand for variety. 


\section{The core: a supply side multi-country/sector model of selection}

\subsection{Introduction}

As mentioned in the previous chapter, in the most basic terms, our model (which can also be referred to as an experimentation platform) can be seen as a multicountry, multi-sector variant of the Nelson and Winter [1982] model and/or various other evolutionary models of growth (especially Verspagen and Silverberg [1995a]) which follow the Nelson and Winter modeling framework, where the main focus is on the heterogeneous firms and the emerging results of aggregating their actions. Accordingly our primary objective in this study is to observe the ways in which a selection-based multi-firm setting may address to several issues/ideas in international trade and economic growth which are dominantly addressed within the equilibrium and/or steady state based framework of the mainstream economics.

As discussed before, the distinguishing future of the evolutionary philosophy is its special emphasis on the very processes of change, especially in cornparison to mainstream economics where the characterization and analyzes of economies are confined to hypothetical stiates of order and regularity (be it equilibria or steady state accumulation). Models in evolutionary economics, often bring forward various dimensions of technological change and learning as the main forces that bring about change in the micro (indiwidual agent) level, and observe the emergent patterms of change in the aggregate level (sector and/or overall economy level). Of course, in a system characterized by incessant micro level changes, potentially anything can happen. Yet, the second major component of the evolutionary thinking, which is selection, works as the underlying intelligence (i.e., meta-rationality) of the system by eliminating some of the varieties generated by the micro level processes of change, leaving behind some others that have the potential to contribute most to the objectives of the system (i.e., mainly higher levels of welfare). If this latter process (selection) ceases, the system can go anywhere, and if the former process (i.e., variety generating micro level change) stops selection may gradually take the system to a fixed point (similar to the equilibrium of mainstream economics), where nothing happens anymore. Accordingly, the dynamics of the resulting system is determined by the complex interactions of these two opposing forces. 
Throughout the rest of the book. we will follow a scheme where our evolutionary experimentation platform will be presented gradually by step-wise introduction of its various features. In this and the next chapter, we start by ruling out any processes of micro-level variety generating change (i.e., no technological change) and merely discuss the part of our model that characterizes the selection process acting on given distributions of firm-level heterogeneity in levells of fitness, imposed as initial conditions, In the next chapten", we will analyze the macroeconomic consequences of this basic selection module in case of closed and open economies, in relation to the static trade models of the mainstream economics, and introduce technological change only from chapter 7 onwards.

As discussed earlier in chapter 2, within a highly broad classification, one can observe in the evolutionary literature on growth (and trade) two alternative formalizations for selection: The oftern-observed characterization draws upon the replicator dymamics as formulated wia various variants of the basic Fisher equation of natural selection, where the price at which a firm sells its output is specified as the solemn determinant of fitness. In this family of models, prices are generally specified as unit costs plus some profits determined by a fixed mark-up over unit costs. Thus, firms" fitness and accordingly the selection mechanism is indirectly linked to unit costs. A salient example to this line of formulation is Dosi et. al [1994].

As also discussed in chapter 2, the second lineage is the "predator-prey" type formulations. In this family of models, where one assumes whatever produced is instantly sold (i.e., no excess demand or excess supply), firms are specified to be price takers, and given this single market clearing price and the wage rate determined according to a Phillips curve on the basis of total labor demand, the profit of each firm determines its investment level according to the simple "all positive (negative) profits are invested (disinvested)" rule. Thus, the firms that produce with unit costs higher (lower) than the market price see their capital stock and equivalently their output level and their market share grow (shrink). The predator-prey characteristic of these models essentially lies in the formulation of the labor markets, which imposes the overall labor force constraint indirectly via a dynamic Phillips curve representation". That is, as the firms tend to invest and expand, and total demand for labor consequently increases, workers gain further bargaining power for higher wages and claim a higher share in output (i.e., lower profits) which puts a break on investment. This set of models generally endogenously generate sustained oscillations ${ }^{2}$ around full employment and also in wage rates, in the share of total wage bill in GDP, and in investments, which is isomorphic to the oscillations in population sizes observed in the predator-prey type models of evolutionary biology. Nelson and Winter [1982], Silverberg and Verspagen [1995a] and Silverberg and Lehnert [1993] are salient examples to this sort of formulation.

Clearly, both formulations implicitly assume clearance in good markets (i.e., total demand equals total supply of goods). For both formulations, the selective forces of the economy work in the similar way and the implications of the selection process (i.e. changes in firms' output levels and accordingly their market shares) come about gradually. The gradual nature of the selection process postpones what is inevitable (i.e., least costly firms take ower the market while the costly ones leave the market), so that thanks to the technological change process that goes simultaneously with the selection process, the less fortunate firms can recover by lucky innovations after going through a tough period/coming to the brink of perishing forever. 
Albeit these seeming similarities of these two methods in terms of the outcomes of the selection mecharism implied ${ }^{3}$, they are highly different with respect to the underlying micro-foundations and causal links. The replicator formulation has a purely demand-side basis. In these set of models, prices are often determined through mark-up pricing over unit costs ${ }^{4}$ and no apparent supply-side reason can be conceived as to why relative growth or shrinkage (market share dynamics) of a firm would be related to its unit costs relative to that of others. Furthemore, the specification of the market share dynamics is also inconsistent with the mainstream microeconomic theory of demand ${ }^{5}$. The replicator dynamics, instead, suggest a gradual evolution of relative demand for each firm (market shares). In other words, even if the prices would remain unchanged, day by day, customers demand more and more (less and less) of the relatively inexpensive (expensive) products. The only meaningful explanation for this process is customers' learning: At a given point in time, relatively expensive firms may enjoy a non-zero market share only due the imperfection of information that customers hawe on the existence of cheaper products. Yet, as time goes by, customers find out about the cheaper products and divert their purchases accordingly. Such a causation that simply assumes that demand somehow creates its own supply, is absolutely devoid of any investment-wise underpinnings and obviously fails to clarify neither the process through which individual firms find out about the extents of the excess demand for their own output, nor the (investment/production planning) process through which they update (or finance) their output accordingly.

On the contrary, the predator-prey type models of growth are supply-side oriented, in the sense that their underlying workings assume a well-defined theory of firm-level investment: "all positive (negative) profits are invested (disinvested)". This may be seen as quite an agreeable first approximation to an agreeable general theory of firm level disequilibrium investment behavior, which unfortunately does not exist in the mainstream economic literature that is focused only in equilibrium (dynamics). Agreeable as it may be, such a theory implies a major diversion from the general incentive schemes suggested by the mainstream economic theory. In terms of its consequences in the aggregate level, the firm level profits are invested rule implies financial institutions that tend to invest all profits (which constitute the savings of the societies) without considering its potential implications on future stream of profits. It is clear that ceteris paribus (i.e., no technological change) a fixed point of the predator-prey type selection process is where profits are zero for every firm. Yet the important question is "why would the capitalists keep on investing on capital, which would eventually push the output prices (relative to nominal wages which tend to increase as demand for labor increase by further investments on capital) and accordingly profit rates down?" 6 . In other words, investment is naturally a sacrifice of current consumption for higher amounts of consumption output of the future will be consumed by the workers, they have little or no incentive to invest on further growth.

One of the objectives of our modeling exercise is to address issues of growth together with issues on international trade in a multi-production factor (labor and sector-specific capital) setting. In our supply-side focused framework, we adopt a selection process formulated in a way similar to that in the predator-prey type evolutionary models of growth. Yet in our adoption, we take an additional step and try to enrich the standard "all profits are invested" rule by specifying firmlevel investments as an outcome of the interaction of firms" individual demand for growth, and the overall evaluation of central fimancial markets. 
In summary, the selection environment we specify in our discrete time simulation model (where each period is referred to by the variable $t$ ) is built upon the simultaneous workings of three different markets. In the central goods market; market clearing (firm level) prices are determined (via inverse demand functions) at every period $t$ of our discrete time model, as a function of the lewel and the (firm level) clistribution of output in all industries. Similarly, output levels, together with firms' labor coefficients (which can be made heterogeneous over the firms) determine the total labor demand. In the labor market, the share of the total wage bill in the national income is determined as a function of employment rate and institutional settings. Given (firm-level) prices and the wage rate, the profits of each firm are determined. Firms that suffer losses, sell an according part of their capital stock (defined as capacity units) to the second hand capital markets. On the other hand, the positive profits (which constitute the savings of the country at period $t$ ) are collected and paoled by the capitalists (in terms of diviclends). "The firms that make positive profits evaluate the current situation and decide on how much they want to grow. Based on this firm level demand for growth and the current performance (profitability) of the firms, the capitalists (through the financial markets) redistribute a part of the collected pool of profits ${ }^{7}$ back to firms. Depending on the magnitude of these credits, firms release their orders for new capital goods. The production of capital goods ${ }^{8}$ and their installation upon the existing stock are assumed take one period. Thus, the productive capacity of a firm at period $t+1$ is equal to its capacity at period t times one minus the depreciation rate, plus the new capital increment that is ordered before, as financed by the credits granted by the financial market (at period $t$ ).

"The main (i.e. non-reproducible) input to production is labor, which is assumed to be homogenous. Labor units are assumed to be perfectly mobile among the various sectors within a country, while being absolutely immobile among countries. At a given period $t$, the labor demand of each firm is determined as by its labor coefficient and productive capacity.

Production also requires capital, which is defined to be sector specific (immobile among sectors) and immobile among countries. Contrary to labor, capital is reproducible and thus is not defined as endowment. Despite the existence of two production factors, we do not specify or use any two-factor (continuous) production function as used in mainstream models. In our formulation, capital is defined as productive capacity and is measured in terms of the units of output, the production of which it makes possible (i.e. in order to produce $n$ units of sector $i$ output a firm needs $n$ units of sector $i$ specific capital). Thus, the capital intensity of production in a sector $i$ at period $t$ is determined by the unit price (production cost) of the sector is specific capital goods at period $t$, which, in our dynamic setting, can also be seen as the incremental capital output ratio in sector $i$ Needless to say, for a given amount of financial credits (or profits), the incremental capital output ratio is an important determinant of firm growth (i.e. units of capital invested is equal to credits/profits divided by the purchase price of capital). Thus, in order. to grow with the same rate, a firm of a more capital intensive sector (where the incremental capital output ratio is higher) needs to make more profits than a firm of a less capital intensive sector).

For each given parameter setting, the model can be run for either the case of antarky on the case of international trade. In case of autarky, each country has its own goods markets. In case of trade (where the products of all sectors are assumed to tradable), we assume a unified world market for each sector $i$ separately. 


\subsection{The basic workings of economic selection}

\subsubsection{Production, labor markets and labor costs}

Let the variable $Q_{k i j}^{t}$ denote the output of firm $k$, and $N F_{i j}^{t}$ denote the number of firms producing good $i=1,2, \ldots, N G$ in country $j=1,2, \ldots, N C$ in discrete time $t=1,2, \ldots, T$. The sector $z$ aggregate output of country $j$ at period $t$ is

$$
Q_{i j}^{t}=\sum_{k=1}^{N F_{i j}^{t}} Q_{k i j}^{t}
$$

The factors of production are labor and capital. The technology used by the firm is primarily determined by its labor productivity coefficient $a_{k i j}^{p}$. Capitial is assumed to be sector-specific, capital stock of a firm is measured by its productive capacity, and each firm, at each period produces an amount equal to this capacity. In other words, one unit of capital is defined to be the capital composite which, combined with $\frac{1}{a_{k ; j}^{t}}$ units of labor, suffices to produce one unit of consumption output. Therefore, a firm $\mathrm{rm}_{k i j}$ produces $Q_{k i j}^{i}$ units of output at period $t$, if and only if it has access to $Q_{k i j}^{t}$ units of sector $i$ specific capital stock. Accordingly, a firm ${ }_{k i j}$, having the productive capacity to produce $Q_{k i j}^{t}$ unitis of output at period t, needs to employ

$$
L_{k i j}^{t}=\frac{Q_{k i j}^{t}}{a_{k i j}^{t}}
$$

labor units in onder to produce up to capacity.

We rule out any immediate labor rationing. Furthermore, workers are assumed to be perfectly mobile between sectors/firms of the same country though perfectly immobile among the countries. Thus, the equation above not only determines the labor demand of the firm but also its actual exmployment at period $t$. Given this, the total labor demand of the final good sectors of country $j$ at period $t$ (which, due to the absence of any immediate labor rationing, is also equal to the number of labor units actually employed by the final good sectors of country $j$ at period t) is

$$
L_{C o n s_{j} j}^{t}=\sum_{i=1}^{N G} \sum_{k=1}^{N F_{i j}^{t}} \frac{Q_{k i j}^{t}}{a_{k i j}^{t}}=\sum_{i=1}^{N G} \sum_{k=1}^{N F_{i j}^{t}} L_{k i j}^{t}=\sum_{i=1}^{N G} L_{i j}^{t} .
$$

However, the sector-specific capital sectors, which are responsible for the production of extra productive capacity (i.e., investments) and also for the compensation of depreciation on the existing capital stock, also contribute to the total employment in each country $j$. Accordingly, the total demand for labor in country $j$ at period $t$

$$
L_{\text {Total,j }}^{t}=L_{\text {Cons, }, j}^{t}+L_{\text {Tnvst, }, j}^{t-1}
$$

where $L_{\text {Trvst,j }}^{t-1}$ is the labor demand of the capital good sector of country $j$ which is determined at period $t-1$ yet realized at period 4 . The capital goods, the demand for which are determined, and which are accordingly ordered by the firms at period $t$, are produced only in period $t+1$. The determination of the level of new capital good production (i.e., the investments on extra productive capacity and 
the compensation of depreciation), and thus the motion of the variable $L_{l_{n: 2},-1}$ will be discussed later in this chapter (see equation 3.31).

As mentioned above, our formulation does not impose any immediate labor constraint that would ration labor and lead to the under-utilization of productive capacity. However, each country is indirectly subjected to a labor constraint. That. is, the totall labor force avallable to country $j$ is denoted by the variable $\overline{L_{j}}$, yet in our formulation which allows for overtme work, as well as unemployment, we do not forcefully impose equilibrium in the labor markets. Instead, we resort to a formulation similar to that used by evolutionary growth models which follow the predator-pray framework, where the imposition of the economy-wide labor force constraint on the model is indirectly achieved through a dynamic Phillips curve relation. Despite the similarity in its basic logic in our model we resort to a slightly different formulation, where we specify a constant (i.e, institutionally determined) increasing relation between employment rate and the share of total wage bill in countries" total nominal income $G D P_{j}$. Assuming a single wage rate $w_{j}^{t}$ at which all workers of the country are remunerated at period $t$, our basic specification follows a formulation as

$$
w_{j}^{t}=w_{j}^{t, M a x} \cdot W g S u p_{j}\left(E m p l R t_{j}^{t}\right)=\frac{G D P_{j}^{t}}{L_{C o n s, j}^{t}} \cdot W g S u p\left(E m p l R t_{j}^{t}\right)
$$

In this formulation $E m p l R t_{j}^{t}=\frac{L_{T o t a}^{t} L_{j}}{L_{j}}$ denotes the employment rate at period $t$. The function $W g S u p_{j}\left(E m p l R t_{j}\right)$, which is specified as

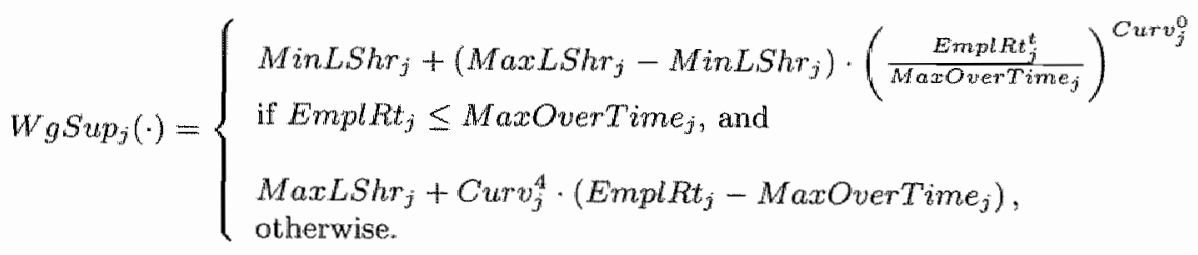

determines the share of total wage bill (income distribution) in the national output of each country $j\left(G D P_{j}\right)$ separately at each period $t$ as a function of the employment rate Empl $R t_{j}^{t}$ of the period in the country ${ }^{9}$.

In this specification, the parameter MaxOverTime $j \geq 1$ stands for the upper limit for the employment rate (including the overtime work), such that in the employment level range $[0$, Max OverTime $]$, the function $W_{g} S_{u p}\left(E_{j} m p l R t_{j}\right)$ exhibits a smooth and monotonically increasing pattern in the interval [MinLShr MaxLShr], the curvature of which is determined by the parameter Curvo (for $0<C w v_{j}^{0} \leq 1$ concave, and for Curv $v_{j}^{0}>1$ convex). The variable MaxLShr (MinLShr, stands for the maximum (minimum) level for the share of total wage bill in $G D P$. For example if one sets $M a x L S h r_{j}=1$, then MaxOverTime represents the employment rate at which workers can claim the whole GDP (which implies no profits at the aggregate level). For employment levels higher than MaxOver Timej, the share of total wage bill in GDP linearly increases (with slope Curv, and may assume values higher than 1 which implies negative aggregate profits (where the economy can not grow but only shrink due to disinvestment). Clearly these country-specific parameters together specify the institutional settings of the labor market of each country $j$ separately.

Figure 3.1 gives an impression ${ }^{10}$ of the function $W g S_{u p} p_{j}\left(E m p l R t_{j}\right)$ for the parameter $C u r v_{j}^{0}>1$. Under settings where the parameter $M i n L S h r_{j}=0$, the 


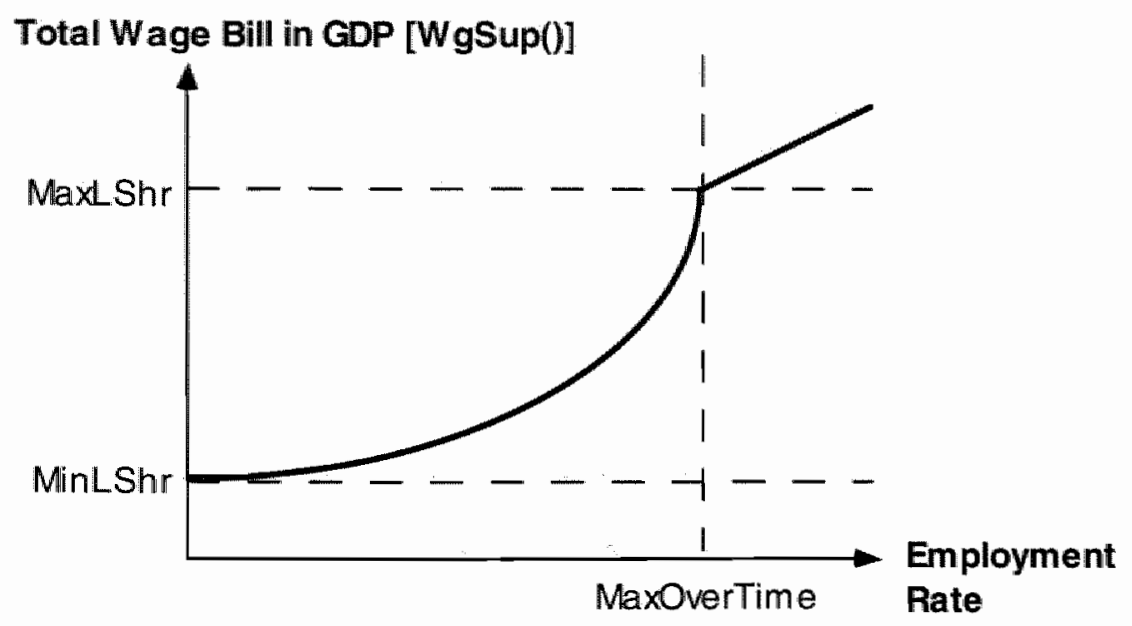

Figure 3.1. The function $W g S u p($.

wage rate $w_{j}^{t}$ defined in equation 3.5 is monotonically increasing in the employment rate $E m p l R t_{j}^{t}$, which is a desired property. 'Thus, in the discussions and control experiments presented in this dissertation, we always set $M i n L S h r_{j}=0$ and mainly manipulatie the prameter $C u r v_{j}^{0}$. As discussed in the following chapters, the parameter $C u r v_{j}^{0}$ can be interpreted as an inverse measure of (wage) elasticity of labor supply.

The functional form specified by equation 3.5 , decomposes the wage determination process into two parts: The first part is the calculation of the aggregate level "zero profit" wage rate $w_{j}^{t, M a x}=\frac{G D P_{j}^{t}}{L_{C o n}^{t} s^{t}}$. This instrumental variable denotes the hypothetical wage rate where the whole output is claimed by the workers of the final good sectors ${ }^{11}$. Besides, this part of the formulation which specifies wages through the share of total wage bill in $G D P_{j}$, makes sure that in settings characterized by labor augmenting technological change, real wages follow labor productivity increases immediately.

The second part of the equation 3.5 , which we refer to as the "wage suppression" function $W g S u p_{j}(\cdot)$, represents the institutional component and shows the aggregate level ability of the institutions in suppressing the wage rate down from the "zero aggregate profits" level. In other words, this function determines the income distribution of the national economy institutionally in relation to the employment rate. Besides, the function $W g S u p_{j}\left(E_{m p l} k_{j}\right)$ which represents the bargaining power of the workers, is assumed to be monotonically increasing in the overall employment rate EmplRt, as in a typicall Phillips curve relation. Although, due to the absence of any immediate labor rationing all firms can produce up to productive capacity, our formulation renders overtime labor quite expensive: The violation of the aggregate labor constraint (overtime work: $L_{\text {Total, }} \geq \overline{L_{j}}$ ) is penalized by the aggregate implication $W_{g} S u p_{j}(\cdot) \geq 1$, which implies aggregate level non-profitability, and renders any further growth of the overall output level (and accordingly of the aggregate demand for labor) infeasible. As will be further clarified later in this chapter, in our formulation where profits are assumed to be the only means of investment/output expansion and negative profits (negative 
investments/dissavings) imply shrinkage of output levels, the wage rate determination process described by equation 3.5 inhibits persistent violations of the labor force constraint.

Finally, since $w_{j}^{t}$ is the common wage rate that is to be paid by all firms independently of the sector in which they operate, the total labor cost of an individual firm ${ }_{k i j}$ at a given period $t$ is $w_{j}^{t} \cdot \frac{Q_{k i j}^{t}}{a_{k i j}^{t}}$ and the unit labor cost is $\frac{w_{j}^{t}}{a_{k i j}^{t}}$.

\subsubsection{The final good markets: Price formation}

As discussed before, our model heavily draws on the formulations of evolutionary growth models such as the Nelson and Winter [1982] and Verspagen and Silverberg [1995a] which assume that goods are perfectly homogenous and product market(s) clear. In more formal terms, the market price (given total output and nominal income) is determined via the inverse demand curve. In these single-sector growth models, there is not even the need to specify an inverse demand function and setting the market price to 1.0 (as the numéraire) suffices. However, for our model, which can be seen as a multi-sector, multi-country, open economies version of these seminal models, two features critically needed are:

1. The formulation of a proper inverse demand function which solves for a (firm-level) market-clearing vector of prices at every period $t$, given the period $t$ levels and distribution of output across firms, sectors and countries

2. The formulation of some mechanism that can impose the balance of payments constraint on the mutually-trading economies.

We have achieved these objectives by a formulation which draws on standard mainstream theories of demand: The final good markets (i.e consumption) and the foreign exchange markets are black-boxed (i.e. integrated) together in the form of inverse demand functions subjected to balance of payments constraints. The inverse demand module is based on well-defned utility/welfare functions. In doing that, we assume a separate representative customer for each country, the preferences and the behavior of which reflect the aggregate preferences and the consumption behavior of the individual customers of the country in question. The wellare functions specified for this purpose draws on the Dixit and Stigliti [1977] formulation used in various mainstream models of intraindustry trade (e.g. Krugman [1981b]), which is a composite of the Cobb-Douglas and the CES functional forms. It can easily be shown that, given the mathematical properties of the welfare function specified below, the choices of our representative agents are consistent with the choices of the customers they represent and thus the representativeness of these representatives agents remains intact with respect to aggregation ${ }^{12}$.

Let us present the broadest specification which allows for product heterogeneity (among the firms of the sane sector) in terms of qualities as reduced to a. single dimension, which allows for a cardinal ordering. Let the output of each individual firm ${ }_{k i j}$ be characterized by a single dimensional quality measure $Q w a l_{k i j}$, which is perceived by all customers in the same way independently of their income level. Accordingly, the period $t$ utility of the representative customer (or the total welfare) of the $j^{\text {th }}$ country in autarky $\left(U_{R, j}^{t, A u t}\right)$ is given by

$$
U_{R j}^{A v t}=\prod_{i=1}^{N G}\left[\sum_{k=1}^{N F_{i, j}}\left[Q u a l_{k i j} \cdot\left(C_{k i j j}\right)^{\theta_{i}}\right]\right]^{\frac{\alpha_{i j}}{\theta_{i}}}=\prod_{i=1}^{N G}\left[\sum_{k=1}^{N F_{i j}}\left[Q u a l_{k i j} \cdot\left(Q_{k i j j}^{t}\right)^{\theta_{i j}}\right]\right]^{\frac{\alpha_{i j}}{\theta_{i}}}
$$


while its utility at trade $\left(U_{R j}^{T+d}\right)$

$$
U_{R_{j}}^{T r d}=\prod_{i=1}^{N G}\left[\sum_{s=1}^{N C N F_{i s s}}\left[\sum_{k=1}^{N u a l_{k i s}} \cdot\left(C_{k i s j}\right)^{\theta_{i}}\right]\right]^{\frac{\alpha_{i j}}{\theta_{i}}} .
$$

As defined before, the variable $N G$ is the rumber of sectors, $N C$ is the number of coumtries and $N F_{i j}^{t}$ is the number of firms operating in the $i^{i t h}$ sectar of the $j^{\text {th }}$ country at discretely specified period $t^{13}$. The variable $C_{k i s j}$ is the part of the output produced by the $k^{\text {th }}$ firm of the $i^{\text {th }}$ sector of the $s^{t h}$ country, which is made available for consumption in the good markets of the $j^{\text {th }}$ country at period t. Each parameter $0 \leq \alpha_{i j} \leq 1$ (where $\sum_{i=1}^{M G} \alpha_{i j}=1$ ) indicaties the budget share which the customers of country $j$ allocate (on the average) for their sector $i$ purchases. Note that it is possible to differentiate each $a_{i j}$ among countries and introduce cross-country preference differences accordingly. The additive part of the CES form (i.e., $\left[\sum[\cdot]^{\theta_{i}}\right]^{1 / \theta_{i}}$, where $0<\theta_{i} \leq 1$ ) captures the demand for variety, or equivalently the extent of substitutability among the products within a sector. In cases where $\theta_{i}<1$, the product of every other firm ${ }_{k i j}$ is perceived by the customers as a different variety in sector $i$.

Clearly, the essential difference between our formulation and that used in a number of mainstream models is that our variant specifies a separate welfare func$\operatorname{tion}^{14}$ for each individual country (as opposed to a single one defined for the representative world customer), which segregates national markets into distinct units. Besides, the formulation allows us to introduce taste differentials among countries (i.e., $\alpha_{i m}$ does not necessarily need to be equal to $\alpha_{i m}$ ), as well as differentials in variety demand/appreciation across sectors (i.e., $\theta_{r}$ does not necessarily need to be equal to $\theta_{s}$ ). Our welfare functions also allows for firm-level product quality differentials on the basis of the assumption on perfect substitutability between quality and quantity (i.e., indifference of the customers between small bundles of high quality products and large bundles of low quality products).

In case of antarky, on the basis of the welfare function given by equation 3.7 , the welfare maximizing and market clearing inclividual inverse demand price for the product of firm ${ }_{k i j}$ can easily be solved. Due to the local market clearance implication, $C_{k i j y}^{t}=Q_{k i j}^{t}$ that characterizes autarky, the the price vector (which consists of $\sum_{j=1}^{N C} \sum_{i=1}^{N G} N F_{i j}^{t}$ prices, each corresponding to an individual firm $k_{i j}$ ) at which all firms can sell their entire output consists of the individual prices hat can be calculated as

$$
P_{k i j}^{t}=\alpha_{i j} \cdot G D P_{j}^{t} \cdot\left[\frac{Q u a l_{k i j}^{t} \cdot\left(Q_{k i j}^{t}\right)^{\theta_{i}-1}}{\sum_{n=1}^{N F_{i j}} Q u a l_{n i j}^{t} \cdot\left(Q_{n i j}^{t}\right)^{\theta_{i}}}\right]
$$

where GDPt is the nominal income of the $j^{t \text { th }}$ country at period $t$. Note that $G D P_{j}^{t}$ is a variable that is defined just for convenience (in order to maintain the compatibility of the various nominal magnitudes) and serves a function similar to that of a numeraire ${ }^{15}$. Thus, the expression $\alpha_{i j} \cdot G D P_{j}^{t}$ stands for the total budget allocated by the customers of country $j$ on their sector $i$ purchases and the expression in square brackets is the sector $i$ market share (in terms of total revenues) of firm ${ }_{k}$ divided by its output level. In this inverse demand relation, the 


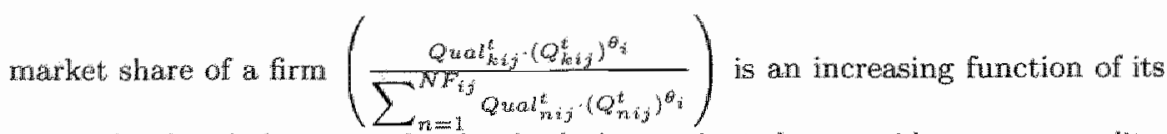
output level and also its quality level relative to the industry-wide average quality.

The firm level inverse demand prices given by equation 3.9 have an interesting property ${ }^{10}$. For the output of two arbitranily given firms of the same sector (say firm $k_{i j}$ and $\operatorname{firm}_{r i j}$ )

$$
\frac{P_{k i j}^{t}}{P_{n i j j}^{t}}=\frac{Q u a l_{k i j}^{t} \cdot\left(Q_{k i j}^{t}\right)^{\theta_{i}-1}}{Q u a l_{n i j}^{t} \cdot\left(Q_{n i j}^{t}\right)^{\theta_{i}-1}}
$$

which implies that in cases where products of the same sector are perfectly substi-

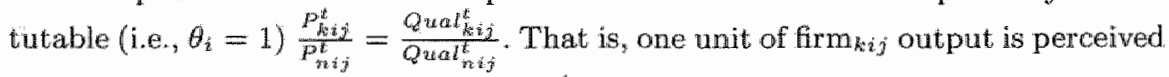
by the customers as equivalent to $\frac{Q u a l_{k i j}^{t}}{Q u a l_{n i j}^{t}}$ units of firm $r_{r i j}$ output. Therefore, the basis of economic selection is not confined to the relative price of a product alone but the relative quality-price ratio $\left(\frac{Q_{u \alpha} l_{k i j}^{t}}{P_{k i j}^{t}}\right)$ of the product Accordingly, relatively more costly firms (firms with low labor productivity has the chance to stand competition by less costly firms provided that the high cost firms produce higher quality products. Cllearly, in addition to firm-level differences in labor productivity, quality differentials introduce a secondary dimension into the economic selection process. Furthermore note that in settings where quality differences between firms are ruled out, and where the competing products of a given sector is perceived as homogenous by the customers, one observes $P_{k i j}^{t}=P_{\text {nij }}^{t}$, which implies a single sector $i$ price level at which all the firms of country $j$ sell their output.

In case of international trade, the calculation of inverse demand prices is a bit more complicated, since the balance of payments constraint cones into the picture. That is, in addition to the market clearing condition, in cases of international trade one needs to impose the condition that given any distribution of output over countries sectors and firms, the inverse demand relative prices ensure that the value of the total exports of each country equals to that of its total imports, or in other words, at each period $t$, the total value of the goods consumed by each country equals to the value of the goods by the country. That is:

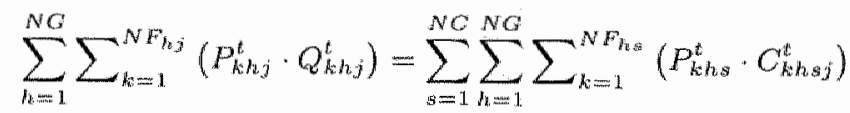

needs to be satisfied for each country $j$ at each period $t$, so that no country accumulates international debt. The calculation of (firm-level) market clearing inverse demand prices which satisfy the balance of payment constraints and which also maximize the welfare of each country on the basis of the welfare functions specified by equation 3.8 , is essentially a linear problem. The solution to this linear system of equations is computed numerically at each period $t$ of our simulation runs. The solution algorithm is presented in an appendix to this chapter which can be found in the accompanying $\mathrm{CD}^{17}$.

\subsubsection{Economic selection 1: Investments and disinvestments}

Having specified the periodic determination of the (nominal) wage rate $w_{j}^{t}$, at which all firms of a country $j$ should remunerate their workers, and also that of 
the firm-level market clearing prices $P_{k i j}^{t}$, the total profit of each firmkij at a given period $t$ is given by

$$
\pi_{k i j}^{t}=Q_{k i j}^{t} \cdot\left(P_{k i j}^{t}-\frac{w_{j}^{t}}{a_{k i j}^{t}}\right)
$$

where the expression $\frac{w_{j}^{t}}{a_{k i j}^{t}}$ is clearly the unit labor cost of the firm. From the perspective of the firm's shareholders, the profitability of the firm can be expressed in terms of the rate of return on capital (i.e., accumulated investment) yielded by the firm

$$
\operatorname{ROR}_{k i j}^{i}=\frac{\pi_{k i j}^{t}}{Q_{k i j}^{t} \cdot P_{-} \operatorname{Capt} t_{i j}^{t}}=\frac{\left(a_{k i j}^{t} \cdot P_{k i j}^{t}\right)-u_{j}^{t}}{a_{k i j}^{t} \cdot P_{-} \operatorname{Capt} t_{i j}^{t}},
$$

where P_Captl $t_{i j}$ stands for the period $t$ unit purchase/replacement price of sector i-specific capital, the measurement unit of which is defined as sector i-specific productive capacity. Note that the calculation of the capital prices P.Captl $l_{i, j}^{t}$ is explained in detail later in section 3.2.6.

The selection mechanism in our formulation is not directly based on the absolute magnitude of profits given by equation 3.12 but indirectly on the variable $R O R_{k i j}^{t}$. We assume that the shareholders of each firmikij expect for current consumption at least $r_{j}$ Captlstcons rate of return on the current value of their accumbulated investment $Q_{k i j}^{t} \cdot P$-Capt $l_{i j}^{t}$. However, note that this expectancy is not forcefully imposed in terms of compulsory dividend payments. As explained just below, the firms that fail to satisfy the minimum expectancy of their shareholders are penalized in a different way: They simply can not get any finances for capacity expansion and more importantly to compensate for the periodic depreciation on the existing capital stock.

The capitalists are assumed to be willing to reinvest all the surplus profits that exceed their current consumption needs, back to firms which need finance to expand their capacity, or at least compensate for the depreciation on physical capital. Let $\Theta_{j}^{t}$ represent the set of all firms that are profitable enough to pay dividends which is not less than the minimum rate expected by the share holders for their current consumption needs (i.e., all firmskij which satisfy ROR

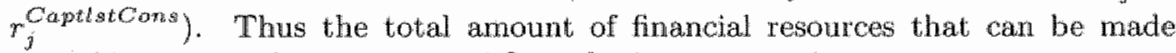
available at period $t$ to country $j$ firms for investments is

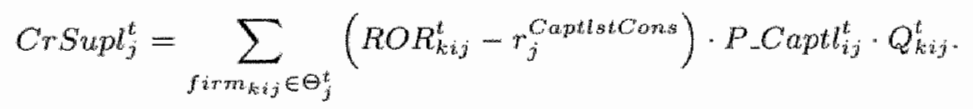

In our model where we rule out the creation of extra credits, the magnitude CrSupl: constitutes the only resources that can be used for capacity expansion and/or the compensation of depreciation. For example, in a one-sector one country setting where the output level at period $t$ is $Q_{j}^{t}$, the economy can only grow by

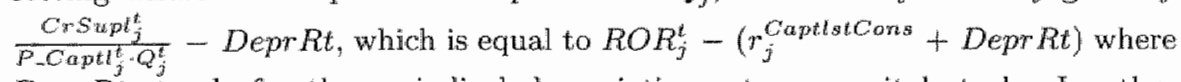
DeprRt stands for the periodical depreciation rate on capital stock. In other words, at the macro level, the condition for a notional steady state of the output adjustment mechanism (i.e., the point where the output level would stop changing between consecutive periods) is

$$
R O R_{j}^{t}=r_{j}^{C a p t l s t \text { Cons }}+\operatorname{Depr} R t=r_{j}^{\text {MinAcopt }} .
$$


At this notional point, the profits of the economy is just enough to satisfy the shareholders current consumption needs and also compensate for the depreciation on the capital stock.

In a multi-sector, multi-firm setting, the selection mechanism is all about the periodical allocation of the available financial resources $\operatorname{CrSupl} l_{j}^{t}$ over the individual firms. The allocation mechanism, which actually constitutes the financial markets of our model, is carried out in terms of a centralized auctioning process which distributes the sum $C r S u p l_{j}^{t}$ over the firms according to their relative profitability and also their individual demand for finance (i.e., frm's individual willingness to expand capacity). The most important feature of this reallocation: process is that the firms the current profitability of which fall short of the level $r_{j}^{\text {CaptlstCoris (i.e., all firmskij }}$ where $R O R_{k i j}^{t} \leq r_{j}^{\text {CaptlstCons }}$ ) are NOT permitted to join the auction for credits. Accordingly, the capacity adjustments of the firms which are not permitted to join the auction for credits are made according to the following principles:

- Contrary to the sufficiently profitable firms which may grow by investing in extra productive capacity, those which fail to satisfy $R O R_{k i j}^{t}>r_{j}^{\text {Captlstoons }}$ shrink by being forced to sell part of their capital to the second hand capital market or by sheer depreciation. For firms that are to grow, the total resources to finance this expansion are restricted by $C r S u p l_{j}^{t}$ every period.

- The firms that suffer negative profits (i.e.,. firms ${ }_{k i j}$ where $R O R_{k i j}^{t}<0$ ) are not permitted to expand their productive capacity further. On the contrary, as mentioned above, they shrink by being forced to cover their loss by selling an adequate part of their capital on the second hand capital market where the capital goods of the shrinking firms are made instantly available to the profitable firms that are to expand their capacity ${ }^{18}$. Accordingly, the output level (1.e., productive capacity) of a firm ${ }_{k i j}$ that makes losses in a period th changes according to

$$
Q_{k i j}^{t+1}=(1-D e p r R t) \cdot Q_{k i j}^{t}+I_{k i j}^{t-1}-C L o s s_{k i j}^{t}
$$

where

$$
C \operatorname{Loss}_{k i j}^{t}=-\min \left\{0, \frac{\pi_{k i j}^{L}}{P_{-} C a p t l_{i j}^{t}}\right\} .
$$

is the magnitude of the capical loss required to cover the period $t$ losses of the firm, and $I_{k i j^{\prime}}^{t-1}$ is the magnitude of investment orders released by the firm. in the previous period $t-1$. Let the variable SecHnd $t_{i j}^{t}$ denote the stock of sector-i-specific capital goods accumulated in country $j$ as of period $t$. The sales of the non-profitable firms imply that the positive increment to the capital stock accumulated in each such second hand market at period $t$ is

$$
\Delta \operatorname{SecH} I n d_{i, j}^{t}=\sum_{k=1}^{N F_{i, j}^{t}} C \operatorname{Los} s_{k i, j}^{i} .
$$

- The firms which make positive profits yet fail to satisfy the current consumption demands of their shareholders (i.e., firms sij $_{\text {w }}$ where $0 \leq R O R_{k i j}^{t} \leq$ $r_{j}^{\text {Capt sit Cons }}$ ) do not need to sell any part of their capital stock (i.e., CLos $s_{k i j}^{t}$ $=0$ ). Yet they are still penalized since having not been permitted to join the auction for credits implies loosing a part of capital stock due to sheer depreciation. 
Hawing penalized the relatively less profitable firms, the financial markets remunerate the rest of the firms according to their relative contribution to the generation of the re-investable resources. In other words, the auctioning process (i.e. the financial market) redistributes every period the amount $C r . S u p t_{j}^{t}$ (i.e., provided that $C r$ Supl $l_{j}^{t}>0$ ) only over the firms which have a contribution of its generation. As mentioned before, the redistribution process follows a scheme where the share of credits in CrSuplt made available to a firmoij is an increasing function of its relative profitability (i.e. $R O R_{k i j}$ relative to those of the other firms) and also its willingness to invest in extra productive capacity.

Let the variable $G r M x_{k i j}^{t}$ stand for the maximum rate by which the firm $k_{i j}$ is willing to grow in period $t$. The determination of this firm-level dynamic variable will be explained in the next section where we focus on firms' growth aspirations. Taking this variable as given for the time being, one can calculate the amount of the financial resources required to fulfill this maximum extent of aspiration to expand capacity as

$$
\operatorname{MxCrDm} m_{k i j}^{t}=\left(Q_{k i j}^{t} \cdot P_{-} C_{a p t l}^{t}\right) \cdot\left(G r M x_{k i j}^{t}+\text { DeprFt }\right) .
$$

This equation clearly suggests that the firms foresee the depreciation on capital and try to get the financial resources required to compensate for this foreseeable loss, by launching orders to the capital good sector in advance.

Based on this, let us define an instrumental function $\mathrm{CrDem}_{k i j}^{t}$ (int $r$ rt), which defines the credit demand of each firm ${ }_{k i j}$ separately as a decreasing logistic function of the interest rate indicator int_rt which is an instrumental variable that is used in the auctioning process. The continuous function $C r D e m_{k i j}^{t}$ (int_rt) has the qualitative properties of the function depicted in figure 3.2. The function takes two arguments: The first one is the variable $M x C r D m_{k i j}^{i}$ which determines the value of the function at zero market interest rate (i.e., $C r D e m_{k i j}^{t}(0)=M x C r D m_{k i j}^{t}$ ).

The second argument of the function is the variable $R O R_{k i j}^{t}$. As shown by figure 3.2 , the variable $R O R_{k i j}^{t}$ constitutes the inflection point for the firm's credit demand function. The value where the function takes at int_rt $=R O R_{k i j}^{t}$ (i.e. $C r D e m m_{i j k}^{t}\left(R O R_{k i j}^{t}\right)$, is not defined as a fixed percentage of $M x C r D m_{k i, j}^{t}$ but as an increasing function of the distance between the firm's actual rate of return on capital at period $t\left(R O R_{k i j}\right)$ and the threshold rate of return $r_{j}^{\text {Captlsticons below }}$ which firms can not receive any credits at all. That is:

- For $R O R_{k i j}^{i} \leq r_{j}^{\text {Captlst Cons }}$, the critical value $C r D e n_{k i j}^{t}\left(R O R_{k i j}^{t}\right)=0$,

- For the intierval $r_{j}^{\text {Captlstons }}<R O R_{k i j}^{t}<r_{j}^{M i n A c e p t}, \operatorname{CrDem} t k i j\left(R O R_{k i j}^{t}\right)$ is specified as

$$
\operatorname{DeprCr} D m_{k i j}^{t} \cdot\left(\frac{R O R_{k i j}^{t}-r_{j}^{C a p t i s t C o n s}}{\operatorname{DeprRt}}\right)^{\frac{1}{\sigma C r e d}}
$$

where $r_{j}^{\text {MinAccpt }}=r_{j}^{\text {CaptlstCons }}+$ Depr Rt as defined before. The variable DeprCrDm $m_{k i j}^{t}=P_{-} C a p t l_{i j}^{t} \cdot \operatorname{Depr} R t \cdot Q_{k i j}^{t}$ is the amount of credits just enough to make up for the depreciation on its existing capital stock,

- And for $R O R_{k: i j}^{t} \geq r_{j}^{M i n A c c p t}$, we specify $\operatorname{CrDem} \operatorname{lom}_{i, j}^{*}\left(R O R_{k i j}^{t}\right)$ as

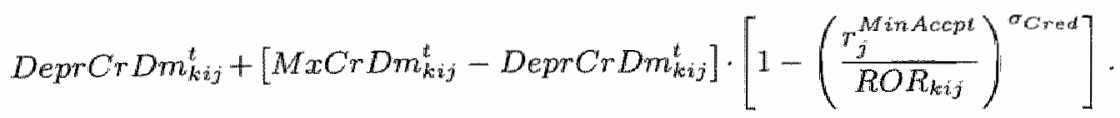




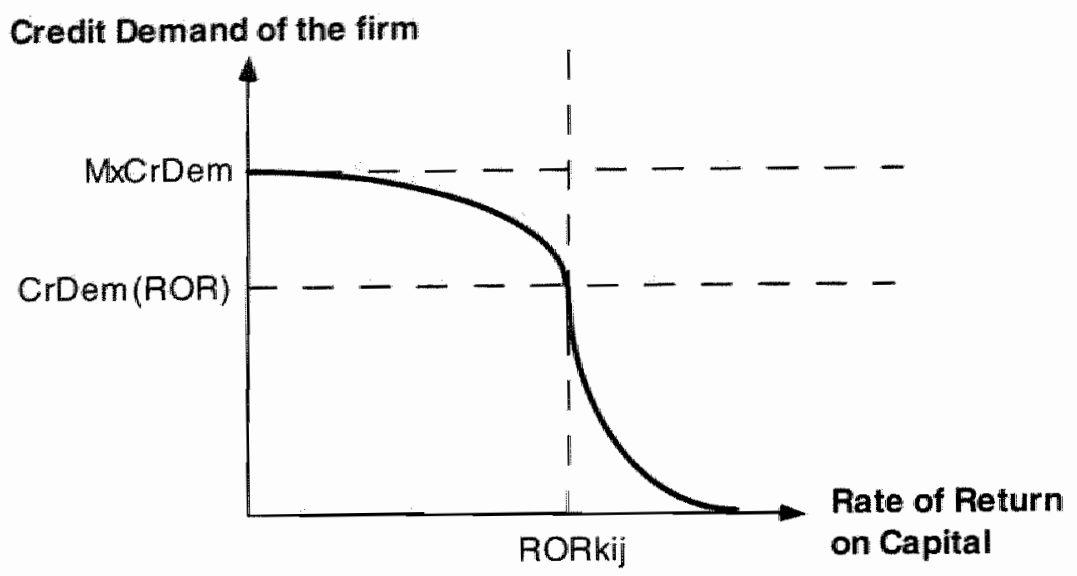

Figure 3.2. The function CrDern $\operatorname{Dijk}($.

In the latter two specifications $\sigma_{C r e d}$ is a parameter that is assigned the value 0.25 . Accordingly, the last two equations together specify the critical value $C r D e m_{i j k}^{t}\left(R O R_{k i j}^{t}\right)$ as an increasing S-shaped mapping of the argument $R O R_{k i j}^{t}$. As mentioned before, the value $r_{j}^{\text {Mindecpt }}$ plays a key role in our model specification in the sense that it specifies the critical rate of return at which the output level of a firm remains unchanged between consecutive periods, since the credits received by the firm at this wery profitability level exactly matches the amount needed to compensate for depreciation. Thus, a hypothetical condition where $R O R_{k i j}=r_{j}^{\text {MinAccpt }}$ for all frmskij of country $j$, describes the notional steady state of the output adjustment mechanism for constant technological coefficients.

Given that $R O R_{k i j}^{\ell}$ is the rate of return on investment which firm kij $_{j}$ has proven to be capable to yield (an indicator of the firm's current performance/fitness as period $t$ ), at market interest rates higher than this value (which would mean that there are other firms which are able to yield bigher rates of return), the firm can receive little or no credits for further growth. In other words, the priority in credit releases is given to firms with higher $R O R_{k i j}^{t}$, which reduces the growth chances of relatively less profitable firms. Furthermore, note that for the firms that are not welcome to the financial market auction (i.e, firms where $R O R_{k i j}^{t} \leq r_{j}^{C a p t l s t C o n s}$ ) $M x C r D m_{k i j}^{i}=0$, which imphies CrDem ${ }_{k i j}^{*}($ int_rt $)=0$ for $\forall$ int $r t \geq 0$.

Having defined the firm-level credit demand function, the total demand for creditis in country $j$ at period $t$ is given by

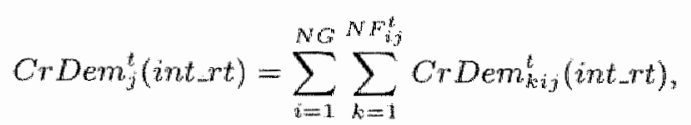

which is clearly a decreasing function of the market interest rate int.rt.

The financial market module is essentially a numerical algorithm that solves for the variable $r_{j}^{t}$ (which can be interpreted as an equilibrium interest rate) that would clear the financial market of each country $j$ separately. The market clearance condition is the equality of the national total credit demand to the national total credit supply, if the resulting interest rate is not lower than the minimum level that reflects the current consumption willingness of the capitalists 
(ive, $r_{j}^{\text {Oaptlatcons }): ~}$

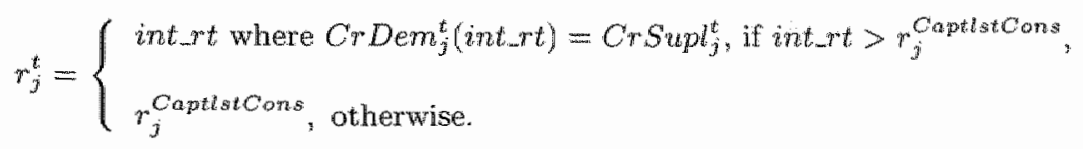

Since the credit demand is an endogenous variable ${ }^{19}$, it is quite possible that cases where credit demand is less than supply for all feasible interest rates $\forall r^{t} \geq$ $r_{j}^{\text {Capusticons }}$ endogenously arises in some periods. In these cases, naturally the total credits granted to firms is equall to $\operatorname{CrDem} \operatorname{De}_{j}^{t}\left(r_{j}^{C a p t s t C o n s}\right)$ and the residual potentiall credits $C r S u p l_{j}^{t}-C r \operatorname{Dem}_{j}^{t}\left(r_{j}^{C a p t h s t c o n s}\right)$ have nowhere to go but back to the capitalists for immediate consumption ${ }^{20}$.

The firm-level function $C r D e m_{k i, j}^{t}($ int_rt $)$ clearly lies at the core of the financial component of the selection process, where at the top of the penalty that forces the non-profitable firms to shrink and eventually die, the profitable ones are remunerated according to their relative profitability. Our financial market specification, which first pools profits and then redistributes the sum back to firms according to their relative current perfornance, closely resembles that in Soete and Turmer [1984], which is also adopted by some other evolutionary models of growth such as Silverberg and Verspagen [1995a]. Nevertheless, our formulation also takes firms" individual demand for credits (i.e., willingness to grow as captured by the variable $M x C r D m_{k i j}^{t}$ ) and the limits to capitalists' willingness to invest (as imposed by the variable $r_{j}^{\text {Captlstcons }}$ ) into account.

The equilibrium interest rates $r_{j}^{t}$ determined in the local financial markets at every period $t$ according to equation 3.22 , determines in turn the credits to be received by each sufficiently profitable firm $k i j$ as

$$
\operatorname{Crd} t_{k i j}^{t}=\operatorname{Cr} \operatorname{Dem}_{k i, j}^{t}\left(r_{j}^{t}\right)
$$

Thus, the investment orders to be released by each firm which satisfy the condition $R O R_{k i j}^{t}>r_{j}^{C a p t l s t C o n s}$ is

$$
r_{k i j}^{t}=\frac{C r^{n} d t_{k i j}^{t}}{P-C a p t l_{i j}^{t}}
$$

and thus the total investment orders released by each sector $i$ is

$$
I_{i j}^{t}=\sum_{k=1}^{N F_{i j}^{t}} I_{k i j j}^{t}
$$

The capital goods ordered at period $t\left(I_{k i j}^{t}\right)$ are normally supplied during the next period $t+1$. That is, the production of the new capital goods and their addition (installation) to the current stocks are assumed to take time (i.e., capital production is subject to a gestation lag of a year), and for orders launched at period $t$, the process is finalized at period $t+1$. Nevertheless, before releasing orders to the investment sector, the firms check out the second hand market and try to get an as large as possible portion of their capital increment immediately without waiting for an entire period. Hence, at the sectoral level two cases are possible. 
1. $Y_{i j} \leq$ SecHnd $d_{i j}^{t}$ : In this case, the second hand capital pool is able to meet the whole demand and hence, for each country $j$ sector $i$ firm $k$

$$
\begin{aligned}
& I n v_{k i j}^{t}=I_{k i j}^{t}, \\
& I_{k i j}^{t}=0
\end{aligned}
$$

and for the sector

$$
\begin{aligned}
& \text { SecHnd } d_{i j}^{t+1}=(1-S H \text { Deprc }) \cdot\left(\operatorname{SecH} n d_{i j}^{t}-I_{i j}^{t}\right), \\
& I_{i j}^{t}=0
\end{aligned}
$$

where $S H$ Depre is the scrapping factor of the second hand capital pool, which we set to $90 \%$ in all our experiments. As mentioned briefly before, a sector-specific second hand capital market is a construction that makes the instant reallocation of capital between the firms. This construct saves the artificial firms from being involved with complex ex-ante production planing computations on capacity utilization. The firms simply produce up to capacity and in case of losses, sell a portion of their capital (i.e.., given P.Captlij, the amount just sufficient to cover the losses) to the second hand capital pool. If such a firm happens to reach profitability in the very short run again, it may buy part of its capital back, but unless bought by any other firm before. However, the odds of such intertemporal reallocation are quite limited, because due to the preferably high value parameter $S H$ Deprc the capital goods pooled in the second hand capital market are scrapped very rapidly (for example for $S H \_$Depr $C=0.9$, the unused stock decays to nearly nothing in $20-25$ periods). Hence, the main task of the second hand capital pool is the instantaneous reallocation of part of the existing capital from the non-profitable firms to the profitable ones ${ }^{21}$

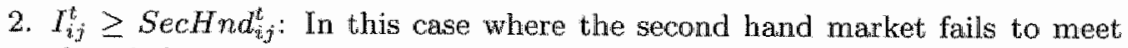
the whole investment demand, for each firm in the sector

$$
\begin{aligned}
& I n v_{k i j}^{t}=\operatorname{Sec} H n d_{i j}^{t} \cdot \frac{I_{k i j}^{t}}{I_{i j}^{t}}, \\
& I_{k i j}^{t}=I_{k i j}^{t}-I n v_{k i j}^{t},
\end{aligned}
$$

and for the sector

$$
\begin{aligned}
& \operatorname{SecH} n d_{i j}^{i}=0, \\
& I_{i j}^{\iota}=\sum_{k=1}^{N n_{i j}^{l}} I_{k i, j}^{i} .
\end{aligned}
$$

Following these adjustments, the capacity of each firm that satisfies the condition $R O R_{\text {tiv }}^{t}>r_{j}^{\text {Captlstcons }}$ is updated as

$$
Q_{k i j}^{t+1}=\left[Q_{k i j}^{t} \cdot(1-D e p r R t)\right]+I n v_{k i j}^{i}+I_{k i j}^{t-1},
$$

contrary to the updates given by equations 3.16 and 3.17 which apply to the firms which fail to satisfy their shareholders' current consumption needs. Evaluation of the last 9 equations together with equation 3.17 clearly shows that our second hand capita market construct implies possibilities of instantaneous as well as 
intertemporal, yet limited reallocation of existing capital stock between the firms of the same sector of the same country.

The labor force that is required to produce the non-met part of the investment demand is

$$
L_{\text {Invat }, j}^{t}=\sum_{i=1}^{N G} \frac{I_{i j}^{t}}{\text { LCoef } f_{i j}^{t}},
$$

where $L C$ Coe $f_{i j}^{i}$ stands for the labor productivity coefficient in the sector-i-specific capital sector of country $j$, which is defined in a later section by equation 3.42 . As mentioned before, the capital orders released in period $t$ are only produced and delivered in period $t+1$. Thus as specified by equation 3.4 , the magnitude $L_{r m w}^{t} t_{i} j$ contributes only to employment at period $t+1$, but not to that at period $t$.

Basically, the saving (investment) mechanism in our evolutionary formulation is nothing but the rendering the final good sector workers devoid of some part of the final output that they have produced and financing with this part of the national final output, the wage bill of the capital good sector workers. In the income distribution sense, one can think of three interest groups: The final good sector workers, the capitalists and the capital good sector workers. The function $W g S u p_{j}\left(E m p l R t_{j}\right.$ ) determines (as in equation 3.5) the instantaneous distribution of the nominal GDP between the final good sector workers and the capitalists. The capitalists offer a certain part of their income into investment and accordingly distribute (at least) part of their income to back frms as credits to finance capacity expansion. Firms transfer these credits to the capital good sector workers. Thus, the presence of profits forces the final good sector workers to sacrifice some part their current potential consumption for an increased consumption in the future and this is made possible by letting them share the rewards of their input to production with the workers employed in the capital good sector.

Capital sector workers are paid in advance (out of the GDP of period $t$ ) in return for their prospective contribution to the capital stock, which is produced and installed only in period $t+1$. This shared part is (partly endogenously and partly by the institutional setings represented by the function $W g S u p_{j}\left(E m p l R t_{j}\right)$ ) determined by the profitability of the production and if profits (which is the solemn savings of the economies) are equal to zero, the final good sector workers enjoy the whole output with no sacrifice but with no further growth of output ati all. The important point is that in our system the saving-investment identity is not necessarily satisfied each period, since the capital goods to be produced (investments) in period $t$ is determined and ordered in period $t-1$. In other words, the actual investments of period $t$ is financed out of the GDP (savings) of period $t-1$.

\subsubsection{Firms' willingness to grow: Demand for investment}

Clearly one of the weakest point of mainstream models is the way in which individual firms" investment behavior is (or better put is not) addressed within the underlying equilibrium framework. In long run formulations that rely on perfect competition, given existing demand and the avallable technologies given by the production function, for each existing firm there exists an optimal technology and for the industry there exists an output level. The convergence to this output level takes place through the process of entry and exit of firms but not necessarily the disequilibrium output adjustments (i.e., investments and disinvestments). Eventually industries are assumed to have the tendency to converge to an equilibrium 
characterized by a high number of measure zero firms. The key property of this equilibrium is that despite the fact that each individual firm is specified as a profit: maximizer, due to the competitive pressure economic profits are suppressed to zero, which implies that the industry behaves like a single profit-constrained output inaximizing entity. On the other extreme where monopolistic or oligopolistic industries are addressed, the basic decision of the firms is their overall output level which is decided at once according to the principles of profit maximization, but not necessarily through gradual disequilibrium adjustments that involve a firm level investment/disinvestment process.

In evolutionary models of growth which are briefly revisited in the previous chapter, the disequilibrium motion of the output level of individual firms are either specified as purely demand driven (i.e., in models such as Dosi et al. [1994] which rely on the replicator dynamics) or alternatively on the premises of the simple "positive (negative) profits are invested (disinvested)" rule. Both formulations specify a rather gradual motion for firm.level output levels and both implant into the system the tendency to convergence to states where the output level of the industry/economy is around the level that would be chosen by a single profitconstrained output maximizer producer. That is, in system where positive profits imply output growth and negative profits output shrinkage, the notional steady state of the gradual adjustment process is naturally the point where the economy produces the highest possible output level that yields zero aggregate profits.

However, neither the fim level investment/disinvestment process, nor the replicator dymamics based, demand driven output motion specification, give individual firms any right to say anything about their output adjustments. In other words, the firm-level output motion simply follow a number of difference/differential equations, which does not involve any (rational or routinized) decision of individual firms. In our model specification we aim to address this shortcoming by the introduction of a firm-level local and adaptive decision routine, which introduces a certain extent of bounded-rationality into the firm-level investment dynamics. In terms of our earlier notation, our formulations which introduce such boundedrationality into the gradual process of firm-level output adjustment processes, simply endogenises the firm-level variable $G r M x_{k i j}^{t}$ (which specifies the upper limit, to the firms' credit demand) dynamically in a local and adaptive manner on the basis of two alternative algorithms.

The first alternative renders firms quite ambitious in their growth aspirations. In terms of its dynamic implications this first alternative is quite similar to the "profits are invested" rule. However, the bounded-rationality imposed by the algorithm hinders firms from being involved in hasty and careless investments that would apparently jeopardize the firm's profitability in the short run. Firms are assumed to be aware of the facti that each investment, which ceteris paribus increases the total market supply, has the potential to push the market price down, push the wage rate up due to the increased labor demand and hence drive profitability down ${ }^{22}$. Accordingly they try to converge to the highest possible output level which would yield profits just enough to satisfy the shareholders 'consumption needs and compensate for depreciation (i.e., $R O R_{k i j}^{t}=r_{j}^{M i n A c c p t}$ ), yet through a gradual process of a series of incremental investments, rather than hastily at once. Due to its potential dynamic implications, we call the corresponding behavior conventionally as "profit-constrained output maximizing".

The second alternative assumes that firms do not pursue higher output levels but higher profits. Accordingly they make their periodic credit demand decisions on the basis of a local search around their current output level and the according 
market share, the objective of the search being an optimal choice on total profits. Due to its dymamic implications we call the underlying investment behavior conventionally as "profit maximizing".

The presence of these two radically alternative behavioral modes in our model, basically makes it possible to make comparisons between mainstream and ewoluthonary models in the context of the relation between industrial organization (i.e. number of firms and firm's size distributions) and aggregate magnitudes such as output level and employment. Now let us look at the formulations that specify these two behavioral alternatives.

For any given firm ${ }_{k i j}$, the consequences of growth plan $\widehat{Q_{k i j}^{t}}$ at period $t$ (expressed in terms of the output growth rate over the existing capacity, such that $\left.Q_{k i j}^{t+1}=\widehat{Q_{k i j}^{t}} \cdot Q_{k i, j}^{t}\right)$ can be estimated as

$$
\pi_{k i j}^{t+1, E s t}\left(\widehat{Q_{k i j}^{t}}\right)=\left[\left(1+\widehat{Q_{k i j}^{t}}\right) \cdot Q_{k i, j}^{t}\right] \cdot\left[P_{k i j}^{t+1, \alpha_{s t}}\left(\widehat{Q_{k i j}^{t}}\right)-\frac{w_{j}^{t+1, B_{s i t}}\left(\widehat{Q_{k i j}^{t}}\right)}{a_{k i j}^{t+1}\left(\widehat{Q_{k i j}^{t}}\right)}\right],
$$

in terms of the expected total profits at period $t+1$, or alternatively as

$$
\pi_{-} S_{k i j i}^{t+1, E s t}\left(\widehat{Q_{k i j j}^{t}}\right)=1-\left[\frac{w_{j}^{t+1, E s t}\left(\widehat{Q_{k i j}^{t}}\right)}{a_{k i j}^{t+1}\left(\widehat{Q_{k i j}^{t}}\right) \cdot P_{k i j}^{t+1, E s t}\left(\widehat{Q_{k i j}^{t}}\right)}\right],
$$

in terms of the profitability (i.e. profits to salles ratio) at period $t+1$.

The last two equations capture the fact that the output price and the wage rate that can be expected in the next period is a function of the firm's growth rate executed at the current period. In case of constant returns to scale the firm's productivity $a_{k i j}^{t+1}$ is not affected by its ontput level, yet as will be discussed later, our model has also an optional feature that introduces scale economies by rendering labor productivity an increasing function of the output level. Thus, the expression $a_{k i j}^{t+1}\left(\widehat{Q_{k i j}^{t}}\right)$ is only relevant in case of scale economies.

Clearly, the price $P_{k i j}^{t+1, E s t}\left(\widehat{Q_{k i j}^{t}}\right)$ and the wage rate $w_{j}^{t+1, E s t}\left(\widehat{Q_{k n}^{t} i_{j}}\right)$ to be observed in the next period(s) is not only a function of the investment decision of firm $_{k i j}$ at period $t$, but also that of the other firms in the economy. However, given that in our evolutionary settings, things do not change abruptly but only gradually, the standard ceteris paribus assumption does not lead to highly erroneous estimations in terms of the short run relation between the firm's individual. decision and its consequences in terms of the price of the firm's product and the wage rate. Accordingly; under the other things constant assumption the firm can estimate

$$
P_{k i j}^{t_{u} E s t}\left(\widehat{Q_{k i j}^{t}}\right)=\frac{P_{k i j}^{t}}{1-\varepsilon_{k i j}^{t, S u p} \cdot \widehat{Q_{k i j}^{t}}},
$$

where

$$
\varepsilon_{k i j}^{t, \sup }=\theta_{i} \cdot\left[1-M S h r_{k i j}^{i}\right]-1
$$

is the supply elasticity of market price for frrmkij ${ }^{23}$, and $M S h r_{k i j}^{t}$ is the period $t$ marketi share (in case of international trade share in world sector $i$ production, and at autarky share in the sector $i$ production in country $j$ ) of the firm. Clearly, the extent of the effect of the firm's growth decision on the price of its product, which is determined by the supply elasticity of price, is an increasing function of the firms 
monopoly power which is determined by the firm "s market share MShr $r_{k i j}^{t}$ and also the extent of the consumer"s demand for variety $1-\theta_{i}$. Our inverse demand curve formultion implies that for a monopolist (i.e., MSh $r_{k i j}=1$ ) the supply elasticity of price is unity, while for a firm in perfect competition (MShr $k i j->0$ ), the elasticity approaches to $\theta_{i}-1$. The latter implies that if products are perfectly homogenous $\left(\theta_{i}=1\right)$, as the number of firms increase, all firms turn into price takers $\left(\varepsilon_{k i j}^{t_{s} S w p}->0\right.$ and thus $\left.P_{k i j}^{t_{*} E s t}\left(\widehat{Q_{i j k}^{t}}\right)->P_{k i j}^{t}\right)$ just as assumed by mainstream models of perfect competition. On the other extreme, as the (within-sector) substitutability of goods are decreased (as $\theta_{i}->0$ ), the (own) supply elasticity of

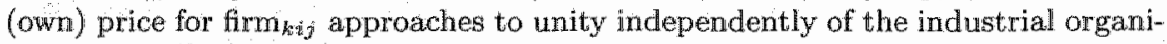
zation, indicating divergence from perfect competition and convergence to a cases of monopolistic competition or monopolistic market niches ${ }^{24}$.

Similarly under the ceteris paribus assumption, and on the basis of equation 3.5 , one can calculate the effect of the firm's investment decision on the wage rate of the rear future, which reflects the extent of the firm's monopsony power as

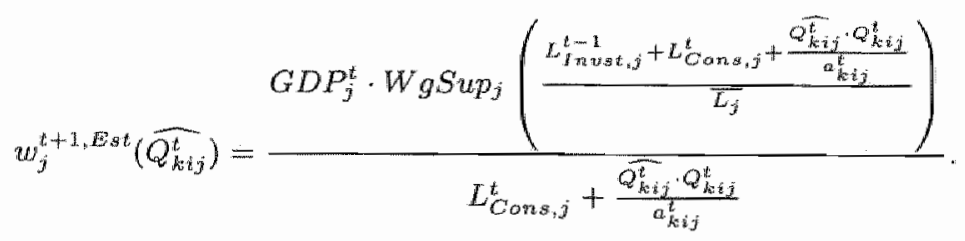

Since $Q_{k i j}^{t} / a_{k i j}^{t}=L_{k i j}^{t}$ is the labor demand of firmpin at period $t$, if we define a variable that indicates the period $t$ share of firm $k_{k i j}$ in total (final good sector) labor demand: $L D m d S h r_{k i j}^{t}=L_{k i j}^{t} / L_{C o n s, j}^{t}$, then the last equation can also be rewritten as

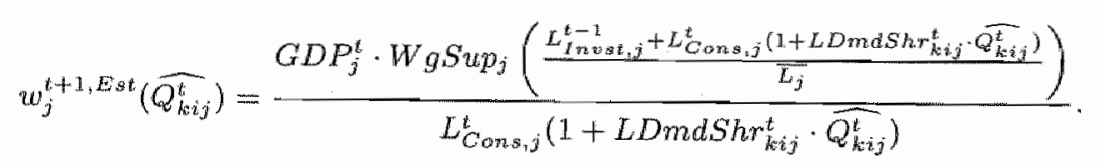

Apparently, for a very small firm (a firm in perfect competition for example) where $L D m d S h r_{k i j}^{t} \approx 0$, the estimated wage rate $w_{j}^{t+1, E s t}\left(\widehat{Q_{k i j}^{t}}\right)$ for the next period $t+1$, is almost equal to the actual wage rate at period $t\left(w_{j}^{t}\right)$, and therefore monopsony cognition does not bring about any change for the firm's calculations. On the other extreme, for a large firm (a monopolist for example) $w_{j}^{t+1, E s t}\left(Q_{k i j}^{t}\right)$ may be quite sensitive to the growth rate $\widehat{Q_{k i j}^{t}}$. Between these two extremes the variable $L D$ madSh $r_{k i, j}^{*}$ interpolates the effect of monopsony power/cognition on investment demand (growth desire).

Based on these derivations, the two behavior alternatives in terms of investment demand are formulated as

- The (dynamic) profit-constrained output maximizer type of firm: As discussed before, the profitability level that would allow a firm to sustain itself without shrinking corresponds to the threshold rate of return value $r_{j}^{\text {MinAccpt }}$. This threshold value corresponds to the minimum acceptable profits to sales ratio which is

$$
\pi-S_{k i j}^{t, M i n, A c c p t}=r_{j}^{M i n, A c e p t} \cdot \frac{P_{-} C_{a p t}^{t}}{P_{k i j}^{t}} .
$$


Clearly, any lewel of profitability $\pi S_{k i j}^{*}>\pi_{-} S_{k i j}^{*, M i n A c p t}$ implies supernormal profits ${ }^{25}$ and notionally conflicts with the underlying idea of output maximization. Thus, while making investment decisions (which has the potential to increase total market supply and decrease market price, especially if within sector substitutability of products is high), a profit-constrained output maximizer tries to converge to the threshold rate $\pi-S_{k i}^{t, M i n A c o p}$ gradually by incremental investments and keep it there. This specification characterizes firms which are willing to increase their output level up to the highest point which, given the shareholders' profitability demands and the depreciation, is viable and sustainable. Accordingly, the maximum desired growth rate of the output maximizing firm ${ }^{26}$, is calculated as the outcome of a local search as

$\operatorname{GrM} x_{k i j}^{i}=\max \left\{\widehat{Q_{k i j}^{t}} \mid \pi_{-} S_{k i j}^{\ell-1, E s t}\left(\widehat{Q_{k i j}^{t}}\right) \leq \pi_{-} S_{k i j}^{t, M i n} A c c p^{*}\right.$ " and $\left.\widehat{Q_{k i j}^{t}} \in[0,0,1]\right\}$,

where $\pi S_{k i j}^{t+1, E s t}\left(\widehat{Q} \widehat{Q}_{k i j}^{t}\right)$ is defined in equation 3.33 before. The locality of the search is reflected by the restriction $\widehat{Q_{k i j}^{t}} \in[0,0.1]$, which rules out large (upwards) jumps in firm sizes and accordingly keep the individual firm growth processes gradual. The maximization problem that seeks the highest possible growth rate in the interval $[0,10 \%]$, is solved by an optimization algorithm (that runs for every firm $k i j$ in every period $t$ ) subjected to the condition given in equation 3.39. In our software implementation, the investment behavior alternative which accordingly implies profit-constrained output maximizing in the medium/long run, is imposed through the parameter $O M_{-} P M_{k i j}=1$.

- The pure (dynamic) profit maximizer type of firm: Contrary to the profit-constrained output maximizing firm, at this other extreme, the firm, instead of the condition defined by equation 3.39 , calculate by a numerical algorithm the optimum output growth rate $\widehat{Q_{k i j}^{t}}=G r M x_{k i j}^{t}$, which maximizes the expected (ceteris paribus) profit function given by equation 3.32. As in the profit-constrained output maximizing behavior, the interval within which the local search for the maximum profits is carried out is set to $[0,10 \%]$. Accordingly the constrained maximization problem that is solved by each firm $k i, j$ at each period $t$ is

$$
\operatorname{Max} \pi_{k i j}^{t, 2 s t}\left(G r M x_{k i, j}^{t}\right) \text { s.t. } \operatorname{Gr} M x_{k i j}^{i} \in[0,0.1],
$$

where the function $\pi_{k i j}^{t, E s t}\left(G r M x_{k i j}^{t}\right)$ that estimates total profits as a function of the target output growth rate, is defined in equation 3.32. Note that in our software implementation, the investment behavior which accordingly implies profit maximixing in the medium/long run, is imposed through the parameter $O M_{-} P M_{k i j}=0$.

- Real profit maximization: Clearly the latter formulation above pertains to the maximization of nominal profits. Now consider a hypothetical profit maximizing monopolist in a single sector setting. In this case oux formular tions that define good markets and production naturally imply that such a profit maximizing monopolist would face a demand curve of unit elasticity, and its production being subjected to constant returns, it would produce an output level of measure zero. This abnormality is an important reason underlying the idiosyncratic formulations of the textbook mainstrearm 
formulations of monopoly/oligopoly models, all of which assume increasing returns and/or demand functions characterized by less than unity price elasticity. Although this is a purely hypothetical case (in reality one can not observe a monopolist producing the whole output of a country allone), a closer look to it brings forward an important property. That is, in this hypothetical situation, maximization of nominal profits is clearly a nonsensical behavior for the monopolist, since the walue of the maximized nominal profits amounts to nothing in terms of its purchasing power. Because, since the profit maximizing output is close to zero (i.e., there is nothing to buy on the markets) there is no way for anyone to enjoy the maximized profits (which is almost equal to GDP). A meaningful work-around to this problem is to redefine the monopolist as a "real" profit maximizer. In a onesector one-firm setting, the formulation of real profits is rather simple. Since $G D P=P \cdot Q$, real profits $\left(\pi^{R e a l}\right)$ is nothing but $\pi / P$. Thus in this simple condition, it is possible to introduce real profit maximization behavior simply by dividing the right hand side of equation 3.32 by $P_{k i j}^{t+1, E s^{3 t}}\left(\widehat{Q_{k} t i j}\right)$. Though the "real profit maximization" notion seems to be a potentially interesting assumption (especially in such a marginal case), in case of mary sectors and many firms within each, the formulation is not as straightforward as in our bypothetical case of" a monopolist producing the entire national output. On the other extreme, in case of perfect competition the effect of a single firm's output decision on the unit value of the Jocal currency (for given level of nominal GDP) is, without doubt, negligible and as formulated by mainstream models, the nominal versus real profits split would not have any effect on behavior. Nevertheless in our model, due to the incessant entry and exit of the firms, many different patterns of industrial organization (ranging from monopoly to perfect competition) may occur even during one single simulation run. Therefore, we introduce the real profit. maximization behavior as an optional assumption that can be activated by a switch variable RealProfitCognon off (indicating whether the firms consider the effect of their output decision on total welfare). Although a sufficiently generic but exact formulation is unfortunately not possible for the multi-sector multi-firm cases, we have developed a heuristic formulation that captures the general idea to introduce this option. This heuristic formulation is discussed in detail in an appendix provided in the accompanying $\mathrm{CD}^{27}$.

Shortly, the behavior of a frm with regard to growth is controlled with one parameter $O M_{-} P M_{k i j}$. It is clear that the distribution of the variable $O M_{-} P M_{k a j}$ over the firms (consequently the distribution of investment behavior) can be quite determining in terms of the total industry output towards which the economy has the tendency to converge. As will be shown analytically in the following chapter, in an industry that consists of only profit-constrained output maximizers, the total industry output is independent of the number of firms and the size distribution. Furthermore, for such an industry, the eventual tatal industry output conld be expected to be the highest among other (hypothetical) industries with identical technological and demand conditions. The obvious reason is the fact that profit constrained output maximizing behavior does not allow any firm to abuse its monopolistic power (by persistent under-investment which keeps output level persistently lower and the market prices persistently higher than the socially optimal levels) and therefore, regardless of the number of firms and the size distribution, 
the total output of an industry of profit-constrained output maximizers may be expected to be the closest (even identical) to that of the mainstream "perfectly competitive" industry ${ }^{28}$, which constitutes the most desirable circumstances for full employment to take place. Thus, the profit-constrained output maximizing assumption (for all firms) seems to have the potential to give our evolutionary dynamics the tendency to converge to states that are close and comparable (independently of the number of firms) to those of the mainstrearn (equilibrium) full employment models. Otherwise (i.e., in case of profit maximizing firms), such comparability could only be achieved by keeping high number of firms (as introduced as an initial condition or procured by high entry rates) in our simulations.

The estimations, upon which the firms" demand for growth calculations are based, are thus no more than simple heuristics which reflect some form of boundedrationality characterized by locality in search and adaptiveness. The element of adaptiveness in our formulations is reflected in equations 3.32 to 3.37 . In their investment decisions, the firms consider their ex post market share together with the (own) supply elasticity of price and accordingly try not to jeopardize their own profitability by excessive investments. Without resort to any complicated rule base, with this characterization, the same formulation can both cope with a competitive market (i.e. where, due to high number of firms, the affect of any firm on market price would be low) and depending on market conditions behave like a monopolist (produce less than it would be produced in a more competitive market) as well.

The element of locality that characterize the bounded nature of such ratio. nality is underlied by two reasons. First, in our model where each instant of the simulation is characterized by a finite number of firms in action, the future outcome of an individual firm's investment decisions are strongly affected also by the current and future decision of other firms. In our procedural formulation of the individual firms' disequilibrium decisions on their incremental investments on productive capacity, we address this source of essential uncertainty caused by such oligopolistic indeterminacies, by the standard ceteris parbus assumption. That is, firms, while making their periodical estimations and their according plans for further growth, assume that other firms of the economy will keep their current output level unchanged in the short-rum. Thus, firm behavior is accordingly not affected by instantaneous game theoretical considerations, and accordingly output levels at a given period $t$ do not necessarily reflect any instantaneous Nash equilibrium in our essentially disequilibrium model of selection and adjustment dynamics ${ }^{29}$. Second, subjected to a major source of essential uncertainty, firms carry out their investment plans gradually without haste. The gradual nature of output adjustments are the outcome of the locality of the search algorithms which only consider output growth options that lie in the interval $[0,10 \%]$. Furthermore, the frm-level calculations determine only the firms" aspirations for growth (i.e., only the upper limit to per period growth) and these aspirations are not necessarily fulfilled as they are, since the ultimate decisions on the magnitude and distribution (over the firms) of output growth are made by the financial market, which considers all firms' individual growth plans simultaneously, and grants them the means (credits) to follow their plans according to their -actually realized-relative performance. Due to the accordingly gradual nature of firm level output adjustments, our: core selection dynamics is characterized by a gradual process of coevolution. As will be discussed in chapter 5, the only source that affects the gradual nature of the day-to day adjustments is technological change, which is formulated in terms of firm-level incremental productivity and/or quality shocks, which disturbs the 
system through a firm-level stochastic (Poisson) arrival process.

Despite the fact that the model essentially works in discrete time steps, due to the element of locality in investment decisions, the set of changes thet can take place in one time step is quite limited and accordingly the properties of our dynamic system is closer to one that is specified in terms of a set of simultaneous differential equations than one specified by a set of difference equations where large changes can take place between consecutive periods. As a result, subjected to essential uncertainties brought about by oligopolistic indeterminacies, individual firms only dare to make incremental moves between consecutive periods on the basis of the ceteris paribus assumption, which actually turns the ceteris paribus assumption into a "self fulfilling prophecy" 30 .

The lack of perfect rationality and the limited nature of agents' perceptive, cognitive, and calculation-wise abilities are highly acknowledged facts in evolutionary thinking and modeling. In evolutionary models, economic life goes on with actual disequilibrium transactions (which are not necessarily outcomes of perfectly rational behavior and foresight), while the selection forces remunerate or punish behavior and usher the system to schemes of resource allocation that are close(r) to optimal; yet only ex-post, gradually, and with a time lag! In other words, in evolutionary models, less than perfectly rational behavior/expectations and the resulting divergence from the optimal allocation of resources may sustain for prolonged periads, before they are eliminated by the forces of selection and the resulting patterns of emerging self organization. "This fact is essentially what gives evolutionary systems their dissipative nature.

\subsubsection{Economic selection 2: Entry and exit of firms}

In addition to the mechanisms that force relatively less profitable firms to shrink in productive capacity and output, the eventual exit of such firms constitute another important dimension of our selection dynamics. Basically:

- The firms whose cumulative capacity loss fall below a threshold percentage of the initial capacity at the very beginning of the downturm go bankrupt and die. Since the death condition depends on cumulative losses (a stock variable), the firms that generate relatively lower (per period) losses (a flow variable) survive longer tinan the ones that generate higher (per period) losses while they gradually shrink before death. The remaining capital stocks of the firms that die are added to the stock of the corresponding second hand capital pool.

- The secondary way in which a firm may exit, is related to the firm's absolute size measured in terms of its Jabor demand. After initialization (or entry) each firm is given Age_Critical $=5$ periods to increase its labor force (which is a function of its output level) above the threshold level $M$ in LabForce = 10. Any firm older than Age_Critical periods, suffers an instantaneous death if the number of workers it demands $\left(\frac{Q_{k-1}^{t}}{a_{k, j}^{t}}\right)$ fall below MinLabForee at any given period $t$. By this method, we mainly avoid the infestation of our simulation runs with many extremely small firms, which (otherwise) significantly slows down the duration of our simulation rums.

The last important issue regarding the selection environment is the entry of the new firms. Entry is stochastic and is subject to a Poisson process, the arrival rate being a sector and country specific parameter EntArr $R t_{i j}$. New entrants are not endowed by any default level of initial capital, but like the rest of the firms, 
they resort to the financial market to get the venture capital. Since the finencial markets do not create new financial resources but only reallocates the existing profits based on relative profitability, for the entrants which has no realized profits yet, the selection is based on potential profitability which is calculated as a function of initial labor productivity level, current prices and the wage ratie. Hence, the new entrants, even in order to get their venture capital, need to be somewhat competitive at the outset. "The entrants that fail to get their wenture capital are immediately eliminated. This mechanism clearly establishes an endogenous link between the overall profitability of the economy and successful entry.

Our software implementation allows a number of alternative assumptions regarding the initial productivity and/or quality coefficients (i.e., $a_{k i j}^{0}$ and $Q u a l=i j$ ) of new entrants. Basically for either of these two dimensions, one can choose to have the software assign each new entrant the corresponding coefficient of the best: practice or the worst practice firm of the instant of entry and of the sector and country in which entry takes place. Alternatively one can have the software make a random assignment to each entrant which is withdrawn from the interval set by the corresponding coefficients of the best and the worst practice firms of the instant of entry and of the sector and country in which entry takes place. The exact. formulation of our entry module is presented in detail in an appendix provided in the accompanying $\mathrm{CD}^{31}$.

\subsubsection{Capital good production and unit purchase/replacement prices of capital goods}

As mentioned before, we define capital in terms of sector-specific productive capacity units which is accordingly immobile between sectors by clefinition. We also assume that capital is perfectly immobile between the countries. In our formulations so far, we have used two key variables $P$.Capt $l_{i j}^{t}$ and $L C o e f_{i, j}^{t}$ which respectively denote the unit purchase/replacement price and the labor coefficient which characterizes the production of the (reproducible) sector- $i$-specific capital. In this section we will describe the endogenous determination of these two important sector-specific magnitudes, together with the underlying reasoning.

Although it is theoretically and practically possible to model the capital sectors in a multi-firm fashion similar to our final good sectors, this avenue is left out of the scope of our project and the current design specifies the sector-i-specific capital good producer of each country $j$ as a separate single entity. Jisach such entity is responsible for the supply of new capacity and/or the compensation of depreciation on capital in a single sector of a single country.

The primary input to capital good production is labor. That is, we assume that capital good production is not subjected to any immediate capacity constraints. Thus the prinary determinant of the unit purchase/replacement prices of capital goods are labor costs. However, as discussed below one may impose also capital costs in capital good prices.

As defined before, the variable $P_{{ }_{\alpha}}$ Captlij represents the unit purchase (or replacement) price of sector $i$ specific capital in country $j$. For the individual determination of these sector and country specific magmitudes, we introduce three alternative assumptions. All three assumptions commonly assume that the productivity of capital production immediately follows (or proportional to) that of the final goods ${ }^{32}$.

1. The first alternative assumes no capital costs in capitall production, which is equivalent to the assumption that the final good producers also produce 
theix own capital in their own workhops. Under this assumption which implies no profits in capital production, the capital good prices are merely determined by labor costs. That is:

$$
\text { P.Captlij }=w_{j}^{t} \cdot \text { LCoef }_{i j}^{t} \text {, }
$$

where

$$
L C a e f_{i j}^{t}=b_{i j j}^{t} \cdot\left[\frac{\sum_{k=1}^{N F_{i j}^{k}} \frac{Q_{k i j}^{t}}{a_{k i j}^{t}}}{\sum_{k=1}^{N F_{i j}^{t}} Q_{k i j}^{t}}\right]=\frac{b_{i j}^{t}}{a_{i j}^{t}} .
$$

The part of the expression in the right hand side parenthesis in equation 3.42 , is nothing but the sectoral output level-weighted average of the firms' individual labor requirement coefficients $\left(\frac{j}{a_{k i j}^{t}}\right)$, which is $\frac{1}{a_{i j}^{t}}$, and $b_{i j}^{t}$ determines the relative capital intensity of the $i^{t h}$ sector at period $t$. In other words, if the production of one unit of final sector $i$ output on the average requires $x_{i j}^{t}\left(=\left[\sum_{k=1}^{N F_{i j}^{t}} \frac{Q_{k i j}^{t}}{a_{k i j}^{t}}\right] /\left[\sum_{k=1}^{N F_{i j}^{t}} Q_{k i, j}^{t}\right]\right)$ units of country $j$ labor, then the production of one unit of sector $i$ capital requires $b_{i j}^{t} \cdot x_{i j}^{t}$ units of country $j$ labor.

2. The second alternative imposes the average profitability of the economy into capital production by replacing equation 3.41 with

$$
P_{\text {COapt }}^{t} t=w_{j}^{t, M a x} \cdot \operatorname{LCoef} f_{i j}^{t}
$$

Reminding that the variable $w_{j}^{t, M a x}$ (introduced in equation 3.5 ) represents the wage rate level that leads to zero aggregate profits, since $w_{j}^{t}=w_{j}^{t, M a x}$. $W g S u p\left(E m p l R t_{j}^{t}\right)$, and $\frac{w_{j}^{t, M n x}}{w_{j}^{t}}=\frac{n}{W_{g} \operatorname{Sup}\left(E m p h R x_{j}^{t}\right)}$ is equal to the average price/unit cost ratio for the economy, equation 3.43 clearly imposes the economy-wide profitability in final good production also into capital good prices, which implies the assumption that capital producers apply the profit mark-up rate $\frac{w_{j}^{t, M a x t}}{m_{j}^{t}}-1$ over their unit labor costs $\frac{w_{j}^{t} \cdot b_{i j}^{t}}{a_{i j}^{t}}$ to determine the unit price of their products.

3. We also introduce a third option for the determination of capital prices. Let us assume that the machinery and equipment used in the production of capital goods for the final good sector $i$ embodies labor that anounts to bCaptl, times the direct labor inputted to capital production. Thus, the value of capital that is used in sector $i$ specific capital becomes $w_{j}^{t}$. LCoef $f_{i j}^{t}$. bCaptl. Since the sharaholders of the capital sector can be assumed to expect $r_{j}^{\text {MinAcept }}$ rate of return over this value, the price of sector $i$ specific capital can be written as (labor costs plus capital costs):

$$
\text { P_Captl } l_{i, j}^{t}=w_{i}^{t} \cdot L C o e f_{i j}^{t} \cdot\left(1+b C a p t l_{i} \cdot r_{j}^{A N i n A c c p t}\right)
$$

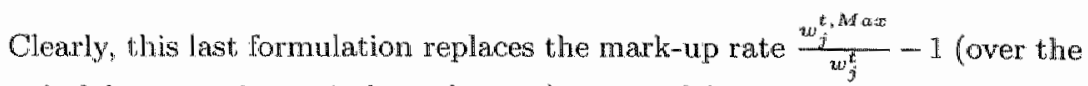
unit labor cost in capital production) assumed by our second altertative method of capital price formation (as in equation 3.43) with the argument $\left(1+b C a p t l_{i} \cdot r_{j}^{M m \text { Accpt }}\right)$. This difference makes capital prices independent of the overall capital intensity in the country and introduces parametric control through the parameter vector bCaptli. 
As we will discuss in chapter 5 , our technological change module defines the motion of the variables $b_{i j}^{t}$ in relation to the pace of labor productivity growth in the final good sectors. Therefore, in settings with no technological change, throughout individual simulation runs the $b_{i j}^{t}$ values remain constant at levels $b_{i j}^{0}$ which are set as parameters. Clearly, these parameter settings impose an individual constant level of capital intensity to final good production separately for each sector $i$ of each country $j$.

In settings where the first method is chosen (i.e., where equation 3.41 is in charge), each parameter value $b_{i j}^{0}$ imposes a fixed capital-labor ratio (in terms of values) for each sector $i$ of each country $j$. Namely, at any period $t$ in country $j$, the amount of labor that it takes to produce the capital that can facilitate the production (within the span of a period) of one unit of sector $i$ output is $t_{i j}^{0}$ times the labor that is (on the average) required to produce one unit of the final good of the same sector.

Alternatively, the second method is an approximation to fixed sectoral capitaloutput ratios (i.e., $P_{-}$Capt $\left.t_{i j}^{t} \approx b_{i, j} \cdot P_{i, j}^{t}\right)^{33}$, which implies that at all times $t$, the current nominal value of capital stock divided by the current nominal value of sectoral final output remains around the fixed level $b_{i j}^{0}$. In relation to the first method, this latter formulation, which assumes that the profitability of capital production follows the average profitability of the country, would only differ in its consequences in the sense that it makes capital costs somewhat higher. Yet more importantly, this choice also introduces the opportunity to experiment with various assumptions regarding capital-output ratio differentials across countries/sectors. In the majority of our experiments, we follow this latter formulation, which is more realistic. Note that we will introduce the option to relax the fixed capital output ratio assumption and replace it by a dynamic formulation when we introduce technological change in a later chapter.

In our software implementation the choice regarding the imposition of these three alternative methods is made by the switch parameter Profits InCaptiPrice.

\subsection{Various extensions built into the simulation software}

In addition to the essential features of our core module of economic selection described in the previous section, and also the technological change module which will be presented in chapter 5 , we have built various auxiliary modular features into our software implementation, each of which can be activated or inactivated by binary switches.

- An important one of these optional modules introduces short-run stickiness in wage rate adjustments. Our labor market formulation (1.e., equation 3.5) assumes instantaneous adjustment of wage rates as a function of current unemployment. The module that introduces some short-run stickiness to this adjustment process is based on the (20 period) moving averaging of the function $W g S u p_{j}\left(E m p l R t_{j}^{t}\right.$ ) (which determines the period $t$ income distribution in country $j$ ), and replaces equation 3.5 accordingly as

$$
w_{j}^{t}=w_{j}^{t, M a x} \cdot W g S u p_{j}^{S t i c k w, t}=\frac{G D P_{j}^{t}}{L_{C o n, s, j}^{t}} \cdot W g S u p_{j}^{\text {stickty } t}
$$


where the instrumental variable $W g S_{u p}^{\text {sticky, }}$ is defined as

$$
W g S u p_{j}^{\text {Sticky,t }}=\frac{W g S u p_{j}\left(E m p l R t_{j}^{t}\right)+\sum_{s=1}^{19} W g S u p_{j}^{\text {Stickyt-s }}}{20} .
$$

As will be explained in the following chapters, in settings where the parameter $C u r v_{j}^{0}$ (the effect of which is similar to that of the wage rate elasticity of labor supply), is set to relatively high values (i.e., $>5$ ) one observes unwanted high-frequercy oscillations (though quite low in amplitude) in output and employment time series. In our simulations short run wage stickiness is observed to have eliminated these undesired oscillations to a large extent.

- As specified by equations 3.32 and 3.33 , the estimations used by the firms in the calculations of their willingness to invest, assume that the firms know the extents of their monopoly and monopsony powers, both of which are increasing in the employment share of the firm in the economy. In our software implementation, we introduce the option to drop either of these assumptions, and assume instead that firms unable to foresee the implications of their investment decisions in terms of their effect on the product price and the wage rate. By setting either or both of the binary switch variables MonopolyCognOn_Off and MonopsonyCognOn_Off to zero, one can respectively impose $P_{k i j}^{t+1, E s t}\left(\widehat{Q_{k i j}^{t}}\right)=P_{k i j}^{t}$ and /or $w_{j}^{t+1, E s t}\left(\widehat{Q_{k i j}^{t}}\right)=w_{j}^{t}$ into equations 3.32 and 3.33 , which restricts the information (or cognitive capabilities) avallable to individual firms. One can accordingly design control experiments to observe the potential contributions of firm-level bounded micro-rationality to the overall meta-rationality constituted by the selective forces of the economy.

- As discussed in section 3.2.4, in addition to the two major behavioral alternatives in terms of firms" willingness to invest, (i.e. dynamic profitconstrained output maximization versus dynamic nominal profit maximiza tion), our model platform features a third option which is the dynamic real profit maximization. The heuristic algorithm underlying this third alternative assumption (which is triggered by the binary switch variable RealProfitCognon of $f$ in our software implementation) is described in detail in an appendix provided in the accompanying $\mathrm{CD}^{34}$.

- Our core formulation of production basically assumes constant returns to scale. That is, the labor productivity of firms $\left(a_{k i j}\right)$ are independent of the output level, so that the labor demand of a firm for given level of output is $L_{k i j}^{t}=\frac{Q_{k i j}^{t}}{a_{k i j}}$. We also introduce two optional assumptions that incorporate some form of increasing returns to scale into our model. As discussed in the introductory chapter, one can find in the literature two types of (static) increasing returns mechanisms, one being internal to individual firm (i.e. the unit costs of a firm is a decreasing function of its output level), and the other being external to the individual firm but internal to the sectorcountry (i.e. the unit costs of a firm $\mathrm{rmij}_{\mathrm{j}}$ is a decreasing function of the total output level of sector $i$ in country $j$ ). In our implementation, we formulated each of these mechanisms separately such that the variable $a_{k i j}^{t}$ represents the highest attainable labor productivity for firmsij at period $t$, while the actual (effective) labor productivity is specified as an increasing yet eventually saturating function of the output level of the individual firm ${ }_{2 i j}$ $Q_{k i j}^{t}$ or alternatively of the total sectoral output $Q_{i j}^{t}$. Our formulations on 
scale economies are presented in an appendix which can be found in the accompanying $\mathrm{CD}^{35}$.

\subsection{List of the key parameters of the core selection module}

A full list, of all parameters and state variables of our model platform is given in an appendix which can be found in the CD accompanying to this dissertation ${ }^{36}$. We will yet give below a list of the key parameters that belong to the formulations of the core selection module of our model.

\section{- Binary switches}

- Int TradeOn_Off (0 or 1): Determines whether the countries are open to international trade.

- ProfitsInCaptlPrice (0 or 1 or 2) : Can be assigned to values 0 (which activates equation 3.41 ), 1 (which activates equation 3.43 ) or 2 (which activates equation 3.44 ).

- StickyWages_On_Off (0 or 1): Determines whether wage rate (or income distribution) adjustments are characterized by short run stickiness (as discussed in section 3.3).

- TechChangeOn_Off (0 or 1): Determines whether the technological change module is on, or production is characterized by fixed coefficients. Clearly, all our discussions until chapter 5 are based on cases characterized by fixed technology coefficients which imposed by the setting TechChangeOn_Of $f=0$.

- Key system parameters

- NC: Number of countries.

- NG: Number of sectors.

- NF $F_{i j}^{0}$ : Initial (i.e., period 0 ) number of firns in the $i^{t / 2}$ sector of country $j$.

- T: Number of simulation periods.

- EntArr Rt $t_{i j}$ : The Poisson arrival (entry) rate of new firms to sector $i$ of the $j^{\text {th }}$ country.

\section{- Capital Production and depreciation related}

- $b_{i j}^{0}$ : Capital intensity parameter for the $i^{\text {th }}$ sector of the $j^{\text {th }}$ country at period $t$ as discussed in section 3.2 .6

- DeprRt: Per period depreciation rate on physical capital.

\section{- Labor market related}

- $\overline{L_{j}}:$ The fixed labor supply in country $j$.

- MaxOverTime $\geq 1$, MaxLShr, $C u r v_{j}^{0}$ and $C u r v_{j}^{4}:$ As in equation 3.6. 


\section{- Welfare and consumption related}

$-\alpha_{i j} \in(0,1)$, (where $\sum_{i=1}^{N G} \alpha_{i j}=1$ ): The budget share, which the customers of country $j$ allociate for their sector $i$ purchases.

$-\theta_{i} \in(0,1)$ : captures the demand for variety, or equivalently the degree/extent of substitutability among the products within sector $i$ as described by equations 3.7 and/or 3.8 .

\section{- Investment and financial market related}

- $r_{j}^{\text {Captistcons }}$ : The minimum rate of return on capital demanded (for current consumption) by the capitalists from each firm.

- $r_{j}^{\text {MinAcept }}$ : The minimum rate of return on capital (which is equal to $r_{y}^{\text {Captlstcors }}+$ DeprRt.) below which a firm can not receive sufficient financial resources to grow or to sustain current ontput level in the long run

- OMPM $M_{k i j} \in\{0,1\}$ : Which determines the furm"s inwestment (i.e. capital expansion) tendency as profit maximizing (i.e., $O M_{-} P M_{k i j}=$ 0) or profit-constrained output maximizing (i.e., $O M_{-} P M_{k i j}=1$ ), as discussed in section 3.2 .4 .

\subsection{Conclusive remarks}

Reconsidering these principles together, one can clearly see that the model introduces a selection mechanism in line with the evolutionary models of predator-prey type which are based on the "all positive profits are invested and negative profits are disinvested" rule. Given the output levels of all firms at period $t$, the firm-level product prices are determined through the inverse demand function, total labor demend determines the wage rate(s) and accordingly the profits of each firm, and based on firms" willing to growth and their profitability, the part of the profits collected by the financial market which exceed shareholders' current consumption need are redistributed back to firms. The profitability and thus the potential growth of a firm at period $t$ (or firm size at period $t+1$ ) is an increasing function of its relative fitness (i.e., productivity which determines relative costs and/or product quality which affects relative prices) at period 4 . Firms' productive capacities which are fully utilized at all times, together with labor productivities determine the instantameous demand for labor (i.e. employment rate) and the wage rate (which applies equally to the whole set of the firms of the country) is an increasing function of the employment rate. The total wage bill is equal to (higher than) the nominal income of the country if the economy is at (above) full employment level. Since profits are the mere savings of the countries, below full employment the economy tends to grow and vice versa. This mechanism, accordingly, have the tendency to keep the economies around employment levels, where average profitability (i.e. rate of return on capital) is around the level which is the sum of the rate desired by the capitalists $\left(r_{j}^{\text {CaptlsiCons }}\right)^{37}$ plus the (per periad) depreciation rate on capital (Depr Rt). However, since the firms are heterogeneous in terms of their productivity, quality, and hence their profitability, around full employment: a zero sum like game is played. That is, around the maximum employment level consistent with the capitalists" consumption/sawing preferences, the highly profitable firms may grow only at the expense of the relatively less (or non-)profitable 
ones: Besides, in case of technological change (which will be introduced in a later chapter), firm level incremental (and heterogeneous) increases in productivity not only keep on maintaining heterogeneity in terms of individual firm growth but, by gradually relaxing the aggregate labor constraint (by decreasing total labor demand), constitute the main engine of growth as well. 


\section{Notes}

1. The demand for labor is an increasing function of the firms" output levels and labor coefficients. As long as the total demand for labor remains above (below) the labor supply, wage rate tends to increase (decrease), also increasing (decreasing) unit costs and inhibiting (bringing about incentives for) further investments and output growth.

2. i.e. Which may be referred to als the "Goodwin cycles", due to Goodwin [1967].

3. Hofbauer and Sigmund [1988], formally show the similarities between the dynamics brought about by the two alternative selection formulations.

4. Which assumes that all firms are equally profitable unless their mark-up rates are rendered heterogeneous by arbitrary parameter settings .

5. Where the vector of relative prices uniquely determine firm level demand and accordingly market shares, independently of time.

6. Counter examples are naturally the mainstream models of growth, where investments stop when the profit rate (i.e. interest rate or the marginal productivity of capital) reaches a lower limit, which reflects the societiles" (or the capitalists') temporal preferences.

7. i.e., What remains from their current consumption.

8. Which is conveniently assumed not to be subjected to any immediate capacity constraints.

9. Consider a Cobb-Douglas aggregate production $Q=A \cdot L^{\alpha} \cdot K^{1-\alpha}$, as in the Solow modlel of growth. Under optimization the parameter $\alpha$, represents the share of wage bill in $G D P$ (i.e., $\frac{2 m \cdot L}{G D P}$ ). Thus, income distribution is not really an endogenous outcome (as opposed to what is often claimed) of models that resorts to the Cobb-Douglas form. Contrary to mainstream formulations, which (elegantly yet highly unrealistically and thus controversially) package issues on income distribution and techmological possibilities into one functional form, we keep these two issues in seperate modules. Our function $W g S u p_{j}($.$) actually calculates income$ distribution (the parameter $\alpha$ of the mainstream formulation), endogenously as a function of employment rate and institutional factors. As will be explained later, in our model, (the evolution of) employment rates and the according income distributions are determined endogenously and dynamically as an emergent outcome of the complex interplay between institutional factors, aggregate capital output ratio, labor productivity, frms' investment behavior and capitalists temporal preferences. Furthermore, note that in our notation we keep a country subscript for the wage suppression function. Naturally, this implies that we allow for heterogeneity in the institutional settings of the labor markets of the countries.

10. The reader can also find in the accompanying $C D$ a simple tool implemented in Microsoft Excel, which aids the visualization of the function $W g S_{u p}\left(E_{j} m p l R t_{j}\right)$ for various parameter settings. The file "Employment\&Wages_Visualize.xls" can be found under the directory/Utils of the accompanying CD

11. If the wage rate $w_{j}^{t}$ happens to be equal to $w_{j}^{t M a x}=\frac{G D P_{j}^{t}}{L_{C o n}^{t}, j}$, then the total wage bill $w_{j}^{t} \cdot L_{C o n s, j}^{t}$ is equal to $G D P_{j}^{t}$, which implies zero profits at the aggregate level.

12. The welfare function we used has the homotheticity property and as we show in an appendix (i.e., the last section of the file "Appendices/Chap3App.pdf" in the accompanying CD) the behavior of the representative customer is identical to the aggregate behavior of the underlying individual customer's, and also that the utility of the representative customer is an unambiguous (and thus valid) proxy for the total welfare of the individual customers. 
13. Note that in our notation, we sometimes drop the superscript for simplicity, whenever doing so does not lead to confusion.

14. Better put, a separate representative customer for each country.

15. Conventionally, throughout our simulation runs, we update GDP (for each country $j$ separately) such that it varies parallel to the country welfare $U_{R j}$ (i.e., for arbitrarily taken initial conditions $G D P_{j}^{0}$, the notion of $G D P_{j}^{i}$ is specified so that $\widehat{G D P_{j}^{t}}=\widehat{U_{R j}^{t}}$, (where a hat denotes rate of change) and is used as an additional welfare measure for each country.

16. Note that this property also holds in case of international trade, for any two firms of different countries provided that they operate in the same sector.

17. In the fle "/Appendices/Chap3App.pdf".

18. Technically speaking, within the logic of our selection dynamics, the only convernient alternatives to the second hand capital market construction is either to assume that capital goods are consumable (as in Silverberg and Verpsagen [1995a] or to assume that the part of capital goods that correspond to the losses of the firm simply disappears, both of which would constitute major sources of dissipation for the economy which do not necessarily exist in reality. Our second hand capital market construction which is essentially a mechanism of sector-specific capital reallocation between the firms, avoids such unjustifiable dissipation and accordingly introduces some smoothness into the output adjustment process.

19. i.e., Basically since the upper limit of the function is the sum of firms' indi-

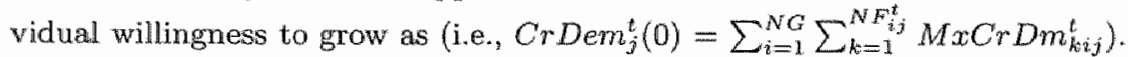

20. This property is reminiscent of the Post-Keynesian arguments an Endogenous Money Supply, which express a certain scepticism about the effectiveness of monetary policies (Given that credits created by the financial market constitutes a significant part of the money supply) on promoting higher employment rates and growth.

21. Capital goods that accumulate in the second hand market decay rapidly (by a high scrapping factor), unless bought and used by other firms instantaneously. Hence, negative total profits at the sectoral level constitute a potential of dissaving. That is, in addition to the immediate consequences (i.e., withdrawal of some part of capital from immediate production at period $t$ implies a lower level of output in the following periods, unless added to the capital stock of some other profitable firms that need to expand), the rapid decay of the unused capital goods waiting in the second hand markets imply a loss of wealth for the capitalist who happen to be unlucky enough to have invested (in the past) on a frm which ex-post does not turn out to be a winner. While the forces of selection keep on eliminating the firms that are least fit (non-profitable) and gradually increase the overall fitness (productivity, profitability etc.) of the economy, in disequilibrium conditions where the majority or all of the firms suffer losses, the capital stock of these firms are eliminated/lost along with the firms. This mechanism, which gives our system a dissipative nature, is quite similar to that in Silverberg and Verspagen [1995a], where (thanks to the single-sector economy setting which rules out any sectoral segregation) the capital of non-profitable firms dissolve into a consumable form and added to the current GDP. Similar to the majority of evolutionary systems, the inefficiency brought about by the lack of perfect ex-ante foresight is gradually eliminated in due course by the selection mechanism, yet the societies eventually pay for the consequences of past decisions which seem (due to essential uncertainties) reasonable ex-ante, and turn out to be otherwise only ex-past.

22. Naturally for any firm, the strength of this effect is an increasing function of market share (i.e., monopoly and monopsony power). 
23. Which can be calloulated from the derivatives of equation 3.9. Note that, in case of taste differentials across the countries, the elasticity of inverse (world) demand prices to firm supply can not exactly be calculated and the following specification remains an approximate figure.

24. i.e. In a case where $\theta_{i}=0$, the output of each individual firmkij is perceived by customers as a totally different product, which makes each firm a monopolist for its own product. In such a case, sector $i$ becomes equivalent to $N F_{i j}$ (or $\sum_{j=1}^{N C} N F_{i j}$ in case of international trade) individual sectors, each receiving a fixed (and equaly budget share out of customers "incomes.

25. As will be discussed in section 3.2 .6 , the expression $\frac{P_{-C a p t} t_{i j}^{t}}{P_{k i j}^{t}}$ is an indication of the capital intensity in production (i.e., the sectoral capital-output ratio), which due to our formulations that determine unit capital prices, tends to remain around the parameter value $b_{i j}$. Furthermore not that, as will be discussed in chapter 7 , profits are the only source to finance R\&D expenditures and firms that are willing to invest or $R \& D$ would not be willing to sacrifice this major source for mindless growth. Thus, in settings with endogenous technological change, the acceptable profitability threshold $\pi \_S_{k i j}^{t, M i n A c c p t}$ is calculated as $\left(r_{j}^{M i n A c c p l} \cdot \frac{P-C a p t l_{i j}^{t}}{P_{k i j}^{t}}\right)+$ $R D T a r g_{k i j}^{*}$, where RDTarg $g_{k i j}^{t}$ is the R\&D to sales ratio targetted by the firm.

26. i.e., Gr $M x_{k i j}^{t}$, which, due to equation 3.19 , is the the key argument of the firm-level credit demand function $\operatorname{CrDem} \operatorname{De}_{k i j}^{t}\left(i n t_{-} r t\right)$.

27. In the file "/Appendices/Chap3App.pdf".

28. i.e, a hypothetical industry that consists of infinitely many, measure zero, profit-maximizing firms.

29. Nevertheless, as will be demonstrated by the simulation runs in the next chapter, steady state regularities that resemble Nash equilibria endogenously emerge.

30. i.e., since 'the others' are apt to realize only incremental changes on their output levels, the ceteris paribus assumption becomes a reasonable one.

31. In the file "/Appendices/Chap3App pdf".

32. Note that in a later chapter" when we discuss technological change, we suggest an alternative formulation (in line with that of Nelson and Winter [1982]) that diverges from this assumption in a systematical way.

33. Note that with this latter formulation, our capital price calculation is identical to that in Silwerberg and Verspagen [1995a].

34. In the file "/Appendices/Chap3App.pdf".

35. In the file "/Appendices/Chap3App.pdf".

36. The file "/Appendices/Eull.Param_Var_List.pdf".

37. Based on the institutional settings of the economies (i.e. the shape and position of the function $W g S u p(\cdot)$ ), full employment is also attainable. In other words, if the wage rate at full employment is low enough to yield capitalists the minimum acceptable profitability level, the economy can operate at full employment. 


\section{4}

\section{Selection with constant technologies: Stationary Fundamentals}

\subsection{Introduction}

The model, which we started to present in the previous chapter, is implemented as a discrete time dynamic system. The computer code of the model is written in $\mathrm{C}+4$ programming language in an object-oriented framework. As described before, a high variety of alternative assumptions and a high number of parameters are built into our model, which can as well be seen as a modeling platform (that introduces various options for various assumptions either by switches or parameter settings) of which single models are specific instantiations. Thus, in order to facilitate our presentation and furthermore to give interested readers a working version of the model (to design their own experiments and build their own scemarios), we have complemented the model with a graphical user interface. The resulting software is capable of letting the user edit/change the key parameters and assumption-wise switches of the model, save these settings as project filles, and retrieve settings from existing project files later, when necessary. Accordingly, for each experiment/scenario that is presented in this book, we supply the associated project file (as well as the output of the simulation) in the accompanying CD. These project files, in which the switches and parameter values of indiwidual scenarios/experiments are saved, can be retrieved (and visualized) by using the software, which can also be found in the accompanying CD. The reader can oper each project fille by using the software supplied, validate our parameter settings (in relation to values presented in the text in this book) and make more simulation runs.

In addition to the facilitation of the presentation, the edition and the retrieving of parameter/switch settings that pertain to various scenarios/experiments, the simulation software supplied on the accompanying CD also helps visualize the output of the simulation runs (various time series of the values of selected aggregate variables and statistics) by Microsoft Excel antomation. The graphical interface features a menu of various alternative aggregate variables (such as sectoral output: levels, consumption, welfare, Herfindahl Index on firm size distributions, number of firms etc.). The user can check any of the items in this menu, and during the runtime of the simulations, the software launches Microsofti Excel, sets up the charts for the selected time series, and plots them on the fly as the simulation progresses over time. Optionally, the user can also have the software only plot 
sannpled time series (i.e. the selected output variables are plotted only once in ewery $S$ periods where $S$ is determined by the user). For the presentations of our experiments, we also supply the Microsoft Excel charts of all time series generated by each scenario on the accompanying $\mathrm{CD}$. In addition to the pre-formatted charts the software also files raw output data (given in ASCII text files) in terms of time series of country-level and sector-level aggregate output variables. The software also produces panel (i.e. firm-level longitudinal) data in ASCII text form, where each line in the output file gives a collection of the state variables of a different firm (such as output level, profits, productivity, market share, investments etc.) at a different point in time. By analyzing these data, one can observe the history (evolution) of each individual firm in the simulation during its lifetime.

A brief "users' manual" of the software is supplied in the accompanying CD" This manual describes the basics of the ways in which the software can be used to make re-runs of the experiments presented in this dissertation and/or designing and running new experiments.

Due to the convenience brought about by the existence of an accompanying CD where the various output time series generated by each of our experiment/scenario are given in readily formatted charts, we have found the opportunity to economize on the number of pages of this dissertation. In addition to allow us to present only the highlights of our simulation results in this dissertation (while keeping the details that a relatively more interested reader available on the alternative medium which is the accompanying $\mathrm{CD}$ ), this economizing is realized also in another context:

Since the main objective of our agent-based evolutionary modeling exercise is to investigate various issues on the relations between technological change, economic growth and international trade, the selected simulation experiments that are to be discussed in this dissertation will only be presented in chapter 6 , just after chapter 5 where the technological change module of our model is presented. However, according to our presentation strategy, having presented the core of our model in the previous chapter, we will first discuss about the stationary fundamentals (i.e. properties of convergence in cases where the system is not disturbed by technological change) of the model both in terms of closed and open economies: To this end, we have made a rather high number of control experiments with rather simple settings. On the accompanying $\mathrm{CD}$, we supply not only the setup and output files that pertain to these demonstrative experiments ${ }^{2}$, but also two appendices ${ }^{3}$ to this chapter where these experiments are discussed in terms of their settings and the sense they make in terms of economic theory. In the current chapter we will only make an overview of such discussions on the steadystate properties of our model, along with a number of reduced-form (analytical) equations which are derived to predict these basic stationary properties that are highlighted under simple settings.

Unlike in mainstream equilibrium models where equilibrium is simply imposed as an inevitable and rapidly reachable outcome and the actual adjustment processes (the fixed point of which characterizes the eventual equilibrium) remain as an informal (verbal) story ${ }^{4}$, in our model which is essentially dynarnic and agentsbased, whatever happens, happens at the agent level and over time, and one is interested in observing any emerging patterns at the aggregate level. Yet as mentioned above, for the sake of a comparative discussion and further clarification, we will present below a number of reduced form (equilibrium) re-formulations which represents the potential fixed point of the selection module of our essentially multi agents-based dynamic model. These equations are based on the presumption that 
in case of no technological change (i.e. fixed production coefficients) our dynamic process tends to converge to an equilibrium-like point where observable change at the aggregate level stops.

Am important question that naturally follows is "for an agents-based dynamic model, where behavior and adjustments are formulated in procedural/algorithmic fashion, and where the long mun properties of the system can accordingly not be analyzed with the tools of linear/non-linear dynamic system theories (reserved for well-defined simultaneous difference/differential equation systems), to what extent one can talk about a fixed point?". Or in other words, "In the absence of technological change, does our dymamic system indeed eventually converge to some point?", "If yes, how close is this point to the one predicted by our reduced form equations, and in what ways/extent do our particular choices amongst the behavioral alternatives (profit versus output maximization, entry rates, etc.), and/or our particular choices on initial conditions (i.e. initial number of firms, initial employment rates etc.), affect this proximity?", "What are the properties of such fixed-points in terms of employment, output level, international trade flows and specialization?" and "How stable is the point of convergence against external disturbances?" These are the main questions, which we aim to address in this chapter.

\subsection{Selection in closed economies: Macroeconomic implications}

\subsubsection{Equilibrium employment and output levels in cases characterized by output maximizing firms}

Let us first summarize the essence of our core formulation of our selection environment. At a given point in time (period $t$ ) the $i^{\text {th }}$ sector of the $j^{\text {th }}$ national economy is characterized by $N F_{i}^{t}$ firms. Production for each firm $k_{i j}$ is characterized by the labor productivity coefficient $a_{k i j}^{t}$ and a product quality level $Q u a l_{k i j}^{t}$, both of which are allowed to be heterogenous across the firms. Firms are assumed. to be producing up to capacity at all times. Capital goods are measured in (sectorspecific) capacity units. The labor productivity in sector i specific capital good production in country $j$, is assumed to be proportional to the current average labor productivity in the same sector and country by factor $b_{i j}^{0}$ (i.e., $b_{i j}^{0}$ " $\frac{\sum_{k=1 j}^{N F_{i j}} Q_{k i j}^{t}}{\sum_{k=1}^{N N_{i j}} \frac{Q_{k i j}^{t}}{a_{k i j}^{t}}}$ ). Accordingly the parameter $b_{i j}^{0}$ determines the capital intensity of sector $i$ production in country $j$ and since all firms purchase their capital goods ${ }^{5}$ from the local capital goods market, at any given time instant; $t$, all firms of the same sector of the same country are homogenous with respect to capital intensity in production ${ }^{6}$. Technological change (which will be discussed in the next chapter) is nothing but the simultaneous temporal change of frm level coefficients $a_{k i j}^{t}$ and $Q u a l_{k i j}^{t}$ and also the sector-country specific parameter $b_{i j}^{0}$. Thus, in this chapter we will confine our discussions only to cases where these three parameter vectors are kept constant.

At every period the inverse demand curve (which is derived from the composite welfare function given by equation 3.7 or 3.8 ) maps the firm level output level vector $\mathbf{Q}$ to the firm level nominal price vector $\mathbf{P}$. This mapping is strongly affected by the CES parameter $\theta_{\text {, }}$ of the welfare function which determines the extent of substitutability between the products of firms competing in the same 
sector of the economy. In cases where products are perfectly substitutalible, all firms of the same sector face an identical inverse demand price if their quality levels are identical ${ }^{7}$. In cases of imperfect product substitutability (i.e. demand for variety), the inverse demand price $P_{k i j}$ faced by the firmkij relative to those faced by other firms, is decreasing in the size (i.e. output level) of the firmaig relative to the size of the other, and increasing in the firms relative quality level.

At each period, the firm level output level vector, together with the labor coefficient vector, determine the labor demand, which, in turn, determines the nominal wage rate $w_{j}$. The country specific parameters of the function $W g S u p_{j}\left(E m p R t_{j}\right)$ which maps employment rate to the share of total wage bill in GDP and accordingly facilitates the mapping of employment rate to the nominal wage rate, reffect the institutional settings of the labor market (i.e. the collective bargaining power of workers or in other words the wage rate elasticity of labor supply) in country $j$.

Our formulation rules out short/medium term loans in finance and accordingly compulsory unterest payments. The only compulsory expenses of the firms are labor costs and thus the profits of the firm ${ }_{k i j}$ at any given period $t$ are given by $\pi_{k i j}=Q_{k i j} \cdot\left(P_{k i j}-\frac{w_{j}\left(\frac{L_{j}}{L_{j}}\right)}{a_{k i, j}}\right)$. Having dropped the opportunity cost of capitall from our immediate cost formulation and define profits as accounting profits, the next question that aaturally follows is "what would the firm do with these profits?".

One can imagine two possible actions: Passing the whole profits over to shareholders as dividend payments, or use them all to purchase new capital goods and expand productive capacity. Naturally, in a capitalistic economy the latter can not be a sustainable option since there exist institntions that would replace managers that persistently follow such a strategy. Thus, we base our working assumption mainly on the former type of action (though we also introduce the latter into our model for comparative thinking experiments). The following question is "what would the capitalist do with the dividend earnings collected from the firms?". Again there are two ways: To spend the dividend earnings for current consumption, or in expectation of increased future consumption, to invest (to redistribute) dividend earnings on firms which are willing to grow. Thus the key issue is the ways in which capitalists allocate their income over these two competing uses.

In the literature on growth one can find two competing formulations. The first formulation (that follows the Keynesian tradition), which is centered around the "marginal propensity to invest" concept, assumes that capitalists (or the entire society) are willing to spend axed share of their income to invest on capital expansion, independently of technological opportumities, prices, market price of capitial, and accordingly the overall profitability of the economy. On the contrary, the modern neodassical formulations (as those in the new growth literature) follow the idealized link between the rate of return on capital (or the marginal productivity of capital), and societies' temporal preferences. According to the latter conceptualization, societies (or capitalists) persistently expect a minimum stream of future income (interest rate) on their accumulated past investments. As long as the rate of return yielded by the accumulated capital exceeds this threshold rate, imvestments carry on building up of the productive capacity of the economy while growth stops below this level. As discussed in the first two chapters, the entire set of mainstream models of "new growth" explore the effects of the potentjal of various mechanisms that could persistently keep the (marginal rate of) return on capital above this threshold value and accordingly lead to sustained growth.

In our model specification, we follow a variant of the latter formulation. Our country-specific parameter $r_{j}^{M i n A c c p t}$ represents the threshold rate of return on 
capital, bellow which capitalists cease to inwest on capital (including the making up of the capital losses due to depreciation). At the point where a firm. yields profits that amounts to $r_{j}^{M i n A c c p t}$ times the value of the capital stock (i.e. $\pi_{k i j}^{t}=\tau_{j}^{M i n A c c p t} \cdot\left(P_{-}\right.$Captl $\left.l_{i}^{t} \cdot Q_{k i j}^{t}\right)$, where P_Captli is the unit purchase price/replacement cost of composite capital which is required to produce one unit of sector $i$ product), the capitalists only finance the making up of the per-period depreciation on capital, and accordingly keep the amount $\left(r_{j}^{\text {AM }}\right.$ in Acept $\left.-D e p r R t\right)$. $\left(P . C a p t t^{t} \cdot Q_{k, j}^{t}\right)$ for current consumption. At periods where capital productivity implies rate of return levels higher than $r_{j}^{M i n A c c p t i}$ (i.e. $\frac{\pi^{t}}{P_{-} C a p t l^{t} \cdot Q_{k i j}^{t}}>r_{j}^{M i n A c c p t}$ ), the amount $\pi_{k i j}^{i}-\left[\left(r_{j}^{M i+A c c p t}-D e p r R t\right) \cdot\left(P_{-} C a p t l_{i}^{t} \cdot Q_{k i j}^{t}\right)\right]$ is made available to the firm provided that is is willing to expand output by releasing orders to the capital sector for the production of new capital goods, eventually to be added to the existing stocks. Thus, as long as profitable firms have some positive growth desire and the rate of return on the existing stock of capital remains above $r_{j}^{\text {Min Acept }}$, more capital (i.e. productive capacity) is added to the existing stock, increasing the output level, pushing down prices, pushing up wages and accordingly decreasing profitability. On the contrary, below $r_{j}^{\text {Min } A \text { ccpt }}$, where depreciation (which is not compensated) erodes capital away, output and employment fall, prices rise, wage rate decreases and profits increase. Accordingly, the only point where change would stop (the fixed-point/equilibrium of the pure selection process in case of no technological change) is where all firms simultaneously make profits equivalent to $100 \cdot r_{j}^{\text {Min.Accpt }}$ percent rate of return on their capital stock. Thus, at the hypothetical equilibrium (fixed point) of our dynamic model of selection, the following relation needs to hold for each sector $i$ firm

$$
\frac{\pi_{k i j}}{P_{-} C_{a p t l_{i j}} \cdot Q_{k i j}}=\frac{P_{k i j}-\frac{w_{j}}{a_{k i j}}}{P_{-} C_{a p t l_{i j}}}=r_{j}^{\text {MiniAccpt }}
$$

This last relation gives the condition for survival for firms. For any two arbitrarily chosen competing firms $k$ and $s$ of sector $i$, the condition for simultaneous survival at equilibrium is $P_{k i j}-\frac{w_{j}}{a_{k i j}}=P_{s i j}-\frac{w_{j}}{a_{s i j}}$. The implications of this equilibrium survival condition can be summarized as follows:

- In cases where the output of competing firms in a given sector $i$ is perfectly substitutable with each other (i.e. $\theta_{i}=1$ ), after the selection forces do their job, the co-survival of a number of firms that are heterogenous in their labor productivity coefficients is possible only if the firms that are relatively less productive can compensate this shortcoming by offering a higher quality (i.e. recall that in cases where $\theta_{i}=1$, the inverse demand function implies that $\frac{P_{k i j}^{t}}{P_{s i j}^{t}}=\frac{Q u a l_{k i j}}{Q \text { Quicl }}$.

- Otherwise (i.e. if firms are homogenous in the quality level of their product), one expects that the selective forces of the economy eliminates the firms with relatively lower labor productivity coefficients, and consequently that the best practice firm of the initial population becomes a monopolist at the equilibrium.

- In cases where substitutability among products is less than perfect (i.e., $\theta_{i}<$ 1), even firms are identical with respect to the quality level of their product, due to the protection of demand for variety against the selective forces of the economy, one can still observe the coexistence of a number of firms that are heterogenous in their labor productivity level. At such an equilibrium, 
one expects that the relatively more productive of the surviving firms have relatively higher market shares. The reason underlying this property is the fact that in cases where $\theta_{i}<1$, our inverse demand function implies that $\frac{P_{k i j}}{P_{s i j}} \geq 1 \Leftrightarrow \frac{Q_{k i j}}{Q_{k i j}} \geq 1$.

Now, let us focus on cases of single sector economies where products are perfectly substitutable with each other (i.e. $\theta_{i}=1$ ) and firms are homogenous in their quality levels. As discussed just above, one expects a single firm (or a number of firms having the identical level of labor productivity) at the potential equilibrium Assuming that this single firm is a profit-constrained output maximizer, let us focus on the macroeconomic properties that one would expect to observe at the equilibrium.

As mentioned before, we have introduced three alternative assumptions for the determination of the price of each sector specific capital unit (capacity). The first one, rules out profits in capital production by assumption (a hypothetical one that assumes firms produce their capital in their own workshops) and formulates the price of capital as $P_{-} C a p t l=w \cdot \frac{b}{a}$, where $a$ is the average labor productivity in the single sector economy. The second one assumes that profitability in capital production equals to the average profitability of the economy so that P_Captl= $w^{M a x}, \frac{b}{c t}$, where $w^{\text {Max }}$ is equal to $G D P$ per employed final sector worker $\frac{G D P}{L}$. The third one specifies the extent of profits in capital prices as an increasing function of the capital-labor ratio in capital production (i.e. $b C a p t l$ ) such that $P_{-} C a p t l=$ $w \cdot \frac{b}{a} \cdot\left(\mathbb{1}+b C a p t l \cdot r^{\text {Min Accpt }}\right)$. Let wis start by considering the first option which is equivalent to assumption that the parameter $b$ reflects a fixed capital-labor ratio, and also ignoring the labor needed to produce the capital goods that compensates for the depreciation on capital (i.e., considering only the employment created by the final good sector). Thus

- Recalling that the wage rate is a $(n$ increasing) function of the employment rate $\left(\frac{L}{L}\right)$, the unit price of capital is $P-C a p t l=b \cdot \frac{w(L / L)}{a}$,

- profit of the output maximizing firm is $\pi=Q \cdot\left[P-\frac{w\left(\frac{L}{L}\right)}{a}\right]$,

- the inverse demand curve implies $P=\frac{G D P}{Q}$ and $L=\frac{Q}{a}$,

- $w\left(\frac{L}{L}\right)=w\left(\frac{Q}{\alpha \cdot L}\right)=\frac{G D P}{L} \cdot W g S u p\left(\frac{Q}{a \cdot L}\right)=\frac{a \cdot G D P}{Q} \cdot W g S u p\left(\frac{Q}{a \cdot L}\right)$.

Accordingly the equilibrium condition that rate of return on capital $\frac{\pi}{b \cdot \frac{w(L / L)}{d} \cdot Q}$ equals $r^{\text {Mith Acopt, }}$, translates into

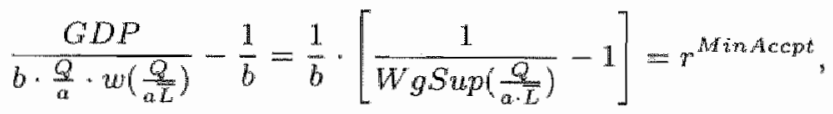

or equivalently to

$$
\frac{L}{\bar{L}}=W g \operatorname{Sup}^{-1}\left(\frac{1}{b \cdot r^{M / n \cdot A \operatorname{copt} t}+1}\right)
$$

and

$$
Q=a \cdot \bar{L} \cdot \operatorname{WgSup}^{-1}\left(\frac{1}{b \cdot r^{M i n} \mathrm{Accpt}^{2}+1}\right)
$$

where $W g S u p^{-1}(\cdot)$ is the inverse function of $W g S u p(\cdot)$. The latter two equations together imply that at a possible equilibrium, output and employment levels are determined by 
- workers' bargaining power (for their collective share in GDP), whith is determined by the parameters of the function $\mathrm{WgSup( \cdot )}$

- the minimum interest rate accepted by the capitalists (i.e. $r^{\text {A inAcopt }}$, which is similar to the parameter that determines the society's temporal preference in mainstream models of growth),

- the capital-labor ratio (i.e. the parameter $b$ which reflects the capital intensity of production),

- and the productivity of labor (i.e. the parameter a). Note that labor productivity does not affect equilibrium employment rate but only the output level.

Under the alternative assumption that the economy-wide profitability applies to capital production (which implies that the parameter $b$ reflects a fixed capitaloutput ratio), the unit price of capital becomes $P$-Captl $=b \cdot \frac{w^{M a x}}{a_{i}}=b \cdot \frac{G D P}{a \cdot L}=$ $b \cdot \frac{G D P}{Q}=b \cdot P$. Then, the equilibrium employment rate would be determined such that

$$
\frac{L}{\bar{L}}=W g \operatorname{Sup}^{-1}\left(1-b \cdot r^{M i n A c c p t}\right)
$$

Clearly, the value of the argument $1-b \cdot r^{\text {MinAccpt }}$ is not equal to yet quite close to that of the argument $\frac{1}{b \cdot r^{M i n} A_{c c p t}+1}$ in equation 4.3 . Thus, the assumption of choice regarding the calculation method of the price of capital is apt to make some but little difference in the determination of output and employment levels in our model.

With our third alternative method of capital price determination (i.e., unit price of capital is $\left.w \cdot \frac{b}{a} \cdot\left(1+b C a p t l \cdot r^{\text {MinAccpt }}\right)\right)$, capitial intensity in capital good production (bCaptl) also joins the list of the determinants of the equilibrium employment rate $\frac{\mathbb{L}}{\mathbb{L}}$ :

$$
\operatorname{WgSup}^{-1}\left(\frac{1}{1+b \cdot r^{\text {MinAccpt }} \cdot\left(1+b C a p t l \cdot r^{\text {MinAccpt }}\right)}\right) .
$$

Let us give a numerical example on the basis of the first method. Assume that the capitalists are expecting a minimum future stream of $r_{j}^{\text {Captlstcors }}=4 \%$ (per period) return on their accumulated investment, the periodic depreciation rate is Depr Rt $=1 \%$, which together yield $r^{\text {MinAcrpt }}=r^{\text {CaptlstCons }}+$ Depr $R t=5 \%$, and the capital output ratio $b$ is 3.0 . The latter two imply that capitalist demand a. future stream of income that amounts to $b \cdot r^{\text {Captstcons }}=12 \%$ of the annual (per period) $G D P$, the compensation of depreciation demands $b \cdot \operatorname{Depr} R t=3 \%$ of the annual (per period) GDP, which together implies that at the notional equilibrium workers can at most claim $1-b \cdot r^{M i n A c c j t}=1-0.15=0.85$ of the GDP. Thus, at full employment, if workers are unable to bargain for an aggregate wage bill (collectively as summarized by the function $W g S u p\left(\frac{L}{L}\right)$ ) higher than $\frac{\| 1}{1+0.15} \approx$ 0.869 of the GDP, then the economy can operate at full employment. Otherwise (reminding that $W g S u p\left(\frac{L}{L}\right)$ is an increasing function of the employment rate $\frac{L}{L}$, or equivalently a decreasing function of the unemployment rate), full employment is not economically viable and structural unemployment is expected at equilibrium. Thus, althongh both workers and capitalists have some power to affect the income distribution, capitalists have the upper hand since they are the ultimate decision makers on investments (which also includes the making up of the capital stock eaten away by depreciation) and thus on the evolution of the capital stock, 
output level, and indirectly the level of employment. Note that, the workers" power in the determingtion of income distribution is of a static (instantaneous) nature (i.e. workers can only bargain on the basis of the labor demand determined by the productive capacity of the economy), while capitalists' power comes from their dynamic control ower the amount of capital stock, which dynamically determines (and has the last word) on the demand for labor, employment and income distribution.

Following this little macro-level exercise which highlights the simultaneous effects of the workers' bargaining power, capitalists' intertemporal preferences and capital intensity on employment, let us do a similar exercise for multi-sector economies where each sector is characterized by another single (output-maximizing) firm (or a number of firms operating at the same labor productivity level such that $a_{k i j}=a_{i}$ for all surviving firms $k$ )

- Multi-sector equilibrium in case of no profits in capital prices: Under the implied constant capital-labor ratio assumption for capital production, for any sector $i$ firm, the equilibrium profitability condition in equation 4.1. reduces to

$$
P_{i}=\frac{w}{a_{i}} \cdot\left(1+b_{i} \cdot r^{\text {Min Accpt }}\right) .
$$

Since $\frac{\underline{w}}{a_{i}}$ is the unit labor costs paid by the firm, and the capitalists expect the same rate of return from all firms (independently of the sector in which they operate), this last equation implies that the firms of the relatively more capital intensive sectors (i.e. the sectors where the price of unit productive capacity $b_{i}$ higher) need to price their products with a higher mark-up rate $\left(b_{k} \cdot r^{\text {Min Accpt }}\right.$ ) over unit labor costs. Furthermore, recalling that our demand system specifies unit price elasticity of demand (i.e. in case of perfect withinsector product homogeneity, sectoral output $\left.P_{i}=\frac{\alpha_{i} \cdot G D P}{Q_{i}}\right)$, the output level of a sector can be expressed as

$$
Q_{i}=\frac{\alpha_{i} \cdot a_{i} \cdot G D P}{w \cdot\left(1+b_{i} \cdot r^{\text {MinAecpt })}\right.}
$$

which implies that the output level of a sector is an increasing function of the income share allocated by the customers to sector $i$, and also the labor productivity level in sector $i$, while it is a decreasing function of the wage rate, the minimum interest rate expected by the capitalists and also the capital intensity of sector $i$ production. As expressed by equation 4.3 , at the equilibrium, the employment rate and the wage rate is determined merely by $T^{M i n A c p p t}$ and a measure of overall capital intensity in the country $\left(b_{A \mathrm{~A} g}\right)$

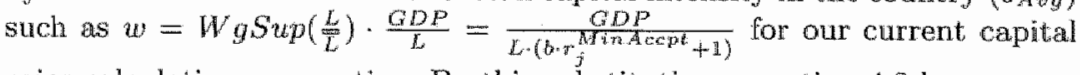
price calculation assumption. By this substitution, equation 4.8 becomes

$$
Q_{i}=a_{i} \cdot L \cdot \frac{\alpha_{i} \cdot\left(1+b_{A v g} \cdot r^{\text {MinAccpt }}\right)}{\left(1+b_{i} \cdot r^{\text {MinAccpt }}\right)}
$$

which suggests that the labor share of sector $i$ in total employment is $\frac{s_{i}}{L_{i}}$

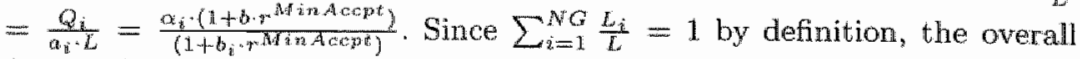
(average) capital intensity in the country can be calculated as

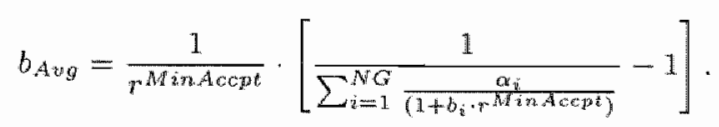


Having solved for the economy-wide capital intensity $b$, the rest of all valiables become determinate: First, equation 4.3 solves for the equilibrium employment rate and accordingly the number of workers employed $(L)^{9}$, and equation 4.9 solves for the output level in each sector separately as

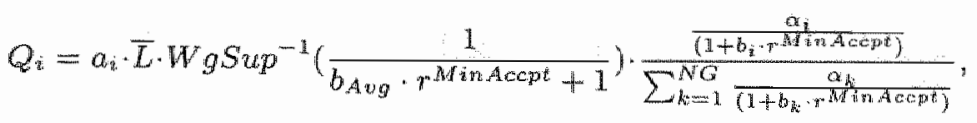

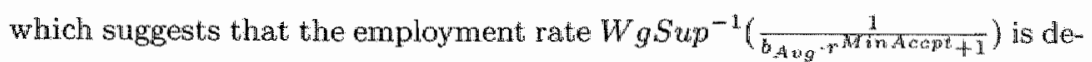
termined merely by the economy-wide capital intensity $b_{A v g}$ and capitalists" reinvestment threshold $r^{\text {Mir. Accpi, }}$, and the employment share of each sector

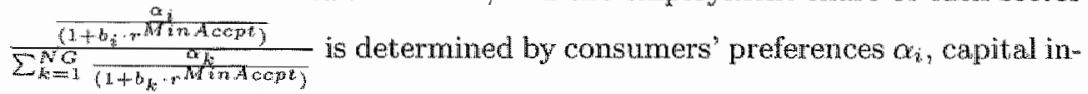
tensities $b_{i}$ and $r^{\text {Min Accpt. }}$. Clearly, in cases where capital intensities do not vary across the sectors (i.e., $b_{1}=b_{2}=\ldots=b_{N G}=b_{A v g}$ ), the labor share of each sector $i$ is simply equal to $\alpha_{i}$, which is the budget share allocated by the customers to sector $i$ products.

- Equilibrium in case of economy-wide profitability in capital production: Under our alternative assumption on capital price determination (capital prices include profits that corresponds to the overall profitability of the economy, so that the parameter $b_{i}$ reflects the sector $i$ specific capitaloutput ratio), equation 4.7 looks slightly different as

$$
P_{i}=\frac{w}{a_{i}} \cdot\left(1+b_{i} \cdot \frac{w^{M a x}}{w} \cdot r^{\text {MinAccpt }}\right)
$$

indicating that due to relatively higher prices of capital goods, the mark-up rate at which final good producing firms need to charge over their unit labor costs is somewhat higher compared to that in equation 4.7 (since $\frac{w^{N a}}{w} \geq 1$ ).

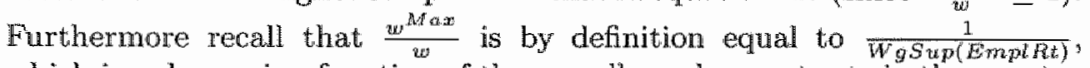
which is a decreasing function of the overall employment rate in the country EmplRt. As discussed in the last part of section ?? of this chapter, at the macro level, employment rate at equilibrium is determined by the workers bargaining power, $r^{\text {Min Accpt }}$, and also the average capital intensity (capital price) in the country $\left(b_{A}, g\right)$, as expressed by equation 4.5 , which can also

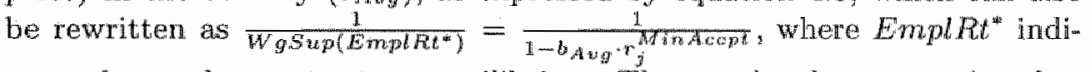
cates the employment rate at equilibrium. Thus, under the assumption that profitability in the capital sector is equal to the average profitability in the country, equation 4.12 takes the form

$$
P_{i}=\frac{w}{a_{i}} \cdot\left(\frac{1+\left(b_{i}-b_{A v g}\right) \cdot r^{M i n A c c p t}}{1-b_{A v g} \cdot r^{M i n A c c p t}}\right)
$$

which also implies that

$$
\frac{Q_{i}}{Q_{m}}=\frac{a_{i} \cdot a_{i}}{a_{m} \cdot a_{m}} \cdot \frac{1+\left(b_{m}-b_{A v g}\right) \cdot r^{M i+A} A_{c c p t}}{1+\left(b_{i}-b_{A v Q}\right) \cdot r^{M i n A c c p t}}
$$

so the conclusions derived from equation 4.8 remains unchanged. Finally, since $L_{i}=\frac{Q_{i}}{a_{i}}$, one can also write the last equation as

$$
\frac{L_{i}}{L_{m}}=\frac{\alpha_{i}}{\alpha_{m}} \cdot \frac{1+\left(b_{m}-b_{A v g}\right) \cdot r^{M i n A c c p s t}}{1+\left(b_{i}-b_{A v g}\right) \cdot r^{M i n A c c p t}}
$$


which implies that the relative shares of sectoral (labor) employment are independent of labor productivities but are only determined as a function of customers" tastes $\left(\alpha_{i}\right)$, sectoral cast of capital intensities $\left(b_{i}\right)$ and capitalists ${ }^{\prime}$ current consumption demand. For the current capital price calculation method, a slight problem presents itself. The exact solution to the equilibrium values of the endogenous model variables (employment rate, wage rate, level of output in each sector) requires the calculation of the overall capital intensity in the country $\left(b_{A w g}\right)$. Since, the labor share of a sector $i$ in total employed labor force $\frac{L_{i}}{\mathrm{~L}}=\frac{\alpha_{i}}{1+\left(b_{i}-b_{A v g}\right) \cdot \mathrm{r}^{M i n} \text { Acept }}{ }^{10}$, the relation $\sum_{i=1}^{N G} \frac{L_{i}}{L_{i}}=1$ implies that

$$
\sum_{i=1}^{N G} \frac{a_{i}}{1+\left(b_{i}-b_{\text {Ang }}\right) \cdot r^{\text {MinAcept }}}=1 \text {. }
$$

Apparently, one can not write an analytical expression for $b$, as in equation 4.10. Thus, for the equilibrium calculations, one needs to solve for $b$ numerically. For the interested readers we supply on the accompanying CD a solver, implemented in Microsoft Excel ${ }^{11}$.

- Equilibrium in case of given capital intensities in capital production: Finally for our third alternative capital price determination method, equation 4.12 can be re-written as

$$
P_{i}=\frac{w}{a_{i}} \cdot\left(1+b_{i} \cdot\left(1+b C a p t l_{i} \cdot r^{\text {MinAccpt }}\right) \cdot r^{\text {MinAccpt }}\right)
$$

This last formulation renders prices and labor share of each sector in employment independent of the average capital intensity in the economy, as in our first alternative capital price determination method. In this case, sectoral allocation of labor force (and thus sectoral output levels) is natnrally also a function of the mark-up rates (bCapt $l_{i}$ ) applied by the capital production sectors ower their unit labor costs.

\subsubsection{An algebraic comparison of the macro-consequences of output vs. profit maximizing behavior}

As discussed in the previous section, in case of profit-constrained output-maximizing behavior, at rates of return on capital stock which exceed the threshold level $r^{\text {Min Accpt }}$, not only the capitalists are willing to providle firms with resources (ive., the unconsumed part of their dividend receipts) to expand capacity, but also the firms are eager to receive the credits that are accordingly made available and use these to build-up productive capacity. Additionally, since rate of return levels that fall below the threshold level $r^{M i n}$ Acopt implies the erosion of existing capital stock by depreciation, the point where rates of return on capital stock equals $r^{\text {Mra }}$ Acept appears to be the equilibrium (i.e. fixed point) of our dynamic adjustment process. However, our alternative assumption on investment behavior which is similar to some sort of dynamic profit maximization, suggest circumstances where firms are less eager to take credits and expand output, since output, expansion implies the decrease of product prices, the increase of the wage rate (i.e. due to the increase in employment) and accordingly the possibility of decrease in profits. Thus, in cases of profit maximizing behavior there is nothing that guarantees the expansion of the capital stock up to the point where the rate of return on capital converges to the threshold level $r^{\text {Min.Accpt }}$. In other words, the equilibrium condition that we 
used to predict employment and output levels, uses its validity in case of hesitant investment behavior characterized by profit maximization.

In order to give an impression of investment behavior (purely profit-constraned. output maximizing ws. purely profit maximizing firms) on total output and employment, we follow the following simple economics textbook equilibrium (similar to Cournot oligopoly) approach assuming a single sector economy composed of NF identical. (in terms of their sizes and productivities) firms. Similar to our general characterization of the demand side, assume that the $N F$ firms collectively face a market characterized by unit price elasticity of demand (i.e, the goods are perfectly homogenous: $\theta=1.0$ ). Then the profits of a given firm $k$ at equilibrium is:

$$
\pi_{k}=Q_{k} \cdot\left(\frac{G D P}{Q^{T o t} \frac{1}{k}+Q_{k}}-\frac{w}{a}\right)
$$

where $Q^{\text {Tot }}=(N F-1) \cdot Q_{k}$ is the total output of all firms but firm $k, G D P$ is the total monetary demand available for the industry output. In order to simplify the algebra, let us ignore the pressure of the financial markets on firms by the assumption that $r^{M i n A c c p t}=0$ (the capitalists have no current consumption demand and they are willing to reinvest all positive profits/dividend payments). Then, $_{\text {, the equilibrium conditios }}$

- for a profit-constrained output maximizer is $\pi_{k}=0$, which implies $Q_{k}=$

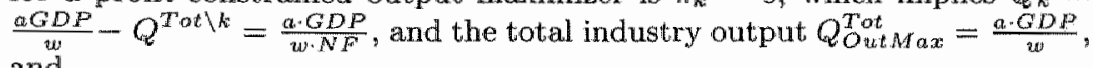
and

- for a profit maximizer $\frac{d m \pi_{k}}{d Q_{k}}=0$, which implies $Q_{k}=\sqrt{\frac{G D P \cdot Q^{T o t} \cdot k_{k} \cdot \underline{w}}{w}}$

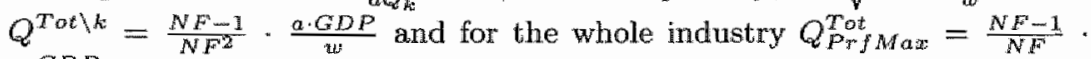
$\frac{a \cdot G D P}{w}$.

Therefore, for the industry of output (profit) maximizers, the total industry output is independent of (dependent on) the number of firms such that

$$
\frac{Q_{\text {PrfMax }}^{\text {Tot }}}{\text { QTat }_{\text {Tax }}}=\frac{N F-1}{N F^{\prime}} \text {. }
$$

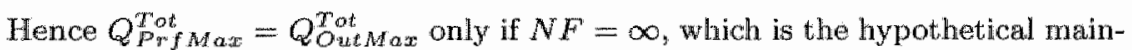
stream case of perfect competition characterized by an infinite number of identical measure zero firms.

Now let us have a look at the macroeconomic consequences (employment and national output) of the two types of investment behavior with the same single sector economy of $N F$ identical firms.

In the case of output maximizers, since $Q_{Q v t M a x}^{T o t}=\frac{a \cdot G D P}{w}$,

$$
L_{\text {rotal }}=\frac{Q_{\text {Onit }}^{\text {Tot }}}{a}=\frac{G D P}{w}
$$

and rewriting equation 3.5 for the one good economy at equilibrium (where investment demand is zero thus, $\left.L_{\text {Total }}=L_{\text {Cans }}\right)$,

$$
w=\frac{G D P}{L_{\text {Total }}} \cdot W g \operatorname{Sup}\left(\frac{L_{\text {Total }}}{\bar{L}}\right)
$$

together yield $W_{g S u p}\left(\frac{L_{\text {Total }}}{\bar{L}}\right)=1.0$. For convenience in presentation, let us pick MaxLShr $=$ MaxOverTime $=1$, together with Curv $=2$, which implies $W g S u p(E m p l R t)=E m p l R t^{2}$, where full-employment comes along only 
with aggregate level zero profitability. Then, $W_{g S u p}\left(\frac{L_{\mathrm{T}} \mathrm{axal}}{L}\right)=1.0$ implies fullemployment of the labor force $\left(L_{\text {Total }}=\bar{L}\right)$, independently of the number of firms. Thus, in this case of pure profit-constrained output maximizers, the (equilibrium) employment rate is merely determined by the institutional settings, and the total output of the economy $Q_{\text {Tut }}^{\text {Tot }}=a \cdot L_{\text {Total }}=a \cdot \bar{L}$ is determined only by the institutional settings and the overall labor productivity.

With a similar line of reasoning, for the case of pure profit maximizers one can easily derive

$$
\operatorname{WgSup}\left(\frac{L_{\text {Total }}}{\bar{L}}\right)=\frac{N-1}{N}
$$

which implies that the employment rate, in addition to institutional settings, is a function of the number of competing firms as well. "Thus, for the institutional settings (the function WgSup(EmplRt)) specified just above

$$
\frac{L_{\text {Total }}}{\bar{I}}=W_{g} S_{u p}{ }^{-1}\left(\frac{N-1}{N}\right)=\left[\frac{N-1}{N}\right]^{\frac{1}{2}},
$$

which suggests that any diversion from perfect competition $(N<\infty)$ implies inevitable (structural) unemployment $\left(L_{\text {Total }}<\bar{L}\right)$ at the equilibrium, brought about by the monopolistic power of the firms. Similarly, the output level of the economy

$$
Q_{P \operatorname{rot} M a x}^{T o t}=a \cdot W g S u p^{-1}\left(\frac{N-1}{N}\right),
$$

is now a function of labor productivity, institutional settings and also the number of competing firms.

\subsubsection{An overview of a number of illustrative simulation runs with closed economies}

In the previous section, we derived a collection of simple equations that describe the macroeconomic properties of the potential fixed point of our dynamic model. Naturally, the next logical step is the verification of whether our core model of selection (with fixed technological coefficients) has anything similar to a fixed point, and whether this point is close to the one calculated by our reduced analytical form equations. In order to achieve this and also to clarify further stationary properties of the core selection module of our model in closed economy settings we have designed and run a large number $(53)$ of controlled simulation runs. The reader can find in the accompanying CD these experiments (settings and output time series) $)^{12}$ as well as an appendix to this chapter ${ }^{13}$ where these experiment settings and the according findings are discussed in detail. In this section we will only summarize the highlights of these findings.

The experiments mentioned above clearly demonstrate that the core selection module of our dynarnic process has strong convergence properties, and the macroeconomic properties (i.e. employment, output level etc.) implied by these convergence points are quite close (i.e. almost exactly) to those implied by the reduced-form equations presented in the previous sections. Given constant technological coefficients (i.e. labor productivities, capital intensities, product qualities), the selection process comverges to a point and stays there persistently, despite the incessant disturbances brought about by the incessant depreciation on capital 
stock. The convergence process (during which the less fit firms of the initially heterogenous population loose market share and/or disappear) is rather rapid. In cases where firms are heterogenous only in terms of their labor productivity (product quality) coefficient, a firm's fitmess is uniquely detemined by its labor productivity (product quality) level relative to that of the others. In cases where firms are heterogenised (initially) with respect to both labor productivity and product quality, fitness of the firm is determined as the multiplicative product of these two firm level coefficients (i.e. for any firm $k_{k i j}, F i t n e s s_{k i j}=Q u_{a l} k_{k i j} \cdot a_{k i j}$ ).

Furthermore, except for cases of increasing returns to scale, the aggregate level properties of the states eventually reached are generally independent of the initial conditions and are uniquely determined by the parameter settings that specify technological coefficients, labor markets and capitalists" savings/investment behavior. The exceptions to this latter property (for example the dependence of the steady state properties on the number of firms etc.) are only observed in cases of profit maximizing types of behavior, as will be further discussed below.

These properties suggest that we seem to have achieved our initial target of building a model compliant, with the "order and change" dichotomy, which is the also basic principle underlying Schumpeter's "creative destruction" concept. That is, having confined the "change inducing" forces acting on economies to processes of technological change ${ }^{14}$, we have demonstrated by our experiments that in the absence of such forces (i.e. in cases characterized by fixed technological coefficients), the selection process rapidly converges to orderly states where, on the aggregate level, nothing significant seems to happen anymore (though at the micro level depreciation incessantly exodes capital and surviving firms keep on compensating for that). Even in cases of the entry of new firms, aggregate variables (such as total production, consumption, employment rates etc.) remain steady at the state of convergence, despite the continuous shifting of productive capacity from large incumbents to the newcomers.

However, it is still not possible to claim that our dynamic model has a fixed point, mainly due to two the reasons. First, the concept "fixed point" is reserved for the convergence state of dynamic systems that are explicitly formulated by simultaneous differential/difference equations, the properties of which can rigorously be shown by the mathematical tools of linear/non-linear systems theories. Our model, on the contrary, relies on a collection of mumerical calculations (both in agent and aggregate level) periodically performed ${ }^{15}$ and in this sense, is an algorithmic/procedural model, the convergence properties of which can not be proven analytically. The best one can do is to run as many simulation runs (with controlled variations of parameter settings) as possible, compare/analyze the results and draw conclusions. The experiments presented in the accompanying CD are hopefully convincing for the reader, though are too few in number to be considered as a rigorous exploration.

Second, in most of our experinents we have obserwed slight oscillations (regular or irregular) of amplitude $0.01 \%$ to $0.1 \%$ of the mean values. Such oscillations appear to be more accentuated in cases where firms are set to be profit maximizers. ${ }^{16}$.

Based on the rather insignificant extent of the oscillations in our time series we can safely claim that the convergence properties of our model (in cases of fixed. technological coefficients) satisfy (at least qualitatively) the qualities set by the defintions of the concepts "equilibrium" or "fixed point". Thus, in order to avoid any conceptual ambiguities we will refer to the convergence states of our dynamic model (in cases where there is one) as "quasi-equilibrium" or "quasi-fixed point" 
in the following chapters.

A great deal of our experiments are devoted to comparative analyzes of the implications (in terms of output levels and employment) of our alternative behavioral assumptions on firm's investment decisions, which are "profit-constrained output maximization", "nominal profit maximization" and "real profit maximization". These efforts have led to the following basic conclusions:

- In cases with output maximizing behavior, full employment can be reached independently of the number and size distribution of the firms. In other words, as predicted by equations $4.3,4.5$ and/or 4.6 , employment and output levels are merely determined by the institutional settings of the labor market (i.e. wage elasticity of labor supply), capitalists' saving/investment propensity, capital intensities and labor productivity ${ }^{27}$, independently from the industrial organization structure.

- In cases of profit maximizing behawior (either of real or nominal profit maximization), output and employment levels are generally lower than those observed wh output maximizing firms. As the theory of perfect competition suggest, the extent of the (profit maximizing behavior induced) welfare and employment losses are decreasing in the number of firms. For example, our experiments demonstrate that the output level produced by around 50 profit-maximizing firms is quite close to that produced by any number of profit-constrained output maximizing firms.

- The two arguments above together suggest that with output maximizing firms, the output and employment levels attained are equal to those which can only be attained by a high number of profit maximizing firms.

These results are highly reminiscent of the perfect competition story of the neoclassical economics. Obviously, this story mainly aims to make an industry (consisting of profit maximizing firms), look like a profit-constrained output (and accordingly welfare) maximizing entity. Ironically, the story that describes the adjustment process that leads to this welfare maximizing state known as "perfect competition", rules out any possibility of growth/investment of individual (incumbent) firns. If a firm happens to grow, it becomes aware of its market power, and in order to maximize its profits it shrinks back. Accordingly, the whole burden of the adjustment process is given to the continuous entry/exit of new firms.

The types of inconveniences introduced into economic theory by the "profit maximizing" assumption are many. For example, all models which consider any industrial orgamization pattern other than perfect competition, need to assume increasing returns to scale and or some demand functions (which lead to concave shaped total revenue curves) which can not be backed-up by homothetic utility functions. Furthermore, profit maximizing behavior which ignores the potiential differences between capitalist's and managers' incentives and interests, is not quite justifiable in empirical grounds ${ }^{18}$. Such considerations have led do the emergence of various altermative behavioral assumptions which have flourished in late 1960s. An example of such is the theory of revenue maximizing (subject to a certain profitability constraint) firms by Baumol [1962]. The output maximizing (subject to a certain level of profitability) behavior we introduce in our model has important similarities to the underlying ideas of these alternative lines of literature ${ }^{19}$.

The other grounds, on which profit maximizing behavior is harshly criticized is the complexity of the profit maximization problem, the solution of which requires a certain type of rationality which can hardly be expected from firms in reality. As discussed before, the sceptics who criticize rationality on such lines, propose 
behavioral assumptions such as "satisficing" or "relying on simple rulles of thumb" not only for contexts. Let us evaluate our output maximizing behavior in terms of such arguments.

The type of incremental investment behavior which we refer to as profitconstrained output maximizing in our model formulation essentially relies on the following rule of thumb: "without bothering with what/how the other firms are doing: go about investing for a higher output level as long as credits are available. Throughout this process, which tends to push prices down, wage rates up and accordingly profitability down, be a bit more prudent if the rate of return on capital you yield for your shareholders is close to the minimum level expected by them (the shareholders)". As we have demonstrated by a number of experiments (i.e. the cases where we set MonopolyCognon_off $=0$, MonopsonyCognon_Of $f=$ 0 and NormRateOfReturnCognOn_Off $=0$ ), the second part of this rule of thumb is not even necessary if the financial market functions properly. That is, ewen firms are not too calculating in their demand for credits/growth, the metarationality ${ }^{20}$ introduced by the financial market is sufficient to lead to orderly states.

In modeling exercises, any simplifying assumption/abstraction constitutes some divergence from reality. Neither profit nor output maximizing behavior can be put forward as the absolutely realistic characterization of real life behavior of firms in terms of their investment/growth decisions. Nevertheless, we believe that the assumption on profit-constrained output maximizing behavior not only introduces various conveniences in modeling but is a closer representation of reality as well. Therefore, despite the fact that we have introduced various behavioral options in our model, in the experiments and discussions that follow in the rest of this dissertation, we will set profit-constrained output maximizing behavior as our main working assumption.

The experiments have also pointed to two of her important observations. The first one regards the relation between increasing returns to (individual firms') scale and industrial organization: In cases of strong increasing returns to scale, the industrial organization (firm size distribution) pattern at the quasi-equilibrium of the selection process is highly dependent on the initial size distribution and the cnitry of new firms. If the initial firm size distribution does not characterize a highly concentrated industry, it is well possible that the process converges to a state of low concentration. In such cases, since no single firm (or a few of them) grows enough to exploit increasing returns efficiently, the economy gets locked into a productivity levell which is far below the level that can be attained in case of monopoly or the oligopoly of few large firms.

The second important observation (which is more of a verification of an issue discussed earlier in this chapter) is the impeding effect of demand for varjety (heterogeneity of products) on the selection process. In case of perfect product homogeneity, the selection process rapiclly eliminates the firms which are less fit (i.e. firms with lower labor productivity coefficients and or lower product quality levels). However, higher demand for wariety (which implies that products within each sector are less substitutable with each other) introduces market niches ${ }^{21}$ which protect firms with higher costs (or lower quality) against the price cornpetition by the others. At the quasi-equilibrium of the process, firms of varying productivities co-survive, although the more productive ones produce higher levels of output than those which have higher unit costs. 


\subsection{International Trade with Constant Technologies}

Having discussed the workings and the properties of the basic selection mechanism of our artificial economy in the context of no international trade (and no technological change), now we switch our focus to multi-country, multi-sector open economy settings and analyze the behavior of our model in various cases of international trade with constant (yet heterogeneous) technologies. We will keep the three major international trade/specialization models of the mainstream economics (the Ricardian model, the specific factors model, and the Heckscher-Ohlin-Sarnuelson model) as points of reference and discuss our experiment settings and the results of each setting, respectively in relation to the assumptions and the predictions of one (or more) of these three dominant models of the literature.

For simplicity, let us assume a two-country two-good economy where each given sector of each given country is characterized by a single profit-constrained output maximizing firm. For convenience, let us refer to the first country as Home and to the second country as Foreign. Accordingly, let us revisit the reduced form equations that describe the potential fixed point of our model once again for the case of international trade. Equation $4.7^{22}$ suggest that in case of autarky, the relative prices in a given country $j$, tend to converge to

$$
\frac{P_{i j}^{A}}{P_{k j}^{A}}=\frac{a_{k j}}{a_{i j}} \cdot \frac{1+b_{i j} \cdot r_{j}^{M i n A c c p t}}{1+b_{k j} \cdot r_{j}^{M i n A c c p t t}},
$$

where the superscript $A$ indicates the case of autarky ${ }^{23}$. The equation suggests that each equilibrium price $P_{i j}$ includes the (implied/emergent) mark-up rate MarkU $p_{i j}=b_{i j} \cdot r_{j}^{M i n, A c c p t}$ charged over the unit labor cast $\frac{w_{i}}{a_{i j}}$.

Now, let us evaluate this equation in the context of the law of comparative advantages, which suggests that if the autarky relative price of a good in Home (say good $i: \frac{P_{i, F}^{A}}{P_{k: H}^{A}}$ ) happens to be less than that in Foreign (i.e. $\frac{P_{i H}^{A}}{P_{k H A}^{A}}<\frac{P_{i F}^{A}}{P_{k F F}^{A}}$ ), provided that the relative world market price of the good in question at trade $\left(\frac{P_{i W}^{T}}{P_{k W}^{T}}\right.$, which is determined endogenowsly after switching to international trade) turns out to be at a level between the alutarky prices $\left(\frac{P_{i}^{A}}{P_{k H}^{A}}<\frac{P_{W}^{T}}{P_{k W}^{T}}<\frac{P_{N}^{A}}{P_{k F}^{A}}\right)$, then there exists incentives for Home (Foreign) to specialize on $\operatorname{good} i(k)$. Accordingly, equation 4.20 suggests that the comparative advantage of a country $j$ in a sector $i$ is (ceteris paribus) an increasing function of the labor productivity $\left(a_{i j}\right)$ and a decreasing function of the sectoral capital intensity, $\left(b_{i j}\right)$.

\subsubsection{Specialization only due to productivity differentials across countries}

After this brief overview, we can assess the extents with which we can converge to the assumptions of the major international trade models of the mainstream economics through the manipulations of the various parameter/switch settings of our model. Let us start with the Ricardian model.

The major point of divergence of our model from the structure of the Ricardian model is obviously the essential presence (absence) of capital in the former (latter). Nevertheless, similar to the Ricardian model, our model is also built upon fixed technological coefficients (rather than a continuous and differentiable multi-factor production function as in neoclassical models) and furthermore, in our model capital is defined as sector-specific productive capacity as opposed to the generic 
(vaguely defined) and immeasurable capital concept of the mainstrean economics. The existence of (sector-specific) capital as a factor of production is an integral part of our model, which cannot be turned off by parameter settings. However, it is possible to elminate the cost (i.e. dividend payments) implications of capital simply by the setting $r_{j}^{M i n A c c p t}=0$, and create settings almost identical to those of the Ricardian model.

To be more precise, let us revisit equation 4.20 , which reduces to $\frac{P_{i j}^{A}}{P_{k, j}}=\frac{a_{k j} j}{a_{i j,}}$, for $r_{j}^{M i n A c c p t}=0$. Substituting this into the basic necessity condition for specialization (the imequality that formulate the law of comparative advantages) yields $\frac{a_{a H}}{a_{i H}}<$ $\frac{P_{i}^{T}}{P_{k W}^{T}}<\frac{a_{k} F}{a_{i} F}$, which exactly is the condition that describes the foundation of the original single factor model of Ricardo. Accordingly, the testing of the proximity of the steady state properties of our model to the Ricardian model remains to a matter of setting $r_{j}^{\text {MfinAcpt }}=0$, and observing through controlled experiments the extents to which varions settings that satisfy $\frac{a_{k H}}{a_{i, H J}}<\frac{a_{k F} F^{*}}{a_{i} F}$ bring about the speciallization of Home (Foreign) on the $i^{t h}\left(k^{t h}\right)$ sector.

As verified by the experiments supplied in the accompanying $C D$, under settings with fixed techmology coefficients with $r_{j}^{\text {MinAccpt }}=0$, as of its steady state implications, our model performs as a generic solver of the Ricardian model (as subjected to Cobb-Douglas preferences) for any number of sectors and countries. This property emerges independently of the sectoral breakdown of capitail intensities since the restriction $r_{j}^{\text {MinAccpt }}=0$ rules out the element of dividend payments from costs.

\subsubsection{Specialization due to productivity and capital intensity differentials}

The reduction $r_{j}^{M i r i A c p t}=0$, which rules out capital costs, is of course a highly unrealistic one, which points to one of the mostly criticized features of the Ricardian model. The assumptions of Ricardian model, with its disregard for capital (and indirectly capital cost and the resulting issues on income distribution) describes more the possible effects of international trade for perfectly (and hypothetically) communist $^{24}$ economies, rather than for capitalist economies. Accordingly, by designing control experiments (running a given scenario once for $r_{j}^{\text {Miracist }}=0$ and other times for various $r_{j}^{M i n A c c p t}>0$, one can assess the extents of the contribution of the extreme assumptions of the Ricardian model on its predictions.

Already by equation 4.20 , one can sense the extremity of the importance at;tached to relative labor productivity coefficients by the Ricardian model. Within its assumptions, the law of comparative advantages transllates into to the law of comparative labor productivities. That is, the autarky relative price condition necessary to have Home (Foreign) specialize in sector $i(j): \frac{P_{i H}^{A} / P_{k H}^{A}}{P_{i F}^{A} / P_{k F}^{A}}<1$, reduces in the Ricardian model (for $r_{j}^{\text {MinAccpt }}=0$ ) smoothly to the condition $\frac{a_{k} w / a_{i k}}{a_{k F} / a_{i F}}<1$. Yet, for $r_{j}^{M i n A c c p t}>0$, the necessary condition (implied by equation 4.20 ) for this particular specialization pattern is instead.

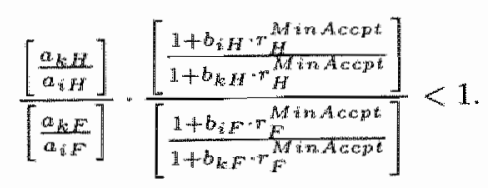


Obviously, capital costs (formulated in a way that is consistent with a notional equilbrium) introduce an anti-Ricardian potential into our model. That is; in terms of labor productivity coefficients alone, Home (Foreign) may have apparent comparative advantages $\frac{a_{k H} / a_{i} H}{a_{k F} / \omega_{i F}}<1$. Yet if, the labor cost advantage of Home (Foreign) in sector $i(k)$, happens to be the result of using highly sophisticated and expensive machines and equipment in sector $2(k)^{25}$, the accordingly high capital costs (minimum dividend payments required) may well deteriorate or even reverse the entire comparative advantage structure.

One can perceive equation 4.21 as a decomposition of comparative advantages into labor cost and capital cost related components. Formally, for

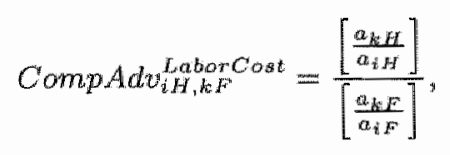

and

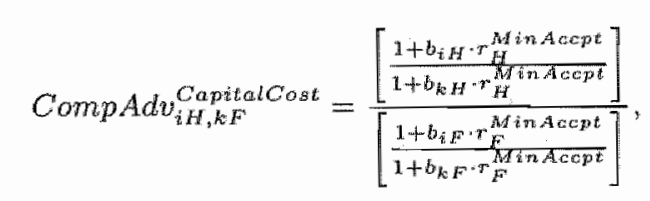

one can reformulate the case where Home (Foreign) has comparative advantages in the $i^{\text {th }}\left(k^{\text {th }}\right)$ sector as CompAdviH,kF $<1$, where

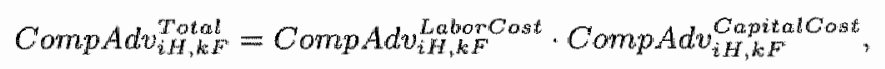

and accordingly if

$$
\text { CompDisAdv CapitalCost }>\text { CompAdvit, LabarCost, }
$$

(where CompDis.Adv $v_{i H, k F}^{\text {Capitalcost }}=\frac{1}{C o m p d A w_{i H, k F}^{\text {CapitalCost }}}$ ), then Home (Foreign), despite comparative labor cost advantage in the $e^{t h}\left(k^{t h}\right)$ sector (i.e. $\left.\frac{a_{k H} / a_{i} H^{2}}{a_{k} / a_{i} F}<1\right)$, needs to specialize in sector $k(i)$ for a viable allocation of resources on the world scale. In other worcls, comparative capital cost disadvantages can outweigh the comparative labor cost advartages and reverse the pattern of specialization that would normally be predicted by the Ricardian model, which ignores capital costs by assumption.

Testing of the potential of our model in generating the circumstances and predictions of the Heckscher-Ohlin-Samuelson and/or the Specific Factors models of trade is not straightforward. Despite the presence of (sector-specific) capital in our model (which makes it somewhat similar to the Specific Factors model), the mostly criticized feature of these two neoclassical models does not exist in our model: Biath in the Heckscher-Ohlin-Samuelson and the Specific Fiactors models, capital stock is imposed as an endowment (exogenous wariable), while in our model, it is determined endogenously as the outcome of dynamic processes of (sectorally segregated) accumulation and decummulation/depreciation. Thus, the only way to generate with our model the circumstances that are similar to the corditions demanded by these former two neoclassical models, is to introduce (cross-country) variations on capitalists' minimum rate of return expectations, and/or variations in sectoral capital intensities, that accompany various patterns of labor productivity differentials across sectors and comtries. 
Sectoral differentiation of capital intensities, however, seems to present an apparent complication. In the process of switching to trade, naturally the cast of sectoral labor productivities and sectoral capital intensities remain intact. Yet, the variable $b^{j}$, which expresses the average capital intensity of production in country $j$ (as expressed by equation 4.16), is by definition determined by the sectoral breakdown of production (i.e. sectoral allocation of the labor force) in the country. That is, if capital intensities of the two sectors are different, during the post-trade transformations that lead to specialization, the average capital intensity of production in a given country tends to converge to that of the sector in which the country in question tends to specialize (i.e. over time $t,\left(b_{i j}-b^{j, t}\right) \rightarrow 0$, for the sector $i$ in which country $j$ tends to specialize). Let us revisit equation 4.5 (or alternatively equations 4.3 or 4.6 ), which suggest that given the minimum rate of return expected by the capitalists $\left(r_{j}^{M i n A c c p t}\right)$, and the institutional settings of the labor market (as determined by the parameters of the function $\mathrm{Wg} S u p_{i}(\cdot)$ ), employment rate in a country $j$ is uniquely determined by the average capital intensity of production (e.g. $\frac{L_{j}}{\bar{L}_{j}}=W g S u p_{j}^{-1}\left(1-b^{j} \cdot r_{j}^{M i n A c c p t}\right)$ ). Thus, for economies where capital intensities are different across the sectors, the process of specialization (triggered by the opening of trade), which implies the changing of the average capital intensity of production in all countries (i.e. $b^{A, j} \neq b^{T, j}$ ), is highly apt to affect the employment rates. For example, assume that both countries operate at full employment at the autarky equilibrium. Then, also assuming that capitil intensities in the two sectors are different, one can predict that trade will bring about unemployment (over-employment) in the country which specializes on the relatively more (less) capital intensive sector, unlless the institutional settings of the labor markets and/or the minimum rate of return expectations of the capitalists somehow change during the transformation from autarky to trade.

\subsubsection{Specialization due to simultaneous differences in productivity, capital intensity and quality}

The simple analytical exercises made so far can also be generalized in a way that captures international quality differences along with labor productivity and capital intensity differences. For Fitness $s_{i j}=Q u a l_{i j} \cdot a_{i j}$, the vector Fitness assumes the wery role played by the labor productivity vector ( $a$ ) in the original (merely labor productivity heterogeneity based) formulation of the Ricardian model. In other words, in the presence of international quality differentials one can reformulate the "law of comparative advantages" as the condition

$$
\frac{\text { Fitnessin } / \text { Fitness } s_{2 H}}{\text { Fitnessif } / \text { Fitnessi2 }}>1
$$

which is necessary and sufficient for Home (Foreign) to specialize in the first (second) sector. Furthermore, as in the original formulation, the superiority of one country in terms of the variable Fitness $s_{i}=Q u a l_{i} \cdot a_{i}$ in both sectors $i=1,2$, implies the partial specialization of this country, together with the full specialization of the other.

Having concluded that the variable vector Fitness smoothly replaces the labor productivity vector of the original Ricardian formulation, we can also modify our "capital cost augmented" reformulation of the law of comparative advantages (as 
given by equation 4.21 ) as

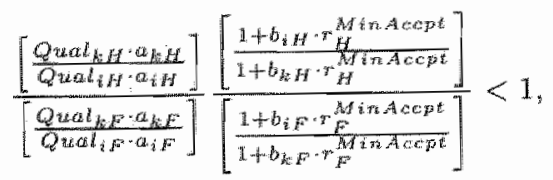

which gives the condition that Home (Foreign) specializes in the $i^{\text {th }}\left(k^{2 / t_{k}}\right)$ sector. Accordingly our multiplicative "comparative advantage decomposition" given by equation 4.24 can be augmented as

$$
\begin{aligned}
& \text { CompAdv } v_{i H, k \text { Th }}^{\text {Total }}=
\end{aligned}
$$

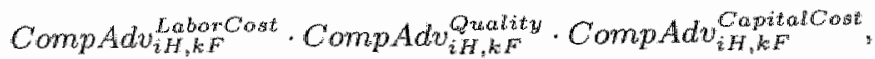

where

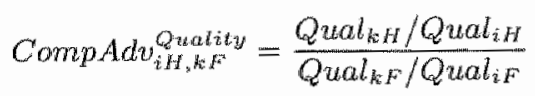

stands for the (solely) quality based comparative advantage of Home in sector :. This decomposition basically suggests that the pattern of international specializa. tion and trade flows are determined by the joint effect of the differences in labor productivities, quality levels, and capital intensities across countries and sectors. The original Ricardian model is a reduced form of this formulation where quality and/ capital cost related comparative advantages/disadvantages do not exist (i.e. CompAdv $v_{i H, h F^{n}}^{\text {Quality }}=1$ and $C o m p A d v_{i H, k F}^{\text {Capital Cost }}=1$ ) or are to small in magnitude to reverse the specialization pattern implied by the labor productivity based comparative advantages (i.e. Comp $A d v_{i H, k F}^{\mathrm{LaborCost}} \gtrless 1$ ).

\subsubsection{An overview of a number of illustrative simulation runs with open economies}

In this section, our essential effort is the comparison of the steady state properties of our model (i.e by ruling out technological change temporarily and by focusing on cases characterized by fixed technological coefficients) with the major equilibrium models of international trade, both in terms of their assumptions and their predictions. In order to observe the steady-state properties of our model (especially in comparison to the analytical specialization predictions discussed in the last four sections), we have designed and run 33 experiments, the settings and output files of which the reader can find in the accompanying $\mathrm{CD}^{26}$. We also supply on the CD another appendix ${ }^{27}$ to this chapter where the settings, ontcomes and implications of these control experiments are discussed in detail. Here, we will only summarize the highlights of the findings that come out of these experiments.

On the basis of our experiments the settings of which reproduce the premises of the original Ricardian model, it can safely be clained that it is perfectly possible to impose the Ricardian model settings/assumptions into our model and consequently observe that the specialization pattern generated by the corresponding simulations are (without any exceptions) are identical with those predicted by the former. Given according settings (i.e., basically $r^{\text {Min Accpt }}=0$, which eliminates capitad costs), our model can even be seen as a generic solver for the Ricordian model (for any arbitrarily given number of comntries and sectors) formulated according to Cobb-Douglas preferences ${ }^{28}$. In other words, for $N C$ countries and $N G$ sectors, and given the labor: force sizes of these $N C$ countries $\left(\overline{L_{j}}\right.$ for $\left.j=1,2, \ldots N C\right)$, the 
distribution (matrix) of labor productivities over these sectors and countries ( $a_{i j}$ for each combination of $i=1,2, \ldots, N G$ and $j=1,2, \ldots, N)$, and the distribution of tastes (budget share allocations) over the sectors and countries (i.e., $\alpha_{i j}$ for each combination of $i=1,2, \ldots, N G$ and $j=1,2, \ldots N C$ ), our model solves both for the autarky and trade levels of production, consumption, trade flows and welfare levels that reflect the optimal allocation of resources (labor forces of given sizes, which are assumed to be immobile among the countries) on the world scale.

The important issue is the fact that these magnitudes, which characterize international speciallization patterns that are fully in line with the predictions of the original Ricardian model, emerge as the properties of the quasi-fixed point of a dynamic selection processes, rather than as the solution to an explicitly formulated optimization problem. Furthermore, they emerge despite the essential dependence of production on capital goods in our model. Yet, the latter is by no means a surprising outcome, since capital in our model is dynamically accumulated (decumoulated) by investments (disinvestments and depreciation) in a way that follows profits: Throughout the processes of transition between autarky and trade equilibria, as long as the economies are not at their trade equilibrium states, the emergent product (world) prices and exchange rates together make sure that, in each country, the sectors that have comparative advantages (disadvantages) always remain more (less) profitable than those with comparative disadvantages (advantages). In our selection environment, profits that exceed (fall short of) the mimimum level of dividends expected by the shareholders are directly translated into investment. in (disinvestment of) capital for their bearers. In other words, capital accumulation/decumulation takes place in the direction commanded by the comparative advantages, and the allocation of labor among the sectors immediately follows the sectoral changes in productive capacities (sectoral capital stock). Within this system, $_{\text {capital intensities (which determine the market price/production costs of }}$ capital goods) do not affect the properties of the eventual trade equilibrium, but only the pace (the speed of capital accumulation/decumulation) with which the transformation from autarky to trade takes place.

However, in reality, the mechanisms through which the existence of capital (as a factor of production) affect the workings of economies are not confined to the convenience of their once and for all production/purchases (i.e. the more expensive capital good prices are, the less can be purchased by a given amount of savings/profits). In capitalistic economies, each firm is expected to make periodic payments to the owners of capital goods (dividend payments to sharehold. ers/capitalists) in return for their sacrifices/savings in the past. Naturally, one would expect firms that use relatively more (expensive) capital goods to be obliged to pay higher sums of capital costs (dividends). In other words, in order to meet the shareholders demands, firms that use more capital-intensive techniques need to charge a higher mark-up ${ }^{29}$ rate over their unit labor costs. Without doubt, compared to the Ricardian model, where relative prices are uniquely determined (at the zero profit equilibrium) by unit labor costs, the existence of capital costs (which are not necessarily uniform over countries/sectors but a function of relative capital intensities) may have a significant effect on the determination of relative prices and accordingly specialization patterns and international trade flows.

In all our experiments that aim to revisit the properties of the Ricardian model, we have conventionally ignored capital costs (dividend payments) by setting the shareholders' minimum level of expected rate of return on their inwestment to zero $\left(r^{\text {MinAccpt }}=0\right)$. However, in simulations that follow, diverging from the Ricardian framework we have relaxed this assumption (by settings where $r^{\text {Minackpt }}$ 
$>0$, which brought us to the domain of the neoclassical models of international trade (the H-O-S and the Specific Factors models) where winit capital costs (in addition to unit labor costs) appear to be an important potential determinant of international patterns of specialization and trade flows. By various experiments we have tested the implications of our model against the neoclassical models, which have yielded the following conclusions.

As formulated by equation 4.24 , in our model specification, the comparative advantage structure implied by a given distribution of internationally exclusive (fixed coefficient) technologies can be (multiplicatively) decomposed into labor cost and capital cost related components. As also verified by our simulation runs, the eventual pattern of specialization is decided upon by the component that outweighs the other. For given labor productivity differentials, the possibility of capital cost differentials to reverse the pattern that would be predicted by the Ricardian model is therefore a decreasing function of the extent of labor productivity differentials, an increasing function of corresponding/respective capitall intensity differentials (of course to the extent of the positive correlation between: labor productivity and capital intensity of competing production techniques) and also an increasing function of $r^{\text {MrnAccost }}$ which translates capital intensity differentials into (compulsory/minimum acceptable) capital cost differentials ${ }^{30}$. Our experiments demonstrate both possibilities: Based on various (and controlled) settings of labor productivity and capital intensity differentials accompanied by various levels of $r_{j}^{M i n A c c p t}$ (which are also permitted to show variations across the countries), we have generated various patterns of specialization; some compliant with the Ricardian prediction and in conflict with the $\mathrm{H}-\mathrm{O}-\mathrm{S}$ prediction (cases where the Leontief paradox is observed), while some other compliant with the $\mathrm{H}-\mathrm{O}-\mathrm{S}$ prediction and in conflict with the Ricardian prediction.

In one of our experiments, we have also provided a potential explanation to the numerous empirical falsifications of the H-O-S prediction, which are generally (and paradoxically) referred to as the Leontief paradox. The experiment that provides the demonstration basically postulates a country Home (similar to the US) which is superior to Foreign (the rest of the world) in terms of labor productivities in both sectors. Yet, the extent of Home's superiority in the first sector is stronger than that in the second sector $\left(a_{1 H}>a_{1 F}\right.$ and $a_{2 H}>a_{2 F}$ while $\left.\frac{a_{1} H}{a_{2 H}}>\frac{a_{1 F}}{a_{22}}\right)$. The capital intensity in the second sector is set to be higher than that in the first sector universally (i.e, $b_{2 H}>b_{1 H}$, and $b_{2 F}>b_{1 F}$ ). Following the the suggestion by Ford [1967], the labor productivity superiority of Home is not let to be capital disembodied but is assumed to the implication of the usage of more expensive/sophisticated capital goods $\left(b_{1 H}>b_{1 F}\right.$ and $b_{2 H}>b_{2 F}$, while $\frac{b_{14}}{b_{1} F^{*}}>\frac{b_{2} H}{b_{2 F}}$ ). In terms of our earlier comparative advantage decomposition (as in equation 4.24), the settings of this scenario imply that Home (Foreign) has comparative labor cost advantage in the first (second) sector. In terms of capital costs, the direction of comparative advantages are just the opposite. However, the labor cost advantages ontweigh the capital cost disadvantages and Home, which eventually builds up more (expensive/sophisticated) capital than Foreign, turns out to have specialized in the relatively less capital intensive (the first) sector, similar to all real world cases which empirically falsify the H-O-S prediction.

Shortly, this experiment suggests that the real world specialization patterns, most of which seem to have falsified the original H-O-S prediction, may have been brought about merely by the Ricardian forces by outweighing the opposing (capital intensity related) forces. Empirically, the validity of this explanation to the Leontief paradox can simply be verified by checking whether the ratio of the 
labor productivity in the US export sectors to that in the US import sectors exced the same ratio for the rest of the world.

The results of our experiments, together with the persistent empirical falsifications of the H-O-S prediction, points to the conclusion that the H-O-S model somehow exaggerates (underestimates) the effect of capital intensity (labor productivity) differences on product prices. If this argument is correct, the element of the H-O-S model that is to blame is naturally the contimuous production functions, which unrealistically provide firms with infinitely many alternative production techniques. First, such production functions (the underlying set of infinite technologies of which are assumed to be accessible by all countries) basically rule out the possibility of capital disembodied technological (cross-country) differences. In terms of our decomposition, the neoclassical models postulate that comparative labor cost (productivity) advantages are strongly counterweighted by comparative capital cost disadvantages (i.e. a higher labor productivity level must be the outcome of the usage of more (expensive/sophisticated) capital goods. With this overrated smoothing, the international (re)organization of production (due to international trade) reduces to a mere issue of the procurement of full employment of both production factors in both countries, the relative proportions of which are taken to be different across the countries by assumption. In other words, according to the neoclassical framework, causation does not rum from given (differences in) technological capabilities (i.e. labor productivities and accompanying capital intensities) and economic incentives to capital accumulation and according organization of production (i.e. allocation of labor among the sectors), but inevitablyr from given endowments (the supply of which are infinitely inelastic) to simultaneous allocation of both labor and capital among the sectors and the corresponding organization of world production.

On the contrary, our formulation with fixed technological coefficients introduces only NC (i.e. number of countries involved in international trade) competing production techniques (i.e. each being a different combination of a labor productivity and capital intensity coefficient setting) for each sector, and by the opening of trade, the selective forces of the world economy gradually eliminates (selects) some of these techmologies in a way that would increase the world welfare as a whole. Specialization comes about as an outcome of this selection processes which effectively works upon the competing technologies at the world scale: During the adjustment process, the profitable sectors gradually build-up exira productive capacity and the non-profitable ones gradually shrink and/or disappear Yet, due to the balance of payment constraints of each country (which is automatically satisfied by the adjustment in exchange rates), the selection mechanism does not work separately sector by sector, but over all sectors and countries simultaneously. This is of course nothing but the basic principle underlying the law of comparative advantages.

The predictions of the H-O-S model are not confined to specialization/trade flow patterns only. One of the features that make this model the mostly referred one (despite its numerous empirical falsifications) is its implications in terns of income distributions. These latter features are given by the two corollaries of the main theorem of the model known as the "Stolper-Samelson theorem" and the "factor price equalization theorem". In our experiments; we have also investigated the proximity of the properties of our model to the income distribution related predictions of these two corollaries of the H-O-S model.

In our framework with fixed coefficient technologies, the prediction of the Stolper-Samuelson theorem emerges as a trivial implication. Consider a coun- 
try making production in two sectors, one being more capital intensive than the other. In our formulation, given the institutional settings of the labor markets and the capitalist: intertemporal preferences (j.e., $r_{j}^{\text {Min Accpt }}$, the income distribution (the share of capitalists in total income) at equilibrium (the quasi fixed point of the dynamic process of selection) is uniquely determined by the average intensity of production in the country. Assume that, with the opening of trade, the relative price of one of the goods (say good i) increases. This automatically satisfies the premise of the Stolper-Samuelson theorem ("...if the relative price of a commodity increases" $)$. According to the law of comparative advantages; the country shifts more of its resources to sector $i$ production. Now, if sector $i$ happens to be the relatively more capital intensive sector, this transformation naturally implies that the average capital intensity in the country is apt to increase and consequently the share of capitalists in total income increases as well. If, on the contrary, sector $i$ happens to be the relatively less capital intensive (or equivar lently relatively more labor intensive) sector, the transformation of the production towards specialization in the $i^{\text {th }}$ sector implies that the average capital intensity in the country decreases, and consequently the share of capitalists (workers) in total income decreases (increases). Either way, the direction of the income distribution transformation is fully in line with the one predicted by the Stolper-Samuelson theorem: "the real income of the factor used intensively in the production of the commadity $i$ increases, while the real income of the other factor decreases".

The compliance of the results of onur model to Samuelson's "factor price equalixation theorem" is however conditional on the pattern of specialization. Consider two countries, one (say Home) employing technologies which are on the average more capital intensive than those employed by the other country (Foreign) and also two sectors, one (say i) being more capital intensive than the other $(k)$ ). Now assume that by the opening of trade Home (Foreign) specializes in sector $k$ ( $i$ ). This transformation will decrease (increase) the average capital intensity of production and consequently the share of capitalists in income in Home (Foreign), which leads to the convergence of income distribution and consequently the factor incomes in the two combries. Of course, there is nothing that guarantees the absolute cross-country convergence of factor incomes (which happens in the H-O$\mathbf{S}$ model thanks to the continuous production function) in our model with fixed technological coefficients, though there is the tendency towards a mutual convergence. On the other hand, if specialization happens to take place in the opposite direction, income distributions (factor incomes) will further diverge rather than converge.

Another important issue is the gains from trade and especially the distribution of these gains over the countries involved in international trade. It is well known that, within the Ricardian framework characterized by fixed labor productivity coefficients, none of the countries can loose from trade (i.e. international trade is always a Pareto improvement over the autarky). In the worst possible case, which can happen in the absolute (labor productivity-wise) superiority of one country in all sectors, this one country benefits nothing from international trade but does not loose anything as well. However, as pointed out by Ethier [1982], in cases where there is increasing returns to scale in one sector and constant returns in the other, and also where one of the countries is smaller in (labor force) size than the other, provicled that increasing returns is not too strong and the size of the small country is not too small compared to the larger one, the (full) specialization of the larger (smaller) country in the industry with constant (increasing) returns to scale may bring about welfare loss for the larger country. On the contrary, if the increasing 
returns effect is strong and/or the size difference between the countries is large, full specialization does not take place and in the case of the corresponding partial specialization scheme, the large country makes neither losses nor gains from trade. By a number of control experiments/scenarios, we have regentrated these results as well.

Welfare loss from trade is neither an outcome of the $\mathrm{H}-\mathrm{O}-\mathrm{S}$ model. The welfare analyzes of the $\mathbf{H}-\mathrm{O}-\mathrm{S}$ model pertain to the region where specialization is only partial for both parties ${ }^{31}$. Yet, we have demonstrated that in case of fixed technological coefficients (where the firms of each sector of each country has access to one exclusive production technique), international trade may bring about welfare losses for one of the countries. This country is the one which is superior over the other in terms of labor productivities in both sectors. As discussed above, in the absence of capital costs (within the Ricardian settings), the superior country would specialize only partially and would neither gain nor loose anything from trade. However, if the labor productivity superiority of this country is capital embodied (procured by the use of more capital intensive technologies), its superiority in labor prodnctivities would not necessarily mean superiority (absolute advantages in both sectors) in terms of unit costs anymore, and accordingly the selective forces of the world economy may drive both countries to full specialization, which brings about welfare losses for the former. In other words, we have demonstrated that if a country, which would normally not fully specialize on the basis of comparative labor productivity advantages alone, is forced (by economic selection) to do so in sector $i$ due to strong comparative capital cost disadvantage in the other sector $k$, international trade brings about welfare losses for this country.

Having gone through the comparative advantages based interindustry trade models of the literature, we have shifted our focused to issues of product heterogeneity and intraindustry trade. Similar to that in a number of "new trade" models which focus on intraindustry trade on the context of monopolistic competition $^{32}$, we have denonstrated that even in cases where there are no incentives for inter-sectoral trade (i.e. no comparative advantages), demand for product variety $^{33}$ introduces incentives for international trade. For example, in a one sector world, where specialization-based (interindustry) international trade is out of question, intraindustry trade may still lead to significant welfare gains if consumers appreciate product variety. Assume that, in this one sector world, Home prow duces $N F_{H}$ product varieties and Foreign $N F_{F}$, such that $N F_{H}>N F F$. With the opening of trade the customers in both countries enjoy a total of $N F H+N F_{F}$ varieties available for consumption. The ability to produce a higher number of varieties, however gives Home the right to consume (i.e. the market power to clain) a higher portion of each variety produced over the world.

With our model it has been possible to generalize such results for cases of many countries and many sectors, where the extent of the demand for variety can also be differentiated across the sectors ${ }^{34}$. Furthermore, the interaction of intraindustry and interindustry trade can be observed by the introduction of technological coefficient differentials along with demand for variety. Pursuing such lines of investigation, we have demonstrated that demand for variety works against the selection forces, which, on the world scale, lead to specialization and interindustry trade. In other words, demand for variety creates niches for relatively high cost firms (or sectors) which would otherwise (i.e., in cases where customers perceive the output of the various firms of the same industry as perfectly homogenous) would not stand the competition with the cheaper products of the other firms (i.e. the same 
sectors of other countries) and consequentiy be driven out of the market. We have also demonstrated that a country which is not as successful as its trading partners in bringing product varieties to the international market, can compensate for this shortcoming by higher productivity (i.e. lower costs) in the sectors where demand for variety is low.

Last but not the least, we have introduced internathonal heterogeneity in output quality levels as an additional explanatory principle to international special. ization. First, we have demonstrated that in isolation (i.e. no labor productivity or capital intensity differences), quality differences smoothly replaces the role played by labor productivity differences in the original Ricardian model. In other words, one can refer to a concept like "quality-based comparative advantages". Second, through a number of control experiments, we have demonstrated that in cases where there are international differences in both qualities and labor productivities, the (cross country-sector) distribution of the multiplicative product of these two variables (Fitnessij $=Q w a l_{i j} \cdot a_{i j}$, which turns out as an overall fitness/competitiveness measure for each sector of each country) nicely assumes the role played by the (cross country-sector) distribution of labor productivities on the dettermination of the pattern of international specialization. Finally, we have concluded that the pattern of international specialization is determined by the joint effect of labor productivity, quality and capital cost based comparative advantages and the total effect can neatly be formulated (see equation 4.27 and also equations $4.22,4.23$, and 4.28 which specify the building blocks of the former) as the multiplicative product of the contribution of these three different sources of comparative advantages, each of which (if considered alone in isolation from the others) may predict alone a specialization pattern that contradicts with the prediction by either or both of the ather two. 


\section{Notes}

1. The file "Appendices/Manual.pdf".

2. Which can be found under the directory "/Chapter4/Experiments".

3. The files "Chap4Appl.pdf" and "Chap4App2.pdf" "which can be found under the directory "/Appendices".

4. Firms that does not pick the best-practice production techniques exit, better ones enter, profits are pushed to zero, all markets clear, long run full-employment is reached etc.

5. For capacity expansion or for the compensation of periodic depreciation on existing capital stock.

6. Note that this restriction can be relaxed by our capital vintages madule which will be discussed in the next chapter in the context of technological change.

7. Note that if the firms are heterogenous in their product quality (i.e. Qualki, $\neq$ Qualsij for any given two firms $k$ and $s$ ), then inverse demand price is proportional to product quality (i.e. $\frac{p_{k i j}^{i}}{P_{s i j}^{i}}=\frac{Q_{u a l_{k i j}}}{Q u a l_{s i j}}$ ).

8. As will be discussed in a later chapter, in our endogenous technological change formulations we will assume that firms retain part of their profits to finance their R\&D activities and distribute the rest as dividend payments.

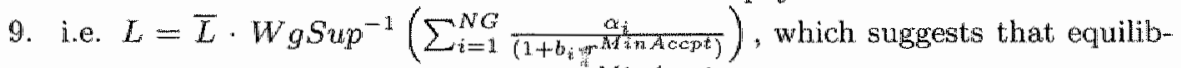
rium employment rate is a function of $r^{\text {Min Accpt }}$, sectoral capital intemsities and also the income share allocated to each sector by the customers.

10. In a closed economy $L_{i}=\frac{\alpha_{i} \cdot G D P}{a_{i} \cdot P_{i}}$. Substituting into this, equation 4.13 , and

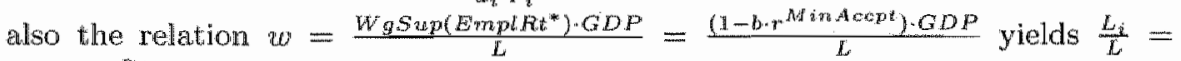

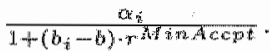

11. The solver solves for $b_{A v g}$, for a given vectors of $b_{i}$ and $\alpha_{i}$ values and a given level of $r^{\text {Min Accpt }}$. Thus, the reader can experiment with various combinations of these variables. We have built two custom versions: One for the two sector case and one for the 5 sector case. Both can be found on the accompanying CD under the directory "/Utils/", respectively with the file names "AverageCapitalIntensity Calc_2Coods.xls" and "AverageCapitallntensityCalc_5Goods.xls".

12. Which can be found under the directory "/Chapter $4 /$ Experiments" .

13. "The files "Chap4App1.pdp" which can be found under the directory "/Appendices"

14. Which will be addressed in later chapters.

15. L.e. Firms' calculations for their demand for credits, the financial market reallocation of profits, the inverse demand function which needs to run a numerical algorithm in cases of taste differentials and/or product heterogeneity, etc.

16. Recall that the simple calculations made by the profit maximizing firms rely on the ceteris paribus assumption. Thus, in settings with more than one profit maximizing firms, the "boundedly rational" estimations built into firm behavior, which ignore oligopolistic indeterminacies (i.e. what the other firms might do), can result in overshooting. Nevertheless, since the interwal in which firms pick up their optimal (per period) growth/investment rate is around [0,0.1], the errors in the calculations do not lead to drastic mistakes. That is, if a firm grows a bit too much at one period, it can always shrink a bit (by not compensating for the depreciation) in the following period. Besides, since credits are rationed/reallocated by the financial market, nothing guarantees that each firm invests (grows) at the rate it desires/calculates. Consequently, such firm level fluctuations, do not translate into significant oscillations on the sectoral (or aggregate) level. 
17. Thus, full employment at equilibrium is only a possibility which can be realized by specific conbinations of the parameters that affect employment.

18. Of course, every manager would like to see his/her firm more profitable than the others. Achiewing this (procuring a high Tobin's $Q$ for the firm) is not only prestigious but also introduces some practical conveniences into management practices, such as the relative ease of getting loans to finance day to day activities etc. Yet does this tendency, constitute sufficient evidence to justify profit-maximizing. behavior? One should also consider that (most) managers also find it prestigious/rewarding to see their firm grow and have the privilege and face the challenges of managing an entity of a larger size.

19. Note that the revenue maximizing buhavior in Baumol [1962] can be meaningful only in case of demand functions that lead to concave total revemue curves. Obviously, demand functions derived from homothetic atility functions do not have such a property. However, for the cases of homothetic utility functions, the implications of output maximizing (subject to certain level of profitability) behavior is similar to that of revenue maximizing behavior.

20. Financial market keeps on granting credits (redistributing pooled profits) as long as the profits yielded by firms exceed the minimum rate expected by the shareholders. The moment this threshold is reached (i.e. the quasi-fixed point of the processi), releases of further credits drop down to zero (or the level just enough to compensate for the depreciation on the existing capital stock).

21. By giving the relatively smaller firms the opportunity to sell their output at relatively higher prices.

22. Recall our three altemative derivations each corresponding to one of our alternative assumptions on the determination of the unit price of capital. For convenience in notation, let us proceed with our current discussion with the formulation, which assumes a fixed capital-labor ratio (no profits in capital sector).

23. Under our altenative assumption that profitability in the capital sectors is equal to the country average, the autarky relative price relation becomes $\frac{P_{i j}^{A}}{P_{k j}^{A}}=$

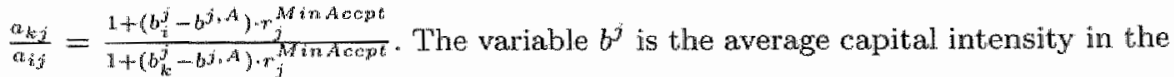
country and since this average is a function of the sectoral allocation of output (labor force), its value may naturally show variations between the cases of antarky and trade. Thus, it is given the superscript $A$ to denote its value at the autarky. 24. We use the term "perfectly communist economies" rather than "command economies" because the essential workings of the Ricardian model assume the axistence of well functioning markets rather than central planning. Ruling out capital costs $\left(7_{i}^{\text {Mintecpt }}=0\right)$ automatically rules out the possibility of a capitalist class which, in return for its ownership rights on the capital stock, claims (and makes a living on) some share out of production. Thus, in terms of the foundations of our model, the Ricardian model appeans to specify economies where all profits (if any) are invested and the rest is consumed only by the workers (i.e. the people). 25. In other words, if the given technological differences that lead to higher labor productivity are capital embodied.

26. Which can be found under the directory "/Chapter4/Experiments".

27. The files "Chap4App2.pdf" which can be found under the directory "/Appendices".

28. As illustrated in the second appendix to Chapter 1 , which can be found in the file "/Appendices/Chap 1App2.pdP".

29. Note that our model formulation does not rety on mark-up pricing rules. Yet, since our selection mechanism implies that the capital stock of firms that fail to 
yield (at least) the minimum expected rate of retum are left (by the capitalist) to shrink and disappear by depreciation, for the frrms that survive the selection one can conveniently decompose prices into unit labor costs $\left(\frac{w_{j}}{a_{k i j}}\right)$ and unit capital costs $\left(\frac{b_{i j} w_{j}}{a_{k j}} \cdot r_{j}^{M i n A c c p t}\right)$, the latter being proportional to the former. This proportion obviously satisfies the definition of a mark-up rate (i.e. $M a r k U p_{i j}=$ $b_{i j} \cdot r_{j}^{\text {Min Acept }}$, but only as an equilibrium property.

30. Comparative advantage of a country $j$ in sector $i$ is an increasing function of the autarky price of the ather good $k$, relative to that of good $i$, (i.e. $\frac{P_{k j}^{A}}{P_{i j}^{A}}=\frac{a_{i j}}{a_{k j}}$.

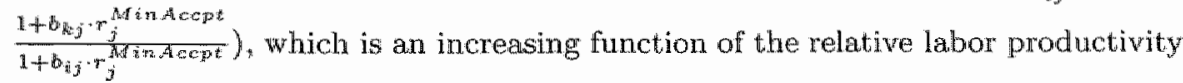
in sector $i\left(\frac{a_{i j}}{a_{k j}}\right)$, a decreasing function of the relative capital intensity in sector $i$ production $\left(\frac{b_{i j}}{b_{k j}}\right)$ and a decreasing (increasing) function of $r_{j}^{M i n A c p t}$, if $\frac{b_{i j}}{b_{k j}}>1$ (if $\frac{b_{i j}}{b_{k j}}<1$ ).

31. As mentioned above, due to the fact that all firms of either countries can pick up a technology among the infinitely many provided by the homothetic production functions. This fact clears away the technological distance between the countries and specialization pattern is decided by the factor proportions. As long as the factor proportions are not too different across the countries, specialization remains partial for both parties.

32. Especially those by Paul Krugman which were discussed in the first two chapters of this dissertation.

33. i.e. In terms the parameters of our model, cases where $\theta<1$.

34. i.e. $\theta_{i} \neq \theta_{k}$ for any two given sectors $i$ and $k$. 


\section{The stochastic technological change formulations}

\subsection{Introduction}

Up to this chapter our effort has been focused on the workings and the implications (in terms of employment, welfare, international trade and specialization) of our basic model of selection for given and fixed technological parameters. In this and the following two chapters, we introduce firm level technological change (i.e. learning/ innowation, imitation) upon our core selection module and present a number of experiments to observe its implications in terms of economic growth and international trade.

Essentially, the core of our technological change formulation is quite similar to that in Silverberg \& Verspagen [1995a] which is capital embodied. However, our model is designed more as a generic experimenting platform than a single well-defined model, and accordingly it offers various alternative assumptions/formulations on technological change, among which one can find also a capital vintages framework. The rest of the alternatives feature capital clisembodied formulations of technological change and are much simpler. Thus, throughout our presentation in this chapter, we will start with these simpler formulations and gradually build up our discussion towards the most complicated one on capital embodied technological change with capital vintages, which is founded upon the existence of a finite collection of technological trajectories (i.e. technological paradigms) each requiring the use of a set of machines and equipment (at least. somewhat) different than those required by the other trajectories of progress.

We have allso built into our model a number of alternative assumptions with regard to the mechanisms which bring about technological change. Our first and simplest alternative (i.e., exogenous technological change) specifies technological change as the (firm-level) contimuous and stochastic arrival of superior production techniques independently of firms' R\&D effort and/or output level. In other words, for this most simplistic formulation which can be seen as sheer learning, firms gradually build up experience and attain higher levels of productivity by the passing of time alone (i.e., without ary deliberate effort such as R\&D). The model incorporates the possibility to heterogenise individual firms with respect to their learming abilities (i.e. the rate at which they build up experience).

The second and the third alternatives endogenise the firm-specific paces with which new and better technologies are discovered by individual firms. The former 
of these endogenous formulations mimic the process referred to as "learning by doing", by specifying the learning/innovation rate for each firm as an increasing function of the firm's output level. Namely, firms which produce higher amounts of output keep on building up experience (i.e. learn) faster thar the rest. In these "dynamic increasing returns" generating settings, in addition to the aggregate output level, the size distribution of firms also has a potential effect on the aggregate rate of technological change. The latter endogenous technological change formulation introduces firm level R\&D effort which incorporates into our model an altemative/complementary mechanism that affect the rate at which new technologies are discovered and integrated into the production processes. This is achieved through a formulation which renders the firm-specific learning rate (i.e., the arrival rate of incremental innovations and/or imitations) an increasing function of the $\mathrm{R} \& \mathrm{D}$ effort (spending) made by each individual firm.

With regard to the magnitude of firm's $\mathrm{R} \& \mathrm{LD}$ expenditures we have built three alternatives in our modeling platform. The first alternative assumes routinized behavior, which specifies the R\&D spending of each firm in terms of a fixed R\&D spending to sales (turnover) ratio, which is allowed to exhibit heterogeneity across individual firms. The second and third assumptions are two alternative formulations that are based on bounded rationality. These formulations present the firms with the information on the relation between own R\&D effort and its expected consequence in terms of own innovativeness, and accordingly let firms set their target $\mathrm{R} \& \mathrm{D}$ expenditures based on firm-specific threshold values that reflect minimum expectations on the return from R\&D effort.

Our core formulations specify technological change primarily as series of firmlevel incremental increases in labor productivities which arrive according to a Poisson process. However, as discussed in the earlier chapters, our model features a secondary dimension "product quality" (as complementary or substitute to the first dimension "labor productivity"), the magnitudes of which have a strong effects on welfare (as suggested by equations 3.7 and or 3.8 ), and which accordingly is highly effective in determining individual firm's competitiveness, survival and growth chances ${ }^{2}$. Our basic technological change formulations that are discussed in this chapter can also be specified in a way that governs series of firm level incremental increases in product qualities together with, or alternatively in isolation from labor productivity increases. The essential modifications that are made to introduce quality-based technological change into our model are discussed in an appendix to this chapter, while the presentation in the main text is confined to productivity-based technological change.

At the end of the chapter we also include another feature of our model which enables the endogenisation of consumers' preferences on the basis of changing (increasing) welfare levels (i.e. total sectoral consumption) brought about by technological change. Our specification of customers" preferences which is essentially based upon the Cobb-Douglas utility function (constant budget share for each sector) obviously suggests unit income elasticity of sectoral demand. Endogenisation of sectoral preferences on the basis of welfare levels leads to varying income ellasticities, which show their effect only over time, as technological change gradually brings about increases in welfare. 


\subsection{Technological change as exogenous increases in labor productivities}

In this section, we will formulate the technological change module of our module in terms of streams of individual firm level increases in labor productivity and also temporal changes in (sectoral) capital intensities the rate of change of which is formulated as relative to the former. In our experiments so far which are focused on the workings of our basic selection module, we have been assigning each firmaij a certain labor coefficient $a_{k i j}$ at birth (as an initial condition) and keeping these coefficients unchanged throughout each entire simulation run. The capital intensity parameters $b_{i j}$ specified for each sector $i$ of each country $j$ separately (yet without discrimination among the firms of the same sector-country) have been determining the unit purchase/replacement cost/price of the sector $i$ specific capitial, and accordingly the value of the accumulated capital stock, as a function of the average labor productivity in the country-sector ${ }^{3}$. Basically, our basic module of technological change procures the simultaneous (and essentially stochastic) in. cremental increases of the firm specific variables $a_{k i j}^{t}$ and sector country specific variables $b_{i j}^{t}$ over time $t$, and each of our alternative formulations specify a set of principles/mechanisms in which these variables (that have been taken as constant parameters in our earlier experiments) change over the periods of our discrete time simulations.

The changes (increases) in the firm level labor productivity coeflicients can happen due to innovations/learning and/or imitation of more productive firms by less productive others. The processes that underlie firm level increases in labor productivity coefficients are specified as stochastic arrival of new technological opportunities which basically follow a Poisson process, the numerical implementation of which is achieved through a series of successive Bernoulli trials.

\subsubsection{Innovations in the final good sectors}

We introduce three alternative mechanisms of learning/innovation within our capital disembodied formulation of technological change. Each of these modules introduces a different set of technological opportunities, specified by different potential trajectories for the temporal increases in each firm level labor productivity coefficient $a_{k i j}^{t}$. For a converient notation let the variable Fitness $s_{k i j}^{t}$ denote the technological level (some fitmess indicator) of firm $k i j$ at period $t$. Furthermore, let us ignore (temporarily) the possibility of imitation among the firms.

For each firm access to a better technology by innovation is modeled as a two stage stochastic process, the first stage determining access to the second. The first stage is a Bernoulli trial approximation to a Poisson arrival processes. For each firm, each trial determines if there is any innovation. In our exogenous (independent of R\&D and/or output level) technological change formulation the

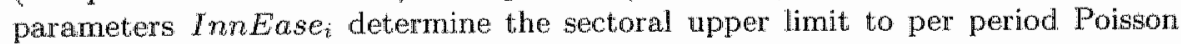
arrival rate of an innovation to each surwiving firm of the corresponding sector $i$. Firms can be made heterogeneous with regard to their abilities towards innovation and imitation. Hence the per period Poisson arrival rate of an innowation for the individual firm $\hat{i n g}_{j k}$ is given by

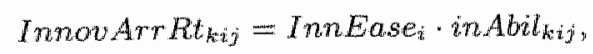

where in $A b i l_{k i j} \leq 1$ is an innate (genotype) parameter unique to each firm, which is determined randomly once and for all when the firm is founded, as firm-specific 
independent uniform draws from U[inAbilMin ${ }_{i j}$, inAbilMa: $\left.x_{i j}\right]$. Through firmlevel variations of the value assigned to this parameter, one can introduce heterogeneity in the innovative abilities of individual firms and is determined. Furthermore through variations in the parameters inAbilMini $\leq$ in AbilMaxij, which can be made through the graphical user interface of the computer implementation of our model, one can introduce controlled cross-country and/or cross-sector differences in the average values of the frm specific technological change ability indicators in $A b i l_{k i j}$ and $i m A b i l_{k i j}$ respectively. One can also interpret these pawameters as indicators for the skills/experience of the R\&D workers employed by the firm, or in other words, as indicators for firm specific human capital.

As mentioned above, the implementation of the firm-level Poisson processes that govern the arrival of innowation opportunities are made through Bernoulli triall approximations. For each period t, this approximation is achieved by 500 Bemoulli trials for each firm. To be more specific, at each period $t$ of the simulation, each firm $_{k i j}$ draws 500 random numbers (from the uniform distribution $U[0,1]$ ) for access to an innovation. For each random draw (say RandNrInnow tij , where $s$

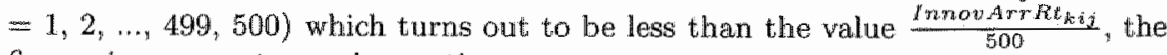
firm gains access to one innovation.

For each such lucky draw (i.e. RandNrInnov $v_{k i j}^{i, s}<\frac{\operatorname{InnavArr} R t_{k i j}}{500}$ ), the firm simply adds an increment Incrmnt $t_{k i j}^{t, s}$ to its current competence level Fitness $s_{k i j}^{t}$, where Incrmnt $t_{k i, j}^{t, s}$ is a random variate withdrawn from the normal distribution such that

$$
\text { Incrmntt } t_{i=j}^{t, s} \sim N\left[m \text { Incrmnt } t_{i},\left(\text { mIncrmnt } \text { In }_{i} \cdot \text { sIncrmnt }_{i}\right)^{2}\right] \text {. }
$$

The parameters mIncrmnt and sIncrmnt $_{i}$, which can be set by the user through the graphical user interface of the simulation software, denote respectively the mean value and coefficient of variation of the normal distribution from which increments to firms' fitness levels are withdrawn.

Let us take a look at the expected properties of this two-stage formulation of firm level progress. The essence of the stochastic innovation/learning process described above can be summarized by the following expected value equation

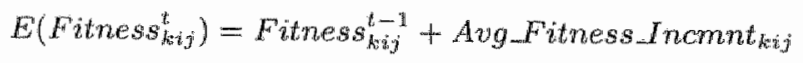

or

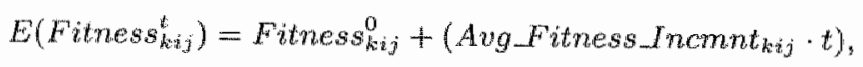

where the operator $E(\cdot)$ denotes the expected value (recall that technological change is stochastic) and

$$
\text { Avg_Fitness_Incmnt }_{k i j}=\text { InnEase }_{i} \cdot \text { inAbil }_{k i j} \cdot \text { mIncrmnt }_{i} \text {. }
$$

These expected value equations basically suggest that the firm-specific fitness measure Fitnesstij can be expected to follow a linear increase trend simillar to the pattern of a random walk with a drift. Conwentionally, we will refer to the realization of each increment to the variable Fitness $t_{k i j}$ as an innowation or a learning step.

In our formulation above the variable Fitness $s_{k i j}^{*}$ clearly plays an auxiliary role, since the firm-level dynamics of actual progress in labor productivity coefficients (or alternatively in product quality coefficients) is formulated as three alternative 
mappings of the motion of the variable Fitness $s_{k i j}^{t}$, where each alternative mapping corresponds to an alternative technological change trajectory. By using the graphical interface of the simulation software, one can choose any of these three alternative assumptions on the technological change trajectories to be followed by the firms. Let us discuss these alternative assumptions of our simulation platform one by one:

\section{Linear technological trajectories}

The first alternative specifies linear yet stochastic (i.e. random walk with a drift) growth paths for labor productivities. According to this formulation (in cases with no imitation among the firms), labor productivity coefficient of each firm, $k$ i $j$ changes according to

$$
a_{k i j}^{t}=a_{k i j}^{0}+\text { Fitness }_{k i j}^{t}
$$

where Fitness ${ }_{k i j}^{0}$ is set to zero for all firms as an initial condition in our simulation runs ${ }^{4}$.

The following expected value expression clarifies the reason why the progress path implied by the mapping in question is characterized by linear technological trajectories.

$$
E\left(a_{k i j}^{t}\right)=a_{k i j}^{0}+\left(\text { Aug_Fitness_Incmnt } t_{k i j} \cdot t\right)
$$

\section{Exponential technological trajectories with constant productivity growth rates}

The second alternative technological trajectory specifies (on the average) constant growth rate for labor productivities where, due to the stochasticity in innovation arrivals, the actual growth rate can exhibit differences between firms:

$$
a_{k i j}^{t}=a_{k i j}^{0} \cdot \tau_{i}^{\text {Fitressisij }}
$$

where $\tau_{i}$ is a sector specific parameter denoting the growth factor.

The following expected value formulation, which predicts an (on the average

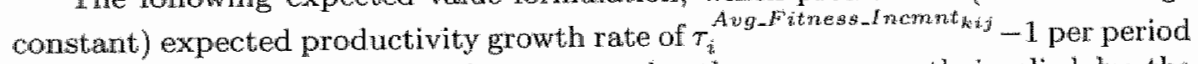
for given firm, alj, clarifies the reason why the progress path implied by the mapping in question is characterized by exponential technological trajectories.

$$
E\left(\alpha_{k i j}^{t}\right)=a_{k i j}^{0} \cdot \tau_{i}^{\text {Avgs Fitness_Incmnt } t_{k i j} \cdot t} \text {. }
$$

\section{Concave (and asymptotically convergent) technological trajectories each pertaining to a different technological paradigm}

The third alternative introduces discontimuities into the learning/innowation processes, in line with the idea of "technological paradigms" 5 . Each paradigm (i.e. radically different way of production) is characterized by a different learning curve as depicted on Figure 5.1. In other words the entire technological opporturnity (labor productivity coefficient) set/interval is divided into finite regions by a cardinal ordering. Each productivity region is assumed to offer a continum of labor coefficients, which exhibit dynamic decreasing returns to innovation/learning. That is, within the productivity boundaries of each paradigm (i.e. $\left[\alpha_{i, P a r d g m,}^{\min }, a_{i, P a r d g r n}^{\max }\right]$ 


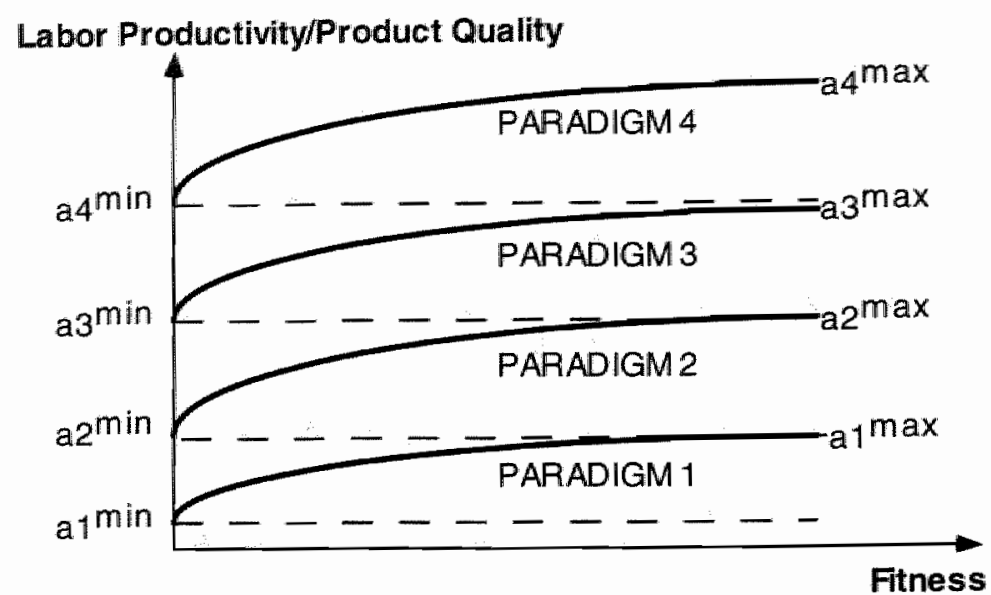

Figure 5.1. Fitness v.s. labor productivity (or product quality) in technological paradigms

for each paradigm indexed by the integer number Pardgm \#), each successive innovation (increment to Fitnesstivi ) brings about a lower increment to labor productivity than those brought about by the earlier innovations (the contribution of successive increments on labor productivity asymptotically converge to zero).

Although technological opportunities are eventually depleted (as learning goes on) within each productivity interval (paradigm), jumping to a higher region of productivity orients the firm into a fresh new learning trajectory, since a new paradigm is by definition a radically different way of doing things, which offer higher productivity levels to those who learn/find out its potentials by experience.

Productivity progress within individual paradigms Figure 5.1 shows an example of a technological opportunity set with (an arbitrary) 4 different notional paradigms. The variable Fitnesstij (which shows up in the x-axis of the chart) retains its instrumental function defined before, yet it now assumes a paradigm specific context. That is, in our paradigms-based technological change formulation, the technological access (labor productivity) of a firm $k_{k}$ at a given period $t$ is not cletermined uniquely as a function of the variable Fitness $s_{k i j}^{t}$ as before, but also by the technological paradigm in which the firm operates. The variable $F$ itnesskij specifies the level of accumulated progress of the firm within the paradigm adopted by the firm. Independently of its fitness level at period $t$, a frm that switches to a new/higher paradigm at period $t+1$, is assigned to Fitness $s_{k i}^{i+3}=0$, which corresponds to the lowest possible (zero experience) labor productivity level made available by the new paradigm ( $a_{P a r d g m}^{\min }$ on the figure). Only in time and by successive innovations/leaming, each resulting in a (on the average) fxed incremental progress along the variable Fitness $s_{k i j}^{t}$, the firm moves up to higher productivity levels (up to $a_{P a r d g m+1}^{\mathrm{min}}$ on the figure) available in the paradigm. Formally, the function that maps the adopted paradigm (indicated by the integer number Pardgm\#) and the fitness (accumulated experience) level within that paradigm to labor productivity is given by

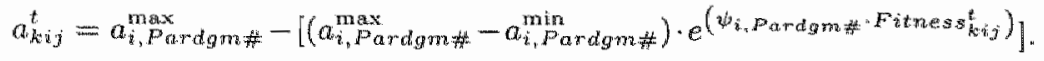


The parameters $\alpha_{\psi, P a r d g m}^{\mathrm{min}}$ and $a_{i, P a r d g m}^{\mathrm{max}}$ denote respectively the minimum (zero paradigm-specific experience) and maximum (infinite paradigm-specific experience) labor productivity levels made avallable by the technological paradigm. referred to by the integer number Pardgm $\#=1,2,3$,., etc. Note that, although

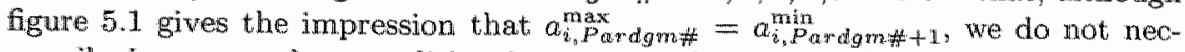
essarily impose such a condition in our actual computer implementation. The paradigm specific parameter $\psi_{i, P \text { ardgm }}<0$ determines the extent of dynamic decreasing returns to innovation (or learning) ${ }^{6}$, within paradigm Pardgma

Clearly, for cases with technological paradigms, it is not possible to write a time homogenous expected value version of equation 5.10 as we did before by equations 5.7 and 5.9. The obvious reason is the fact that the value of Fitness $s_{i j j}^{t}$ for a frm that operates in paradigm Pardgm \# at period $t$, is dependent on the period $t_{k i, j}^{\text {Pardgm }}$ at which firm $k_{i j}$ first adopts (switches to) the paradigm in question. That is, for our formulation with paradigms, the expected value of the period $t$ labor productivity of a firm, which happens to have switched to Pardgm \# at period $t_{\text {Rij }}^{\text {Pardgm }}<t$ is

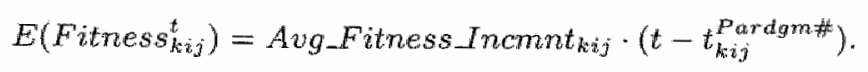

Introduction/invention of new technological paradigms This last equation naturally raises an important question: "Exactly at which period is a new paradigm inwented by a firm?". Similar to the arrival of the (within paradigm) incremental innowations, the arrival/discovery of new paradigms also take place through a stochastic process. In simple terms, each firm, every time it makes a successful draw for an incremental innovation (i.e. the periodical Bernoulli trial process), is given the chance to make one secondary Bernoulli trial the success of which makes the firm in question the inventor of new state of the art paradigm. The firm responsible for the new paradigm (say paradigm Pardgm +1 ) is pro-

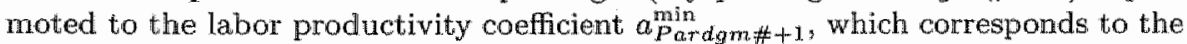
paradigm Pardgm\# +1 specific experience level at Fitness $s_{k i j}^{t}=0$. From this moment onwards no other firm can reinvent this paradigm. At the subsequent periods, the adoption of the new paradigm Pardgm +1 by the rest of the firms remains to a matter of direct imitation of the pioneer or of indirect imitation via. another firm that has luckily been able to imitate the pioneer before.

The success probability of the secondary Bernoulli trial which determines access to a new paradigm is normally determined by the sector-specific parameter PrNxtPar, to which one normally assigns quite low values to render the discovery of new paradigms. (which are basically radical/drastic innovations) much more rare events than the arrival of (within paradigm) incremental innovations.

We have also built into our model the option to render this probability (i.e. the probability to pioneer Pardgm\#+1 when the best practice paradigm is Pardgm \#) an increasing function of the level of expertise in the currently best: practice paradigm (i.e. Pordgm*), or in other words an increasing function of Fitness $s_{k i j}^{t}$ which assumes a paradigm specific context in case of our concave technological progress assumption. The exact formulation of this optional module (which reflects some sort of cumulativeness in technological progress) is as follows:

In settings where technological change is characterized by more than one technological paradigms, each firm that has access to an innovation is given the chance to be the inventor (pioneer) of a new (the next) paradigm which is not already invented by any other firm before period $t$. Namely, if the state of the art paradigm in sector $i$ at period $t$ is Pardgm\#, each firmbij which already 
has access to this state of the art technology and which also satisfies the con-

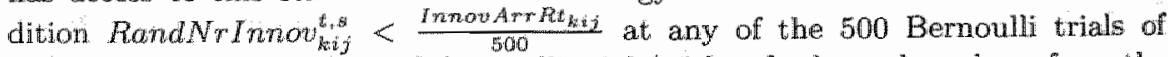
period $t$, makes an additional Bernoulli trial (with a fresh random draw from the uniform distribution $U[0,1]$ ), in onder to be the inventor of the next paradigm Pardgm \# +1 . Normally the success rate of this additional Bernoulli trial is de termined by the parameter $P r N x t P a r_{i}$, which should naturally chosen to be rather small number indicating that the invention of a new paradigm is a rather rare event.

Let us reiterate that our specification suggests that only the firms which al-

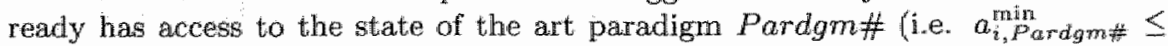
$\left.a_{k i j}^{t}<a_{i, P a x d g m i}^{\max }\right)$ are given the chance to be the pioneer of the next paradigm Pardgm \# +1 . The cumulativeness of technological change already imposed with this restriction can also be further reinforced by making the probability of being the pioneer an increasing function of the potential pioneer's level of competence in the state of the art paradigm Pardgm\#. Let the variable $\operatorname{Pr}_{h i j}^{*}\left(P_{\text {ardgm }}^{*}+1\right)$ denote the probability that a firm ${ }_{k i j}$ becomes the pioneer of technological paradigm Pardgm \# (provided that the firm has first access to an innovation at period $t$ by

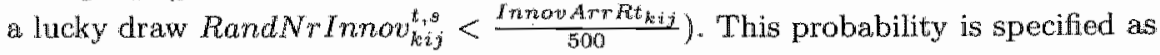

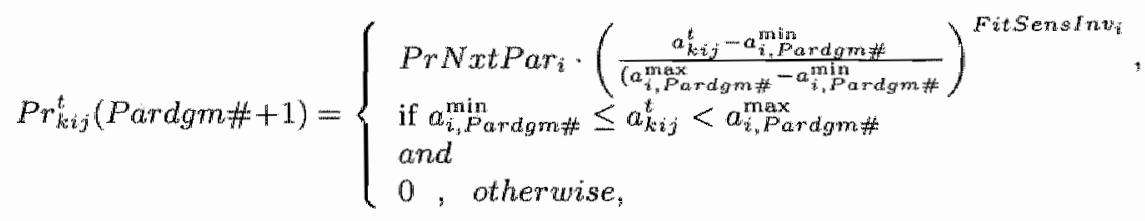

where FitSensInvi $>0$ is a parameter that determines the strength of the corresponding effect while $\operatorname{Pr} N x t P a r_{i}$ remains as a fixed parameter as defined before. This formulation (especially for relatively larger values of the parameter FitSensInvi) gives the firms that are relatively more experienced in the current paradigm, a bigger chance to be the pioneer, indirectly enforcing the firms to follow the full predetermined techmological path gradually without any big jumps (as long as the jump does not cone with a lucky imitation).

\subsubsection{Imitations in the final good sectors}

In our discussion so far, we have conveniently been assuming away imitation possibilities in order to focus on the pure implications of firm level innovations. How ever, mechanisms of imitation among individual firms (of only the same industry) are also built into the model. At any given period, there exist some possibility that a firm adopts the superior production technique used by another firm and due to this adoption enjoys a highes labor productivity level in due course. The imitation process is modelled in a way that is similar to the two-stage algorithm that governs innovations. Namely, as the first step, the firm's access to any imitation is determined by a Poisson process the arrival rate of which is given by the parameter: ImitArrRt $t_{k i j}$. This parameter is determined as the product of a sector specific parameter ImEase, which determines the sectoral upper limit to the per period Poisson arrival rate of an imitation to each surviving firm of the corresponding sector $i$, and a firm specific parameter im $A$ bil $l_{k i j} \leq 1$, through which firms can (optionally) be made heterogeneous with regard to their abilities towards imitation (i.e. heterogeneity in the "technological absorptive capacity of firms"), 
such that

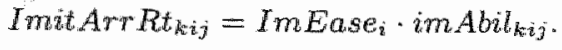

The assignment of the innate (genotype) variables $i m A b i l_{k i j}$ to indiwidual firms is antomatically made by the simulation software as firm specific independent uniform draws from the uniform distribution $U\left[i m A b i l M i i_{i j}\right.$, im Abil Maxij]. The

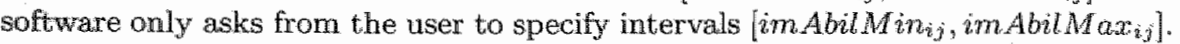

Similar to the case with innovations, the implementation of the Poisson processes that govern the arrival of imitation opportunities is made through Bernoulli trial approximations. For each period $t$, this approximation is achieved by 500 Bernoulli trials".

For each firm $k_{k j}$ that gains access to an imitation opportunity in these periodical Bernoulli trials, a second stage addresses the question "which other firmuin will be imitated by the firmkij?" or in other words "what are the conditions that determine the possibility (difficulty or ease) of the imitation of a given firm ${ }_{l i h}$ by another firm $k i j$ ?".

Each time a firmoij gains access to an imitation opportunity at the Bernoulli trials stage, starting from the most productive firm in the world (of the same sector) and proceeding down the list of all other firms sorted in descending order (according to their technological superiority), explores the possibilities of imitation firm by firm until a fortunate success. For every other firm tried, the possibility of an imitation is made a function of the nationality and the size of the targeted firm, the technological distance between the firms, and the time passed since the adoption of the superior (targeted) technology by the leading firm (i.e., appropriability). The actual possibility is determined by the most binding one of these separate factors. The explicit relation among these variables and the resulting probability of imitation is given by

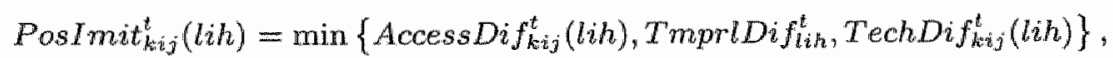

where Postmit kij $\left(\right.$ lih) denotes the possibility that firm $k$ of the $i^{\text {th }}$ sector of the $j^{\text {th }}$ country (provided that it has gained access to an imitation opportunity at the first stage), imitates firm $l$ of the $i^{\text {th }}$ sector of the $h^{t h}$ country at period $t$. For every other firm in $_{\text {tried, firm }}$ i:j draws a random number from the uniform distribution $U[0,1]$, and if the number drawn is less than PosImitwig (lih) then firmkij gains access to the superior technology of firm $t_{i n}$ and stops searching. In other words, the second stage of the imitation process consists of an additional series of Bernoulli trials, one for each other firm that has access to a superior" technology.

The variable Access $D i f_{k i j}(l i h) \in[0,1]$ denotes the limitations to imitation regarding general access (i.e. the possibility that firm $k_{i j}$ spots and targets firm $l_{i h}$ for imitation) and is specified as

$$
\text { Access Dif }_{h i j}^{l}(l i h)=\operatorname{SampPrb}_{\downarrow i h}^{l} \cdot \operatorname{RelImEase}_{i}(j, h)
$$

where RelImEase $(j, h)$ is a parameter that specifies the relative difficulty of an international imitation (i.e. if $j \neq h$ then RelImEase $(j, h) \leq 1$ ) vis-à-vis a national one (i.e. if $j=h$ then $\operatorname{Rel} \operatorname{ImEase}(j, j)=1$ ). Through the variable SampPrbyit which is defined as

$$
\text { SampPrb }_{l i h}^{t}=\text { SampEase }_{i}+W M \text { Shrih }_{i n}^{*} \cdot\left(1-\text { SampEase }_{i}\right),
$$


we introduce a mechanism which renders larger firms more likely to be detected and targeted by others for imitation. In equation 5.16 the variable WMShrth $=Q_{l i h}^{t} / \sum_{j=1}^{N C} Q_{i j}^{t}$ stands for the period $t$ market share of firmik in world sector $i$ production, and the parameter $0 \leq$ SampEase $\leq 1$ determines the extent of the effect in question. By setting SampEase $=1$ this constraint is rendered redundant (imitators monitor/target for imitation the whole set of other firms equally easily), and otherwise (i.e. SampEase $<1$ ) the bigger a firm the higher is the probability that it spotted and targeted by others for imitation.

The other factor that affects the likelihood of imitations is time. It is reasonable to assume that after a new technology is discovered by a firm, it takes some time for the others to find out about the existence of this new technology, and collect the information required for a successful imitation. Accordingly, we introduce into our formulations the option to make the likelihood that a given technology is imitated by athers, an increasing function of the time interval between the period when the targeted technology in question is first discovered/adopted and the period when the imitation attempt is made. This source of imitation inhibition is captured by the wariable $0 \leq T$ mprlDifin $\leq 1$. Assume that the technology used by firmin at period $t$ happens to have adopted (by an innovation or an imitation) at period $t^{*}<t$ so that it has been used by firm ${ }_{i, k}$ for Tech Age $e_{i i h}^{*}=t-t^{*}$ periods. The variable $0 \leq T$ TmplDif tin $\leq 1$ is specified as an increasing logistic function of TechAgeth such that

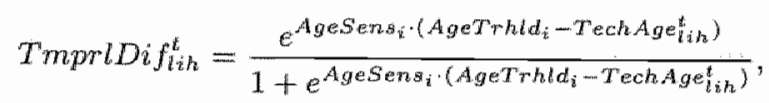

where the sector specific parameter AgeTrhldi determines the inflection point and AgeSens determines the curvature of the function. For high values of AgeSens, the function approximates a step function at AgeTrhld, which may be used to represent patents that last AgeTrhldi periods. Namely, TmprlDifin $\approx 0$ whiclu remains as long as TechAgetih $<$ AgeTrhld implies that PosImix Fij $_{i j}$ (lih) (specified by equation 5.14) remains close to zero for AgeTrhld periods following the adoption of the technology in question, so that it can not be imitated during this time interval.

The technological distance between the prospective imitator and the twarget of imitation is specified as an imitation inhibitor. The variable $0 \leq T_{e c h}$ Dif $f_{k i j}^{t}($ lih $) \leq$ 1. clenotes the restraining effect of technological distance on the probability of imitation. For the determination of technologicall distance between two firms, two dimensions may be considered. First, for the firms that operate under the same paradigm, we define technological distance as an increasing function of the difference between the paradigm specific competency levels of the firms which is

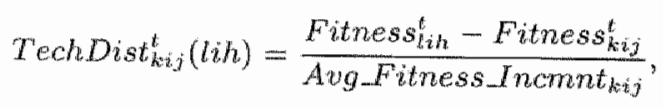

where the variable Agg Fitness Incmnt kij $_{\text {ij }}$ that scales the difference in fitness (as defined equation 5.5 before) denotes the average increment to firm kij $_{j}$ fitness under normal circumstances of innowation/learning. Thus, equation 5.18 defines the variable TechDist $t_{k i j}(l i h)$ as the number of innovation with which firm $k i j$ could (on the average) increase its fitness level to that of firm ${ }_{l i h}$. Therefore, the natural unit of the variable Tech Dist $t_{i j}^{t}(l i h)$ is number of incremental innovations.

Accordingly the possibility of an imitation between two given firms of the same sector is specified as a decreasing logistic function of this technological distance measure TechDistik $(l i h)$ between the potential imitator ( firm $_{k i j}$ ) and the firm 
targeted for imitation (firmiih). In other words, the higher the technological distance (measured in equivalent number of innovations), the lower the possibility of an imitation such that

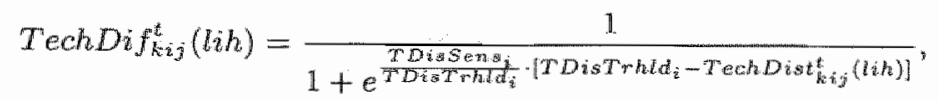

where TDisTrhld and TDisSens, are parameters, the former determining the inflection point and the latter determining the curvature of the logistic function.

For the firms that operate under different paradigms, the specification given by equation 5.18 naturally does not make sense. In such cases we consider the difference in paradigm numbers. Assume that firm ${ }_{i \text { ih }}$ operaties in paradigm Pardgm \# lin whereas firm operates under paradigm Pardgm $k i j$ such that the integer number $m=P$ ardgm $\#_{l i h}-P a r d g m \# k i j>0$. In such cases, instead of the relation given by $5.19, T e c h D i f_{k i j}^{t}($ lih $)$ is calculated by the following relation

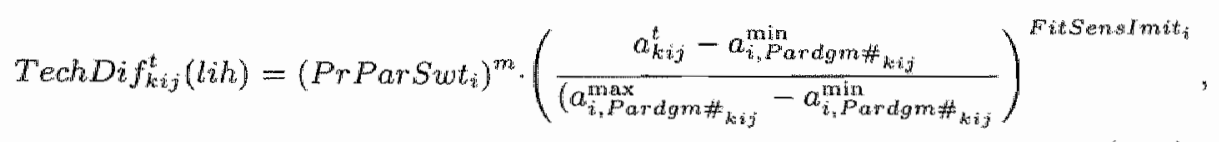

where $0<\operatorname{PrPar} S w t_{i} \leq 1$ and FitSensImit $>0$ are sector $i$ specific parameters, the former cletermining the general difficulty of an imitation involving a paradigm switch of distance $1^{8}$, and the latter determining the effect of the potential imitator"s competence (within the paradigm currently in use) on its chances in a paradigm switch. The latter effect reinforces the extent of cumulativeness in imitations in a way similar to the logic of equation 5.12 discussed above. Thus, reconsidering equation 5.12, one can suggest that the ratio $\frac{P_{r} P_{a r} \text { Pwt }_{i}}{P_{r} N_{x} P_{i}}$ denotes the ease of having access to a superior technological paradigm by imitation relative to having access by innowation (a pioneering invention). Furthermore in actual experiment: designs, it would naturally make sense to keep FitSensImit $t_{i}=$ FitSensInvi in $^{\prime}$ order to achieve consistency between the extent of cumulativeness in innovation and cumulativeness in imitation in the context of switching between paradigms.

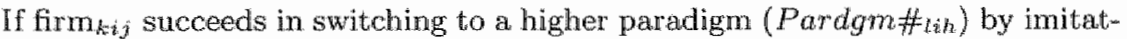
ing a firm ${ }_{l i k}$, it is assigned an initial competence level in this new paradigm which is a random fraction of the imitated firm's (Pardgmftus specific) competence level:

$$
\text { Fitness } s_{k i j}^{t+1}=R F^{t} \cdot \text { Fitnessith }
$$

where $R F^{t}$ is a fresh random draw from $U[0,1]$. In other words, imitation of a firm using a higher paradigm presents the imitator with access to this superior paradigm but it does not necessarily promote the imitator to the very competence level of the imitated firm at once.

In the walk of technological change, firms make innovations every now and then and adopt better technologies. Each time this happens, the model software files the old technology and keeps it until obsolete. These records can also be reached by other firms for imitation. However, accessing to these files are not different than imitating an actually used technology. In other words, the possibility of imitating another firm's old technology is also affected by the potential inhibitors (i.e. technological distance and technological age) discussed above.

With the technological change framework described in the last two sections, various factors that determine the likelihood of innovations and spill-overs are 
orthogonally decomposed. The formulation features a collection of factors that potentially enable innowations and/or hinder imitations, and by experimenting in a systematic way with warious combinations of the associated parameter values, various circumstances with regard to technological change can be created, and the analysis of their effect on growth, specialization, and cross-country growth and wage differentials and endogenous industrial organization patterns can be studied. Examples to such exercises will be presented in the following two chapters.

\subsubsection{Technological change in the capital sectors: The motion of capital intensities}

All the innovation/imitation mechanisms we have been discussing so far have one important thing in common: Whenever a final good sector firm comes across (wia innowation/learning or as an imitation possibility) a technology that offers a higher labor productivity than the technology it uses at the moment, it adopts this superior technology and applies it upon its entire production activities immediately. Namely, our discussion has implicitly been assuming capital disembodied technological change (i.e. each new technology can be adopted without the necessity to make ary changes in the quantity and composition of the existing capital stock) and naturally capital intensity (cost) related issues are no concern for the firms in making their decisions in adopting new technologies. While we will relax this assumption in our capital vintages framework (as discussed in the following section), in terms of capital costs an important question remains for our current discussion: "What happens in the capital producing sectors, while technological change keeps on increasing labor productiwities in the final good sectors?"

Recall from our earlier discussions that in our formulation where capital production is not explicitly modelled as in the individual firms-based formulations of the final good sectors, the production (or replacement) costs/prices of capital goods ${ }^{9}$ are specified to be proportional to the (average) labor productivity coefficients in the corresponding final good sectors. In other words, labor productivity in each sector $i$ specific capital production in country $j$ is specified to be proportional to that in the final good sector $i$ of country $j$, where the parameters $b_{i j}$ (our capital intensity parameters) determine these proportions such that

$$
\text { P.Captl } t_{j,}^{t}=\frac{w_{j}^{t}}{a_{i j}^{C a p i t a t, t}} \cdot\left(1+\text { Captl SectorMark_U } p_{i, j}^{t}\right)
$$

where, $a_{i j}^{\text {Capital,t }}$ is the labor productivity coefficient in sector $i$ specific capital production in country $j$, the and CaptlSectorMark $U p_{i, j}^{t}$ is the mark-up rate ${ }^{10}$ charged by the capital sectors over their unit labor costs $\frac{w_{j}^{t}}{a_{i j}^{C a p t t a l, k}}$. Our formulation so far have been specifying that

$$
a_{i j}^{\text {Capital,t }}=\frac{a_{i, j}^{t}}{b_{i j}}
$$

where $a_{i j}$ is the (weighted) average labor productivity $\left(a_{i j}^{t}=\frac{\sum_{k=1}^{N / F_{i j}} Q_{k i j}^{t}}{\sum_{k=1}^{N F_{i j}} \frac{Q_{k i, j}^{t}}{c_{k i, j}^{t}}}=\frac{Q_{i, j}^{t}}{L_{i j j}^{t}}\right.$ ) in sector $i$ of country $j$. Thus, the sector $i$ capital output ratio in country $j$ is

$$
\frac{P_{-} \text {Capt }_{i j}^{t}}{P_{i, j}^{t}}=b_{i j} \cdot \frac{\left(1+\text { CaptLSectorMarkUU } p_{i j}^{t}\right)}{\left(1+\text { Mark_Up } p_{i j}^{t}\right)}
$$


Note that, given our definition of capital as productive capacity, the presence of one single capital price $P$-Capt $l_{i j}^{t}$ for each country-sector combination implies that our model assumes equal productivity of capital for all firms of the same sector of the same country. However, within our capital vintages based technological charige formulation this assumption can be relaxed.

Yet what could these mean in cases of technological change, formulated as temporal increases in individual firms" labor productivity coeflicients (i.e. $\widehat{a k i j} \geq$ 0), which (also with the help of selection forces of the economy) imply increases of the average labor productivity of sectors over time (i.e. $\widehat{a_{i j}} \geq 0$ )? Let us rewrite equation 5.22 together with equation 5.23 once again in rate of change form, ignoring the effect of any changes in the wage rate (or measuring capital costs/prices in terms of the wage rate):

$$
P_{-\widehat{C a p t} l_{i j}}=\widehat{b_{i j}}-\widehat{a_{i j}} \text {. }
$$

First, let us assume that the capital intensities remain constant (i.e. $\widehat{b_{i j}}=0$ ), which implies $P_{-} \widehat{C a p t}_{i_{i j}}=-\widehat{a_{i j}}$. This suggests that in the presence of labor productivity augmenting technological change in final good sectors, the fixed capital intensity coefficient assumption $\left(\widehat{b_{i j}}=0\right)^{11}$ is directly equivalent to the assumption that the effects of learning/innovation in the final good sectors immediately spill over to the capital sectors, or in other words, labor productivity in each sector $i$ specific capital production in country $j$ immediately follows the temporal changes (increases) in the average labor productivity attained in the same sector of the same country.

Now, let us take a look at the other extreme, where there is no technological change in the capital sectors ${ }^{12}$, so that capital good prices (measured in terms of equivalent labor units) remain constant (i.e. $P \_\widehat{C a p t} l_{i j}=0$ ). According to equar tion 5.25 this condition implies $\widehat{b_{i j}}=\widehat{a_{i j}}$. Namely, in circumstances where there is no technological change (productivity increase) in capital sector, the existence of technological change in final good sectors $\left(\widetilde{a_{i j}}>0\right.$ ) automatically implies a continuous temporal increase in the capital intensity of production $\left(\widehat{b_{i j}}>0\right)$.

In our technological change module, we introduce a formulation which interpolates (as well as extrapolates) between these two extreme possibilities. In settings characterized by technological change, the parameter matrix $b$ (with elements $b_{i j}$ defined separately for each sector $i$ specific capital production in each country $j$ ) the settings of which is made through the graphical user interface of our implementation, only sets the initial (period $t=0$ ) values of the vector. At the subsequent periods of the simulation, each capital intensity coefficient $b_{i j}$ is endogenously updated according to the average labor productivity changes in final good sectors by a sector-country specific parameter CaptlProdFollowRate ij $\geq 0$ which determines the rate at which learning/innovation (or labor productivity increases) in each capital sector follows that in the corresponding final good sector. The effect of this new parameter is specified to be asymmetric around the value 1.0. That is, in cases where the user sets CaptlProdFollow Rate $i j \leq 1$, the software updates the labor productivity in capital sector ${ }_{i j}$ such that

$$
a_{i j}^{\text {Capital,t }}=a_{i j}^{\text {Capital,t-1 }} \cdot\left(1+\frac{\left(a_{i j}^{t}-a_{i j}^{t-1}\right)}{\left(a_{i j}^{t-1}\right)} \cdot \text { CaptlProdFollowRate } i j\right)
$$

which, in terms of rates of change, implies

$$
\widehat{a_{i j}^{\text {Capital,t }}}=\widehat{a_{i, j}^{t}} \cdot \text { CaptlProdFollow Rate } e_{i j,}
$$


and also due to equation 5.23

$$
\widehat{b_{i j}^{t}}=\widehat{a_{i j}^{t}} \cdot\left(1-\text { CaptiProdFollowRate }_{i j}\right) \text {. }
$$

Obviously, CapulProdFallow Ratie $i_{j}=0$ implies no technological change in the sector $i$ specific capital sector in country $j$, whereas CapLProd Follow Rate $i j=1$ implies perfect and instantaneous technological spill-overs from the final good to the corresponding capital good sector.

It is also possible to set CaptlPradFollow Rate $i j>1$ to impose higher techmological change/learning rates in capital sectors than in final good sectors. Such settings are interpretied such that labor productivity growth in the capital sector is higher than that in the final sector by CaptlProdFollow Rate $i j-1$. Accordingly the software updates the labor productivity in capital sector $i j$ as

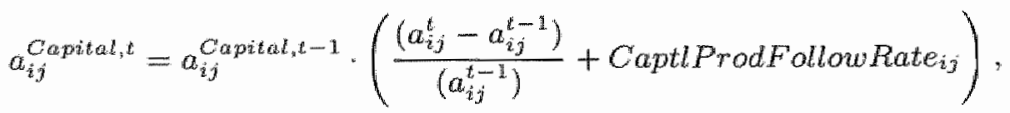

which, in terms of rates of change, implies

$$
\widehat{a_{i, j}} \widehat{\text { Capital }_{i} t}=\widehat{a_{i j}^{t}}+\left(\text { CaptlProdFollow Rate }{ }_{i j}-1\right) \text {. }
$$

and also due to equation 5.23

$$
\widehat{b_{i j}^{t}}=1-\text { Capil ProdFollow Rate } e_{i j} \text {, }
$$

which is naturally less than zero (i.e. temporal decreases in capital intensity).

As will be discussed in the following chapter, the ability to control (by the parameter vector CaptlProdFollow Rate) the rate of technological change in capital production as relative to that in the final good sectors makes it possible to derive interesting conclusion on various causal links that relate technological change, economic growth, income distribution and employment rates. In other words, in terms of income distribution and employment, in addition to the rates of technological change, also the distribution of the technological change over the two key segments of the economy (capital and the final good sectors) turns ont to be an important determinant.

\subsubsection{A capital vintages framework}

In cases where technological change is (at least partially) capital embodied, capital intensities (or capital good production costs) may also have other effects on the processes that rellate productivity increases to growth. As mentioned above, as long as new technologies (that offer higher labor productivity levels than the ones already used) does not bring along higher capital costs, the economy (one or mone firms) immediately adopts this new technology immediately as it becomes avalable. Yet, what if this condition is not satisfied? In other words, what if a new techmology (or a technological paradigm) just discovered commands the use a set of more sophisticated/expensive capital goods than those which constitute the already accumulated capital stock of the economy? Does the economy (or any of the firms) adopt this new technology and make it a dominant part of its production practices or does the new technology be ignored? Besides, who is the eventual decision maker of the answer to this last question?

The introduction of these issues in our model is achieved through the incorporation of a captal vintages framework, which is basically built upon our technological paradigms framework. Since every technological paradigm describes a 
specific way of doing production, it is reasonable to assume that the type and cost of capital goods required by the production techniques given by each technological paradigm can be different than those given by other paradigms. In other words, different technological paradigms may command the usage of different sets of capital goods, which may imply different capital intensities.

The building-up of new vintages is essentially a matter of investments (financial resources and their allocation over firms/technologies), which implies that the financial market should have an important role in the diffusion processes of new capital embodied technologies (paradigms) into the economies. In order to introduce this effect, our capital vintages framework is built upon the following principles:

It the capital vintages module of our model is activated, basically each firm opens a new separate workshop for each of the paradigms to which it has (either by being a pioneer or by imitation) access to. The opening of the new workshop takes place at the instant of access to the technological knowledge of the new paradigm. From this moment onwards, the behavior of each workshop is pretty much similar to that of the individual finms as discussed in the previous chapters. Namely, each workshop makes its own growth (capacity expansion) calculations/plans and asks for credits for their implementation from the financial market. In the process of granting of credits, the financial market perceives each workshop as a separate firm and accordingly each workshop is evaluated on the basis of its own profitability. Ewen at the period of initial foundation, the new workshop relies on the financial market for its start-up capital.

In oun formulation, there are three ways in which the operations of individual workshops differ from that of individual (single workshop) firms. The first one becomes observable in cases where demand for product variety exists (the CES parameter of the utility function $\theta$ is less than 1.0). In such cases, independently of the number of underlying workshops, consumers only observe differences between the products of different firms (brand names) and not the workshops. Namely, despitie the usage of technologies of different paradigms, each workshop of the same firm produces the same product variety and therefore the prices at which the output of the various workshops of the same firm are sold, are identical. Accordingly the individual profits of the workshop $m$ of firm $k_{i j}$ is given by

$$
\pi_{i m k i j}^{i}=Q_{m k i j}^{t} \cdot\left(P_{k i, j}^{t}-\frac{w_{j}^{t}}{a_{m k i j}^{t}}\right)
$$

and due to the fact that each workshop produces under a different paradigm, labor productiwities and hence profitability vary across the workshops.

The second difference is related with increasing returns to scale. In cases of increasing returns to individual firm's scale, the economies (labor productivity gains) enjoyed by each workshop is not a function of the output level of the individual workshop but of the total output level of all workshops which belong to the same firm (i.e. the total ontput level of the firm as a whole).

The third difference is that, based on the consideration that the composition (type of machinery/equipment) of capital goods required by different technological paradigms may show variations (as well as common elements), our models allows for capital (capacity) transfer among the workshops (i.e. the possibility of mutual and limited convertibility among capital vintages) of the same firm. Consider a technological paradigm that relies on the use of machines $\mathbf{A}, \mathbf{B}$ and $\mathbf{C}$ and another on machine types $\mathbf{A}, \mathbf{B}$ and $\mathbf{D}$. Obviously a firm can switch from the first to the second technology, (gradually or instantaneously) scrapping its machines of type 
$C$ and replacing them with machines of type $D$ purchased from the capital producers. If the purchase/market price of machine type $\mathrm{D}$ is higher (lower) than

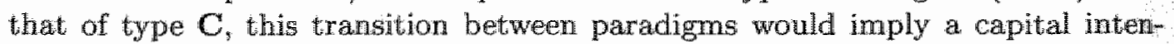
sity increase (decrease) in production. Furthemore, if the second technological paradigm yields a higher labor productivity than the first the transition would lock like substitution of labor with capital (i.e. leading to a higher capital-labor ratio). Now consider a third technological paradigm, which requires a totally dif ferent set of machine types; say $\mathbf{E}, \mathbf{F}$ and $\mathbf{G}$. Since the building up of new capital goods needs investment (the resources for which may be limited in the short run). one can expect a full transition from the first to the third paradigm to be more costly and (given limited financial credits) thus slower than a full transition from: first to the second paradigm, of course unlless the unit price of capital type $\mathbf{D}$ alone happens to be significantly higher than the total of the unit prices of capital types $\mathbf{E}, \mathbf{E}$ and $\mathbf{G}$ (i.e. the second paradigm is more capital intensive than the third).

The majority (if not all) of existing models on capital embodied technological change assume no such commonalities between different capital vintages. Thus in such models, the diffusion of a new capital embodied technology implies a process through which the new capital vintage is gradually built up from the scratch, while the old one is completely scrapped. This is not only an enormous source of waste for the system but is also an exaggerated source of friction that slows down the diffusion pace of new technologies into the economies. From a pure modeling perspective, this may be a highly convenient assumption. Nevertheless, we have built into our model the possibility to diverge from such extreme ${ }^{13}$ mutual excluisivity by a set of parameters that specify the extents of the heterogeneity between vintages in terms of their composition ${ }^{14}$. Despite the common parts of capital which can be reallocated to the superior workshop, reallocation requires extra resources to finance the purchasing of the uncommon components required by the superior paradigm. Hence, the magnitude of the reallocation at any period is bounded by the financial resources (credits) of that period and more important the economic rationality of the transfer which is evaluated by the financial market. Our formulations regarding the mechanisms/decisions through between-workshop capital transfer facilitates the building-up of productive capacity in new vintages are described in an appendix to this chapter ${ }^{15}$.

\subsection{Endogenisation of technological change}

In our presentation so far, we have been treating technology as a stream of opportunities that arrive at firms through a memoryless and time homogenous process, at notionally equal paces and without any costs. The only source of systematical firm level heterogeneity with respect to success in generating (and enjoying the benefits of) technological change has been specified by the firm level parameters in $A b i l_{k i j}$ and $i m, A b i l_{k i j}$ which (as given by equations 5.1 and 5.13 ) randomly render firms heterogeneous in their (innate) capabilities of making use of the given leaming/innovation and imitation opportunities (which arrive regularly proportional to the basis Poisson arrival rates InnEase and $_{i}$ ImEase I $_{\text {) }}$ respectively. This formulation suggests that for any fim, sustainable technological superiority is only possible in case of sustainable good luck (which is statistically unlikely) and/or superior innate technological capabilities which is achieved once and for all, at birth.

In this section our aim is to endogenise the firm-level variables Innov ArrRt $t_{k i j}$ and Imit.Arr $R_{k, j}$ which are otherwise exogenously determined by parameter set- 
tings as mentioned above. In our according formulations, we suggest three alternative/complementary mechanisms for the firm level endogenisation of these two variables which otherwise determine the general arrival rate of technological progress opportunities. The first two mechanisms follow the cumulativeness principle which is common to all models on endogenous growth where it is put forward as the underlying mechanism of sustainable growth. The first of these alternative cumulativeness-based modules two follows a formulation which mimics knowledge/human capital accumulation (such that each innovation increments the cumulative knowledge/human capital), while the second draws on the "learning by doing" concept which suggests a positive relation between production (output) level and the arrival of technological opportunities which can as well be interpreted as a learning process. The third mechanism which is formulated to work consistently with the former two suggests that firms can increase their learning rates (i.e, innovation and imitation arrival rates) by regularly investing part of their resources (which would otherwise be paid out as dividends on be used for capital expansion) on $\mathbb{R} \& D$ activities. The eventual arrival rate of technological opportunities are formulated as an overall function of these three alternative/complementary effects.

\subsubsection{Cumulativeness as an endogenising principle}

Our first module that endogenises technological change introduces cumulativeness into the incremental component of oum technological change process by making the arrival rate of incremental innovations an increasing function of the (cumulative) number of innovations made earlier. With this module activated, innovations not only bring about a -once and for all- increment to labor productivity, but the experience/knowledge generated by the imnovation enriches the knowledge/human capital stock and feeds forward the future of the innovation process as well.

Let the variable NoInnov tij denote the total number (a sheer count) of the number of innovations made by firm ${ }_{k i j}$ between the initial period and the $t^{t h}$ period of the simulation. Accordingly $N a N$ atnl_Innov $v_{i j}^{t}=\sum_{s=1}^{N F i j} N_{a}$ Innov $v_{s i j}^{t}$ is the cumulative number of innovations made by the sector $i$ firms of country $j$ prior to period t. Similarly No.World_Innov ${ }_{i}^{t}=\sum_{j=1}^{N C} \sum_{s=1}^{N F_{i j}}$ Nornnov Nij $^{t}$ stands for the cumulative number of inmovations made in the entire world as of period $t$. Now consider the following defimition

$$
\begin{aligned}
& \text { Cumul_Factor } t_{k i j}=
\end{aligned}
$$

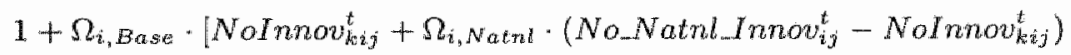

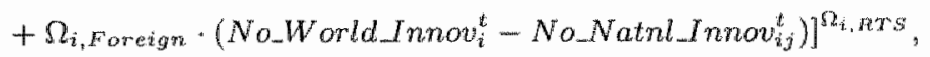

which is an aggregated (as weighted by the sector specific parameters $\Omega_{i, \text { awa }} \geq 0$, $0 \leq \Omega_{i, N a t n l} \leq 1$, and $0 \leq \Omega_{i, \text { Foreign }} \leq 1$ ) measure of three different sources of cumulativeness from the perspective of firm ${ }_{k i j}$. These three sources which may feed the innovative success of a firm are first the knowledge/experience accumulated through the firm's own learning/innovation history (as proxied by the variable NoInnov this ), second, the spill-overs of the knowledge/experience accumulated by the other (sector $z$ ) firms of the same country (i.e., NoLNatni_Innovi, - NoInnov $v_{k i j}^{t}$ ), and finally the spill-overs of the knowledge/experience accumulated by the (sector i) firms of foreign countries (i.e., No.World Innovi No Natni_Innov $\left.i_{j}\right)$. The parameter $\Omega_{i, R T S}>0$ introduces a returns to scale effect into the cumulativeness formulation. 
If the cumulativeness module is activated (by seting the corresponding switch variable CumulinInnovon to 1), the expressions that determine the (Poisson) arrival rate of innovation ${ }^{16}$ are multiplied by the variable Cumul_Factor ${ }_{k i j}^{*}$ for each firmkij. In the absence of learning by doing or R\&D effort related effects (which will be discussed below) the arriwal of innovations (as expressed by equation 5.I for cases of purely exogenous arrivals) accordingly turns into

$$
\text { InnovArrRt kij }=\text { Cumul_Factor }{ }_{k i j}^{*} \cdot\left(\text { InnEasei }-i n A b i l_{k i j}\right) \text {. }
$$

By manipulations of the parameters $\Omega_{i, B a s e}, \Omega_{i, \text { Natnl }}$, and $\Omega_{i, \text { Foreign }}$ one can introduce various assumptions into the settings of the model. For example, the combination $\Omega_{i, B \text { aze }}>0, \Omega_{i, N a t n l}=0$, and $\Omega_{i, \text { Foreign }}=0$, implies strong "tacitness" in knowledge/experience accumulation process. Namely, firmis can only draw on their own accumulated experience in the process of further learning/innovating. With higher settings for the parameter $\Omega_{i}$ Natnl one can decrease the extent of tacitness (i.e., increase the extent of codifiability) of accumulated experience and also the extent of experience/knowledge spill-overs within national borders ${ }^{17}$. A higher value for the paraneter $\Omega_{i, F o r e i g n}$ also introduces international knowledge spillovers. For example, for the extreme case $\Omega_{i_{n} N_{a} \text { tril }}=1$, and $\Omega_{i, F \text { oreign }}=1$, the variable Cumul_Factor ${ }_{k i j}^{t}$ reduces to $1+\Omega_{i, B a s e} \cdot$ No_World_Innov ${ }_{i}^{t}$, which implies that all sector i firms of the world equally utilize the total accumulated world experience/knowledge in their innovative activities.

Note that the activation of the cumulativeness module introduces a secondary (and different) dimension of knowledge spill-overs over the existing dimension characterized by direct imitation between the firms. Direct imitations only serve the instantaneous closing of the technological gaps and homogenize the pace of technological progress among the firms, but it does not necessarily help in the pushing of the technological frontier forward. However, accumulated knowledge, as formulated in our cumulativeness formulation, feeds the innovative processes and introduces an important source of dynamic increasing returns into the innovative processes. Furthermore, even in the absence of knowledge spill overs (i.e. $\Omega_{\text {Naml }}=0$, and $\Omega_{\text {Foreign }}=0$ ) our cumulativeness formulation (which reduces to Cumul Factor ${ }_{k+j}^{t}=1+\Omega_{i, \text { Base }} \cdot$ NoInnov ${ }_{k i j}^{t}$ ) introduces strong dynamic increasing returns in the technological change process.

\subsubsection{The alternative "Learning By Doing" formulation}

This module essentially renders the arrival rate of technological opportunities for each firm an increasing function of its (and optionally, the other firms") output: level in a linear fashion such that for

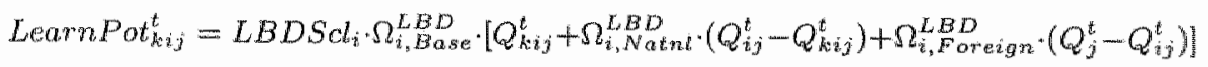

equation 5.1 tums into

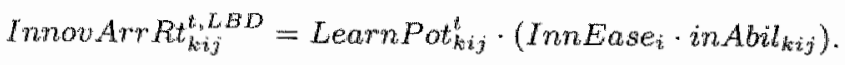

The sector-specific parameter $\Omega_{i, B a s e}^{C B D}>1$ determines the strength of the learning by doing effect on innovation arrivals, whereas the other parameters $\Omega_{i, N a t n}^{L B D}$ $\leq 1$, and $0 \leq \Omega_{i, F}^{L B D}$ oreign $\leq 1$ determine respectively the extents of knowledge spillovers in the context of leaming by cloing, and their effects are similar to those of the 
two parameters $\Omega_{i, N_{a} \text { atra }}, \Omega_{i, F o r e i g n}$ discussed in the previous section. The sectorspecific $L B D S$ S $_{i}$ scaling variable eliminates an undesirable scale implication from the highest level of aggregation (world or country) by defining

$$
\operatorname{LBDSCl}_{i}=\frac{1}{\bar{L}}
$$

for single-country settings, and alternatively

$$
L B D S C l_{i}=\frac{1}{\sum_{j=1}^{N C} \bar{L},}
$$

for multi-country settings ( $\overline{L_{j}}$ is total labor force of country $j$ as defined before).

Having specified the variable $L B D S$ cl $_{\text {, }}$ let us take a look at the essence of our learning by doing formulation for the case where knowledge spill-overs between the firms are ruled out (i.e. the case where $\Omega_{i, N a t n l}^{L B D}=0$, and $\Omega_{i, F \text { oreign }}^{L B D}=0$ ). Since, due to the fact that $\frac{Q_{k i j}^{t}}{a_{k i j}^{t}}=L_{k i j}^{t}, \frac{Q_{k i j}^{t}}{L B D S C_{i}}=\frac{Q_{k i j}^{t}}{L_{k i j}^{t} / L a b h_{h r_{k i j}^{t}}^{t}}=a_{k i j}^{t} \cdot L a b S h r_{k i, j}^{t}$, it follows that equation 5.36 turns into an explicit form as

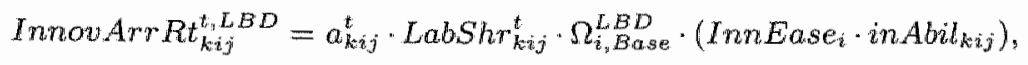

implying that the output level of the firm actually works as a proxy for its labor productivity level $\left(a_{k i j}^{t}\right)$, which is a good indicator of its past (i.e. curmulative) innovative (as well as imitative) success.

The "direct" cumulativeness module we presented in the previous subsection (which is centered around knowledge/human capital accumulation), apparently is considerably more justifiable and transparent in terms of its micro-foundations. Yet, learning by doing is an interesting explanatory principle (especially when considered at the firm level ${ }^{18}$ ) which basically suggests an indirect mechanism of cumulativeness which is not radically different from our main cumulativeness formulation in the previous subsection. In our cumulativeness formulation, the variable Cumul Factor expresses a knowledge/human capital accumulation process explicitly as the cumulative number of the number of innovation in the past. On the other hand, in the learning by doing formulation, output level (or output per worker) is used as an implicit indicator (proxy) for the cumulative measure of the amount of innovative activity of the past.

Note that in cases where the learning by doing module is switched off, the simulation software assigns Learn $P_{0}^{t} t_{k i j}=1$.

\subsubsection{The "R\&D effort" formulation: Basics}

Assume that at a given period $t$, a given firm $k i j$ spends the amount $R D B u d g e t_{k i j}^{t}$ on R\&D, hoping to increase its future labor productiwity coefficient (i.e., which implies lower labor costs and higher profitability) by having access to new technological opportunities. Further assume that the wage rate for an R\&D worker is equal to $w_{j}^{t, M a: c}$ (i.e. the aggregate lewel "zero profit" wage rate ${ }^{\text {ing }}$ ) as defined by equation 3.5. Thus, with its R\&D budget the firm can employ

$$
\operatorname{RDFOrCe}_{k i j}^{t}=\frac{R D B u \operatorname{dget}_{k i j}^{t}}{w_{j}^{t, M a x}}
$$

R\&D workers at period $t$. Our formulation which endogenises technological change on R\&D effort, suggests that for each period t the contribution of R\&D effort on 
the arrival rate of technological opportunities (during period $t$ ) is an increasing logistic (S-shaped) function of the R\&D workers employed by the firm such that

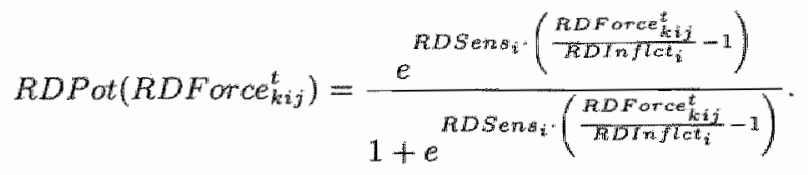

The function $R D P O\left(R D F\right.$ orce $\left.e_{k i j}^{2}\right)$ generates the logistic relation such that for number of R\&D workers employed which are bellow (above) the sector $i$ specific parameter value $R D / n f^{\prime \prime l}$ ct $i$, the function is convex (concave) on its argument. At $R D F$ orce $e_{k i f}^{t}=R D I n f_{c} t_{i}$, the function yields 0.5 and for higher number of R\&D workers RDPot $t_{k, y}$ asymptotically converges to $1.0^{20}$. That is, the function implies first increasing and then decreasing returns to $\mathbb{R} \& D$ effort and the positive effect of R\&D effort on the arrival of technological opportunities eventually saturates. The parameter $R D$ Sens $_{i}>1$ determines the curvature of the logistic function.

Now let us introduce a new set of (sector specific) paraneters MaxInnEase and MaxlmEase $i$ where the former (latter) determines the maximum attainable Poisson arrival rate of innovation (imitation) opportunities in sector $i$. With these parameters, the contribution of $\mathbb{R} \& D$ effort on the arrival rate of technological opportunities are given by

$$
\begin{aligned}
& \operatorname{InnovArr} R t_{k i j}^{R a D D}= \\
& {\left[\text { InnEase }_{i}+\left(\left(\text { MaxInnEase }_{i}-\operatorname{InnEase} i\right) \cdot \text { RDPot }_{k i j}^{*}\right)\right] \cdot \operatorname{in} \text { Abil }_{k i j}}
\end{aligned}
$$

and

$$
\begin{aligned}
& \operatorname{ImitArrRt} \operatorname{Rt}_{k i j}= \\
& {\left[\operatorname{ImEase}_{i}+\left(\left(\text { MaxImEase }_{i}-\operatorname{ImEase}_{-i}\right) \cdot \text { RDPot }_{k_{i j}}^{*}\right)\right] \cdot \operatorname{imA} \text { Ibil }_{k i j} \text {. }}
\end{aligned}
$$

Note that these formulations decompose the arrival of technological opportunities into two parts: A fortuitous component (given by our earlier parameter Inn Ease used in our exogenous arrival formulation) which is exogenously given, and an endogenous part which can be affected by firm's R\&D decisions. That is,

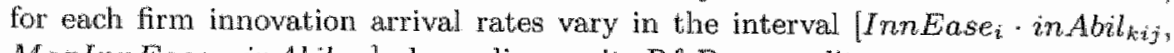

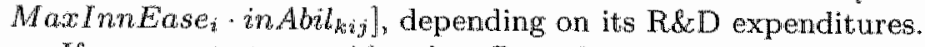

If one wants to consider the effect of cumulativeness allong with that of R\&D effort, the resultant rates for the Poisson arrival of new technologies (the endogenous versions of equations 5.1 and 5.13) are specified as

$$
\text { InnovArrRt } t_{k i, j}^{E n d o g}=\text { Cumul_Factor }_{k i, j}^{t} \cdot \text { InnovArr } R t_{k i, j}^{R \& D}
$$

and

$$
\operatorname{Imit} A r_{r} R t_{k i j}^{E n d o g}=\operatorname{Imit} A r r R t_{k i j}^{R \& D} .
$$

In cases where the learning by doing and/or R\&D effort modules are simultaneously turned on, equation 5.44 is modified as

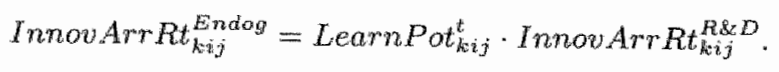


The multiplicative nature of the relation given by equation 5.44 and/or 5.46 suggests that accurnulated knowledge/human capital not only increases the probability of making (or the arrival rate of) fortuitous innovations (i.e. Cumul Factorting - InnEase $\cdot$ inAbil $l_{k i j}$ ) but increases the efficiency of R\&D activities as well. That is, the imnovative success that one can expect from a given amount of R\&D expense is an increasing function of the accumulated knowledge/human capital.

Equation 5.45 suggests that by R\&D firms can not only increase the probability of making innovations but increase their imitative capabilities (i.e. absorptive capacity) as well.

\subsubsection{R\&D expenditures and rationality}

The "R\&D effort" formulation suggests that technology is no more a free and equally distributed good, but it should first be deserwed by showing some effort on research and development. Assuming that the financial sector is not purposefully willing to supply the necessary (desired) funds for R\&D, the firms' means to finance this effort reduce their own profits, out of which they retain a part according to their attitude towards R\&D. Hence, the firms' R\&D effort is linited with their individual profitability and this fact introduces into our framework a strong dynamic increasing returns mechanism that can be summarized with the phrase "success breeds success". Relatively more profitable firms (especially if they are large in size) have higher opportunities of R\&D, and as long as they utilize these temporary opportunities they can maintain and reinforce their otherwise temporary competitive edge. The evolutionary forces eventually penalize those who, instead of making use of their profits for $\mathrm{R} \& \mathrm{D}$, use them for mindless growth by excessiwely investing on capacity expansion. The profits of the firms set the upper limit to R\&D spending, yet the question "how much does/should a firm invest on $\mathbb{R} \& D$ ?" remains. Or expressed in our notation "how is the firm level variable $R D B u d g e t_{k i j}^{t}$ determined?" We introduce three alternative approaches as answer to this key question.

\section{A simple "routinized behavior" approach}

Our first alternative is purely based on a "routinized behavior" approach. Namely, firms are assumed to rely on "rules of thumb" with regard to their level of R\&D expenditures formulated as constant "target $\mathrm{R} \& \mathrm{D}$ to sales ratios" which are allowed to exhibit heterogeneity across individual firms. Accordingly, let the variable RDT $a g_{k i j}$ denote the target R\&D to sales ratio that pertain to fim $\mathrm{R}_{k i j}$. In our routinized behavior formulation, we assume that the number RDTarg $g_{k i j}$ is (randomly) determined when a firm is born and remains unchanged during its lifetime. With this variable and the profitability constraint which sets an upper limit to a given period's R\&D expenditures, R\&D expenditures of any given the frm (at a given period $t$ ) is determined as

$$
\operatorname{RDBudget}_{k i j}^{t}=\min \left(\pi_{k i j}^{t}, \operatorname{RDTarg}_{k i j} \cdot \operatorname{Revn}_{k i j}^{t}\right)
$$

where $\pi_{i, j k}^{t}=Q_{k i j}^{t} \cdot\left(P_{k i j}^{t}-\frac{w_{j}^{t}}{a_{k i j}^{t}}\right)$ is the firms" profit and Revn $k_{i, j}^{t}=P_{k i, j} \cdot Q_{k i j, j}$ is the firm's sales revenue (turnover), both at period $t$. 


\section{Two alternative (bounded) rationality formulations}

Although reliance on such "rules of thumb" is suggested by various seholars as an empirically justifiable specification of strategic behavior (especially in circumstances where essential uncertanty is bigh), a given $R \& D$ to sales ratio can naturally imply over or under investment in R\&D, given the technological opportunities (or better put, the function that relates the arrival of technological opportunities to $R \& D$ effort). It is hard to assume that furms in reality have access to the exact knowledge of such an explicit relation, yet then again one can still assume that firms have at least some idea (or expectations) on the potential outcome of their R\&D effort, especially in terms of incremental innovation efforts ${ }^{21}$ and these expectations must: have some effect on their preferred R\&D spending level. Let us explore the possibilities to incorporate such lines of "bounded rationality" based mechanisms into our framework through an "expected value of R\&D effort" framework.

The expected value equations used by the firms in their simple calculations ignore virious sources of essential uncertainty such as:

- The possibility of the arrival of new technological paradigms (i.e. radical innovations $)^{22}$ which are, by definition, highly rare and thus unpredictable events,

- The R\&D behavior of other firms (i.e. what are other firms doing, what will they do in the future and how lucky will they get, none of which can not be formulated in clear probabilities) and the potential effect of the outcome of these external factors on the relation between own R\&D effort and profitability,

- The passibility of being imitated by other firms, which may affect the future of own profitability significantly.

Under these conditions and additional ceteris paribus assumptions (such as unchanged prices and wage rates), one can write a number of expected value formulations that link an individual firm's R\&D spending to its effect on the future profitability of the firm, purely on the basis of the relation given by equation 5.42 or 5.44 or alternatively 5.46 , which confines individual firms' rationality to a mere understanding to the S-shaped relation between their $\mathbb{R} \& D$ effort and the resulting arrival of incremental innowations which form the basis of simple calculations on individual firms' expectations on the profitability potential of alternative R\&D spending schemes.

Combining and rearranging our earlier formulations, one can write the expected value of the incremental change in firm's technological competence as a function of R\&D spending (as an endogenised equivalent of equation 5.5) such as

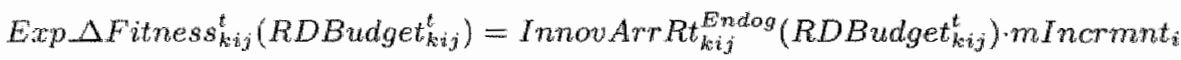

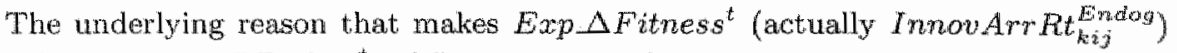
a function of $R D B$ adget $t_{k i j}^{*}$ follows the specifications given by equations 5.44 (or $5.46), 5.42,5.41$ and 5.40 together. Now let us observe the implications of of a. giver amount of R\&D spending on the future profitability of the firm in terms of the expected value of the change in the profitability of the firm for given Exp $\triangle$ Fitnesstaj which is an increasing function of R\&D spending RDBudget

$$
\operatorname{Exp} \Delta \pi_{k i j}^{t}\left(R D B u d g e t_{k i j}^{t}\right)=\pi_{k i j}^{t+1}\left(\operatorname{Exp} \Delta F_{i t n e s s_{k i j}^{i}}\right)-\pi_{k i j}^{t}
$$


Based on these definitions we will discuss below the formulations of our two alternative modules on bounded rationality in RED expenditures. One can also find in the last appendix to this chapter a further discussion on a number of properties of these formulations.

\section{"Satisficing" on the basis of marginal rate of return on $\mathrm{R} \& \mathrm{D}$ effort} The R\&D spending of each period can be seen as a new project, which is (ceteris paribis) expected to add a future stream of increment to current profits (i.e. $\operatorname{Exp} \triangle \pi_{k i j}^{i}\left(R D B u d g t_{k i j}^{t}\right)$ in return for an initial investment that amounts to $R D B u d g e t_{k i j}^{i}$. Thus the expected marginal rate of return on $R \& D$ investment (at the point of the invested sum) can be calculated as

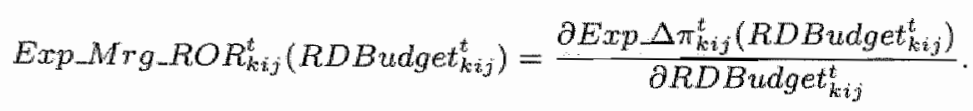

Naturally the function $\Delta \pi_{k i j}^{t}\left(E x p \_\right.$Fitness $\left.s_{k i j}^{t}\right)$ and thus $E x p M r g \_R O R_{k i j}^{t}$ both depend on the type of technological change (quality or labor productivity based) and also the type of technological trajectories assumed (linear, exponential, or concave within paradigms). More explicit forms of the function $E x p \_M r g \_R O R_{k i j}^{t}(\cdot)$ are given for each combination in the fourth appendix to this chapter.

Our satisficing formulation assumes that each firm ${ }_{k i j}$ has a threshold value $T_{k i j}^{R S D}$ in mind which denotes the minimum acceptable rate of marginal expected return on an $\mathrm{R} \& \mathrm{D}$ investment/project. In other words, despite the underlying (ceteris paribus-based) bounded rationality, firms" R\&D behavior is still affected by an element of "ambition", which is a decreasing function of value of the parameter risij

Accordingly if the satisficing module is activated, at each period $t$, the firm adopts the higher $R \& D$ expenditure scheme $R D B u d g e t_{k i j}^{t}$ which satisfies

$$
\operatorname{Exp} \operatorname{Mrg}_{\text {ROR }} R_{k i j}^{k}\left(R D B u d g e t_{k i j}^{t}\right)=r_{k i j}^{R \& D} \text {. }
$$

$\operatorname{Exp} M r g-R O R_{k i j}^{t}$ is a single peaked function of $R D B u d g e t_{k i j}^{*}$ which (due to the S-shape of our R\&D function given by equation 5.41) asymptotically converges to zero. Thus, in cases where equation 5.49 solves for two values for the variable RDBudget $k_{i j,}$, the firm picks up the solution which yields the higher value for RD Budget tij

The interpretation of our satisficing is as follows: Due to the S-shape of the R\&D function given by equation 5.41 , the efficiency of R\&D is first increasing then decreasing in R\&D effort. The saturation of this function implies that the efficiency of $\mathrm{R} \& \mathrm{D}$ rapidly converges to zero. This property is reflected by the single peaked function $E x p M r g \_R O R_{k i j}^{t}(\cdot)$, which measures the expected efficiency of R\&D effort. Accordingly, the firm specific parameter $r_{k i j}^{R \& D}$ indicates the lower acceptable efficiency level that is expected by firm, ${ }_{k j}$, which targets the highest R\&D expenditure scheme (let us call it Satis f $A R D T$ T $g_{k i j}^{t}$ ) that does not seem to be less efficient than this threshold.

However, as discussed before, at each period $t$, R\&D expenditures are bounded by current profits. In periods where current profits $\left(\pi_{k i j}^{t}\right)$ are less than the target expenditure Satisf $f_{-} R D T a \operatorname{Tar}_{k i j}^{t}$, the firm spends only $R D B$ Bdget $t_{k i j}^{t}=\pi_{k i j}^{t}$ if

$$
\operatorname{Exp} M r g \operatorname{RO} R_{k i j}^{t}\left(\pi_{k i j}^{t}\right) \geq r_{k i j}^{R \& D}
$$

and nothing (i.e. $R D B u d g e t_{k i j}^{t}=0$ ) otherwise. 
An alternative formulation of bounded rationality in $R \& D$ : Opt1mization on the basis of net discounted value of the future strearm of expected profits As discussed above, on the basis of its simple (ceters paribus assumption based) estimations, the firm expects a future stream of (extra) profits $\operatorname{Exp} \Delta \pi_{k i j}^{t}\left(\right.$ RDBudget $\left.t_{k, j}\right)$ at each period that follows the R\&D investment. Let $0<\rho_{k i j}^{R L D}<1$ (which is a firm specific parameter) be the discount rate used by the firming in its R\&D project evaluations. Since $\sum_{\tau=0}^{\infty}\left(\rho_{k i j}^{R} D\right)^{T}$ $=\frac{1}{1-p_{k i j}^{K E D}}$, the discounted (current) estimated value of an R\&D project, which spends $R D B$ adget $t_{k i j}^{*}$ at period $t$ is

$$
\begin{aligned}
& \operatorname{Exp} D i \operatorname{sentdLVal}\left(R D B u d g e t_{k i j}^{t}\right)= \\
& \frac{1}{1-\rho_{k i j}^{R L D}} \cdot \operatorname{Exp} \Delta \pi_{k i j}^{t}\left(R D B u d g e t_{k i j}^{t}\right)-R D B u d g e t_{k i j}^{t}
\end{aligned}
$$

One can easily derive the explicit forms of this function ${ }^{23}$ by following the examples given (originally for our satisficing formulations which are quite similar to those used in our rational R\&D strategies formulations) in the fourth appendix to this chapter.

Since Exp_Discntd $V$ all $(\cdot)$ is a single peaked function of $R D B u d g e t_{k i g}^{t}$, our rational $R \& D$ strategies formulation essentially suggests that each firm bases its R\&D strategies on the maximization of the function Exp_Discntd_Val(c). If the rational $R \& D$ strategies module is activated (by setting the corresponding switch variable Rational $R \& D=1$ ), at each period $t$, each firm $k i j$ calculates its target R\&D expenditure (let us call it Rational RDTarg $g_{k i j}^{t}$ ) as the $R D B u d g e t_{k i j}^{t}$ value which maximizes the expected discounted value expression Exp_Discntd_V all $(\cdot)$.

If, at any given period $t$, the current profits $\left(\pi_{k i j}^{t}\right)$ of the firm ${ }_{k i j}$ is less than the (optimum) target expenditure Rational_RDTarg $g_{k i j}^{t}$, the firm spends $R D B$ adget $t_{k i j}^{*}$ $=\pi t_{k i, j}^{t}$ if

$$
\operatorname{Exp}_{-} \text {Discretd_Val }\left(\pi_{k i j}^{t}\right) \geq 0
$$

and nothing (i.e. $R D B$ udget $t_{k i j}^{t}=0$ ) otherwise.

\section{Firms' output growth decisions versus R\&D expenditures}

Before finalizing this section, we also meed to mention one last modification that needs to be made over our existing formulation in cases where technological change is endogenised on R\&D effort. As discussed in chapter 3 , profit-constrained output maximizer firms, while making their capacity expansion plans (i.e. calculation of their desired rate of growth), try to make sure that their capacity expansion does not decrease their profitability below a certain threshold ${ }^{24}$.

In our earlier chapters where technological change is ruled out, this threshold ( $\pi S_{k i j}^{M i n}$ expressed as the minimum acceptable level of profits to sales ratio) has been set to the lower profitability limit expected by the shareholders (i.e. $\pi_{-} S_{k i, j}^{M i n}=b_{j} \cdot r_{j}^{M i n A c c p t}$ ). Nevertheless, in settings with endogenous technological change, at the top of the shareholders' expectations firms also need to consider their target R\&D expenses and try not to fall below a profitability level (by mindless capital expansion) which make sure that they can finance their own R\&D activities. Accordingly, in settings where firms make R\&D, we update the variable $\pi_{-S_{k i j}}^{M i n}$ that represents the minimum profitability threshold for the firm as $\pi \_S_{k i j}^{M i n}=\left(b_{j} \cdot r_{j}^{\text {MinAccpt }}\right)+$ RDTarg ${ }_{k i j}$ in case of our constant R\&D strategy 
formulation and $\left(b_{j} \cdot r_{j}^{\text {MinAccpt }}\right)+$ SatisfCuDTarg $g_{i j}^{t}$, and $\left(b_{j} \cdot r_{j}^{\text {MtinAcpt }}\right)+$ Rational_RDTarg tizj in cases of our satisficing and rational R\&D strategy formulations respectively

Yet note that this precautionary effort by no means guarantees to keep the frms at the profitability level sufficient to keep their shareholders and their R\&D departments simultaneously happy, unless the industry is characterized by monopolists which can fully control the market price through its decisions on output level. In more competitive enviromments, even if firms individually try not to push market output up and consequently market price down below a certain level, the actions of other firms (including the entry of new firms) may well push the profitability of an individual firm down to levels where the targeted R\&D spending can not be realized.

\subsection{Initial technological competency of new entrants}

In our discussion of chapter 3 , we have introduced various optional assumptions regarding the initial technological competence (initial labor productivity and product quality) of new entrants. Having completed the discussion on technological change module, we can now discuss our last optional assumption which is reminiscent of the Nelson and Winter [1982] specification.

According to this last optional formulation, firms (potential entrants) live a pre-entry period, in which they try to explore the possibilities of making an entry that makes sense. During this period, just like the rest of the firms (the incumbents) they join the innovation-imitation sessions. In other words the potential entrants may be seen as unrealized raw ideas floating around, starting from a very premature level (which initialized according to the technological competence of the worst practice firm sector) seeking for progress.

The model, at each period $t$, for each country and sector keeps NPotEnt of these imaginary firms in reserve. As long as they do not actually enter into the real production they try to built up a higher technological competence level (labor productivity and or product quality) by innovating (upon their current imaginary productivity level) or imitating. The (Poisson) innovation and imitation arrival rates for the potential entrants are given by

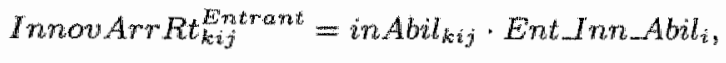

and

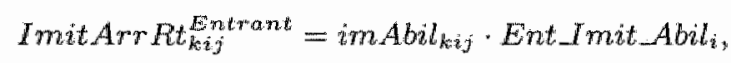

where Ent Inn_Abilij and Ent Imit_Abil are sector specific parameters, through which the user can adjust respectively the innovative and imitative abilities of potential entrants relative to that of the incumbent firms.

Each time the system decides for an entry to any sector in any country (which is an outcome of a Poisson arrival process with the annual arrival rate EntArr Rt) one of the NPat Ent candidates pertaining to that sector and country is randomly selected as the prospective entrant. It immediately joins the financial market reallocation session of that period, and based on the current circumstances (the current availability of financial resources and the prospective entrant's current potential profitability) it tries to get its venture capital. If it manages to get its start-up capital, the potential entrant makes a successful entry and otherwise it is immediately terminated. In any case, the waiting candidate pool is immediately 
replenished by the introduction of a new candidate seeded by the technological competence parameters of the world worst practice firm of the sector. Hence, before their actual entry, the candidates wait on the average for $\frac{N P \text { Pont }}{E r \text { Arr }}$ periods during which they have the opportunity (by imitation or innovation) to compensate for their rather low default assignment and reach to a viable technological competence level (which hopefully wables them to get their venture capital from the financial market).

\subsection{Decomposition of necessity and chance}

So far, we have been discussing our technological change formulation on the basis of the stochastic processes which determine the arrival of firm level innovations. The endogenisation of technological change is also based on formulations which consider the systematical effect of various factors (cumulativeness, learning by doing, R\&D effort) on the arrival rates of inmovations to individual firms. That is, even the strongest endogeneity principle does not bring about certainty to firms" individual destinies.

In order to be able to make decompositions in terms of chance and necessity (especially in cases of endogenous technological change), we introduce into our software implementation to turn stochasticity off and make control experiments accordingly. In cases where stochasticity in innovations are turned off, the fitness level of each firm is updated every period according to the expected value equation 5.5. Note that the term InnovArr Rt $t_{k i j}$ in this equation is determined in alternative ways depending on the assumption regarding the principle by which firm level innovation arrivals are endogenised (as in alternative specifications expressed by equations $5.34,5.36,5.36,5.44$ and 5.46 .

In cases where stochasticity in imitations is turned off, independently of the value firm specific variable Imit Arr $R t_{k i j}$, each firm is given one chance to make an imitation at the end of the Bermoulli trials (for innovations) of each period. Naturally, the firm explores the imitation opportunities starting from the best practice firm of the sector and moving down to the second, third, ... and so on. Yet, whether or not the firm makes a successful imitation or the firm actually imitated depends on the extents of the usual imitation barriers, which were discussed in the section devoted to our imitation formulations.

\subsection{Endogeneity of sectoral preferences}

Although it is an empirically justifiable fact that as people's real income rises the income shares of the goods that constitute their choice set change, the incorporation of this phenomenon into formal modeling exercises on growth and international trade is rather rare. For the neoclassical economics, the reasons are clear. Despite the fact that various functional forms (utility functions) that exhibit nonlinearities on income are suggested, these functional forms (by definition) do not posses the homotheticity property. Two major problems accordingly arise. First, since utility functions that lead to nonlinearities of demand on income are justifiable as individual utility functions, due to the well known problems of aggregation, their use as the utility function of a representative customer (as a social welfare function) remains theoretically unjustifiable. Second, non-linearity of demand on income (similar to increasing returns to scale) introduces the possibility of multiple equilibria into the general equilibrium framework. Shortly, although 
issues on demand functions that are non-linear on income are widely discussed in the partial equilibrium framework of the mainstream economics, one can rarely obserwe such issues in general equilibrium based formalizations. As discussed before, also out of the mainstream one can find quite a low number of examples two of which are Verspagen [1992] and Andersen [1997].

Our specification of customers' preferences, which is essentially based upon. the Cobb-Douglas utility function (constant budget share for each sector) obviously suggests unit income elasticity of sectoral demand. Yet, now that we have introduced technological change into our model, one can expect increasing welfare levels (i.e. purchasing power) over the runtime our simulation experiments, it seems highly reasonable to introduce also mechanisma through which our unit income elasticity assumption can be relaxed. Accordingly we suggest a formulation, which systematically adjusts the sectoral budget share parameters of the Cobb-Douglas component of our welfare function as technological change gradually brings about increases in welfare. Namely, the income share parameters that characterize consumption $\left(\alpha_{i}\right)$, are let to vary dynamically as a function of customers" purchasing power.

In doing that, we define a sectoral priority structure such that the goods are orclered according to the level they are indispensable or necessary. For example, if the sectors $i=1,2,3$ correspond to agriculture, manufacturing and services, the first sector has a natural priority in the consumption basket, such that only after making sure of the possibility of consuming a minimum amount (the survival threshold) the customer can start considering her purchases of the second good. As the purchasing power increases, the share of agricultural products in the income steadily decrease and taken over by manufactured goods and then services. As income levels further increase, the share of agriculture and manufacturing in consumption budged keep on decreasing and at all times, the share of services is determined as a residual.

Based on this "necessity" based ordering our formulation of endogeneity of sectoral preferences follow the following lines. First we assume that the rank of the sectors in terms of their necessity based priority follows the sector number $i$ that refers to sectors. Namely, the products of each sector $i$ are assumed to be more of necessity goods than those of sector $z+1$ and accordingly has a higher priority. Thus let us start our formulation with sector 1 which has the highest: priority amongst all. Let us define a variable Pur Pow ${ }_{1 j}^{i}$ which denotes the purchasing power of customers in terms of sector 1 output alone. In other words PurPow $w_{j}^{t}$ indicates the maximum number of sector $i$ output which can be purchased/consumed by the consumers of country $j$ at period $t$. Thus

$$
\text { PurPow } w_{1, j}^{t}=\frac{G D P_{j}^{t}}{P_{1 j}^{t}}
$$

where $P_{i j}^{t}$ is the (quality corrected) average unit price of sector 1 product in country $j$. Accordingly we define another variable PotentCons $s_{i j}^{t}$ which denotes the potential level of sector 1 output which the country $j$ customers are willing to consume given their purchasing power:

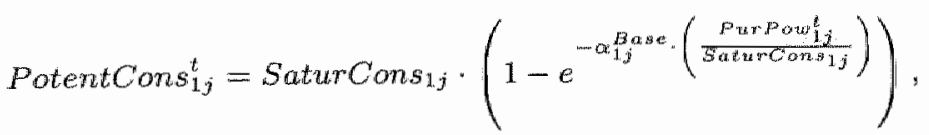

where SaturCons $s_{1 j}$ is a parameter that denotes the maximum (saturation) consumption level that would be demanded with infinite income and $\alpha_{1 j}^{B_{j} \text { ase }}$ is an- 
other parameter that denotes the budget share allocated to sector 1 at income (Pur Pow $w_{j}^{\text {) }}$ levels close to zero.

Having calculated PotentConsti, the budget share to be allocated to sector 1 $\left(\alpha_{i j}^{t+1}\right.$ at period $t+1$, as a function of purchasing power at period $\left.t\right)$ is updated as

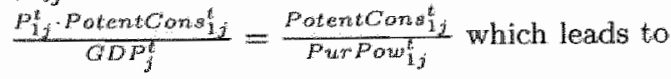

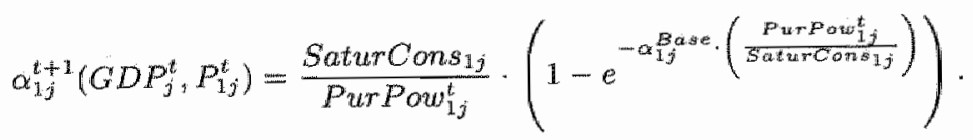

This function satisfies the properties $\alpha_{1 j}^{t+1} \rightarrow \alpha_{1 j}^{B a s e}$ as $G D P_{j}^{t} \rightarrow 0$ (or equivalently $P_{1 j}^{t} \rightarrow \infty$ ) and also $\alpha_{i j}^{t+1} \rightarrow \frac{\text { SaturCons } x_{i j}}{P_{u r} P_{0} w_{i j}^{t}}$ as $G D P_{j}^{t} \rightarrow \infty$ (or equivalently $P_{1 j}^{t} \rightarrow 0$ ). Between these extremes $\alpha_{\mathfrak{j} j}^{t+1}$ is a monotomically decreasing (and smooth) function of PurPow $w_{1 j}^{t}$.

The determination of the budget shares of each following sector follows a similar formulation. Going one by one through the sectors, the budget share of each is determined as a function of the budget share taken by (i.e. leftover from) the previous sectors. That is, for each sector $1<i<N G$ (except for the last one) the purchasing power in terms of sector $i$ products is

$$
\operatorname{PurPow} w_{i j}^{t}=\frac{G D P_{j}^{t} \cdot\left[1-\sum_{s=1}^{i-1} \alpha_{s j}^{t+1}\right]}{P_{i j}^{t}}
$$

and similar to equation 5.56

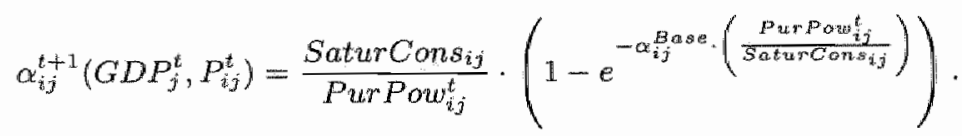

Finally, the budget share for the last sector $(i=N G)$ is determined purely as the leftover from the other sectors as

$$
\alpha_{N G j}^{t+1}=1-\sum_{s=1}^{N G-1} \alpha_{s j}^{t+1}
$$

Figure 5.2 depicts an example for endogeneity of sectoral preferences for three sectors and axbitrarly chosen parameters ${ }^{25}$. As seen on panel (a) of the figure, within the national income (nominal GDP) interval covered by the figure, the potential consumption indicators (PotentCons $s_{1}$ and PotentCons $s_{2}$ ) for the first two sectors converge to their saturation level as set by the parameters SaturCons 1 $=6000$, SaturCons $2 .=4000$. However, that of sector 3 increases indefinitely as income level rises. Being the basic necessity good, the budget share for sector 1 monotonically decreases as income rises (as seen on panel (b) of figure 5.2). As customers keep on richer, sector 1 consumption becomes less of a concern and customers start to increase their sector 2 and 3 budget. Having a priority over sector 3 , initially the budget share allocated to sector 2 is much higher than that allocated to sector 3. Nevertheless, as income level further rises and demand for sector 2 products keep on converging to its saturation level, the budget share of sector 3 (which is determined as residual) takes over.

In terms of income elasticities, the two charts on figure 5.2 imply the following: The income elasticity of the demand for the basic mecessity good produced by 

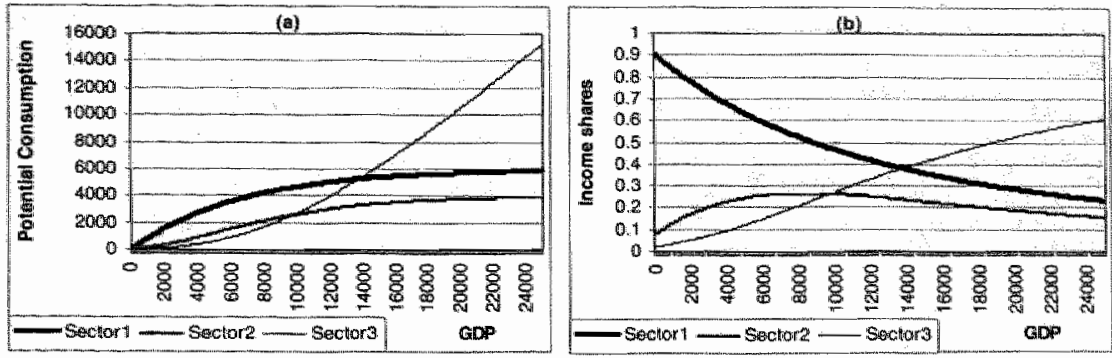

Figure 5.2. A three-sector example of endogeneity of preferences.

sector 1 is always less than unity. That of sector 2 is more than unity at relatively low levels of income (in the order of magnitudes valid for the settings of figure 5.2, GDP $<8500$ ), yet it drops below unity as income level rises. The income of the demand for the (luxury) good produced by sector 3 remains always higher than 1.0 , only it asymptotically converges to unity (from above) as income level converges to infinity.

\subsection{An overview of the technological change formulations}

In our simple formulation firm-level incremental innovations make firms progress through a single dimension which we call fitmess. The pace with which a firm proceeds through this single dimension is determined by the arrival rate of innovations (which is formulated by a Poisson arrival process) and the fitness increment introduced (on the average) by each innovation.

Given this basic movement, the progress of the firm in the labor productivity (or product quality) dimension is determined as a mapping of the fitness of the firm. For this mapping we introduce three alternative formulations which are a linear mapping where labor productivity/quality is assumed to be equal to the fitness level, an exponential mapping where labor productivity/quality is formulated to be an exponentially increasing function of firms fitness and finally a rather more complicated mapping which we call paradigm specific concave trajectories where progress in labor productivity/quality is subjected to decreasing returns whin each technological paradigm. However the arrival of new paradigms (by major innovations/breakthroughs which are specified as highly rare, "serendipity" dependent events) open up new and superior progress trajectories. Thanks to this paradigm formulation, our capital vintages (capital embodied technological change) framework (which associates capital vintages with technological paradigms) is saved from the otherwise inevitable extreme association of capital vintages with incremental innovations. In addition to the capital vintages associations, it has also been possible to associate paradigms with a secondary progress dimension. In other words, while incremental innovations along the paradigm specific progress trajectories represemt progress in labor productivities (product qualities) it has also been possible to introduce quality (labor productivity) ladders, where each discrete quality (labor productivity) level is associated with another paradigm. These alternative formulations give the opportunity to experiment with numerous technological opportunity assumptions in various scenarios. 
All of this formulation is confined to the progress in final good sectors. Al though it was a possibility to formulate explicitly independent capital good mar ket: (the technological change in which takes place along lines similar to those in the final sectors) we did not choose this option. In order to observe (in a controlled manner) the possible effects of the possible discrepancies of (i.e., biases) technological progress between final and capital good sectors, we have formulated the progress in the latter relative to that in the former. As we will further discuss in the next chapter, this formulation has opened up possibilities to systematically explore the effects of technological change biases between the final and capital good sectors on income distribution, employment and international trade.

Our basic exogenous technological change formulation is also enriched by the introduction of various/alternative modules which endogenise innovation arrivals on the basis of cumulativeness, leaming by doing, and most importantly purposeful R\&D effort. For the $\mathbb{R} \& D$ effort formulation we have built three alternative modules, one of which assumes that firms have no idea on the relationship between the R\&D effort and its positive consequences, anc accordingly follow "rules of thumb" such as constant "R\&D to sales ratio" targets. The other two options assume that firms are boundedly rational and base their R\&D expenses on simple calculations which talke account of the estimated relation between R\&D effort and return.

Without doubt, stochasticity may have an important impact on the outcome of our experiments. In order to be able to decompose the effects of chance and necessity, we have also introduced into our software implementation to passibility to turn stochasticity off and let things happen according to the expected value equations that are presented in this and the next chapters.

\subsection{An overview of the technological change related parameters}

\subsubsection{Basis parameters (Innovations)}

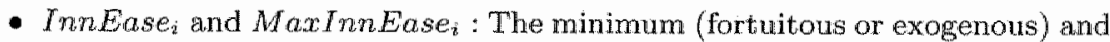
maximum levels for the Poisson innovition arrival rates.

- mIncrmnt and sIncrmnt: Sector specific parameters which respectively denote the mean value and coefficient of wariation ${ }^{26}$ of the normal distribution from which increments to firms" fitness levels (Incrmnt: $t_{* i j}$ ) are withdrawn in case of innovations. See equation 5.2.

- Progress_Traj $(0-2)$ : Determines the type of progress trajectories to be assumed by the model:

- 0: Linear progress trajectories,

- 1: Exponential (convex) progress trajectories,

- 2: A finite number of concave technological trajectories each pertaining to a different technological paradigm.

- $\tau_{i}$ : The sector specific parameter denoting the (proportional) growth factor of productivity/product quality (as described by equation 5.8.

- $m A b i l_{k i j}$ : The relative capacity (ability) of the $k^{t / k}$ firm of the $i^{\text {th }}$ sector of the $j^{\text {th }}$ in exploiting innovation opportunities. 
- InnovStochast_OnOff (0 or 1): Determines whether innovation arrivals are stochastic or take place deterministically according to the expected value specifications (as discussed in section 5.5).

- CapthProdFollowRote : Determines the rate at which learning/innovation (or labor productivity increases) in each capital sector follows that in the corresponding final good sector (as specified by equation 5.26 for cases where Captl ProdFollow Rate $i_{j} \leq 1$ and equation 5.29 for CapllProdFollow Rate ${ }_{i j}$ $>1$.).

\subsubsection{Imitations-related parameters}

- ImEasei and MaxImEase : The minimum (fortuitous or exogenous) and maximum levels for the Poisson imitation arrival rates.

- imAbilkaj : The relative capacity (ability) of the $k^{\text {th }}$ firm of the $t^{\text {th }}$ sector of the $f^{\text {th }}$ in exploiting imitation opportunities.

- Imitstochast_On of $f$ (0 or 1): Determines whether imitation arrivals are stochastic (as discussed in section 5.5).

- SampEase : Sector specific parameter which relates the possibility that a sector $i$ firm is detected and targeted (by another sector $i$ firm) for imitation to the firm's market share (as specified by equation 5.16).

- RelImEase $(j, h)$ : Sector specific parameter matrix, that specifies the relative difficulty of an international imitation (i.e. if $j \neq h$ then $\operatorname{RelIm}_{\operatorname{Lase}}(j, h$ ) $\leq 1)$ vis-à-vis a national one (i.e. if $j=h$ then RelImEase $(j, j)=1$ ), as in equation 5.15 .

- AgeTrhld and AgeSensi : Sector specific parameters that specify the relation between the age of a technology and the possibility that it is imitated by a firm other than its current user (as specified by equation 5.17).

- TDisTrhld and TDisSens $s_{i}$ : Sector specific parameters of the logistic function given by equation 5.19 , which determines the extent of the decreasing relation between the possibility of an imitation and the technological distance measure (Tech Dist $t_{k i j}^{t}(l i h)$ as defined by equation 5.18 ) between the potential imitator (firmsiy) and the firm targeted for imitation (firmik ).

\subsubsection{Parameters of the technological paradigms module}

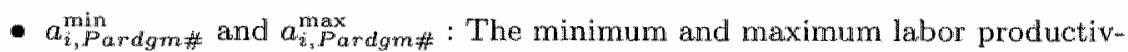
ity levels that characterize the technological opportunities made available by the technological paradigm Pardgm \# in sector $i$.

- $\psi_{i_{v} P a r d g m \#<0}<0$. Determines the extent of the dynamic decrease in marginal returns to innovation (or learning) ${ }^{27}$, within paradigm Pardgm\# in sector $i$.

- PrNxtPar and FitSensInvi: Sector specific parameters that determine the probability of the introduction (discovery) of a new technological paradigm (as defined by equation 5.12).

- PrParSwt and FitSensI mit $_{i}$ : Sector $i$ specific parameters, the former determining the general difficulty of an imitation involving a paradigm switch of distance $1^{28}$, and the latter determining the effect of the potential imitator's competence (within the paradigm currently in use) on its chances in a paradigm switch. 


\section{Parameters of the capital vintages module}

- $b_{i}^{s}$ :Determines the capital intensity of the $s^{\text {th }}$ capital vintage in sector $t_{\text {, }}$ relative to that of the basis capital intensity in production $b_{i j}$. See the discussion on our capital vintages formulation in appendix to this chapter ${ }^{29}$.

- ShrCommon requirements of paradigms $m$ and $n$ (say $m>n$ ) in sector 4

\subsubsection{Parameters related to the endogenisation of technological change}

\section{R\&D-based endogenisation of technological change}

- RDInflct and RDSens.s: The sector specific parameters of the function (specified by equation 5.41) which specifies the logistic relation between the number of R\&D workers employed by a firm and the arrival rate of technological opportunities.

- R\&D_Behavior $(0-2)$ : Determines assumption with regard to firm's decisions on the level of their R\&D expenses

- 0 : Firms are assumed to rely on firms rely on constant "target R\&D to sales ratios", which is specified by the parameter RDTargkij for each firm in $_{i j}$

- 1: Assumes that firms are boundedly rational in their R\&D behavior (i.e. firms only undertake R\&D projects the net expected value of which are positive). Under this assumption, each firm follows the intertemporal discount rate $\rho_{k i j}^{k \& D}$ which is a firm-level parameter. See equation 5.51 .

- 2: Assumes that firms R\&D behavior is characterized by satisficing in the sense that they only undertake $\mathbb{R} \& D$ p projects the expected marginal rate of return of which are above a threshold level. Under this assumption, each firm decides on its R\&D expenditures on the bosis of the mimimum acceptable expected rate of return on $R \& D P$ r $r_{k i j}^{k} D$ which is a firm-level parameter. See equations 5.49 and 5.50 .

\section{Cumulativeness-based endogenisation of technological change}

- $\Omega_{i, B a s e,} \Omega_{i, N_{a t n h}}, \Omega_{i, \text { Foreign }}$ and $\Omega_{i, R T S}$ : The sector specific parameters of the function (given by equation 5.33 ), which introduces cumulativeness into the technological change (innovative) process. The first parameter determines the extent of the cumulativeness effect and the second (the third) the extent of national (international) knowledge spill-overs.

\section{Learning by doing-based endogenisation of technological change}

- $\Omega_{i, B a s e}^{L B D}, \Omega_{i, N a t n l}^{L B D}$, and $\Omega_{i, F \text { oreign }}^{L B D}:$ The sector specific parameters of the function (given by equation 5.35), which introduces a learning by doing effect into the technological change (innovative) process. The first parameter determines the extent of the learning by doing effect and the second (the third) the extent of national (international) knowledge spill-overs. 


\subsubsection{Parameters of the "Endogeneity of Sectoral Preferences" module}

- $\alpha_{i j}^{B a s e}$ and SaturCons $s_{i j}$ : Parameters of the function (specified by equations 5.56 and 5.58 ), which relates sectoral budget shares to purchasing power in cases where endogeneity in sectoral preferences are assumed. 


\section{Notes}

1. i.e. which follow a time homogenous Poisson arrival process.

2. Recall from our discussion in chapter that our formulation reduces quality to one dimension (a scalar), which enables a cardinal ordering of various products. This formulation captures the trade-of between quality and quantity in a smooth way such that (in cases where products are perfectly substitutable) customers

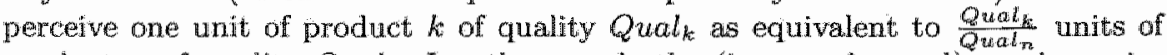
product $n$ of quality $Q u a l_{n}$. In other words the (inverse demand) market price of product $k\left(P_{k}\right)$ appears to be equal to $\frac{Q u a l_{k}}{Q_{k} l_{n}} \cdot P_{n}$. Thus, firms of relatively Jover labor productivity levels can survive the competition by offering products of relatively higher quality levels.

3. Recall that the direct labor cast of each firm $k_{i j}$ is $\frac{w_{j}}{a_{k i j}}$. The avergige unit labor requirement in sector $i$ of country $j$ is $a_{i j}=\frac{\sum_{k=1}^{N F_{i j}} Q_{k i j}}{\sum_{k=1}^{N F_{i j}} \frac{Q_{k i j j}}{Q_{k i j}}}$. Accordingly in country $j$, the unit labor costs in sector $i$ specific capital production is specified as $\frac{w \cdot b_{i j}}{a_{i j}}$. 4. As discussed earlier, initial firm level labor productivities $a_{k: i j}^{0}$ are already determined (and assigned to firms by the simulation software) stochastically at period $t=0$, which leawes no necessity to heterogeneise also the initial fitness levels.

5. For an elaborate discussion on the concepts "technological paradigms" and "technological trajectoriss" refer to Dosi [1982].

6. The curvature of the paradigm specific function $a_{k i, j}^{t}=f\left(P_{\text {ardgm }}^{t}\right.$, Fitness $\left.s_{k i j}^{t}\right)$ given by equation 5.10 , and/or as it appears in figure 5.1

7. In addition to the 500 Bernoulli trials that determine access to an innovation, each firm at each period $t$ also makes 500 Bernoull trials for having access to an imitation. Independently of success in Imnovation, for each random draw in this second set (say RandNrTmit $t_{k i j}^{t, s}$, where $s=1,2, \ldots, 499,500$ ) which turns out to be less than $\frac{I m i t A r r R t_{k i j}}{500}$ (where ImitArrRt $t_{k i j}$ is specified in equation 5.13 ) the firm gains access to one imitation attempt.

8. Thus, for an imitation of paradigm-wise distance $m$, the possibility of an im!-

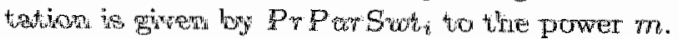

9. Which also determine the asset value of the accumulated capital stock and accordingly the minimum amount of dividend payments expected by the shareholders.

10. Also recall that we have introduced three alternative assumptions on the determination of capital prices: For the first one which rules out any profits in capital production CaptlSector $M a r k-U p_{i j}=0$. The second one assumes that profitability in capital sectors are equal to the average profitability (of the final good sectors) in the country and implies that CaptlSectorMark. $U_{p_{i j}}=\frac{w_{j}^{t, M a x}}{w_{j}^{t}}-1$. The third assumption explicitly specifies a capital intensity parameter for each sector-country (bCapt $l_{i j}$ ) which, together with the profitability expectations of the shareholders,

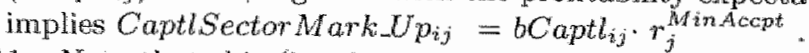

11. Note that this (i.e. intertemporarily constant capital-output ratio) is the assumption followed by the Silverberg \& Lehnert [1993] and Silverberg \& Verspagen [1.995a] models.

12. i.e. No technological spill-overs from the final good sectors.

13. At least considering that buildings, and many generic use equipment, such as trucks, cranes etc. can hardly be considered as vintage specific components. 
14. A parameter matrix of entries Shr Commonim, each of which denotes the percentage fraction of the capital common to the requirements of paradigms $n$ and $n$ (say $m>n$ ) in sector $i$. The relative capital intensities of these two paradigms are giwen by $b_{i}^{\text {sn. }}$ and $b_{i}^{n}$, which in terms of the purchase prices of the

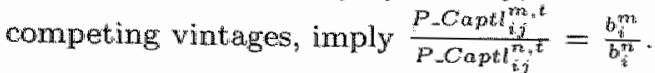

15. Which can be found in the file "/Appencices/Chap5App.pde" in the accompanying CD.

16. i.e. Equation 5.1 that refers to exogenous technological change or equations 5.44 and 5.46 that correspond to general cases of endogenous technological change 17. For example, for $\Omega_{N \text { atnl }}=1$ and $\Omega_{\text {Foreign }}=0$, which implies perfect national knowledge spill-overs, the variable Cumul_Factor ${ }_{k i j}^{*}$ reduces to $1+\Omega_{B a \text { se }}$ - No Natnl Innovit, which is independent of firmkij's own innovation history (NoInnovitij).

18. I.e., as will be demonstrated by actual experiments in chapter 7 , firm-level learning by doing establishes a quite interesting causal link between industrial organization and (productivity) growth.

19. Which makes $\mathrm{R} \& \mathrm{D}$ worker wage rate somewhat higher than ordinary workers.

20. Note that RDPot( 0 ) is not necessarily equal to zero as one would desire. Thus we impose the property as transforming the expression given by equation 5.41 as $R_{D P o t}^{*}\left(R D F \operatorname{Rrce}_{k, j}^{t}\right)=\left[R D P o t\left(R D F o r c e_{k i j}^{t}\right)-R D P o t(0)\right] /[1-R D P o t(0)]$

21. i.e. many development projects.

22. Of course, this is only binding in cases where the technological paradigm modulle is activated.

23. For the various combinations of type of techmological change (quality or labor productivity based) and type of technological trajectories assumed (linear, exponential, or concave within paradigms).

24. As explained in section 3.2.4.

25. The settings are such that $P_{1}=P_{2}=P_{3}=1$, SaturCons $1=6000$, SaturCons $=4000, \alpha_{1}^{B a s e}=0.9$ and $\alpha_{2}^{B a s e}=0.8$.

26. i.e., The variance of the normal distribution is equal to m Incrmnt $t_{6}$, Incrmat.

27. The curvature of the paradigm specific function $a_{k i j}^{t}=f\left(\operatorname{Pardgm}_{\#}\right.$, Fitness $\left.s_{k i j}\right)$ given by equation 5.10, and/or as it appears in figure 5. 1 .

28. Thus, for an imitation of paradigm-wise distance $m$, the possibility of an imitation is given by PrParSwt, to the power $m$.

29. Which can be found in the file "Appendices/Chap5App pdo" in the accompanying $C D$. 


\section{Technological change growth and trade in simple settings}

\subsection{Introduction}

The allm of this chapter is to discuss the consequences of technological progress (in most cases, generated endogenously) for economic growth and international trade. "The chapter can be seen as a logical follow-up to chapter 4 , where the steady-state properties of the model were analyzed in situations without technological progress. Here, based on the ways in which technologicall change has been endogenised in the previous chapter, we will investigate how the outcomes of the model change with technological progress. The emphasis will still be on situations that are relatively tractable, i.e., we will assume away the heterogeneity at the micro level that is central in evolutionary models. The reason for doing so is that in the current chapter, we wish to show how a number of particular features found in existing models and theories (most of which can be characterized as "mainstream") can be reproduced by our rather broad model (that encompasses a number of theories and models found in the literature), and how our model produces additional insights not very common in the literature. In selecting which specific issues to address, the experiments will be rather eclectic, because a full search of parameter scope is impossible given size restrictions. The issue of micro heterogeneity will be fully embraced in the next chapter, and hence one can find there a number of simulation experiments that are closer to the topics analyzed in the evolutionary literature.

The first section below will discuss the basic properties of the model with technological change, by means of the derivation of reduced form equations for a simple context of the nodel. In section 6.2 .4 , the relationship between technological change and unemployment will be considered in a dynamic growth context. In section 6.2 .5 , the issue of capital embodiment of technological change is discussed, and the consequences for growth analyzed. In section 6.2 .6 , the Schumpeterian theory of business cycles will be rewisited in the context of technological paradigms and cumulativeness. In section 6.2.7, the model is run as a so-called 'history friendly model", illustrating the role of structural change in economic growth. Finally, section 6.3 will investigate the welfare consequences of international trade with technological progress. 


\subsection{Technological change and growth}

\subsubsection{Basic properties of technological change-induced growth}

In a way similar to that in chapter 4 , we will derive some reduced form equations, with the aim of finding expressions for the long-run dynamic behavior of the macroeconomic time series (such as output, employment and income distribution). The discussions in this chapter are confined to labor productivity-based technological change. Labor productivity-based technological change is apt to bring about output growth by gradually relaxing the labor constraint of the economies. On the contrary, quality progress does not relax any resource constraint but is apt to bring about welfare growth only due to the perceptions of the consumers. Consequently; as one can conclude from our earlier formulations, in settings with quality-based technological change, nothing interesting may happen in the macroeconomic sense (i.e. output level and employment remain constant, quality levels increase, consumers feel better-off due to the welfare function given by equation 3.7).

As in the previous chapters, assume a one-country one-sector setting, where a profit-constrained output-maximizing national monopolist produces a composite product (units of real $G D P$ ). Equation 4.4 suggests that given constant technology coefficients, equilibrium output level for such settings is

$$
Q^{t}=a^{t} \cdot \bar{L} \cdot E_{\text {mplRt }}{ }^{t}=a^{t} \cdot \bar{L} \cdot W g S u p^{-1}\left(\text { LabrShr } r^{t}\right),
$$

where LabrShrt is the share of wage bill in GDP at period $t^{1}$. Now let us rewrite the inverse function $E m p l R t^{t}=W g S u p^{-1}\left(L a b r S h r^{t}\right)$ explicitly for the functional form and settings discussed earlier ${ }^{2}$ :

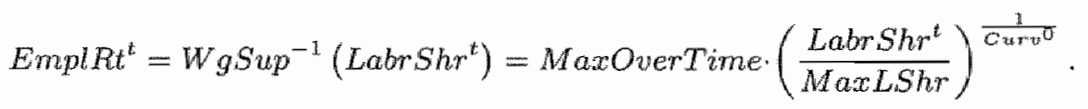

In the context of technological change, which implies temporal changes in labor productivity and capital intensity, the equilibrium condition given above can be translated into a dynamic moving equilibrium process, characterized by

$$
\widehat{Q}^{t}=\widehat{a}^{t}+\widehat{E m p l R} t^{t}=\widehat{a}^{t}-\left(\frac{C a p t l S h r^{t}}{C u r v^{0}}\right) \cdot \widehat{b}^{t}
$$

which expresses output growth as an additive function of the given rate of growth in labor productivity $(\widehat{a})$ and the given rate of growth in capital intensity $(\widehat{b})$. "The variable Capd Shr stands for capitalists" share in GDP at period $t$, which is by definition equal to $1-\operatorname{LabrSh} r^{\text {t }}$ and thus is an increasing function of capital

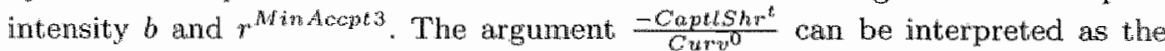
capital intensity elasticity of labor supply (i.e. $\frac{E m p l R t^{t}}{b^{t}}$ ). In our formulation, the wage elasticity of labor supply (labor demand elasticity of wage rate) is a decreas-

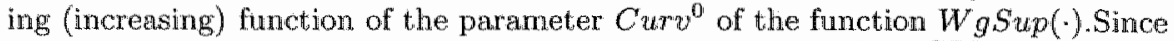
the wage rate in a country at period $t$, is specified as $w^{t}=\frac{G D P}{L^{t}} \cdot$ MaxLShr

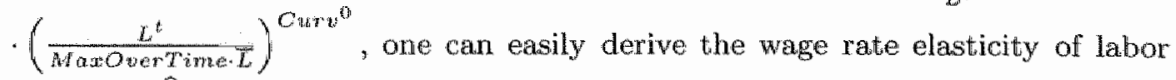
supply as $\frac{\widehat{L}}{\widehat{C}}=\frac{1}{C u r v^{0}-1}$, which is a decreasing function of the parameter $C u r v^{0}$. Perfect inelasticity thus requires $C u r v^{0}=\infty$.

As discussed in the previons chapter, our formulations allow us to express the rate of productivity growth in capital production as relative to that in final good 
production. Also incorporating this specification given by equation 5.31, one can equivalently express the last equation as

$$
\widehat{Q}^{t}=\widehat{a}^{t} \cdot\left[1-\frac{(1-\text { CaptlintFollow Rate }) \cdot \text { Captsh } r^{*}}{\text { Curvo }}\right] .
$$

Equations 6.3 and/or 6.4 imply that:

- As long as the labor productivity increases (technological progress) in the final good sections perfectly spill over to the capital good sector so that capital intensity in production does not increase over time (i.e., Captl Int Follow Rate $=1$ or equivalently $\widehat{b}=0$ ), the attainable output growth rate is equal to the growth rate of labor productivity in the economy $\left(\widehat{Q}^{t}=\widehat{a}^{t}\right)$. In other words, labor productivity growth directly translates into total factor productivity (TIP) growth. Throughout the growth process the income distribution remains unchanged. The process that translates labor productivity growth directly to output growth is clear: Throughout the technological change process each incremental increase in productivity, given output capacity, decreases labor costs, increases profitability (i.e. rate of return on capital) above the equilibrium level $r^{\text {MinAccpt }}$ and stimulates investments which imply capacity and thus output growth. Note that the smoothness of the relation $\widehat{Q}^{t}=\widehat{a}^{t}$ only expresses a long-run property of the model, to which we have arrived under the convenient assumption of a (full-employment) moving equilibriurm process just in the context of our current exercise. As we will discuss later in this chapter (i.e. section 6.2.4), the actual growth motion generated by our model can not be characterized by the qualities of a moving equilibrium process, since one can observe in actual simulations quite some fluctuations around the path $\widehat{Q}^{t}=\widehat{a}^{t}$ which are brought about by the fluctuations in employment rates.

- If the rate of labor productivity increases in the capital sector lags behind that in the final good sector (Captl IntFollow Rate $<1$ and consequently $\widehat{b}$ $>0$ ), as long as the parameter Curv (which determines the wage elasticity of labor supply) is less than infinity, output growth is apt to be less than labor productivity growth in the final good sector (i.e. $\hat{Q}^{t}<\widehat{a}^{t}$ ).

The second point above clearly points to a potential unemployment generating mechanism, which apparently runs through the link between income distribution and employment rates (as specified by the inverse function EmplRt $=$ $W g S u p^{-1}\left(L a b r S h r^{t}\right)$ which implies $\frac{\partial \text { EmplRt }}{\partial \operatorname{LabrShr}}>0$ and introduces the central logic of the Phillips curve relation).

As technological change in the final good sector keeps pushing final good prices down (by increasing profits which turn into investment on further capacity and accordingly increasing the output level), if this change is not matched by proportional decreases in capital good prices, the part of national output that can be claimed by the capitalists (workers) keeps on increasing (decreasing) over time, changing income distribution for the benefit of the capitalists. Unless labor supply is infinitely elastic $\left(C u r v^{0}<\infty\right)$, the lagging of real wage increases behind llabor productivity increases translates into unemployment, which is the basic ream son why aggregate output growth rate is apt to lag behind the aggregate labor productivity growth rate in settings where Captl Int Follow Rate $<1$.

The causal link suggested above highlights a potential (negative) impact of technological change on income distribution and mployment rates ${ }^{4}$ : In terms of income distribution and employment, the important determinant is not only the 
rates of technological change but is rather the distribution of the technological change over the two key segments of the economy: capital and the finall good sectors. If the rate of technological change in the former lags behind that in the latter, ower time, capital costs decrease slower than labor costs, increasing the share of capital costs in final good prices and inevitably shifting the income distribution against workers" interests. This transformation is highly apt to bring about structural unemployment. However, the extent of this unpleasant implication is a decreasing function of the extent of workers' willingness to offer their services for a lower share in the national output (i.e. wage inelasticity of labor supply). If labor supply is sufficiently inelastic, such unbalanced technological change patterns imply a lower (higher) share out of a sigmificantly larger pie for the workers (capitalists). Otherwise (in cases of elastic labor supply), workers (capitalists) get a lower (higher) share out of a smaller pie ${ }^{\delta}$. Consequently, it can be suggested that for countries which can not achieve sufficiently rapid technological change in capital good production (which keeps capital prices and accordingly capital costs too high relative to final good prices), institutions such as labor unions (which give workers higher bargaining power for wages) can be unaffordable. Of course, this last argument by no means constitutes a policy recommendation. However, one can (at least casually) observe that in more developed countries which are generally more competent in capital production than the undeveloped (or underdeveloped) countries, many of which purchase a great deal of their capital from developed countries at quite high relative prices (compared to the low added value they can generate), democratic institutions that pursue workers' interests are generally more established and powerful. The causal mechanism we suggest above may (at least partially) constitute an explanation to this empirically justifiable correlation.

Note that the relation that links technological change to changes in incone distribution and especially unemployment is only one of two of such links which emerges as implications of our model. The second link that relates labor productivity to employment, unlike the first one discussed just above, emerges as an implication of the disequilibrium process that characterizes investment and labor market adjustments. This link will be discussed on the basis of actual simulation. runs in a later section (i.e. section 6.2 .4 ) of this chapter.

\subsubsection{A comparison with the Solow growth model}

Equations 6.3 and/or 6.4 give an impression of the long run growth properties of our model under the assumption of a steady state. How does this steady state compare to the one found in the most basic neoclassical growth model (i.e.s the Solow model with exogenous labor-augmenting technological progress)? In order to answer this question, we can impose the key definitions of our formulation into the Cobb-Douglas production function that is assumed in the Solow model. Due to our diflerent definition of capital, this is not entirely straightforward. As a work-around, let us reformulate capital in terms of the labor embodied in each unit of capital. Then, the Cobb-Douglas production function $Q=A \cdot L^{\beta_{L}} \cdot K^{\beta_{K}}$ (of a single-sector economy) would look like

$$
Q=A \cdot\left(\frac{Q}{a}\right)^{\beta_{L}} \cdot\left(\frac{Q}{a} \cdot \frac{b}{1-b \cdot r^{\text {MinAcopt }}}\right)^{\beta_{K}}
$$

Note that as opposed to defining output as a function of inputs, we have plugged into the Cobb-Douglas function the amount of each factor input required 
to produce a given level of output $Q$. According to our fixed coefficient specification $L=\frac{Q}{a}$. Similarly, our capital and capital price formation definitions imply that in each unit of capitall (output capacity) $\frac{b}{a}$ units of direct; labor is embodied. Furthermore, the assumption that there are also profits in capital production, implies that capital production also uses capital ${ }^{6}$. Since we assume that profitability in capital production is equal to the overall profitability of the economy (i.e. the capitall sector adds the mark-up rate $\frac{w^{M a x}}{w^{M}}=\frac{1}{1-b \cdot r^{M} \text { in } A c c p t}-1$ over its direct unit labor costs $\left.w \cdot \frac{b}{a}\right)$, one can conclude that the amount of labor embodied in the

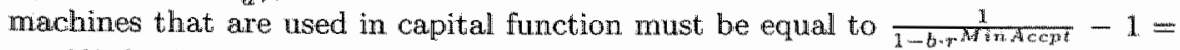

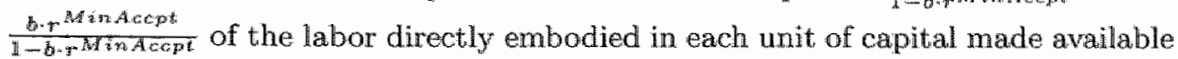
to the final good sectors ${ }^{7}$.

Having converted capital into the equivalent embodied units of labor (as in the pure labor theory of value), we can have a look at the costs in production. In order to produce $Q$ units of output, workers must be paid by (the total wage bill

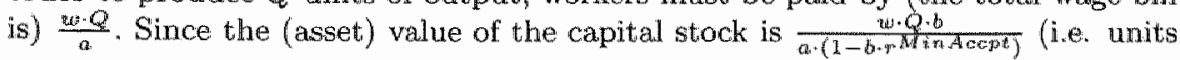
of embodied labor in the capital stock times the wage rate $)^{8}$, in order to meet the shareholders' minimum rate of return requirement $r^{M i n A c c p t}$, the dividends

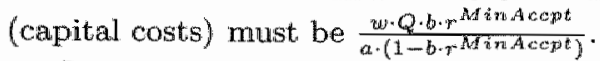

Under cost optimization, the Cobb-Douglas form suggests that the ratio of the total wage bill to the total capital cost should be equal to $\frac{\beta_{L}}{\beta_{K r}}$. Thus

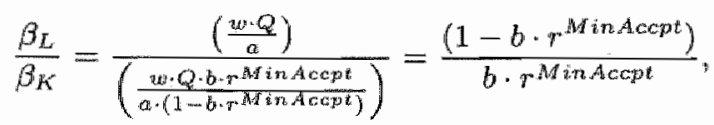

and since $\beta_{L}+\beta_{K}=1$, one can solve for $\beta_{L}=1-b \cdot x^{\text {MinAccpt }}$ and $\beta_{K}=$ $b \cdot r^{\text {MinAccpt }}$. These two relations highlight an important difference between our specification and that of the Solow model: In the latter $\beta_{L}$ and $\beta_{K}$ are given (fixed) parameters that define the capital-labor substitution possibilities and under the cost minimization and perfect competition assumptions, they uniquely determine the income distribution in the econorny. Naturally, this result is made possible by the additional assumption that capital markets are infinitely inelastic so that any increase in the capital stock is accommodated by a proportional decrease in the interest rates (or rate of return on capital). In other words, income distribution is determined by capital-labor substitution possibilities and not the very technologies (capital and labor coefficients) that are actually used.

Although our specification does not rule out that possibility, the variable $r^{\text {MinAcpat }}$ is not the actual interest rate but the minimum level bellow which the actual interest rate (rate of return on capital) can not fall for sustained periods. Therefore, in the long run of our system, any increases in capital intensity also tends to increase the share of capitalists in the economy. Furthermore, since the share of the capitalists can not exceed $100 \%$ of the total output (i.e. $b \cdot r^{\text {Min Accpt }}$ $\left.=\beta_{K} \leq 1\right)$ the variable $x^{\text {Mir.accpt }}$ also sets the upper limit to the capital intensity of production (i.e. $b \leq \frac{1}{r_{\text {MinAccpt }}}$ ). Furthermore, since our formulation specifies a positive relation between the employment rate and share of the total wage bill in the economy (i.e. as specified by equation 4.5), unless labor supply is assumed to be infinitely inelastic (which can be imposed by appropriate settings of the parameters of the function $W g S u p(\cdot))$, higher capitall intensity levels may also lead to structural unemployment.

With the according substitutions (of $\beta_{L}$ and $\beta_{K}$ ), the original Cobb-Douglas 
form in equation 6.5 reduces to the following relation

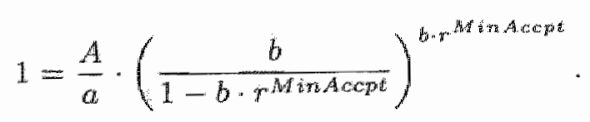

In order to observe the implications of this last relation ${ }^{9}$, let us re-write it in a. "rate of change" form (i.e. where $\widehat{x}=\frac{d x}{x}$ ):

$$
\widehat{A}=\widehat{a}-B \cdot \hat{b} \text {. }
$$

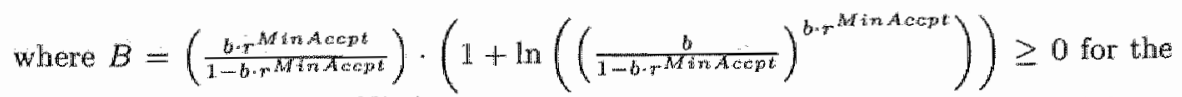
feasible interval $0<b \cdot r^{M i n A c p t}<1$. In terms of the concepts of the growth literature, $\widehat{A}$ is the total factor productivity (TFP) growth, $\widehat{a}$ is the labor productivity growth, while $\widehat{b}$ (which is not a concept generally used in the growth literature) is the growth rate of capital intensity ${ }^{10}$.

For the genuine Cobb-Douglas production function, which assumes that capital supply is infinitely inelastic, equation 6.7 would look like $1=\frac{A}{a} \cdot\left(\frac{b}{1-\beta_{K}}\right)^{\beta_{K}}$, and accordingly equation 6.8 as

$$
\widehat{A}=\widehat{a}-\beta_{K} \cdot \widehat{b}
$$

indicating a linear relation among $\widehat{A}, \widehat{a}$ and $\widehat{b}$.

Within the limitations of $\widehat{A}=0$ (i.e., no TFP growth), the relation in equation 6.8, represents a typical isoquant of the production function: An economy can increase its labor productivity (i.e. save labor) only by producing and installing (or replacing the current capital stock with) more sophisticated and expensive capital goods. That is, the relation. $\widehat{a}=B \cdot \widehat{b}$ apparently specifies the set of capitallabor substitution possibilities. The important difference of our conceptualization from that of the neoclassical one is the fact that for the latter, substitution of labor for capital means using a higher number of capital units (or more capital) in production, whereas for the former (which defines capital as productive units) "more" means "more sophisticated/complicated and costly/expensive".

Now, consider an economy that can increase its labor productivity by $\widehat{a}$, only by replacing its existing capital stock with more sophisticated and expensive machines/equipment (capital embodied technological change). If the complexity/price of the renewed capital stock does not exceed that of its predecessor by more than $\widehat{a} / B$, this change can be considered as technological progress (TFP growth: $\widehat{A}>0$ ). Alternatively, an economy that invents a set of sophisticated machinery/equipment (which promises an $\widehat{a}$ labor productivity growth) can still enjoy "TFP growth by replacing its existing capital with this new type, but only if it can also find efficient methods to produce this new capital vintage so that the production costs/prices of this new equipment does not exceed that of the previous vintage by more than $\widehat{a} / B$.

Without doubt, the best case (in terms of the welfare of the society) is disembodied technological change: If the economy can increase its labor productivity only by learning and/or inventing new production processes that do not meed the replacement of the existing capital stock with a more expensive composite (i.e. $\bar{b}$ $=0$ ), then it can increase its output level and welfare by the highest extent (i.e. $\widehat{A}=\widehat{a}$ ), without being affected by the negative implications of increased capital costs. 
Finally, by comparing equations 6.3 and/or 6.4 with 6.9 , one can clearly observe the differences between the implications of our basic formulations and those of the Solow model. The steady-state properties of the Solow model imply that the growth rate of output is equal to that of the capital stock (i.e. $\widehat{Q}^{t}=\widehat{K}$ ). which indirectly implies a constant capital output ratio (i.e. $\widehat{b}=0$ ) Under this condition, TFP growth in the Solow model is by definition identical to labor producivity growth (i.e. due to equation $16.9, \widehat{A}=\widehat{a}$ ). In terms of our formulation of teclnological change as potentially different between the final and the capital good sectors, this clearly implies that the Solow model implicitly assumes an equal rate of productivity progress in these two sectors of the economy. Consequently, the income distribution remains intact throughout the growth process.

As implied by equation 6.3, our formulation of technological progress establishes a causal link between the final goods sector and the capital goods sector, and suggests that a potential leakage in growth rates can be brought about by temporal increases in capital intensities which decrease the share of wage bill in GDP and lead to unemployment if labor supply is less than infinitely inelastic (i.e. Curv $\left.v^{0}<\infty\right)$. Naturally in a neaclassical growth model such as the Solow model, which assumes infinitely inelastic labor supply, full employment of labor is guaranteed and this causal link does not exist.

\subsubsection{Progress trajectories and sustainability of growth}

So far we have conventionally taken labor productivity growth $\left(\hat{a}^{t}\right)$ as given. How ever, in our model, labor productivity growth emerges as the outcome of a stochastic process. As discussed in the previous chapter, our exogenous technological change formulation specifies a sequence of increments to the firm-level variable Fitness $s^{t}$, each of which arrive through a Poisson process the arrival rate of which is given by the firm-level parameter Innov ArrRt. The increments introduced by each incremental innovation arrival are assumed to be normally distributed around the walue mlncrmnt. The labor productivity coefficient of each firm $\left(a^{t}\right)$ is determined as a mapping of the variable Fitness ${ }^{t}$, and for this mapping we have introduced three alternative formulations, each of which implies an alternative progress trajectory for the labor productivity coefficients. We will now discuss these three alternative mappings.

Our formulations that endogenise technological change basically render the firm-level parameter InnovArrRt a dynamic variable (i.e. InnovArrRt $t^{t}$ ) on the basis of three alternative and/or complementary explanatory principles such as cumulativeness, learning by doing and $\mathbb{R} \& D$ effort. In this section, starting from our simple exogenous innovation arrival formulation, and based on a number of expected value formulations, we will discuss the implications of our alternative progress trajectories in the context of sustainability of growth.

\section{Growth with linear progress trajectories}

For our first and simplest formulation, which we call as the linear progress trajectories, equation 5.7 already gives an impression on the expected motion of the labor productivity coefficients in case of exogenous technological change. In the rate of change form, this equation implies that the expected productivity growth rate of the firm at a given period $t$ is

$$
E\left(\widehat{a}^{t}\right)=\frac{E\left(a^{t+1}\right)-E\left(a^{t}\right)}{E\left(a^{t}\right)}=\frac{\text { Avg_Fitness_Incmnt }}{E\left(a^{t}\right)},
$$


where, Avg Futness Incmnt $=$ Innov Arr Rt $\cdot$ mIncrmnt is a constant determined by parameter settings in case of exogenous technological change. It is clear that since, due to the (on the average) steady progress in labor productivities. $E\left(a^{t+1}\right)>E\left(a^{t}\right)$ and $E\left(a^{t}\right) \rightarrow \infty$ as $t \rightarrow \infty$, the last equation implies that labor productivity growth is apt to decrease over time and asymptotically converge to zero (i.e. $E\left(a^{t}\right) \rightarrow 0$ as $t \rightarrow \infty$ ). This, of course implies nothing but that our linear productivity trajectory formulation is unable to generate allone sustained labor productivity and (since, as discussed above $\widehat{Q}^{t}=\widehat{a}^{t}$ on the long run) output growth.

\section{Growth with exponential progress trajectories}

In case of our exponential growth trajectory settings, the case is quite different. The expected value estimation already given by equation 5.9 , which, in the rate of change form, turns into

$$
E\left(\widehat{a}^{t}\right)=\frac{E\left(a^{i+1}\right)}{E\left(a^{t}\right)}-1=\tau_{i}^{\text {Avg-Fitness_Incmnt }}-1,
$$

implies a constant rate of expected labor productivity, and consequently sustainable output growth under the condition that $\widehat{Q}^{t}=\widehat{a}^{t}$.

If one examines the structure of all models of growth in the literature, the unequivocally common property is that sustainable output growth depends on exponential progress in labor productivity (or for models with more than one production factor, total factor productivity). As discussed in the first chapter, formulations such as the Post-Keynesian Harrod-Domar model and the Solow [1956] model impose such exponentiality upon the system exogenously, while models of the newgrowth generate it endogenously due to some dynamic increasing returns mecharism introduced in one way or another. In this sense, our exponential progress trajectory formulation specifies significant similarities to the Harrod-Domar model in terms of its premises. First, our exponential technological progress formulation exogenously imposes the condition that each innovation adds more (in terms of absolute value) to productivity than added by the previous one, while the underlying reason remains unexplained. Second, our technolagical change formulation does not rely on a continuous production function but is based on the secular changes in production coefficient(s) which are otherwise constant (i.e. recall that the Harrod-Domar model uses a Leontief type fixed coefficient production function). Yet despite these similarities, there is also an important difference: In the Harrod-Domar model, capital accumulation is determined partially exogenously due to the "constant propensity to invest out of income formulation". On the contrary, in our model investments are determined fully endogenously due to the explicit formulations of a labor and a financial market, which, together with the final good markets, determine wage rates, prices, profits and the share of profits which are made available to the industry for capital expansion.

The total effect of these similarities and differences in premises make the implications of our model (under the exponential technological change trajectory assumption) diverge significantly from that of the Harrad-Domar model. In our model, despite the essential stochasticity, the emergence of a "balanced growth path", is dependent neither on the initial conditions of the system, nor the saving propensity of the society. Instead, independently of the rest of the settings, the model generates time series which satisfy $\widehat{K}=\widehat{Q} \approx \widehat{a}$ (a balanced growth path), similar to the Solow model, the theoretical underpinnings of which are quite different than those of ours. However, note that, as we will demonstrate later in 
this chapter, the adjustment processes which translate productivity growth into output growth are subjected to disequilibrium in the labor markets and does not classify as a steady state growth process. Then again, the property $\widehat{Q} \approx \hat{a}$ emerges as a long run property of the model.

\section{Linear trajectories with cumulativeness: Endogenous generation of sustainable growth}

Cumulativeness on the basis of cumulative innovative history In this section we aim to demonstrate that the principle of cumulativeness, which is introduced into our model in two alternative formulations, suffices to generate exponential and thus sustainable growth endogenously. As described in the previous chapter, our first cumulativeness formulation essentially renders the innovation arrival rate an increasing function of the cumulative number of innovations made before, in a way that represents a process of experience, knowledge or (to some extent) human capital accumulation. In the context of a single-firm setting, in terms of expected values, the cumulative number of innovations at a given period $t$ can be expressed as

$$
E\left(N o I n n o v^{t}\right)=\text { NoInnov } v^{t-1}+\operatorname{InnovArr} R t^{t-1} \text {. }
$$

In the absence of cumulativeness InnovArrRt $t^{t}=$ InnEase in Abil and thus for the initial condition $N o I n n o v^{\circ}=0$, one can derive $E\left(N_{o I n n o v^{*}}\right)=$ InnEase - inAbil $\cdot t$. Now let us assume a linear technological change trajectory which implies (due to equation 5.5) that the expected value of labor productivity at period $t$ is $E\left(a^{i}\right)=E\left(\right.$ Fitness $\left.^{t}\right)=a^{\mathbb{0}}+m$ Incrmnt $\left.\cdot E(\text { NoInnov })^{t}\right)=a^{0}+$ mIncrmnt - InnEase - inAbil - $t$. Thus as shown before, with exogenous linear technological change, the growth rate of labor productivity (and thus output growth)

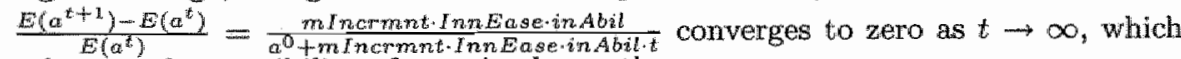
rules out the possibility of sustained growth.

However, cumulativeness can change things drastically. Let us demonstrate this under the setting $\Omega_{i, R T S}=1$ (cumulativeness effect is linear). With cumulativeness, the expected cumulative number of innovations becomes

$$
E\left(N o I_{n n o v}\right)=N o I n n o v^{t-1}+\left(1+\Omega_{B a s e} \cdot N o I n n o v^{t-1}\right) \cdot \text { InnEase } \cdot \text { in Abil }
$$

For the initial condition NoInnov ${ }^{0}=0$, this difference equation is solved for

$$
E\left(\text { NoInnov } v^{t}\right)=\text { InnEase } \cdot \text { in Abil } \cdot \sum_{\tau=0}^{\tau=t-1}\left(1+\Omega_{B a s e} \cdot \text { InnEase } \cdot \text { inAbil }\right)^{\tau}
$$

Since, in our linear progress trajectory formulation, the expected value of labor productivity at period $t$ is $E\left(a^{t}\right)=m I n c r m n t \cdot E\left(N o I n n o v^{t}\right)$, the growth rate of labor productivity can be calculated as

$$
\frac{E\left(a^{t+1}\right)-E\left(a^{t}\right)}{E\left(a^{t}\right)}=\frac{1}{\sum_{\tau=0}^{\tau=t-1}\left(1+\Omega_{B a s e} \cdot \text { InnEase } \cdot \text { in } A b i l\right)^{\tau-i}},
$$

which is equivalent to

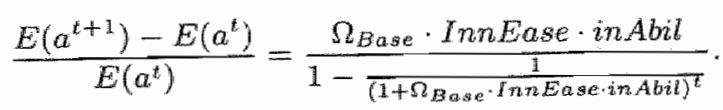


As $t \rightarrow \infty$, labor productivity growth asymptotically converges to the constant rate

$$
\lim _{t \rightarrow \infty} \frac{E\left(a^{t+1}\right)-E\left(a^{i}\right)}{E\left(a^{i}\right)}=\Omega_{\text {Base }} \cdot(\text { InnEase } \cdot \text { in Abil })
$$

which implies sustamable growth (with a fixed rate) despite the fact that (due to the underlying linearity assumption) each innovation adds an increment of fixed size over the existing labor productivity lewel. Cumulativeness simply increases the arrival rate of innovations over time and despite that each innovation introduces only a (on the average) constant increment over the existing productivity level (i.e. as opposed to a proportional increase), one observes sustained growth.

Note that the constant growth rate implication only pertains to the assumption that $\Omega_{R T S}=1$ (the cumulativeness effect is linear). For $\Omega_{R T S} \neq 1$, (drawing on equation 6.11 and the relation $E\left(a^{t}\right)=a^{0}+m / n c r m n t \cdot E\left(\right.$ NoInnov $\left.\left.{ }^{t}\right)\right)$ the expected growth rate in labor productivity can be expressed as

$$
\frac{E\left(a^{t+1}\right)-E\left(a^{t}\right)}{E\left(a^{t}\right)}=\frac{1}{N o I n n o v^{t}}+\Omega_{B a s e} \cdot \operatorname{InnEase} \cdot \text { in Abil } \cdot(\text { NoInnov })^{\text {sats }-1} .
$$

Clearly, if $\Omega_{R T S}<1$ (i.e. dynamic decreasing returns to cumnlativeness), as $t \rightarrow \infty$ and accordingly NoInnov ${ }^{t} \rightarrow \infty$, labor productivity growth asymptotically converges to zero, which rules out the possibility of sustained growth. On the contrary, for $\Omega_{R T S}>1$, labor productivity is apt to grow in ever increasing rates (an accelerated growth).

Cumulativeness on the basis of learning by doing It is also possible to show in a similar way the potential of "leaming by doing" on endogenously generating sustained growth. For a simple, one-sector, one-country one-firm formulation, the learning potential function reduces to

$$
\text { Learn } P t^{t}=L B D S C l \cdot \Omega_{B a s e}^{L B D} \cdot Q^{t} .
$$

Given the specifications given by this equation and also on the basis of our linear technological progress trajectory assumption which implies $E\left(a^{t}\right)=$ mI ncrmnt - Innov Arm $R t^{t} \cdot t$, with onr learning by doing formulation which assigns Innov Arr $R t^{t}$ $=$ InnouArr $R t^{t, L B D}$ as specified by equation 5.36 , the expected rate of labor productivity growth for the single representative firm (i.e., the economy) can be calculatied as

$$
\frac{E\left(a^{t+1}\right)-a^{t}}{a^{t}}=\frac{m I n c m m t \cdot(\text { InnEase } \cdot i n A b i l) \cdot L B D S c l \cdot \Omega_{\text {Base }}^{L B D} \cdot Q^{t}}{a^{t}} .
$$

Since the expression $\frac{Q^{t}}{a^{t}}$ is nothing but the number of labor units remployed by our single ontput-maximizing firm (i.e. $L^{t}$ ), equation 6.18 seems to suggest that (other things constant) for larger firms labor productivity growth tends to be faster than for the smaller ones, and similarly larger sectors and/or larger countries should grow faster than the smaller ones (provided that the underlying industrial organization structures are not too different). Of course, empirically this is not at quite verifiable suggestion, yet this property can be observed in some celebrated models of the growth literature as well. For example, the results of the implications of the second model in Lucas [1988] heavily depend on this scale effect. Similarly, 
the same effect exists in Aghion-Howtt [1990], although it has been presented by the anthors as an wnfortunate implication.

Howewer, as defined in the prewious chapter, the scaling variable $\angle B D S$ d, which is defined in equations 5.37 and 5.38 as the multiplicative reciprocal of the labor force (i.e. $\frac{1}{\bar{L}}$ ), eliminates this undesirable scale implication from any level of aggregation but the firm level. Substituting this definition into equation 6.18 yields the following expected rate of productivity growth equation:

$$
\widehat{a^{t}}=(\text { mIncrmnt } \cdot \text { InnEase } \cdot \operatorname{inAbil}) \cdot \Omega_{B a s e}^{L B D} \cdot \frac{L^{t}}{\bar{L}}
$$

which, in case of steady employment rates $\left(\frac{L^{2}}{\bar{L}}\right)$, implies a constant growth rate for labor productivity and output. Note that in this form, our formulation is qualitatively equivalent to that of the second model in Lucas [1988].

One can immediately observe by comparing equation 6.15 with equation 6.19 that in simple settings (i.e. a single firm in a one-sector economy), the growth implications of our two alternative modules of cumulativeness are qualitatively identical, in the sense that they both bring about sustainable growth with a (n on the average) constant expected growth rate. The essential difference emerges in cases of industrial organization structures other than monopoly. For the case of learning by doing, technological opportunities for larger firms (i.e. firms employing larger shares of the total. work force, thus learn faster ${ }^{11}$ ) are more abundant. Given that the employment shares of the firms are determined endogenously (larger firms of today are those which have been favored more by the selection mechanisms in the past), the learning by doing formulation introduces a "success breeds success" type causal mechanism, which is apt to introduce an important source of "path dependency" into our dynamic system. Of course, the same causal link also exist in our first cumulativeness formulation where the scope of the effect (firm, country or world level) can be adjusted by the manipulation of the parameters $\Omega_{N a n i}$, and $\Omega_{\text {Foreign. }}$. The parameters $\Omega_{i, N_{a t n l l}}^{L B D}$, and $\Omega_{i, \text { Foreigre }}^{L B D}$ which determine the extents of national and international spill-overs play a similar role and setting these to values close to or equal to 1.0 eliminates all possible scale effects from our learming by doing formulation.

\subsubsection{Experiment \#1: Technological Change and Unemployment}

The relationship between innovation and employment has been a long-standing issue in the economic literature (even dating to pre-classical economics, see Freeman and Soete [1994] for an overview). Traditionally, this debate has focused on the question whether the labor-saving nature of (process) innovations (possibly embodied in specific new capital goods) would lead to a decrease in labor demand by the innovating firm. The answer to this question depends on the relative magnitude of the direct, labor-substituting, effect of the innovation, and a variety of indirect effects. Examples of the latter are an increased demand for the good, due to lower prices as a result of the cost-saving nature of innovation (obviously, price elasticity of demand plays a large role in this), and an increased (clerived) demand for the capital goods that embody the innovation. Both of these examples would lead to an increase in labor demand.

In the modern literature, a number of models have been formulated (e.g., Katsoulacos [1986] and Vivarelli [1995]) in which this perspective has been formalized 


$\begin{array}{lll}\text { Labor } & \bar{L} & =10000 \\ \text { Related } & \text { MaxOverTime } & =1.2 \\ & \text { Curv } 0 & =1.0034 \\ & b & =1.1 \\ \text { Capital } & \text { rinAccpt } & =3 \\ \text { Related } & \text { DeprRt } & =5 \% \\ & \text { CaptlintFollowRate } & =1\end{array}$

Table 6.1. The structural parameters that characterize Experiment 1

in a static equilibrium context. The essence of these models has been to investigate how the static equilibrium of the labor and output markets is affected by a once-and-for-all labor augmenting innovation. However, in the dynamic context of growth theory, this is at best only one of the interesting questions. The other question is how employmerit along the dynamic growth path is affected, and how this relates to static equilibrium. For example, in the model of Goodwin [1967], the steady state employment level (around which the growth path of the economy fluctuates) is positively influenced by the (exogenous) rate of labor productivity growth.

Such arguments about the importance of the dynamic employment path as opposed to a static equilibrium analysis were also made in Freeman and Soete [1987]. They adopt a Schumpeterian perspective in which disequilibrium is the natural state of the economy. It is the aim of this experiment to investigate how the relationship between employment and innovation evolves in the dynamic context of the growth path in the model formulated here, and hence to provide some formal underpinning to the more informal theorizing in Freeman and Soete (1987).

To this aim, we have designed a control experiment on the basis of exogenous technological change, where the control variables are those which determine the Poisson arrival rates of inmovations (i.e. InnEase) and the impact of each arrival on labor productivity (i.e. mIncrmnt). As the benchmark for employment rates generated by our controlled experiments, first we start with a "base rum" characterized by no technological change.

\section{The "base run" with no technological change}

As argued in chapter 4 , in cases characterized by no technological change and profit-constrained output maximizing behavior, regardless of the initial conditions, the economies rapidly converges to stable fixed-points, which we refer to as quasiequilibria. The employment rates characterized by each of such quasi-equilibrium is uniquely determined by the institutional settings of the labor market (i.e., the parameters of the function $W g S u p(E m p l R t)$ ), capital intensity in production (i.e. b) and the minimum rate of return on capital expected by the shareholders (1.e.,

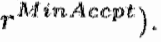

Accordingly, our base run features a simple single-sector economy characterized by a single profit-constrained output maximizing firm. The parameter settings that characterize this base rum are chosen as those indicated in table 6.1, together with the initial labor productivity coefficient $a^{0}=1$, and also Inr Ease $=0$ and $m$ Incrmnt $=0$ which eliminate technological change and accordingly ensure that the labor productivity coefficient $a^{t}$ remains equal to the initial level 
$a^{\circ}=1$ throughout the simulation run. In terms of our alternative capital price determination formulations we chose the one which assumes economy-wide profitability in capital markets, so that the parameter setting $b=3$, together with the one Captl Int Follow Rate $=1$ (which implies instantaneous productivity spillovers from the final to the capital sector), implies that the capital-output ratio in production remains at the constant magnitude 3.0 .

For these settings, the analytical equations that we derived before (i.e. equation 4.5 and 6.2 together) predicts the equilibrium employment rate in final good markets as

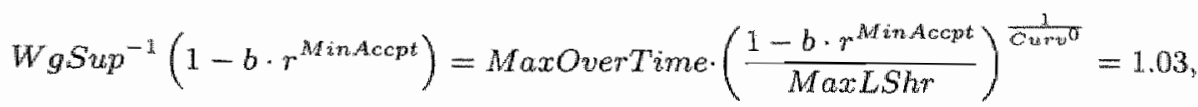

which, gives the impression of over-mployment. However, equilibrium is also characterized by the regular making-up of the periodic depreciation on capital. In other words, a stable equilibrium requires that the economy employs $b \cdot \operatorname{Depr} R t=$ $3 \%$ of its labor force in the capital sector, in order to produce the capital goodis just enough to compensate for depreciation. Given this, $103 \%$ total employment implies that, at the equilibrium, the final good sector employs 10000 workers (i.e., $100 \%$ of the labor force), while the capital sector employs 300 workers (i.e. $3 \%$ of the labor force) to overcome depreciation.

The actual simulation run rapidly converges to a quasi-fixed point characterized by the magnitudes estimated just above. At this equilibrium where $100 \%$ of the workforce is employed in the final goods market, the econony produces $a \cdot \bar{L}=10000$ units of output.

\section{The control experiments}

In order to observe the potential effects of technological change on unemployment, we have designed 6 control experiments over which all but two parameters are kept constant at the levels specified at the base run. The 6 control runs introduce various variations over the combinations of the magnitudes of the two control parameters InnEase and mIncrmnt, which respectively specify the Poisson arrival rates of innovations and the impact of each arrival on labor productivity. All experiments assume exponential progress trajectories which are characterized by the parameter setting $\tau=1.431$. Since eacin experiment is characterized by a single firm, there is no room to introduce any heterogeneity with respect to firms' innovative abilities and thus the firm level parameter in Abil is simply set to 1.0 .

As one can predict by the expected value estimation given by equation 6.10 (and also equation 5.5, which clarifies the former), the rate of technological charige, and accordingly the output growth to be enjoyed by the economy is merely a. function of the multiplicative product InnEase - mincrmnt, such that $E\left(\widehat{a}^{2}\right)=$ $\tau^{(\text {InnEase-mIncrmot })}-1$. This property gives us the first basis upon which we build our control experiments: We categorize our 6 experiments into two groups which correspond to two different rates of technological change. That is, all the three combinations of InnEase and mIncrmnt in the first group conform to the condition InnEase.mIncrmnt $=0.005$, where the commonality that underlies the three experiments of the second group is given by higher technological change opportunities imposed by InnEase $\cdot$ Incrmnt $=0.02$. Thus, according to the expected value estimation recalled just above, one can expect the economies characterized by the three experiments of the first set to enjoy, on the average, an expected productivity growth of $E\left(\widehat{a}^{t}\right)=1.431^{0.00510}-1=1.8 \%$ every 10 periods, while 
one can expect an average of $E\left(a^{t}\right)=1.431^{0.02 \cdot 10}-1=7.43 \%$ of productivity and output growth for every 10 periods of the economies characterized by the settings of the second group. The actual parameter wariations are made as follows

- Experiments with low technological opportunities:

- Low Opp.Base: $\{$ InnEase, mIncrmnt $\}=\{0.1,0.05\}$,

- LowOpp_Occ Long: \{InnEase, $m$ Incrmnt $\}=\{0.02,0.25\}$, which, in comparison to LowOpp.Base, implies a sequence of innovations which arrive relatively less frequently, yet which also make a relatively higher impact on the labor productivity coefficient,

- LowOpp_Freq_Short: $\{$ InnEase, InInctmnt $\}=\{0.5,0.01\}$, which, in comparison to LowOpp Base, implies a sequence of innovations which arrive relatively more frequently, yet which also make a relatively lower impact on the labor productivity coefficient,

- Experiments with low technological opportunities:

- HighOpp_Base: \{InnEase, mIncrmnt $\}=\{0.2,0.1\}$.

- HighOpp_Occ_Long: $\{$ InnEase, mIncrmnt $\}=\{0.04,0.5\}$, which, in comparison to HighOpp.Base, implies a sequence of innovations which arrive relatively less frequently, yet which also make a relatively higher impact on the labor productivity coefficient,

- HighOpp.Freq_Short: $\{$ InnEase, mIncrmnt $\}=\{1.0,0.02\}$, which, in comparison to HighOpp_Base, implies a sequence of inmovations which arrive relatively more frequently, yet which also make a relatively lower impact on the labor productivity coefficient.

\section{The experiment results}

The output of our control experiments are summarized in figure 6.1 and table 6.2. The first column of table 6.2 , which gives the average growth rates per ten periods, basically verifies the order of magnitudes of our earlier estimations on average growth rates: In the first (second) three settings which are characterized by low (high) technological opportunities, the economies grow by around $2 \%(7.5 \%)$ on the average per 10 periods. The slight differences between the experiments that pertain to the same level of technological opportunities and also their slight divergence from the estimated magnitudes (i.e. $1.8 \%$ and $7.43 \%$ respectively) are simply due to the stochasticity underlying these different realizations.

The last column of table 6.2 gives the average employment levels abserved in our 6 experiments, whereas the second and the third columns give the breakdown of these averages respectively over the final good and capital good sector. By comparing these numbers by their corresponding levels observed in the base run (i.e., $100 \%$ and $3 \%$ respectively), one arrives at the following conclusions:

- Technological change introduces underemployment in the final good sectors. The extent of this unemployment effect is more pronounced in the case of high technological opportunities (i.e. around $4.5 \%$ ) than that observed in cases of low technological opportunities (i.e. around 1.25\%).

- Technological change, being the engine of growth, increases the number of workers that work in the capital sector. The extent of this increase is more pronounced in the case of high technological opportunities (i.e. around 


\begin{tabular}{c|c|c|c|c|} 
& \multirow{2}{*}{$\begin{array}{c}\text { Growth } \\
\text { Rate }\end{array}$} & \multicolumn{3}{|c|}{ Employment } \\
\cline { 4 - 6 } & Final & Capital & Total \\
\hline LowOpp_Freq_Short & 0.0182 & 0.989 & 0.0351 & 1.024 \\
\hline LowOpp_Base & 0.0209 & 0.987 & 0.0357 & 1.022 \\
\hline LowOpp_Occ_Long & 0.0232 & 0.985 & 0.0361 & 1.022 \\
\hline HighOpp_Freq_Short & 0.0751 & 0.956 & 0.049 & 1.006 \\
\hline HighOpp_Base & 0.0771 & 0.954 & 0.049 & 1.004 \\
\hline HighOpp_Occ_Long & 0.0717 & 0.955 & 0.047 & 1.002 \\
\hline
\end{tabular}

Table 6.2. Growth and Unemployment Results

1.8\% of the labor force) than that observed in cases of low technological opportunities (i.e. around $0.5 \%$ of the labor force). This observation verifies that the main reason why labor productivity growth leads to output growth is the excess profits that are brought about by labor productivity increases which are invested in due course to increase productive capacity.

- The sum of the two opposing effects mentioned above amounts to unemployment in the overall economy. In other words, despite that the new investment orders that translate productivity growth to output growth allso create some extra demand for labor, the according increase in employment in the capital sector, fails to compensate for the loss of jobs in the final good sectors. The extent of unemployment is more pronounced in the case of high technological opportunities (i.e. around $2.7 \%$ ) than that observed in cases of low technological opportunities (i.e. around $0.75 \%$ ).

These conclusions clearly point to the unemployment generating potential of ongoing technological change processes which is increasing on the rate with which technological change brings about labor productivity growth. However, the unemployment figures given on table 6.2, each of which denotes the average of the values over an entire simulation run, neither suffices to discriminate between the different cases that pertain to the same level of technological opportunities, nor tells anything on the causal link that relates unemployment to technological change. However, the actual time series on employment and its breakdown on final and capital sectors, which are shown in figure 6.1 for each of our 6 control experiments, address both issues. To summarize:

- Unemployment time series (total unemployment as well as its breakdown to sectors) exhibit irregular oscillations,

- The frequency of these oscillations increases with the arrival rate of innovations (i.e. InnEase)

- The amplitude of these oscillations increases by the average impact of each arrival on labor productivity (i.e. the value assigned to the parameter mIncrmnt)

- For each individual run, employment time series in final good sector is negatively cointegrated with that in the capital good sector (i.e., $180^{\circ}$ phase shift in oscillations).

Based on these observations, one can easily see the process that generates unemployment. Upon the arrival of each productivity-augmenting innovation, the firm, being unable to increase its productive capacity immediately, lays-off a number of workers. The according economy in labor costs increase profits which 

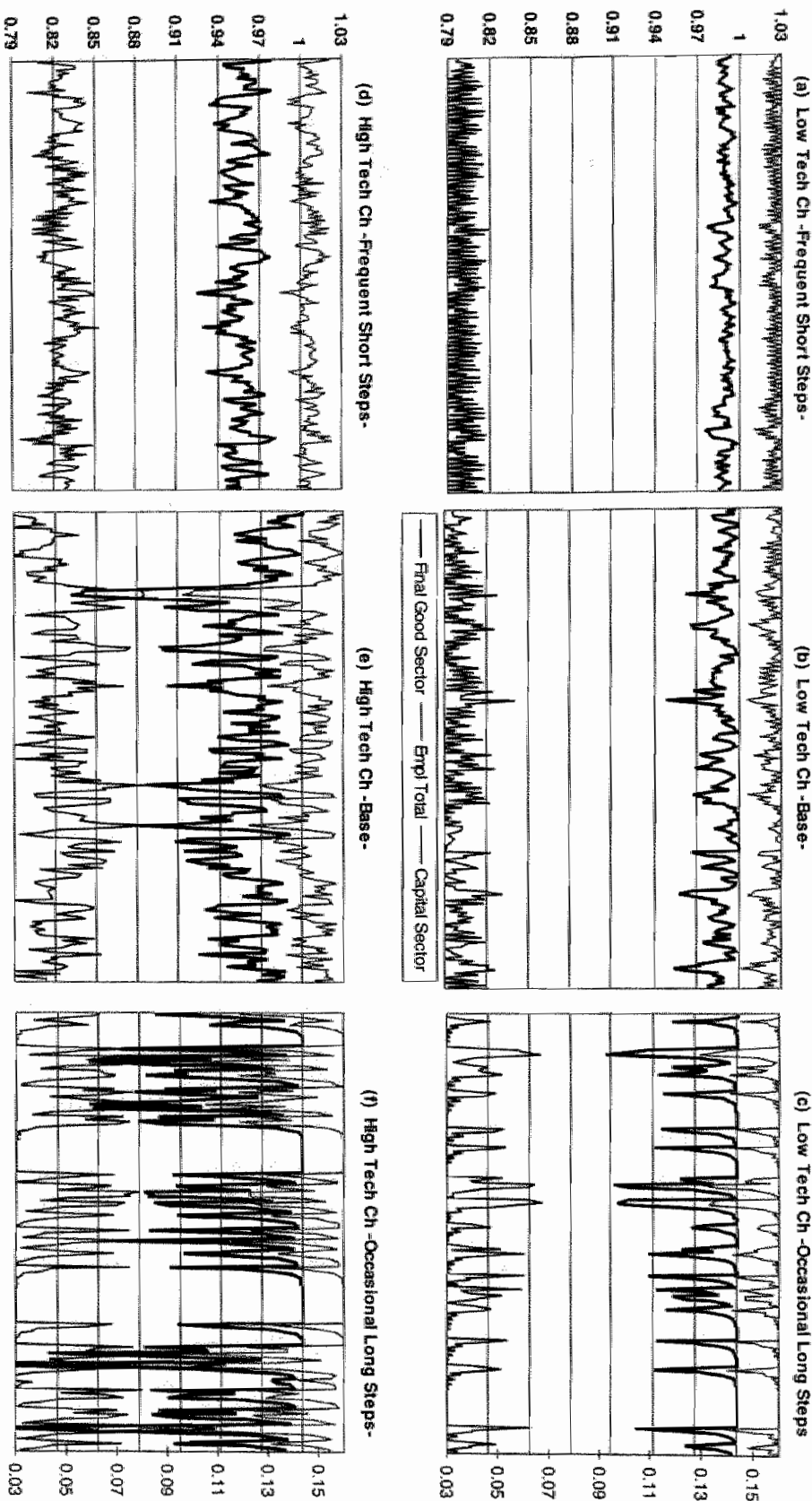

Figure 6.1. Employment time series in Experiment 1. 
are translated into new investments that increase capacity. As productive capacity gradually increases, the workers that find themselves unemployed initially are gradually reabsorbed into production again and the economy moves towards fullemployment gradually. This asymptotic restoration process is visiblie most clearly in the experiments characterized by the relatively slow arrival of innovations of strong impact on productivity (i.e, panels $c$, and $f$ in figure 6.1), where one can observe many occasions in which full employment is fully restored before the economy is disturbed again by the arriwal of the next innovation. Contrary to these cases, in experiments characterized by more frequent innovation arrivals, although the economy enters into the process that tends to reestablish full employment, the economy is disturbed again by the arrival of new innovations which makes employment further diverge from full-employment.

In short, the investment process that translates productivity growth to output growth is capable of restoring full-employment, yet only gradually, since the resources that determine the rate of new investments are not infinite but restricted by the profitability of the economy. The key point is thus that in cases of continuous innovation (as opposed to a once and for all disturbance), the effect of technologrical change on employment is maturally a matter of the pace and extent with which technological progress disturbs the system, relative to the pace with which the unemployed labor is reabsorbed. This implies that (historical') time becomes of essence for the relationship between technology and employment. The output of our simulation experiments show that in case of continuous arrival of technological change, due to the insufficiency of immediate financial resources (i.e., profits), the pace of umemployment eliminating processes falls behind the pace of unemployment generation, which brings about persistent technological unemployment. From a theoretical point of view, this calls for analyzing the employment innovation relationship from a dynamic perspective, in which both issues directly related to techmology and innovation, and issues related to market constraints facing firms become of crucial importance.

\subsubsection{Experiment \#2: Economic selection and diffusion of capital embodied technologies}

A particular feature that distinguishes many evolutionary models of economic growth from the neoclassical ones, is the assumption with regard to substitution between production factors. Where the neoclassical approach traditionally assumes that such substitution is possible and to be analytically distinguished from technological change, scholars in the evolutionary tradition have traditionally assumed a much closer linkage between technological progress and substitution. In the words of Rosenberg, "today's substitution possibilities are yesterday's innovar tions" i.e., substitution and innovation are closely related and it may make little sense to analytically consider them as distinct processes.

In this vein, evolutionary models typically start from a fixed coefficients ('Leontief') production function, and model innovation as a change in the factor coefficients (e.g., the model in Nelson and Winter [1982]). "This gives rise in a natural way to an analytical distinction between capital-saving and labor-saving technological progress (i.e., reductions in the separate coefficients of the production factors, usually labor and capital). When progress is positive along both dimensions (i.e., reductions in both coefficients), it seems obvious that selection unequivocally favors any innovation over its predecessor. But when one of the factor coefficients 
increases, and the other decreases, this is no longer obvious, and the question whether the innovation is viable depends on other factors in a model.

This is shown by Silverberg [1987], who introduces a vintage capital setting in what is essentidlly a model of diffusion and the resulting growth pattern of an economy. In this model, a single innovation is analyzed (on a 2-dimensional plane, where the dimensions correspond to reductions in each of the factor coefficients). It is shown that the set factor reductions that are compatible with a take-off of an innovation into the economy is dependent on factors such as the capital depreciation rate and the rate of population growth. In the Silverberg model. these factors determine the relative scarcity of the production factors, and hence they are the key ingredients in the context that determines which innovations are most viable. For example, when (exogenous) population growth is high, labor is relatively abundant, and capital saving innovations are more likely to diffuse (ceteris poribus).

The Silverberg [1987] model was the basis for a series of evolutionary simulation models dealing more explicitly with the issue of economic growth (e.g., Silverberg and Lehnert [1993] and Silverberg. Verspagen [1995a]). In these models, the single (once-and-for-all) innovation context was generalized into a more dynamic setting of continuous innovations. These continuous innovations either arrive according to an (exogenous) time homogenous Poisson process (Silverberg and Lehnert), or according to an endogenous process where firms investi in R\&D (Silverberg and Verspagen). In this way, a full-fledged evolutionary growth model results. However, in these models, the context of two-dimensional technological progress was lost, because the capital coefficient was frozen into a single parameter (constant over time).

While the reasons for this decision are somewhat mystified, it is clear that in the context of the Silverberg [1987] model, a continuous process of capital-saving technological progress has a potential to make profit rates (profits as a fraction of capital) explode, and this leads to unstable growth trajectories. In the current model, due to the specific modeling of a capital goods-producing sector, it is easier to accommodate technological progress along two dimensions in a fully dynamic context. This is the topic of the second experiment in this chapter.

\section{The control experiments}

The base rum starts from parameter settings identical to that of the base run of Experiment \#1 (i.e. as in Table 6.1), and in addition InnEase = 0.1 and mincrmnt $=0.05$. The issue of capital embodied technological progress is analyzed in the context of the vintage capital module of the model, which based on our technological paradigm formulation. For this experiment we introduce 10 notional paradigms, each of which introduces $122.5 \%$ labor productivity increase over its predecessor. That is

$$
a_{s+1}^{\max }=1.225 \cdot a_{s}^{\max } .
$$

where the labor productivity level for the first paradigm is set to $a_{1}^{\max }=1$, i.e., the economy can reach the eventual productivity level $a_{10}^{\max }=1 \cdot 1.225^{9} \simeq 6.21$, provicled that all of the notional paradigms are invented during a simulation run.

Furthernore we rule out learning within paradigms by the specification

$$
a_{s}^{\max }=a_{s}^{\min }+0.001
$$

or practically $a_{s}^{\text {max }} \simeq a_{s}^{\text {nain }}$, which implies that the labor productivity potential embodied in each paradigm is readily accessible at the instant of invention, without 
the necessity to go over a prolonged duration of a learning process. In these conditions, the paradigm specific parameters $\psi_{s}$ have no impact at all, and their value is set to 1.0 for all paradigms s. The parameters PrNxtPar and FuSensinv, which, together with InnEase adjusts the probability at which new paradigms are invented, are set to the values 0.08 and 1.0 respectively.

The technology underlying each paradigm is assumed to be capital embodied, i.e., each paradigm is associated with a specific capital vintage and each vintage is set to be $22.5 \%$ more capital intensive than its predecessor (i.e., $b^{s}=1.225 \cdot b^{8-1}$ for each paradigm $s>1)^{12}$. Obviously the rates of 'capital emibodiment' and labor productivity growth have been chosen to be equal, in order to provide a case of maximum analytical interest.

In order to ease the diffusion process, we further assume that each new vintage $s+1$ uses $100 \%$ of the machinery and equipment used by its predecessor $s$ (i.e. ShrCommon ${ }^{s, 7 n+1}=1$ ), yet it needs further equipment which amounts to $22.5 \%$ (in value) of the vintage $s$. Therefore, the diffusion of each new vintage (provicled. that it happens) clearly implies a substitution of labor with capital in the short run. In order to minimize the possible effects of rapid (high frequency oscillations) on our simulations, as in the second run of Scenario \#1, we turn our "short-run wage stickiness" module on.

Within these base settings, we first vary the (real) wage elasticity of labor

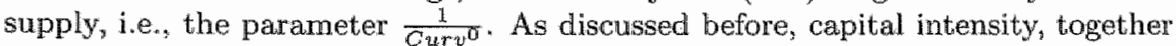
with the institutional settings of the labor market, are the key factors that determine the employment rate in the economy. Thus, varying the elasticity of labor supply is roughly similar to Silverberg's (1987) strategy of tuning factor scarcity and investigating the effects on diffusion. We therefore run the model once with the setting $C u r v^{0}=1.1$ and once with $C u r v^{0}=5$ (where the latter corresponds to lower elasticity) ${ }^{13}$.

In the base run, the paradigms are introduced sequentially, (stochastically) one by one. A further sub experiment is carried out by starting the simulation with 10 firms, each producing with a different one of the 10 capital vintages defined as above. This setting clearly gives firms conflicting advantages/disadvantages in terms of capital and labor costs. In other words, the firms that use vintages that present labor productivity advantages, have these advantages at the expense of higher capital costs. The key question then becomes whether the selective forces. of the economy will select/eliminate any of the firms (i.e. capital vintages), and, if so, will the economy end up with the dominance of one or more of the competing wintages. We run this simulation for each of the two values of $C u r v^{0}$.

\section{Results}

In the base run $\left(C u r v^{0}=1.1\right)$, productivity and output growth proceed only up the point where the vintage that pertains to our $7^{\text {th }}$ paradigm ${ }^{\text {ta }}$ completely diffuses into the economy. Vintages \#8, \#9 and \#10, despite their introduction, can not diffuse at all. In other words, all vintages up to $\$ 7$ rise and dominate the economy temporarily, until being replaced by the next vintage. But, the $7^{\text {th }}$ wintage is not replaced by any further productivity increasing new vintage and accordingly productivity growth stops after the complete diffusion of this wintage. The diffusion of each new vintage naturally implies a temporal increase in the capital intensity of the economy ${ }^{15}$. As discussed before any increase of economy-wide capital intensity shifts income distribution for the benefit of the capitalists $^{16}$, which translates into unemployment in extents determined by the 
wage lasticity of labor supply. Accordingly, in the base run, where wage where labor supply is rather elastic, we observe that unemployment level increases up to the extremely high steady state value $38 \%$. Before the eventual dominance of the $7^{\text {th }}$ wintage (after which the economy enters into a steady state since none of the following vintages can not diffuse into the economy and productivity growth stops accordingly), one observes long waves in employment rates and output levels. We even observe negative output growth during the downturn of the waves.

The change to the setting $C u r v^{0}=5$ produces results that are similar to the previous ones, with the exception that at the eventual steady-state, again clyaracterized by the absolute dominance of the $7^{\text {th }}$ vintage, the economy operates at full employment. Due to the more inelastic settings of the labor markets, despite the fact that the capitalists' share in GDP drastically increases throughout the process of the diffusion of new vintage, each of which increases capital intensity in production, the workers remain ready to offer their entire services to production, even in return for a much lower share in GDP.

When we introduce the 10 vintages simultaneously as each one adopted by a different firm, the eventual steady-states reached are identical to those of the initial two runs (with respective values of $C u r v^{0}$ ). That is, in both runs the economy eventually selects the $7^{\text {th }}$ vintage, and at the according steady-state characterized by the absolute dominance of the $7^{\text {th }}$ vintage, the unemployment: rates are observed to be around $38 \%$ and $0 \%$ respectively. The most interesting finding of these two runs (except the eventual dominance of vintage \# 7 as in the previous runs) concerns the diffusion/elimination paths followed by the individual vintages. Figure 6.2 depicts the motion of vintage market shares. It is clear from these figures that despite the simultaneous existence of all vintages at the initial period, there is still an element of sequentiality in the diffusion pattern of the competing vintages, which are not monotonic functions of time: Vintages \#10, \#9 and \#8 are initially elliminated. Similarly vintage \#7 which is the eventual winner of the competition, and its close competitor \#6 initially loose market share. Meanwhile, vintages $\# 1, \# 2, \# 3$, \#4 and \#5 start to increase their market share. However after a while, each of these initial forerunners start to loose market share one by one (first vintage \#1, then $\# 2, \# 3, \# 4$ and eventually $\# 5$ after capturing almost $50 \%$ of the market alone), while vintage \#6 followed by vintage \#7 make a rapid come-back and take-over. As one can observe in Figure 6.2 , in the run with the high $C u r v^{0}$ value, vintage $\# 7$ captures the economy smoothly while with the low Curv value, fierce competition with vintage \#6 takes three dramatic turns in market share dynamics.

The selection of vintage $\$ 7$ thus seems to be a quite robust finding for this model setup. Can we find a scenario under which later vintages also diffuse into the economy, and hence productivity growth does not die out? To show that this is possible, we run a final sub experiment,. which is similar to the base run $\left(C u v^{0}=1.1\right)$, except that now CaptlProdFollowRate $=1.0009127$, i.e, the(per period) productivity increase in capital production is higher than that in final good sector by $0.09127 \%$. In this run, unlike in the rest of the other runs, all of the 10 vintages diffuse into the economy, ending up with the absolute dominance of the $10^{t / 2}$ vintage, which among its other competitors offers the highesti labor productivity. Unlike in the other runs, income distribution does not exhibit any trend for the benefit of the capitalists and despite, the existence of long waves (each triggered by the introduction of a new vintage), income distribution remains around a steady level (i.e. $85 \%$ for the wage bill and $15 \%$ dividend payments $)^{17}$. Due to this last fact, which indicates the absence of any temporal 

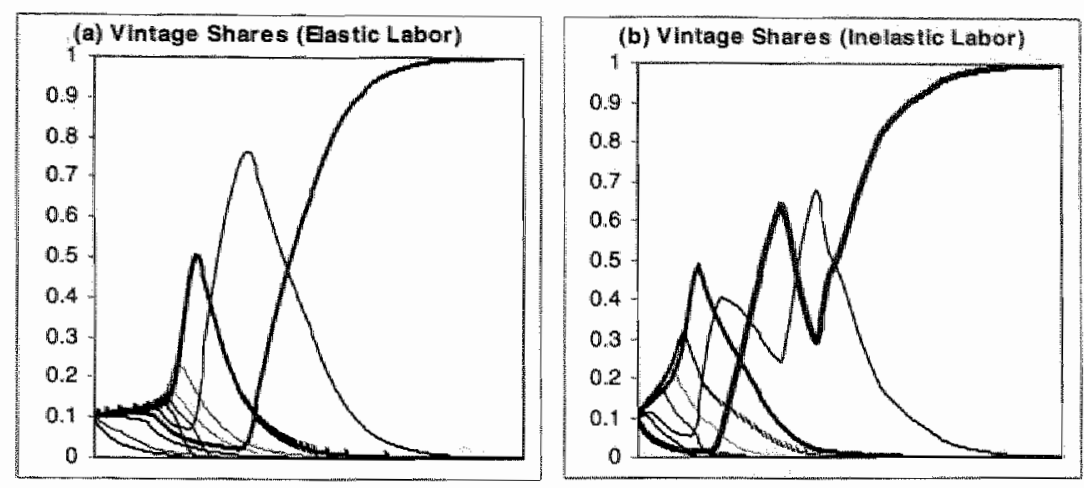

Figure 6.2. Motion of vintage market shares in runs with simultanous introduction of vintages.

trend in the economy-wide capital intensity, despite the rather elastic nature of the labor supply, the economy remains around its full employment level, yet again, exhibiting long waves each triggered by the introduction of a new wintage. Apparently rapid productivity growth in capital production (which exceeds that in final good sector) prevents the economy from the adverse effects of the positive capital intensity differences between successive vintages, the diffusion of which otherwise increase the economy-wide capital intensity of production inevitably and accordingly inhibits the diffusion of new vintages that imply relatively more expensive capital goods. At the terminal period of the simulation, labor productivity in the final. sector comes to the level offered by the $10^{\text {th }}$ vintage $\left(a_{10}^{\max } \approx\right.$ $6.2)$. In other words, since $a_{1}^{\max }=1$, throughout the 2000 period simulation, labor productivity in final good sector increases by around 6.2 times. During the

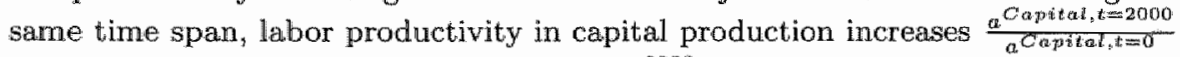
$=\left(\text { CaptlProdFollowRate }+\left(\frac{6.2-1}{1}\right)^{\frac{1}{2000}}\right)^{2000}=32.192$ times $^{18}$. That is, relative to that in final good sector, labor productivity in capital production increases $\frac{32.192}{6.2}=5.2$ times. This difference, which of course is an outcome of our carefully selected value assignment to the parameter CaptlProdFallow Rate made for illustrative convenience, exactly compensates for the capital intensity growth mandated by the diffusion of successive vintages $\frac{b^{10}-b^{2}}{b^{1}}=\frac{(3 \cdot 6.2)-(3 \cdot 1)}{3 \cdot 1}=5.2$. Thus, capital intensity in production (i.e. the capital output ratio) remains around its period zero value 3.0 (except for the periods around the jumps brought about by rapid diffusion shocks, followed by a gradual convergence back to 3.0 ) and accordingly sustainable growth is achieved along a process where income distribution and employment follow a steady motion, with long waves of large amplitude, yet without any temporal trend.

\section{An analytical discussion on the experiment findings}

The basic question regarding the first four control experiments we discussed above is: "Given that each new vintage introduces (over its predecessor) a proportional labor productivity and capital intensity increase of equal magnitude, why each of all wintages up to \#8 completely diffuses into the economy (and remains as the only vintage until replaced by the next vintage) while the rest do not? " or "why 
does the $7^{\text {th }}$ vintage appears to be the one eventually selected among others by the selection dynamics of the system?". Simple arithmetic clarifies the reason:

Consider the equilibrium point where a given vintage $s$ is the only one used in the economy. Under our current assumption on unit capital determination (constant capital-output ratio assumption) which implies that $P$-Capt $t^{t}=b \cdot P^{t}$ (where $b$ is the constant capitalloutput ratio), the equilibrium condition $\frac{p^{t}-\frac{y^{2}}{P^{2}+C a p t i}}{t}$ $=r^{\text {Miracept}}$, which is derived in our earlier discussions, indicates

$$
\left(\frac{w^{\prime \prime}}{P}\right)^{s}=a_{s}^{\max } \cdot\left(1-b^{s} \cdot r^{\text {Mindaccpt }}\right)
$$

Now, while the economy is at this equilibrium, another vintage (say $n$ ) arrives. If, given the vintage $g$ equilibrium real wages $\left(\frac{w}{P}\right)^{s}$, the rate of return on capital to be yielded by the new paradigm is higher than $\gamma^{\text {Min Acopt }}$ (which is the equilibrium rate of return yielded by the old wintage), one expects the new vintage to diffuse and replace the old one(s). Let the variable Diff Pot $(n \backslash s)$ denote the profitability (rate of return on capital) difference between the new ( $n$ ) and an old vintage ( $s$ ). Then in terms of economic incentives, the diffusion condition for the new paradigm (given the equilibrium conditions implied by the old paradigm) is

$$
\text { Diff } \operatorname{Pot}\left(n \backslash s^{\prime}\right)>0
$$

where

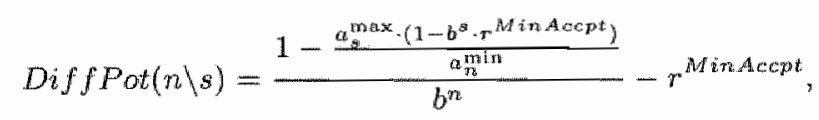

which can easily be derived through equation ??.

Since the parameter settings of the experuments rule out any paradigm-specific learning effects (which is imposed by the settings $a_{s}^{\min } \approx a_{s}^{\mathrm{max}}$ ), the last inequality can also be witten as

$$
\operatorname{DiffPot}(n \backslash s)=\frac{\widehat{a}(n \backslash s)-1}{(\widehat{a}(n \backslash s) \cdot \widehat{b}(n \backslash s))-1}-\left(b^{s} \cdot r^{\text {MinAaccpt }}\right) \text {, }
$$

where $\vec{a}(n \backslash s)=\frac{a_{n}^{\max x}}{a_{s}^{\operatorname{man} x}}$ and $\vec{b}(n \backslash s)=\frac{b^{\text {th }}}{b_{s}}$ respectively denote the proportional labor productivity and capital intensity increase introduced by the vintage $n$ over the vintage $s^{19}$. We have calculated the variable DiffPot $(n \backslash s)$ for all possible pair-wise vintage combinations $(s$ and $n$ ). Table 6.3 summarizes these calculations. Each cell $(s, n)$ in the table shows the arithmetic sign of the variable Diff $P$ at $(n \backslash s)$, or whether the vintage $n$ that arrives during the reign of wintage $n$ would diffuse and replace vintage $s$. The cells marked with " ++ " show the vintage $n$ which has the maximum diffusion potential (DiffPot $\left.(n) s^{4}\right)$ during the reign of vintage $s$.

From Table 6.3 , or by inspecting the condition given by inequality 6.21 as well, one can see the apparent reason why the economy gets locked-in the $7^{\text {th }}$ vintage, especially given the sequential arrival of new vintages $(1,2, \ldots, s, s+1,$.$) in$ thew two first runs. The variable DiffPot $(s+1 \backslash s)$ (i.e., the step-wise diffusion potential function) has a positive sign for all $s<8$ and a negative $\operatorname{sign}$ for $s>7$, and the reason for this switch is the presence of the term $b^{s}$ in inequality 6.21 : The diffusion potential of a new vintage (which offers a labor productivity increase at the cost of higher capital intensity) is a decreasing function of the level of economywide capital intensity implied by the extant (old) vintage. In other words, with 
TO $\mathbf{n}$

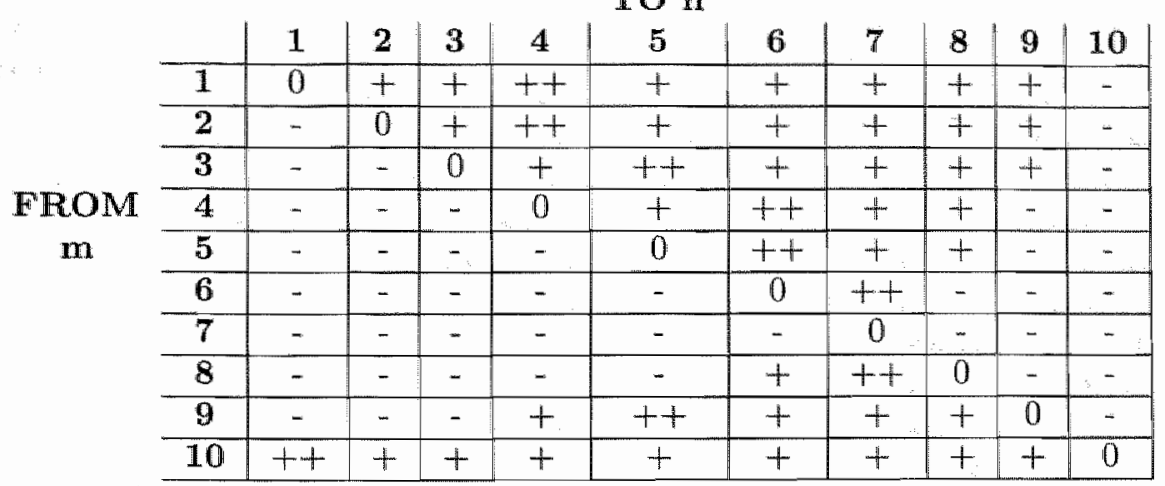

Table 6.3. Diffusion potential matrix for experiments 2.2 and 2.3

sequential arrival of innovations, at the instants where vintages $\# 8, \# 9$ and $\# 10$ arrive, the capital intensity of production (due to the reign of vintage\# 7 ) is already so high that despite the higher labor productivity they offer, none of these lasit three vintages can ever diffuse into the economy and the reign of vintage \#7 accordingly emerges to be the absorbing state of technology selection dymamics.

With simultaneous introduction of innovations, the key to the explanation of the dramatic (sequential) dynamics of vintage market shares is the mutual relation between the vintage diffusion process and (clisequilibrium) real wage dynamies. First, the diffusion potential of a vintage (the rate of return yielded by a vintage relative to that yielded by other vintages) at a given time instant $t$ us

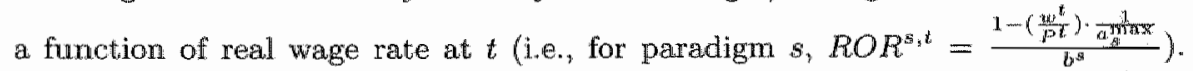
On the other hand, the real wage rate at period $t$ is nothing but the multiplicative product of average labor productivity $\left(a_{A v g}^{t}\right)$ and the share of wage bill in national income $e^{20}$. As discussed in the previous chapters, the share of wage bill in the economy $\left(W_{g S u p}{ }^{t}(\cdot)\right)$ tends to converge to $\left(1-b_{A v g}^{t} \cdot r^{M i n A c c p t}\right)$ asymptotically, where $b_{A v g}^{t}$ is the economy-wide (average) capital intensity at period $t$. Thus, one can write

$$
\frac{w^{t}}{P^{t}}=a_{\text {Avg }}^{t} \cdot\left(1-b_{\text {Avg }}^{t} \cdot r^{\text {Min A Acept }}\right)
$$

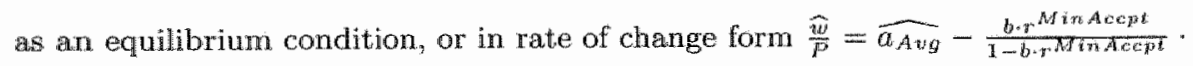
$\widehat{b_{A v g}}$, which implies that the rate with which real wage rate increases showld be equal to the labor productivity growth rate, unless average capital intensity also increases along the techmological change process.

In short, the relative diffusion potential (or market share dynamics) of each vintage is a function of the real wage rate, real wage rate is a function of economywide labor productivity and capital intensity, and finally given that each vintage is characterized by a different labor productivity-capital intensity combination, economy-wide labor productivity and capital intensity are both functions of the market shares of the vintages in the economy ${ }^{21}$. "This two way causal relation between real wages and wintage selection clearly explains the interesting sequential patterm observed with sequential introduction: At the initial periods when all vintages have equal shares and the real wage rate is rather low, there are no incentives for the "high productivity-high capital intensity" vintages to diffuse (as 
one carl also induce from the first two tows of Table 6.3), and accordingly the first few vintages increase their market shares at the expense of the others. Yet, as these vintages (especially \#3,4 and 5) diffuse, the average labor productivity in the economy and thus the real wage rate gradually increase (despite the negative effect of the increase in the average capital intensity in production), opening the way to the diffusion of vintages $\# 6$ and $\# 7$, which become eventually attractive for investors. As this process develops, vintiage \#7 takes also over vintage \#6 and captures the entire economy eventually.

The most important message given by the first four runs is on sustainability of growth in cases of capital embodied technological change: If labor augmenting technological opportunities are strongly dependent on the use of more sophisticated and expensive machines and equipment, an economy can only experience growth for a limited period of time, since the temporal increase of capital intensity eventually inhibits the diffusion of new capital vintages. Is such a result, which is in line with the more static result in Silverberg [1987], in line with reality? One may argue that in reality, an increase in the sophistication of the machinery and equipment used in production has been the rule rather than the exception, and has led to increasing the productivity of other factors of production (especially labor). This may indeed be taken as evidence of capital embodied technological change as in this simulation experiment. However, unlike in the first four sub-experiments, meither have we observed a significant temporal positive trend in average capital intensity ${ }^{22}$, nor has the income distribution been changing drastically in favor of the capitalists ${ }^{23}$.

However, this paradoxical picture has a very reasonable explanation, related to our last sub-experiment, and which can be illustrated with an example from the computer industry. Each new generation of computers is significantly more sophisticated and expensive than its predecessor. Yet, the prices of the new generation computers fall rapidly to the levels of those of their predecessors, and accordingly despite the significant increases in quality and performance, customers pay (on the average; except those which only buy state of the art as soon as it becomes available) the same, or ever a llower amount every time they replace their old computer with a new one. If one generalizes this example to the macro level, it seems that if an economy is subjected to capital embodied technological change, sustainable output growth (especially with steady income distribution) is only possible if productivity growth in capital production is sufficiently high. Yet, how does one define what "sufficiently high" is?

The five sub experiments, as well as additional non-documented runs, suggest that positive labor productivity growth in the final good sector, accompanied. by capital sector productivity growth which is larger (even slightly) than that in the final goods sector, is sufficient to keep marginal productivity of capital high enough to keep investments going (i.e.,CaptlProdFollowRate $>1$ ). For sustainable growth in cases of capital embodied technological change, the economy is dependent on the capital sector not only in terms of product innovations (i.e. successive introduction of labor saving machines and equipment), but also in terms of process innovations that bring about rapid productivity growth in capital good production in excedance of the productivity growth rate in the final good sector. In neoclassical terms, in cases of capital embodied technological change, the protection of the marginal productivity of capital at levels sufficient to keep investments (and output growth) going is heavily dependent on the rate of process innovations in the capital sector.

Summarizing, the results in this experiment show that in the context of fixed 
coefficient technologies, which is the usual vehicle for modeling productiwity-based technological progress in evolutionary models of economic change, capital embodied technological change may seriously alter the results on the viability of long-run economic growth. Normally, technological progress is assumed not to be capital embodied, and the experiment shows that this may lead to relatively optimistic conclusions with regard to the sustainability of long-run growth.

As a parenthesis, this line of argumentation is reminiscent of the model in Grossman and Helpman [1992, ch 3]. In this model, innovation is an endogenous process driven by profit-motivated R\&D investment. However, in the base line model, the innovations resulting from this $R \& D$ drive down the profit rate in the economy, and this lowers the incentive for R\&D. Thus, ultimately, R\&D investment ceases and growth is unsustainable in the long run. Grossman and Helpman 'solve' this by introducing a knowledge extemality in R\&D, which is essentially a mechanism of increasing returns at the aggregate level. In this way, long-run growtil becomes sustainable, although a steady state is only found for a specific value of 1 for the knowledge externality. Stronger externalities introduce exploding growth paths, weaker externalities Iead to unsustainable growth. Grossman and Helpman, and the "new growth" tradition in general, discuss this property in terms of decreasing marginal returns to investment, and conclude that this is an obstacle to growth in the long run. The results in this experiment suggest that in the context of capital embodied technological change, economic growth in an evolutionary setting may be susceptible to similar problems, and a similar 'solution' (rapid process innovation in capital goods production that has 'external effects' for the total economy) exists.

\subsubsection{Scenario \#1: Technological Progress in Paradigms and Long Waves in Growth Rates}

Schumpeter[1939] suggests an interesting theory of business cycles, which draws on Fondratieff [1926/1935] who claimed to have identified long waves (i.e. low frequency oscillations of around 50-year periodicity) in historical time series. In his explanation, Schumpeter [1939] asserts that major innovations followed by a host of imitations give rise to an investment boom, and when the innovations are fully exploited or over-exploited, the economy relapses into a recession and even a depression until new ideas re-introduce an euphoric climate of a new wave of innovating investments.

One line of research ${ }^{24}$ that addresses Schumpeter's suggestion critically depends on the proposition that the introduction of (basic or major) innovations are mot evenly distributed in time but they tend to cluster, which is equivalent to the rejection of the hypotheses that technological change processes can be represented by time homogenous Poisson processes (i.e., constant arrival rate) and/or by Poisson processes where arrival rates increase temporally. The empirical verification of this clustering phenomenon has been addressed by a number of studies that follow various methodologies and leading to alternative conclusions. For an example and an overview see Silverberg and Verspagen [2003], who, on the basis of the methodology of Poisson regression (applied on time series of the introduction dates of basic/major innovations), conclude that basic innovations exhibit only a "weak" form of clustering which can be referred to as "overdispersion".

In addition to empirical studies, Silverberg and Lehnert [1993] show by a formal model that clustering is not a necessary condition for the emergence of the Schumpeterian long waves but non-uniformities in innovation arrivals sufice. The 
model essentially leatures a capital vintages framework, where vintages arriwe according to a time-homogenous (or accelerating) Poisson process. The diffusion of each vintage into the economy follows an S-shaped (logistic) pattern. which introduces a lag between an innowation and the period where its full impact in productivity and output level is realized. Under the S-shaped transformation of innovations into actual output growth, the underlying stochasticity which, in actual realizations disturbs the actual time homogeneity of innowation arrivals, are nicely shown to be capable of leading to identifiable long wave patterns.

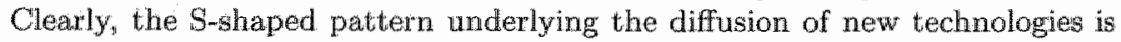
the key element leading to the emergence of the long-wave phenomenon shown. by Silverberg and Lehnert [1993]. In this formulation, the full diffusion of the new technologies into the economy sets the point of full exploitation which is responsiblle for the slowing down of productivity and output growth. However, as discussed by Freeman [1982, p. 216], Wolff's law ${ }^{25}$ clearly constitutes a substitute and/or complementary mechanism which can be responsible for the temporary reductions in the opportunities that can otherwise keep investments and output growth at high levels.

One can see the strong match between this line of thought and the "technological paradigns" concept suggested by Dosi [1982]. As mentioned in chapter 5, we have built into our model platform a module that captures the essence of the concept "technological progress through technological paradigms". Furthermore, our formulations also allow for the introduction of the principle of cumulativeness in the context of individual technological paradigms. Drawing on these two formulations, with the current experiment we aim at making an illustration of Schumpeter's suggestion on business cycles, in the context of "consequent paradigm specific learning trajectories", as an alternative to the existing 'diffusion-based" illustrations.

\section{The simulation settings}

Although the causal link that we will demonstrate here can also be seen as complementary to the -diffusion-based-explanations, in order to sharpen illustrativeness, we exclude the element of diffusion from our experiment by assuming capitaldisembodied technological change and representing the economy by a single sector operated by a single "profit-constrained output maximizing" firm, which rules out the possibility of imitations.

The basis (i.e. structural) parameter settings are iclentical to those that characterize Experiment 1, which are given in table 6.1. As discussed in the context of Experment 1, these settings set the stage for the economy to converge to at full-employment equilibrium characterized by $100 \%$ employment in the final and an extra $3 \%$ employment in the capital sector in the presence of any technological change.

The essential difference lies in the builtwin trajectory through which the technological opportunities are revealed to the economy. In contrast to that in Experiment 1, where the trajectory to be followed by the labor productivity coefficients is specified as a continuous and exponential path, in the current scenario, the technological opportunities reveal thenselves through a series of concave productiviby progress paths, each corresponding to another technological paradigm within which progress opportunities decrease as further knowledge/experience is brilt. We introduce into our simulation 20 of such notional paradigms. As described in the previous chapter, each notional paradigm s needs to be specified 
by 3 parameters: $a_{s}^{\min }, a_{s}^{\max }$ and $\psi_{s}$. The first two parameters respectively denote the zero experience and the infinite experience labor productivity level that can be attained within the boundaries of paradigm s. The third parameter determines the curvature of the concave trajectory of the paradigm, which determines the extent of decreasing returns to learning. Our settings of the parameters $a_{s}^{\text {min }}, a_{s}^{\text {max }}$ are based on the following two rules:

$$
\begin{aligned}
& a_{s+1}^{\min }=1.15 \cdot a_{s}^{\min }, \\
& a_{s}^{\max }=a_{s+1}^{\min x}-0.001,
\end{aligned}
$$

for each notional paradigm $s=1,2, \ldots, 20$, where $a_{1}^{\text {min }}=1$. This formulation suggests that each notional paradigm $s+1$ promises an eventual $15 \%$ potential increase in labor productivity over the level that can be attained within the learning limitations of the previous paradigm $s$. The parameters $\psi$ s are set to the level 4.0 for each notional paradigms $s$.

Having specified the trajectory through which technological process should move, the next step is to set the parameters that determine the speed of adjustment through the given opportunity trajectory. The two basis parameters that respectively determine the average pace of innovations and the average increment that each adds to the paradigm specific experience level (i.e., Fitness ${ }^{t}$ ) are set as InnEase $=0.1$ and mIncrmnt $=0.00025$. As mentioned before the main point we aim to make with this scenario is the potential of paradigm specific learning on fluctuations on growth rates. "To this end, we activate our" "cumulativeness" modwhe, which endogenises the Poisson arrival rates of incremental innovations on the basis of the cumulative number of paradigm specific number of past innovations, and make the relevant parameter settings as $\Omega_{B a s e}=0.2$ and $\Omega_{R T S}=1^{26}$.

The three parameters InnEase, $\Omega_{B a s e}$, and $\Omega_{R T S}$ collectively determine the dynamics of the (Poisson) arrival rate of incremental innovations that characterize paradigm-specific learning. However, paradigm arrivals, each of which is a radical innovations that moves the economy into a fresh new and more promising learring path, are highly rare events by definition. As defined in the previous chapter, the probability that an ordinary innovation turns out to be the pioneering invention of a new paradigm is given by the parameter $P r N x t P a r$, which is assigned the value 0.075 . Also recall from the definitions in the previous chapter that another paramew ter Fitsens Inv $\geq 0$, the non-zero values of which render the invention probability of each next paradigm $s+1$ an increasing function of the extent of accumulated experience/knowledge in the existing state of the art paradigm $s$. For the current scenario we set FitSensInv $=10$, which imposes this effect quite strongly. In other words, in the early periods that follow the invention of a paradigm $s$, while labor productivity is still close to $a_{s}^{m i n}$, the probability that paradigm $s+1$ is invented is close to zero. However, as learning in paradigm s proceeds, this probability converges to PrNxtPar $=0.075$ as actual labor productivity converges to $a_{s}^{\max }$.

Note that none of the last 7 parameters detemine anything structural but essentially affect the pace of progress collectively. In this context, one can say that we have chosen these values conventionally (and after a bit of experimentation) in order to illustrate the point we aim to make in a most convenient way. In particular, our settings aim to ensure that

1. Within the number of periods for which the simulation is run (i.e., 3400 periods) the economy goes through the entire trajectony of learning opportunities made available by the 20 notional paradigms introduced, 
2. New paradigms do not arrive at very early stages where the majority of learning opportunities still remain unexploited ${ }^{27}$, so that we observe the economy go through the entire learning curve implied by each individual paradigm gradually, without any drastic jumps in labor productivity.

3. The economy does not wait prolonged periods between the saturation of learning in one paradigm and the arrival of the next one.

\section{The simulation output}

Scenario 1a Figure 6.3 depicts various charts that pertain to a single 3400 period run of a simulation run parameterized by the settings listed above. The first 2 charts, panel (a) and (b) respectively give the output time series of labor productivity and output level. Upon sheer visual inspection, both appear rather smooth, pointing to exponential growth in the very long run. "Throughout the simulation run, the economy invents all of the 20 paradigms which brings about a total productivity and output growth rate around $1.15^{19}-1=1323 \%$.

However, as indicated by panels (c) and (e), which respectively show the motion of output and labor productivity growth rates, under the hood, things are far from being that smooth. One can observe high frequency oscillations (that look like white noise) as modulated on low frequency oscillations which look like long waves. Furthermore, the temporal variations of productivity and output growth rates appear to be highly correlated over time.

Thanks to the rather long period of our simulation and the high number of paradigm arrivals, it has been possible to test the long waves hypothesis by spectral density plots. These plots are depicted in panel (d) and (f) of Figure 6.3 respectively for output and productivity growth rates. Despite the presence of a wide range of various frequencies (i.e. cycle periods), both density functions make a significant peak around the cycle period around 175. This periodicity, given the fact that the simulation is run for 3400 periods, imply $\frac{3400}{175} \simeq 19$ full cycles or 19 long waves ${ }^{28}$, which happens to coincide with the number of new paradigms introduced during the simulation run. This coincidence maturally suggest that each productivity/output growth cycle is triggened by the arrival of another paradigm.

One can also observe low frequency periodicity also in the motion of unemployment: rates although they are barely identifiable by visual inspection due to the accompanying bigh frequency oscillations (see panel (g) of 6.3). The spectral density plot for the unemployment time series (given on panel (h) of 6.3) confirms the existence of Jong waves in unemplayment time series, though in a relative more vague sense. That is, the cycle period of this low frequency component is not so strikingly clear as in output and productivity growth rates, since the peaking park of the spectral density chart looks more like a plateau at the salient part of the spectral density plot (covering the cycle period range 160 to 300 ) than a sharp spike.

Scenario $1 \mathrm{~b}$ The fuzziness in the periodical behavior of unemployment points to the possibility that wage rate dynamics strongly interfere with the rest of the system dynamics. In order to check this possibility we run the same simulation. once again, but this time we turn on our short-term wage rate stickiness module, which, as described in chapter 5 , smooths the wage rate dymamics by a short term moving averaging process.

Figure 6.4 depicts the motion of the productivity and output growth rates, as well as their spectral density plots, all of which pertain to this second, slightly 
modified run. As one obserwes from these charts, the effects of short term wage rate stickiness are drastic: Almost all high frequency oscillations have disappeared, not only from unemployment time series but from the motion of output growth rates as well. This is further confirmed by the spectral density plots which show the absence (or insignificance) of all but one cycle periods (i.e., the 175-period long-waves). In other words, despite the underlying stochasticity, both series look almost as if they are generated by a deterministic process.

Unlike output growth and unemployment, the motion of labor productivity growth is naturally not affected from wage rate dynamics. Namely, labor productivity growth in this secondary modified run looks similar to that in the previous scenario (i.e. as in panel (e) of Figure 6.3), in the sense that it is disturbed by a range of high frequency oscillations, which are nothing but white noise. However, in case of short-term wage stickiness, the wage rate/investment dynamics of the system filters out a significant part of the white noise which is reflected in the highly regular pattern of output growth rate and unemployment motion.

A simple cross-correlation analysis among the observed motion of unemployment, output growth rates and productivity growth rates, nicely complements our usuall story line on the workings on the links between productivity and output growth: We have found that unemployment and labor productivity growth rates are cross correlated (by around 50\%) at zero time lag (i.e. each innovation immediately brings about an initial unemployment). The maximum cross-correlation coefficient (by around 50\%) between output growth and labor productivity growth is found at a 30 period time lag, which suggest that the restoration process of full employment following a productivity shock ${ }^{29}$ is completed in about 30 periods. Given these two cross-correlations, it is of course not surprising to find a strong $(90 \%)$ cross-correlation between output growth and unemployment, which is also maximized at a 30 period lag.

\section{Conclusive remarks}

The scenario illustrates the endogenous emergence of long waves in output and productivity growth (as well as in unemployment rates). The spectral analyzes that pertain to these time series strongly suggest that each cycle of these long waves are triggered by the introduction of a new technological paradigm into the econony. Clearly, the arrival of each paradigm introduces significant opportunities for productivity increase. Yet, since the firm has no knowledge/experience on this new set of opportunities, during the periods that follow the introduction of the new paradigm, progress is rather slow. As experience/knowledge is gradually built up (as indicated by the cumulative number of innovations), the arrival rate of incremental innovations accelerates and the economy enters into a period of rapid progress in productivity. Nevertheless, this process does not proceed forever, since the progress opportunities offered by any given paradigm are limited. That is, although the pace of incremental innovations keeps on accelerating, the contribution of successive incremental inmovations on productivity converges to zero, and the rate of progress in productivity and output growth slows down.

The explanation above suggests that the emergence of long waves in growth is an emergent outcome of the interplay between the decreasing returns to paradigmspecific innovations and the principle of cumulativeness. The latter principle suggest paradigm-specific convexity in the innovation arrival processes whereas the former implies a paradigm-specific concave mapping of the latter, Such an interplay clearly brings about paradigm-specific learning curves which appear to 

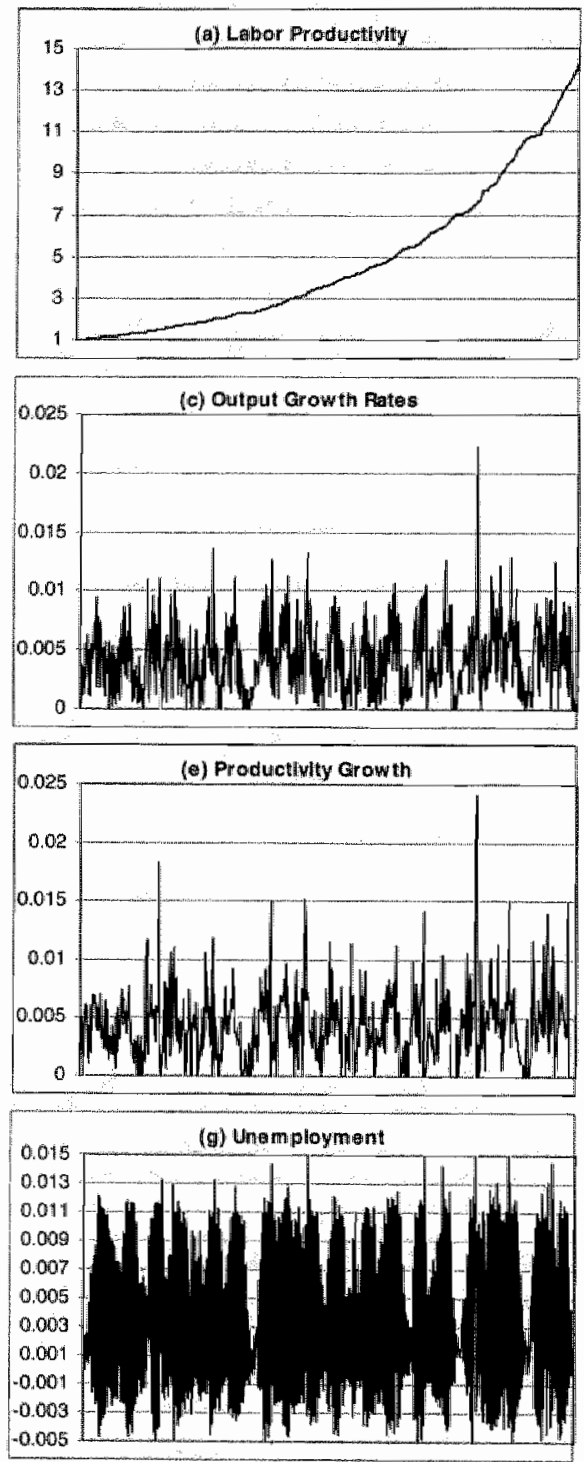
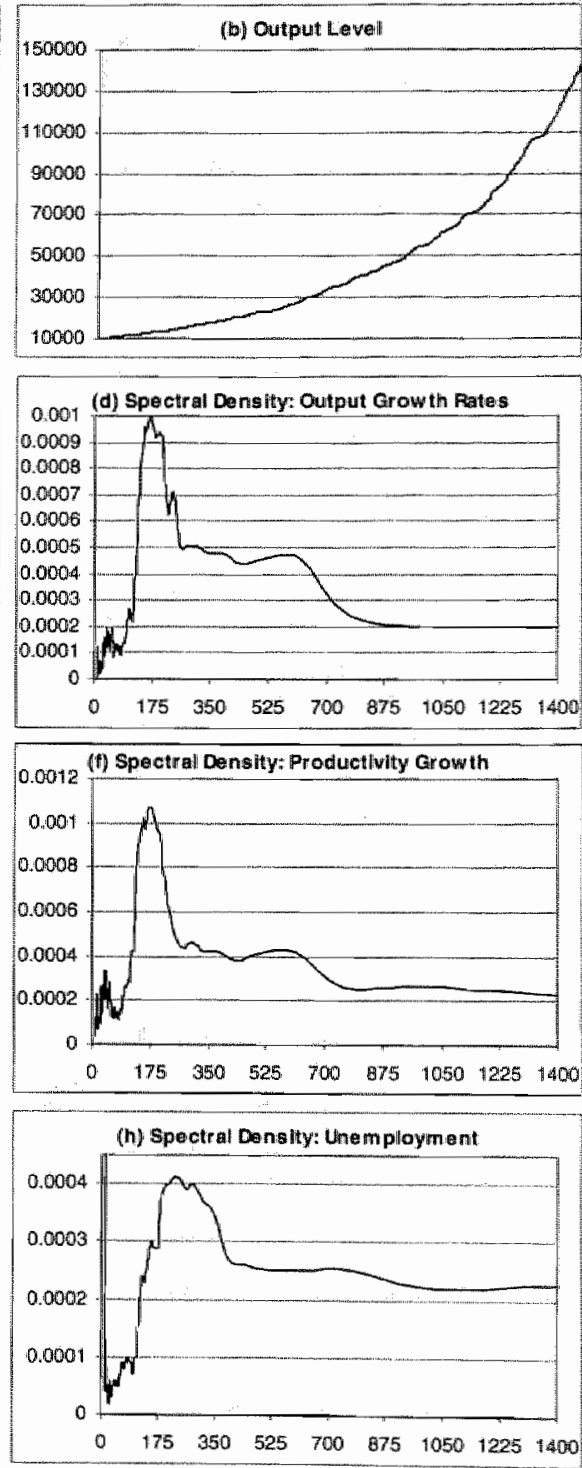

Figure 6.3. Productivity, Output Growth and Unemployment in Scenariola 

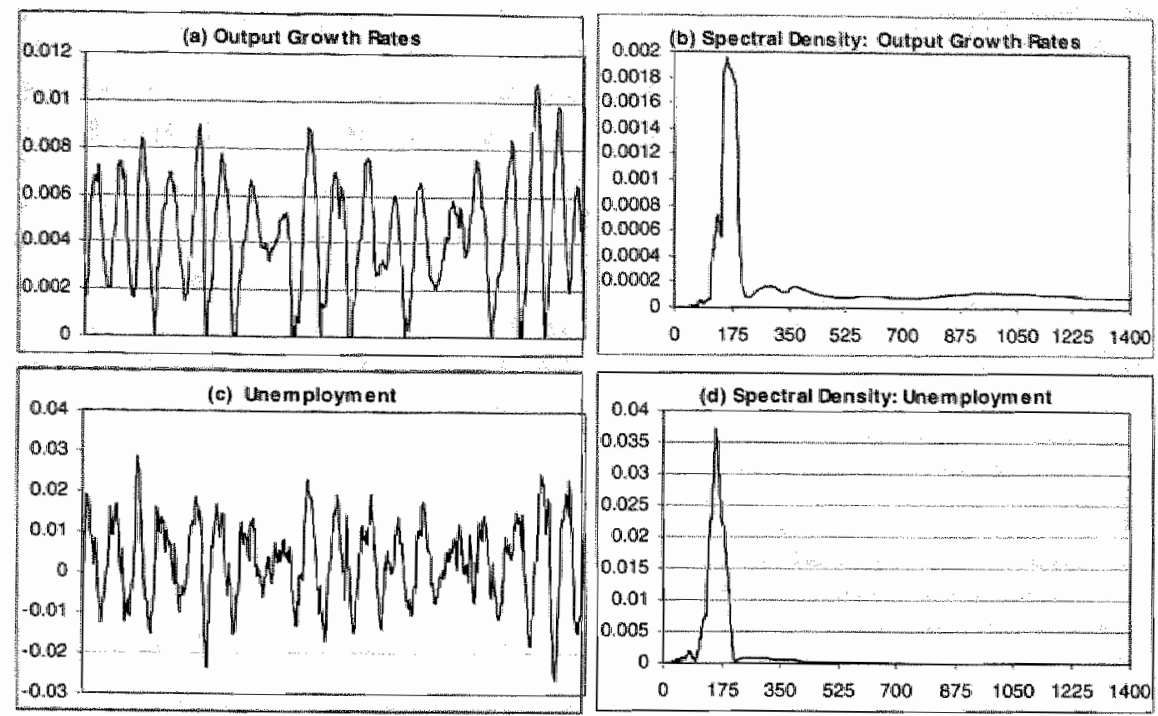

Figure 6.4. Output Growth and Unemployment Motion in Scenariolb

be S-shaped functions of time ${ }^{30}$, where the early stages of progress is dominated by the convexity implied by the principle of cumulativeness, while later stages are dominatied by the concavity implied by the eventually decreasing returns to innovations. Between the early and late stages, lies a time interval where the (cumulativeness related) accelerated pace of incremental innovation arrivals coincide with the highly exploitable region of the technological apportunity set introduced by the paradigm, and accordingly rapid progress in productivity and output is observed.

The emergence of S-shaped progress trajectories, are interesting in the sense that paradigm-specific progress is actually a process of learning and learning processes are generally associated with S-shaped (logistic) dynamics in the cognitive literature. Yet the more important point is that our scenario illustrates the emergence of long waves purely on the context of a sequence of emergent S-shaped patterns of learning; while the other models that aim to illustrate Schumpeterian business cycles rely on $\mathrm{S}$-shaped diffusion of a sequence of capital embodied technologies.

\subsubsection{Scenario\#2: Economic growth in multi-sectoral settings}

As one can easily conclude from the formulations presented in the last chapter, "general equilibrium" dependencies are not quite strong in our model. First, our technological change module is highly sector-specific. That is, our formulation does not feature technology or knowledge spill-overs among sectors. In this sense, each sector is an independent unit within which firms compete with others in terms of technological fitness levels. Second, onr capital definition is also sectorspecific. In other words, capital is not mobile between the sectors despite the fact that for each individual sector, the capital stock (i.e. productive capacity 
which is formulated as reproducible is determined through an endogenous acoumulation/decumulation process the extent of which is limited by the profts of the entire cconomy" . Third, except for cases where the "endogeneity of sectoral preferences" module (which introduces income elasticities that diverge from unity) is activated, consumer demand is characterized by constant budget shares for each sector due to the Cobb-Douglas component in our welfare function which faclitates the detemination of the relative price vector through the inverse demand function it implies. The only obvious element that links sectors is labor, which is assumed to be perfectly mobile between the sectors. The inevitable implication is that at each given period, all firms in all sectors pay their workers at the same nominal wage rate.

Given all these properties, one wonders about the motion of the employment shares of individual sectors in case of technological change. Our earlier reduced form derivations on convergence properties of our model (see equation 4.15 ) suggest that sectoral employment shares tend to be determined merely by the budget share allocations of the customers and the relative capital intensities, and are independent of the relative labor productivities. Thus, one may expect that as long as the relative capical intensities and the budget allocations over the sectors remain constant, the allocation of the labor force over the sectors is expected to be independent of the relative paces of technological change over the sectors. This situation can be expected to change in cases of "endogeneity of sectoral preferences" where the sectoral budget share allocation vector is formulated as a dynamic function of the sectoral consumption vector, and also in cases where technological change rates are not equal between the final good and the capital production sectors (which affect the relative capital intensities of sectoral production).

Endogeneity of sectoral preferences, which, in our formulation, implies nonunity of sectoral income elasticity of demand, which is revealed only over time as economies grow and customers get wealthier, is a highly interesting and important: causal relation originally suggested by Pasinetti[1981], which one can hardly see in the modeling literature except in few cases as Verspagen [1993] and Andersen [1997]. Formulated as in Verspagen [1993] and as in our model, since it shows its effect gradually through a process of economic growth, it does not have the grave consequences (in terms of Jeading to multiple equilibria) of the demand functions that are underlied by non-homothetic utility functions (and accordingly lead to non-unity of income elasticities) suggested by mainstream formulations.

On the basis of these considerations, a simulation $\mathrm{rm}$ will be performed that illustrates the potential of our model to be used as a tool for so-called history friendly modeling" (Malerba et. al [1999]). In this type of model, a specific historical process (in the existing literature until now, usually the development of a specific industry) is mimicked by modeling some of the salient features of the process, after which parameters are calibrated, and a simulation is undertaken to reproduce the historical process in a stylized way. In this way, the specific historical features that are responsible for the observed development can be outlined and analyzed in a counterfactual analysis.

The story that we have in mind is broadly what Kuznets has called 'modern economic growth" (e.g., Kuznets, [1971] $)^{32}$. For Kuznets, modern economic growth begins with industrialization, which leads to a sustained increase in the rate of growth of productivity. Associated with this are structural changes in the economy, both in terms the sectoral composition, and in terms of other phenomena, such as urbanization and increased interaction with other countries. Of this broad description, we chose to focus on generating a "history" in our model in which 
the sectoral composition drives the growth process. Thus, the first phenomenon we wish to generate is the rise of manufacturing and the associuted take off of productivity growth.

The rise of serwices is the next phase in our broad interpretation of modern economic growth. Here we draw inspiration from the work by Baumol [1967], and the model there that became known as Baumol's disease. Essentially, the argument is that high income elasticities for services induce a rise of this sector, but that due to a generally slow rate of technological progress in this sector, a macroeconomic productivity slowdown is the result.

\section{The simulation settings}

The basis settings of this simulation rum, which is the base run for the current experiment, is identical to those of the earlier simulations presented earlier in this chapter (i.e. as in table 6.1). Now we introduce three sectors, each occupied by a single profit-constrained output maximizing firm. Let us label these sectors conventionally as agriculture, manufacturing and services respectively. Demand is characterized by sectoral preferences that are endogenous on income. We set the saturation levels of consumption for agriculture and manufacturing respectively as SaturCons Agr $=5 \cdot 10^{4}$ and SaturConsmanuf $=1.8 \cdot 10^{6}$, together with the saturation slope parameters as $\alpha_{1}^{B a s e}=\alpha_{2}^{B a s e}=0.96$.

Technological change takes the form of learning by doing, which means, in a single-firm context, that the learning rate of each individual sector is proportional to its employment share. The learning by doing parameter settings are $\Omega_{A g r}^{L B D}=$ $1.5, \Omega_{M a n t u f}^{L B D}=3.0, \Omega_{\text {Serw }}^{L B D}=1.01$, together with InnEase Agr $=0.1$ InnEase Mant $f$ $=0.2$ and InnEase Serv $=0.075$. Obviously, we tune the parameters in such a way that manufacturing is a sector with high technological opportunities, while this is lower in agriculture (inspired by Kuznets) and even lower in services (the latter broadly in line with Baumol). Throughout the simulation, the labor force (population) is constant so that the trend in GDP is identical to that of GDP per capita.

\section{Results}

Since a welfare function does not give a cardinal but only an ordinal ordering of given consumption patterns, in settings where the endogeneity of sectoral preferences module is activated, the welfare function can not be used as a real GDP indicator since its parameters vary over. time. Instead, we adopt an indicator similar to the Laspeyres index, which is based on the period-wise comparison of nominal GDPs as calculated by the prices of the previous period. In other words, at every period $t$ we calculate the indexing-based growth rate of real GDP as

$$
\widehat{G D P_{I r d e x}^{t}}=\frac{\sum_{i=1}^{N G} P_{i}^{t-1} \cdot Q_{i}^{t}}{\sum_{i=1}^{N G} P_{i}^{t-1} \cdot Q_{i}^{t-1}}-1
$$

Based on this measure it is possible to generate a real GDP index that repllaces the welfare measure we have been using so far with

$$
G D P_{\text {Index }}^{i}=\prod_{\tau=1}^{t}\left(G \widehat{D P_{I n d e x}^{t}}+1\right)
$$

We run the model for 4500 periods. The time series for this real GDP index over the total simulation period is given in Figure 6.5, where the thick solid line 
represents the actual time series for the GDP index, and the dotted line an exponential trend through the complete time series. Compared to the exponential trend fitted to the entire time series, one observes three distinct phases, each of which are associated with the rise of a particular sector. The latter are presented in Figures 6.6, 6.7 and 6.8. Initially, we observe (exponential) growth, but only at: a relatively slow rate. In this period of pre-industrial growth, the economy is still dominated by agriculture (Figure 6.6).

As time goes by, due to technological change, productivity in agriculture steadily increases. In line with historical accounts, this productivity rise in agriculture is necessary for industrialization ultimately to take off, both because demand for agricultural products has not saturated yet, and because (labor) resources need to freed up to provide inputs in the manufacturing sector. Customer satisfaction increases with the growing agricultural output, but the budget share allocated to this sector gradually decreases because consumers increase their interest in the product of the manufacturing sectior. Although capacity in this sector is still low, the shift in demand leads to excessive profits and thus outpat and employment growih. Thus, when preferences for agricultural production saturate, manufacturing can starts its rise. This takes place at about half the simulation period (Figure 6.7). Aggregate growth rises above the overall trend around this time, clearly as a result of rapid technological progress in the rising manufacturing sector (industrialization).

Finally, see the rise of services sector (Figure 6.8), in combination with a clear saturation of demand for manufacturing products. At this time, the macroeconomic rate of productivity growth slows down, and the trajectory in Figure 6.5 becomes linear rather than exponential. Clearly, this transformation is reminiscent of the phenomenon known as the Banmol's Disease. The secular shift of employment from the first (say manufacturing) to the second (services), clearly implies a significant productivity slowdown in the economy. That is, if one formulates the average labor productivity in the economy as the labor share weighted average of sectoral labor productivities (i.e., as $a_{A V G}^{*}=\frac{\sum_{i=1}^{N G} a_{i}^{t} L_{i}^{t}}{\bar{L}}$ ), the according time series that can be generated from the time series outputted by the current scenario obviously exhibit a concave pattern of time where $\widehat{a_{A V G}^{t}} \rightarrow 0$ as $t \rightarrow \infty$. With the transition to a sector with high technological opportunities (agriculture to services), such a productivity slowdown did not take place.

\section{Concluding remarks}

The multi-sector exencise demonstrates that productivity growth in a sector does not necessarily translate fully into output growth in that sector, but by relleasing some part of the workers, it can bring about output growth in other sectors as well. As the experiments demonstrate, the temporal reallocation of the labor force among the sectors can not be explained by the relative pace of productivity increases over the sectors, but given these differences, by temporal changes in sectoral capital intensities, and/or" non-unity income elasticities. "Temporal changes in sectoral capital intensities are not necessarily an outcome of capital-labor substitution but can be explained by the productivity growth differentials between the final and the capital sectors. As such, they give rise to the typical dynamics that have been analyzed in the literature on structural change (e.g., Pasinetti [1981]), and which have been argued to be an important aspect of modern economic growth. Indeed, the historically observed growth patterns seem to be reproducible in a 'history friendly' application of our model. 


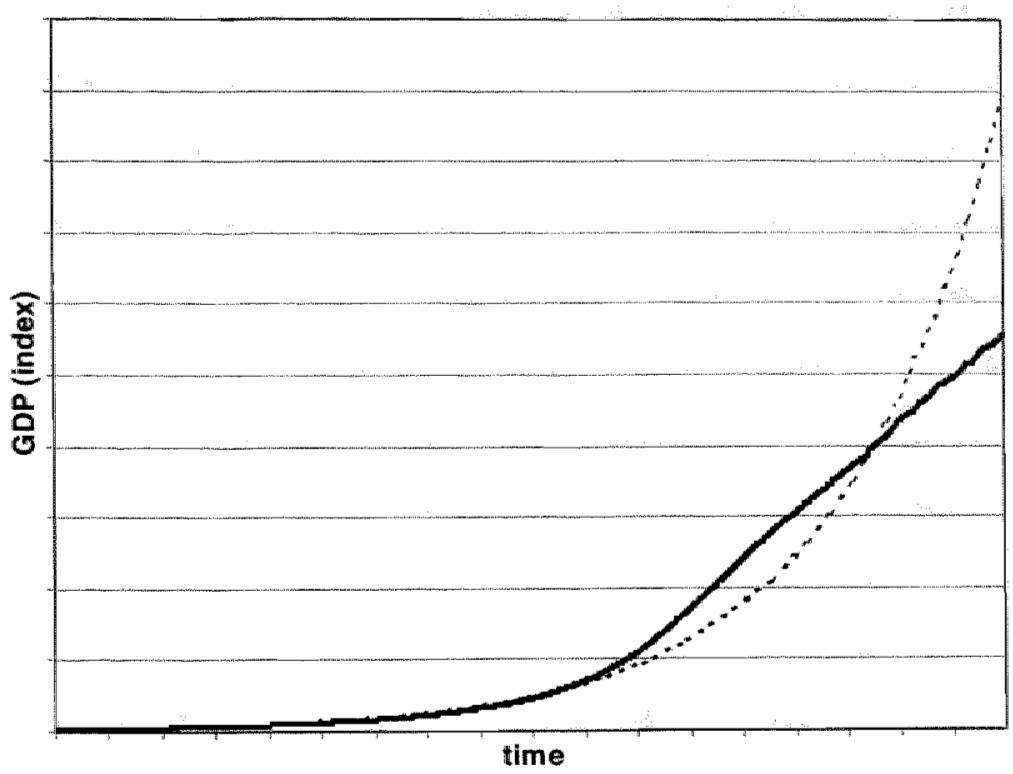

Figure 6.5. Growth of GDP Index

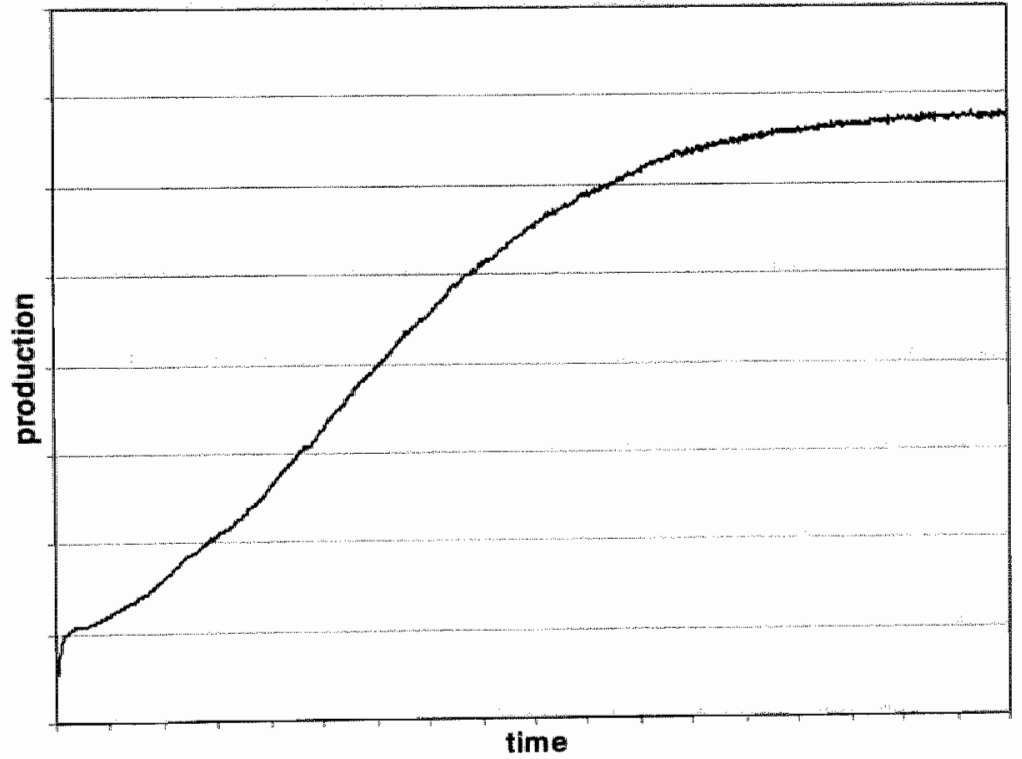

Figure 6.6. Growth path of production in agriculture 


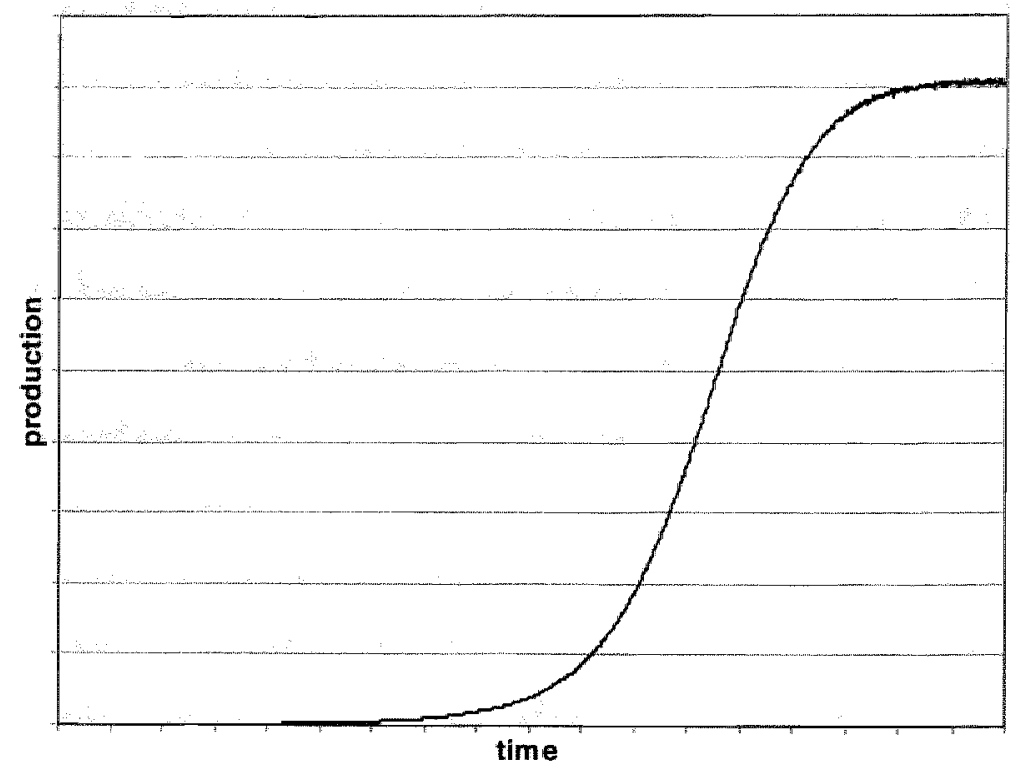

Figure 6.7. Growth path of praduction in manufacturing

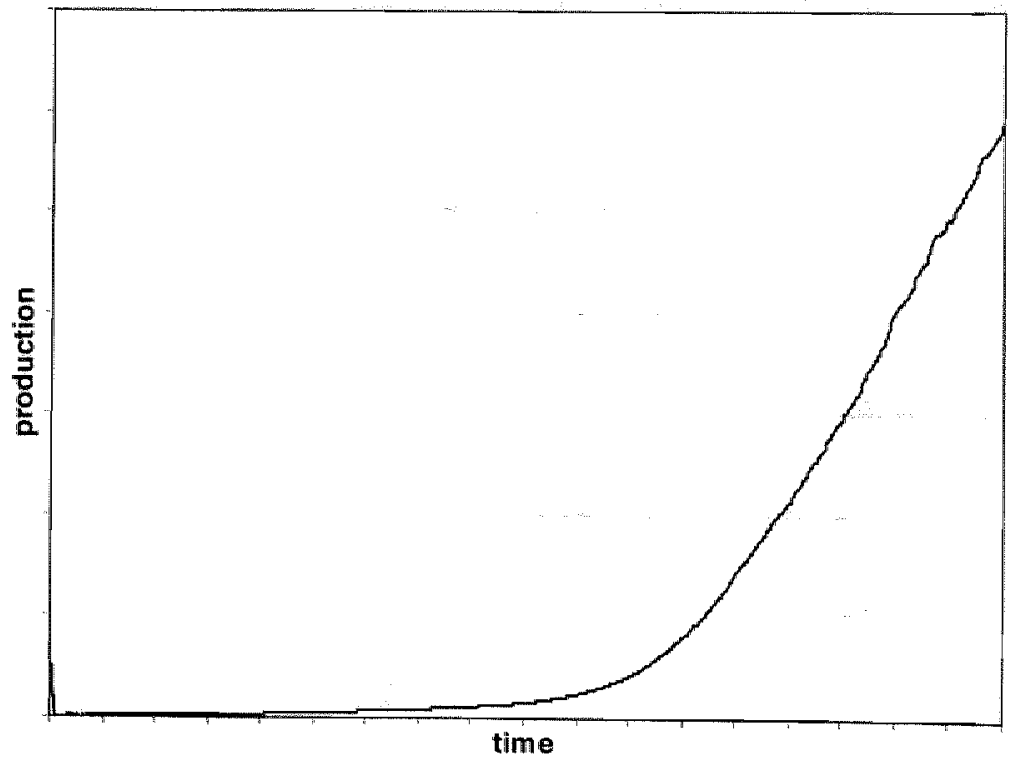

Figure 6.8. Growth path of production in services 


\subsubsection{Concluding remarks on economic growth in the model}

The analytical derivations and the following simulation experiments in this chapter show that the model is able to generate a rich variety of growth patterns, that both correspond to a number of growth theories (models) found in the literatine, and to historical patterns obserwed in time. The analytical deriwations show that the model encompasses explanations for steady state growth patterns that are similar to the neoclassical Solow model, or to more recent steady state models of endogenous growth, as for example in Romer [1986] and Lucas [1988].

The experiments that were carried out were aimed at issues removed far from steady state dynamics, and hence fit better in the evolutionary tradition of analyzing economic dynamics. Here we looked first at the relationship between employment and technological change. The simulation experiment on this issue concluded that comparative statics may provide a misleading picture of the employment effect of innovation. While the basic mechanisms in the normal comparative statics analyzes are also present in out model, the dynamic growth context make them less relevant, and adjustment mechanisms predicted in the standard models of technology and employment may not realize in historical time. Hence, technological change has a persistent negative (albeit small in absolute terms) effect on employment.

The second experiment has shown that with capital embodied technological progress, the issue of sustainable growth arises even in the context of evollutionary theory. Whether or not long-run growth is sustainable is a prime issue in the transition from neoclassical models of exogenous growth (Solow) to the more recent: endogenous growth models. The issue has not arisen to the same extent in the evolutionary growth literature, but our results show that capital embordinent (indeed often simply overlooked in evolutionary models) may lead to unsustainable growth in the long run. In line with the new growth theory, a "solution' that may restore sustainability lies in external effects.

The final experiment was set in the tradition of history friendly modeling, i.e., the model was calibrated to reproduce a particular pattern that has been observed in history. In this case, we looked at the transition of agriculture to manufacturing ('industrialization'), and the rise of the services sector ("post-industrialization'). The model was tuned in such a way that the first of these transitions generated a marked increase in the growth rate of the economy (Kuznets's idea of modern economic growth), while the second transition generated a productivity slowdown (associated to Baumol"s disease). Differences in technological opportunities, in combination with endogenous preferences developing under the influence of real income growth, were seen as the key ingredients in this history friendly mode of the model.

\subsection{Technological change and international trade}

In chapter 4 , in the context of fixed technological coefficients, we have concluded that in absence of capital cost or quality related international differences, the selection mechanism brings about specialization purely in lines of the Ricardian model. In cases where relative capital cost (intensity) and/or quality differences are also brought into the picture, specialization can still take place, yet the comparative advantage structures that decide on the specialization pattern are jointly deter 
mined by the distribution of labor productivities, capital intensities and quality levels over the countries and the sectors.

Yet, these earlier discussions rely on fixed technologicall coefficients. Given that in our formulation technological change basically brings about changes in these coefficients stochastically, in settings with technological change one can expect temporal changes in comparative advantages and the implied specialization patterns. The reader can find in the accompanying $C D$ a number of sirnulation runs with simple settings based on exogenous technological change and also discussions on these experiments in an appendix to this chapter ${ }^{33}$. These simple experiments basically address the potential effects of pure chance in international trade and specialization in two-country, two-sector settings where both sectors of both countries are parameterized identically in every possible way including the exogenous technological opportunities and initial conditions.

Under such circumstances, according to expected value estimations, the identical nature of technological opportunities and the absence of any scale economies and/or any dynamic externalities, would normally imply identical (exponential) productivity growth paths and accordingly no comparative advantages and specialization. However, the simulations illustrate the emergence of comparative advantages and accordingly specialization, which are brought about by the stochastic nature of technological change.

Although stochasticity introduces random labor productivity differentials that translate into comparative advantages and specialization, it is also capable of clearing away these differences and introducing new ones in the direction opposite to the previous ones. As discussed in chapter 4 , in cases of no capital intensity and/or quality related additional differences, in a two-country two-sector setting: the direction of comparative advantages is determined by whether the expression $\frac{a_{1 F} / a_{2 H}}{a_{1 F} / a_{2} F}$ (which indicates the existence and direction of productivity-based comparative advantage) is greater or less than 1.0 , or alternatively in a dynamic form whether $\left[\left(\widehat{a_{1 H}}-\widehat{a_{2 H}}\right)-\left(\widehat{a_{1 F}}-\widehat{a_{2 F}}\right)\right] \lessgtr 0$. Thus, even the divergence of the growth of any of these four labor productivity levels from proportionality (i.e., from $\widehat{a_{1 H}}=\widehat{a_{2 H}}=\widehat{a_{1 F}}=\widehat{a_{2 F}}$ ) by chance is sufficient to generate, eliminate, or reverse comparative advantage structures over time. One also observes that the extent of specialization is affected by the extent of techmological opportunities. That is, in settings with lower values for the parameter mIncrmnt, one still observes rather persistent yet occasionally reversed patterns of specialization, while specialization patterns remain mostly partial since the lower value of the parameter: mIncrmmt implies a lower productivity increase per innovation and the temporal irregularities in innovation arrivals (i.e., the historical accidents due to the Poisson process) imply productivity differentials of lower magnitudes.

Nevertheless, despite the existence of a number of dramatic reversals in specialization patterns, independently of the extent of technological opportunities, one observes that economies tend to remain specialized in one or the other sector persistently for rather prolonged durations. In other words, specialization patterns do not exhibit high frequency oscillations as one would expect from a purely stochastic technological process with no externalities that would lead to persistence, but instead a pattern which seem like irregular long waves. These specialization patterns which are not permanent yet somewhat persistent, emerge from the realization of a purely unbiased stochastic process by pure chance. Namely, they are not the outcome of any self-reinforcing process (such as some dynamic externality), are yet. somewhat characterized by a weak form of hysteresis. Although international productivity differentials brought about by stochasticity lead to rapid specialization, 
the (partial) elimmation of these differences (by the arrival of new imnovations which can close the gap) does not take the economy back to less or no specialization. The elimination or rewersal of any established specialization pattern only takes place in case of the complete reversal of the existing comparative advantage structure.

Although chance may be a determinant of international trade and specialization, the models that one finds in the theoretical literature are usually focused on more systematic explanations either in terms of given (innate) differences in sectoral and national characteristics (as in the Ricardian and/or Heckschen - Ohlin - Sammelson models) or of various extemalities characterized by dynamic/static scale economies (as in models of new trade by Krugman and/or Grossman and Helpman). Especially, the models of the latter type go beyond issues of allocative efficiency and focus on the dynamic potentials of international trade and specialization in boosting economic growth on the basis of various sources of dymamic externalities pertinent to techmological change.

In chapter 4 , we have already discussed the similarities and differences between our model and static mainstream models of the former type mentioned just above, in the context of fixed technological coefficients. However, the range of models that aim to illustrate specialization and gains from trade on the pure basis of welldefined cross-country/cross-sector differences are not confined to static equilibrium formulations as in the native form of the Ricardian and/or Heckscher - Ohlin Samuelson models, but also include dynamic approaches (such as in Grossman and Helpman [1991b]), which belong to the domain of the "new trarle" literature. In the rest of this chapter we will present a control experiment, which is similar to these dynamic approaches in various semses.

\subsubsection{Experiment \#3: Cross-country/sector asymmetries-based specialization with technological change}

As mentioned above, the models that one can classify as the "variants of the Heckscher - Ohlin - Samuelson model" have one important element in common: countries are differentiated in some property and the sectors are differentiated in some other. For example, in the original $2 \times 2$ version of the Heckscher Ohlin - Samuelson model, countries are differentiated according to their capital endowments, while sectors are differentiated according to the capital intensity in their production.

Our experiment here is aimed at investigating the consequences of technological change and international trade for the international distribution of welfare, in the context of such differentiation schemes as the one above. Thus, we will have a two-country" two-sector experiment, where each sector in each country is operated by a single profit-constrained ontput maximizer firm. The basic settings that characterize either of the trading economies are similar to those given by table 6.1. except for some minor divergences explained below. The basic questions that the experiment will ask are, first, how specialization emerges as a result of the differentiation between sectors and countries, and, second, what specialization implies for welfare (i.e., compare welfare under trade and antarky).

The actual settings common to our control runs given by table 6.4 for both. countries $j=1,2$. Clearly the only two differences from the settings given by table 6.1 is the sizes of the labor force $\left(\overline{L_{j}}\right)$ which conventionally are doubled due to existence of two sectors, and parameter Curvo the value of which controls 


\begin{tabular}{|c|c|c|}
\hline & $\overline{L_{j}}$ & $=20000$ \\
\hline Labor & MaxOverTime, & $=1.07$ \\
\hline Related & $\begin{array}{l}\text { MaxLShri } \\
\text { Curvi }\end{array}$ & $\begin{array}{l}=1.0054 \\
=10\end{array}$ \\
\hline & $r_{j}^{M i n A C C p L}$ & $=5 \%$ \\
\hline Related & DeprRt & $=1 \%$ \\
\hline
\end{tabular}

Table 6.4. The structural parameters that characterize Experiment 4

the wage elasticity of labor supply which is increased in this experiment to avoid unemployment due to changes in capital intensities (which is apt to happen in the current setting). Also note that, in order to eliminate the high frequency oscillations that are observed in cases where Curv $v_{j}^{0}$ is high, we also turn on the short-term wage rate stickiness module, which, as described in chapter 5 , smooths the wage rate dynamics by a short term moving averaging process.

For all the simulations we assume exogenous techmological change that follows exponential progress trajectories characterized by the common parameter settings $\tau_{i j}=1.431$, and $m I n c r m n t_{i j}=0.05$ for both sectors $i$ of both countries $j$. We assume that the consumers of both countries divide their income equally over the two sectors (i.e. $\alpha_{i j}=0.5$ for both countries $j$ and both sectors $i$.)

Based on these common structural settings we have designed our control runs on the basis of the following dimensions that differentiate the sectors and the countries:

\section{Dimensions of differentiation over the countries}

a) The innovative abilities of the countries in final good sectors: As discussed in chapter 5 , by the parameter vector in $A$ bil $l_{i j}$ one can introduce countries and/or sectors according to their relative abilities in innovativeness. In the current experiment wre only differentiate countries such that $\left(i n A b i l_{11}=i n A b i l_{21}\right) \neq\left(i n A b i l_{12}=i n A b i l_{22}\right)$. Clearly, with no differentiation over the sectors, but only over the countries, this parameter can also be interpreted as a proxy for the countries" relative "human capital stock".

b) The innovative abilities of the countries in capital good sectors relative to that in final good production: As discussed before, the variable CaptlProd Follow Rate $i j$ determines for country $j$, the pace of prom ductivity growth in sector $i$ specific capital good production as relative to that in sector $i$ final good production. By settings which conform to (CaptlProdFollow Rate $11=$ CaptlProdFallowRaten $) \neq$ (CaptlProdF ollow Rate ${ }_{2}=$ CaptlProdFollow Rate.22), one can also differentiate countries with respect to their dynamic ability (i.e., innovativeness) in decreasing capital costs.

\section{Dilmensions of differentiation over the sectors}

a) Relative capital intensities in production: By settings of the initial capital intensity parameter vector $b_{i, j}^{0}$ according to $\left(b_{11}^{0}=b_{12}^{0}\right) \neq\left(b_{21}^{0}\right.$ $=b_{22}^{0}$ ), one can differentiate the two sectors according to their relative capital intensity. Note that in settings where CaptlProdFallow Rate 1 capitall intensity (i.e., $b_{i j}^{t}$ ) remain at the level set by $b_{i j}^{0}$. Otherwise, the motion of the capital intensity $b_{i j}^{t}$ is determined endogenonsly as 
relative to the pace of labor productivity progrese in the final sector of country $j$.

b) Technological opportunties : By settings of the imnovation arrival rate parameter vector InnEase according to (InnEasen = InnEasen) $\neq\left(\operatorname{Inn} E\right.$ ase $_{21}=$ InnEase 22$)$, one can differentiate sectors as high-tech and low-tech.

On the basis of these dimensions we have designed 4 simulation runs, which are labelled as CapInt_Aut, CapInt_Trd, TechDiff_Aut and TechDiff_Trd, according to the following parameter combinations:

- CapInt_Aut and CapInt_Trd: The frrst basis setting focuses on the emergence of capital intensity differentials, by the combination of the differentiation dimensions $1 \mathrm{a}, \mathbf{1 b}$, and $2 \mathrm{a}$, mentioned above. Under the assumption of equal notional technological opportunities across the sectors and the countries (i.e., InnEase $11=I n n E_{12 e_{12}}=I n n E_{a s e} 1=I n n E_{a s e} 2=0.1$ ), the countries are clifferentiated with respect to their innovative abilities such that the second country is unable to make any innovations at all (in $A b i_{i 1}$ $=1$ while in $A b i l_{i 2}=0$ in both sectors i). Yet we introduce perfect and instantaneous international imitation possibilities in the final good sectors ${ }^{34}$, which eliminate the technological disadvantages of the second country by making it a free-rider of technological change. This assumption is reminiscent of the Heckscher - Ohlin - Samuelson model which rulles out international differences in access to alternative technologies. However, by the settings CaptlProdFallow Rate . $_{1}=1$ and CaptlProdFollow Rate ${ }_{22}=0.25$ for both sectors $\dot{z}=1,2$, we arrange that the productivity growth in capital production which can be achieved by the second country is one fourth of the rate it can achieve in the final good sectors (as explained just below by only imitations). Due to this cross-country difference, the perfection of innovation opportumities remains confined to the final good sectors. In other words, for the second country, the international imitation possibilities in the capital sectors significantly lag behind those in the final sectors. The sectors are differentiated in their initial capitial intensities such that the first sector is initially the one where production is relatively more capital intensive (i.e., $b_{1}^{0}=4, b_{2}^{0}=2$ ). In arder to be able to make welfare comparisons, this setting is run twice; one for the case of autarky (i.e., run CapInt_A_Aut) and one for the case of international trade (i.e., run CapInt_A_Trd).

- TechDiff_Aut and TechDiff_Trd: The second basis setting focuses on sectoral differences in technological opportunities together with cross-country differences in innovativeness (or in human capital stock) as defined by the dimensions 1a and $2 b$ mentioned above. After ruling out the capital intensity related sources of differentiation by the settings $b_{1}^{0}=b_{2}^{0}=3$ and CaptiProdFollow Rate $i 1=$ CaptlProdFollow Rate ${ }_{i 2}=1$ for both sectors $i$ and also eliminating any imitation possibilities between the countries, we introduce our alternative differentiation scheme by the settings InnEase I $_{j}=$ 0.1, InnEase In $_{j}=0.02$ for both countries $j$, which impose that the notional technological (i.e., productivity progress) opportunities are relatively higher in the first sector, and inAbil $l_{1}=1$ together with inAbiliz $=0.5$ for both sectors $i$, which imply that the ability to exploit the notional technological opportunities (i.e., innovative ability) is relatively higher in the first country. In a different interpretation, the human capital stock of first country is twice as large (or productive) as that of the second country. In order to be 
able to make welfare comparisons, this setting is run twice; one for the case of autarky (run TechDiff_Aut) and one for the case of international trade (run TechDiff Trd).

In order to be able to make a clear welfare comparison between trade and autarky, in all 4 runs we turn off stochasticity in innovations for convenience in terms of sharpness in presentation.

\section{Results}

\section{Runs CapInt_Aut and CapInt_Trd:}

Given the absence of any labor productivity differentials across the countries, due to the instant and perfect international imitation opportunities in the final good sectors, initially, there exists no reason/incentives for specialization. However, as technological progress goes on, the lagging of capital sector productivity in the second country behind that in the first country starts to show its effect: Dwe to the consequently emergent cross-country differentiation in unit capital costs, the second (first) country rapidly specializes in sector two (one) where capital intensity in production is initially lower (higher). From the perspective of the second country, despite the temporal increase in capital intensity in both sectors, the second sector remains relatively less capital intensive during the rest of the simulation and accordingly the second country remains perfectly specialized in the second sector. For the first country where capital intensities in both sectors remain unchanged, the high capital costs reffected in the prices of the products of the second country, imply that the prices of both importable goods are mode expensive than own products. Nevertheless, despite this apparent case of absolute advantages in both sectors, due to comparative advantages, international trade and specialization take place , though, unlike for the second country specialization is only partial for the first country.

Due to the temporal increase of capital intensity in the second country, the share of capital costs in the price of country 2 products also increases over time. At the terminal period of the simulation (i.e., $t=1000$ ), the share of capital costs in the prices of sector 2 products that are produced and exported by the second

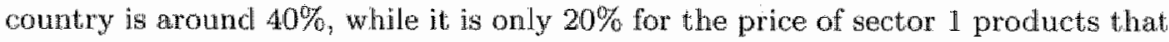
are produced and exported by the first country. In other words, if one applies the Leontief test ${ }^{35}$ on data of the terminal period of the simulation output, one observes that on the basis of the composition of added value in current prices, the capital content in country 2 exports is almost double of that in country 1 exports. Furthermore, due to the increased capital intensity in production, one calculates (on the basis of exchange rate corrected prices) that the totall value of the capital stock of the second country turns out $65 \%$ higher than that of the first country. These two last anguments together imply that on the basis of a test similar to that made by Leontief [1953], our simulation output verifies the Heckscher - Ohlin theorem on specialization: Each country exports the good, the production of which is relatively more intensive in the factor owned by the country in rellative abundance.

However, the explanatory mechanism which underlies this case, has apparently nothing to do with an endowments-based causal link. The reason why the second country seems to have more capital (as measured in exchange rate corrected values), is simply the relative disability of the second country in increasing productivity in capital production, which, given the rapid productivity progress in the final good sectors, increases the relative prices of the capital goods. In other words, 
a higher capital stock value by no means implies the usage of more capital (per labor) in production but only the usage of more expensively (or less efficiently) produced capital goods in final good production. Shortly, the key point of this experiment is the fact that unlike in the Heckscher-Ohlin-Samuelson model, an energent specialization pattern is not explained by given capital endowment differentials, but by relative innovation-related cross-country productivity differentials in capital production, which, as in the current scenario, can not be eliminated due to the international imitation lags in the capital sectors.

The comparison of the alternative runs CapInt_Trd and CapInt_Aut shows that the major difference brought about by international trade tums out to be the income distribution, especially in the second country. Due to the lagging of capital productivity behind final good labor productivity and the resulting secular increase in capital intensity in production, the income distribution in the second country steadily moves against the interests of the workers, with or without international trade. In case of trade, since the production of the intrinsically more capitalintensive good is taken over by the first country, the workers of the second country suffer less from the effects of this temporal positive trend in economy-wride capital intensity.

Comparison of the welfare time series generated by our two alternative rums CapInt_Trd and CapInt_Aut shows that in terms of growth rates, international trade does not introduce any extra benefits. In both runs the growth rate enjoyed by the second country is slightly lower than that by the first country, despite the perfect and instantaneous imitation possibilities in the final good sectors. The lagging behind of the second country in growth is clearly an outcome of the upward trend in capital intensities in this country (i.e., $\widehat{b}>0$ ), which implies a leakage from the potential growth, as predicted by equation 6.3 and/or 6.4 .

Despite the absence of any growth boosting effect, international trade still brings about a positive level effect in consumers' welfare. In case of autarky, despite the rather inelastic setting of the labor supply (i.e. $C u r v_{j}^{0}=10$ ), the large shift of income distribution against the benefit of the workers still cause some unemployment in the second country. As discussed above, international trade decreases the extent of this temporal shift and thus the extent of unemployment, which keeps the output level somewhat higher at all times.

\section{Runs TechDiff_Aut and TechDiff_Trd:}

These control runs are reminiscent of the model given in the $7^{\text {th }}$ chapter of Grossman and Helpman [1991b], where one of the sectors is assumed to be more high-tech than the other, and one of the countries is assumed to be endowed with relatively more human capital than the other. "The outcome of the simulation is also similar to the model in Grossman and Helpman [1991b] in terms of its specialization prediction: The country with higher (lower) innovative abilities specializes in the sector where productivity progress opporturities are higher (lower'). However, the underlying mechanism that leads to this result is different than in Grossman and Helpman [1991b]. The latter is essentially based on the causal principles of the Heckscher-Ohlin-Samuelson model. In our case, the mechanism is completely Ricardian. As may be calculated from the expected value equations 5.5 and 5.9 , the expected value of labor productivity in sector 2 of coun-

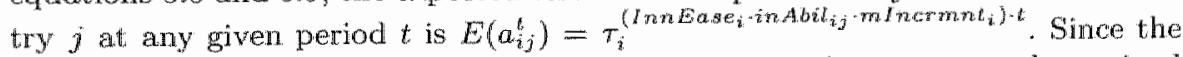
direction of the labor productivity based comparative advantages are determined by whether the ratio $\frac{E\left(\omega_{13}^{t}\right) / E\left(a_{21}^{t}\right)}{E\left(a_{12}^{t}\right) / E\left(a_{22}^{t}\right)}$ is less or greater than 1.0 , it can be easily shown analytically that this ratio is equal to $\tau^{d \cdot m / n c r m n t_{i} \cdot t}$ where $d=[$ InnEase

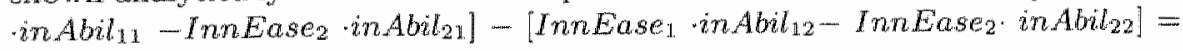


0.055 for the settings of the current experiment. Since $d>0$, also due to our current settings; $\tau_{1}=\tau_{2}=1.431$ and mIncrmnt $1=$ mincrmnt $t_{2}=0.05$, one can easily calculate that $\frac{E\left(a_{11}^{t}\right) / E\left(a_{21}^{t}\right)}{E\left(a_{12}^{t}\right) / E\left(a_{23}^{t}\right)}=\tau^{d \cdot m I n c r m n t_{i} t}$ is greater than 1.0 at all periods $t>0$ and furthermore is increasing in $t$, which (due to the law of comparative advantages) implies that the first (second) country should specialize in the first (second) sector, as actually observed in our simulation run. Furthermore, since the first country keeps on building absolute advantages in both sectors (the extent of which increases over time due to the cross-country differences in innovative rates in both sectors), one expects that the first country specializes only partially, while the second country completely specializes in the second sector.

As discussed in chapter 4 , in case of the absolute advantages of one country in both sectors, the technologically superior country (which specializes partially to avoid the worsening of its terms-of trade) gains nothing from international trade while the inferion country reaps all the gains. This basic result on comparative (between trade and autarky) "levels" of welfare, which is discussed earlier for cases of fixed technological change, remains also valid in the context of "growth rates" in case of the current dynamic setting with technological change: Intermational trade does not have any positive contribution to the growth rate of the country which is superior in the technology race in both sectors, while the less innowative country reaps all the dynamic gains from trade in terms of higher growth rates in consumption and accordingly in welfare. In other words, for a country trading with another that is inferior in innovativeness in all sectors, engaging in international trade is no more than an act of charity. Of course, this conclusion does not necessarily apply to cases where demand for product variety is high (i.e, different products within sectors are perceived to be heterogenous by the consumers) and/or where technological change has some endogenous component that has the potential to introduce some sort of dynamic increasing returns (i.e., such as learning by doing) into productivity progress.

\section{Concluding remarks and outlook}

This experiment shows that our model is capable of dynamically generating the same specialization and international trade patterns as suggested in a number of (mainstream) models in the literature. Differentiation of sectors and/or countries on a number of key parameters may induce the dynamic generation of comparative advantages, and this leads to international specialization. In general, we find the same welfare enhancing effects of trade as are found in the traditional literature, although the underlying causal mechanisms in our model are generally different. While this result in itself is not surprising or very original, it does provide a good starting point for the more elaborate analysis of international trade under conditions of micro heterogeneity and complexity, as they are carried out in the next chapter. Now that it has been established that the model, in its simplest core, is compatible with the basic mechanisms of trade and specialization as found in the literature, it is clear that we have a sound basis to evaluate the various effects of the heterogeneity that is crucial in an evolutionary view of the economic world. 


\section{Notes}

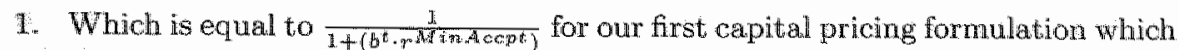
assumes no profits in capital prices. For our second altemative (i.e. profitability in capital sector is equal to that in final sector) $L a b r S h r=1-\left(b^{b} \cdot r^{\text {Min } A c o p t}\right)$, and for our third alternative (i.e. for explicitly specified capital intensity coefficients

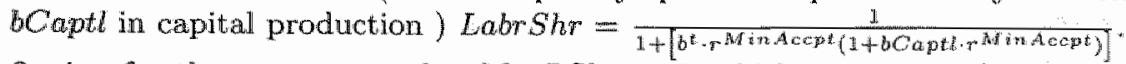

2. i.e. for the parameter value $M i n L S h r_{j}=0$, which guarantees that wage rate is an increasing function of the employment rate and makes $W g S u p\left(\operatorname{Empl} R t^{t}\right)$ $=\operatorname{Max} L S h r \cdot\left(\frac{E m p l R t^{t}}{\text { MaxOwerTime }}\right)^{C u r v^{0}}$, for employment levels where Empl Rt $\leq$ MaxOverTime.

3. For our first, second and third alternative capital pricing formulations the

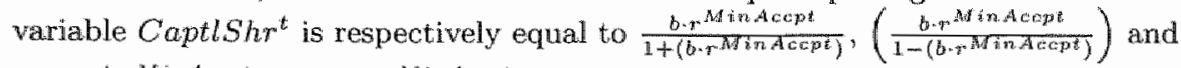

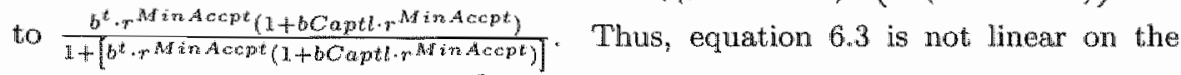
growth rate of capital intensity $\widehat{b}$.

4. A variety of such discussions can be found in the literature. For example, refer to Freeman and Soete [1994].

5. Based on equation 6.3 and that $\widehat{\text { LabrSh }} r^{*}=C u r v^{0} \cdot \widehat{\text { EmplRt }}{ }^{t}$ (which can be derived from the derivative of the function $\operatorname{Labr} S h r^{\circ}=W_{g S u p}(\operatorname{EmplRt})$ ), the temporal rate of change of the of workers' consumption level can be calculated as

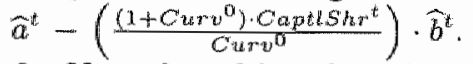

6. Note that although capital production also requires capital, to avoid technical complications we assume that capital sector is not subject to capacity constraints).

7. With this formulation capital-labor ratio of the economy can be calculated as $\frac{K}{L}=\frac{b}{1-b \cdot m^{M} \text { in } A c c p t}$.

8. At the equilibrium where output level ceases to change, total revenues are equal to the sum of the total wage bill and total capital costs. That is $P=$

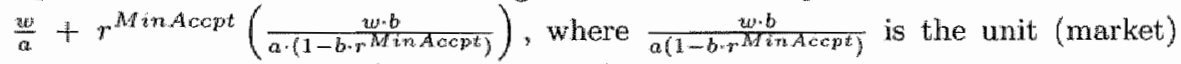
price of a unit of capital (output capacity) defined by the variable P_Captl before. Accordingly one can calculate the incremental capital-output ratio of the economy as $\frac{P-C a p h i l}{P^{p}}=b$.

9. Recall that we have three alternative methods for the determination of capital good prices. For the method which assumes fixed capital-labor ratios (no profics in capital production) the relation would be $1=\frac{A}{a}(b)^{b \cdot m^{M} \cdot r_{1} \text { Acept }}$. Alternatively, for the method which assumes given capital intensities in the capital sector it would look like as $1=\frac{A}{a} \cdot\left[b \cdot\left(1+B C a p t l \cdot r^{\text {Min Accpt }}\right)\right]^{\text {b. Min. Acept }}$.

In a multi-sectoral setting, the production function in a given sector $i$ can similarly

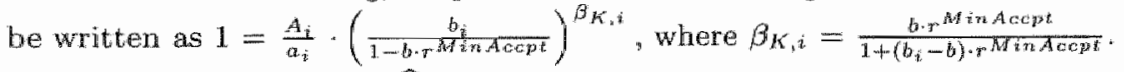

10. i.e. In our formulation, $\widehat{b}>0$ implies that the economy uses more sophisticated and expensive machinery/equipment in production. On the contrary, $\widehat{b}=0$ implies that the labor productivity in capital production follows that in the final good sectors, so that the unit (market) price of capital goods always remains a fixed multiple (b) of the unit price of the final good.

11. Note that in cases characterized by many sectors and many firms the expected value estimation given by equation 6.19 , appears as $\widehat{a_{k i j}^{t}}=\left(\right.$ Incrmnt $_{i} \cdot$ InnEase $_{i}$ - inAbilkij) $\Omega_{i, B a s e}^{L E D} \cdot L a b S h r_{k, j}^{t}$, where $L a b S h r_{k i j}^{*}$ is the employment sliare of 
firm $_{k i j}$ in the economy.

12. The capital intensity of (i.e. capital output ratio for) vintage \#1 is set to $b^{1}$. $=3$. Thus, the capital intensity of the second vintage is $b^{2}=1.225 \cdot b^{11}=3.675$, of the third viritage is $b^{3}=(1.225)^{2} \cdot b^{1}=4.5$ and so on to $b^{7}=3.375 \cdot b^{1}=10.135$ and finally $b^{10}=6.2 \cdot b^{1}=18.6$.

13. Note that labor supply is perfectly inelastic only if $C u r v^{\circ}=\infty$. However the setting $C$ ur $\psi^{\circ}=5$ prowes to be sufficient to represent quite an inelastic labor supply.

14. Which offers the labor productivity $a_{7}^{\max }=3.375$ with capital intensity $b^{7}=$ 10.125.

15. At the initial period where econony-wide capital intensity (which is equal to that of the first vintage) is $b^{1}=3$. As vintages with higher capital intensity diffuse in, the economy-wide capital intensity increases as well and at the final steady state (reign of paradigm \#7 alone) it reaches to $b^{7}=10.125$.

16. In the current scenario, the capitalists" share in income starts with $b^{1} \cdot r^{M i n}$ Acept $=3 \cdot 0.05=15 \%$ and ends up with $b^{7} \cdot r^{M i n A c c p t}=10.125 \cdot 0.05=50.625 \%$.

17. i.e. The distribution which characterizes the equilibrium condition for the first and least capital intensive vintage: $1-\left(b^{\mathbb{1}} \cdot r^{\text {MinAccpt }}\right)=1-(3 \cdot 0.05)=0.85$ as the share of wage bill in income and $b^{\mathbb{1}} \cdot r^{\text {Min Accpt }}=0.15$ as the share of capital.

18. See equation 5.29 .

19. Since each new vintage introduces over its predecessor $22.5 \%$ increase both in labor productivity and capitall intensity, the paradigm specific settings of the experiments imply $\widehat{a}(n \backslash s)=\widehat{b}(n \backslash s)=1.225^{n-s}$ for all vintages $s$ and $n$.

20. Namely, since $w^{t}=\frac{G D P^{t} \cdot W g S u g^{t}(\cdot)}{L^{t}}$ in our model, given that GDP $P^{t}=P^{t} \cdot Q^{t}$ $=P^{t} \cdot L^{t} \cdot a_{A v g}^{t}$ by definition, one solves for $\frac{w^{t}}{P^{t}}=a_{A v g}^{t} \cdot W g S u p^{t}(\cdot)$.

21. i.e. $a_{A w g}^{t}=\sum_{s=1}^{\text {NoOfvintages }}{ }^{t}\left(M S h r_{s} \cdot a_{s}^{\text {max }}\right)$ and $b_{A v g}^{t}=\sum_{s=1}^{\text {Noofvintages }}{ }^{t}\left(M S h r_{s}\right.$. $\left.b^{s}\right)$.

22. i.e. Economy wide (average) capital-output ratios are estimated to remain around the value 3.0 for extended periods.

23. So that mainstream economists, who use Cobb-Douglas type production functions $\left(Q=A \cdot L^{1-\alpha} \cdot K^{\alpha}\right)$ in their estimations, find values for the parameter $\alpha$ (which, under optimization, represents capitalists' share in income) persistentlv ranging in the interval $[0.25,0.4]$.

24. For example, Kuznets [1940], and Mensch [1975/1979].

25. Which asserts that the scope of improvement for any technology is limited and accorclingly the cost of incremental improvement increases as technology approaches to its long-run performance level, especially when considered in the context of key technologies that affect economies beyond the boundaries of individual industries.

26. Recall that our cumulativeness formulation takes four parameters. Yet, since the current scenario features only one country and one firm, knowledge spill-overs are naturally out of question and thus the magnitude of the parameters $\Omega_{i, N a t m l}$

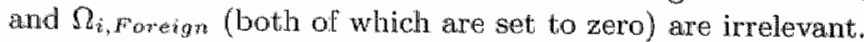

27. I.e. by the high value assigned to the parameter FitSensInv, which implies that opportunities for radical technological breakthroughs are strongly dependent on the knowledge accumulated in existing technologies.

28. At $t=0$ the economy is already in the first paradigm, which leaves only 19 new paradigms to be invented and exploited.

29. This is also the process by which the cost saving potential of each innovation is exploited in terms of output growth.

30. Given the scale of the chart given in panel (a) of Figure 6.3 which covers the en- 
the history of progress through the 20 paradigms specified, the paradigm-specific S-shaped progress curves are not clearly observable. However, in scales which magnify narrower productivity interwals, despite the noise generated by stochasticity, one can clearly observe the S-shape within the productivity boundaries of each of the 20 paradigms. As in all of our experiments and scenarios the data is supplied in the accompanying CD.

31. Then again, the allocation of the total profits of the economy over the sectors for capitall expansion is determined by the relative profitability of the firms and accordingly of the sectors at the more aggregate level.

32. Obviously, a detaled account of the historical growth pattern is beyond the scope of this chapter, and we can therefore only provide a broad caricature here.

33. The settings and output files of these supplementary simulations can be found under the directory "/Chapter6/SupplRuns" and the discussions in the file "Appendices/Chap6App2.pdf".

34. All entries of the parameter matrix RellmEase $(j, h)$ which control the relative extent of international imitation possibilities (as defined in equation 5.15) are set to 1.0 and also technological distance and technological age related barriers to imitation are eliminated by the settings $I m E a s e_{i}=1, T$ DisTrhld $=300$, AgeTrhid: $=0.0001$ for both sectors $i$.

35. As in Leontief [1953], where the author tests the validity of the H-O-S model empirically. 


\section{7}

\section{Industrial Organization and International Trade}

With the simulation experiments in the previous chapter, we have addressed various issues on the macroeconomic implications of technological change in a singlesector (and mostly) single-firm framework. Naturally, these simplified experiments ignore the possible direct effects of competition (or economic selection) on industrial dynamics. Following the line of argumentation in the first part of this book, there are several reasons why the explicit medeling of firm and industry level dynamics is important. First, the possibility of technological imitations between firms (directly as well as indirectly in cases where various dynamic increasing returns mechanisms, such as learning by doing or scale effects in R\&D efficiency, are in action). may have a major potential impact on the macro dynamics of technological change. Second, heterogeneity at the firm level may be an important source of variations (over time, sectors or countries) in performance at the macro level.

For these reasons, we start the analysis in this chapter with a set of experiments covering topics in industrial dynamics. Here we address the issue of firm size distributions and firm growth rates (Sutton, [1997], Bottazzi and Secchi [2003a,2003b]), and the issue of R\&D strategies (Nelson and Winter [1982], Silverberg and Verspagen (1995a)). We show how the model can generate specific stylized facts of industrial organization found commonly in the literature, and we focus the discussion on how these stylized facts are related to macroeconomic properties such as economic growth.

In a second part of the chapter, we extend the model to a context of international trade by introducing multiple countries and multiple sectors, while maintaining the model settings in terms of firm heterogeneity and micro dynamics. In this part of the analysis, which concludes the simulation experiments in the dissertation, we show how micro dynamics interact with macro results in the specific case of analyzing the relationship between specialization and economic growth.

\subsection{A brief look at industrial organization and dynamics}

As described in Chapter 5, we have built into our model various elements which may affect industrial dynamics/organization and technological change processes 
significantly. First, in our agents-based specification, technological change process proceeds through firm-specific productivity shocks. In other words, the basic unit to which innovations arrive is the firm. Thus, one may generally expect that more firms imply more innowation arrivals, unless innovation processes are characterized by strong dynamic increasing returns to individual firm size (i.e., learning by doing or the scale effects in R\&D efficiency). However, since technological change takes place along pre-specified technological trajectories (linear, exponential, paradigmsbased), the total number of innovation arrivals to the economy does not necessarily imply laster technological progress, due to the repetition of innovations across the firms (i.e., each firm may be independently learning/discovering the same thirngs learned/discovered by the others). Yet, imitations among firms may change this significaritly by eliminating the repetition in innovations. The model provides a number of avenues for experimentation with the processes that stimulate or inhibit the flow of knowledge and innovations between firms (e.g., the age of the technology used by the firm targeted for imitation, which represents patent protection, technological distance between the imitator and the target firm, international barriers in imitations etc.).

The other important element that has the potential to affect industrial organization and dynamics, as well as the pace of technological change, is the entry of new firms. By various parameter settings, it is possible to control the entry rates and more importantly the initial competence level of new entrants (i.e. close to the best/worst practice technology, or to the industrial average etc.) which has a strong impact on the survival chances of the entrants and accordingly the firm. size distributions.

Our model also introduces the possibility to experiment with various levels of substitutability between products (i.e. demand for variety) which is a major determinant of the selection forces in the economy (i.e. competition). As demonstrated in earlier chapters, high demand for variety (low product substitutability") introduces niches in which less productive firms are protected against the strong selection forces of the economy. Hence, demand for variety appears to be an important factor affecting industrial dynamics.

\subsubsection{Experiment \#4: Firms' Size and Growth Rate Distributions}

One of the most celebrated (but also criticized) empirical regularities in industrial economics is Gibrat's law on the distribution of firm growth rates, and the consequent mature of the distribution of firm sizes (see Sutton [1997] for an overview of research in this field). Gibrat"s law states that (proportionate) growth rates of firms are normally distributed (irrespective of firm size), and as a result, the size distribution (size is the integrated effect of growth rates) of firms is lognormal. Whether or not the normal and lognormal distributions are in fact appropriate has become a matter for debate (Dosi et, al. [1995]), and, for example, the Pareto distribution has been suggested as an alternative for size distributions. But general agreement exists on the (stylized fact) that size distributions of firms are highly skewed on the left: a large majority of frms is very small, and only a few giant firms emerge out of the process of market competition (e.g., Bottazzi and Secchi $[2003 \mathrm{~b}]$ ).

It is the aim of this experiment to investigate under which circumstances the model can generate such skew, Pareto-like firm size distributions. We will use a one country, one sector, multi-firm setting, and the basis parameter settings are 
set identical to that of the base run of Experiment H1 (i.e., as in Table 6.1). Upon these basis settings our control experiments are based on three factors that influence firm growth rates and knowledge interaction between firms: learning by doing, imitation between firms, and knowledge spill-overs."

As discussed in the previous chapter, our cumulativeness modnles are formulated in a way which also allows the introduction of knowledge spill-overs. In single-country single-sector settings, the parameters $0<\Omega_{\text {Natnl }}^{L B D}<\mathbb{1}$, determines the extent of knowledge spill-overs among firms. We further specify the common settings InnEase $=0.1$, and mIncrmnt $=0.05$. Then, the parameter settings that correspond to the alternative states of the learning by doing module are follows

- Learning By Doing Off: In cases characterized without learning, technological change is assumed to follow exponential trajectiories specified by the parameter setting $\tau=1.431$.

- Learning By Doing On: In cases characterized by learning, the basis learning $\Omega_{B \text { ase }}^{L B D}$ is set to the value 1.793 .

- Without knowledge spill-overs: $\Omega_{\text {Natnl }}^{L B D}=0$,

- With knowledge spill-overs: $\Omega_{\text {Natnl }}^{L B D}=0.1$.

Imitation opportunities among the firms are varied as follows:

- Imitations Off: Imitation possibilities are eliminated by setting the Poisson arrival rate of imitation arrivals to zero (i.e. ImEase $=0$ ).

- Imitations On: Imitation possibilities are assumed to arrive at indiwidual firms exogenously according to a Poisson process the arrival rate of which is set to ImEase $=0.1$ (i.e. on the average one imitation chance every ten periods). Furthermore, by the settings TDisTrhid $=100$, TDissens = 50, AgeTrhld $=1 e-5$, AgeSens $=50$, SampEase $=1$ (all of which are defined in section 5.2 .2 ), we eliminate all potential inhibitors to imitations among firms. These settings ensure that whenever a firm gains access to an imitation possibility (from the Poisson process), it directly imitates the best-practice firm of that period.

Note that the values assigned to the parameters $\tau$ and $\Omega_{B \text { ase }}^{\angle B D}$ are not arbitrarily chosen, but are somehow related to each other in order to make results comparable between different states of the model. Our expected valne estimation given by equation 6.10 suggests that in case of exponential exogenous technological change, the average productivity growth that one would expect is $1.431^{(0.1 \cdot 0.05)}-1=$ $0.18 \%$ per period. The other expected value estimation, which is given by equation 6.19 for the case of endogenous technological change with learning by doing, under the assumptions of a single firm (or aliso for many firms and perfect knowledge spillovers), estimates the growth rate as $(1.793 \cdot 0.1 \cdot 0.05)=0.9 \%$ per period. Clearly, the latter estimation is only half the value of the former. However, it will be seen that with many firms and less than perfect knowledge spill-overs, the cases with exogenous technological change yields growth rates that are of similar order of magnitude with cases with learning by doing.

In the dimensions, specified by the parameter variations explained above, we have designed the following 5 alternative configurations:

- BaseNoLBD: Learning by doing and imitations are both ruled out (i.e. technological change is purely based on exogenous arrivals of incremental innovations to individual firms), 


\begin{tabular}{|c|c|c|c|c|c|c|c|}
\hline & \multirow{2}{*}{ 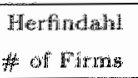 } & \multirow{2}{*}{$\begin{array}{l}\text { Avg. Agg. } \\
\text { Crothth Rt }\end{array}$} & \multicolumn{5}{|c|}{ Firm Lewel Groweth Rates } \\
\hline & & & Mean & Median & Sdev & Sikennesg & Kurbositis \\
\hline \multicolumn{8}{|l|}{ Theta $=0.95$} \\
\hline BatastoLDOD & $8 / 4$ & 0.030 & -0.0 .01 & -0.088 & 0.240 & 3.902 & 16.23 \\
\hline NoLBDAtrint & $51 / 51$ & 0.129 & 0.14 & 0.099 & 0.252 & 1.136 & 1. .78 \\
\hline FaseLD & $1.3 / 1.3$ & $0.07 \%$ & 0.05 & -0.095 & 0.557 & 1.509 & $12 \%$ \\
\hline LED & 95,109 & 0.023 & 0.027 & -0.006 & 0.152 & 2.954 & N7. 14 \\
\hline$\triangle B D+K \triangle O$ & $6.8 / 1.7$ & 0.037 & -0.014 & -0.095 & 0.309 & 3.034 & 9.27 \\
\hline \multicolumn{8}{|l|}{ Theta $=0.85$} \\
\hline BaseNoLidid & $49 / 38$ & 0.021 & 0.011 & 0.0007 & 0.146 & 4.124 & 338.4 \\
\hline Nol BD- Imit & $62 / 64$ & 0.140 & 0.151 & 0.095 & 0.272 & 1.478 & 3.004 \\
\hline BraseLAD & $5: / 47$ & 0.005 & -0.013 & -0.024 & 0.156 & 5.37 & 47.10 \\
\hline LBD-IrLit & $\$ 6 / 113$ & 0.020 & 0.021 & -0.002 & 0.141 & 3.919 & 24.65 \\
\hline $\mathrm{LBD}+\mathrm{KSO}$ & $40 / 40$ & 0.012 & $0.0 \overline{09}$ & -0.0149 & 0.167 & 4.635 & 31.27 \\
\hline \multicolumn{8}{|l|}{ Theta $=0.75$} \\
\hline Bas NoLBD & $69 / 74$ & 0.021 & 0.022 & 0.0001 & 0.16 & 4.985 & 4307 \\
\hline NoLPD - Imit & $70 / 74$ & 0.149 & 0.161 & 0.101 & 0.278 & 1.62 & 403 \\
\hline Basel BD & $91 / 10 \%$ & 0.001 & 0.009 & -0.008 & 0.111 & 7.109 & 61.03 \\
\hline L.BD + Inid & $95 / 110$ & 0.021 & 0.020 & $-0,003$ & 0.121 & 5.424 & 49.81 \\
\hline $\mathbb{L B D}+\mathrm{KSO}$ & $81 / 98$ & 0.011 & 0.005 & -0.025 & 0.244 & 2.774 & 16.99 \\
\hline
\end{tabular}

Table 7.1. Summary table for the results of Experiment 4

- NoLBDImit: Learning by doing is turned oft while imitations are on,

- BaselBD: Learning by doing is turned on, but both types of spill-overs (i.e. knowledge spill-overs and imitations) are ruled out

- LBD_Imit: Learning by doing and imitations are on; knowledge spill-overs are ruled out.

- LBD_KSO: Learning by doing and knowledge spill-overs are on; imitations are ruled out.

As discussed before, demand for product variety introduces a strong link that protects firms against the fierce forces of selection. Clearly, in circumstances where technological change incessantly introduces firm level productivity changes and thus heterogeneity, such protection has some explanatory power on the survival and growth chances of individual firms and thus on firm level growth rates and firms" sized distributions. Accordingly, each of the 5 combinations above were run for 3 different levels of variety demand, which are imposed by the alternatives. $\theta=\{0.95,0.85,0.75\}$. Thus the total number of control runs in this experiment is 15.

Each run is intiated by 30 initial firms, which are identical in their initial sizes and labor productivity coefficients (i.e. $a_{k}^{0}=1$ ). Furthermore, throughout the simulations, we allow the entrance of new firms which are introduced according to a Poisson process with arrival rate EntArrRt $=0.1$. The initial labor productivity coefficient of each firm is determined as a random draw from the uniform distribution the boundaries of which are determined by the productivity coefficient of the worst and the best practice firms of the period of entry.

\section{The experiment results}

The key results of our control runs are summarized in table 7.1 and figure 7.1 , for each of the 15 individual cases. The first column of table 7.1 shows the Herfindahl 
equivalent number of firms (i.e., $1 /$ Herfindahl index) in a $X / X$ manmer, where $X$ stands for the average of the last 300 periods and $Y$ for the value ant the terminat period of the simulation. The second column gives the average aggregate growth rate per 10 periods, observed in the last 300 periods of each 800 period an. The last 5 columns of table 7.1 present a set of descriptive statistics (i.e. mean, median, standard deviation, skewness, kurtosis) on firm level growth rate as sampled over 10 periods from the last 300 periods of each run.

Figure 7.1 depicts the distribution of firm sizes, on the basis of the panel data that pertains to the last 300 periods of our control runs. Each plot gives the distribution of individual firm sizes (present at a given period) as a decreasing function of the underlying rank indicator (i.e. 1 for the largest firm, 2 for the second large etc.) in log-scale as

$$
\ln \left(Q_{k}\right)=f[\ln (k)]
$$

where $Q_{k}$ is the output level of the $k^{\text {th }}$ largest firm in the population. One can find in the literature (e.g. Dosi et al. [1997]) empirically supported suggestions that at high aggregation levels, firm size distributions (in reality) follow a Pareto distribution. That is, in the logarithmic scale, the relation between firm sizes and their rank is approximately linear as

$$
\ln \left(Q_{k}\right)=\beta_{1}-\beta_{2} \cdot \ln (k),
$$

where $\beta_{2} \approx 1$. Nevertheless, it has also been argued (e.g. Van Dijk [2000]) that at lower levels of aggregation (i.e., individual industries etc.) size distributions may depart from this specification significantly, either in the sense of the linearity of the log scale distribution or in terms of the proximity of the slope parameter $\beta_{2}$ to unity. Yet, the basic conclusion that arises from such studies is the fact that in reality firm size distributions significantly diverge from the extremity of the theoretical distributions ${ }^{2}$ assumed by the majority of the mainstream formulations.

Briefy the results highlighted by table 7.1 and figure 7.1 can be summarized as follows. First, demand for variety and imitation leads to less concentrated industries. This is evident by comparing the values in the first column between the three blocks corresponding to different values of $\theta$. Essentially, this is the result from the fact that lower levels of $\theta$ imply bigher level of protection to selective forcesin

Second, as one can conclude from 7.1 , the model generates a wide variety of firm size distributions. One one end of this range one observes uniform distributions which particularly emerge in cases of higl imitation possibilities. On the other extreme one can see polarized distributions characterized by very large firms allong with a number of smaller firms on the fringes of the distributions. In between, one also finds a number of intermediate cases that conform to the specifications of the Pareto distribution. All four factors that constitute the control dimensions of our experiment (learning by doing, demand for variety, imitation and spill-overs) have an impact on firm size distributions uniform. The strongest influence is established by product substitutability. Among all cases depicted by 7.1, those which are close to a Pareto distribution are all characterized by low or intermediate levels of product substitutability. It thus appears that in the model, sheltering of firms from the forces of selection, leading to the simultaneous survival of firms of a wide range of sizes, is the main source of Pareto-like size distributions. In cases of low demand for variety, the strong forces of selection transform productivity differences that emerge due to the incessant firm-level technological shocks, into polarized distributions of firm sizes. 
Third, although one might expect that firm level externalities brought about by learning by doing would imply strong path-dependency by rendering the (otherwise) temporary effects of change on firm-level heterogeneity in productivities persistent, and accordingly lead to polarized differences in firm sizes, this is in fact not the case. However, there exists a secondary causal relation (which we will address in the following experiment in more detail) that obscures the former relation in terms of our experiment results. In cases characterized by low and medium levels of product substitutability and learning by doing with no knowledge spillovers, the firms' size distributions are flatter (i.e. as in panel (b)) than those generated by exogenous technological change. The reason is the fact that under the protection of variety demand, the industry accommodates a high number of small firms, none of which can exploit the scale economies inherent to learning by doing. Accordingly, for all firms, innovation arrivals (i.e. the learning rates) remain quite low, and the consequent pace of technology arrivals fails to heterogenise firms as sharply as they do in cases of exogenous innovation arrivals. As one clearly observes, in comparison to cases with learning by doing without knowledge spill-overs, the cases with learning by doing and knowledge spill-overs lead to size distributions which are closer to those observed in cases of exogenous technological change.

Fourth, and perhaps the most salient observation that emerges from the results given in table 7.1 , is the positive values of the skewness and kurtosis measures of the firm-level growth-rate distributions, which respectively indicate a tail towards positive values and a relatively peaked distribution. The median values which indicate the whereabouts of the peak of the underlying distributions, are in the negative domain except for the cases characterized by exogenous technological change with high imitation possibilities. In all cases, the median values are smaller than the mean values and the variation around the mean (i.e. standard deviation) is quite high, which further verify the skewness of the underlying distributions and the existence of a tail in the positive domain.

Fifth and finally, there is an interesting discrepancy between the average aggregate growth rates and the corresponding averages of the growth rates of individual firms. In cases characterized by high imitation possibilities and/or high consumer demand for variety, the former are exceeded by (or not less than) the latter, whereas the opposite is true for the rest of the cases. Thus, without the protection of imitations and demand for variety, at any given instant the selective forces promote the growth of only a small subset of best practice firms, whille the rest (i.e., the majority of the firms) loose market share. In such cases the total growth of the former type of firms outweighs the total shrinkage of the latter type, and is thus responsible for the aggregate growth.

Concluding, we see a number of illustrations of the tendency that is typical for evolutionary models (e.g., Dosi et al. [1995], Bottazi and Secchi [2003b]) to find a combination of significant turbulence at the micro level with (somewhat) smooth and regular patterns at the macro level. Specifically, we observe significant turbulence in growth rates at the micro level, while growth seems to be rather smooth at the macro level. At the same time, the model is able to reproduce the most salient regularities in industrial economics, such as the rather skew nature of firm size distributions. While the model may generate the specific Pareto distributions of firm sizes that has sometimes been suggested, this is only the case in specific settings with regard to cumulativeness (learning by doing), spill-overs, imitation and product differentiation. 

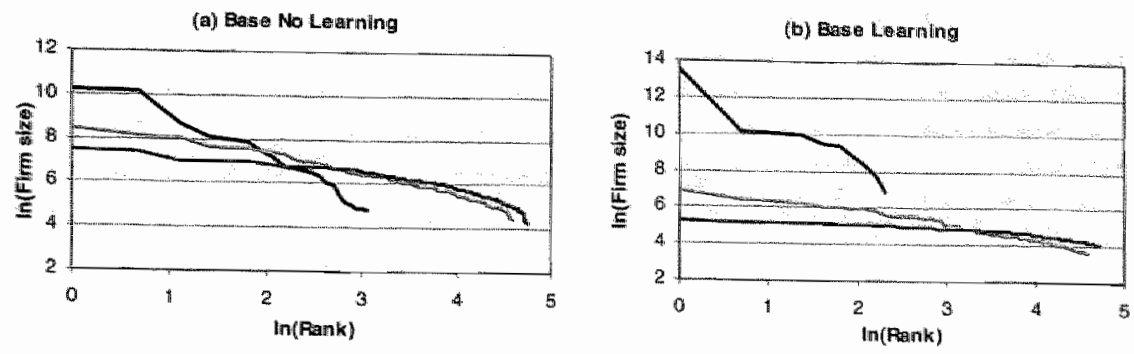

(c) Learnimit

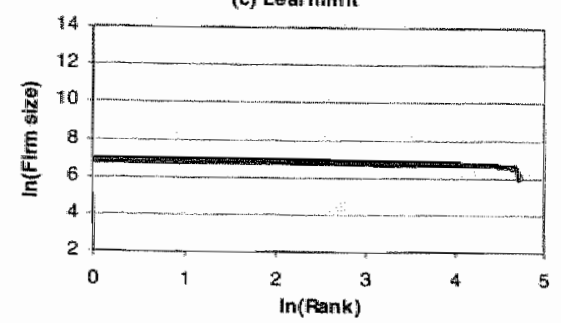

(d) Learin Splt|l
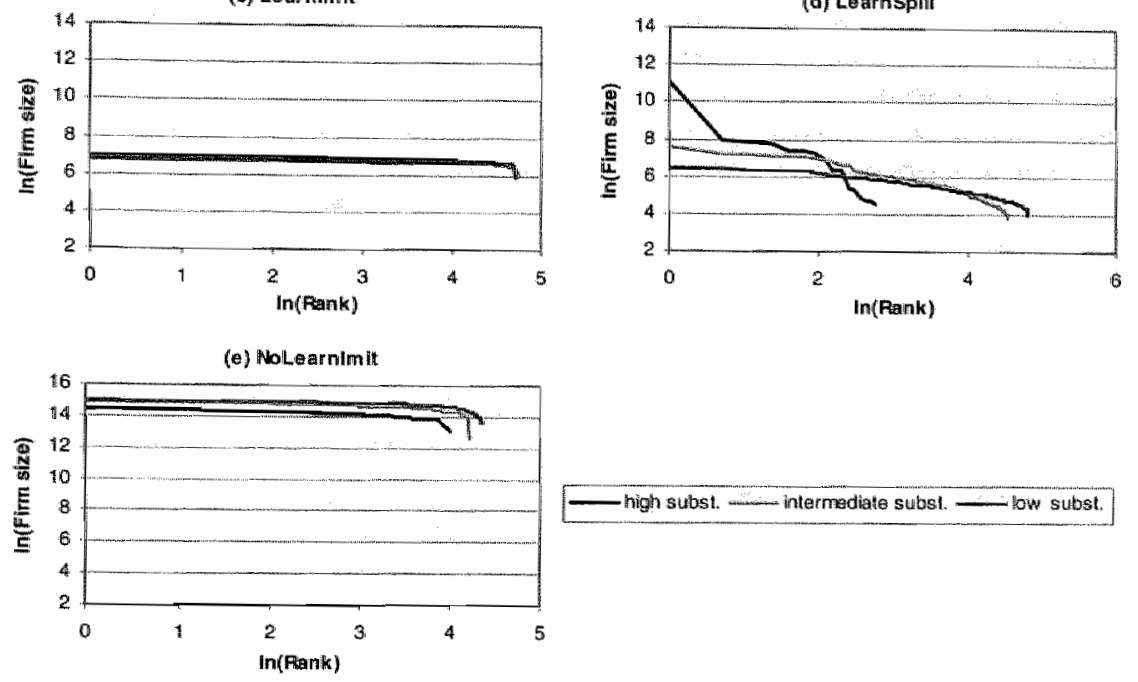

Figure 7.1. F̈̈lrm's size distributions in Experiment 4.

\subsubsection{Experiment \#5: Industrial Organization and Aggregate Growth}

In the next experiment, we investigate the implications of microdynamics for mactoeconomic growth in a one sector, one country context. We address the central issue in (early) new growth theory, i.e., that technology spill-overs are the main source of sustained aggregate economic growth (e.g., Romer, [1990] and Grossman and Helpman [1991]). In our model, given a constant number of firms, one can expect aggregate growth rates being an increasing function of imitation possibilities, as well as the extent of knowledge spill-overs between the firms. And similarly, given the fact that the basic entity to which incremental innovations arrive is 'the firm', one can also expect some positive relation between the number of firms and the total number of innovation arrivals to the economy at large, and thus aggregate growth. These last two arguments, together suggest a causal chain that links spill-overs to aggregate growth: But spill-overs do not only have the potential to boost aggregate growth directly, but also indirectly due to their dynamic effect on the number and sizes of firms that coexist in the economy. On the other hand, consumers" demand for wariety is shown by Lucas (1988a) to have a growth impeding effect, also in the context of a new growth model, and this seems broadly 
in line with the microeconomic results obtained in the prewous experiment.

Starting from our usual base settings given by table 6.1 , in this one country, one sector, multi-firm setting, the technological change parameters are set. as InnEase $=0.1$ and mIncrmnt $=0.01$. In all the control runs of the current experiment, technological change remains endogenous in the context of learning by cloing. The learning by doing module is activated according to the parameter $\Omega_{B a s e}^{C B D}=1.793$ which is identical to the magnitude used in the previous experiment.

Except for its exclusion of exogenous technological change, this experiment is rather similar to the previous one in terms of its control dimensions. That is, the three dimensions over which we base our control settings are knowledge spillovers, imitations (i.e., technology spill-overs) and the extent of demand for variety. For each of the former two dimensions, we choose three alternative levels which yields 9 possible combinations. Each of these 9 combinations is specified by the combination of only two parameters that are $\Omega_{\text {Natnl }}^{L B D}$ and ImEase, which determine the extent of knowledge spill-overs and imitation possibilities respectively.

- NoSpillOvers: $\Omega_{\text {Na.tn }}^{L B B D}=0$ and ImEase $=0$,

- Imitations (but no knowledge spill-overs):

- Partial: $\Omega_{\text {Natnl }}^{L B D}=0$ and ImEase $=0.2$,

- Perfect: $\Omega_{N a t r l}^{L B D}=0$ and ImEase $=1.0$,

- Knowledge spill-overs (but no imitations):

- Partial: $\Omega_{\text {Natnl }}^{L B D}=0$ and ImEase $=0.5$,

- Perfect: $\Omega_{\text {Natml }}^{\text {EBD }}=0$ and ImEase $=1.0$,

- BothSpillovers:

- LowImit_LowKSO: $\quad \Omega_{\text {Natnl }}^{L B D}=0.5$ and ImEase $=0.2$,

- LowImit_HighKSO: $\Omega_{\text {Natnl }}^{L B D}=1.0$ and $\operatorname{ImEase}=0.2$,

- HighImit_LowKSO: $\Omega_{N a t n l}^{\angle B D}=0.5$ and $I m$ Ease $=1.0$,

- HighImit_HighKSO: $\Omega_{N a t n l}^{L E D}=1.0$ and ImEase $=1.0$,

Note that, as in the previous experiment, by the settings TDisTrhld $=100$, TDisSens $=50$, AgeTrhd $=1 e-5$, AgeSens $=50$, SampEase $=1$, we eliminate all potential inhibitors to imitations among firms and ensure that access to an imitation possibility (from the Poisson process), leads to the actual imitation of the best-practice firm of the given period.

Each of the 9 combinations specified above are further diversified for two al ternative levels of demand for variety: One for the case of perfect substitutability of products (i.e., $\theta=1$ ) and one for a rather high extent of product substitutability (i.e., $\theta=0.5$, which results in 18 alternative settings. Each one of these 18 settings are run 5 times, each with a different random seed.

Eack simulation is initiated by 30 firms that are identical in their sizes and productivity coefficients (i.e., $a_{k}^{0}=1$ ). As in the previous experiment, by the setting EntArrRt $=0.1$, we arrange that on the average one new firm enters into the economy every ten periods. Similarly, the imitial productivity coefficients of the new entrants are determined as uniform random draws from the interwal dynamically set by the sectoral extremes (i.e. the labor productivities of worst and best practice firms of the period of entry). 


\begin{tabular}{|c|c|c|c|c|c|c|}
\hline \multirow{3}{*}{$\begin{array}{r}\text { Imaitut } \\
\quad y\end{array}$} & \multicolumn{3}{|c|}{ Perfectly Substinate Products } & \multicolumn{3}{|c|}{ 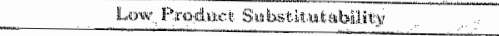 } \\
\hline & \multicolumn{3}{|c|}{ Kmowledge Spill Orens } & \multicolumn{3}{|c|}{ 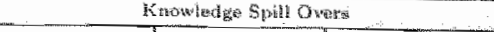 } \\
\hline & Nome & Partial & Perfect & Nonita & Partal & Perpert \\
\hline \multicolumn{7}{|c|}{ Aggregate Outpat Growth Rave Per 10 Periods: } \\
\hline hone & $0.016 \pm 3.6 \%$ & $0.0162 \pm 4.8 \%$ & $0.02 \pm 2.3 \%$ & $0,0002 \pm 2,38$ & $0.009+1.0 \%$ & $0.0178+1.09$ \\
\hline Perifiall & $0.01 \pm 1.3 \%$ & $0.03044 \pm 1.89$ & $0.0404 \pm 1.1 \%$ & $0.0089 \pm 6.1 \%$ & $0.0381 \pm 122 \%$ & $0.10488 \pm 67 \%$ \\
\hline Perfect & $0.015 \frac{1}{2} 2.49$ & $0.0405 \pm 0.6 \%$ & $0.0502 \pm 0.3 \%$ & $0.01 .45+1.8 \%$ & 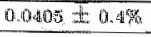 & $0.0802+0.6 \%$ \\
\hline \multicolumn{7}{|c|}{ Terminal Pertod of Firms: } \\
\hline Mone & $3.52 \pm 21 \%$ & $4.24 \pm 30 \%$ & $13.04 \pm 18+18$ & $13188+10 \%$ & $133,1+2.6 \%$ & $120.0 \mathrm{~s}=0.0 \mathrm{~s}$ \\
\hline Prartional & $904.42 \pm .5 \%$ & $86.0 \pm 6.3 \%$ & $80.3 \pm 5.29$ & $128.96=10 \%$ & $127.76 \pm 6 \%$ & $99048=7.928$ \\
\hline Perfect & $132.36 \pm 5.3 \%$ & $131.5 \pm 3.99$ & $131.9 \pm 3.9 \%$ & $134.30 \pm 8.28$ & $12424 \pm 8.98$ & $12916 \pm 10.8 \%$ \\
\hline \multicolumn{7}{|c|}{ Terminal Period Herfindall Equvalent 将 of Firms: } \\
\hline Noble & $1.012 \div 0.49$ & $1.02 \pm 0.7 \%$ & $285 \pm 44 \%$ & $131.48 \pm 10 \%$ & 139.6 \pm 268 & $12896 \pm 60.6 \%$ \\
\hline Partial & $26.21=340$ & $45.39 \pm 1.4 \%$ & $35.02 \pm 9 \%$ & $128.78 \pm 9.1 \%$ & $127.08 \pm 6.8 \%$ & $129.73 \pm 7.2 \%$ \\
\hline Pewrocit & $67.8+6.2 \%$ & $68.8 \pm 4.5 \%$ & $70.4 \pm 4.7 \%$ & $134,22 \pm 8.1 \%$ & $12415 \pm 8.19$ & $128.9 \%$ is $10.8 \%$ \\
\hline
\end{tabular}

Table 7.2. Summary Table for Experiment 5

\section{The experiment results}

The key results of our 18 control experiments are summarized in table 7.2. Each cell of the table shows the average value and percentage variation (around its mean) of some magnitude over the corresponding 5 simulations, each of which is another realization of a common setting with different random seeds. The table is arranged in three vertically aligned blocks. The cells in the first block indicate the average output growth rates (per 10 periods), observed ower the 800 period simulation runs. The cells in the second block indicate the number of firms observed at the terminal period (i.e., $t=800$ ) of underlying combinations. Similarly the cells in the third block indicate the Herfindahl equivalent number of firms (i.e. 1.0 divided by the Herfindahl index) observed at the terminal period. Each block has three rows, which in the vertical order (from top to bottom) correspond to increasing levels of imitation opportunities. The table has also two vertical blocks. The first block corresponds to experiments with perfect product substitutability and the second to those with high variety demand by customers. Each of these two vertically differentiated blocks has three columns, which in the horizontal order (from left to right) correspond to increasing extents of knowledge spill-overs.

The results in table 7.2 can be summarized as follows:

First, in the absence of imitation possibilities, demand for variety significantly increases the number of firms that the economy accommodates, and due to the consequently high number of firms, none of which can exploit the learning by doing related scale economies, this results in very low aggregate growth rates. This result reproduces the argument suggested by the second model in Lucas (1988a), which shows the existence of a trade-off between output growth and a more desirable product mix, in an aggregate two-sector economy setting. Learning by doing clearly implies dynamic increasing returns to scale and since demand for prodwet variety does not let the market concentration increase, production can not be consolidated under the roof of one/or few large firms, and the learning/innovation rates that can be achieved by a collection of small firms remain quite low compared to the potential. In other words, in cases where learning by doing governs the innovative process, one can suggest a positive relation between market concentration and productivity/ontput growth rates.

Second, knowledge spill-overs between firms, which have an unconditional growth boosting potential, may suffice to compensate for this loss, but only if the spill-overs are perfect. That is, partial knowledge spill-overs can only save a part of the growth bygone that arises due to the existence of a high number 
of small firms which learn at quite a slow rate. The same argument is true for imitations. However, since imitations only reduce the redundancies in the parallell learning paths of a multiplicity of firms, but not necessarily imply higher learming rates, even in the case of perfect (i.e., instantaneous) imitation possibilities, the loss in growth rates is not fully recovered.

Third, in the absence of knowledge spill-overs and with no demand for variety, imitation possibilities, despite their growth boosting potential, decreases growth rates. The reason for this puzzling result actually lies in the previous argument. That is, initation possibilities tend to clear away the heterogeneity in the productivity levels of competing firms and gives a high number of firms the chance of simultaneous survival with small sizes (as in perfect competition). Consequently the economy can not exploit the dynamic scale economies inherent to learning by doing and loss in output growth follows. The growth boosting potential of imitations fail to make up for this lass. If the market concentration is already kept low by irnitation possibilities, variety demand does not introduce an extra loss in output growth. This is an interesting finding, that (metaphorically) brings out the difference between competition in an evolutionary sense, and competition in the neoclassical sense. In an evolutionary context, competition creates varirety, and this variety boosts growth. In a neodassical sense, competition creates homogenous firms, and, in our model, this has a negative impact on growth.

Finally, we observe that in cases where knowledge spill-overs and imitation possibilities both exist, the aggregate growth rate is increasing with the extent of either of these two spill-over types.

In summary, the relation that links knowledge spill-overs, imitations and variety demand to aggregate growth is a non-linear and complicated one. That is, as summarized above, the effect of each of the three dimensions is not linear on the value of the parameter that specifies the extent, and more importantly not independent from the other two. In orcler to clarify this rather complicated picture, we run a linear regression that explains the variation of aggregate growth rates over our control settings, but only after a non-linear transformation of our independent (i.e. control) variables. Recalling that our 90 simulation runs are characterized by 18 alternative parameter settings where each setting is given by the combination

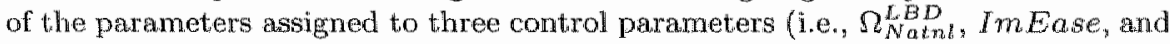
$\theta$ ), we have designed a data set of 90 observations where the dependent variables is defined as

- AggGr : Is the average aggregate growth rate per 10 periods, as observed over the entire duration of simalation run $k=1,2,3, \ldots, 89,90$.

and the independent variables as

- $I m i t_{k} \in\{0,0.85,1\}$ which respectively correspond to the values $\{0,0.5,1\}$ assigned to the imitation arrival rate parameter ImEase at run $k$.

- $K S O_{k} \in\{0,0.75,1\}$ which respectively correspond to the values $0,0.1,1$ assigned to the knowledge spill-over parameter $\Omega_{N a k n}^{L B D}$ at run $k$.

- Subst $=1$, if $\theta=1$ and $I m t_{k}=0$ at rum $k_{2}$ and $S u b s k_{k}=0$ otherwise

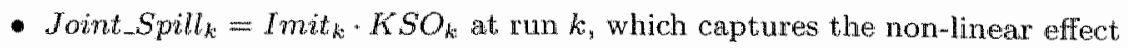
through which the two different types of spill-overs feed on each other.

Based on this preprocessing of the independent variables, the linear regression.

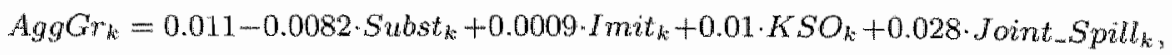


yelds the adjusted $R^{2}$ walue $9 \% 6 \%$, with all the estimated coefficients significant at $99 \%$ confidence level, except the coefficient on $I$ mit, which is significant only at $60 \%$ confidence level. The low value of this coefficient indicates the ambiguous effect of imitations on growth in cases characterized by the lack of knowledge spillovers. The negative and large value on Substa is the validation of the similarity between ovr findings and that of the second model in Lucas (1988a). The positive and large value on $\mathrm{KSO}_{k}$ verifies the unambiguous effect of knowledge spill-overs on aggregate growth rates. And finally, the positive and large value on 0.028 shows the significant effect of the non-linearity by which innovations and knowledge spillovers boost the positive effect of each other in terms of aggregate growth.

In summary, the model reproduces some important insights from new growth theory, such as the positive impact of spill-overs on growth, and the negative innpact of the demand for variety as suggested by Lucas (1988a). But the model differs crucially from the new growth models in arguing that variety is a main source of spill-overs. As soon as variety dies out in the world described by the model, for example because imitation between firms is so high that firms become very similar, growth stops. Thus, where the model produces a textbook world of perfect competition, growth rates will be relatively low. In our model, micro heterogeneity is not only a way to generate with persuasive micro-foundations similar results as in the neoclassical growth theory (as in Nelson and Winter [1982]). Indeed, heterogeneity is a main source of growth itself, and this underlines the evolutionary nature of the model.

This effect of competition and heterogeneity on aggregate growth is not often. investigated in evolutionary macro models. Mostly, these models (e.g., Dosi et. al [1994], Silverberg and Verspagen [1995a]) will relate differences in technological competencies to differences in growth rates, either over time or between countries. Thus, more heterogeneity leads to more variety in growth rates. Our model brings out a different tendency, i.e., that more heterogeneity might lead to higher growth rates.

\subsubsection{Experiment \#6: Optimality versus arbitrariness in R\&D expenditures in the context of selection}

As in all mainstream models, the new growth models assume that ReD behavior of firms is characterized by a high degree of rationality. This is based on the assumption that there exists a well-defined relation between $R \& D$ effort and the expected returms on it, and that this is known by the firms. Even in stochastic formulations such as Aghion and Howitt [1990], firms have full excess to the information in terms of expected values. The other building blocks of the models (1.e., calculating steady state paths as optimal control problems that maximize the societies' long rum welfare under the perfect foresight assumption) ensure that the resolution of the essential intertemporal trade-off that underlies R\&D investments reflects the societies' intertemporal preferences, at least in the absence of externalities.

Evolutionary economists reject such a strong demand on rationality of the firms, for example because the retums to $\mathbb{R} \& \mathrm{D}$ are highly uncertaim. In evolutionary models, the specification of firm's R\&D behavior generally reflects some sort of "routinized behavior" or "bounded rationality" following Herbert Simon. For example, Dosi et. al [1994] formulate "routinized behavior" in terms of firmis which determine their R\&D spending on the basis of a constant R\&D to sales ratio. Given their formulation of an $R \& D$ potential function which specifies inno- 
wativeness as a monotonic function of $R \& D$ expenditures, constant R\&D to sales. ratios imply that a larger firm can spend more on $R \& D$ and is thus more innovative than the smaller ones. This formulation implies a strong externality which contributes to the emergence of growth rate differentials between countries and also international specialization. The R\&D to sales ratios followed by firms are simply assigned as arbitraxily chosen parameters which are not heterogenised over the firms.

Nelson and Winter[1982] formulate some sort of bounded rationality which suggests that firms engage in R\&D activities on a "need to do" basis. More precisely, according to this "satisficing" formulation firms engage in R\&D activities (towards innovations or imitations) only if their profitability fall below a certain (arbitrarily assigned) level.

Clearly, neither of these two madels discriminates between too much or too little R\&D effort. In other words, neither make an attempt to address the question "how much a firm should/would spend on R\&D". To our knowledge, the only attempt that addresses this issue in a formal evolutionary model of growth is the Silverberg and Verspagen [1995a] model which approach this issue more in the context of "sustainability" (or "evolutionary stability") than that of optimality. Similar to Dosi et. al [1994], in this model firms determine their R\&D expenditures on the basis of target $R \& D$ to sales ratios (i.e., R\&D strategies), yet these magnitudes are not given exogenously but are allowed to vary over time according to a firm-level learning process. The learning process is formulated as a genetic algorithm where firms experiment by introducing local variations over their current strategies or by imitating the stratiegies followed by more successful firms. The simulations of the model show convergence to rather steady states where the heterogeneity in R\&D strategies are strongly reduced. One can associate the R\&D strategies that emerge from the parallel processes of economic selection and (social) learning with concepts like "feasibility" or preferably "sustainability" but. not with the social optimality definitions of the mainstream economics, which are based on the intertemporal preferences of the society/capital owners.

As mentioned before, our model shares quite some common elements with the Silverberg and Verspagen [1995a] model in terms of the workings of the basic selection mechanism. However, there are also differences (which will be discussed later in this section) in certain elements of our formulations which potentially leads to different implications. Most impartant of all, the current version of our model is not endowed by a strategical learning process as in Silverberg and Verspagen [1995a]. Instead, as explained in chapter 5 , we introduce three alternative formulations that are based on different assumption on firms' R\&D behavior. Two of these are based on some sort of rationality, albeit bounded, and one on "routinized behavion".

The question we accordingly address is "By initiating our model by a high number of firms, identical in all senses but their attitudes towards R\&D, can one derive any meaningful conclusions on the potential of economic selection on the elimination of arbitrariness in R\&D behavior (i.e., wasteful and/or sub-optimal R\&D investments)?" The key dimensions on which simulation runs are varied are (bounded) rationality, stochasticity and firm-level heterogeneity in R\&D targets.

\section{The main experiment design: Experiment 6a}

In this single-country, single-sector, multi-firm experiment, the base parameters are set according to table 6.1, except for one difference which is that the labor force 


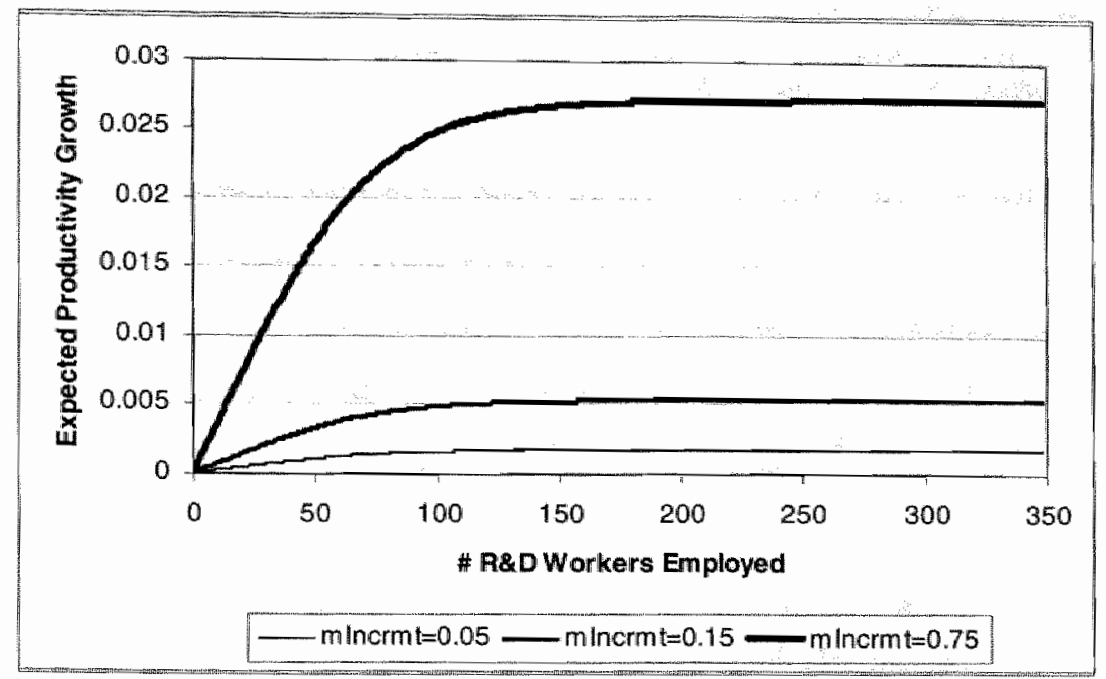

Figure 7.2. The relation between $R \& D$ effort and expected average productivity growth in Experiment 6.

size of the economy is set to $\bar{L}=50000$. Cumulativeness in technological change is eliminated and $R \& D$ expenditures are brought forward as the endogenising factor in technological change which is assumed to follow exponential trajectories characterized by the setting $\tau=1.431$.

As described in chapter 7, our R\&D based technological change formulation is based on an S-shaped R\&D potential function (see equations 5.41 and 5.42 ) which maps the $R \& D$ expenditures (i.e., R\&D workers) of each individual firm to the Poisson arrival rate of incremental innovations it enjoys. The boundaries of this mapping are given by two parameters InnEaseMin and InnEaseMax, which are set to the values 0.0001 , and 0.1 respectively for the current experiment. The inflection point and curvature of the R\&D potential function are respectively set as $R D I n f l c t=15$, and RDSens $=0.5$. The mapping defined by these parameter settings is depicted by figure 7.2 , which clearly indicates the decreasing returns to R\&D effort. That is, below $250-75$ R\&D workers (per firm), the relation between R\&D effort and innovation arrival rate is increasing (though concave), yet marginal returns to $R \& D$ are close to zero after this level. In other words, any level of R\&D spending that corresponds to 250-275 workers or more is clearly wasteful.

On the basis of the common settings listed above, we have built a collection of control experiments. Each run is initiated by 50 firms that are identical in their sizes and initial productivity coefficients, yet heterogenous in terms of the single parameter that determines their R\&D behavior. In order to sustain firm level heterogeneity, the entry of new firms is allowed by the parameter setting EntArr $R t=0.1$ as in the previous two experiments, but unlike in these earlier experiments, in the current experiment we assume that the initial productivity level of new entrants is equal to that of the best-practice firm of the period of entry. Furthermore, we introduce a slight demand for variety by the setting $\theta=0.975$, in order to decrease the impact of pure chance on our selection environment and accordingly to avoid monopolization ${ }^{3}$. 
The control settings of our experiments are characterized by three dimensions:

- Technological opportunities: This dimension is controlled by the parameter macrmt that determines the magnitude of the fitness increment introduced by each inmovation. We have chosen the three alternative magnitudes $\{0.05,0.15,0.75\}$ which respectively correspond \{low, medium, high \} technological opportunities.

- R\&D Behavior: We have experimented with two alternative behavioral assumptions in terms of R\&D expenditures of individual firms.

- Constant share of $R \& D$ spending in revenues: The first alternative assumes that firms have no idea on the R\&D potential function depicted in figure 7.2 , and simply rely on constant $R \& D$ spending schemes characterized by a constiant R\&D to sales ratio (i.e. RDT $\mathrm{Rrgh}_{\mathrm{k}}$ ). For each firm, (i.e. the 50 firms introduced at period zero as well those which make an entry during the simulation) the parameter $R D T a n g_{k}$ is determined by a random draw from the uniform distribution $U[0.05$ $, 0.195]$ (i.e., $0.1 \pm 95 \%$ ). The randomness in this assignment basically introduces firm-level heterogeneity directly in terms of R\&D spending.

- Satisficing in R\&D pay-off expectations: As discussed in chapter 7 , our satisficing formulation basically supplies the firm with the knowledge of the S-shaped relation between $\mathrm{R} \& D$ effort and innovam tion arrival rates, and lets each firm pick the highest R\&D expenditure scheme that promises (ceteris paribus) a marginal expected return on R\&D that is no less than the firm-specific parameter value $r_{k}^{R \& D}$. Given the technological opportunities, a lower $r_{k}^{R \& D}$, which indicates satisfaction from a lower return, implies higher R\&D spending and acm cordingly the value of this parameter is a direct (inverse) measure of the firm's greediness (ambition) towards R\&D. Our model allow the heterogenisation of this key behavioral parameter over the firms. In the experiments characterized by satisficing R\&D behavior, the value of $r_{k}^{R \& D}$ for each of the initial 80 firms (as well as each new firm that enters in due course) is determined by a random draw from the uniform distribution $U[0.006,0.054]$ (i.e., $0.03 \pm 80 \%$ ). The randomness in this assignment basically introduces firm-level heterogeneity in R\&D spending indirectly in terms of arribition towards $\mathbb{R} \& D$.

- Stochasticity in innovation arrivals: As explained in chapter 5, in order to be able to decompose the effects of chance and necessity, we have built into our software implementition the option to eliminate stochasticity from the firm-level innovation arrival processes in a way such that the fim-level productivity growth process follows the expectied value equations presented in the previous chapter. We run each of the control settings 10 times with stochasticity in innovation arrivals and 5 times without, where the random number generator is fed with a different random seed each time. Note that even in cases where stochasticity in innovation arrivals is eliminated, other dimensions of stochasticity remairn: First the module that heterogenises firms with respect to their $\mathrm{R} \& \mathrm{D}$ related behavioral paraneter (i.e., RDTargk or $r_{k}^{R S D}$ ) is based on random draws from uniform distributions, and, second, the Poisson arrival process that is responsible for the introduction of new firms into the economy also remains stochastic. Shortly, 
the motivation to run the settings that exclude stochasticity from movathon arrivals more than once is to experiment, with different distributions of heterogeneity in firm's R\&D behavior.

\section{The results of the main experiment $6 \mathrm{a}$}

The results of the control runs are depicted on figures 7.3 and 7.4 . The former figure corresponds to the settings where stochasticity is eliminated and the lat, ter to experiments with stochasticity. Each chart on each figure gives a collection of thme series that shows the motion of the total number of R\&D workers employed by the economy. The time series on any given chart correspond to the same control settings, but to a different seed of the random number generator. "Thus, each chart in figure 7.3 (7.4) gives 6 (11) time series, where 5 (10) corresponds to the alternative runs and the $6^{t h}\left(11^{t h}\right)$, which is indicated by a darker line, is the average of the former 5 (10). Under each chart one can also find some further information on the average output growth rates observed throughout the underling simulations, as well as the averages of the employment rate, the number of firms and the Herfindahl equivalent number of frms observed at the terminal periods of the simulations.

The results implied by these figures can be summarized as follows.

First, in each run, despite entry; market concentration increases and the simulations end up with an oligopoly of a low number of large firms accompanied by a much higher number of very small firms. "Thronghout this process, a great deal of the initial heterogeneity in R\&D behavior is eliminated. As the firm-level dati shows, the first exiters are those which spend too little on R\&D. In settings characterized by constant R\&D strategies, one also abserves the exit of firms which are too prodigal in their $R \& D$ expenditures. Apparently, selection/competition increases the R\&D efficiency by eliminating the firms that are on the margins (i.e. those which spend ton much as well as those which spend too littile). Namely, the meta-rationality, which is constituted by the selective forces of the economy, has some ability to discriminate between too much and too few effort made on R\&D. The magnitude of R\&D expenditures that emerge as the outcome of selection is clearly increasing in technological opportunities.

However, in cases characterized by constant R\&D strategies, this ability is rather linited. Due to the inability of individual firms to perceive the scale de pendency of R\&D efficiency and their, accordingly, "blind" individual commitment to constant (size independent) R\&D to sales ratios, the economy makes an excessively redundant effort on R\&D. I.e, in the experiments with constant R\&D strategies, the number of R\&D workers employed by each firm of the eventual oligopoly goes far beyond the level where the innovation potential function almost completely saturates (i.e, $275 \mathrm{R} \& \mathrm{D}$ ) workers. "The corresponding levels of R\&D spending is clearly wasteful in terms of current output levels, yet at the same time is high enough to fully exploit the technological opportunities. One can observe that the growth rates realized under constant $R \& D$ strategies are, on the average, somewhat higher than those attained under the satisficing-based bounded rationality assumption. This makes perfect sense if one considers the fact that in the settings characterized by satisficing $\mathrm{R} \& \mathrm{D}$ behavior, even the least greedy firm expects $0.6 \%$ marginal expected retum on $\mathrm{R} \& \mathrm{D}$.

Second, in runs characterized by satisficing, the firms that survive the competition are those which are less greedy in their R\&D return expectations (i.e., those which base their R\&D on the lowest $r_{k}^{R \& D}$ values of the interval from which these 


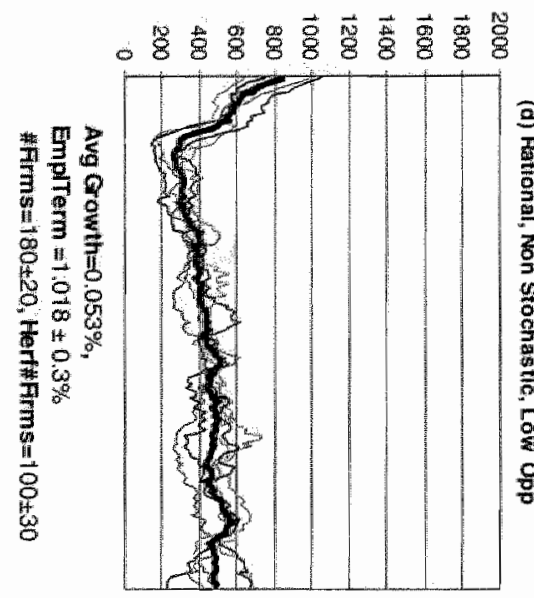

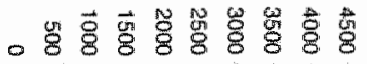
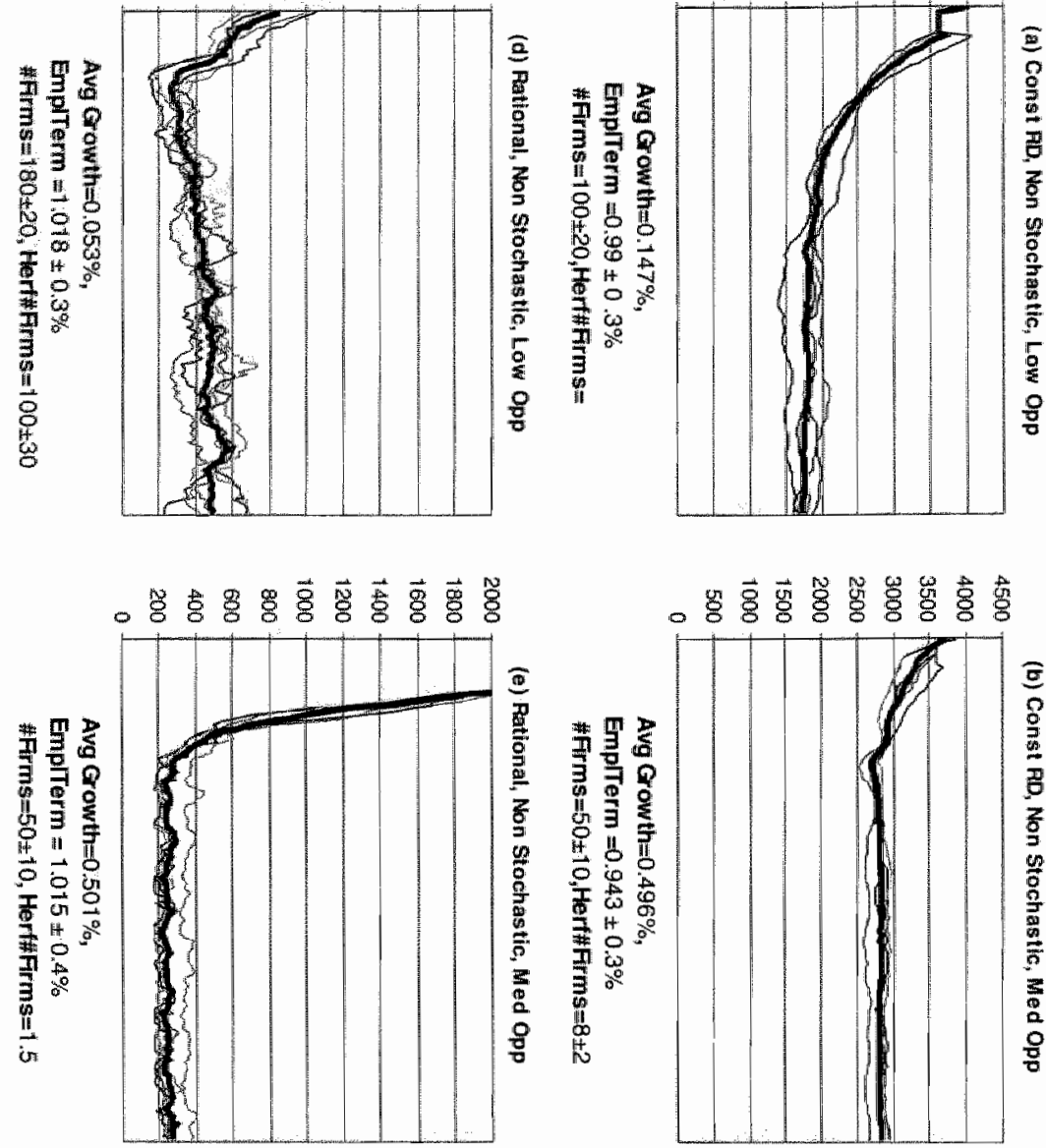

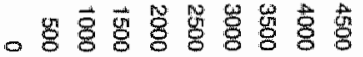

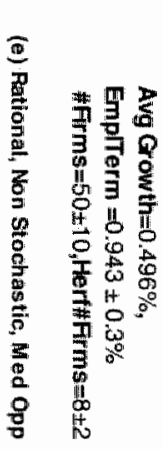

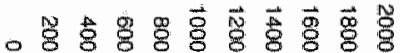
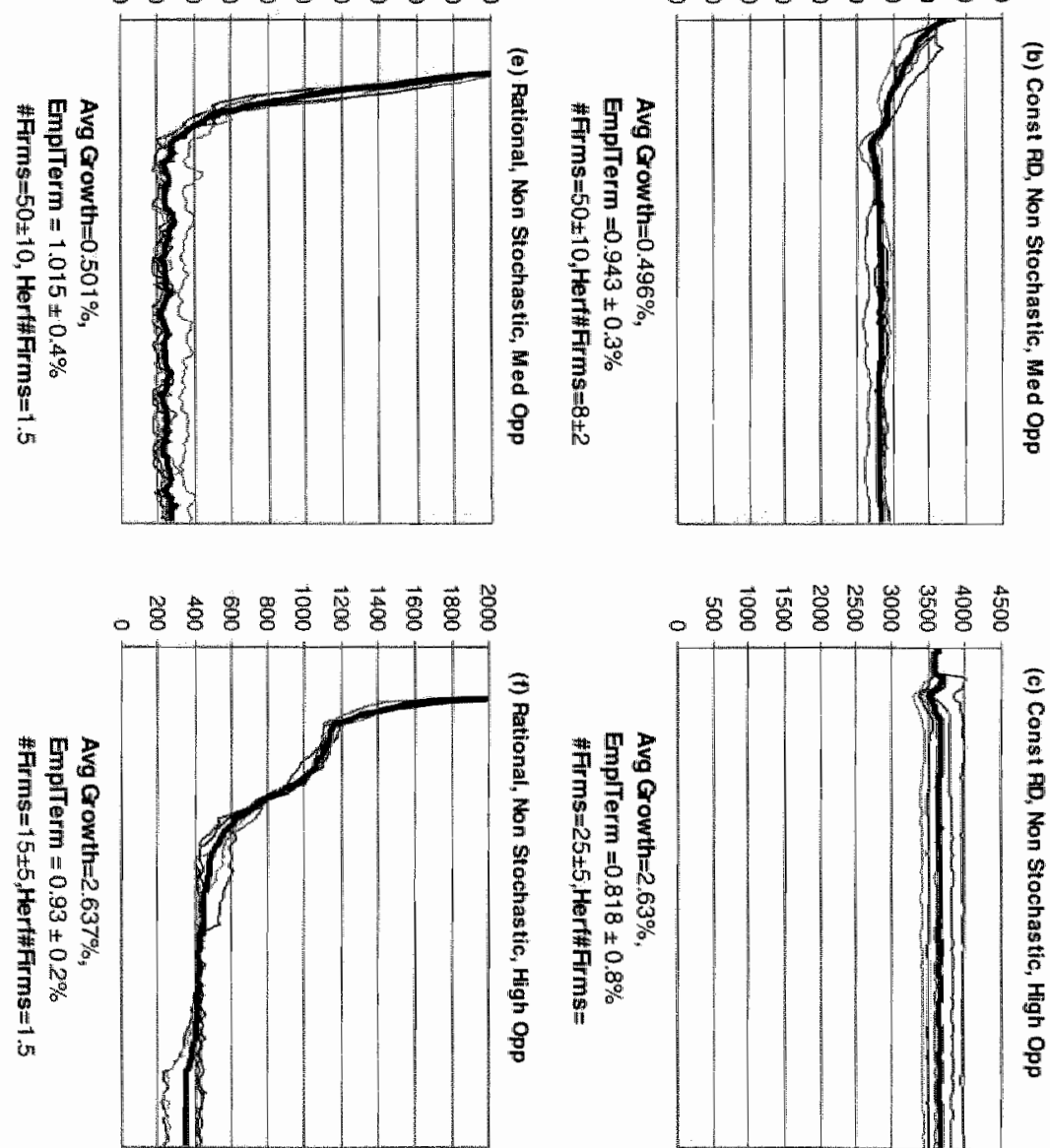

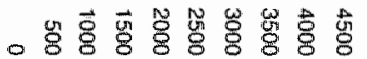
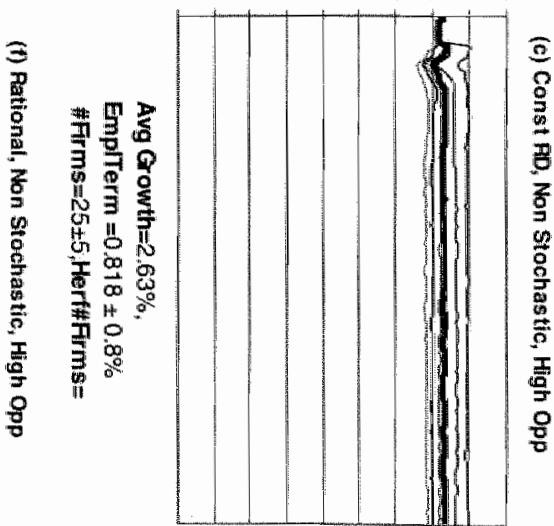

Figure 7.3. Summary charts for the non-stochastic runs of Experiment $6 a$. 

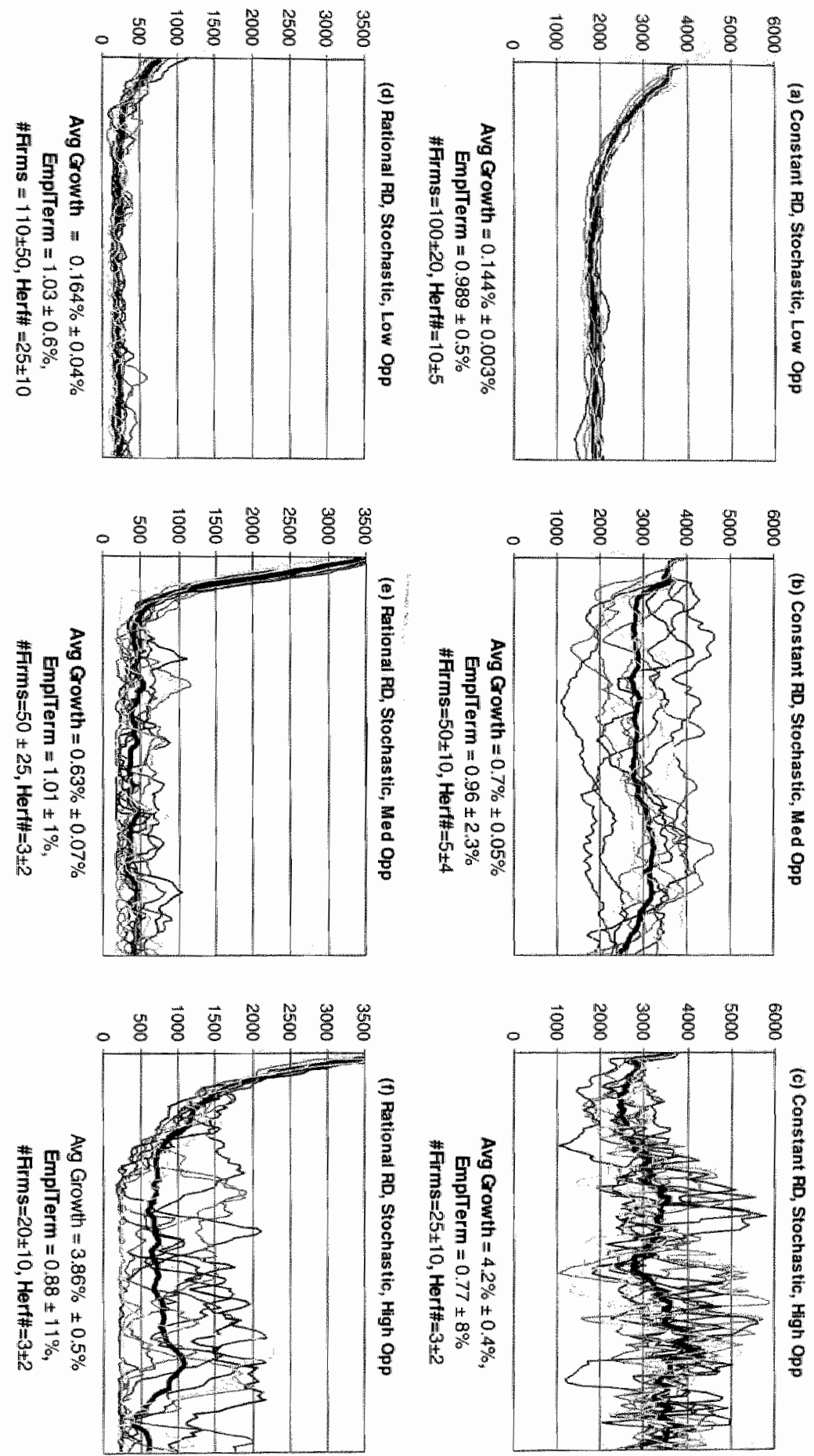

Figure 7.4. Summary charts for the stochastic runs of Experiment 6a. 
magnitudes are randomly drawn). However, due to the bounded rationality that underlies our satisficing formulation, ambition in R\&D by no means implies wastefulness. That is, none of the firms emplloys more than $250-275$ R\&D workers, which, given the parametrization of the R\&D potential function, sets the boundary between ambition and wastefulness as discussed before.

Third, a characteristic of the bounded rationality that underlies our satisficing formulation, is that successful firns save on R\&D later in their life time. This is clearly observable from the time series given by panels $d, e$, and $f$ of figures 7.3 and 7.4: As selection leads to market concentration, and accordingly the employment shares of a few firms rises, the total R\&D expenses of the economy dramatically decrease. In other words, firms, as they increase their employment share, decrease the share of $R \& D$ expenses in their sales revenue. Obviously, this is not the case in case of constant R\&D strategies.

Fourth, stochasticity has a significant potential to undermine selection between alternative R\&D behaviors. In cases where stochasticity in innovation arrivals is eliminated (i.e. where the relation between $R \& D$ effort and returns is not subjected to any stochasticity) one observes only insignificant temporal fuctuations in the number of R\&D workers employed by the economy, and furthermore the variations among the runs with different random seeds are also quite small. On the contrary, in cases with stochasticity, the motion of R\&D expenditures show quite some variations not only over time within given simulations, but also between the alternative runs each fed by a different random seed. The extent of these temporal and cross-sectional variations are clearly increasing in the extent of technological opportunities ${ }^{4}$. Given that sellection does not act directly upon R\&D behavior but its impact on firms' productivities, the strong element of chance in the timing and the extent of the arriving firm-level technological shocks bring about temporary niches in which some firms with the less favorable R\&D strategies temporarily increase their market share and affect the overall $R \& D$ spending of the economy. This effect of stochasticity is exacerbated by the entry of new firms which are assigned the productivity level of the best-practice firm of the entry period ${ }^{5}$. However, on the average (i.e., in terms of the averages of the 10 time series which correspond to another random seed), the total $\mathbb{R} \& D$ spending of the economies remain in similar ranges between runs with stochasticity and those without. In other words, selection retains its discriminative power, but only "on the average".

The "narrow band" of R\&D behavior that results in the simulations may appear as a result of a neoclassical type of optimization by firms. But in the context of selection acting on heterogeneity in R\&D behavior, the key principle that leads to this, is "sustainability" and not necessarily "optimality". Since the only source of R\&D financing is the stream of profits generated by the innovative success in the past, being subjected to competition with others, the necessary condition for a firm to be able to sustain its target R\&D strategy without loosing market share, is the ability to sustain a profitability level that suffices to cover its R\&D expenses. Since current profitability for a firm is strongly dependent on the firm's innovativeness relative to that of the others, and given the fact that innowativeness and proftability of today is a reflection of the resources put into $\mathbb{R} \& \mathrm{D}$ in the (recent) past, a sustainable R\&D behavior/strategy is one which is at least sufficient to generate innovations and thus profitability to finance itself. Firms, that want to commit to R\&D expenditures that exceed this sustainable level, do this at the expense of continuous output and market share loss, which leads to elimination from the market eventually. Similarly, in case of the existence 
of other firms which pursue higher yet sustainable R\&D expenses, firms that stick to low R\&D strategies, despite their short term advantage in terms of R\&D costs (i.e., extra resources which can be used to expand current productive capacity), fall behind in innovativeness and thus productivity and profitabillty in due course and are eliminated. Thus, in competition with the others, form can sustain its R\&D strategy (without shrinking and going bankrupt but mantaining a positive or at least zero growth) only if the stream of profits generated by R\&D effort of the past minus the current R\&D expenditures implies a level of profitiability which is not less than that of the competitors. What remains in the economy is a rarrow band of coexisting alternative $R \& D$ strategies. As shown by our experiments, the width of this band is an increasing function of stochasticity and technological opportunities, which together can blur the sustainability condition upon which economic selection acts. However, even in such cases where the metarationality constituted by the selective forces of the economy is less than efficient, presence of firm-level bounded-rationality helps greatly in terms of narrowing the band in which competing R\&D strategies can coexist.

Let us revisit the model in Silverberg \& Verspagen [1995a] in the context of the discussion above. Except for the existence (in Silverberg and Verspagen) of a genetic learning algorithm in which firms dynamically update their (otherwise fixed) R\&D strategies by local mutations or imitations, the underlying selection mechanism and the way in which technological change is endogenised on R\&D is quite similar to our formulation. In Silverberg \& Verspagen [1995a], at any given instant of the simulation the economy is characterized by a number of firms which are potentially heterogeneous in their temporarily constant $\mathrm{R} \& \mathrm{D}$ (to sales and/or profits ratio) strategies. Naturally, nothing necessarily guarantees that profits are enough to finance the R\&D expenditure implied by each targeted strategy. Even in such cases, the firm realizes its target R\&D expenditures at the expense of losses and the consequent loss in productive capacity ${ }^{6}$. This mechanism already implies the key role played by sustainability in terms of imposing an attractor on. the selection dynamics: A firm can sustain its R\&D strategy (without shrinking and going bankrupt but maintaining a positive or at least zero growth) only if the profits generated by $R \& D$ effort in the past is not less than the R\&D expenses demanded by the strategy in question. Thus, for the overall economy, the theoretical attractor (or the notional steady state) of such dynamics is characterized by an R\&D intensity level which generates a steady stream of profits that is just enough to finance the same R\&D intensity in the future, and also some output growth (investments) that measures up to the growth in labor productivity. The firms of the Silverberg \& Verspagen [1995a] model initially have no idea on the whereabouts of this feasible and sustainable R\&D intensity level. The model nicely demonstrates that in a population where individual firms carry on experimenting with alternative $R \& D$ strategies and/or imitating the strategies followed by the more successful firms, the economy can collectively find out the attractor of the system, though the process leading to this end is by no means simple and straightorward but is somewhat vulnerable to path dependency.

However, Silverberg \& Verspagen [1995a] formulation has two key features, which clears the path of firm's strategy learning process from two different sorts of complications which exist in our formulation: The first is the extent of the potential of stochasticity (as shown in our main experiment) in obscuring the link between $\mathrm{R} \& \mathrm{D}$ effort and its effect on productivity and consequently the sharpness of economic selection; and the second is the existence of scale effects in the R\&D potential function. 
With regard to the firgt; although the technological change formulation of Silwerberg \& Verspagen $[1995 \mathrm{a}\rfloor$ is almost identical to our formulation which we call "technological change with exponential trajectories", the Silverberg \& Verspagen [1995a] model is essentially a capital vintages model, whereas in our model capital embodied technological change only pertains to our discrete technological. paradigms formulation and not to the processes of incremental innovations. In other words, in the Silverberg \& Verspagen model each innovation (thousands of which arrive in a typical simulation run) that leads to a proportional increase in productivity requires the usage of a different type of capital vintage and accordingly the labor augmenting potential of each innovation becomes available to the innovating firm only gradually (as opposed to an instantaneous shock) as the new vintage diffuses into the firm's production facilities. On the contrary, in our capital disembodied incremental imnovation formulation, the relatively rapid arrival of a series of consecutive innovations in lucky period of time can give the firm temporary but strong adwantages in increasing market share in quite a short whille, regardless of whether this advantage is based on the firm's $R \& D$ strategy or pure Juck.

With regard to the second, in the silverberg \& Verspagen model, scale effects in $R \& D$ output are conveniently eliminated by a formulation which renders innovation arrival rate a function of the $R \& D$ strategy (targeted $R \& D$ to sales ratio) but not R\&D expenditures. For example, a firm making a turnover of a million euros, and spending a hundred thousand on R\&D, is assumed to be capable of making a number of innovations which is equal to the number that can be expected from a smaller firm making a thousand euro turnover and spending a hundred on R\&D; because both firms spend $10 \%$ of their revenues on R\&D. Thanks to this assumption, the viability of R\&D strategies are independent of the firm size (distribution) and imitation of strategies are meaningful only then. Furthermore, the absence of the scale effect gives new entrants. (which replace the firms that exit and accordingly maintain the amount of potential variety in the system) fair chances to survive and grow. Contrary to Silverberg \& Verspagen [1995a] and similarly to Dosi et al. [1994], our model specifies innovativeness as a function of the actual R\&D expenditures instead of the underlying R\&D strategies, which implies a strong scale effect and consequently a temporal externality.

\section{An auxiliary experiment on the social optimality of $R \& D$ related sacrifices at the aggregate level (Experiment 6b)}

As shown by the control experiments just discussed, even without firm-level rationality the meta-rationality constituted by selection may suffice to discriminate between waste and too little. Stochasticity in the relation between R\&D effort. and innovativeness decreases the sharpness of the discriminative ability of selection. Firm-level (bounded) rationality greatly contributes to the capability of forces of economic selection at least in the elimination of wastefulness in R\&D expenditures.

However note that, with or without firm-level bounded rationality, selection can accomplish this task only when there is sufficient heterogeneity in alternative R\&D strategies, over which it can make a discrimimation. In other words, as shown by our main experiment above, given a broad range of arbitrary $\mathbb{R} \& D$ strategies, selection reduces the overall extent of arbitrariness. But what if the economy is characterized by a collection of firms that follow the same arbitrarily chosen R\&D strategy? ${ }^{7}$ Or what if an industry operates under the monopoly of a firm (due to 


\begin{tabular}{|c|c|c|c|c|c|c|c|}
\hline & $\begin{array}{l}\text { MDExp } \\
\text { in GDP }\end{array}$ & $\begin{array}{l}\text { PDWrk } \\
\text { Per Firm }\end{array}$ & $\begin{array}{c}\text { Growt bi. } \\
\text { Rate }\end{array}$ & $\begin{array}{l}\text { Empl } \\
\text { Rate }\end{array}$ & $\begin{array}{c}\text { Sacrificed } \\
\text { Istabor }\end{array}$ & $\begin{array}{l}\text { ROR } \\
\text { Total }\end{array}$ & $\begin{array}{c}\mathrm{ROR} \\
\mathrm{RD}\end{array}$ \\
\hline & \multicolumn{7}{|c|}{ Low Technological Opportumities } \\
\hline 1 Firm & $0.39 \%$ & 196 & $0.175 \%$ & 1.02 & $1.39 \%$ & $12.55 \%$ & $44.47 \%$ \\
\hline 10 Finms & $2.72 \%$ & 135 & $0.163 \%$ & 0.99 & $6.71 \%$ & $2.42 \%$ & $5.99 \%$ \\
\hline \multirow[t]{2}{*}{50 Firms } & $7.52 \%$ & 75 & $0.116 \%$ & 0.91 & $.19 .52 \%$ & $0.59 \%$ & $1.548 \%$ \\
\hline & \multicolumn{7}{|c|}{ Medium Technological Opportunities } \\
\hline 1. Fima & $0.46 \%$ & 230 & $0.528 \%$ & 11.0075 & 2.7190 & 19,495 & 114.779 \\
\hline 10 Firms & $3.35 \%$ & 167 & $0.51 .5 \%$ & 0.97 & $9.35 \%$ & $5 ., 5 \%$ & $15.35 \%$ \\
\hline \multirow[t]{2}{*}{50 Firnes } & $10.64 \%$ & 106 & $0.446 \%$ & 0.846 & $29.03 \%$ & $1.53 \%$ & $4.19 \%$ \\
\hline & \multicolumn{7}{|c|}{ High Technological Opportmnities } \\
\hline 1. Fitin & $0.55 \%$ & 275 & $2.676 \%$ & 0.932 & $10.35 \%$ & $25.85 \%$ & $486.34 \%$ \\
\hline 10 Firms & $4.15 \%$ & 207 & $2.65 \% \%$ & 0.878 & $19.35 \%$ & $13.72 \%$ & $63.91 \%$ \\
\hline $50 \mathbb{F i r m}$ & $12.16 \%$ & 121 & $2.457 \%$ & 0.661 & $49.02 \%$ & $5.01 \%$ & $20.19 \%$ \\
\hline
\end{tabular}

Table 7.3. Summary Table for Experiment 6b

entry barriers) which persistently follows an arbitrarily chosen R\&D strategy? In our belief, except for the selective forces of the economy which is potent only when subjected to heterogeneity of $\mathbb{R} \& D$ behavior over a population of firms, there exists no necessary mechanisms that could eliminate arbitrariness and impose optimality (and/or the societies' intertemporal preferences) upon the economy.

An additional control experiment, which draws on our main experiment is designed to illustrate this argument. All runs in this auxiliary control experiment are based on the satisficing behavior in R\&D expenditures. In all cases, we arrange that all firms are homogenous in all senses, including their R\&D ambition by the setting $r_{k}^{R S D}=0.006$, which is the lower bound of the uniform distribution by which firms are heterogenised in our main experiment. Also based on the elimination of stochasticity from innovation arrivals, we heve made 9 control runs, each being another combination of one of the three technological opportumity levels specified in our main experiment (i.e, mincrmt $\in\{0.05,0.15,0.75\})$, and three preset number of firms, the alternatives being 1, 10 , and 50 identical firms, where entry of new firms is also ruled out.

It is clear that, since all initially introduced firms of each given setting are made identical in all senses and stochasticity in innovation arrivals is conventionally eliminated, frrms shall not be affected by the forces selection at all, and follow the identical path during the entire simulation. Thus the current exercise, unlike the previous one, is not an exploration of the effects of selection on R\&D behavior, but is merely an illustration of the link between industrial organization and the aggregate R\&D expenditures of an economy as the emergent outcome of satisficing behavior as characterized by a purely arbitrary threshold parameter $r^{R \& D}$.

In this auxiliary experiment, due to the absence of stochasticity and any heterogeneity over the firms, each of the simulations rapidly converges to a steady state where R\&D expenditures and economic growth converges to steady levels. Table 7.3 depicts observations that pertain to these stearly state growth paths. To summarize:

As shown by the first and the third columns of table 7.3, the total R\&D expenditures, and thus the growth rate of the economy are both increasing in the extent: of technological opportunities as in our main experiment. That is, the incentives to spend on $\mathrm{R} \& \mathrm{D}$ are increasing in the extent of technological opportunities. The 
total R\&D expenditures of the econony is also increasing in the number of firms in the economy. However, the R\&D effort per firm (i.e., the number of $R \& D$ workers employed per firm, as given in the second colum of table 7.3 ) is decreasing in the number of firms. Consequently, given the extent of technological opportunities and no imitation possibilities (which implies repetition in $\mathbb{R} \& D$ effort), economic growth is decreasing in the number of firms. This scale-economies-related outcome is quite similar to that in Experiment $\$ 5$ but in a different sense: At smaller scales, the highly ambitious firms of the current setting choose to increase the share of R\&D expenditures in their sales turnover, yet this increase fails to match the diseconomies of scale in R\&D output, and leads to wastefulness at the aggregate lewel. Clearly, the (bounded) rationality in individual firms" behavior fails to bring about a collective rationality at the aggregate level.

This negative relation between economic growth and the number of firms, implies a negative relation between the total R\&D expenditures of the economy and output growth in this specific context (which is can clearly be observed by evaluating the first and the third columns of table 7.3), and thus waste. Also given the fact that in our model the mere means by which R\&D expenses can be financed are profits, one wonders where the profits that finance the redundancy-related wastefulness in R\&D expenditures come from, in cases characterized by high number of firms. The simple fact is, when a firm or a number of similar firms persistently pursue unsustainable $R \& D$ strategies the rewards of which do not match the effort put in, the resulting losses translate into loss of productive capacity. As we observed in our main experiment, while this is happening only to a group of firms, if there are other firms around that follow better (i.e., sustainable) R\&D strate gies, the shrinkage of the first group of firms are matched by the output growtin of the latter group, which is exactly the process through which selection guides the economy towards sustainable R\&D strategies. However, in case of too little or no heterogeneity in R\&D behavior as in our current auxillary experiment where the shrinkage of the users of unsustainable or irrational R\&D strategies is not matched by the growth of some other firms, simply the total output and employment in the economy/industry keeps on decreasing down to the point where product prices increases, wage rate decreases, and the corresponding increase in profits eventually suffice to finance the waste in $R \& D$ expenditures. In other words, if there exist no firm(s) that the selective forces of the economy would favor, the same forces render the existing arbitrary and unsustainable $\mathbb{R} \& D$ strategies sustainable by decreasing employment and output and accordingly generating forcefully the supernormal profits required to finance the collective irrationality of the firms. This argument is somewhat reminiscent of the Schumpeterian argument on the importance of monopoly profits in financing $\mathbb{R} \& D$ expenditures. Nannely, a monopolist is able to finance any arbitrarily chosen R\&D spending scheme simply by the deliberate manipulation of the product price through adjustments of its output level. Of course, this is not necessarily an option for the firns of a highly competitive market if the firms are heterogenous in their R\&D behavior. However, our discussion above suggests that if the firms of a competitive environment are sufficiently homogenous in their arbitrary R\&D aspirations, the adjustment processes of the economy is capable of accommodating these unsustainable strategies on the firms' behalf, which increases the extent of the total sacrifices that the economy should go through in order to have technological change and economic growth.

This last point is clearly observable in the fourth column of table 7.3 which gives the employment rates observed in our control runs. The evaluation of these 
figures together with the figures given in the first and third columis of table 7.3 points to an interesting outcome which is the fact that given each technological opportunity level, there exists a strong increasing relation between unemployment and the total R\&D expenses of the economy where the latter is an increasing: function of the number of firms. This relation may appear to be purzling, in the sense that for a given technological opportunity level, it implies the possibility of a negatiwe relation between output/productivity growth and the unemployment rate, which, at the first look, seems to conflict with our findings of Experiment \#1 where we demonstrated that technological change brings about persistent unemployment, the extent of which is increasing in the pace of productivity growth. However, this phenomenon is brought about by the causal mechanism explained just above, which suggests an important secondary link between (endogenous) technological change and unemployment, which is the outcome of a self-organizing process that generates the profits that could sustain an arbitrarily chosen R\&D expenditure scheme in cases of little or no heterogeneity among firms.

It is quite straightforward to calculate the total sacrifices of the economy in terms of the opportunity costs of technological change and economic growth in terms of current output level. The basis parameter settings of the current experiments (which are identical to those in. Experiment \#1) imply the steady-state full-employment rate $103 \%$ in case of no technological change. Thus in each of our simulation runs, the extent of the sacrifices made to achieve technological change can be calculated as 1.03 minus the steady-state employment rate observed in the simulation, plus the share of R\&D workers in the total labor force. These figures, which indicate the amount of labor force withdrawn from current final good production, are given in the fifth column of table 7.3. Division of the abserved (steady-state) growth-rate by these figures yields an exact indication of the rate of return on $\mathrm{R} \& \mathrm{D}$ effort which can be found on the sixth column of tarble 7.3 . These figures naturally give an indication that includes the unintended unemployment effects of technological change. The rate of return figures which does not capture the unintended sacrifices made in terms of the endogenously generated technological unemploymert, which are calculated simply by dividing the observed (steady-state) growth-rate by the share of R\&D workers in the labor force, are given on the seventh column of table 7.3. Naturally, the latter figures are much higher than the former. Both rate of return figures are increasing in technological opportunities and decreasing in the number of frms.

Clearly, these rate of return figures, which reflect the actually paid opportunity costs of output growth in terms of bygone current consumption, show significant wariations over our control experiments. This implies that in our evolutionary model, this intertemporal trade-off is resolved endogenously by self-organization, a process which does not per se reflect any notion such as the societies' intertemporal preferences. It is clear from our formulations presented in chapter 5 that the firm-lewel parameter $r_{k}^{R \& D}$ (which denotes the minimum acceptable rate of marginal expected return on an $R \& D$ investments from the individual firms' perspective) has some potential to reflect the societies' intertemporal preferences, especially if this parameter is set to the identical level across all firms of the economy as in the current experiment. Howewer, as the results of the (main and the auxiliary) experiments in this section together imply, the total R\&D expenses of economies which determine the rate of technological process and economic growth are determined by the complex interplay between, technological opportunities, the extents of the heterogeneity in firms $R \& D$ strategies, the selective forces of the economy, endogenous industrial organization dynamics and, as discussed just be- 
10w, the extent of technology spill-overs and/or irnitation possibilities. In other words, the total sacrifices of the economy for productivity and output growth, which refects the resolution of the trade-off between economic growth and current output level, is far from being a mere revelation of the perceptions and the behavior of individual firms (i.e., $r_{k}^{R \& D}$ in case of boundedly rational behavior), but is rather an outcome of a complex process in which the two-way causality between technological change and industrial organization plays the dominant roles. Also considering the results of the first two experiments of this chapter, one can clearly see that demand for product variety, which strongly affects the patterns of industrial organization by niches that protects firms from the forces of selection, may also play an important role in the endogenous determination of the total $R \& D$ related sacrifices of the economy, the resulting economic growth, and consequently the rate of return on $\mathrm{R} \& \mathrm{D}$ effort at the aggregate level.

\section{Further remarks}

In addition to the experiment presented in this section one can also find in the accompanying CD various further simulations on the subject matter along with an appendix to this chapter where one can find discussions on these extra experiments. One of these experiments introduce perfect imitation opportunities over the settings of Experiment 6a. As common sense would suggest, the simulation ends up with the monopoly of the firm which is committed to the lowest of the 50 alternative $R \& D$ strategies randomly generated and assigned to the initial 50 firms. Since selection evaluates firms on the basis of their relative profitability (which is jointly determined by success innovation relative to resources allocated to R\&D) but not their individual contribution to the general technological progress of the economy, in case of perfect technology spill-overs, the number one free rider of the economy, which enjoys an equal extent of technological progress by investing the minimum amount, takes over the market. As the natural consequence of this the economic growth observed is significantly lower than the potential that would have been enjoyed in case of no imitation possibilities. Clearly imitation possibilities introduce a significant trade-off into R\&D based endogenous technological change. As cliscussed in the earlier experiments in this chapter, especially in cases characterized by knowledge spill-overs (or rather exogenous technological change as in sheer learning), imitation possibilities introduce an important externality which has a growth boosting potential. Flowever, in cases where technological change is dependent on $\mathrm{R} \& \mathrm{D}$ effort, imitation possibilities totally change the direction in which economic selection discriminates between alternative R\&D strategies and the consequent rise of free-riding firms drives the economy into a low growth trap.

\subsection{International trade and endogenous growth}

\subsubsection{Introduction}

In the previous chapter, and in line with the "traditional" trade theories, we discussed international trade mainly as an emergent result of intrinsic differences between countries and/or sectors. These differences, whether they be differences in endowments, differences in capabilities or differences in technological characteristics, lead to comparative advantages, and hence to welfare-enhancing specialization and trade. An alternative causation mechanism can be found in new trade literature (e.g., Krugman as discussed before) in the form of dynamic increasing 
returns to scale mechanisms (such as learning by doing). In this case, countries and sectors may start out as identical, but an historical process creates comparative advantages. Accordingly, the answer to the question "which country would specializes on which good" remains a matter of path dependency and is indeterminate in the model. In other words, comparative advantages are imposed in the first strand of trade models while they are built endogenously and mitiated by charce in the alternative approach. We will explore here the ways in which our model can work along the lines of this alternative approach.

In the evolutionary modeling literature, the potential links between international trade are not thoroughly explored within the framework of multi-country, multi-sector, muliti-firm settingsi One of the existing attempts is Dosi et al. [1994]. This model can be seen as one in the tradition of endogenously generated comparative advantages through a process similar to those described by Krugman metaphorically as "a river that digs its bed deeper".

In Dosi et al. [1994] technological change takes place as series of firm-level productivity-augmenting incremental shocks, the firm-Jevel arrival rate of which is a strictly increasing function of the R\&D workers employed by the firm. All firms are assumed to have an identical and arbitrarily assigned $R \& D$ to sales ratio. These two elements clearly constitute a "success breeds success" type mechanism, since larger firms employ relatively more R\&D workers, and as a result enjoy more rapid productivity growth, consequently increase their market shares, and are able to hire even more $R \& D$ workers, etc., which leads to a wirtwous cycle. The authors report simulation results indicating that these firm-level dynamic increasing returns translate into country level virtuous cycles leading to international specialization and persistent cross-country growth rate differentials.

Although not discussed by the authors, one may conjecture that in Dosi et $a$. [1994] the self-organization process that leads to the emergence of cross-country and cross-sector differentials is an implication of the stochastic and endogenous heterogenisation of the firm sizes. One expects that simulations of the Dosi et al. [1994] model generate increasing extents of market concentration as a result of the reinforcement of stochastic differences between firms, and the timing and pace of this concentration process is resporsible for the emergence of specialization and growth differentials.

The first experiment of this section aims at reproducing these broad results of a multi-way causal relationship between technological change, industrial organization, growth and international trade, as found in Dosi et al. [1994]. In first instance, we will focus on the increasing returns setting familiar from the Dosi et al. setting; by focusing on our learning by doing mechanism (which is isomorphic to the Dosi et al. setting of constant R\&D to sales ratios). In the first experiment, we will also introduce product differentiation as a potential way of offsetting the increasing returns to scale mechanism that is so dominant in the Dosi et al. model. In the second experiment of the section, we will present an alterative set of runs that explore, in line with some of the models in the new growth tradition, techmology spill-overs as a counteracting force to the self-reinforcing dynarnics of Dosi et al., and investigate how this affects the relations between industrial organization and growth in the context of international trade. The last experiment of the chapter and the dissertation focuses more specifically on the dynamic galins or losses from international trade in the context of the technological change as endogenised on firm-level boundedly rational $R \& D$ behavior. 


\subsubsection{Experiment \#7: Self-organized emergence of specialization and international growth differentials}

Common to all 21 control runs that we present here, lies a 10 country setting where the basis parameters are set as in table 6.4 for each of the countries. Technological opportunities are given by the parameter settings $\tau=1.431$ and $\mathrm{m} / \mathrm{ncm} \mathrm{m}=0.1$ as in a number of earlier experiments. The S-shaped R\&D potential function (see equations 5.41 and 5.42) which maps the R\&D expenditures (i.e, R\&D workers) of each individual frm to the Poisson arrival rate of incremental innovations it enjoys is parameterized by InnEaseMin $=0.0001$ and $I n n E a s e M a x=0.22 \mathrm{int}$ terms of its boundaries. The inflection point and curvature of the R\&D potential function are respectively set as $R D I n f l c t=30$, and $R D$ Sens $=0.05$. Furthermore, we impose that all firms in $_{j}$ stick to the identical $\mathrm{R} \& \mathrm{D}$ to sales ratio $R D T$ Trgir $=$ 0.05 to determine their R\&D expenditures every period. Based on these common settings we build our control experiments on the basis of differentiation in three dimensions:

- Number of sectors: We experiment with 1 sector, 2 sectors and 10 sectors ( $N S \in\{1,2,10\})$. Given the underlying 10 country setting, a different number of sectors clearly represents different extents of possibilities for specialization. In experiments with more than 1 sector, we assume that customers allocate equal budget shares to each sector ${ }^{8}$.

- Variety demand: As in the first two experiments in this chapter, we differentiate our simulations according to the extent of the substitutability between the products of the firms of the same sector, expecting (again) that the parameter $\theta_{i}$ has a strong effect on the workings of the selection mechanism and thus the industrial organization patterns. The three alternative values chosen to be used in our experiments are $\theta_{i} \in\{1,0.92,0.8\}$.

- Country sizes: As discussed before, similar to Dosi et al. [1994], in our formulation of $R \& D$ based technological change, firm-level scale effects are quite dominant. Given the number of sectors and the number of firms within each of them, the labor force size of a country affects innovativeness, since it determines the number of workers that can be employed by individual firms. Accondingly we introduce the labor force sizes of the economies $\left(\overline{L_{j}}\right)$ as the third dimension of variation in our control experiments. In our basic Iuns we assign $\overline{L_{j}}=20000$ workers to each country. In addition to these, in our experiments with more than 1 sectors $(N S>1$ ) we also experiment with labor force sizes $\bar{L}_{j}=20000 \cdot N S$, which basically aims at keeping the number of workers employable by each sector at the same level across the experiments with different number of sectors.

Given these three control dimensions, the alternative combinations chosen for the current experiment are as follows:

- 1-sector settings:

- H: Sectorally homogenous goods such that $\theta=1$, and $\overline{L_{j}}=20000$ for all countries $j$,

- VD: Variety demand such that $\theta=0.92$, and $\overline{L_{j}}=20000$ for all countries $\dot{j}$, 
- +VD: Higher variety demand such that $\theta=0.8$, and $\overline{L_{1}}=20000$ for all countries $j$.

\section{- 2-sector settings:}

- H: Sectorally homogenous goods such that $\theta_{i}=1$ for both sectors $i$, and $\overline{L_{j}}=20000$ for all countries $j$.

- VD: Variety demand such that $\theta_{i}=0.92$ for both sectors $i$, and $\overline{L_{j}}=$ 20000 for all countries $j$;

- VD+LC: Variety demand and larger country sizes such that $\theta_{i}=0.92$ for both sectors $i$ and $\overline{L_{j}}=40000$ for all countries $j_{*}$

- $+\mathrm{VD}+\mathrm{LC}$ : Higher variety demand and larger country sizes such that $\theta_{i}=0.8$ for both sectors $i$ and $\overline{L_{j}}=40000$ for all countries $i$.

\section{- 10-sector settings:}

- H: Sectorally homogenous goods such that $\theta_{i}=1$ for both sectors $i$, and $\overline{L_{j}}=20000$ for all countries $j$;

- VD: Variety demand such that $\theta_{i}=0.92$ for both sectors $i$, and $\overline{L_{j}}=$ 20000 for all countries $j$,

- VD++LC: Variety demand and larger country sizes such that $\theta_{i}=$ 0.92 for both sectors $i$, and $\overline{L_{j}}=200000$ for all countries $j$,

- +VD + LC: Higher variety demand and larger country sizes such that $\theta_{i}=0.8$ for both sectors $i$, and $\overline{L_{j}}=200000$ for all countries $j$.

All settings, except for the case of homogenous goods with one sector (where, by definition, international trade can not take place) are run once for the case of autarky and once with international trade each for 800 periods. Imitations between firms are ruled out by the setting $I m E a s e_{i j}=0$. Similar to our earlier experiments, by the setting EntArrRt $=0.1$, we arrange that on the average one new frm enters into the economy every ten periods. The initial productivity coefficients of the new entrants are determined as uniform random draws from the interval dymamically set by the labor productivities of worst and best practice firms of the period of entry. Finally, note that in all simulations all countries and all firms are initialized by exactly the same values.

\section{Results}

We document nine descriptive aggregate indicators for the simulation outputs generated by our control experiments. For these indicators, we tabulate in tables 7.4 and 7.5 , respectively, the mean values (over the countries and/or the sectors) and their variation over the countries and/or the sectors (the latter defined as the coefficient of variation, i.e., standard deviation divided by the mean'). The indicators presented in these two tables are defined as follows:

- Welf_Grw: Based on the welfare indicators given by equations 3.7 and 3.8, the average welfare growth rate of each country is calculated on a "per 10 period" basis. Means and wariation are over the macroeconomic aggregates of the 10 countries. 
- Outpt_Grw: The real output growth index (as defined in equation 6.22) is generated for each country separately. The mean and variances are for the macroeconomic aggregates over 10 countries.

- Cons_Grw: This indicator is similar to the previous one except that, instead of the output time series, it is based on the consumption time series. Note that this indicator is quite similar to Welf.Grw in case of homogenous goods. However, given that new firms enter during the simulations, in cases with variety demand (i.e., $\theta<1$ ) where the product of each firm is perceived by the customers as a (somewhat) different product variety, welfare growth may exceed consumption growth.

- Herf\#Firms: Based on the Herfindahl-equivalent number of firms in each sector of each country at each period, the average walue of this magnitude is calculated for the last 300 periods of each simulation run separately for each country-sector combination. Means and variation are calculated over countries and sectors.

- \#Firms: This indicator is similar to the previous one but it uses the actual number of firms instead of the Herfindahl equivalent number of firms.

- Exp/Cons: This indicator is only callculated for the simulation runs with international trade, and expresses the share of exports/imports in total world consumption for each sector separately. The mean values and variation are calculated over sectors, and are taken as an indication of the degree of specialization. For example, in a 2 (10) sector setting, the value 50 (90) would suggest full specialization.

- Eq\#Exprtr: This indicator measures the "extensiveness" (how many producer countries are involved in trade?) of international trade over the world. For ExpShare $e_{i j}^{t}$ being the share of country $j$ in total sector $i$ net exports, one can calculate the Herfindahl equivalent number of sector $i$ exporters as $E q \not t E x p r t r_{i}^{t}=\frac{1}{\sum_{j=1}^{N C}\left(E x p S h a r e_{i j}^{t}\right)^{2}}$ for each period $t$. For each sector we first calculate the average of this magnitudes over the last 300 periods of our 800 period runs for each sector separately, and then calculate the mean and variance of these averages over the sectors.

- Eqfomprtr: This indicator is similar to the previous one, except that it is based on the shares of the countries in total net imports. Hence it yields the Herfindahl-equivalent number of importers. Given that all our experiments are based on 10 countries identical in labor force sizes, the difference of the sum Eq\#Exprtr + Eq\#Imprtr from 10 indicates the extensiveness of trade over the world.

- Spec Index: The previous two measures indicate together the extensiveness of specialization but say nothing about the intensiveness of it. The indicator Spec.Index aims at arriving an overall index of specialization which takes into account both intensiveness and extensiveness of specialization. Let the variable Tot Imp indicate the total sector $z$ consumption which is served by net imports (i.e., $\sum_{j=1}^{N C} \max \left(0, C_{i j}^{t}-Q_{j j}^{t}\right)$ ) and ImprtrComs $s_{i}^{t}$ the total sector $i$ consumption of the countries that are net importiers in this sector. (i.e., $\sum_{\forall j \text { where } C_{i j}^{t}-Q_{i j}^{t}>0} C_{i j}^{t}$ ). Accordingly, the magnitude $\frac{T o t m p p_{i}^{*}}{\text { Tmprtircons } s_{i}^{t}}$, which measures the sector $i$, period $t$, reliance of the 


\begin{tabular}{|c|c|c|c|c|c|c|c|c|c|c|c|c|}
\hline & \multicolumn{3}{|c|}{$1 \mathrm{GOOD}$} & \multicolumn{4}{|c|}{2 GOODS } & \multicolumn{4}{|c|}{$10 \mathrm{GOODS}$} \\
\hline & & \multirow[t]{2}{*}{$H$} & \multirow[t]{2}{*}{$\mathrm{WD}$} & \multirow[t]{2}{*}{$+V D$} & \multirow[t]{2}{*}{$\mathrm{H}$} & \multirow[t]{2}{*}{ WD } & \multirow{2}{*}{$\begin{array}{l}1 \mathrm{D} \\
+\mathrm{LC}\end{array}$} & \multirow{2}{*}{$\begin{array}{l}+V D \\
+L C\end{array}$} & \multirow[t]{2}{*}{$H$} & \multirow[t]{2}{*}{ 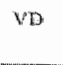 } & \multirow{2}{*}{$\begin{array}{c}\mathrm{WD} \\
+\mathrm{LC}\end{array}$} & \multirow{2}{*}{$\begin{array}{l}+W D \\
++4 L\end{array}$} \\
\hline & & & & & & & & & & & & \\
\hline \multirow[t]{2}{*}{ Wolmorw } & A & $4 . E$ & 3.94 & 1.26 & 2.35 & 0.58 & 2005 & 0.58 & 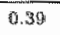 & 0.28 & 2.89 & 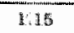 \\
\hline & $\mathrm{T}$ & & 2.4 & 1.98 & 4.61 & L.M.4. & 5.218 & 1.89 & 4.32 & 0.54 & 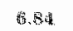 & 1.89 \\
\hline \multirow[t]{2}{*}{ Ontpt_Grw } & A & 4,6 & 1.92 & 0.35 & 2.35 & 0.365 & 2.02 & 0.34 & 0.39 & 0.02 & 1. 36 & 0.31 \\
\hline & $\mathrm{T}$ & & 2.1 & 0. 35 & 4.60 & 0.7 & 5.08 & 0.31 & 4.32 & 0.01 & 6.55 & 0.34 \\
\hline \multirow[t]{2}{*}{ Coms_Girw } & A & 4.6 & 1.92 & 0.35 & 2.35 & 0.36 & 2.02 & 0.31 & 0.39 & 0.02 & 1.86 & a.3. \\
\hline & $T$ & & 2.22 & 0.35 & A. & 0.80 & 5.24 & 0.31 & 4.34t & $0.0 \%$ & 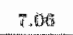 & 0.35 \\
\hline \multirow[t]{2}{*}{ 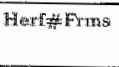 } & $\mathbf{A}$ & 1.01 & 8.04 & 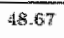 & 1.06 & 27.94 & 587 & 54.77 & 1.79 & 55,4 & 7.01 & 85 \\
\hline & $T$ & & 6. 3.3 & 51.36 & $10 \mathrm{~L}$ & 18.50 & 1. 10 & 34.97 & 1.00 & 55.83 & 3.04 & 53.30 \\
\hline \multirow[t]{2}{*}{ Firms } & $A$ & 4.71 & 35.4 & 65.37 & 6.79 & 80.74 & 30.42 & 71.75 & 11.80 & 61.24 & 900.70 & $6,9,96$ \\
\hline & $\mathbf{T}$ & & 32.85 & 70.57 & 2.67 & 50.16 & 6.03 & 69.45 & 1.40 & 63.31 & 2,05 & 68.09 \\
\hline Exp/Con & & & 5.22 & 21 & 50.00 & 34,88 & 50.00 & $5.8 \mathrm{dith}$ & 89.56 & 11.87 & 87.35 & 14.52 \\
\hline Ed Exprt & & & 1.47 & 2.75 & 4.60 & 2.80 & 3.80 & 3.58 & 1.00 & 2,79 & 1.110 & A.29 \\
\hline 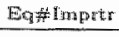 & & & 6.58 & 3.75 & 460 & 3.65 & 410 & 3.58 & 9.00 & 4.47 & 781 & 4.57 \\
\hline Specindex & & & 9.1 & 2.42 & 91.93 & 43.28 & 79.01 & 8.8 & 929.96 & 14.94 & 88.86 & 17.04 \\
\hline
\end{tabular}

Table 7.4. Summary Table for Experiment 7-Mean Values-

\begin{tabular}{|c|c|c|c|c|c|c|c|c|c|c|c|c|}
\hline & \multicolumn{3}{|c|}{$1 \mathrm{GOOD}$} & \multicolumn{4}{|c|}{$2 \mathrm{GOODS}$} & \multicolumn{4}{|c|}{$10 \mathrm{GOODS}$} \\
\hline & & $\mathrm{H}$ & VD & $+\mathrm{VD}$ & $H$ & $Y \mathrm{D}$ & $V D$ & $+W D$ & $\mathrm{HI}$ & $V D$ & $\mathrm{VD}$ & $+\mathrm{VD}$ \\
\hline & & & & & & & ALC & $+4 \mathrm{LO}$ & & & $+\mathrm{LCO}$ & +40 \\
\hline \multirow[t]{2}{*}{ Welf.Grw } & $A$ & 0.5 & 48.7 & 10.4 & 4.8 & 24.9 & 25.7 & 24.9 & 13.5 & 1.9 & 12.1 & 2.4 \\
\hline & $\mathbf{T}$ & & 42.3 & 5.65 & 11.35 & 29.3 & 12.3 & 1.8 & 0.0 & 1.1 & B..1. & 1 \\
\hline \multirow[t]{2}{*}{ Oudptich } & A & 11.9 & 53.8 & 48.7 & 4.8 & 49.7 & 28.1 & 12.6 & 1.4. & 30.3 & 13.4 & in \\
\hline & $\mathbf{T}$ & & 55.8 & 491.4 & 11.5 & 57.5 & 14.7 & 14.7 & 11 & 70.7 & 10.8 & 8.7 \\
\hline \multirow[t]{2}{*}{ Cons Gur } & $\bar{A}$ & 11.9 & 530 & 48.7 & 4.8 & 49.7 & 2.1 & 12.6 & 14 & 30,3 & $13 \times 4$ & 118 \\
\hline & "T" & & 45.6 & 30.1 & 11.5 & 415 & 12.3 & 10.65 & 0 & 29 & 8 & 5.4 \\
\hline \multirow[t]{2}{*}{ 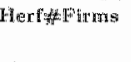 } & A & 0.2 & 83.3 & $2 \overline{6} .1$ & 10 & 40.1 & git & 1.4.9 & 32 & 12.6 & 71.69 & 17 \\
\hline & $\mathbf{T}$ & & 88.9 & 20.7 & 0.0 & 55.6 & 20.5 & 13.7 & 0.4 & 12.2 & 14.8 & 1.6 .3 \\
\hline \multirow[t]{2}{*}{ 菻Firnma } & A & 12.5 & 53.3 & 11.0 & 15.8 & 10.5 & 57.9 & 10.2 & 29.6 & 9.6 & 47.1 & 11.6 \\
\hline & $\mathbf{T}$ & & 59,8 & 11.9 & 63.7 & 44.7 & 88.6 & 9.4 & 88.2 & 13.1 & 132.6 & 1.1 \\
\hline Exp/Cons & & & & & 0,0 & 0.7 & 0.0 & 1.4 & 0.01 & 30 & 4.4 & 39.65 \\
\hline Equaxprer & & & & & 1.6 .5 & 10.0 & $15.6 \mathrm{ii}$ & 8.2 & 0.0 & 33.2 & $24: 5$ & 21.8 \\
\hline 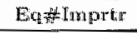 & & & & & 16.6 & 6.4 & 1.1 .4 & 11.6 & 0,0 & 16.1 & 5.4 & 23.1 \\
\hline Specmindex & & & & & $0: 00$ & 41 & 1.6 & 1.3 & 0.02 & 27.8 & 4.7 & 439 \\
\hline
\end{tabular}

Table 7.5. Summary Table for Experiment 7 -Percentage Variation Around Means-

importing countries on imported goods, is an exact measure of the intensiveness in sectoral specialization. Our overall measure of sectoral specialization is thus

$$
\text { Spec_Index }{ }_{i}^{t}=100 \cdot \frac{\operatorname{TotImp}_{i}^{t}}{\operatorname{ImprtTCons_{i}^{t}}} \cdot \frac{E q \# E x p r t r_{i}^{t}+E q H I m p r t r_{i}^{t}}{N C},
$$

where the number of countries $N C=10$ in all experiments. Clearly $0 \leq$ Spec Index ${ }_{i}^{i} \leq 100$, where 0 indicates no specialization and 100 perfect specialization at the world scale. For each sector $i$, we first calculate the average of Spec Index ${ }_{i}^{t}$ over the last 300 periods of our 800 period runs for each sector separately, and then calculate the mean and variance of these averages over the sectors.

Before starting with our discussion on the implications of the indicators given in tables 7.4 and 7.5 , let us take a look at he properties of our R\&D potential function in the context of the particular parametrization that underlies the current experiment. Figure 7.5 depicts the firm-level relation between the number of 


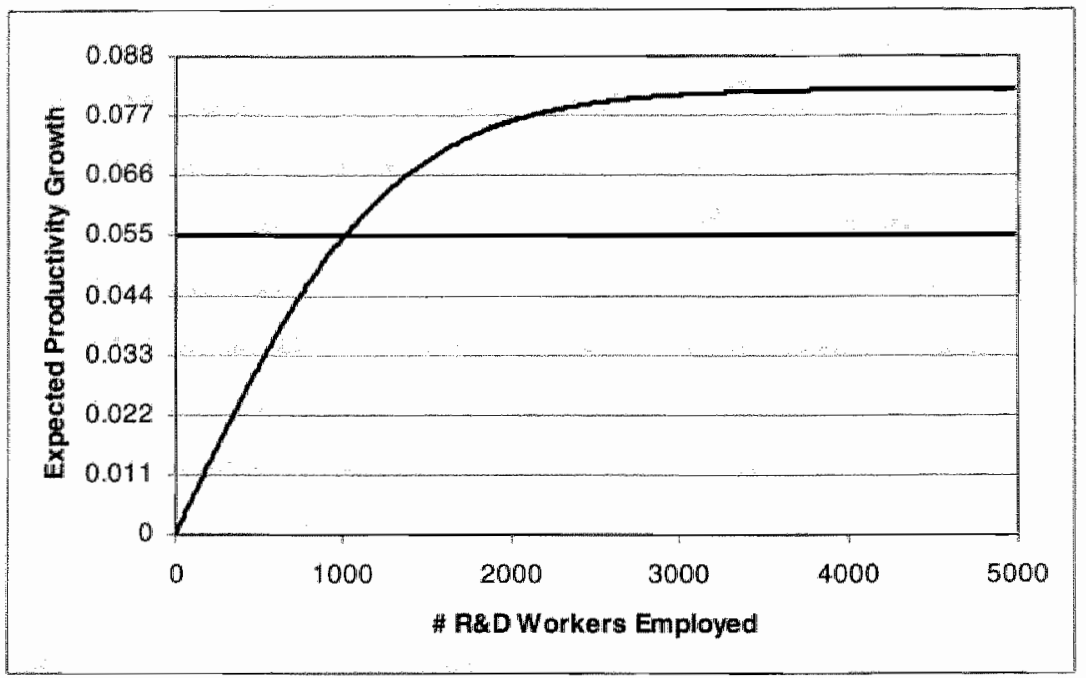

Figure 7.5. The firm-level relation between R\&D effort and expected average (per 10 periods) productivity growth in Experiment 7.

workers employed and the expected (per 10 period) average productivity growth. Now assume a hypothetical case where the entire production is made by a single firm in a country. In settings with normal country sizes (i.e., $\overline{L_{j}}=20000$ ), the constant $5 \%$ R\&D to sales ratio target imposed in our current experiment would approximately amount to $20000 \cdot 5 \%=1000 \mathrm{R} \& \mathrm{D}$ workers, which, according to figure 7.5 implies $5.5 \%$ productivity and output growth per ten periods. For the settings with $\overline{L_{j}}=40000$ (i.e., $40000 \cdot 5 \%=2000$ ), the attainable growth rate is $7.7 \%$. However, for the settings where $\overline{L_{j}}=200000$ (i.e., $200000 \cdot 5 \%=10000$ ), we reach the saturation of the $R \& D$ potential function (which lies at approximately $4000 \mathrm{R} \& \mathrm{D}$ ), and the attainable growth rate rises to only around $8.3 \%$. Thus, except for this last case of very large country sizes, the relation between R\&D effort and the consequent productivity growth rate is monotonically increasing. Hence, except for the largest country size, our model resembles the settings in Dosi et al. [1994t].

Clearly, these output and productivity growth rates can only be reached if a country fully specializes in a sector and this sector is taken up by a monopalist. In all other possible cases (less than perfect specialization and market concentration less than monopoly) one expects growth rates that are less than the estimations given above. Thus, these estimations provide a yardstick for the output and welfare growth rates endogenously generated by our experiments, the cross-country means and variances of which are tabulated in tables 7.4 and 7.5 . One can derive the following conclusions from these indicators.

First, in settings with more than one sector, one observes different extents of international specialization. Generally, the extent of specialization (Exp/Cons, Eq Exprtr, Eq\#Imprtr, Spec-Index) is a decreasing function of the demand for variety. As indicated by table 7.5, one does not observe large differentials in the extents of specialization across-the sectors. However, in cases where specialization is less than perfect at the world scale, one generally observes (not documented) sig- 
nificant cross-country differentials in the extents of specialization. That is, in cases where the sum Eq Exprtr + Eq\#Imprtr is less than $N O=10$, a coalition of Eq\#Exprtr + Eq\#Imprtr countries trade mutually, and a number of others are left out of international trade. Thel-sector experiments with demand for variety also yield intraindustry trade. In the experiment with nedium extent of variety demand, 2 countries are net exporters while the rest are net importers. Note that the specialization indicators given in table 7.4 are based on net trade flows, and thus measure the extent of inter-industry specialization. Hence, specialization in our single-sector experiments clearly refers to specialization into quantity and rariety, leading to net trade flows where the net exporters export masses of products with little - within- variety at relatively low prices, in return for smaller bundles of a mixe of high product variety at relatively higher prices. The high extent of crosscountry, cross-sector variation in sectoral market concentration (i.e., Herfindahl equivallent number of firms) and also in sectoral number of firms, also support this argument. However, in case of increased variety demand such specialization is less pronounced. That is, despite the presence of intraindustry trade, no country emenges as a major exporter of high quantities with low variety in return for lesser quantities of higher variety.

In settings with more than one sectors and variety demand, introindustry trade still takes place. Yet as discussed in chapter 4, there exists a trade-off between intra- and inter-industry trade. That is, since variety demand works against the selection forces (i.e., by creating protective niches for relatively high cost firms), which, on the world scale, lead to specialization and inter-industry trade on the basis of productivity differentials, in cases with variety demand one observes less inter-industry trade and specialization. On the other hand, intraindustry trade wolume is an increasing function of variety demand.

The second main conclusion is that in all cases, international trade clearly leads to higher growth rates in output, consumption and welfare at the world scalle (Welf_Grw, Outpt_Grw, Cons_Grw). Both in cases of autarky and trade, growth rates turn ont to be a decreasing function of variety demand, and given identical levels of variety demand, an increasing function of country sizes. Sectoral market concentration (indicated by Herf\#Firms, \#Firms) also turns out to be a decreasing function of variety demand, and given identical levels of variety demand, an increasing function of country sizes. These two tendencies together highlight the positive relation between market concentration and output/consumption growth, or, equivalently, the trade-off between product wariety and productivity/output growth, which we demonstrated before in Experiment 5 in the context of learning by doing. In this sense, the implications of the endogenisation of techriological change in the current experiment is isomorphic to those of a firm-levell learning by doing formulation, and to the Dosil et al.[1994] findings.

In all cases, significant extents of output growth differentials endogenously emerge across the countries (see table 7.5). These differentials are at a minimum with sectorally homogenous goods (when one observes extreme market concentration). Output growth differentials peak in cases with a medium level of variety demand, and decrease as variety demand is further increased (i.e., an inverse Ushaped relation). However, unlike output growth rates across the countries and sectors, cross-country dispersion in aggregate consumption growth, and especially welfare growth, are diminished by international trade, which, due to specialization, increases the division of labor and thus the interdependence over and among the countries. Most pronounced is the 10 sector case that assumes perfect substitutability of products within sectors. Here international specialization is perfect 
(1.e. each of the 10 countries is specialized in a different sector). and despite the existence of cross-country differences in output growth, cross-country dispersion in consumption and welfare remains zero both in terms of growth rate and levels.

International trade alone does not necessarily bring about a change in the average number of firms per sector. However, with or without trade, one observes significant cross-country and cross-sector differentials in terms of the industrial organization indicators. Similar to growth rate differentials, the cross-country and cross-sector variations in number of firms in each sector and sectoral market concentration turn out to be inverse $U_{m}$ shaped functions of the extent of demand for variety. Note that in all cases, the number of firms is significantly higher than the Herfindahl equiwalent number of firms, which indicates that firm level size distributions are far from uniform. In terms of product variety, this finding indicates that the magnitude of effective variety (i.e., Herfindahl equivalent number of product varieties) is less than the actual number of products (i.e., the number of firms). Clearly, conntry size has a significant effect on the trademoff between variety and quantity in consumption. Comparison of the welfare growth and Herfindahl equivalent number of firms indicators in the runs $V D, V D+L C,+V D+L C$, and $+\mathrm{VD}++\mathrm{LC}$ shows that, for a given level of variety demand, a higher country size leads to less product wariety, but higher quantity of consumption. If demand for variety is sufficiently high, countries can afford to enjoy significantly higher extents of product variety at lower opportunity costs in terms of growth of the quantity consumed.

These results are readily comparable to a number of results one can find in the literature addressing similar issues. First, they reproduce the findings of Dosi et al. [1994]: despite the identicity of everything at the initial period, the dymamic stochastic process endogenously differentiates the firms to such extents that the countries are also differentiated in terms of the composition of their production (i.e., specialization) and growth rates. Another interesting similarity is not documented here: spectral analyzes applied to the welfare time series of the countries indicate a dominant periodicity of 40-50 periods, which, compared to the duration of our simulation runs (i.e., 800 periods each), can be evaluated as long waves. The emergence of such periodicity is clearly an outcome dynamics similar to those shown in Silverberg and Lehnert [1993].

Furthermore, we have also been able to relate the extents to which these results occur to the extent of variety demand and country size, which takes the discussion towards mainstream models that address "economic growth by wariety". As discussed in the introductory chapter, in models that follow such lines, economic growth is presented as an increase in product variety, and the key question addressed is "what mechanism keeps $R \& D$ aimed at introducing new product varieties going?". One can find answers such as population growth, education (i.e. investment in human capital), knowledge spillmovers, and international trade. There exist also a number models that combine productivity growth with product heterogeneity in the context of the trade-off in between, e.g., Lucas [1988] and Romer [1994]. For example, the latter demonstrates that despite the fact that trade liberalization instantly increases the number of product varieties available to consumption, due to international specialization that emerges as a result of scale effects in production, the number of product types produced per country is apt to decline dynamically. In a recent work, Straathof [2005] also shows that in the context of economic selection, firm-level productivity shocks can lead to the increase of the aggregate quantity of production/consumption at the costi of the decreasing of product variety in the consumption mix. Our results discussed 
above, which emerge from various combinations of variety demand, country sizes, and international trade which affect the firm-level pace of labor productivity and output growth, are apparently quite in line with these latter suggestions.

Yet while optimization is behind much of the results in these models, our model is much more in line with Dosi et al. [1994] in terms of its explanation of the emergence of specialization from conditions where all sectors, firms and countries are identical. The central role in this process is for the stochasticity of firmlevel technology shocks, which keeps on generating small productivity differences among the individual firms which are dynamically magnified by selection together with firm-level scale effects in imnovation. As observed in our experiments that assume sectoral product heterogeneity (i.e., $\theta_{i}=1$ ), in cases where firms are most fiercely exposed to the forces of economic selection (and void of protection by variety demand), firm-level productivity differentials, despite their initial small size, are translated gradually by economic selection into significant market share differentials. The strong scale effect in firm-level innovation increasingly translates these (otherwise temporary) market share differentials into more significant and persistent productivity and market share differentials, and this locks industries into highly concentrated market schemes, despite the continuous entry of new firms). The differentiation of countries in terms of output growth and specialization is simply a matter of the temporal order along which such transformations emerge across individual sectors in individual countries. In other words, if sector $i$ of country $j$ experiences this -market concentration increasing-transformation before the $i^{\text {th }}$ sector of the other countries, it has a great chance to specialize in this sector. The timing of the same process across the sectors and the countries also explain the growth differentials that endogenously emerge across the countries as a pure matter of stochasticity which is translated into a path-dependent process by the scale effect in relative innovativeness.

Clearly, variety demand foils this transformation strongly. That is, despite the fact that stochasticity keeps on heterogenising firms with respect to their relative productivity, variety demand creates niches that protect relatively less productive firms against the forces of economic selection, and small productivity differentials can not find the opportunity to be transformed into substantial market share differentials and persistent and larger productivity differentials. In terms of growth, variety demand accordingly introduces some kind of vicious circle: As long as market concentration can not be increased, the economy remains trappedt in low productivity growth (i.e., low inmovation arrival rate), and as long as the rate of technological change is accordingly slow, the likelihood that stochasticity brings about cross-firm heterogeneity that is large enough (given the high extent of variety demand) to trigger a substantial increase in market concentration remains low. The continuous entry of firms, which, due to the protection of variety demand, continuously decreases the market shares of incumbent firms, renders the situation only "worse". The result is a low growth, low specialization trap, the only positive side being the high number of product varieties that can be enjoyed by the society.

It is also possible to evaluate our findings in comparison to Krugman [1979], who, as we discussed in chapter 1 , demonstrates that in case of static increasing returns to scale, the trade-off between variety and quantity is resolved rationally such that the number of product varieties that can be produced by an economy is $\frac{\bar{L} \cdot(1-\theta)}{F^{2} C}$, which implies proportionality to the labor force size $\bar{I}_{\text {, }}$, and to the extent of variety demand (i.e., $1-\theta$ ), and inverse proportionality to the firm-level fixed costs in production FC (which underlie the existence of static scale economies). Our experiment demonstrates that in case of dynamic scale economies, the trade- 
off in question is resolved purely by self-organization. However, despite the fact that the number of warieties produced by the economy is still affected by country size and the extent of variety demand, the relation that links the latter two to the former is not necessarily as straightforward as a multiplicatiwely proportional relation.

Finally, note that in our formulation the parameters RDInflct and RDSens that together determine the number of $R \& D$ workers above which the positive relation between $\mathrm{R} \& \mathrm{D}$ effort and return saturates (i.e., according to the function given by equation 5.41). Let the variable SatRD denote this magnitude. Then $S a t R D$ has an effect similar to the firm-level fixed cost parameter $F C$ of the Krugman [1979] formulation. Given the constant R\&D to sales ratio target RDTarg followed by each firm, one can calculate the threshold firm size (in terms of total employment) above which the scale effect in innovativeness saturates, as $\frac{S a t R D}{R D T}$. Clearly, in an industrial organization scheme at which none of the firms are larger than $\frac{\text { SatR.D }}{R D T a r g}$, the trade-off between product variety and the growth of consumption quantity does not exist. In other words, an NS sector economy can afford

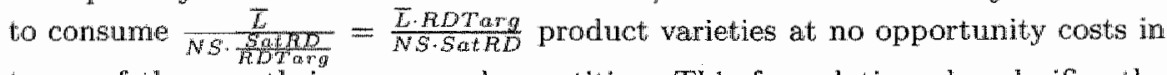
terms of the growth in consumed quantities. This formulation also clarifies the positive effect of intermational trade on product variety: In a case of specialization in one of the sectors, since the country car stop production in $N S-1$ sectors and buy these from abroad in return for its exports, it can afford to produce $\frac{\bar{L} \cdot R D T a r g}{S \operatorname{at} R D}$ effective product varieties whithout bearing any opportunity costs in terms of the growth in quantities.

In the context of the settings of the current experiment, where $R D T a r g=5 \%$, $S a t R D \approx 4000$, the magnitude $\frac{\bar{L} \cdot R D T a r g}{N S \cdot S a t R D}$ is less than 1 for all the three alternative country sizes assumed in our control experiments (i.e., 20000, 40000, and 200000), which explains the strong implications of wariety demand and international trade on production and consumption growth rates. Of course the same is true for Dosi et al. [1994] where there is no saturation effect in the monotonically increasing relation between $R \& D$ effort and innowation arrivals (i.e., $\operatorname{Sat} R D=\infty$ ). The current experiment does not feature the saturation element in its control dimensions. Yet with additional experiments not documented here, we have verified that the extent of the dynamic variety-quantity trade-off and also the extent of the positive effect of international trade on output growth is indeed decreasing in the extent of the scale effect in R\&D output (i.e., SatRD, which is controlled by the parameters RDInflet and RDSens as mentioned before).

\subsubsection{Experiment \#8: Knowledge spill-overs and specialization}

In the previous experinent, we reproduced the evolutionary Dosi et al. [1994] context of strongly cumulative technological change, and showed how this, as in. Dosi et al., leads to specialization and persistent growth rate differentials (although regulated by the extent of product differentiation). We also showed that this is similar to a number of models in the mainstream that also stress cumulative technological change. In the next experiment, we undertake to investigate how knowledge spill-overs influence this outcome. If knowledge spills over between firms within the same country, or even between countries, what will be the effect on specialization, and do growth rate differentials still persist? 
Our learning by doing formulation allows for the introduction of knowledge spill-overs in varying extents and scopes through the parameters $\Omega_{i} N_{\text {Nam }}$, and $\Omega_{i}^{L B D}$ Foren. Based on the above mentioned isomorphism between the endogenising principle of the previous experiment and learning by doing, we now turn-off our R\&D based technological change module and turn on the leaming by doing module instead. We then follow a quite simple experimenting strategy which is somewhat similar to that in Experiment $6 \mathrm{~b}$. Instead of waiting for stochasticity and entry to create differences in firms sizes and productivity levels, we will differentiate countries and sectors with respect to the number of firms from the beginning, and hence 'seed' the model with country-sector level heterogeneity in industrial organization. Consequently, we focus solely on the implications of international differentiation of industrial organization on growth and international specialization in the context of knowledge spill-overs of varying scopes.

Each of the control runs in the current experiment are based on a two-country two-good setting where the basis parameters are assigned values as in table 6.4 . The learning by doing module is activated by the basis setting $\Omega_{i, B a s e}^{L B D}=2$ for both sectors $i=1,2$, which implies quite a strong learning by doing effect. Countries are identical in their labor force sizes and all the existing firms are assigned the identical initial labor productivity level. The only built in cross-country and sector heterogeneity is the number of firms: We introduce 10 firms in the first (second) sector of the first (second) country and 20 in the second (first) sector of the first, (second) country.

Over these basic settings we have 9 control runs. The main control dimension is the scope of knowledge spill-overs:

- The 3 experiments belonging to the first set (E9a_Det_Aut, E9a_Det_Trd, and E9a_Stoch_Trd) assume perfect knowledge spill-overs between firms within each sector, regardless of the country of origin (i.e., $\Omega_{i, N a t n l}^{\mathrm{LBD}}=1$ and $\Omega_{i, F \text { omeign }}^{L B D}=1$ for both sectors $i$. (See equation 5.35).

- In the 3 experiments of the second set (E9b_Det_Aut, E9b_Det_Trd, and E9b_Stoch_Trd), sectoral knowledge spill-overs are confined to national borclers only, by $\Omega_{i, \text { Natnl }}^{L B D}=1$ and $\Omega_{i_{n} F \text { Foreign }}^{L B D}=0$ for both sectors $\dot{i}$.

- In the 3 experiments of the last set (E9c_Det_Aut, E9c_Det_Trd, and E9c_Stoch_Trd), knowledge spill-overs are ruled out by the settings $\Omega_{i_{*}}^{L B D}$ Ranl $=0$ and $\Omega_{i}^{L E D}$ Freign $=0$, which reduces the innovativeness of each firm to an increasing function of its own size, as in the previous experiment.

For each of the three knowledge spill-over conditions, we rum three control simulations. In the first two runs of each experiment, we turn off the stochasticity module (i.e., such that the productivity progress for each firm follows the motion specified by the expected walue equations). Under these deterministic technological change settings, we run each experiment once for the case of intermational trade (i.e., E9x_Det.Ted) and once for autarky (i.e., E9x_Det_Aut). In the third run of each set, stochasticity is turned on and international trade is allowed (i.e., E9x_Stoch_Trd).

\section{Results}

The key indicators are summarized in table 7.6. In a deterministic context first row, second column of the table), perfect global knowledge-spill overs completely clear away the incentives for international trade and specialization. That is, given that in the current settings the only possible reason for speciallization is 


\begin{tabular}{|c|c|c|c|c|}
\hline & & Det_Aut & Deet_Trd & Stoch_Trd \\
\hline \multirow{3}{*}{ E9a } & Growth & $2.6 \%$ & $2.6 \%$ & $2.6 \%$ \\
\hline & Specialization & & None & Perfect \\
\hline & E4 HFirns per sector & $10 / 20$ ass at $t=0$ & $10 / 20$ ats at $t=0$ & $1-2$ \\
\hline \multirow{3}{*}{$\mathbf{E} 96$} & Growth & $1.2 \%$ & $1.2 \%$ & $2.5 \%$ \\
\hline & Specialization & & None & Perfect \\
\hline & Ee HFirms per sector & $10 / 20$ as at $t=0$ & $10 / 20$ as at $t=0$ & $2-3$ \\
\hline \multirow{3}{*}{ E9c } & Growth & $0.09 \%$ & $0.25 \%$ & $2.1 \%$ \\
\hline & Specialization & & Perfiect & Perfect \\
\hline & Ha H Firms per sector & $10 / 20$ as at $t=0$ & 10 & 1 \\
\hline
\end{tabular}

Table 7.6. Summary Table for Experiment 8

the dynamically-generated productivity differentials brought about by the firmlevel scale effects, global knowledge spill-overs (which render innovativeness independent from the sizes of individual firms) inhibit the emergence of such crosscountry differentials despite the existence of the (built-in) cross-country differentials in sectoral patterns of industrial organization. With perfect global knowledge spill-overs, international specialization takes place with stochasticity. In this case, random innovations bring about market concentration, which persists and leads to specialization. However, the cross-country and cross-sector heterogeneities in industrial organization do not bring about cross-country differentials in growth raties $^{10}$.

If, on the other hand, knowledge spill-overs are confined to national borders, international trade does increase growth rates of economies through specialization, but (as reflected by run E9b_Stoch_Trd) only if stochasticity brings about random productivity differentials among the firms and accordingly leads to high market concentration at the global scale.. In a deterministic context, we do not observe specialization or a different growth rate than under autarky. When specialization does take place (i.e., in a stochastic context), global monopolization in each sector combined with specialization, despite the confinement of knowledge spill-overs to national borders, leads to growth rates as high as in the case with global knowledge spill-overs. However, in case of non-stochasticity, since all firms have access to the same restricted level of knowledge, cross-country heterogeneities in size distribution do not bring about specialization and learning ratues remain restricted by the size of national economies.

The case with no knowledge spill-overs is the one where intemational trade brings about the highest potential to accelerate learning rates and output growth. This is the case that is similar to the previous experiment, although now even in the non-stochastic case with trade (i.e., E9c_Det.Trd), cross-country differences in sectoral size distributions are sufficient to bring about heterogeneity in leaming rates, and accordingly specialization takes place. However, since market concentration remains low, even in the case of specialization, due to the lack of any knowledge spill-overs, the realized growth rates turn out to be much lower than those observed in runs E9a_Det_Trd and E9b_Det_Trd.

This latter experiment (E9c) provides the link between the context of the Dosi et al. [1994] model of the previous experiment, and the results on specialization and growth in the new growth models of, for example, Grossman and Helpman 1991a]. In the latter tradition, knowledge spill-overs are the prime driver of endogenous growth, and when knowledge spill-overs are less than "perfectly globall", international trade and specialization will have an effect on growth. The results in this experiment are completely consistent with Grossman and Helpman, in the sense that they show that with spill-overs, trade has an important potential to 
increase growth rates at the global level. But note that the underlying context of how firms interact is not based on optimization as in Grossman and Melpman, but rather on selection and bounded rationality as in the ewolutionary model of Dosi et al. [1994]. Hence, our results suggest that, rather than the issue of evolutionary selection versus neoclassical optimization, the prime difference between the evolutionary context of Dosi et al. [1994] and the mainstream new growth models lies in the assumptions about spill-overs. Without international spill-overs, our model reproduces the Dosi et al case of persistent growth rate differentials, but with knowledge spill-overs turned on (in various degrees), we reproduce the new growth results of Grossman and Helpman.

\subsubsection{Experiment \#9: Specialization in the context of boundedly rational $R \& D$}

On the basis of the discussions above, one may conclude that the new growth and trade theories on the one hand, and evolutionary theories of trade and growth on the other hand, may be closer related than is sometimes suggested by the polemics in the literature. However, despite the proximity in model implications, apparent differences between the fundamental building blocks of the two strands of modeling exercises are still observable. As discussed before, one of the major issues that distinguishes between evolutionary and mainstream formulations of growth and international trade is the role of rationality in behavior. In mainstream models where the central issue is the "incentives to invest", the endogenisation of technological change and the consequent growth are essentially demonstrations of various alternative mechanisms that would keep the marginal rate of return on investment on technological change inducing factors (such as R\&D and/or human capital etc.) above a certain threshold "so that investments that would bring about sustainable growth remains alive. In many models of new trade, the main welfare/growth boosting potential of international trade lies in its potentiall to increase the incentives to invest on growth stimulating undertakings.

Nevertheless, the cognitive processes that perceive the incentives and translate them into actual investment behavior are purely based on rationality which is strongly criticized by scholars of evolutionary economics, who express these criticisms also by model formulations that rely on various forms of bounded rationality or routinized behavior. For example, Dosi et al. [1994] is an extreme case where incentives play no role in the endogenisation. That is, the model basically assumes that firms spend a constant share on R\&D, and given the monotonically increasing function imposed between R\&D effort and productivity angmenting innovations, sustainable productivity and output growth follows inevitably. In this model where decision making (i.e., choices) is eliminated, sustainable growth is exogenously imposed on the economy and the focus is turned to firm level scale economies and the -self organization induced-differentiation of countries in terms of growth and specialization. In the last two experiments we have also demonstrated similar arguments where the firm-level technological change processes do not involve any element of decision making or choice but simply take place independently of the underlying incentives.

Without expressing any judgement on the relative extent of realism in these marginally polarized alternative approaches, in our experimentation platform we have built in the flexibility to make assumptions of not only routinized R\&D behavior but some forms of bounded rationality as well. The latter feature is already utilized in Experiment \#6 in the context of single-sector single-country economies. 
In the final experiment of this dissertation, in two-country two-sector settings, we will present two comparative simulations that address the issue of dynamic gains from trade in the context of incentives and bounded rationality in frm-level R\&D effor. That is, in an (admittedly) extreme context of parameter settings, we aim to show that depending on parameter settings, it is both possible that trade leads to Pareto welfare improvements, and that trade leads to dynamic welfare losses in one country (in comparison to an alternative history in autarky). Contrary to the last two experiments, we now turn on rationality in R\&D behavior, i.e., we let the firms chose their R\&D to sales ratio based on (boundedly) rational decisionmaking (as in Experiment \#6). We will use a two-country two-sector settings, and, rather than doing a grid search in parameter space, will simply present two comparative simulations that illustrate the potentially widely differing impact of trade. The first experiment demonstrates a simple case where international trade leads to higher growth for both economies in comparison to a history in autarky. In the second one, we demonstrate a contrary case characterized by international differences in innovative abilities, where trade and specialization brings about a dynamic welfare loss for the advanced country.

The basis settings of these two comparative simulations are identical to those in Experiment 7 , except for the curvature and the inflection point of the R\&D potential function. which are set $R D S e n s=0.5$ and $R D$ rnflct $=15$ as in Experiment $\# 6^{\mathbb{I} .}$. We assume bounded-rationality in firms' $R \& D$ behavior where all firms stick to the identical (and rather ambitious) discount rate $\rho_{k i j}^{R \& D}=0.98$ in their calculations of the arnount to be spent on R\&D. In both settings, the experimenting strategy followed is similar to that in Experiment. \#8: In order to filter out the effect of chance, sharpen illustrativeness and focus on the effects of firm sizes, stochasticity is turned off and entry of new firms is not allowed.

\section{Experiment 9a}

Having in mind the aim to produce a case in favor of tradle, i.e., to show that trade leads to dynamic welfare gains for all countries involved, we assume that technological opportunities, and their dependence on R\&D effort, are identical across the sectors (MaxInnEase $i=0.1$ for both sectors $i=1,2$ ). Also, by the parameter setting $h_{A} A b_{i} l_{i,}=1$ for both sectors $i=1,2$ and both countries $j=1,2$, countries are assumed to have identical innovative abilities. As in Experiment \#8, countries are differentiated only in terms of the sectoral distribution of the number of firms: 10 firms in the first (second) sector of the first (second) country and 20 in the second (first) sector of the first (second) country. The simulation is run twice; one for the case of intemational trade and one for no trade.

In the run without international trade, the cross-country heterogeneity in firm sizes leads to a significant disparity between sectors at the national level. In the first (second) sector of the first (second) country, each of the 10 firms choose to spend around $1.85 \%$ of its sales revenue on R\&D regularly, and these sectors enjoy a. $0.51 \%$ growth every period in return. However, in the second (first) sector of the first (second) country, which are occupied by 20 firms of smaller size, one observes no R\&D activity and accordingly almost, zero productivity/output growth. The reason is that the employment share of each firm in the industry with small firm size is lower by half, which implies significantly lower R\&D efficiency. Thus, the individual rational calculations of each of these 20 firms on the basis of the given discount rate points to the infeasibility of any $R \& D$ (i.e., negative net present expected value of any $R \& D$ project independently of the level of $R \& D$ spending). 
Obviously, the absence of R\&D in half of the economy leads to dynamic welfare losses in autarky, which manifests itself when evaluated in comparison to the case with international trade. Due to the built-in symmetry of the industrial organization patterns and the resulting change in the R\&D incentives, each country specializes in the sector where R\&D incentives are non-zero. "The firms that occupy the lowly concentrated sectors (which fall behind in productivity at the global scalle) rapidly exit and in every country 10 firms remain (in country 1 only sector 1 firms and in country 2 only sector 2 firms). Accordingly, each country compensates for the autarkic consumption growth deficiency in the other, and both countries already get better-off due to a more desirable consumption basket. Furthermore, specialization also increases (doubles) the sizes (employment shares) of the firms of the specialized industries. R\&D efficiency and accordingly the R\&D activities significantly increases (i.e., in case of trade each surwiving firm spends $3.8 \%$ of its sales revenues on R\&D). Accordingly both countries can enjoy around $0.85 \%$ growth every period which is much higher than the rate achieved in the no-trade case.

\section{Experiment $9 b$}

Now that we aim to illustrate a contrary case, where trade is not unequivocally welfare improving; we eliminate the firm size/number related differences across the sectors and the countries imposed in Experiment \#9a, and assign 10 firms to each sector in each country. Instead, we strongly heterogenise countries with respect to their innovative abilities by the parameter settings in $A b i l_{k i 1}=1$ (for all firms $k$ of sector $i$ of country 1 ) and in $A b i l_{k i 2}=0.25$ (for all firms $k$ of sector $i$ of country 2). Furthermore, the two sectors are differentiated slightly according to the extent of technological opportunities: The maximum innovation arrival rates that; can be achieved at the saturation level of the R\&D potential function are MaxInnEase. $=0.1$ and $M a x I n n E a s e_{2}=0.08$. Again, the simulation is run twice; one for the case of international trade and one for no trade.

This setting demonstrates a hypothetical case where the country endowed with higher innovative abilities (or more productive R\&D workers) experiences less welfare growth (than the potential achievable in autarky) due to getting involved into trade with a non-innovative country.

In the simulation run without international trade, one observes that the first country enjoys rapid welfare growth $(0.56 \%$ per period) characterized by $0.69 \%$ productivity and output growth in the first and $0.44 \%$ in the second sector. All firms of both sectors of the first country choose a non-zero R\&D expenditure scheme (i.e., $5.5 \%$ and $4 \%$ of sales revenues respectively in the first and second sector). On the contrary, despite identical technological opportunities, and due to the low quality of the potential R\&D workers (low value of in $A b i l_{k i 2}$ ), none of the firms in the second country chooses to undertake any R\&D and accordingly the country does not enjoy any productivity or output growth.

In the run with international trade, one observes rapid specialization. The R\&D behavior is initially not different than the autarky case. However, the distribution of $R \& D$ activities over the world, together with the sectoral difference in technological opportunities imply productivity growth paths where $\left(a_{1}^{t}>a_{21}^{t}\right)>$ $\left(a_{12}^{t}=a_{22}^{t}\right)$, which due to the law of comparative advantages, makes specialization of the first (second) country in the first (second) sector possible. Since the first country has absolute advantages in both sectors, its specialization remains only partial. Yet, the shrinkage of the employment share of the second sector proves 
to be sufficient to decrease the R\&D efficiency in the second sector of the first country to the poirit where firms stop their R\&D spending. Meanwhile, nothing changes in the second country: Due to the low quality of R\&D workers, despite the potentially higher R\&D efficiency in the second sector (in which the second country finds itself specialized); firms still choose not to spend anything on R\&D. Accordingly, in sector 2 R\&D activities and thus productivity and output growth stops globally. In the first sector of the first country, R\&D efficiency increases due to specialization. However, the dynamic gains implied by this efficiency increase (productivity growth in the first sector increases from $0.69 \%$ ti $0.89 \%$ per period in case of trade) fail to suffice to compensate for the global welfare losses brought about by the global cessation of productivity growth in the second sector. As a consequence, welfare of the first country grows only by $0.46 \%$ per period (which is less than the autarky growth rate $0.56 \%$ ). The second country enjoys $0.42 \%$ welfare growth for free (i.e. despite no output growth in own production) as a result of trading with the first country.

In chapter 4 , we have demonstrated that in cases of the persistent productivity superiority of one country in both sectors, this country avoids (terms of trade worsening related) welfare losses by partial specialization. In such cases the superior country benefts nothing from international trade yet due to the gains of the inferior country, international trade remains Pareto efficient. The last scenario demonstrates the possibility that in cases where R\&D efficiency related scale effects are strong, international trade and the consequent specialization (though partial) can bring about inevitably persistent welfare losses (i.e., relative to the case of an alternative history with autarky in terms of lower consumption/welfatre growth) to the country that has a higher innovative potential (i.e., an R\&D force of higher productivity).

The setting of this final experiment is similar to Grossman and Helpman [1991, p. 257], who conclude that "a human-capital rich country may find that integration into the world economy [... implies that ...] the country may innovate more slowly in the trade equilibrium than in autarky". However, Grossman and Helpman then argue that there are still benefits of trade relatied to product differentiation and static scale efficiencies, and the human capital-rich country (which is comparable to country 1 in our experiment) may still benefit from trade despite the slow-down in domestic innovation. Such a result is also possible in our model, for example by following Grossman and Helpman by turning on product differentiation, but we will limit the analysis to simply showing that a case where a technologically advanced country loses from engaging in trade is one possible outcome of our model.

\section{Further Remarks}

Due to the modular nature of our model, with various alternative bullding blocks for sub-parts of the model, the experiments presented in this chapter reflect only a subset of the possibilities that are built into our experimentation platform. For example, we experimented by our learning by doing module keeping the R\&D-based technological change endogenisation module off, or vice versa. We did not present any settings that use our cumulativeness module which renders the innovativeness of (the productivity of the R\&D workers of) each firm an increasing function of the cumulative number of innovations of its own and/or all firms of the same sector in the same country and/or all firms of the same sector in the world. Furthermore, we did not present any experiments which activate combinations of these three en- 
dogenisation modules simultaneously. Note that this selective strategy essentially aims to keep the dimensions of parameter space of our control experiments within controllable bounds, and accordingly to increase the illustrative shanpness of our experiments. Inspired by the existing literature, the focus of these experiments has been firm-level dynamic scale economies and industrial organization, in the context of economic growth and international trade.

However, our modular software implementation allows the user to turn on either of the cumulativeness and the learning by doing modules together with the R\&D-based technological module under both the routinized and boundedly rational behavior assumptions. Particularly, the combination of cumulativeness in innovativeness together with boundedly rational R\&D expenditure behavior, constitutes quite a promising area to be explored. As mentioned in the discussion of Experiment \#9b, in case of boundedly rational R\&D behavior, the average productivity of the R\&D workers who can be employed for $R \& D$, is an important determinant of the volume of the R\&D activities chosen by the firms. Our cumulativeness formulation establishes an increasing relation between past innovative activity and current productivity of R\&D workers. This has an apparent potential to generate highly interesting path-dependent dynamics, where, unlike in the learning by doing based dynamics, the effects of the developments of the past are more pronounced than the -scale economies based-effects of industrial organization and dynamics. Using our simulation software supplied on the accompanying CD, the reader can design his/her own experiments along such lines. 


\section{Notes}

1. In the model an essential difference between technology spill-overs and knowledge spill-overs exists. Firms may simply adopt the production methods and techniques used by more productive firms (imitation). However, this process does not imply or requires that the knowledge/experience embodied within the imitated technologies also spills over along the actual production methods and techniques that are imitated. Imitations naturally give imitators the knowledge to increase productivity (or quality) up to a higher (or even the state-of the art) level but they do not necessarily supply the means to build further upon the imitated levels. In other words, imitations save the day but do not necessarily render imitators more innovative in the longer run.

2. L.e., on one side, perfect/monopolistic competition characterized by a high number of very small firms of an identical size, and on the other highly concentrated configurations characterized by one or two firms as in models on monopoly or duopoly.

3. Note that the extent of protection that would be introduced by relatively higher extents of variety demand has the potential to foil the process of selection which is meant to act upon the heterogeneity of firms in terms of thejr $R \& D$ behavion:.

4. I.e., in cases with higher technological opportunities, the impact of any given incrementall innovation is higher than the impact in case of lower technological opportunities. This fact naturally increases the impact of chance in rendering individual firms heterogenous in their productivity levels.

5. The entry of new firms in such conditions is a measure taken to keep on introducing variety into the system and accordingly to decrease the likelihood of the premature and unfair monopolization of some firm by sheer luck. Yet note that, the imposed initial conditions on entrants constitute a strong externality into the growth process in a way that imitation possibilities would. This is the reason why the growth rates observed in stochastic settings turn out to be higher than in those without.

6. In such cases, the deficits covers the deficit by presenting its R\&D workers

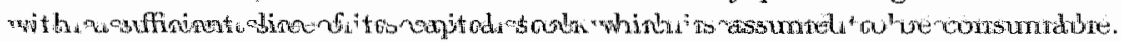

7. For example, consider cases where firms tend to imitate the R\&D strategy of the most successful firm of the industry very rapidly.

8. Namely, in settings, with 2 sectors, the budget share parameters of the welfare functions are set as $\alpha_{i j}=\frac{1}{2}$, while in the 10 sector settings $\alpha_{i j}=\frac{1}{10}$ for all sectors $i=1,2, \ldots, 10$, and for all countries $j=1,2, \ldots, 10$.

9. For example, as indicated by figure 7.5 , in the current experiment the saturation point of the relation between $\mathrm{R} \& \mathrm{D}$ effort and innovativeness saturate at around $4000 \mathrm{R} \& \mathrm{D}$ workers

10. Of course, this result is based on a comparative welfare analysis between the case with and without trade, under the ceteris paribus assumption that the extent of international spill-overs are not affected by whether the countries trade or not. If one prefers to assume that the extent of international knowledge flows is an increasing function of the increasing international flow of goods and services (for example, due to increased reverse engineering possibilities, international networking and the resulting acceleration of the dissemination of ideas etc.), then as one can conclude by comparing the outputs of runs E9b_Det_Aut and E9a_Det_Trd, international trade has an effect on growth rates as suggested by Grossman and Helpman [1991a] and/or Romer [1990]. 
11. Where the extent of scale economies in innovativeness is much less since the R\&D potential function saturates already at much lower number of R\&D workers per firm. 


\section{8}

\section{Final notes and future perspectives}

\subsection{Introduction}

In the first four introductory chapters, following a rather technical discussion on a. selected set of mainstream models of international trade and growth, we enumerated a number of epistemological and illustrative shortcomings for the mainstream formality and argued that the evolutionary philosophy offers a promising potential to compensate for these. Following this broader scope, we made a more refined discussion on a specific subset of evolutionary models (such as Nelson and Winter [1982] and alike, which we call as semi-agent-based models since the agent-based nature of these models are confined to firms), which address issues on growth and/or international trade on higher levels of aggregation. We conchuded that models under this category (to which our model also belongs) are inevitably less complex, and less organic (as opposed to mechanic) and generally less behavioristic, compared to those evolutionary models which focus on issues of lower levels of aggregation ${ }^{1}$, yet, given these limitations, they nicely illustrate examples of the translation of firm-level heterogeneity and change into aggregate level phenomena such as growth, international specialization and industrial organisation in explicitly formulated dynamic settings, without resort to a collection of unrealistic and restrictive assumptions that one generally finds in the mainstream literature. Accordingly we described our research target as the building of an evolutionary model, which elaborates upon such evolutionary semi-agents based models, and accordingly the addressing of various issues on the relations between technological change, international trade and growth from a broader perspective.

Thus, the study that underlies this dissertation has essentially been a modeling exercise. Quantitative models, which are tools to demonstrate the essence of one or a collection of suggestive ideas on the relation between a set of variables on whe basis of a well-defined causal structure, are generally used to provide explanations to a collection of well-defined empirical observations (i.e., phenomena or stylized facts) or to make extrapolations/interpolations. However, our modeling exercise did not set out by an explicit enumeration of such phenomena or stylized facts as the justifying target of its existence, except that the focus of the study is confined to economic growth, international trade and technological change. Instead, our first objective has been to present the reader with a fully-functional and generic-use computer application that can be used to make experiments and build scenarios on an artificial world, which functions according to various principles suggested by evolutionary economics, and also insights from literature on technological change. 
Given our research focus, the central element of such a construction is a generic module which supplies functionality similar to that of the general equilibrizm fromework of the mainstream economics (for many sectors and countries). yet formulated in a way that complies with the evolutionary principles of selection, micro-level heterogeneity and gradual disequilibrium adjustments. In our model framework, the basic module that gives such functionality consists of commodities, labor, capital financial, and currency markets that are formulated in ways that are consistent with (and complementary to) the basic idea of economic selection, which acts upon a finite number of explicitly defined heterogeneous firms. This central module is complemented with various auxiliary modules which are responsible for the generation of firm-level heterogeneity. For the introduction of heterogeneity, we have built in a number of mechanisms. The first one generates heterogeneity as a part of the initial condition settings of the simulation runs. The second one is the technological change module which introduces a stream of firm-level technological shocks throughout the simulation runs. The third one contributes to heterogeneity by the introduction of new firms during the process. Including the central module, each module gives the user to make choices among a given set of alternative assumptions (and according parameter settings), and with each specific combination of these alternative assumptions, our experimentation platform turns into a different model.

Clearly, the experiments built and analyzed throughout this dissertation is only a subset of the possible configurations that one can construct by our evolutionary scenario building software, which is the major end-product of our research. Each of the experiments presented here is built on some selected cross-section of the various features present in the platform, and is used not only to demonstrate a variety of basic results obtainable from our model, but also to give an alternative/critical illustration of various ideas/suggestions which are illustrated in different ways by other models, which one finds in the literature on intermational trade and economic growth. In addition to the explanatory ideas and the causal suggestions ${ }^{2}$ themselves, our critical and illustrative approach also focuses on the ways in which these are illustrated by formal models. In this latter context, one can also describe our effort in this dissertation as some critical literature overview, presented in terms of (or in contrast to) the emergent properties/outcomes of a generic-use evolutionary model, specifically built for the purpose. In different words, our experiments and our discussions on our findings are generally presented in terms of their similarities and/or divergences from some other models (mainstream or evolutionary), and in this sense our effor thas gone beyond the reproduction and/or reconstruction of already existing results.

\subsection{Summary}

\subsubsection{Chapter 4}

In the first stage of our analysis, we have investigated the convergence properties of our model under hypothetical conditions, where technological change is taken out of the picture. For this purpose, we have first derived some reduced form equations which describe the macro properties (i.e. employment, investments, income distribution etc.) of the potential fixed-points of our selection dynamics under constant technology coefficients, and at the later stage we have investigated whether the actual processes converge to such fixed points. 
Compared to the ways in which the evolutionary models of growth and trade are typically presentied, our appraach (which breaks the presentation into two distinct stages) may seem a bit unusual. That is, in the presentation of many evolutionary models one typically observes a number of experiments where all of the built-in features of the model are simultaneously turned on, and the results are based on the time series generated by simulation runs during which the selection processes are incessantly disturbed by the arrival of novelty. However, we converged to such settings only gradually throughout the flow of the dissertation. That is, before presenting results featuring selected contexts of complexity, we have also made an effort to understand and demonstrate the behavior of our basic formulations of economic selection (i.e., the playground of the model) in terms of their convergence properties in cases where the process is not disturbed by technological change. These exercises have indeed proven to be fruitful in at least three different ways.

The first point is related to the testing and verification of the various modules of the model. "Thanks to our warious experiments with no technological change", we have ensured that our basic formulations of economic selection behave exactly as they are meant to. In other words, in this first stage, we have convinced ourselves (and hopefully the reader) that the modules responsible for economic selection are 'bug-free'. As anyone experienced in building agent-based models characterized by complexity knows (or learns the hard way), that even small bugs (i.e., logical errors in the computer code) in the computer implementation of the madel can lead to unexpected and potentially misleading consequences in the model results, especially in cases where different sources of friction and complexity are simultaneously in action, interfering with each other. Indeed, throughout the process of building and running the experiments the outcomes of which are summarized in chapter 4 , by comparing the convergence properties of our model with the predictions of our reduced form equations, we have ascertained that the computer code is not bothered with such major bugs.

Second, the exercises that focus on the convergence properties of the model have pointed to the basic (macroeconomic) properties of the economies that are characterized by our formulations of the selection processes. For example, as we will further discuss below, our formulations put forward a theory of income distribution which is based on the (economy-wide) capital intensity in production and the institutional settings of the labor markets. Actually, under the hood, the Nelson and Winter [1982] model is also characterized by a similar theory of income distribution, yet the ways in which the authors build and present their experiments do not highlight the income distribution properties of the model.

Third, the elementary analyzes summarized in chapter 4 have given us the opportunity to compare and contrast the basic (convergence) properties of our model with those of a number of mainstream models that are based on a static equilibrium approach. We have demonstrated that a dynamic agent-based model, even under highly restrictive settings (such as the absence of technological change) suffices to demonstrate the existence of supply-side disequilibrium adjustment; processes whose convergence properties can regenerate (as well as diverge from) the clear-cut predictions of equilibrium models such as the Ricardian model and/or the Heckscher - Ohlin - Samuelson model. These exercises, as compared and contrasted to the (truly dynamic) experiments presented in chapters 6 and 7 , aim to highlight the fundamental differences between the evolutionary and the mainstream philosophies in building and analyzing quantitative models.

In a number of experiments, the findings of which are briefly summarized 
in chapter 4, our first focus has been on firm's behavior with regard to investnents on capital (capacity expansion), consumers' demand for variety, and scale economies. With various experments featuring constant technological parameters, we have verified that except for cases of increasing returns to scale, the properties of the ultimate (eventually reached) states are generally independent of the initial conditions and are uniquely determined by the parameter settings that specify technological (labor productivity, quallity, and capital intensity) coefficients, labor markets, and capitalists"s consumption/saving behavior. These convergence states appear to be highly stable, which makes it possible to call such states as the quasi-fixed-potnts or quasi-equilibria of our dynamic artificial economies. The macroeconomic properties of these quasi-fixed-points are found to comply perfectly to the reduced form equations we derived, which basically suggest an interesting relation that links capital intensity in production, the minimum rate of return on capital expected by capitalists for their current consumption, and the institntional settings of the labor market (i.e. wage elasticity of labor supply) to income distribution and unemployment.

The behavioral alternatives we have built into the model specify three different investment decision procedures, which are respectively equivalent to profitconstrained output maximization, nominal profit maximization and real profit maximization $^{4}$. In terms of the steady state (quasi-fixed-point) properties of our experiments with fixed technological coefficients, we have observed that in cases of profit-constrained output maximizing behavior, full employment is reachable independently of the number and size distribution of the firms, while in cases of profit maximizing behavior (either of real or nominal profit maximization), output and employment levels are generally lower than those observed with output maximizing firms, depending on the number of firms. These two arguments together suggest that, with profit-constrained output maximizing firms, the (total) output and employment levels that can be attained are close to those which can be attained only by a very high number of profit maximizing furms. In cases with profit maximization, as the theory of perfect competition suggest, the extent of the -profit maximizing behavior induced-welfare and employment losses appear to be decreasing functions of the number of firms.

These findings basically point to the drastic differences between the milcrofoundations of general equilibrium based manstream models and those of a number of evolutionary models of growth, which rely on accumulation processes that translate firm-level profits to firm-level investments on capital ${ }^{5}$. The perfect competition story of the neoclassical economics mainly aims to make an industry characterized by a multiplicity profit-maximizing firms eventually look like a single profit-constrained output-maximizing entity. However, this story is only justifiable in case of infinitely many (measure zero) firms all of which are price takers. Contrary to this, the evolutionary models, which are based on the gradual processes where firm level profits translate into investment on capital, directly assume profitconstrained output maximiring as the central behavior that characterizes individual firms, accordingly save themselves from the perfect competition/homogeneity straightjacket, and be able to make models that are characterized by a finite number of heterogeneous firms. Given that the extent of realism in the profit maximization assumption is questionable on various grounds, the evolutionary assumption which suggests that firms rely on simple rules of thumb similar to "Without bothering with what/how the other firms are doing, go about investing for a higher output level as long as credits are available. Throughout this process, which tends to push prices down, wage rates up and accordingly profitability 
down, be a bit more prudent if the rate of return on capital you yield is close to the minimum level expected by the shareholders", does not seem to violate the limits of realism more than any other alternative assumption. Accordingly, having made our point with regard to our various assumptions on irvestment behavior, in all experiments presented in the dissertation, we have set profit-constrained output maximizing tendency as our main working assumption.

The predictable nature of the steady-state of the adjustment process however disappears in case of firm-level increasing returns to scale. With this source of nonlinearity in action, we have observed that the industrial organization (firm size distribution pattern at the quasi-equilibrium of the selection process is highly dependent on the initial size distribution and the subsequent entry of new firms. If the initial firm size distribution does not characterize a highly concentrated industry, the economy can converge to a state of low concentration. In such cases, since no single firm (or a few of them) finds the opportumity to grow enough to exploit increasing returns efficiently, the economy gets locked into a productivity level which is far below the level that can be attained in case of monopoly or the oligopoly of few large firms.

The most important result that emerges from our experiments with fixed technical coefficients is the effect of consumer's demand for variety on the outcome of the economic selection process acting upon a variety of competing technologies. In many evolutionary models, generally customers are assumed to perceive the product of different firms as perfectly substitutable (i.e., homogenous). Yet due to the versatility of our customer demand formulation, we have been able to investigate the various effects of divergence from the assumption on homogenous goods, on the workings of the selection process and accordingly industrial organization (i.e., firm size distribution). We have observed that demand for variety has a strong impeding effect on the selection process. That is, while in cases of perfect product homogeneity, the selection process rapidly eliminates the firms which are less productive (firms with lower labor productivity coefficients or lower quality), higher demand for variety (which implies that custoners are not only interested in the quantity or quality, but also the number of product varieties in their consumption baskets) introduces market niches which protects firms with higher costs (or lower quality) against the competitive pressures. Accordingly, at the quasi-equilibrium of the selection process, one observes firms of varying prodnctivities (or qualities) cosurvive, although the roore productive (or higher quality) producers, still tend to capture relatively higher market shares than those which have higher unit costs (or lower quality).

At the secondary stage of our exercises with constant technology coefficients, we turned our focus to multi-sector multi-country cases where countries trade with each other. In our experiments where we distributed given constant technology coefficients unevenly over the countries, our essential effort has been on the comparison of our model with the traditional mainstream models of international trade, both in terms of their assumptions and their predictions.

First, we considered hypothetical settings which ignore capital costs (i.e., where shareholders do not consume anything but reinvest all profits) and accordingly built circumstances reminiscent of the assumptions that underlie the Ricardian model of trade. We have ascertained that under such settings, the steady state of our dynamic process is characterized by strong specialization patterns that are identical with those predicted by the Ricardian model (formulated according to Cobb-Douglas preferences), independently of the number of sectors and countries assumed. The important issue is the fact that, specialization in Ri- 
cordian lines emerges as a property of the quasi-fixed point of dynamic selection processes, rather than as the solution to an explicitly formulated optimization problem, and equally importantly this result is observed despite the essential dependence of production on capital goods in our model (which does not exist in the original single-factor Ricardian model). We observed that throughout the processes of transition between autarky and trade (quasi) equilibria, as long as the economies are not at their trade equilibrium states, the emergent product prices and exchange rates together ensure that, in each country, the sectors that have comparative advantage (disadvantage) always remain more (less) profitable than those with comparative disadvantage (advantage). Since capital in our model is dynamically accumulated (decumulated) by investments (depreciation) in a way that follows profits, capital accumulation/decumulation takes place in the direction commanded by the comparative advantages, and the allocation of labor among the sectors immediately follows the sectoral changes in productive capacities (sectoral capital stock). Within this system, capital intensities (which determine the market price/production costs of capital goods) do not affect the properties of the eventuall trade equilibria, but only the pace (the speed of capital accumulation/decumulation) with which the transformation from autarky to trade takes place.

At the second step, we brought capital costs (i.e. dividend payments expected by shareholders for current consumption) back into the picture, which brought us to the domain of the neoclassical models of international trade (the $\mathbf{H}-\mathbf{O}-\mathbf{S}$ and the Specific Factors models) where unit capital costs (in addition to unit labor costs) appear to be an important potential determinant of international patterns of specialization and trade flows. We have compared and contrasted the implications of our model against those of such neoclassical models. Naturally, the major difference between our model and the neoclassical models is the fact that the latter, by their usage continuous multi-factor production productions, assume infinitely many alternative production techniques all of which are readily available to all firms of all countries. On the contrary, our formulation with fixed technological coefficients introduces only $N C$ (i.e., number of countries involved in international trade) competing production techniques for each sector, and by the opening of trade, the selective forces of the world economy eliminates (selects) some of these technologies. Specialization comes about as an outcome of this selection processes which effectively works upon the competing technologies at the world scale. Yet due to the balance of payment constraints of each country (which is automatically satisfied by the adjustment in exchange rates), the selection mechanisms do not work separately sector-by-sector but over all sectors and countries simultaneously.

We have derived some reduced form equations that characterize the expected steady-state properties of our model for the case of international trade. This exercise has shown that the comparative advantage structure implied by a given distribution of internationally exclusive production techniques (fixed labor and capital coefficients) can be (multiplicatively) decomposed into labor cost and capital cost related components. As also verified by various simulation runs, the eventual pattern of specialization is decided upon by the component that outweighs the other. For given labor productivity differentials, the possibility of capital cost differentials to reverse the pattern that would otherwise be predicted by the Ricardian model, is therefore a decreasing function of the extent of labor productivity differentials (i.e., comparative labor costs), an increasing function of the corresponding/respective capital intensity differentials (i.e., extent of the correlation between labor productivity and capital intensity of competing production techniques ${ }^{6}$ ) and also an 
increasing function of the shareholders" current consumption propensity ${ }^{7}$, which translates capital intensity differentials into steady-state capital cost differentials. Our experiments demonstrate both possibilities: Based on warious contralled combinations of cross-country labor productivity and capital intensity differentials, and also considering cross-country differences in shareholder's demands, we have generated various patterns of specialization; some compliant with the Ricardian prediction and in conflict with the H-O-S prediction (i.e, cases where the Leontief paradox is observed), while some other compliant with the H-O-S prediction and in conflict with the Ricardian prediction. With a number of experiments where the Leontief paradox is observed, we also investigated the possible reasons underlying the predictive failure of the original $\mathbf{H}-\mathrm{O}-\mathrm{S}$ model. We have also compared the income distribution implications of international trade in our model with that of the H-O-S model.

Following the comparative advantages based interindustry trade, we have shifted our focus to issues of product heterogeneity and intraindustry trade. First, we have observed that even in cases where there are no incentives for interindustry trade (i.e., no comparative advantages), demand for product variety introduces incentives for international (intraindustry) trade as suggested various models in the new trade literature (summarized briefly in the first chapter of this dissertation). Second, we have investigated the interaction between intraindustry and interindustry trade by the introduction of technological coefficient differentials across the countries and the sectors along with demand for variety. We have accordingly demonstrated that demand for variety works against the selection forces, which, on the world scalle, lead to specialization and interindustry trade. In other words, demand for variety creates niches for relatively high cost firms which would otherwise (i.e., in cases where customers perceive the output of the various firms of the same industry as perfectly homogenous) would not stand the competition with the cheaper products of other firms and be driven out of the market. We have also argued that a country which is not as successful as its trading partners in bringing product varieties to the international market, can compensate for this shortcoming by higher productivity (i.e., lower costs) in the sectors where demand for variety is low.

Furthermore, we have introduced international heterogeneity in output quality levels as another explanatory principle to international specialization. First, we hawe shown that in isolation (i.e. no labor productivity or capital intensity differences), quality differences smoothly replaces the role played by labor productivity differences in the original Ricardian model. In other words, one can refer to a concept like "quality-based comparative advantages". Second, by analytical derivations, we have demonstrated that in cases where there are international differences both in qualities and labor productivities, the (cross country sector) distribution of the multiplicative product of these two variables $\left(F_{i t n e s s_{i j}}=Q_{\text {ual }}\right.$ ij $a_{i j}$. which turns out as an overall fitness/competitiveness measure for each sector of each country) nicely assumes the role played by the cross courtry-sector distribution of labor productivities on the determination of the pattern of international specialization. Finally, we have concluded that the pattern of international specialization is determined by the joint effect of labor productivity, quality and capital cost based comparative advantages and the total effect can neatly be formulated as the multiplicative product of the contribution of these three different sources of comparative advantages, each of which (if considered alone in isolation from the others) may predict alone a specialization pattern that contradicts with the prediction by either or both of the other two. 
As a general implication of our findings, we argued that it is possible to tutilize the real life existence of variety for demand, and heterogeneity in product qualities as the arguments of a reasonatble answer to the question "why do we not observe in reality the extreme levels of specialization suggested by the Ricardian model?". The reason that we suggest is that in reality, products (even those which can be classified under the definition of a given sector) are not homogenous as critically assumed by the Ricardian model ${ }^{8}$. Accordingly, empirically-observed cost differentials may well reflect (proportional) quality differences, or the potential of cost differentials in bringing about specialization may be eliminated/reduced by the presence of protective market niches created by customers" demand for variety. Of course, this by no means implies that the Ricardian model is necessarily erroneous or misleading. Like all the models, Ricardian model as well, depicts an exaggerated picture (via its assumptions) of the basic idea it suggests and especially given the enpirically observed correlations between comparative cost advantages and sectoral export performance, one can still see comparative costs differentials as the important/dominant determinants of international trade flows.

As discussed in our introductory chapters, the organization of the presentation. of the formulation and results of our model broadly follows an "order and change" theme. That is, in the first two chapters of our discussions on the model, we have taken technological change out of the picture and focused on the convergence (i.e. steady state) properties of our model. We have observed that without the disturbance of firm-level technological shocks, starting from an initial settings characterized by given firm-level heterogeneity in technological coefficients and a state of disequilibrium, the forces of selection eventually takes the system to an orderly state which one can refer to as a steady-state or a fixed point. The findings, which we have summarized so far in this section, are observations made at such steady-states. For example, in our experiments with international trade, starting from an initial disequilibrium state, economies first converge to an autarky equilibrium which lasts until it is disturbed by the opening of international trade. At this point the economy again enters into a state of disequilibrium and eventually converges to a new (trade) equilibrium. In other words, the process is essentially a. once and for all phase transition from autarky to trade. Eventually the questions one asks are "what are the differences between the economic implications (i.e. production, consumption, welfare etci) of these two equilibrium points? ${ }^{9 n}$ and "how cloes the adjustment process take the economy from the first to the second equilibrium?"

\subsubsection{Chapters 5 and 6}

In the three chapters that follow, we have turned our focus to "change". In chapter" 5 , we described the formulation of our technological change module and in the two chapters that follow, we have presented a number of experiments that highlight the essence and implications of our technological change module, which basically introduces a stochastic strean of firm-level technological shocks. These experiments which are characterized by disequilibrium dynamics (as opposed to moving. equilibrium processes where adjustments take place instantaneously) differ from the earlier ones in an important way. Each of our simulation runs characterized by technological change tells a story on what has happened in a finite time interval (i.e. during the simulation rum) and why things happened as they did, as opposed to where did the system has eventually reach. For example, in experiments with international trade, we rum each simulation twice for identical parameter/initial 
condition settings; one for the case of autarky and one for the case of international trade. Doing so gives two alternative histories and the discussion that follows is essentially on the comparison of these alternative histories rather than on the comparison of the eventual states reached in the alternative rums.

In chapter 6, we have investigated the various implications of our -labor prom ductivity based- technological change formulation on economic growth and employment first in terms of analytical exercises and than by actual simulation runs with rather simple settings. With the analytical exercises we have first shown that in our model where technological change is the only engine of growth, as long as the labor productivity increases (i.e., technological progress) in the final good sectors perfectly spill over to the capital good sectors (so that capital intensity in production does not increase over time), the attainable ontput growth rate is equal to the growth rate of labor productivity in the economy. In other words, labor productivity growth directly translates into total factor productivity (TFP) growth and throughout the growth process the income distribution remains unchanged. However, if the rate of labor productivity increases in capital good production lags behind that in the final good sectors output growth is apt to be less than labor productivity growth in the final good sector as long as the wage elasticity of labor supply is less than infinity. As techmological change in the final good sector keeps pushing final good prices down (by increasing profits which turn into investment on further capacity and accordingly increasing the output level), if this change is not matched by proportional decreases in capital good prices, the part of national output that can be claimed by the capitalists (workers) keeps on increasing (decreasing) over time, changing income distribution for the benefit of the capitalists. Unless labor supply is infinitely elastic, the lagging of real wage increases behind labor productivity increases translates into unemployment, which is the basic reason why aggregate output growth rate lags behind the aggregate labor productivity growth rate in final good sectors. With our analytical derivations we have also shown the potential of "cumulativeness" in translating otherwise unsustainable output growth trajectories into sustainable ones.

In the control experiments that follow our main focus has been on the fact that our model characterizes disequilibrium adjustment processes as opposed to accumulation through moving equilibria. That is, each innovation disrupts the existing order at the micro-level and puts the economy in a new adjustment path as the innowation and its repercussions make their way (i.e. difluse) through the econony. The adjustment is naturally not instantaneous, and furthermore, long before the adjustment process reaches a new equilibrium, the economy may be further disturbed by the arrival of a number of other innovations. Yet, despite the disequilibrium nature of the adjustment processes, in our model where technological change is the one and only source of economic growth, output, consumption and welfare growth closely follow the growth in productivity that is brought about by the arrival of innovations to individual firms, the effects of which are propagated through the economy either by imitations or by the selective forces of the economy that gradually grants more productive firms higher market shares.

One of the major implications of this disequilibrium process is clearly observed in unemployment rates. Following each new innovation which increases the labor productivity, the first response of the firm, which can not increase its output cam pacity instantaneously, is to lay-off a number of workers, economize on its labor costs and increase profitability. Over time, higher profitability translates into investments and capacity expansion which implies the re-employment of the workers initially laid-off and the according restoration of full employment. However, this 
process takes a while, and innovations that arrive in the meantime keep on disturbing the full-employment. As we have shown by a set of control experiments, the resultant of these two forces (disturbance and restoration) brings about structural (persistent) unemployment, which can also be referred to as "technological unemployment". These arguments about the importance of the dynamic employment path as opposed to a static equilibrium analysis, provide some formal underpinning to the more informal theorizing in Freeman and Soete (1987), who adopt a Schumpeterian perspective in which disequilibrium is the natural state of the economy.

The following issues, which we took under inspection in chapter 6, are the adoption and diffusion of capital embodied technologies, which we have addressed with our capital vintages framework by the specification of a finite number of alternative technologies, each characterized by a different labor productivity-capital intensity combination. Since the relative diffusion potential (or market share dynamics) of each vintage is a function of the real wage rate, the real wage rate is a function of the economy-wide labor productivity and capital intensity, and finally given that each virtage is characterized by a different labor productivity-capital intensity combination, the economy-wide labor productivity and capital intensity are both functions of the market shares of the vintages in the economy. This twoway causal relation between real wages and vintage selection brings about very interesting sequential patterns of vintage diffusion, which ends with the absolute dominance of one of the vintages. For example, at the initial periods when all vintages have equal shares and the real wage rate is rather low, there exist little or no incentives for "high productivity-high capital intensity" vintages to diffuse, and accordingly the vintages characterized by relatively lower productivity-lower capital intensity combinations, increase their market shares at the expense of the others. Yet as these vintages diffuse, the average labor productivity in the economy and thus the real wage rate gradually increases (despite the negative effect of the increase in the average capital intensity in production), opening the way to the diffusion of the vintages "high productivity-high capital intensity" vintages, which become eventually attractive for investors. In other words, even if a number of competing technologies are available at once (as in mainstream multî-factor production functions), the capital-labor substitution process goes through various phrases which is far from a straightforward and instantaneous adjustment. Ar important point is the fact that this process eventually stops at a point since many vintages which offer higher labor productivities can not diffuse into the system due to their high capital intensity. Accordingly, economic growth ceases. If one generalizes this example for the macro level, the following necessity condition presents itself: If an economy is subjected to capital embodied technological change, where the sustenance of labor productivity growth is highly dependent on the usage of a. succession of competing capital goods temporally increasing in sophistication and cost, sustainable ontput growth (especially with a steady income distribution) is only possible if productivity growth in capital production is rapid enough to match the pace of productivity growth made available to final good sectors by the introduction of new capital vintages.

In another set of experiments, we demonstrated the endogenous emergence of 'long waves' in output and productivity growth (as well as in unemployment rates) in the context of "paradigm specific leaming". In our technological paradigm formulation, the arrival of each paradigm introduces significant opportunities for productivity increase. Yet, since the firm has no knowledge/experience on this new set of opportunities, during the periods that follow the introduction of the 
new paradigm, progress is rather slow. As experience/knowledge is gradually built up (as indicated by the cumulative number of innovations), the arrival rate of incremental innovations accelerates and the economy enters into a period of rapid progress in productivity. Nevertheless, this process does not proceed forever, since the progress opportunities offered by any given paradigm are limited (i.e., decreasing marginal returns to innovations). That is, although the pace of incremental innovations keeps on accelerating, the contribution of successive incremential innovations on productivity converges to zero, and the rate of progress in productivity and output growth eventually slows down

The explanation above suggests that the emergence of long waves in growth, is an emergent outcome of the interplay between the decreasing marginal returns to paradigm-specific progress and the principle of (paradigm-specific) cumulativeness. The latter principle suggest paradigm-specific convexity in the innowation arriwal processes whereas the former implies a paradigm-specific concave mapping of the latter. Such an interplay leads to the emergence of paradigm-specific learning curves which appear to be S-shaped functions of time, where the early stages of progress is dominated by the convexity (i.e. increasing returns to subsequent innovations) implied by the principle of cumulativeness, whille later stages are dominated by the concavity implied by the eventually decreasing returns to innovations. Between the early and late stages, lies a time interval where the (cumulativeness related) accelerated pace of incremental innovation arrivals coincide with the highly exploitable region of the technological opportunity set introduced by the paradigm, and accordingly rapid progress in productivity and output is observed. The emergence of $\mathrm{S}$-shaped progress trajectories are interesting in the sense that paradigm-specific progress is actually a process of learning, and learning processes are generally associated with S-shaped (logistic) dynamics in the cognitive literature. Yet the more important point is that our simulations illustrate the emergence of long waves purely on the context of a sequence of emergent S-shaped patterns of learning, while the other models that aim to illustrate Schumpeterian business cycles rely on S-shaped diffusion of a sequence of capital embodied technologies. That is, if one associates technological paradigms with the major breakthroughs in the history (such as the introduction and pervasion of the steam engine, chemical and material technologies, electronics, information technologies etc.), the emergence of long waves in our model can be seen as a literary demonstration of the business cycles explanation of Schumpeter [1939]. Due to its paradigmatic context, our demonstration diverges (in a complementary way) from various other approaches that address the long waves issue in the context; of the 'temporal clustering of major innovations' and 'diffusion of capital embodied technologies' themes.

Our analytical derivations demonstrate that in our model as long as consumers' sectoral preferences are assumed to remain constant (i.e. unit income elasticity of demand), the effect of cross-sector differences in productivity growth on the economy-wide output/welfare growth remains linear. In other words, GDP growtl or welfare growth is a weighted average of the sectoral ontput growth rates, the weights being the share of each sector in comsumer's budget. However, by diverging from this assumption and endogenising consumers ${ }^{3}$ sectoral preferences on welfare, one can explain temporal variations in economy-wide productivity, GDP and/or welfare growth as the outcome of cross-sector differences in productivity growth. For a demonstration we have designed an experiment in the tradition of history friendly modeling, (i.e., the model was calibrated to reproduce a particular pattern that has been observed in history). In this case, we looked at the 
transition of agriculture to manufacturing ('industrialization"), and the rise of the services sector ("post-industrialization"). The model was tuned in such a way that the first of these transitions generated a marked increase in the growth rate of the economy (Kuznets's idea of modem economic growth), while the second transition gexierated a productivity slowdown (associated to Baumal's disease). Differences in technological opportunities, in combination with endogenous preferences developing under the influence of real income growth, were seen as the key ingredients in this history friendly mode of the model.

In the last experiment of chapter 6 , we turned our focus to international trade. A number of efforts in the new trade literature can be classified as the "variants of the Heckscher - Ohlin - Samuelson model" due to an important element in common: countries are differentiated in some property and the sectors are differentiated in some other. For example, in the original $2 \times 2$ version of the Heckscher - Ohlin - Samuelson model, countries are differentiated according to their capital endownents, while sectors are differentiated according to the capital intensity in their production.. Our simple international trade experiment in chapter 6 is aimed at: investigating the consequences of technological change and international trade for the international distribution of welfare, in the context of such dual differentiam tion schemes. In different settings we have differentiated countries in terms of their imnovative abilities in the final good or capital sectors, and the sectors in terms of the capital intensity in production or the extent of technological progress opportunities. With this experiment we have basically demonstrated that our model is capable of dynamically generating specialization and intemational tradle patterns that the similar to those suggested in a number of (mainstream) models in the literature. That is, the simultaneous differentiation of sectors and countries on a number of key parameters proved to suffice in inducing the dynamic generation of comparative advantages, which, in turn, leads to international specialization. In general, we find the same welfare enhancing effects of trade as are found in the traditional literature, although the underlying causal mechanisms in our model are generally different. These findings provide a good starting point for the more elaborate analysis of international trade under conditions of micro heterogeneity and complexity, as they are carried out in chapter 7 . That is, having established that the model, in its simplest core, is quite compatible with the basic mechanisms of trade and specialization as found in the literature, the evaluation of the various effects of the heterogeneity that is crucial in an evolutionary view of the economic world is left to the analyzes in chapter 7.

\subsubsection{Chapter 7}

In chapter 7 , we have broadened our focus to the firm-level dynamics and heterogeneity in order to explore the possible links among firm-level technological change (innovations, imitations and knowledge spill-avers between individuals firms), economic selection, industrial organization, growth and international trade. Clearly, the interplay between stochasticity (in firm-level innovation arrivals), heterogeneity and evolutionary selection has strong implications in terms of industrial arganazation/dynamics. First, one observes the potential of historical accidents (the timing of the distribution of the stochastic innovation arrivals) in bringing abouti highly concentrated market structures. That is, the productivity/quality advantage gained by a firm due to sheer luck, suffices to wipe out many other firms rapidly from the market. The situation is aggravated in cases where technological change is affected by cumulativeness (or learning by doing), especially if knowledge 
spill-overs between firms are limited.

The tendency of economic selection to bring about highly concentrated marw kets, is highly pertinent to most of the evolutionary models which assume homogeneity of products. In such models, generally one aims to preserve the potential heterogemeity in the economy by replacing the exiters with new firms, the initial fitness of which are assigned to a level that is (on the average) around those of all surviving firms in the economy. The other mechanism that works against the rapid concentration of market structures is the possibility of imitations between firms, which have an homogenising rather than heterogenising effect. This mechanism implies quite a strong positive externality for the pace of technological progress.

These two mechanisms are built in our model ${ }^{10}$, yet we also have a third mechanism, which may be put in action by decreasing the substitutability between the products of competing firms. As discussed before, consumer demand for product variety introduces productive niches for relatively less fit firms against the selective forces of the economy. Through control experiments, which incorporate various combinations of these three mechanisms, together with varying degrees of cumulativeness in innovativeness and knowledge spill-overs, we have demonstrated that our model can generate a wide range of industrial orgenization patterns and dynamics (i.e. number of firms, firm size distributions, firm-level turbulence which can be observed from the panel data generated by the model). The highly skewed firm size distributions observed in warious experiments also include cases that can be described by the Pareto distribution, which is observed empirically at relatively high levels of aggregation. While the model may generate the specific Pareto distributions of firm sizes that has sometimes been suggested, we observe that the exact nature of the distribution (i.e., whether it is Pareto or not) is determined by the combinations of settings with. regard to cumulativeness (learning by doing), spill-overs, imitation and product differentiation. Furthermore, we have also observed a variety of firm-level output growth rate distributions, which also exhibit highly skewed patterns as suggested by the empirical literature. Specifically, we observe significant turbulence in growth rates at the micro level, while growth seems to be rather smooth at the macro level.

In a following experiment, we have also shown a potential causal link running from industrial organization to economic growth: Normally, the basic unit of innovation is the firm, a higher number of firms imply a higher number of innovations. A higher number of innovations may also imply redundancies (repetition) and does not necessarily lead to faster growth. Yet in cases where imitation possibilities between the firms are high (or at least exist), the consequent technology spill-overs not only give a higher number of firms better chances to survive but also eliminate (at. least) some part of such redundancies ${ }^{11}$, and the resulting externality boosts productivity and output growth significantly. This mechanism also implies another highly interesting (indirect link) between demand for variety and growth: Demand for variety, which protects firms against the selective forces of the economy, keeps the number of innovating firms higher, and accordingly facilitates the attainment of higher productivity growth rates, yet only provided that the possible redundancies in innovations are eliminated/reduced by imitations between the firms. However as we demonstrate by our experiment, this positive relation between demand for variety and output growth remains valid only to the extent with which technological change can be considered as exogenous. On the contrary, if technological change is endogenous and is characterized by increasing returns to firm's scale (i.e. learning by doing with low knowledge spill-overs, or scale economies in R\&D success), the case is quite the contrary as suggested by Lucas 
[1988a]. Demand for product variety does not let market concentration increase, and the learning/innovation rates that are accordingly achieved by a collection of small firms remain quite low compared to the potential that can be attained by a few number of firms which can exploit the dynamic increasing returns in learning/innovativeness. Due to this positive relation between market concentration (i.e. consolidation of production under the roof of one/or few large firms) and productivity growth, there exists a trade-off between higher output growth and a more desirable product mix.

With the following control experiments, we switched our focus to the issue of 'social optimality of R\&D effort', in the context of a high number of competing firms, which are made heterogeneous in their behavior on $\mathrm{R} \& \mathrm{D}$ spending. First, under the assumption that firms do not have any idea on the relation between the level of R\&D effort and the consequent success, we have initiated our model with a high number of firms, identical in all senses but their attitudes towards R\&D (i.e. many firms pursuing different R\&D to sales ratios). We have obserwed that the meta-rationality which is constituted by the selective forces of the economy, has sone ability to discriminate between too much and too few effort made on R\&D. Yet, the selection forces only impose on firms a condition which can be seen more of a matter of sustainability than a matter of optimality. That is, in competition with the others, a firm can sustain its R\&D strategy (without shrimking and going bankrupt but maintaining a positive or at least zero growth) only if the stream of profits generated by the R\&D efforts of the past minus the current $R \& D$ expenditures implies a level of profitability which is not less than that of the competitors.

However, in a dynamic sense, the discriminative ability of selection between to much and too little $R \& D$ turns out to be rather limited, since, due to the scale effects in R\&D efficiency ${ }^{12}$, the aggregate level of a sustainable R\&D expenditure scheme is also a function of the number and size distribution of the firms (or market concentration) in the economy. Since selection tends to increase the market concentration over time, due to the firms' blind individual commitment to constant (size independent) $R \& D$ to sales ratios, the economy eventually reaches a state where it makes an excessively redundant effort on R\&D. That is, initially when frms share the market more or less equally, economic selection can discriminate between frms investing too much and too little on $R \& D$ and eliminate these rapidly. Yet, due to the decrease in the marginal returns to $R \& D$ effort, the R\&D behavior which proves to be optimal (and thus survives the selection) in the initial circumstances characterized by low market concentration (i.e. small firm sizes), can not be consictered as optimal anymore after the elimination of the firms that pursue marginal R\&D strategies, which eventually increases market concentration and average frm sizes.

We also made a number of similar experiments under our alternative formulation of boundedly rational $R S D$ behavior, which assumes that firms have some idea on the (nonlinear) relation between effort and outcome, despite that their understanding of a fair rate of (expected) return on $R \& D^{13}$ are not identical. In conclusion, we argued that selection alone is hardly sufficient to eliminate anbitrariness and bring about (social) optimality in $R \& D$ behavior especially in cases where the sharpness of selection is blurred by stochasticity and/or the protection of variety demand. Individual (bounded) rationality of firms greatly helps to keep economies from R\&D expenditure schemes that can be considered as wasteful. Yet, in the remaining range which inchudes the under-investment possibility, the R\&D effort of the economy and thus productivity growth are functions of techno- 
logical opportunities, and firms' arbitrary extents of ambition towards R\&D (i.a.; their individual understanding of an acceptable retum on R\&D effort).

The ability of selection to reduce the extent of arbitrariness in R\&D expenditures is also limited by the extent of homogeneity across firm's individual R\&D behavior. We have shown that in cases where the firms follow similar R\&D strategies, even if these strategies are underlied by bounded rationality, since there remains nothing for the selection forces to discriminate among, axbitrariness in total R\&D effort remains. The simplest example of lack of heterogeneity in R\&D behavior is naturally the case of a monopolist. With our control experiments we have argued that a monopolist which can manipulate its profitability by output adjustments can impose any arbitrary (i.e., too little on too much) R\&D scheme and thus any arbitrary output growth rate on the economy. The corresponding downward adjustments in output clearly constitutes a significant source of unemployment. Furthermore, even in cases characterized by a multiplicity firms which are rather homogenous in terms of their attitudes fowards $R \& D$, due to the inability of selection to eliminate arbitrariness from R\&D behavior, the same unintended unemployment effecti still prevails. That is, if the gap between current $\mathbb{R} \& D$ expenditures and the extra profits generated by the $R \& D$ activities of the past is high (and similar) for all firms, given that the only means to finance R\&D expenditures are supernormal profits, the adjustment processes of the economy forces the total output and employment in the economy/industry keep on decreasing down to the point where product prices increases, wage rate decreases, and the corresponding increase in profits eventually suffice to finance the gap. In other words, if there exist no firm(s) that the selective forces of the economy would favor, the same forces render the existing arbitrary and unsustainable R\&D strategies sustainable by decreasing employment and output and accordingly generating forcefully the supernormal profits required to finance the collective arbitrariness in the fims' R\&D targets. In our simulation runs we observed that in different settings that: feature combinations of alternative number of homogenous firms and alternative levels of technological opportunities, the opportunity costs of output growth in terms of bygone current consumption show significant variations over our control experiments. This implies that in our evolutionary model, this intertemporal trade-off is resolved endogenously by self-organization, a process which does not per se reflect any notion such as the societies" intertemporal preferences as suggested by mainstream formulations.

At the last part of chapter 7 , we turned our focus to the relations between technological change and international trade in the context of industrial organization. In our first experiment we demonstrated the self-organized emergence of specialization and cross-country growth differentials in the context of R\&D-based endogenous technological change in a way similar to that in Dosi et al. [1994]. In addition to reproducing the results of Dosi et al. [1994] we also analyzed the potential effects of demand for product variety, in the context of the self-organized emergence of comparative advantages, cross-country growth differentials and the gains from trade.

Another issue suggested by the experiment mentioned above is isomorphism between the implications of an R\&D-based endogenisation of technological change (as in Dosi et al.[1994]), and those of a firm-level learning by doing formulation, in the sense that both are apt to lead to a "success breeds success" type dynamic increasing returns mechanism at the firm-level, which translates into country level virtuous cycles leading to international specialization and persistent cross-country growth rate differentials. Accordingly in the following experiment, by various 
simulations characterized by learning by doing (i.e., technological change endogenised on the principle of cumulativeness) and various scopes (national versus international) of knowledge spill-overs, we have generated results similar to those of various models in the literature on new trade, which mainly demonstrate the growth boosting potential of international trade in case of dynamic increasing returns to scale brought about by learning by doing/cumulativeness. Our results suggest that, rather than the issue of evolutionary selection versus neoclassical optimization, the prime difference between the evolutionary context of Dosi et al. [1994] and the mainstream new growth models lies in the assumptions about spill-overs. Without international spill-overs, our model reproduces the Dosi et al. [:1994] case of persistent growth rate differentials, but with knowledge spill-overs turned on (in various degrees), we reproduce the new growth results of Grossman and Helpmar [1991a]. Within this context one may conclude that the new growth and trade theories on the one hand, and evolutionary theories of trade and growth on the other hand, may be closer related than is sometimes suggested by the polemics in the literature. However, despite the proximity in model implications, apparent differences between the fundamental building blocks of the two strands of modeling exercises are still observable, especially in terms of the extent and the nature of rationality that underlies the model results.

In the last experiment of chapter 7 , we have first demonstrated a case where international tracle accelerates the growth of both economies due to the attainment of higher $R \& D$ efficiency which results from the increasing returns to scale effect brought about by international trade. In the second one, we have presented a scenario where, in case of international differences in innowative abilities (i.e., human capital stock), trade and specialization may bring about dynamic welfare losses (i.e. as compared to an alternative history in autarky) for the country that has a more (skilled) human capital stock.

\subsubsection{An overall overview}

Having summarized our results, in this section we aim to give a short discussion on the added-value of our modeling exercise to the economic literature, both in comparison to the mainstream and to the earlier exolutionary work on growth and international trade.

An important factor which seems to inhibit the diffusion of evolutionary theories into the hard core of economic theory is related to the comparative methodologies used in mainstream and evolutionary models. Clearly, evolutionary models not only involve complexity but are generally complicated in their formulation and structure. The technical background, and the rather simple algebra underlying the general 'form' of mainstream economics is taught to allmost any student of economics, which renders mainstream models tractable and understandable for a greater mass of audience. However, for readers of evolutionary work who are not specifically trained in non-linear dynamic systems, simulation models, and complexity, a full appreciation of evolutionary models is less likely. That is, the majority of the formal evolutionary work is embodied in journal articles, which generally present simulations on the fully-fledged parameterizations of (mostly non-modulax) models, yet, due to space limitations, confine analysis to the presentation and discussions on end results focused on specific research targets/issues rather than a comprehensive exploration of the basic properties of the model. In such cases, the readers which are not specialized on the building and analyzes of such models may not fully appreciate what has really been happening under 
the hood. A good example of such possibilities is expressed by Paul Krugman, a quote from whom is included in our discussions in chapter $2:$ "... but just reinining a lot of simulations and seeing what happenss is a frustrating and finally unoroductive exercise unless you can somehow create a "model of the model" that lets you understand what is going on".

This concern has affected the way in which we present our model: Based on the "order and change" dualism, we have built the presentation of our modular model in a way that gradually moves from simple steady states to more complex settings. The first stage, which is closest to the usual analysis in mainstream economics because it puts much emphasis on 'steady states', has been the analysis of the stationary fundamentals of our model in case of no technological change. Despite the emphasis on stationary states, these efforts, in addition to showing the 'order generating' potential of evolutionary selection (which is pertinent to most evolutionary models of growth), have pointed to three steady-state properties of our model which can readily be contrasted to the properties of the majority of static (or steady-state-based) mainstream models.

The first one is the theory of income distribution that underlies our model. As we have discussed in terms of analytical derivations and also verified by actual simulations, in our model, incone distribution emerges endogenously as an emexgent steady-state property, primarily as a function of the institutional settings of the labor markets, the profitability expectations of the capitalists, and the capitall intensity of the 'actual' technologies in use. This is quite a radical difference from the income distribution implications of the mainstream economics where (under optimization, perfect inelasticity of labor supply etc.) income distribution is merely determined by the extent of factor substitution possibilities freely offered by the production production.

'The second one highlights the unwritten (i.e., implicit) fact that differentiates mainstream models from the evolutionary models of growth including ours: Mainstream formulations assume firm-level profit-maximization and by their perfect competition assumption (which underlies the general equilibrium approach) make industries behave like profit-constrained output maximizers. On the contrary, evolutionary models such as Nelson and Winter [1982], Silverberg and Verspagen [1995a], Silverberg and Lehnert [1993], assume profit-constrained output maximizing tendency which is an implicit implication of the mechanism that links incremental investments to profits. Our model incorporates both assumptions and hence clarifies the differences arising from these implicit assumptions.

The third, -international trade related- one, arises from the exclusion of a contimuous production function in our model, which is typical of most evolutionary models. In this context we have shown the emergence of various patterns of international speciallization as an outcome of cross-country differences in technology coefficients. The potential variety in specialization patterns is observable in different cases, some of which seem to conform to the prediction of the Heckscher - Ohlin model, and some of which do not. Given the fact that the prediction of the Heckscher - Ohlin model generally fails to pass empinical venifications, one can think of a long list of technical reasons that underlie this failure. Our -constant technology coefficients based-results point to the fact that among all such reasons, the most important one may be the continuous multi-factor production functions which assume the costless and instantaneous availability of an infinity of alternative production techniques. In this sense, we believe that despite its failure in unearthing the process of international specialization and trade flows, the Heckscher Ohlin model has a great contribution in demonstrating, though in a specific con- 
text, the general potential of the "contmuous multi-factor production" construct in generating highly misleading results.

In the second stage of our bottom-up approach in presentation, we have highlighted a number of issues that point to the added value af a disequilibrium dynamic approach, as opposed to a steady state imposition to models. This is a more "usual" evolutionary topic in the literature. In addition to our results which are summarized in the previous sections, we have argued that with an evolutionary formulation of the disequilibrium processes of capital aceumulation and economic growth, one does not need the "continuous multi-factor production" construct (as in the Solow model) to avoid the instability properties pertinent to the HarrodDomar model. This observation, which links some discussions dating to 1950 s to recent evolutionary formulations, is of course one of the basic implications of some other evolutionary models as well (e.g. Silverberg and Verspagen [1995a]), though these authors do not embed the issues in the traditional growth discussion of the 1950s. In our bottom-up manner of presentation we have also found the opportunity to highlight such links.

It is possible to decompose this discussion into the qualities of our model in terms of its evolutionary nature and its agents-based nature. Our discussion so far basically points to the differences of the basic implications of our approach with that of the mainstream formulations in the context of its evolutionary qualities. In terms of its agent-based foundation, we have demonstrated that the model has properties that highlight the importance of agent heterogeneity and selection in the emergence of self-organized patterns of industrial organization, which in turn has strong implications for economic growth. Such exercises allready exist in the evolutionary literature in various forms and contexts. In our view, the added value of our own effort in relation to these earlier evolutionary efforts is two-folded. First, the incorporation of international trade into evolutionary models is quite rare. Second, and perhaps more importantly, is the incorporation of variety demand into a multi-sector multi-country evolutionary model, which, to our knowledge, is unique.

In mainstream models of new growth and new trade, demand for variety is quite a recurrent theme, which is generally used to demonstrate an alternative and/or complementary dimension of economic (i.e., welfare) growth, in addition to the quality and quantity based sources. However, in the context of evolutionary models, the central logic of which is primerily based on selection dynamies, demand for variety implies a totally new context: In typical evolutionary models of growth, where products are assumed to be homogenous, selection directly acts on the heterogeneity in firm's relative fitness levels. Yet, as we have shown in a number of experiments, demand for variety introduces protective niches to firms and accordingly foils this causal link. Our CES welfare function-based formulation (that is based Dixit and Stiglitz [1977]) allows to control this effect by a single parameter. In the majority of our experiments in chapter 7 , we have utilized this parameter to demonstrate the complex multi-way links between the self-organized emergence of industrial organization patterns and economic performance, in settings characterized by various mechanisms of firm-level dynamic increasing returns. We have observed that in one extreme (i.e., homogenous goods) the processes that lead to cross-country growth differentials and specialization, which emerge through a process of increases in market concentration, are strongly affected by stachasticity that underlies firm-level inmovation arrivals, while at the other extreme (i.e., high demand for variety), which leads to highly concentrated market structures and low growth, the effects of stochasticity and the emergent cross-country differentials are 
less pronounced. In other words, our control experiments with varying extents of variety demand generates on one extreme results similar to the evolutionary model in Dosi et al. [1994] and also results that are remimiscent of those of the monopolistic competition-based models of the new growth literature. In intermediate cases, intermediate industrial organization patterns emerge by self-organimation as the outcome of the complex interplay between the effects of stochasticity and the (limited) abilities of economic selection. As an implication, the trade-off between product variety and output growth is resolved by self-organization, which does not necessarily reflect any collective rationality as suggested by a number of mainstream models.

Clearly, there are important commonalities between a subset of our results with those of some others, not only evolutionary but also mainstream models of growth and trade. In terms of the mainstream models, such qualitative similarities are more pronounced under specific assumptions and restrictions. Yet, except: for such specific circumstances, the differences are more visible. These differences are most pronounced in the context of the rationality in $\mathbb{R} \& D$ effort. Contrary to the mainstream literature, which suggest a link between individual and collective rationality, we have argued that neither individual (bounded) rationality nor the meta-rationality constituted by the selective forces of the econony necessarily suffice to eliminate the potential arbitrariness in $R \& D$ behavior and accordingly to impose a collectiwe type of rationality that would reflect the societies' interternporal preferences in the economies' $R \& D$ effort. We have observed that the selective forces of the economy have some limited power to discriminate between too much and too little effort, yet even this limited power is potentially inhibited by various factors such as stochasticity, the extent of potential heterogeneity in individual behavior and also demand for variety which strongly affects the discriminative potential of economic rationality.

These differences obviously lead to conflicting policy implications. A general theme in the mainstream literature on growth perceives knowledge and technology spill-overs as a positive externality that should be internalized by R\&D subsidies. This argumentation is strongly dependent on the presumption that the R\&D decisions of firms somehow reflect the intertemporal preferences of the society. However, the more one considers the elements of arbitrariness and self-organization (and less of any collective rationality per se) in R\&D effort, as in our model, the less one perceives such (highly generic) policy recommendations as appropriate.

Although we have not built into our model any parametric control for policy impacts, the implications of our 'technological paradigms' formulation readily point to some specific policy suggestions in the context of R\&D efforts. In the model, in a giwen technological paradigm, the marginal returns to innovations decrease as learning opportunities are exploited over time. The Schumpeterian link which we demonstrated in chapter 6 , also suggests a clear correspondence between the saturation in paradigm-specific learning and the low productivity growth episodes of business cycles. Also given that the discovery of new technological paradigns is, by definition, rare (i.e., is a 'serendipity-dependent' event), an awkward situation readily presents itself in terms of a conflict in private incentives towards R\&D effort: At the recession phase of each business cycle, due to the saturation in paradigm-specific learning, incentives for R\&D towards incremental innovations approach to zero. The onlly thing that can break the recession. is the discovery of a new technological paradigm, which puts the economy into a promising learning and progress path. However, since the discowery of a new paradigm is a rare and unpredictable event, from the perspective of individual 
firms, the incentives to do R\&D aiming at some 'serendipity dependent" discovery are close to zero, at least in terms of rational expectations. Consequently, the creumstances where the economy is at the peak of its desperation for $\mathbb{R} \& \mathbb{D}$, the fim-level priwate incentiwes to do so are at theirr lowest level.

This vicious cycle clearly points to the potential importance of public spending towards R\&D efforts a ming at 'serendipity-dependent' technological targets (i.e. 'basic research'), which can be too risky and expensive from the perspective of private incentives. Furthermore, even after the initial set of discoveries, the initially flat part of the paradigm-specific learning curves might well constitute an inhibition for the economy to makne the initial (private) investments to accumulate the paradigm-specific knowledge stock required to move to the steep part of the learning curve, where opportunities are exploitable. Public spending can also be crucial at these initial periods of taking-off. For example, the significant spending of some national and supramational bodies on the recently emerging "nanotechnologies" or other key (or promising) technologies, clearly is a good example of a policy that enibodies the essence of our techmological paradigms-based argumentation.

In this dissertation, we aimed at showing the added-value of our modeling exercise through selected demonstrations of its capacity to generate results that can be linked to various issues and arguments in economic literature. Another contribution of our effort, which, in our view, is not less important than the former, is embodied in the software which we distribute in the accompanying CD. As argued in the beginning of this section, probably the most inhibiting factor that slows down the diffusion of evolutionary ideas and methodologies into the hard core of economic theory is the problem of reproducibility and verifiability of evolutionary results by second and third parties, which is a result of the fact that the computer codes and or executable implementations of evolutionary models are generally not distributed in a user-friendly structure. In our effort in building a modular experimentation platform that accommodates warious alternative assumptions on key issues, and distributing the end product in a form that can be used by other parties to verify our claims and also to build their own comparative experiments, we aim to set an example for researchers, who are also willing to contribute to the future success and acknowledgment of evolutionary economics.

\subsection{Future perspectives}

In this clissertation, we have discussed the results of a number of experiments made with our multi-use model on a selected set of issues. Clearly, our effort constitutes a small subset of experiments/scenarios that can potentially be made with our model, which brings together a range of altermative assumptions and modules characterized by a broad parameter space. Thus, our first major objective for the future is to make a more thorough exploration of the model and generate more results.

As in many evolutionary models, our model essentially demonstrates the pom tential richness of observations that one can make with the use of an evalutionary model that duaws on disequilibrium dy namics rather than on a moving equilibrium perspective. The firm-level, gradual and stochastic arrival of new technologies, the temporal heterogeneity and discontimuities in technology arrivals, the gradwal diffusion of these through the economy; and various lags in the restoration of labor market equilibrium which is repetitively disturbed by each new technology shock, are examples of the basic ingredients of the disequilibrium dynamics, which, together characterize economies that evolve throngh temporal patterns that 
can hardly be observed in mowng equibrim formulations and their steady-state based analysis.

However, the selection forces of the econony which penalizes (remunerabes) inferiority (superiority) in terms of fitness or behavior, prevents erratic behavion and keep the economies in rather onderly states. Although the elinmation of the less fit, together with the simultaneous remuneration of the fitter, do not happen instantaneously, they happen eventually through a smooth, and gradual process, which proves to be sufficient to suggest that selection constitutes some form of mett-rationality for the economy at large. In other words, due to its gradual nature, the selection process is not instantaneously efficient but it, at least, koeps the economies steadily in the right direction at all times. For example, although they do not perish instantaneonsly, firms that suffer negative profits always shrink and loose market share. Similarly, the profitable ones gradually expand capacity and gain market share. At the core of this system, hes the financial market through which shareholders collect dividends, allocate a part for current consumption, and redistribute the rest to the relatively more profitable firms to finance their investment on capital.

This description appeals to economic intuition by all means, yet by reducing the financial system to the relation between frms and shareholders, it ignores a potentially important element of the modern financial systems, which is the short/medium rum ability of banks to create money in terms of credits. Consider the following scenario: Assume that firms that make losses do not cover these by selling part of their capital stock and reducing output level, but relying on tomorrow, they instead, ask for loans from banks. Further assume that the economy is in an optimistic state, and banks are willing to accommodate the credit demand by money creation and the frms get the chance to cover their looses accordingly. This would definitely undermine (or at least postpone) the essential workings of the selection mechanisin. Furthermore, as the non-profitable firms carry on financing their losses accordingly, together with the burden of interest payments, they would accumulate significant amounts of debt over time. If many firms follow this behavior, the level of the aggregate cumulative debt eventually pushes up interest rates and pushes down banks' ability to create more money. Having lost their ability to postpone the inevitable by refinancing, mary firms leave the market by instant death (i.e., selling of all assets at once to pay for the accumulated debt) and the economy experiences an intense period of shaking-out.

The essence of this hypothetical scenario is highly reminiscent of the "financial instability hypothesis" suggested by Minsky [1982], which, drawing on the post-Keynesian concept of "endogenous money supply", explains the endogenous emergence of business cycles, as an outcome of the inefficiency of financial institutions (especially in periods of euphoria, where expectations for the future are overoptimistic) to discriminate between the future profitability (or feasibility) of" competing investment projects, all of which demand credits. In our variant expressed by the hypothetical scenario above, we suggest that if inefficiencies in the economy are not eliminated instantianeously or rapidly enough due to reasons such as carelessly granted bank loans which spoil the efficiency of the selective forces of the economy, their burden on the economy may accumulate over time and gradually bring the economy to a critical (unstable) state, which eventually ends up with a rapid shake ont, where all of the inefficiencies are finally eliminated at once. Having eliminated its weakest links (though with a significant delay) within a rather turbulent period of time, the economy resumes to its gradual course until the emergence of the next shake-out ${ }^{14}$. 
In the current version of our model, naturally such things can not happen, since our specification of the selection system does not incorporate any mechamism which tolerates persistent inefficiencies for prolonged periods. However, by the introduiction of a banking system (through which money/credits can be created and destroyed by pay-backs) into our model, it can be possible to incorporate very interesting mechanisms, through which micro-level inefficiencies are sustained and are propagated to the macro-level in a cumulative manner. Such mechanisms may levd to new insights with post-Keynesian flavor on the possible links between: (sector-specific) technological change process and the endogenous generation of aggregate-level business cycles.

An other element that is missing in the current version of our model is the existence of national governments which can affect the course of economic selection and technological change by its redistribution and/or schooling policies. In future versions of our model we are planning to make up for that. However, the important issue is the alternative ways in which such incorporation can be achieved. Instead of building in parametric modules that would describe once and for all the behavior of policy makers (i.e. whom and how much to tax, use accordingly raised resources in state $R \& D$ labs for basic research or to support/subsidize private firm's R\&D activities, etc.), our intention is to turn our software into an active "evolutionary policy game", where users (players) can interrupt the model in rum. time every now and then, and set/update their policy choices as they will. It is also possible to design the game as a competitive one, where more than one players (each assuming the role of the govermment of a different country') play against each other, their objective being the maximization of the welfare of the artificial country which they govern. One of our aspirations for the future is to use our evolutionary experimentation platform as a pedagogical tool in courses that aim to teach students the basics of evolutionary theorizing on technological change, economic growth and international trade. Although, in its current fully functional form the software is quite ready for such a purpose, it can be more entertaining and pedagogically useful in a competitive game form as we intend to do in the future.

Last but certainly not the least, an important issue is the possibility to turn our semi agent-based model into a fully agent-based one. That is, one may ask whether it is possible to open the black-box which constitute our equilibriumbased (inverse) demand module, and incorporate into the model an agent-based disequilibrium demand/price formation module, where product prices and international distribution of products emerge from the local interactions of individual customers with individual firms.

As discussed in chapter 2 , the extents with which demand related issues are addressed in evolutionary models exhibit a sharp decline as the level of aggregation increases. That is, one finds a high number of sector/industry level agent-based models which are dedicated to explain the dymamics of prices, market transactions, and buyer-seller network formations on highly behavioristic grounds, as emergent outcomes of local leaming and local interactions among agents. Among many, an important overall lesson one can derive from this cliverse collection of studies is the fact that an essential ingredient in convergence to realism in modeling markets, is the acknowledgment of the idiosyncrasies that characterize different types of markets (e.g., financial, labor, perishable goods, durable goods, second hand markets, auctioning markets etc.). Incorporation of such diversity in a multi-sector, multi-market framework that aims to address emergent properties at the highly aggregate levels is, without doubt, a highly ambitious (if possible) undertaking. 
Accordingly, evolutionary models of high aggregation levels conveniently by-pass demand-side issues by assuming instantaneous market clearance in final good naxkets $^{15}$, while allowing for disequilibrium in other markets. This is exactly what has been done in our model as well.

Making a fully agent-based model of international trade and economic growth is technically possible in many conceivable ways, especially if one is ready to make a number of simplifying assumptions of a kind, which ignores the idiosyncrasies of the disequilibrium dynamics in different types of markets ${ }^{16}$. Furthermore a model that incorporates individual customers as separate entities also need an agreeable theory of individual level income distribution, which is quite a challenging issue, unless one is willing to experinent with arbitrary assumptions. In our view, the extent of the potential divergences from reality that would be brought about by such assumptions (and given the modeling toolbox available at the time being) are not less than that one already faces by assuming simultaneons market clearance in product markets. In other words, one should suggest good reasons to justify the undertaking of such a challenging effort. Of course, the introduction of any extra dimension of disequilibrium dynamics or sources of friction into a model, can potentially contribute to the emergence of interesting complex phenomena. However, when one talks about the modeling of disequilibrium dynamics, the reward is proportional to the proximity of the building blocks of the formulation to reality, the potential of which does not look too strong in the case of a multisector multi-country framework.

However, in the context of our model, we can suggest a potentially good reason to incorporate a fully agent-based demand module into our framework. As we have been demonstrating in this dissertation, the equilibrium based inversedemand module we used in our model already introduces interesting insights in terms of the potential effects of demand for quality and demand for product variety on the workings of an evolutionary selection mechanism, which otherwise discriminates firms solely on the basis of their productivity levels. Yet, due to the aggregation related problems that challenge the link between individual and aggregate demand, our demand-side formulation remains justifiable only if one assumes that the trade-off between quantity and quality and also that between quantity and product variety, are perceived by all customers of the world in the identical way, independently of their individual incomes or preferences. However, customer level heterogeneity (i.e., endogeneity in personal income level) in these two perceptive dimensions may have an immense potential in the explanation of firm's international marketing (i.e. pricing and exporting) strategies and accordingly of trade flows between countries ${ }^{17}$.

Outside of the scope of the study that underlies this dissertation, we have been building such a model framework, with which we are willing to replace the black-boxed demand module of orin current model in the futare. The key ingredient of this model is that it addresses the two-way causality between price and quantity adjustments by placing these into different time frames, where the price adjustments are assumed to be made by shops (i.e., every firm is assumed to hawe a shop in every other country, while the decisions regarding the level and the distribution of the total output over the shops in various countries, are made by the shops with a periodicity different than that of the price updates by firms ${ }^{18}$. So far, we have only made a few tentative experiments with this hobby model and basically observed that in settings where individual customers are homogenons in their quality and product variety perceptions (as we critically assume in our main, demand-side back-boxed model), the disequilibrium process remains close to 
the equilibria characterized by the black-boxed demand module of the supply-side focused model, which is presented in this dissertation. 


\section{Notes}

1. Such as formation of networks, emergence of social and behavioral norms, price and market formation on isolated markets as emergent outcomes of individnal buyrer-seller interactions and learning etc.

2. Such as that technological charnge is the main/only engine of growth, that externalities arising from the accumulation and spilling-over of technologies and/or knowledge keep incentives for investments alive, render economic growth sustainable, and can also explain growth rate differentials and specialization puttems between countries etc.

3. Which the reader can find in the accompanying $\mathrm{CD}$, and also the highlighted results of which are discussed in chapter 4.

4. Actually, the term 'maximization' can be a bit misleading, since, in our formulation where the per period capacity growth of firms are limited by the current: profits of the economy, firm growth/shrinkage is a gradual process. In this sense, our alternative behavioral assumptions, which are essentially local and adaptive, specify alternative ways in which individual firms periodically answer the question: "given our current profitability (financial resources), market share (which effects the elasticity of demand facing the firm) and anticipated depreciation, how much do we want to invest on new capital goods this period?"

5. Which is equivalent to profit-constrained output maximizing behavior.

6. I.e. The capital embodiedness of labor productivity differentials.

7. Which is reflected by the minimum rate of return on capital that they expect. from firms.

8. An assumption which is somehow relaxed by various models that one finds in the new growth/trade literature as discussed in the first introductory chapter.

9. As in comparative statics.

10. Besides, we also introduce alternative assumptions regarding the initial fitness of entrants (i.e. minimum of all firms, a random draw between the best and worst practices, maximum of all firms, or as determined by stochastic imitations etc.).

11. Since each new innovation does not necessarily increment not upon the cumulative level reached by own innovations of the firm but upon a higher level, which is closer to the maximum level achieved by all firms collectively.

12. As in our formulation, which specifies the probability of an innovation as an S-shaped function of the number of workers employed for R\&D.

13. I.e. Each "satisficing" firm has in mind a threshold (satisfactory) level of rate of return on $R \& D$ investments, and adopts the highest $R \& D$ expenditure scheme which is expected to yield a rate of return that is no less than this value.

14. A process which can be described by the "punctuated equilibria" concept.

15. E.g.. Growth models such as the Nelson and Winter [1982] model, which assume a single sector single country setting, or the Dosi et al. [1994] model, which assumes Cobb-Douglas preferences (fixed income shares) for the allocation of demand among sectors and the (price-based) replicator dynamics for the distribution of total sectoral demand over individual firms.

16. The causal links between price and quantity adjustments can hardly be considered as identical (or similar) across different markets. Not only the relative frequencies of these adjustments are heterogenous but the roles of the parties involved in the decision making processes (i.e., who sets the prices, are there any intermediaries) also show variations across markets.

17. For example, potential effects of income levels and distribution (running through demand for variety) on the international trade and specialization are discussed by 
Linder [1961], Barker [1977]. A formal model that aims to link income distribution, quality preferences and international specialization can be found in Flam and Helpman [1987].

18. Assume that at a given time $t$, the firm $k i j$ produces $Q_{k i j}^{k}$ units of output every period and sends $q_{t r j s}^{t}$ of this total to the shop in country s. Untill this allocation is updated by the firm, the assignment of each shop is try to sell this periodical inflow of goods at the highest possible price without accumulating any stocks. Individual customers go out shopping every period, visit a number of shops (in the country where they live), and make their purchases starting from the from the ones which offer the highest quallity-price ratio. If these preferable shops are out of stock, the customer informs the shop about its excess demand and goes to the less preferable shops in the sample. Based on the total excess demand/supply determined accordingly, the shop makes price adjustments every $P_{2} \geq 1$ periods (i.e. by a rule similar to: "if unintended inventories are observed to be accumulating in the recent past, decrease the price slightly, and if excess demand is observed increase the price slightly"). Every $P_{3} \geq P_{2}$ periods, the firm reconsiders the international distribution of its output (i.e. the allocation. $\frac{q_{k i j a}^{t}}{Q_{\text {kij }}^{t}}$ over the shops). And finally every $P_{4} \geq P_{3}$ periods the total output level of firms change. Namely, everything (that pertains to the supply-side) that happens periodically in the model presented in this dissertation, takes place by the period $P_{4}$ in our auxiliary model. Naturally, the adjustments in the international currency markets are also characterized by a disequilibrium process, which is formulated in a. way (similar to that in Dosi et al. [1994]) where exchange rates follow countries" accumulated international debt. 


\section{A}

\section{Appendices and extras (on the accompanying CD)}

As mentioned at various occasions in the text, we have supplied extra material to this dissertation on the accompanying CD-ROM.

The directory "SOFTWARE" includes the installation files of the simulation software of our model.

Under the directory "APPENDICES", the reader can find appendices to individual chapters and also the user's manual for the simulation software (all in PDF format;), and a full list of the parameters and variables of the simulation platiform.

Under the directory "UTILS", we supply a number of visualization tools for various functions that are part of our model formulation.

Furthermore, under some of the directories devoted to individual chapters (i.e., directories named as "CHAPTER4" "CHAPTER6" etc.) the reader can fiad the project and output files of individual simulations which are either discussed in the dissertation or discussed in the appendices as suppiementary material. 


\section{References}

Aitiken, N.D., (1973), "The Effect of the EEC and EFTA on European Trade: A Temporal Cross-Section Analysis", American Economic Review, Vol. $63(5)$, pp. $8811-92$.

Aghion, P. and P. Howitt, (1990), "A Model of Growth Through Creative Destruction", NBER Working Paper, 3223.

Amable, B., (1992), "Competition among Techniques in the Presece of Increasing Returns to Scale", Journal of Evolutionory Economics, Vol. 2, pp. 147-158.

Andersen, E.S., (1997) "Escaping Satiation in an Evolutionary Model of Structural Economic Dymamics", DRUID Working Paper, 98-9.

Arifovic, J, and C. Eaton, (1994), "Coordination via Genetic Learning", Papers 94-11, Simon Fraser - Department of Economics.

Arrow, K.J.and G. Debreu, (1954), "Existence of Equilibrium for a Competititve Economy", Econometrica, Vol 22, pp. 265-290.

Arrow, K.J., (1962), "The Economic Implications of Learning-by-Doing", Review of Economic Studies, Vol. 29. pp. 155-173.

Axtell, R., (2000), "Why Agents? On the Varied Motivations for Agent Computing in the Social Sciences", Center on Stocial and Economic Dynamics, Working Paper No. 17, November.

Balassa, B., (1963), "An Empirical Demonstration of Classical Comparative Cost. Theory", Review of Economics and Statistics, 45.

Baldwin, R. En, (1992), "Measurable Dynamic Gains from Trade," Journal of Political Economy, Vol. 10o(1), February, pp. 162-74.

Barker, J., (1977), "International Trade and Economic Growth: An Alternative to the Neoclassical Approach", Cambridge Jounal of Economics, Vol 1, pp. $153-172$.

Baumol, W., (1962), "On the Theory of Expansion of the Firm", American Economic Review, Vol. 52(5), pp. 1078-1087.

Baumol, W.J., (1967) "Macroeconomics of Unbalanced Growth: The Anatomy of Urban Crisis." AmericanEconomic Review, Vol. 57, pp. 415-426.

Bhagwati, J.N., (1958), "Inmiserizing growth: A Geometrical Note" "Reviev of Economic Studies, Vol 25, pp. 201-205.

Bhagwati, J., (1964), "The Pure Theory of International Trade: A Survey", Economic Journal, Voll 74, March pp. I-84.

Bhagwati, J., (1972), "The Heckscher-Ohlin Theorem in the Multi-commodity Case", Joumal of Political Economy , Vol 80, pp. 1052-1055. 
Blad, M.C. and H. Keiding, (1990), "Microeconomics: Institutions, Equilibrium and Optimally"y", Amsterdam Elsevier.

Bottazi, G, and A.Secchi, (2003a), "Common Properties and Sectoral Specificities in the Dynamies of U.S. Manufacturing Companies", Review of Indwstrial Orgonization, Vol. 23 , pp. $217-232$.

Bottazzi, G. and A.Secchi, (2003b), Why are distributions of firm growth rates tent-shaped?", Economic Letters, Vol. 80, pp. 415-420.

Caves, R.E., (1965), "Vent for Surplus", in R.E. Caves et.al eds., Models of Trade and Growth, pp. 95-115.

Chamberlin, E., (1962), "The Theory of Monopolistic Competition", Cambridge: Harvard University Press.

Chen, S.H., and C.H. Yeh, (2001), Evolving Traders and the Business School with Genetic Programming: A New Architecture of the Agent-Based Artificial Stock Market", Journal of Economic Dynamics and Control, Vol. 25, pp. 363-393.

Cimoli, M., (1988), "Technological Gaps and Institutional Asymmetries in a North-Sonth Model with a Continum of Goods", Metroeconomica, Vol 39(3), pp. 245-274.

Cimoli, M. and L. Soete, (1992), "A Generalized Technology Gap Trade Model", Economie Apliqué, Vol XLV(3), pp. 33-54.

Conlisk, J., (1989), "An Aggregate Model of Technical Change", Quarterly Journal of Economics, Vol. 104, pp. 787-821.

Coricelli, F. and G. Dosi, (1988), "Coordination and order in Economic Change and the Interpretative Power of Economic Theory", in Dosi, G. et al (eds.), Technical Change and Economic Theory, London: Pinter, pp. 124-147.

Dawkins, R., (1976), "The Selfish Gene", N.Y: Oxford University Press.

David, P. (1985), "Clio and the Ecomomics of QWERTY", American Economic Review, Proceedings, Vol. 75, pp. 332-337.

Davis, D.R., (1995), "Trtra-industry Trade: A Heckscher-Ohlin-Ricardo Approach" Joumal of Intermational Economics, Vol. 39(3), pp. $201-226$.

Day, R. H., (1994), "Complex Economic Dynamics Vol I", MIT Press.

Deardorff; A.V, (1973), "The Gains from Trade in and out of Steady-state Growth," Oxford Economic Papers, Vol. 25(2), Jully, pp. 173-91.

Deardorff, A.V., (1980), "The General Validity of the Law of Comparative Advantage," Jowmal of Political Economy, Vol. 88(5), pp. 941-57.

Deardorff, A.V., (1979), "Weak Links in the Chain of Comparative Advantage", Joumal of Imternational Economics, Vol 9, pp. 197-209.

Deardorff, A.V., (1984), "Testing Trade Theories and Predicting Trade Flows", in Jones, R.W. et al (eds)., Handbook of International Economics, Vol 1, Amsterdam: North-Holland, pp. 467-517.

Debreu, G., (1974), "Excess Demand Functions", Journal of Mathematical Economics, Vol 1., pp. 15-21

Dixit, A.K. and V.D. Norman, (1980), "Theory of International Trade: A Dual, General Equilibrium Approach", Cambridge: Cambridge University Press 
Dixit, A.K. and J.E. Stiglitz, (1977), "Monopolistic Competition and Optimum Product Diversity", American Economic Review, Vol. 67(3). June, pp. 297 308.

Dornbush, R., (1975), "Exchange Rates and Fiscal Policy in a Popular Model of International Trade", American Economic Review, Vol 65, pp. $859-871$.

Dormbusch, R., Fischer, S. and P.A. Samuelson, (1977), "Comparatiwe Advantage, Trade, and Payments in a Ricardian Model with a Continum of Goods: American Economic Review, Vol. 67(5), December, pp. 823-39.

Dosi, G., (1982), "Technological Paradigms and Technological Trajectories: A Suggested Interpretation of the Determinants and and Directions of Technical Change", Research Policy, Vol. 11 ,pp. 147-162.

Dosi, G., Orsenigo, L. and G. Silverberg, (1988), "Innovation, Diversity and Diffusion: A Self-organisation Model.", The Economic Journal, Vol. 98(127), December, pp. 1032-1054.

Dosi, G., Freeman, C., Nelson, R., Silverberg, G. and Soete, Lin, (eds.) (1988b), "Techmical Change and Economic Theory", London: Pinter.

Dosi, G., Pavitt, K. and L. Soete, (1990), "The Economics of Technical Change", Brighton: Harvester Wheatsheaf.

Dosi G. and R.R. Nelson, (1993), "Evolutionary Theories in Economics: Assesment and Prospects" , MASA Working Paper, WP-93-064.

Dosi, G., Fabiani, S., Aversi, R. and M. Meacci, (1994), "The Dynamics of International Differentiation: A MultiwConntry Evolutionary Model", Industrial and Corporate Change, Vol 3(1), pp. 225-242.

Dosi, G., Marsili, O., Orsenigo, L. and R. Salvatore, (1995), "Learning, Market Selection and the Evolution of Industrial Structures", Small Business Economics, Vol. 7, pp. 411-436.

Dosi, G., Fagiolo, L. and L. Marengo, (1996), "Learning in Evolutionary Environments", IIASA Working Paper, WP-96-124.

Dosi, G., Malerba, F", Marsili O., and L. Orsenigo, (1997), "Industrial Structures and Dynamics: Evidence, Interpretations and Puzzles", Industrial and Cor. porate Change, Vol. 6(1), pp. 3-24.

Epstein, J.M., (2001), "Learning to be Thoughtless: Social Norms and Thdividual Computation", Computational Economics, Vol 18, pp. 9-24.

Epstein, J. M. and R. Axtell, (1996), "Growing Artificial Societies: Social Science from the Bottom Up", Cambriclge, MA: MIT Press.

Ethier, W.J., (1982a), "Decreasing Costs in International Trade and Frank Graham's Argument for Protection", Econometrica, Vol. 50(5), pp. 1243-1268.

Ethier, W.J., (1982b), "National and Intermational Returns to Scale in the Moden Theory of International Trade", American Economic Review, Vol. 72(3), pp. $389-405$.

Falvey, R.E., (1981), "Comparative Advantage in a Multi-Factor World", Inter" national Economic Review, Vol 22, June, pp. 401-413.

Findlay, R., (1970), "Factor Proportions and Comparative Advantage in the Long: Run," Journal of Political Economy: Vol. 78(1), pp. 27-34.

Findlay, R., (1974),. "Relative Prices, Growth and Trade in a Simple Ricardian System," Economica, Vol. 41(127), February, pages 1-13. 
Findlay, R. (1981), "Fundamental Determinants of the Terms of Trade", in Grassman, S. and E. Lundberg, (eds.), The World Economic Order: Past and Prospects, London: Macmillan, pp. 430-434.

Findlay" R. and H. Grubert, (1959), "Factor Intensities, Technological Progress and the Terms of Trade", Oxford Economic Papers, Vol 11, pp. 111-121.

Fisher, R.A., (1930), "The Genetical Theory of Natural Selection", Oxford: Clarendon Press.

Flam H and E. Helpman, (1987), "Vertical Product Differentiation and NorthSouth Trade", The American Economic Retrew, Vol 5, pp. 810-822.

Ford, J.L., (1967), "On the Equivalence of the Classical and the Factor Models in Explaining Interaational Trade Patterns", The Manchester School, Vol 35, May, pp $185-198$.

Freeman, C., (1982), "The Economics of Industrial Innovation" London: Frances Pinter.

Freeman, C., and L. Soete, (eds.), (1987), "Technical Change and Full Employment" London: Basil Blackwell.

Freeman, C. and L. Soete, (1994), "Work for All or Mass Unemployment", London: Pinter Publishers.

Gandolfo, G., (1987), "International Economics I: The Pure Theory of International Trade", Berlin Heidelberg: Springer-Verlag.

Goodwin, R.M., (1967), "A Growth Cycle", in Feinstein C.H. (ed.), Socialism, Capitalism and Economic Growth, London: Macmillan.

Grandmont, J.M. and G. Larque, (1986), "Stability of Cycles and Expectations", Journal of Economic Theory, Vol 40, pp. 138-151.

Grossman, G.M., (1987), "The Employment and Wage Effects of Import Competition in the US", Journal of International Economic Integration, Vol 2, pp. 1.23 .

Grossman, G.M and E. Helpman, (1989), "Product Development and International Trade", Jourmal of Political Economy, Vol 97(6), pp. 1261-1283.

Grossman, G.M and E. Helpman, (1991a), "Quality Ladders in the Theory of Growth", Review of Economic Studies, Vol. 58, pp. 86-91.

Grossman, G.M and E. Helpman, (1991b), "Innovation and Growth in the Global Economy", Cambridge Mass: MIT Press.

Grossman, G.M.and K. Rogoff (eds.), (1995), "Handbook of International Eco" nomics, Vol. 3", Amsterdam: Elsevier.

Helpman, E., (1988), "Growth,Technological Progress and Trade", Paper presented in the symposium on Structural Economic Problems and Internalional Trade (organized by the Confederation of European Economic Associations), Hernstein: Austria, 2-4 March 1988.

Henkin, G.M. and V.M. Polterowich, (1991), "Schumpeterian Dynamics as a Non-linear Wave Theory" "Journal of Mathematical Economics, Vol. 20, pp. $551-590$.

Herberg, H., (1969), "On the Shape of the Transformation Curve in the Case of Homogenous Production Functions", 2eitschrift fir die Gesamte Staatswissenschaft, Vol 125, pp. 202-210. 
Hicks, J.R., (1932), "The Theory of Wages", London: Macmillan.

Hirsch, S., (1967), "Location of Industry and International Competitiveness", Oxford University Press.

Hofbauer, J, and K. Sigmund, (1988), "The Theory of Evolution and Dynamical Systems", Cambridge: Cambridge University Press.

Houthakker, H.S., (1950), "Revealed Preference and the Utility Function", Econometrica, Vol 17, pp. 159-174.

Hufbauer, G.C., (1956), "Syntetic Materials and the Theory of International Trade", Harvard University Press.

Hufbaner, G.C. and J.G. Chillas, (1974), "Specialization by Industrial Countries: Extent and Consequences", in Giersch, H., (ed.), The International Diviston of Labour: Problems and Perspectues, Tübingen: J.C.B. Mohr.

Jerison, M., (1984), "Social Welfare and the Unrepresentative Representative Customer", Discussion Paper, State University of New York at Albany.

Johnson, H.G., (1953), "Equilibrium Growth in an International Economy", The Canadian Journal of Economics and Political Science, Vol 19, pp. 478-500.

Johnson, H.G., (1955), "Economic Expansion and International Trade", The Manchester School Economic and Social Studies, Vol23, pp. 95-112.

Johnson, H.G., (1959), "Economic Development and International Trade", $N a$ tionalOkonomisk Tidssrift, Vol 97, pp. 253-272.

Johnson, H.G., (1971), "Trade and Growth: A Geometrical Exposition", Journal of International Economics, Vol 1, pp. 83-101.

Jones, J.I., (1995a), "Time Series Tests of Endogenous Growth Models", Quarterly Joumal of Economics, Vol, 110(2), pp. 495-525.

Jomes, J.L., (1995b), "R\&D-Based Models ofEconomic Growth", Journal of Political Economy, Vol. 103(4), pp. 759-784.

Jones, R.W., (1956), "Factor Proportions and the Heckscher-Ohlin Theorem", Review of Economic Studies, Vol 24, pp. 1-10.

Jones, R.W., (1961), "Stability Conditions in International Trade" A General Equilibrium Analysis", International Economic Review, Vol 2, pp. 199-209.

Jones, R.W., (1971), "A Three-factor Model in Theory, Trade, History", in Bhagwati, J.N, Jones, R.W, Mundell, R.A and J. Vanek (eds.), Trade, Balance of Payments, and Growth: Essays in Honor of Charles P. Kindleberger, Amsterdam: North-Holland, pp. 2-21.

Jones, R.W., (1974a), "Trade with Non-traded Goods: The anatomy of Interconnected Markets", Economica, Vol 41, pp. 121-138.

Jones, R. W., (1974b), "The Small Country in a Many-commodity World" . Australian Economic Papers, Vol 13, pp. 225-236.

Jones, R.W. and P.B.Kenen (eds).(1984), "Handbook of International Economics, Vol. 1". Amsterdam: North-Holland

Jones R.W and J.P. Neary, (1984), "The Positive Theory of International Trade", in: Jones, R.W., et al (eds)., Handbook of International Economics, Vol 1., Amsterdam: North-Holland, pp. 1-62.

Kaldor, N., (1980), "Essays on Economic Stability and Growth" $2^{\text {nd }}$ ed., London: Duckworth. 
Katsoulacos, Y., (1986), "The Employment Effect of Technical Change. A theoretical study of new technology and the labour market", Brighton: Wheatsheaf.

Kirman, A.P, (1992), "Whom or "What Does the Representative Individual Represent?" Joumal of Economic Perspectives, Vol. 6(2), Spring, pp. 117-36.

Kirman, A, and N.J. Vriend, (2001), "Evolving Market Structure: An ACE Model of Price Dispersion and Loyalty", Joumal of Economic Dymamics and Control, Vol 25, pp. 459-502.

Kondratief, N.D., (1926/1935), "Die Langen Wellen der Konjunctur", Archiv für Sozialwissenschaft und Sozialpolitik, Vol 56, pp. 573-609 (English translation: The Long Waves in Economic Life, The Review of Economic Statistics, Vol. 17, pp. 105-115).

Krugman, P.R., (1979), "Increvising Returns, Monopolistic Competition and International Trade", Joumal of International Economics, Vol 9(4), pp. 469479 .

Krugman, P.R, (1979), "A Model of Imnovation, Technology Transfer, and the World Distribution of Income", Journal of Political Economy, Vol 87, pp. $253-266$.

Krugman, P.R., (1980), "Scale Economies, Product Differentiation and the Pattern of Trade", American Economic Review, Vol 70, pp. 950-959.

Krugman, P.R., (1981), "Trade, Accumulation and Uneven Development", Journal of Development Economics, Vol 8, pp. 149-161.

Krugman, P.R., (1981b), "Tntraindustry Specialization and the Gains from Trade", Journal of Political Economy, Vol 89(5), pp. 959-974.

Krugrian, P.R., (1986), "A Technology Gap Model of International Trade", in Krugman, P.R, Rethinking International Trade, The MIT Press, pp.152164.

Krugman, P.R., (1987), "The Narrow Moving Band, the Dutch Disease, and the Competitive Consequences of Mrs. Thatcher: Notes on Trade in the Presence of Dymamic Scale Economies", Joumal of Development Economics, Vol 27, pp. 41-55.

Kuznets, S., (1940), "Schumpeter's Business Cycles", American Economic Review, Vol. 30, pp. $257-271$.

Kuznets, S., (1971), "Modern Economic Growth: Findings and Reflections", Nobel Prize Lecture, 11 December 1971.

Lane, D.A., (1993), "Artificial Worlds and Economics. Parts 1 and 2" , Journal of Evolutionary Economics, Vol 3, pp. 89-108, 177-197.

Langton, C.G., (eds.), (1989), "Artificial Life", Redwood City, CA: AddisonWesley.

Langton, C.G., Taylor, C., Farmer, J.D and S. Rasmunssen, (eds.), (1992), "Artificial Life II", Redwood City, CA: Addison-Wesley.

Leamer, E.E., (1980), "The Leontief Paradox Reconsidered", Journal of Political Economy, Vol 88, pp. 495-503.

Leamer, E.E. and J. Levinsohn, (1984), "International Trade Theory: The Evidence", in: Grossman, G.M. et al (eds.), Handbook of International Economics, Vol 3, Amsterdam: Elsevier, pp. 1339-1394. 
Leontief, W., (1953), "Domestic Production and Foreign Trade: The American Clapital Position Re-examined", Proceedings of the American Philosophical Society, September, pp. 332-349.

Lewis, W.A., (1954), "Economic Dewelopment with Unlimited Supplies of Labour", Manchester School of Economiz and Social Studies, Vol 21, pp. 139-191.

Linder, S.B., (1962), "An Essay on Trade and Transformation", New York: Wiley.

Limnemann, H., (1966), "An Econometric Study of International Trade Flows", Amsterdam: North-Holland.

Lotka, A.Y., (1925), "Elements of Physical Biology", Baltimore: Wiliams and Wilkens.

Lucas, R.E.B., (1988), "On the Mechanics of Economic Development", Journal of Monetary Ecanomics, Vol. 22, pp. 3-42.

MacDougal, G.D.A., (1951), "British and American Exports: A study Suggested by the Theory of Comparative Costs, Part I", Economic Journal, Vol 61 , December.

MacDougal, G.D.A., (1952), "British and Armerican Exports: A study Suggested by the Theory of Comparative Costs, Part II", Economic Journal, Vol 62, September.

Malerba, F., Nelson, R., Orsenigo, L. and S. Winter (1999), "History friendly models of industry evolution: the computer industry", Industrial and Corporate Change, Vol. 1, pp. 3-41.

Marshall, A., (1890), "Principles of Economics", London: MacMillan.

McKenzie, L., (1954), "On the Existence of General Equilibrium for a Competitive Market", Econometrica, Vol 27, pp. 54-71.

Mensch, G., (1975/1979), "Das Technologische Patt", Frankfurt: Umschau, English translation: "Stalemate in Technology. Imnovations Overcome Depression" , Cambridge: Ballinger.

Metcalfe, J.S., (1988), "Trade, Technology and Evolutionary Change", University of Manchester, mimeo.

Metcalfe, J.S..(1994), "Competition, Fisher's Principle and Increasing Returns in the Selection Process", Journal of Evolutionary Economics, Vol 4, pp. 327,346 .

Minsky, H.P., (1982), "Can 'It' Happen Again: Essays on Instability and Finace", New York: M.E. Sharpe.

Myint, H., (1958), "The 'Classical Theory' of International Trade and the Underdeveloped Countries", Economic Journal, Vol 68, pp. 317-337.

Neary, J.P., (1978), "Short-Run Capital Specificity and the Pure Theory of International Trade,", Economic Joumal, Vol. 88(127), September, pp. 488-510.

Nelson, $\mathbb{R}$. and S. Winter, (1982), "An Evolutionary "Theory of Economic Change", Cambridge: Harvard University Press.

Nicolaisen, J., Petrov, V. and L. Tesfatsion,(2001), "Market Power and Efficiency in a Computational Electricity Market with Discriminatory Double-Action Pricing", IEEE Transactions an Evolutionary Computation, Vol 5, pp. 504 523. 
Oniki, H. and H. Ugawa, (1965), "Patterns of Trade and Investment in a Dyramic Model of International Trade" , Review of Economic Studies, Vol 32, pp. 1538.

Pasinetti, Li, (1981); "Structural Change and Economic Growth: A Theoretical Essay on the Dynamixs of the Wealth of Nations", Cambridge University Press:

Posner, MV., (1961), "Intemational Trade and Technical Change", Oxford Economic Papers, Vol 13, pp. 323-341.

Poyhonen, P., (1963), "A tentative Model for the Volume of Trade Between Countries", Werltwirtshaftiches Archiv, Vol 90, pp. 93-99.

Prebisch, R., (1950), "The Economic Development of Latin America and its Principal Problems", New York: ECLA, United Nations

Prigogine, I. and I. Stengers, (1984), "Order Out of Chaos: Man's Dialogue with Nature", New York: Bantam Books.

Reinganum (1989), "The timing of imnowation: research, development, and diffusion.", in Schmalensee R. and R. D. Willig (eds), Handbook of Industral Organization, Vol I, Amsterdam, Elsevier, pp. 849-908.

Ricardo, D., (1817), "On the Principles of Political Economy and Taxation", London: John Murray.

Romer, PM., (1986), "Increasing Returns and Lon-Run Growth", Journal of Political Economy, Vol. 94(5), pp. 1002-1037.

Romer, P.M., (1990), "Endogenous Technological Change", Jourral of Political Economy, Vol. 98(5), pp. 71-102.

Romer, P.M., (1994), "The Origins of Endogenous Growth", Journal of Economic Perspectives, Vol 8(1), pp. 3-22.

Romer, P.M., (1994b), "New Goods, Old Theory, and the Welfare Costs of Trade Restrictions", Journal of Development Ecomomics, Vol 43(1), pp. 5-38.

Samuelson, P.A., (1952), "The Transfer Problem and Transport Costs: The Terms of Trade when Impediments are absent", Economic Joumal, Vol 62 , pp. $278-304$.

Samuelson, P.A., (1962), "Parable and Realism in Capital Theory: The Surrogate Production Function", Rewiew of Economic Studies, Vol 29, pp. 193-206.

Samuelson, P.A., (1971), "Ohlin was Right", Swedish Journal of Economics, Vol $73, \mathrm{pp}, 365-384$.

Schumpeter, J.A., (1939). "Business Cycles: A Theoretical, Historical and Statistical Analysis of the Capitalist Process" , New York: MoGraw-Hill.

Seers; D., (1962), "A Theory of Inflation and Growth in Under-developed Economies Based on the Experience of Latin America", Oxford Economic Papers, Vol. $14(2)$, pp. 173-95.

Silverberg, G., (1987), "Technical Progress, Capital Accumulation and EffectiveDemand: A Self-Organization Model", in Batten, D.C.J. and B. Johansson, (eds), Economic Evolution and Structural Adjustment, Berlin, Heidelberg, NewYork and Tokyo: Springer-Verlag.

Silverberg, G., (1988), "Modelling Economic Dynamics and Technical change: Mathematical Approaches to Self-Organisation and Evolution*, in Dosi, G., Freeman, C., Nelson, R., Silverberg, G. and Soete, L., (eds.), Technical Change and Economic Theory, London: Pinter. 
Silverberg G. and D. Lehnert, (1993), "Long Waves and 'Evolutionary Chaos' in a Simple Schumpeterian Model of Embodied Technical Change", Structural Change and Economic Dynamics, Vol 4, pp. 9-37.

Silverberg G. and B. Verspagen, (1995a), "From the Artificiall to the Endogenous: Modelling Evolutionary Adaptation and Economic Growth" IIASA Working Paper WP-95-08.

Silverberg G. and B. Verspagen, (1995b), "Evolutionary Theorizing on Economic Growth", IIASA Working Paper WP-95-78.

Silverberg, G. and B. Verspagen, (2003), "Breaking the Waves: A Poisson Regression Approach to Schumpeterian Clustering of Basic Innovations," Cambridge Journal of Economics, Vol. 27(5), September, pp. 671-693.

Simon, H.A., (1962), "New Developments in the Theory of the Firm" American Economic Review, Vol. 52(2),pp. 1-15.

Simon, H.A., (1986a), "Rationality in Psychology and Economics", in Hogarth, R.M. and M.W. Reder (eds.), The Behavioral Foundations of Economic Theory, special issue of The Joumal of Economics, Vol 59, pp. 209-224.

Simon, H.A., (1986b), "On the Behavioral and Rational Foundations of Economic Dynamics", in Day R.H. and G. Eliasson (eds.). The Dynamics of Market Economies, Amsterdam: North-Holland.

Singer, H.W., (1950), "The Distribution of Gains Between Borrowing and Investing Countries", in Willams, B. and Bryan-Brown J. (eds.), Knowns and Unknowns in Technical Change, Technical Change Center, London.

Smith A. (1776), "The Wealth of Nations", Cannan Edition (1976), Chicago: University of Chicago Press.

Smith, A., (1984) "Capital Theory and Trade Theory", in Jones, R.W. et al (eds)., Handbook of International Economics, Vol 1, Amstendam: NorthHolland, pp. 289-324.

Soete, L. and R. Tumer, (1984), "Technology Diffusion and the Rate of Technical Change", Economic Journal, Vol. 94, pp. 612-623.

Solow, R.M., (1956), "A Contribution to the Theory of Economic Growth", Quarterly Journal of Economics, Vol 70, pp. 65-94.

Solow, R.M., (1957), "Technical Progress and the Aggregate Production Function", Review of Economics and Statistics, Vol 39, pp. 312-320.

Solow, R.M., (1970), "Growth Theory: An Exposition", Oxford: Oxford University Press.

Stern, R. and K. Maskus, (1981), "Determinants of the Structure of the US Foreign Trade 1958-76", Joumal of International Economics, Vol 11, pp. $207-224$.

Sutton, J, (1997), "Gibrat's Legacy", Jowrnal of Economic Literature, Vol XXXV, pp. $40-59$

Tay, N.S.P. and S.C. Linn, (2001), "Fuzzy Inductive Reasoning, Expectation Formation, and the Behavior of Security Prices", Journal of Economic Dynamics and Control, Vol 25, pp. 321-361.

Tesfatsion, L., (1995), "How Economists Can Get Alife," Economic Report 37, Iowa State University Department of Economies. 
Tesfatsion, L., (2002), "Agent-Based Computational Economics: Growing Economies from the Bottom Up," Staff General Research Papers 5075, Iowa State Universiby, Department of Economics.

Tinbergen, $J_{.}$(1962), "Shaping the World Economy: Suggestions for an Interniational Economic Policy", New York.

Trefler, D., (1993), "Intermational Factor Price Differences: Leontief was Right!"; Journal of Poltical Ecomomy, Vol 101(6), 961-987.

Trefler, D., (1994), "The Case of the Missing Trade and Other HOV mysteries", University of Toronto, mimeo.

Uzawa, H. (1961), "On a Two-sector Model of Economic Growth", Revieu of Economic Studties, Vol 29 , pp. 40m 4 .

Van Cayseele, $P$, (1998), Market structure and innovation: a survey of the last twenty years", De Economist, Vol 146 , pp. 391-417.

Van Dijk, M.F., (2000), "Technological Change and the Dynamics of Industries: Theoretical Issues and Empirical Evidence from Dutch Manufacturing", Maastricht University (Dissertation).

Viner, J., (1.937), "Studies in the Theory of International Trade", New York: Harper \& Brothers.

Vernon, R., (1966), "International Investment and International Trade in the Product Cycle", Quarterly Journal of Economics, Vol 8, pp. 190-207.

Verspagen, B., (1993), "Uneven Growth Between Interdependent Economies", Aldershot: Avebury.

Vivarelli, M., (1995), "The economics of technology and employment. Theory and empirical evidence", Aldershot: Edward Ellgar Publishing.

Volterra V., (1930), "Lecons sur la Theorie Mathematique de la Lutte pour la Vie", Paris: Gauthier-Villars.

Vriend, $\mathbb{N}_{\text {. }}$., (2000), "An Illustration of the Essential Difference Between Individual and Social Learning, and its Consequences for Computational Analyses", Jowrnal of Economic Dynamics and Control, Vol 24, pp. 1-19.

Wakelin, K., (1997), "Trade and Innovation: Theory and Evidence", Cheltenham, UK: Edwand Elgar.

Walras, L., (1874), "Wiléments d'économie politique pure", Lausanne: L. Corbaz. (English translation by Jaffé, W., (1954), Elements of Pure Economics, London: Allen and Unwin). 


\section{Nederlandse Samenvatting}

De studie waraver dit proefschrift rapporteert is een modelleer oefening. Het doel is om een mulit-agent, multi-landen, mult-sector model te bouwen, waarin bedrijven met elkaar concurreren. Het model is agent-based: het beschouwt de economie als een verzameling van afzonderlijke en heterogene entiteiten. Iedere individuele agent in het model bestudeert zijn omgeving, interageert met andere agenten en formuleert zijn strategie op basis van begrensde rationaliteit (bounded rationality). Het model poogt het proces van internationale handel en economische groei te beschrijven als een emergente uitkomst. (emergent property) in de aggregatie van het micro proces van technologische concurrentie tussen bedrijven. Op deze manier is het model gefundeerd in micromeconomische dynamiek, en heef een sterk evolutionaire inslag.

In contrast met de gangbare economische modellen, is heterogeniteit in de evolutionaire economie een potentieel verklaringsmechanisme. Gebaseerd op het idee dat hetereogeniteit op de langere termijn geëlimineerd zal worden door selectie, beperken de gangbare economische modellen zich tot het formaliseren van een hypothetisch systeem waarin economische agenten identiek aan ellkaar zijn.

In de evolutionaire economie ligt de nadruk op het verklaren van verandering over tijd, en hoe een bestaande situatie tot stand is gekomen. In deze visie werken mechanismen die de heterogeniteit (langzaam) bevorderen gelijktijdig samen met; selectie die heterogeniteit elimineert. Dit vormt de kern van het evolutionaire antwoord op de bovenstaande vragen.

In de evolutionaire economie kan men een bepaalde mate van compartimentering van onderzoeksonderwerpen onderscheiden. Economische groei, industriële organisatie en internationale handel worden in aparte modellen geanalyseerd. Dit geeft een onterechte indruk dat de analyse in deze verschillende domeinen gebaseerd is op werschillende uitgangspunten en formalisaties. Bovendien is het onderwerp internationale handel een enigszins ondergeschoven onderwerp in evolutionaire modellen. Het eerste doel van deze studie is het proberen te overbruggen van de afstand tussen deze verschillende onderwerpen, door middel van een rnodel dat functionaliteit ui al deze gebieden combineert in een gemeenschappelijk experimenteel, modulair (computer) platform.

Het eindresultaat kan dan ook niet gezien worden als één model. Het is een experimenteel platform warbinnen verschillende modellen geconstrueerd kunnen worden als een combinatie van verschillende assumpties in de verschillende delen van het model. Door het modulaire karakter van het model kan men in de analyse niet alleen parameterwaarden veranderen, maar ook hele modules in- of witschakelen. Op deze manier kunnen experimentele omgevingen ontworpen worden die in hoge mate variëren in complexiteit. Men kan bijwoorbeeld experimenten ontwerpen met, een variabel aantal landen en sectoren, internationale handel aan- of uitzetten, 
innovatie exogeen of endogeen maken, de latste op basis van verschillende scenario's (zoals R\&D of leereffecten) en technologische inputs, stochasticiteit aanof uitzetten, de mate van technologische spillovers variëren, toetreding reguleren, en de startwaardes veranderen.

De cd die bij dit proefschrift gevoegd geeft toegang tot het platform. Als toevoeging aan de beschrijving van het model in het proefschrift geeft de cal de mogelijk aan lezers om zelf te experimenteren met het model. De cd bevat ook een antal analytische beschrijuingen van hoe het model convergeert, en wat de steady state karakteristieken van het model zijn. Dit laatste dient niet alleen een verdere verduidelijking van het model en haar uitkomsten, maar maakt ook een gedetailleerde vergelijking met andere modellen in de literatuur mogelijk (vooral een aantal gangbare modellen voor economische groei en internationale handel). Als laatste geeft de cdrom ook toegang tot een aantal uitgebreide simulatie experimenten.

De discussie wan de modelsimulaties in het proefschrift heeft betrekking op 9 gecontroleerde experimenten met behulp van het model, en twee scenario analyses. Deze kumen als volgt beschreven worden.

In het model met technologische verandering als drijfveer voor groei, wordt de economie gekenschetst als een dynamisch niet-evenwicht-systeem. Tedere innovatie op bedrifsniveau zorgt voor een nieuwe verstoring van het evenwicht, en zet de economie op een nieuw aanpassingspad. Het aanpassingspad beschrijft het diffusiepad van de innovatie door het economische systeern. Op macro niveau leidt dit tot werkloosheir. In de dynamische context leidt innovatie tot "technologische werkloosheid".

In het tweede experiment worden lapitaalgoederen jaargangen geïntroduceerd met variabele kapital intensiteiten. Het model beschrijft dat in deze economie, groei alleen mogelijk is als de groei van de productiviteit in de kapitaalgoederen sector gelijke tred houdt met de productiviteit in de finale goederen sector die het gevolg is van de introductie van nieuwe kapitaalgoederen jaargangen.

In het derde experiment werd de endogene werking van zogenaamde lange golven in economische groei (productie, productivitieit) en werkloosheid beschreven. Deze lange golven zijn het gevolg van een samenspel tussen afnemende meeropbrengster in "paradigma specifieke leereffecten" en "paradigma specifieke cumulativiteit". Dit model kan gezien worden als een formalisatie van Schumpeter"s lange golven theorie.

Het volgende scenario in het proefschrift is gebaseerd op de zogenaamde "history friendly modellen" in de evolutionaire economie. In dit model wordt een specifteke calibratie geintroduceerd met betrekking tot verschillen in technologische mogelijkheden tussen sectoren in combinatie met endogene voorkeuren van consumenten, die zich ontwikkelen onder invloed van inkomensgroei. In dit scenario worden groeivoetwerschillen over de tijd verklaard door dynamische variaties in productiviteit tussen sectoren. De scenario-uitkomst laat eer standaard ontwikkelingspatroon zien warin een economie getransformeerd wordt van agrarisch naar industrieel, en uiteindelijk natar een diensteneconomie. Specifieke patronen van productiviteitsgroei handen samen met deze transformaties, en men kan fenomenen zoals de Industriële Revolutie of Baumol's cost disease in het scenario herkennen.

Met betrekking tot internationale handel toont een experiment aan dat het modell, met arbitraire startwaarden en parametersettings, aanpassingspaden genereert die leiden tot specialisatiepatronen die het midden houden tussen Ricardiaanse specialisatie en het Hecksher-Ohlin-Samuelson model voor internationale handel. 
Differentiatie tussen sectoren en landen is genoeg om dynamische comparatieve voordelen te genereren.

Als uitbreiding op dit resultaat is gekeken naar micro-resultaten, om de relatie tussen technologische innovatie op bedrijfsniveau, economische selectie, industriële organisatie en economische groei te bestuderen. Het model kan, afhankelijk van de mate van productdifferentiatie, een variëteit aan markstructuren genereren. Een specifiek resultaat in dit gedeelte is dat de vorm van de verdeling van bedrijfsgroottes sterk beïnvloedt wordt door de cumulativiteit van technologische verandering, spillovers, mogelijkheden voor imitatie, en productdifterentiatie. Ook de verdelingen van bedrijfsgroei variëren met deze parameters. Op deze manier kan worden vastgesteld wellke parametersettings het meest compatibel zijn met de in de empirische literatur geobserveerde scheefheid van de genoemde verdelingen. De experimenten tonen eveneens aan dat relatief geleidelijke groeipatronen op macroniveau gebaseend kunnen zijn pop cen hoge mate wan turbulentie op microniveau.

In de Inacro-economische experimenten wordt de vraag gesteld in welke mate de uitkomst van het evolutionaire proces alis optimaal beschouwd kan worden. Het gedrag van individuele bedrijven is niet gebaseerd op sterke rationaliteit. De specifieke context van dit experiment is de vraag of er macro-economisch gezien genoeg (of te veel, of te weinig) in R\&D wordt geinvesteerd door bedrijven. De conclusie van het experiment is dat de selectieomgeving zorgt woor een overlevingsrestrictie: bedrijven met een inefficiënte strategie verdwijnen uit de markt. Echter, dit impliceert niet dat macro-economisch gezien de totale R\&D uitgaven niet noodzakelijk optimaal zijn. Te lage R\&D uitgaven kunnen bijvoorbeeld het gevolg zijn van een te geringe diversiteit van strategieën op het microniveau.

In de experimenten met betrekking tot internationale handel en economische gravi lag de nadruk eerst op het reproduceren wan een aantal patromen in bestaande evolutionaire modellen. Dit gedeelte van het experiment toont aan dat in een zelforganisatie context met endogene technologische vooruitgang groeivoetverschillen en speciallisative endogeen ontstaan. De rol van productdifferentiatie wordt in de bestaande literatuur niet uitgebreid behandeld, maar komt in de experimenten in dit proefschrift met betrekking tot groei en handel ruimschoots aan bod.

In deze experimenten spelen learning-by-doing en spillovers (tussen landen of slechts binnen landen) een grote rol. Internationale handel heeft, net als in de bestaande literatuur vooral een groeibevorderend effect als er sprake is van dynamische schaalwoordelen. Een van de experimenten toont aan dat het belangrijkste verschil tussen het evolutionaire model van Dosi et al., en de gangbare neoklassieke modellen, niet zozeer ligt in het onderscheid evolutionaire selectle versus optimalisatie, maar veel meer in de aanwezigheid of afwezigheid van spillovers. Zonder internationalle spillowers reproduceert het model de Dosi et al resultaten, met spillovers de resultaten van het (neoklassieke) model van Grossman en Helpman. Men kan hieruit afleiden dat de evolutionaire en neoklassieke modellen dichter bij elkaar liggen dan de polemiek in de literatuur suggereert.

Het laatste experiment toont alan dat internationale handel economische groel kan versnellen in alle landen die aan wrije handel deelnemen. Echter; in geval van een specifiek scenario waarin (extreme) internationale verschillen in innovatie capaciteiten bestaan, kumen handel en specialisatie leiden tot welvartsverlies in het land met de meer geavanceerde menselijk kapitaal voorraad. 



\section{About the Author}

Onder Nomaler was borm in Ankara on April 28th 1970. He attended secondary education in Ankara Atatürk Anadolu Lisesi (Junior High School 1981-1985) followed by Ankara Fen Lisesi (High School of Natural Sciences 1985-1988). In 1993 he received his BSc degree in Industrial Engineering at the Middle East Technical University in Ankara. In 1996 he received a MSc degree in Economics at the Economics department of the same university, where he also worked as a research and teaching assistant for two years. In May 1996 he started his PhD studies in Maastricht Economics Research Institute on Innovation and Technology (MERIT) of University of Maastricht. Between May 2000 and December 2001 he worked as research fellow in MERIT on a European project aimed at measuring the extent of "Brain Drain" from Europe. Between 2001 and 2005 he worked in Eindhoven University of Technology (TMcc) as senior research fellow for various European projects, one of them (PatVal) being particularly aimed at measuring the economic value of European patents. Onder is currently employed as Assistant Professor at the Technology Management department of, Eindhoven Uraiversity of Technology. 